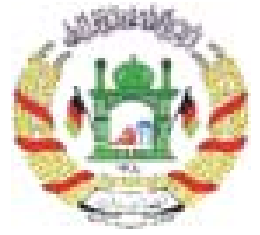

Islamic Republic of Afghanistan Ministry of Rural Rehabilitation and Development

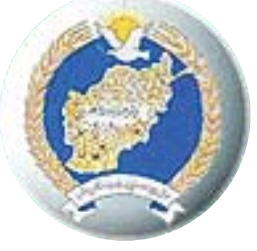

National Solidarity Programme

Post-war

Reconstruction $\&$ Development Unit (PRDU)

THE UNIVERSITY of fork
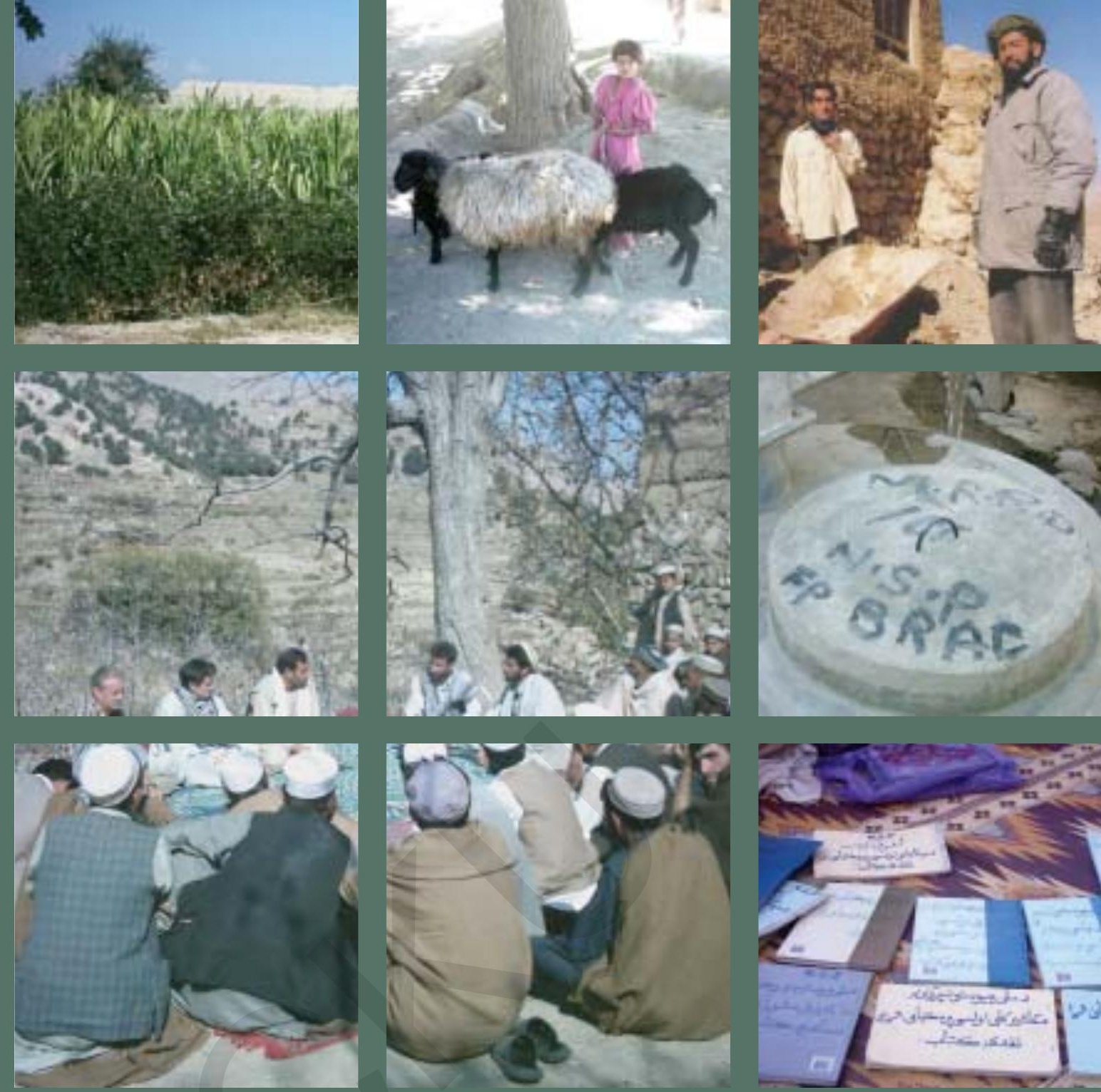

$$
\text { May } 2006
$$




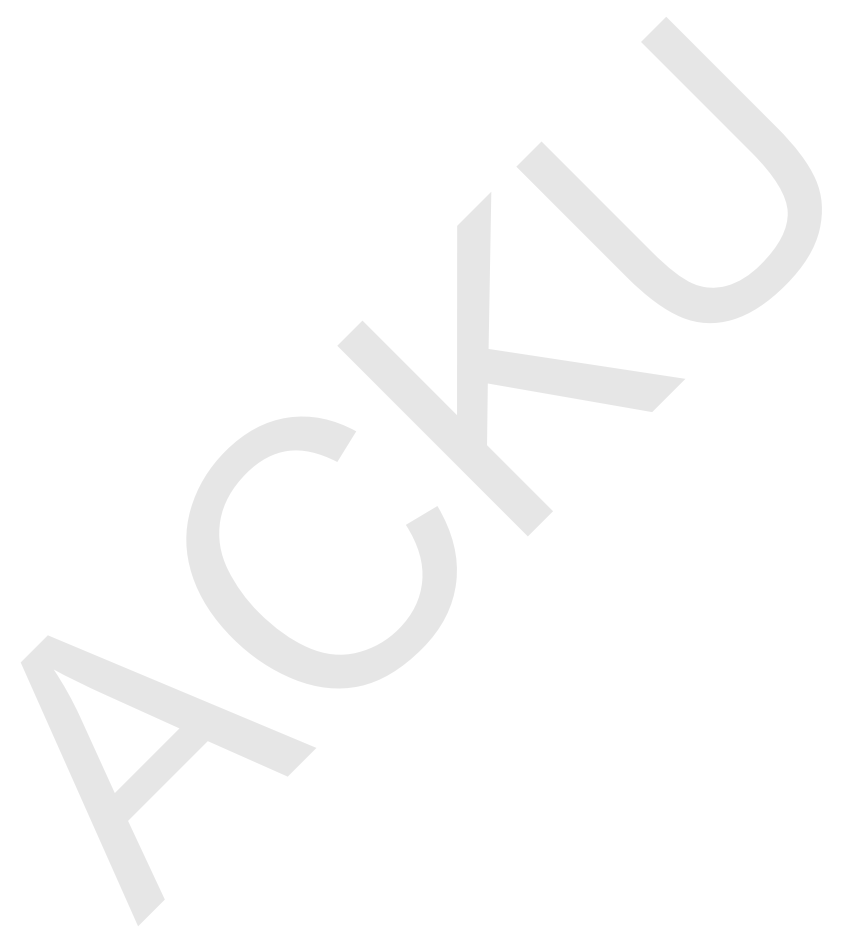




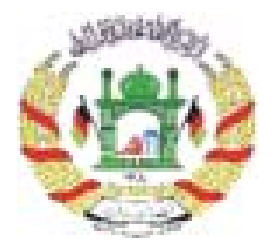

Islamic Republic of Afghanistan

Ministry of Rural Rehabilitation and Development

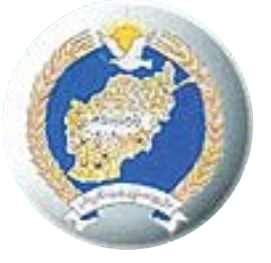

National Solidarity Programme

\section{Mid-term Evaluation Report of the National Solidarity Programme (NSP), Afghanistan}

\section{May 2006}

Evaluation Team Leader

Professor Sultan Barakat

Post-war Reconstruction \& Development Unit (PRDU)

THE UNiversity of fork 


\section{Evaluation Team}

\section{Team Leader:}

Professor Sultan Barakat

(BSC, MA, DPhil, ICDDS)

Founding Director of the Post-war

Reconstruction and Development Unit, University of York.

\section{Specialist in Public Institutions:}

Professor Mark Evans (BA, PhD) Head of Department of Politics, University of York.

\section{Specialist in \\ Community Development:}

Dr Arne Strand (MA, PhD)

Researcher at Chr. Michelsen Institute, Bergen, Norway.

\section{Specialist in Infrastructure Projects:}

Engineer Richard Brown (BSC, MBA, MA, CEng, CDipAF, DipM, FICE, FCILT, MCMI, MCIM)

Associate Director, Arup, UK.

\section{Regional Assessment Team Leaders:}

Dr Margaret Chard (BA, MA, MSc, PhD)

Dr David Connolly (BA, MA, PhD)

Dr Richard Jones (BA, MA, MSc, PhD)

Mr Waheed Omer (BA, MA)

Mr Mirwais Wardak (BA, MA).

\section{Regional Assessment Team Members:}

Mr Khushal Akhtar

Mr Malaiz Daud

Mr Jawed Nader

Ms Marina Nawabi

Mr Samiullah Nazemi

Dr Lida Rahimi

Mr Qutabuddin Roydar

Dr Khalid Sharifi

Ms Asila Wardak

Mr Idrees Zaman.

\section{(C) 2006}

Post-war Reconstruction \& Development Unit (PRDU), The University of York; and Ministry of Rural Rehabilitation and Development, Islamic Republic of Afghanistan

All rights reserved.

No part of this book may be reproduced or transmitted in any form or by any means electronic, mechanical or otherwise without the prior permission from the publishers - Post-war Reconstruction \& Development Unit (PRDU), The University of York 


\section{Table of Contents}

page

\section{Preliminary Pages}

List of Abbreviations

List of Illustrations

Preface

\section{Main Report}

Executive Summary

Programme design and rationale

3

National level programme management and delivery

Sub-national coordination and operational delivery of the NSP

The role of Community Development Councils in programme management and operational delivery

The enhancement of NSP engineering projects

NSP Financial Operations

Community Development

Councils and future

governance in Afghanistan

Linkages with the evaluation of other community-driven development programmes

Programme costs, expectations and impact

\section{Findings and Recommendations:}

1. Programme Design

and Rationale

Analysis

Summary and recommendations for programme design and rationale

2. National Level Programme Management and Coordination

National level coordination committees
The role of the NSP Oversight Consultant in programme management and coordination

Summary and recommendations for national level coordination

3. Sub-national Level Coordination and Operational Delivery of the NSP

The MRRD and provincial and district government

The provincial OCs and teams

The role of the Facilitating Partners in NSP coordination and operational delivery

4. The Role of Community Development Councils in Representative Governance and Community Development

The strategy for evaluating Community Development Councils

The Community Development Council Community Power Survey

Principal findings

The Household Survey

Conclusions

Recommendations for CDCs

5. An Analysis of National Solidarity Programme Engineering Projects

Methodology

Project relevance

Project quality and sustainability

Project management

Intangible benefits

Key recommendations for the enhancement of NSP engineering projects 
6. National Solidarity Programme Financial Operations

Financial processes

Obstacles to effective operational delivery

Key recommendations for financial operations

7. Programme Enhancement

A new institutional venue for the National Solidarity Programme

Community Development Councils and future governance in Afghanistan

The role of the National Solidarity Programme in poverty reduction

Measuring the performance of the National Solidarity Programme

Government capacity development in National Solidarity Programme Phase 2

The Management of cultural change in the National Solidarity Programme Phase 2

Gender issues for Phase 2 of the National Solidarity Programme

8. In Conclusion

- Programme Costs,

Expectations and Impact $\quad 121$

Approach

Programme costs

Programme expectations

Programme benefits

Programme efficiency and effectiveness

\section{Annexes}
A1. General Introduction $\quad 135$ Map of Research Districts $\quad 136$

A2. Evaluation Methodology 137

\section{Field Research Findings:}

A3. Badghis Province 143

A4. Balkh Province 163

A5. Bamyan Province 203

A6. Herat Province 217

A7. Kabul Province 223

A8. Kundoz Province 245

A9. Nangarhar Province 265

Annex 1. Laghman Province 296

A10. Paktia Province 301

A11. Paktika Province 307

A12. Takhar Province 313

B1. Terms of Reference 321

C1. Stakeholders Consulted 327

D1. References 333 


\section{List of Abbreviations}

AKDN

Aga Khan Development

Network

ARTF Afghanistan Reconstruction Trust Fund

BRAC Bangladesh Rural Action Committee

CBD

Community Based

Development

$\mathrm{CDC}(\mathrm{s}) \quad$ Community Development Council(s)

CDD Community Driven Development

CDP Community Development Plan

CDSO Community Development Support Officers

CIDA

Canadian International Development Agency

CHA Coordination of Humanitarian Assistance

DAB Da Afghanistan Bank

DAI Development Alternatives Incorporated

DFID Department For International Development

DRRD Department for Rural Rehabilitation and Development

EU European Union

FHH Female Headed Households

FP(s) Facilitating Partner(s)

GRSP Ghanzi Rural Support Programme

GTZ/IS Deutsche Gesellschaft für Technische Zusammenarbeit/ International Services

IDA International Development Association

IDP Internally Displaced Person

JICA Japan International Cooperation Agency

MHP Micro Hydro Power

MIS Management Information System
MISFA Micro Finance Investment Support Facility of Afghanistan

$M \& E \quad$ Monitoring and Evaluation

MRRD Ministry for Rehabilitation and Rural Development

MoU Memorandum of Understanding

NABDP National Area Based Development Programme

NEEP National Emergency Employment Programme

NGO Non-Governmental Organization

NSP National Solidarity Programme

$O C$ Oversight Consultant

OECD Organization for Economic Cooperation and Development

OM Operational Manual

PCU Public Communication Unit

PO Provincial Office

PRT(s) Provincial Reconstruction Team(s)

PRDU Post-war Reconstruction and Development Unit, University of York

PSG Professional Skills for Government

RAT(s) Regional Assessment Team(s)

RuWATSAN Rural Water Supply and Sanitation Programme

SDF Sanayee Development Foundation

SO Social Organizer

UNAMIR United Nations Assistance Mission for Rwanda

UNHCR United Nations High Commision for Refugees

UNICEF United Nations International Children's Emergency Fund

USAID US Agency for International Development

WB World Bank 


\section{List of Illustrations}

page

page

\section{Boxes}

Box 1. The organizational structure of the NSP Oversight Consultant, GTZ-DAI

Box 2. The training of DRRD staff in Kundoz

Box 3. Transportation stress in Bamyan

Box 4. Villages unified in Balkh

Box 5. Weak community capacities in Nangarhar

Box 6. An integrated approach to DRRD capacity development in Kabul

Box 7. BRAC in Nangarhar

Box 8. Identifying community priorities through project selection - Examples from $\mathrm{CHA}$ and UN-HABITAT

Box 9. Examples of the issue of appropriate design and construction - $\mathrm{CHA}$ District Team in Balkh

Box 10. Examples of the issue of appropriate design and construction - The BRAC Team in Nangarhar

46

64

65

\section{Figures}

Fig 1. Professional skills for government

Fig. 2. Composition of NSP total costs (Dec 04 to Feb 06)

Fig. 3. Composition of NSP programme delivery costs (Dec 04 to Feb 06)

Fig 4. Mapping obstacles to NSP success/failure

\section{Tables}

Table 1. The operations of NSP Facilitating Partners

Table 2. The disbursement process in the context of programme development

61 Table 3. Governance in the Islamic Republic of Afghanistan

Table 4. The Impact of the NSP on community poverty

Table 5. Programme obstacles

Table 6. NSP outputs - September 2003 to February 2006

Table 7. NSP capacity development 131

Table 8. NSP projects 
$1_{\text {The other } 4 \text { programmes }}$ include: NEEP - the N ational Emergency Employment Programme, aimed at assisting the most vulnerable with employment opportunities in public infrastructure; WATSAN - the Rural Water and Sanitation Programme, aimed at improving health, hygiene and improving the child mortality rate; MISFA - the Micro-Finance Investment Support Facility of Afghanistan, aimed at improving the lives of the poor and vulnerable through the provision of micro credit; and N ABDP - the N ational Area Based D evelopment Programme, aimed at developing the capacity of national, provincial, and local authorities to enable them to plan, finance, and manage recovery and development interventions.
Twenty-five years of conflict has left Afghanistan with a profound need for extensive intervention to address reconstruction and development requirements, particularly in rural areas, many of which were never reached by consecutive governmental developmental plans. In 2002, the transitional administration of the country recognized that the legitimacy of the new government by the rural population depended in no small measure on its ability to deliver long-awaited assistance to rural communities across the country, and the idea for the National Solidarity Programme was born. The Programme was designed and initiated in 2003 under the Ministry of Rural Rehabilitation and Development (MRRD), and was financed by a consortium of international donors coordinated by the World Bank.

The Programme attempts to target the needs of rural communities by employing community-driven development, delivered through a collaborative partnership, encompassing central government, local and international non-governmental organisations (NGOs), and the communities - represented by specially devised Community Development Councils (CDCs). Today, the NSP forms the central component of an architecture of national programmes managed by the MRRD, designed both to help the Afghan people to rebuild their lives and nation, and to demonstrate that the Afghan government, with technical assistance, could develop the inclusive governance structures required to sustain a stable state. 1

As described in the founding document of the NSP, the goal of the Programme is to reduce poverty through empowering communities with regard to improved governance, and social, human, and economic capital. It attempts to achieve this goal through pursuing two main objectives: (1) to lay the foundations for a strengthening of community-level governance, and (2) to support community-managed sub-projects comprising reconstruction and development that improve the access of rural com- munities to social and productive infrastructure and services.

The implementation strategy of the NSP consists of four core elements: (1) facilitation at the community level to assist communities to establish inclusive community institutions (CDCs) through elections, reaching consensus on priorities and corresponding sub-project activities, developing eligible sub-proposals that comply with NSP appraisal criteria, and implementing approved sub-projects; (2) a system of direct Block Grant transfers to support rehabilitation and development activities (sub-projects) planned and implemented by the elected CDCs; (3) a series of capacitybuilding activities to enhance the competence of members of CDCs (both men and women) in terms of financial management, procurement, technical skills, and transparency; and (4) activities linking local institutions to government administration and aid agencies with available services and resources.

The MRRD recognizes that the quality of the implementation process of the NSP is essential for the long-term sustainability of community investments and for the overall success of the Programme. As such, at the community level the identification of priorities and the planning of sub-projects are based on the basic principles of participatory planning through: inclusive community meetings and representative elected development councils; community contributions to capital costs and operation and maintenance; and project transparency and accountability to the community. In order to help the MRRD achieve its targets, an Oversight Consultant (GTZ/IS) was contracted to oversee the overall management and supervision of the NSP. In addition, the MRRD has contracted 22 NGOs (both national and international) and UNHABITAT to facilitate the delivery of the NSP in selected districts, across all the provinces of Afghanistan. These non-governmental organizations are termed Facilitating Partners (FPs), and their role is to facilitate community participation in the planning, 
implementation and management of subprojects financed by the NSP Block Grants.

While the NSP-Oversight Consultant (OC) has been unable to meet the targets for December 2004 to August 2006 established in its contract with the MRRD, its progress has nonetheless been remarkable since it started in September 2003. Moreover, the importance of the NSP is reflected by its overt achievements to date. Its reach encompasses 193 districts in all 34 provinces, and has benefited 10.5 million Afghans. More specifically, it has engaged with 22,500 rural communities covering 38,000 rural settlements, which has so far resulted in the election of more than 10,000 CDCs. From this, 14,000 projects in 8,000 communities have been financed, with Block Grant disbursements amounting to US \$166.1 million and total Block Grant commitments of US $\$ 214.6$ million. Overall, more than 4,000 sub-projects have been completed successfully. ${ }^{2}$ In addition, this evaluation identifies significant evidence of: (1) increased public faith in the system of government; (2) improved community relations; (3) improved state-civil society relations; and (4) the empowerment of CDCs.

In November 2005, the Post-war Reconstruction and Development Unit (PRDU) at the University of York, U.K., led by Professor Sultan Barakat, was contracted by the MRRD to undertake a mid-term evaluation of the NSP over a period of 6 months. The central aim of the evaluation was to examine the achievements and drawbacks of the Programme two years into its implementation. The midway point for the NSP was seen as an opportune moment to reflect on what has been achieved and to make recommendations for improving the post mid-term evaluation phase (Phase 2) of the Programme. The PRDU was asked to report its findings in relation to the efficiency and effectiveness of the implementation of the NSP as well as its potential impact, rationale and longer-term contribution to governance and development in Afghanistan. The team was also asked to provide recommendations with regard to: the approach and institutional arrangements to improve the delivery and impact of the Programme; and the long-term strategy for the integration of relevant programme functions into the institutional profile of the MRRD. Accordingly, this evaluation report considers not only the physical outputs and other more tangible programme benefits, but also goes further by investigating evidence for qualitative sustainable impacts on the core objectives of the Programme, namely, local governance and poverty reduction. 3

Any evaluation of reconstruction efforts in war-torn countries inevitably suffers from the same constraints as the efforts themselves: inadequate time and resources, the inaccessibility of key sites, incomplete information and a tight work schedule. With this being a mid-term evaluation, there is the added complication of examining a programme that is very much on 'the move': millions of dollars are being disbursed as we evaluate, and policy adjustments are being made; a new version of the Operational Manual has now been completed; and plans and pledges have been made for Phase 2. By way of illustration, it is noteworthy that several of our recommendations in our November Inception Report have already been implemented testimony to the reflexivity of the $\mathrm{OC}$ to issues of programme enhancement. In our Inception Report we originally defined the cut-off point of the period of evaluation (in terms of data and reports consulted) as the end of July 2005 . We have subsequently amended the period of evaluation to the end of March 2006 to include commentary on some notable developments in programme management and enhancement.

In addressing these challenges to the nature of our assessment of the Programme, the PRDU employed a composite and participatory evaluation approach. A range of investigation methods were used based on the nature of the data available and the questions posed. ${ }^{4}$ While informed by best practice theory located within specialized academic literature, this evaluation is grounded in qualitative empirical data drawn from: extensive national and subnational level interviews, and a series of exploration and validation workshops held with the groups of NSP stakeholders. Within each of the 11 provinces researched, the research teams interfaced with the main NSP actors and their respective levels of authority (provincial governor, provincial and district level RRD, OC and FP). ${ }^{5}$ The scope was then extended to strategically sampled communities and districts within these provinces. Both community power and household surveys were employed to capture a gender-balanced perspective of the NSP from the viewpoint of its chief beneficiaries. The interviews and surveys also
2 See N SP O C (2006), Analysis of the Experiences and Lessons Learned in Program Implementation, GTZ-IS, Kabul, March 2006, pp. 3-5.

3 See Annex B, 'Terms of Reference'.

4 See Annex A2, 'Methodology'.

5 See Annex C, 'Stakeholders Consulted'.

N SP AFG HAN ISTAN Mid-term EVALUATIO N REPO RT 
contained an engineering-based assessment, which provided a technical understanding of the physical outputs. Throughout these integrating levels of inquiry, documentary and multi-level institutional analyses proved essential. In the absence of base-line time series data, a pragmatic inclusive approach to evaluating programme costs and benefits was deployed to provide an assessment of the overall impact, efficiency and effectiveness of the NSP. The field data was then studied in York during three main stages of analyses.

The PRDU brings to this task 13 years of diverse experience in linking theory to practice in post-conflict reconstruction and development in over 15 countries. This includes expertise both in Afghanistan, and in community rehabilitation and rural development. As the team leader, I have had the gratification of working with an extremely competent team. At the national and strategic level, the insights of Professor Mark Evans (public institutions), Dr Arne Strand (community development), and Engineer Richard Brown (infrastructure projects) were central to the successful completion of this evaluation. The extensive field research at the sub-national level was equally crucial and was conducted by PRDU Research Fellows Dr Margaret Chard, Dr David Connolly, and Dr Richard Jones. In completing this field research they in turn were joined by an excellent team of Afghan researchers: Mr Waheed Omer, Mr Mirwais Wardak, Mr Khushal Akhtar, Mr Malaiz Daud, Mr Jawed Nader, Miss Marina Nawabi, Mr Samiullah Nazemi, Dr Lida Rahimi, Mr Qutabuddin Roydar, Dr Khalid Sharifi, Mrs Asila Wardak, and Mr Idrees Zaman.

Finally, I would like to express my utmost appreciation to all NSP stakeholders for the cooperation afforded to this evaluation at all levels. This has included the MRRD, donors, OC (national and provincial levels), provincial governors, provincial and district RRD staff, the Facilitating Partners (national, provincial and district levels), the NSP communities themselves, and even communities not benefiting from the NSP. All of these gave their time unreservedly. In particular, I am especially grateful to HE Hanif Atmar (Minister for RRD), Ehasan Zia (Deputy Minister for RRD), Raz Mohammad (Deputy Minister, Finance, for RRD), Asif Rahimi (NSP Chief Coordinator), Andreas Schild (OC Team Leader), and Jovita Thomas (OC Deputy Team Leader). I hope that the learning process captured in this document can be used to safeguard and stimulate further policy development and best practice for the reconstruction of Afghanistan.

Professor Sultan Z Barakat NSP Mid-Term Evaluation Team Leader PRDU, University of York, York, U.K. 3 May 2006 


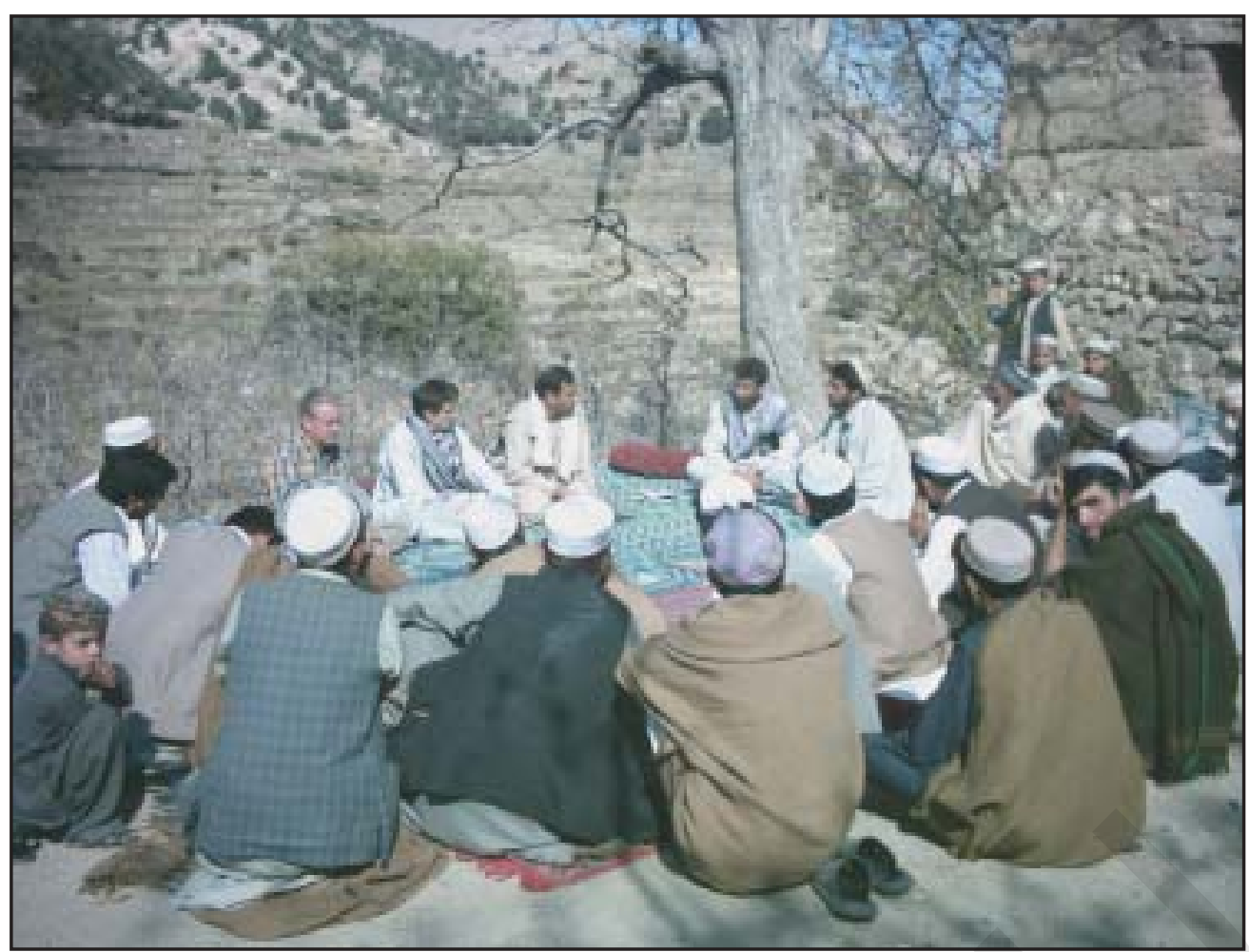

N SP AFGHAN ISTAN

Mid-term EVALUATIO N REPO RT 


\section{Executive Summary}

1 See Independent

Evaluation Group (2005),

'The Effectiveness of World Bank Support for Community-based and -driven Development',

Washington, World Bank,

available on-line at $h t t p: / /$

www.w orldbank.org/ieg/cbdcdd/.

2 Although it should be observed that CDD's are provided with significant technical support and it is often difficult to disentangle the views of Facilitating Partners from the views of communities. Hence the claim of perfect autonomy is questionable.
Since the late 1990s donor support via the World Bank for community participation has shifted away from community-based development (CBD) with its emphasis on collaboration, consultation and informationsharing, towards community-driven development (CDD) which affords communities control over decision-making processes and resources in the design and implementation of sub-projects. ${ }^{1}$ This evaluation argues that the Islamic Republic of Afghanistan's National Solidarity Programme (NSP) has the potential to become a beacon of good practice amongst CDD programmes. ${ }^{2}$ Phase 1 of the NSP has undoubtedly been a success given the difficult environment in which it has operated. Indeed, only a small minority of our respondents questioned the success of the Programme. It is observed that:

- the establishment of the NSP was a rational and far-sighted response to the need for rapid signs of state building in the rural communities of Afghanistan;

the achievements of the NSP, particularly in terms of building community and national solidarity through the establishment of Community Development Councils (CDCs) and CDD sub-projects, outweigh its initial design and operational weaknesses;

given the extremely challenging environmental constraints that have bedevilled the implementation of the NSP, all stakeholders have a good reason to be proud of their achievements in Phase 1 - Government, provisional government, Oversight Consultant (OC), Facilitating Partners (FPs), communities and their CDCs; and, the benefits of the NSP justify the overhead costs of the Programme, particularly in years one and two of the Programme. Moreover, overhead costs should diminish dramatically as a consequence of: a) lesson-learning from Phase $1 ; b)$ the elimination of unnecessary bureaucracy through the simplification of delivery systems; and c) the provision of political support to remove bottlenecks in the delivery process.

However, we are also of the view that with some fundamental refinements - anchored in improved programme management and coordination at the national and provincial levels, the simplification of delivery systems and the consolidation of CDCs - the postmid term evaluation of the NSP (or what we will term NSP Phase 2) could yield some outstanding developmental achievements in terms of both sustainable institutionbuilding and economic growth.

We therefore recommend that the donor community should support the NSP for a medium- to long-term period of 10 years in order to consolidate its gains and fulfil its potential. During this period a new institutional venue will need to be established for the delivery of the NSP so that the MRRD can assume the role of the OC. We recommend the creation of an executive agency, a model of service delivery currently deployed in most Organization for Economic Cooperation and Development (OECD) member states, as the key features of an executive agency fit with the MRRD's immediate institutional and human resource needs.

It is also recommended that the NSP coor- 
dination problems that have been experienced at all levels of governance in Phase 1 need to be dealt with in Phase 2, through more effective donor coordination and the establishment of a 'whole government' approach to the national coordination of the NSP as the pillar of a national rural development strategy. This would foster multi-level inter-ministerial cooperation and improve the opportunity for more proactive donor support through enhanced collaborative decision structures at the national level. In addition, the potential for sharing resources between the two main complementary national programmes implemented by MRRD - the NSP and the National Area Based Development Programme (NABDP) - should be fully realized. Our suggestion would be to pool some of the Oversight Consultant resources for the two programmes in a manner that ensures effective coordination and economies of scale, and maximizes impact in terms of economic growth and good governance at the provincial and village levels. This recommendation could be further articulated as part of the OC exit strategy that is currently being finalized.

The role of the FPs has been crucial in the social mobilization and capacity development of CDCs, and will need to continue for the short- to mid-term due to limited MRRD capacity at the district and community levels. The future role of the FPs rests on whether the NSP remains purely a development programme or whether the governance component of the programme assumes a greater role in NSP Phase 2 . We would encourage the latter, in which CDCs are granted a constitutional role with statutory responsibilities at the village level. By implication this would involve the extension of the public administrative system from the district to the CDC level through the establishment of an elite of Community Development Support Officers (CDSOs). The role of the CDSO would be to assume the role of FPs and provide technical support to the CDC in all of its core competences. The establishment of this technocratic elite, with attractive conditions of service, is central to the long-term sustainability of CDCs and should be a key component of the NSP's consolidation strategy. This proposal will also require a long-term capacity development strategy which should be integrated with broader processes of civil service reform.

The programme design itself should also be further developed, with consideration given to the strengthening of the CDCs, the sustainability of its impact and the long-term capacity development of the MRRD. In particular, further strategies need to be developed to enhance the participation of women, both in community governance and in project implementation, and the inclusion of the poorest of the poor and disadvantaged as beneficiaries.

Finally, NSP Phase 2 would also benefit from launching a longitudinal study of the programme in association with the University of Kabul and other international centres for the study of reconstruction and development, to ensure that lessons learnt are well documented and that archive material is utilized in the training and education of Afghanistan's future development cadre.

There follows an overview of the key findings of the mid-term evaluation and recommendations for Phase 2 which correspond to: programme design and rationale; national level programme management and coordination; sub-national level programme management and coordination; the role of CDCs in programme management and operational delivery; programme enhancement; and programme costs, expectations and impact. The evaluation draws on qualitative data derived from: extensive national and sub-national level interviews; two workshops held with all NSP stakeholders; a community power survey; a household survey; an engineering analysis; and documentary and multi-level institutional analysis. An inclusive approach to evaluating programme costs and benefits is deployed to provide an assessment of the overall impact, efficiency and effectiveness of the NSP.

The NSP is now recognized both by the people of Afghanistan and the international community as the central policy instrument for Afghan state building and development. The MRRD, the NSP OC and the FPs should be proud of their achievements. The following recommendations for NSP Phase 2 aim to build on and consolidate these impressive achievements. However, two notes of caution need to be addressed at this juncture. First, it is necessary to emphasize the importance of differentiating between short- and longer-term recommendations, particularly in relation to the MRRD assuming the operational delivery role at the national, provincial and district levels. This will need to be careful phased in, and rests on developing the capacity of MRRD
N SP AFGHAN ISTAN Mid-term EVALUATION REPORT 
officials to act. Secondly, the consideration of these courses of action should take into consideration the costs of change, which should be calculated on: a) their capacity to improve qualitative rather than quantitative output, and b) the likelihood that they will survive for a considerable time.

\section{Programme design and rationale}

The evaluation of NSP programme costs and benefits reveals significant gains to the Afghan people in relation to institutionbuilding (limited democratization), capacity development (mainly in skills development), and social solidarity at the national and community levels (and to a lesser degree at the provincial and district levels). Impressive benefits have also been derived economically by: creating livelihood opportunities and direct forms of economic development through improved productive capacity and the provision of work in relation to certain NSP projects; and the provision of indirect forms of economic development, facilitated by increased economic activity arising from improved infrastructure and savings derived from lower costs of production. Important gains in gender equality have also been achieved in certain regions.

These benefits justify the overhead costs of the Programme particularly in years 1 and 2 of the Programme. Moreover, overhead costs should diminish dramatically as a consequence of: a) lesson-learning from Phase $1 ; b)$ the elimination of unnecessary bureaucracy through the simplification of delivery systems; and c) the provision of political support to remove bottlenecks in the delivery process. However, these achievements will need to be consolidated in the ways suggested above in order to ensure the long-term future of what may be deemed a development programme of outstanding potential.

\section{Design improvements in overview}

Overall, Phase 1 of the NSP has undoubtedly been a success, given the difficult environment in which it has operated. Indeed, only a small minority of our respondents questioned the success of the Programme, given the extrao rdinary constraints under which it has operated. Nonetheless, several challenges can be identified in terms of policy formulation, implementation and monitoring and evaluation arising from problems in the process of programme design and inception, which have created operational obstacles that need to be surmounted in Phase 2.

\section{Recommendation 1}

The political objectives of the NSP (e.g. the establishment of CDCs within the formal system of local governance) need to be expressed more overtly within the Programme objectives.

Recommendation 2
New 'simplified', 'realizable' and publicly
'knowable' programme objectives and a
'simplified' and 'realizable' set of perform-
ance indicators need to be drawn for NSP
Phase 2 which express the governance,
capacity development and economic
growth objectives of the NSP more explicitly
so that they can be measured over time.
Monitoring systems should be simplified to
focus on developing time series data around
a simplified set of performance indicators. A
coherent and consistent representative
sample of community profiles drawn to
common criteria needs to be completed for
comparative and evaluative purposes.

Recommendation 3
NSP Phase 2 should be a period of consoli-
dation rather than expansion. The aim of
rolling out the NSP to 6,800 communitiesin
Year 3, despite the considerable backlog of
Year 1 and 2 projects, is not tenable. There
should be a greater focus on quality rather
than quantity to allow for effective social
mobilization and institution-building to
take root, and for projects to be sustained
through high quality community develop-
ment planning. A twin track process of
consolidation and expansion should be
devised. A Phase 2 Consolidation Strand
should be aimed at CDCs who have suc-
cessfully completed sub projects. An action
zone approach should be deployed where
appropriate within this strand whereby
CDCs sharing common CDP goals should
be encouraged to engage in joint program-
ming to meet community priorities and
achieve economies of scale. The Phase 2
Expansion Strand should focus on the
strategic roll-out of the NSP to ensure
nation-wide coverage of the NSP, but with a
bias towards integrating vulnerable com-
munities.




\section{Recommendation 4}

NSP Phase 2 needs to embrace a 'whole government approach' both in order to gain greater political legitimacy in the eyes of political elites, and to coordinate national development planning and programming more effectively to gain economies of scale and to a void waste and duplication.

\section{Recommendation 5}

An International Comparisons and Lessons Learnt Unit should be established in the MRRD to help support effective policy learning both in Phase 2 of the NSP and the Ministry's other major development programmes.

The Unit could start by working through the institutional memory of the OC. It should ideally be linked to an independent academic body, such as Kabul University, to ensure objectivity.

\section{Recommendation 6}

Phase 2 needs to place a greater emphasis on increasing the direct economic benefits of the NSP through both incentivizing CDCs and encouraging income-generating programmes to meet its economic growth strategy.

\section{Recommendation 7}

NSP Phase 2 requires more effective donor coordination. Donors should be aware of the consequen ces of action when they pick and choose where their NSP funding goes. An integrated approach should be adopted by the donor community, both to ensure that international funding helps to support national development priorities and to provide for better coverage.

\section{National level programme management and delivery}

This section of the report focusses on the management and coordination of the NSP at the centre of the Afghan political system focussing on the work of national level coordination committees, the MRRD and the NSP OC. The analysis draws mainly on qualitative data derived from extensive nationallevel interviews and two workshops held with NSP stakeholders, including representatives from: all the core ministries involved with the NSP; MRRD and NSP/OC staff; FPs and all the participating donors (Canadian International Development Agency, Department for International Development, European Union, US Agency for International Development, Japan International Cooperation Agency).

\section{National Level Coordination}

It is observed that the NSP suffers from poor coordination at three different levels: donor coordination; inter-ministerial coordination; and large-scale development projects. Poor donor and inter-ministerial coordination has clearly presented the NSP with some steering problems. While certain of these problems are self-inflicted (e.g. the inactive coordination committees and lack of strategic thinking across its key development programmes), others are the product of its success in bidding for external funding, such as petty inter-ministerial jealousy resulting in the deliberate engineering of bottle-necks in the delivery process (e.g. financial disbursement processes). These problems can only be dealt with effectively through the establishment of a 'whole government' approach to the management and delivery of Phase 2 of the NSP which will require the reform of existing decision structures.

\section{Recommendation 8}

A new institutional structure is recommended for the national level coordination of the NSP. The dysfunctional External Review Committee and the Inter-ministerial Committee should be replaced with three new committees - an NSP Steering Committee, a donor Support Group and an Inter-ministerial Committee.

The NSP Steering Committee should meet every two months, it should be chaired by the Ministry with oversight of local governance matters, and be comprised of the NSP
N SP AFG HAN ISTAN Mid-term EVALUATION REPORT 
Coordinator, the first and deputy Minister of the MRRD, the OC, the NSP Coordinator, representatives from partnering ministries, five $C D C$ representatives from NSP regions, and a representative of the facilitating partners.

The donor Support Group should meet quarterly; it should be chaired by a presidential nominee, and be comprised of all the donor stakeholders, the First and Deputy Minister of the MRRD, and the NSP Coordinator. In addition to ensuring donor accountability, the role of the group will be to convene 'action-oriented' meetings with minutes in order to support the work of the NSP more effectively.

The Inter-ministerial Committee should meet quarterly and be chaired by a presidential nominee and include representation from all partnering ministries. Its key role will be to identify areas of duplication and waste, potential areas of joint working, and NSP input into ministerial development plans and vice versa. Day to day management of the NSP would remain with the NSP/OC.

This institutional design would provide the architecture for a 'whole government' approach to the national coordination of the NSP, foster greater inter-ministerial and presidential collaboration, and provide for more proactive donor support. A 'whole government' approach should be integrated at all levels of programme delivery in appropriate areas of programming.

3 See N SP O C (2006), Analysis of the Experiences and Lessons Learned in Program Implementation, GTZ-IS, Kabul, March 2006, pp. 3-5.

We also recommend that the MRRD develops a strategic plan to integrate the NSP with other national programmes such as: the Water and Sanitation Programme (WATSAN); emergency employment (NEEPRA), mostly for labour-intensive road building; the Microfinance Programme (MISFA); the Emergency Response Programme (in Badghis, Bamyan, Herat, Kabul, Kundoz, Nangarhar, Paktia, and Paktika), and, in particular, NABDP. It is crucial to adopt a strategic approach to large-scale development programming to ensure that a joined-up approach is taken that avoids duplication and waste, and

\section{Recommendation $\mathbf{1 0}$}

We recommend the establishment of: a rational NSP Phase 2 Operational Manual with a coherent set of programme objectives which can be measured over time, and a simple set of key performance indicators for monitoring progress in relation to the achievement of these objectives.

\section{The Role of the NSP Oversight Consultant in programme management and coordination}

The evaluation of the role of the Oversight Consultant in NSP programme management rests on an assessment of its ability to deliver on its core responsibilities. While the NSP-OC has been unable to meet the targets set for December 2004 to August 2006, established in its contract with the MRRD, its achievements have nonetheless been remarkable. Since its involvement in September 2003:

the NSP has encompassed 193 districts in all 34 provinces in Afghanistan;

- the NSP has reached 22,500 rural communities covering 38,000 rural settlements;

- the NSP has benefited 10.5 million people and established 10,000 CDCs;

- 14,000 projects in 8,000 communities have been financed with Block Grant disbursements amounting to US \$166.1 million and total Block Grant commitments of US $\$ 214.6$ million; - more than 4,000 sub-projects have been completed successfully. ${ }^{3}$

In addition, this survey identifies significant evidence of: meets broader national development goals. increased public faith in the system of government;

- improved community relations;

- improved state-civil society relations; and

$\checkmark$ the empowerment of CDCs.

In addition, the OC has provided informal 'on the job' training, with an estimated total of 50,000 person training days for MRRD (central, regional and provincial), $O C$ and FP staff and formal training with approximately 9,000 person days for the same target groups. Information and awareness campaigns are provided by the Public Communications Unit (PCU) to underpin the training activities. 
It is therefore unsurprising that the overall performance of the OC was evaluated as 'highly satisfactory' by the World Bank Supervisory Mission of October/November 2006. This evaluation concurs with the general tenor of this assessment. It identifies four major obstacles to effective delivery. First, the targets for 2004-6 were not developed with a rational understanding of how much time community mobilization and sub-project implementation takes. Secondly, several bottle-necks emerged in the process of programme implementation, which have undermined the ability of the $\mathrm{OC}$ to meet targets. Prolonged delays occurred in: the procurement process for securing critical goods; the disbursement process due to the absence of Block Grant funds, and the inefficient transfer of funds from Da Afghanistan Bank to CDC bank accounts. Thirdly, long delays have also occurred in the approval of extension contracts for existing FPs and the contracting of additional FPs. Fourthly, it is also evident from our survey that there has been very little 'political' help forthcoming from the MRRD or the donor community to help the NSP/OC deal with these bottle-necks in the disbursement process.

However, our evaluation does identify some shortcomings in relation to the $\mathrm{OC}^{\prime}$ 's role in capacity development and programme management and enhancement which are largely explained by the need to negotiate significant programme constraints. Indeed, it is argued that from the outset it was impossible for the $\mathrm{OC}$ to adopt a 'rational' approach to programme management for at least 3 main reasons: the obligation to deliver on output-driven objectives has meant that they had to hit the ground running to establish the delivery system for the rapid creation of CDCs and the disbursement of Block Grants; the absence of clear programme objectives has meant that they have always been engaged in institutional 'catch-up' in relation to new priority settings identified by the MRRD and donors; and the lack of a settled understanding of the role of the OC by the MRRD and the donors has meant that they have had to shift human and institutional resources to support non-core NSP activities in response to changing political expectations (e.g. the Management Information System).

Hence, the $O C$ was not provided with the time to initiate a phasing-in strategy during which: a) a rational Operational Manual could be finalized with clear programme objectives; b) consistent performance indicators could be identified and effective monitoring systems established; c) coherent and consistent community profiles completed; d) a capacity development strategy for MRRD staff could be developed; e) a human resource management strategy could be devised for NSP OC staff; f) a rational NSP/OC exit strategy devised; and g) a logical framework for implementation completed.

All of these areas of 'rational' programme management are now being attended to, but this does mean that much of the institution-building and the capacity development work that needed to be completed to allow for a hand-over to the MRRD in July 2006 is in the process of completion.

\section{Recommendation 11}

While we recognize that excellent work is being conducted in these areas, the $\mathrm{OC}$ needs to complete its work at the strategic level with regard to the completion of its: human resources strategy; change management strategy; logical framework to guide programme management around the achievement of milestones; needs a ssessment for MRRD staff; capacity development strategy with linkages into the broader process of civil service reform in Afghanistan; a quality assurance strategy to ensu re sustainable programming; and a final NSP/OC exit strategy.

\section{The central institutional venue for operational delivery}

There is currently significant debate within the MRRD and the NSP/OC over the most suitable institutional venue for the delivery of the NSP in Phase 2 once the MRRD has taken over the management of the Programme. Three options have been debated: full integration; re-tender for a new OC; or, create a 'not for profit' semiautonomous organization as a special project under the Ministry. The third option is being proposed by the MRRD as it provides the Ministry with the ability to secure the services of high quality, experienced staff in the field of rural community development who demand high salaries, while simultaneously developing the capacity of national staff. However, we believe that these aspirations can be met through a fourth option; the creation of an executive agency for the operational delivery of the NSP.
N SP AFGHAN ISTAN Mid-term EVALUATION REPO RT 
We recommend the creation of an Executive agency, a model of service delivery currently deployed in most OECD member states and pioneered in the UK context in the late 1980s. The key features of an executive agency fit with the MRRD's institutional and human resource needs:

1. An executive agency is semi-detached from its parent department (MRRD), with its own budget, freedom from some aspects of departmental regulation (particularly in relation to recruitment), with the organization under the direction of a chief executive and other unit managers often recruited through open competition.

2. Executive agencies are accountable for the performance of specific operational tasks as a corporate unit, including output-focussed performance targets set by the parent department (in this case the MRRD), and the personal accountability of the chief executive for meeting performance targets.

3. Executive agencies are established through a Framework Document issued by the minister of the parent department (MRRD). Although the Framework Document is an official document, it is not a law. Hence agencies are not legally distinct from the departments that supervise them, and of course all of the employees are public servants, even though the managerial élan is often recruited from outside the public sector.

It should be noted, however, that this proposal is geared towards meeting the particular needs of the MRRD for a form of organization that will allow it to retain specialist staff on internationally competitive salaries to deliver the NSP. This is not to say that executive agencies are not without their problems - lines of accountability can become blurred, and separating policy from administration can lead to the emergence of implementation gaps.

\section{Recommendation $\mathbf{1 2}$}

We recommend the creation of an executive agency as a new institutional venue for the delivery of the NSP; a model of operational service delivery currently deployed in most OECD member states (see Section 7 for more detail).

\section{Sub-national coordination and operational delivery of the NSP}

This section of the report focusses on the role of two further groups of stakeholders in the coordination and operational delivery of the NSP - sub-national governments, Provincial OCs and their teams and facilitating partners.

\section{The role of the provincial MRRD}

According to the MRRD respondents and the provincial governors, the NSP has significantly improved the relationship between the participating communities and the government, in addition to creating stronger intra- and inter-community relations, to the extent that cases of conflict management have emerged. Furthermore, there is evidence of community empowerment. Government officers at the senior level draw upon development experience from the NSP and within the wider national policy framework. Furthermore, there were several instances of institutional cooperation and some evidence of institutional learning in practice. However, general capacity levels are poor. The following significant deficiencies and threats also emerged from the analysis, which in turn prompt some recommendations:

- The cap on the budget allocation ('regardless of the number of real beneficiaries') has caused significant distress within the Programme and risks causing rivalry and grievance.

- There is considerable frustration with delays in the transference of funds from the $\mathrm{OC}$ to the communities, which needs to be continuously reviewed.

While the official complaints procedure was used, the approach to its implementation varies considerably, to the extent that it risks disappearing in some provinces; this is especially worrying considering the natural barriers to establishing transparency and accountability in the context of a war-ravaged State.

- There is a need to reconcile conflicting models of governance, both at the community and programme design level.

- In recognizing the values of fair representation, inclusion and legitimate authority, the role of women in the decision-making processes needs to be advanced to ensure that their development needs are protected. 
Greater efficiency and effectiveness would be gained by improving cooperation between government departments via inter-ministerial coordination of development projects.

- Operational and human resources are limited and unevenly distributed.

- Institutional learning and monitoring and evaluation also proved uneven.

- NSP training was equally patchy in its nature and style.

Provincial MRRD staff are optimistic that CDCs will become 'the government at the district level'. Although the provincial MRRDs are confident that a 'whole government' approach to the NSP involving indicative ministries can be achieved, evidence from some FPs, the OC, some of the CDCs, and national level research would suggest otherwise. For example, projects have been delayed because of inter-ministerial arguments over whether the NSP should be building a school, or initiating an agricultural project. Moreover, the validity of the NSP itself is continually questioned by other provincial level ministries. This problem provides further evidence to support the recommendations outlined above for a 'whole government' approach to the NSP, with full and active presidential support.

While the provincial level MRRD acknowledges that it does not have the capacity to directly implement the NSP, its capacity to monitor progress is also questionable given acute staff shortages, the high number of projects, and its limited understanding of project management and programming on the ground.

\section{Recommendation 13}

A strategic plan needs to be devised by the MRRD in order for the provincial level administration to ultimately assume a long-term NSP delivery role. This must involve a significant ca pacity devel opment dimen-sion. Provincial DRRD staff will need to play a greater role in NSP quality control, enhancement and disbursement processes by the end of the Programme.

However, due to the absence of a culture of sub-national government in modern Afghanistan, it is crucial that the decentralization of operational delivery functions to DRRD provincial and district officers is carefully phased in. Indeed, it should only occur when it is clearly demonstrable that DRRD officers have the capacity to assume the role. In the meantime there is an urgent need to build DRRD management and operational delivery capacity at the provincial level and to extend it down to the district level through a phasing strategy. Until then the continued presence of an OC-type organization would be prudent to insulate the NSP against political pressure and corruption, and to ensure independent quality control and monitoring and reporting to donors.

\section{Recommendation 14}

The cap on budget allocation ('regardless of the number of real beneficiaries') is causing significant distress within the Programme and risks precipitating conflict. The problem of budget caps based on poor population surveys needs to be looked at and acted upon by central MRRD as a matter of urgency.

\section{Recommendation $\mathbf{1 5}$ \\ While the official CDC complaints pro- cedure is used, the approach to its imple- mentation varies considerably, to the extent that it risks disappearing in some provinces. This is especially worrying con- sidering the natural barriers to establishing transparency and accountability in the context of a war-ravaged state. The com- plaints procedure therefore needs to be standardized and entrenched.}

\section{Recommendation 16}

There is a need to reconcile conflicting models of governance, both at the community and programme design level. Similarly, the question of sustainability (CDCs and projects) should also be addressed at both levels.

\section{Recommendation 17}

Greater efficiency and effectiveness would be gained by improving cooperation between government departments at the provincial and district levels, with a focus on coordination. As a minimum requirement, it is important for government departments to have accurate information concerning the responsibilities and operational tasks of their counterparts to avoid confusion or jealousy.
N SP AFG HAN ISTAN Mid-term EVALUATION REPO RT 


\section{Recommendation $\mathbf{1 8}$}

Sufficient operational and human resources need to be provided by the MRRD in the field in order to maintain levels of community confidence in government.

\section{Recommendation 19}

Processes of institutional learning need to be standardized and monitored.

\section{Recommendation 20}

The nature and style of training demands consistency and effectiveness, with special emphasis on improving the provision of technical skills training.

\section{The role of the provincial Oversight Consultant}

According to respondents, the NSP has significantly improved the relationship between the participating communities and the government, in addition to creating stronger intra- and inter-community relations. However, we recommend:

\section{Recommendation 21}

The capacity development of the DRRDs by the OCs needs to be made relevant to the implementation environment and the rationale of the NSP in order to avoid institutional dependency while ensuring the Programme advances.

\section{Recommendation 22}

The level of skills and capacities of community members required by the Programme to reach its targets needs to reflect the actual skills and capacities of the community members. The advancement of targets would demand training to address the gaps and weaknesses in these areas, as identified by the $O C$ in consultation with each CDC, DRRD and FP.

\section{Recommendation 23}

As a particular concern within the recommendation above, the skills and capacities of women CDC members need to be improved towards ensuring gender-equal participation and decision-making at the community level.

\section{Recommendation 24}

The cap on budget allocation ('regardless of the number of real beneficiaries') is causing significant distress within the Programme and risks precipitating conflict. The problem of budget caps based on poor population surveys needs to be looked at and acted upon by provincial OCs and teams as a matter of urgency. Connected to this, in overcoming project budget shortfalls, further action is required to form links to other international donor programmes.

\section{The role of the Facilitating Partners}

The role of the FPs has been crucial in the social mobilization and capacity development of CDCs, and will need to continue for the short- to mid-term due to limited MRRD capacity at the district and community levels. All the FPs have serious doubts whether the CDCs will be able to function without further capacity development and direct external support. The future role of the FPs rests on whether the NSP remains purely a development programme or whether the governance component of the programme assumes a greater role in NSP Phase 2. If the former applies, then their engagement will be concluded at the end of the project, but if the governance dimension is emphasized they will: a) need to undertake further training to prepare the CDCs for taking on such a governance role; and b) need to be funded to maintain contact with the CDCs over a period of time to organize re-elections and complete the further training of the newly elected members. We would encourage the latter, in which CDCs are granted a constitutional role with statutory responsibilities at the village level. By implication this would involve the extension of the public administrative system from the district to the CDC level through the establishment of an elite of CDSOs. The role of the CDSO would be to assume the role of FPs and provide technical support to the CDC in all of its core competences.

\section{Recommendation $\mathbf{2 5}$}

Processes of lesson-learning across FPs should be improved, particularly in areas where certain FPs possess significant expertise e.g. UN-HABITAT and economic development activity or gender-oriented development programming or BRAC and working in areas with security problems. 


\section{Recommendation $\mathbf{2 6}$}

A community-ba sed programme requires a high degree of trust between the communities, the FPs and the government - this is easier to achieve if the FPs have previous rural development experience in Afghanistan. FPs therefore need to be carefully selected; a criteria is suggested below. A national NGO with prior engagement in rural development and a professional administration and monitoring capacity is the ideal choice as they don't carry overhead costs for expatriate staff, establishing new offices or costly lines of communication, and they do have a tested system for community development that can be further improved. In second place would be international FPs with considerable experience working in Afghanistan, a majority of Afghan staff at all levels, offices and experience of working in different parts of the country with rural development projects. These two categories of FPs are also better prepared to handle and mitigate security risks and have the necessary degree of trust within the communities to evoke community protection. The least 'cost effective' FPs would be those who are new to Afghanistan, overly reliant on expatriate staff that has a tremendous challenge to gain the trust of communities and government.

\section{Recommendation 27}

For some FPs the constant comparison to others working in less difficult areas is disheartening, and in some circumstances has led to a feeling of a lack of appreciation. Extra support and allowances should be given to FPs working in problematic areas, particularly in terms of a more flexible timetable and a reaffirmation of the generally good work they are doing in such trying circumstances.

\section{Recommendation $\mathbf{2 8}$}

The definition of 'project completion' should be reviewed in consultation with FPs in order to incorporate an appreciation of the intangible outcomes of the NSP (e.g. community empowerment, ability to maintain facilities, etc).

\section{Recommendation 29}

The Operational Manual should be changed as little as practicable; this would ease the pressure on the national OC and allow all other stakeholders time to consolidate practice. $^{4}$

\section{Recommendation 30}

Some of the administrative forms that require completion by the $\mathrm{CDC}$ are too complex for barely literate people to complete. There needs to be a balance between transparency and expediency, particularly for the CDCs. This is especially the case for accounting and procurement forms and the sub-project proposal completion form. A failure to adopt a more realistic approach to capacity development and community empowerment will continue to ensure that FPs remain 'Implementing Partners'.

\section{Recommendation 31 \\ NABDP and NSP thinking needs to be har- monized in order to join-up Provincial- District-CDC coordination of development programming to avoid waste and duplica- tion.}

\section{The role of Community Development Councils in programme management and operational delivery}

The following observations about the role of CDCs in the NSP are drawn from two sources: a community power survey and a household survey. The community power survey was conducted with the principal aim of assessing the extent to which CDCs had been able to assume the two key roles assigned to them by the Programme: representative governance and community development. In practical terms this involved assessing their capacity to function independently as a democratic leadership of their communities and their ability to select, plan and manage development projects. The household survey was designed both to assess the impact of the NSP in respect of its goal and objectives, and to provide evidence of progress in developing inclusive community governance as a means of empowering communities to improve their
4 This recommendation has been adopted post publication of the PRDU's Inception Report, N ovember 2005.

N SP AFGHAN ISTAN Mid-term EVALUATION REPORT 
lives, as well as detecting changes in public perceptions of government.

In the absence of baseline data, community leaders and householders in matched communities not participating in the NSP were interviewed with a view to corroborating the retrospective accounts of the CDC of governance before the NSP, and in order to distinguish between general post-war trends and changes directly induced by the Programme. It is envisaged that this research strategy will continue to be useful for the NSP until adequate baseline data is generated by the Programme through the compilation of enhanced community profiles and statistical records.

It is observed that Programme objectives should be re-focussed on the consolidation of the CDCs to ensure the sustainability of the Programme, and that the OC should seek to simplify unnecessarily complex bureaucratic disbursement processes. In particular, further strategies need to be developed to enhance the participation of women, both in community governance and in project implementation, and the inclusion of the poorest of the poor and disadvantaged as beneficiaries. It is further observed that the NSP must be viewed as a long-term process; the NSP is a radical programme in the context of Afghanistan and it is unrealistic to expect lasting change within a short time frame. For example, female participation is highly problematic in the eastern region, and Nangarhar in particular. The east is a very conservative area and FPs and the OC acknowledges that an increase in female participation will only occur gradually, a point certainly borne out by this research. Nonetheless, NSP communities have far more tools than non-NSP communities for envisaging problems, linking priorities and planning. NSP communities are therefore less reactive and more proactive, and have a significantly more favourable opinion of the government. This is underpinned by optimism for the future that non-NSP communities do not share. The non-NSP communities have a strong distrust for government and little faith in its ability to address their problems. Indeed, there are many misplaced perceptions about the government, and Afghanistan in general, because there has not been any formal contact with governmental organizations to clarify the facts. As one villager put it, in a non-NSP community, 'the government has done nothing for us'.
We therefore suggest a broad range of recommendations for CDCs aimed at improving project delivery through simplification of bureaucratic processes, and enhancing gender balanced institutionbuilding and developing capacity at the local level through processes of consolidation.

\section{Simplification}

\section{Recommendation 32}

The Disbursement system is too onerous and should be made in one instalment. 5

\section{Recommendation 33}

While the fund transfer mechanism system has improved through the delegation of approval to the Provincial OC, and by reducing the number of instalments, we still believe that much could still be done to speed up the approval process and disbursement process through, for example: a less bureaucratic CDC and project formulation processes; allowing villagers to establish a bank account where the money might be deposited, rather than having to bring the money to the village and, not least, by giving the villagers a fixed date when the funding will be available.

\section{Consolidation}

The sustainability and long-term success of the NSP can only be guaranteed by the development and consolidation of the capacity of the CDC.

The idea that capacity is essentially concerned with the ability of people to function effectively to influence the conditions of their communities, and 'implies a long-term investment in people and their organizations', has long been recognized. (Eade, 1997:1-3)

However, although capacity-building may be concerned fundamentally with investing in the human capabilities of a community or organization, that development also requires the advancement of necessary resources and conditions. Failure to grasp that the capacity, or power, to act effectively is conditioned by these circumstances as well as personal knowledge and ability, has probably been at the root of many difficulties with capacity-building programmes, 
where donors have seen the need to develop institutional and personal capacity through "training", while recipients have been focussed on accessing financial resources. In the field of community development, promoting the ability of the poor to take control of resources, access markets and information, and participate in decision-making, or empowerment, is also now widely considered as an important component of capacity-building.

It is probably for this reason that the term capacity development is now preferred, because it indicates a more holistic approach which encompasses all three aspects of capacity associated with participatory development practice: human ability, material resources and power (Whyte, 2004:19).

In Phase 2 the NSP needs to ensure that the CDC's capacity to function in each of these aspects is consolidated and developed by creating favourable institutional, social and economic conditions, as well as opportunities for further skills development. The field research also clearly indicates that the precise combination of strategies required after the completion of Phase 1 will vary from one community to another, depending on their basic level of development and local socio-economic conditions. The following recommendations are by no means exhaustive.

\section{Recommendation 34}

A greater focus should be placed on effective social mobilization, capacity development and institution-building. This is especially relevant in CDCs where the vast majority of people are illiterate. Again, a failure to adopt a more realistic perspective will mean that the FPs will continue to be 'Implementing Partners', placing the longterm sustainability of CDCs at risk. A twin track process of consolidation and expansion should be devised. A Phase 2 Consolidation Strand should be aimed at CDCs who have successfully completed subprojects. An action zone approach should be deployed where appropriate within this strand whereby CDCs sharing common CDP goals should be encouraged to engage in joint programming to meet community priorities and achieve economies of scale. The Phase 2 Expansion Strand should focus on the strategic roll-out of the NSP to ensure nation-wide coverage of the NSP, but with a bias towards integrating vulnerable communities.

\section{Recommendation 35}

In order to en sure the long-term survival of CDCS, the NSP process needs to be incentivized. We recommend the use of 'top-up' grants and 'matching funds' to reward CDC initiatives on NSP priority areas such as gender based and alternative livelihood programming.

\section{Recommendation 36}

Where appropriate, certain projects should have a component which should specifically benefit the poorest of the poor and encourage pro-poor growth. In the future there will need to be more emphasis on poverty reduction initiatives that focus on livelihoods rather than physical infrastructure. Our research findings suggest that there is a desire to consolidate community gains made through the NSP with related initiatives for employment, income generation and further skills training. However, there needs to be a careful balance between institution-building objectives and the establishment of programmes that have a genuine impact on pro-poor growth. Indeed, in the medium term pro-poor growth programmes should only be rolled out on a strategic basis in areas where CDCs have become socially embedded and are capable of acting benevolently.

\section{Recommendation $\mathbf{3 7}$}

Continued support should be given to women-only CDCs. The gradualist approach to more significant women participation within the NSP process should also continue, and where possible womenonly priorities should be addressed as a priority. A separate NSP fund for projects targeting women and children should be created and bids encouraged, but this needs to be accompanied by the strengthening of women's capacities within the CDC. These findings support the view that separate women's groups with separate project budgets are necessary in the shortterm to develop women's capacity. At the same time this should not be used as a mechanism for institutionalizing their exclusion from decision-making in the general CDC. 


\section{Recommendation $\mathbf{3 8}$}

There is significant concern about the longterm sustainability of CDCS once NSP projects have been completed. It is therefore recommen ded that CDCs should assume a broader range of responsibilities with community development planning and programming to provide them with an ongoing role in community governance. This should be introduced through a phasing process linked to the attainment of certain levels of capacity. The new responsibilities could include: resolving internal community disputes (e.g. land, water rights); bargaining with traders; sharing lending risk; bargaining for better share cropping arrangements; bargaining between CDCs and developing district plans and projects, thus achieving economies of scale; and the registration of births, marriages and deaths. A more ambitious and longer term task, which is nonetheless worthy of consideration, is to use CDCs to collect local taxes on the basis that they would retain the large part of the levy for community development activities, while transferring the remaining part to government.

\section{Lesson-learning and} capacity development

See also recommendations 22 and 23 above.

\section{Recommendation 39}

In relation to engineering projects there is a need for a formalized system of appointment for 'site managers' by CDCs. Focussed training is required for those appointed. CDCs should provide overall project direction but a separate project management team should be appointed. CDC members should remain unpaid (to show commitment to the community) but the project management team should be paid allowances.

\section{Recommendation $\mathbf{4 0}$}

The recent CDC jirga was very well received by rural communities and helped to convince the cynics that the NSP was a positive step forward. Regional and national CDC jirgas should be arranged on a regular basis to reinforce the government's position, consolidate the perceptions of existing CDC members and demonstrate the government's support for newly created CDCs.

\section{Recommendation 41}

CDC members have benefited from 'exposure visits' to other local CDCs. In the spirit of a national programme advocating solidarity, provision should be made for regional or national 'exposure visits' to enable lessons to be learned and relationships to be formed - both of which would directly contribute to state building.

\section{The enhancement of NSP engineering projects}

We also undertook an evaluation of the quality of NSP engineering projects. It was observed that standards of project design and construction varied to extremes, although most were appropriate and adequate. At one end of the scale one could cite the impressive micro-hydropower project at the village of Salakhail, Skakardar District (Kabul Province) where relevance, specification, design, construction and sustainability were all covered very well, resulting in an excellent project all round. At the other end of the scale one could mention the school at Markaz-eDawlatabad, Dawlatabad District (Balkh Province) where relevance was inadequate, specification and design were sub-optimal (in terms of school size and earthquake mitigation), and construction standards were sometimes poor.

There appear to be satisfactory processes for checking engineering designs, particularly for infrastructure where failure could lead to human casualties. [Particular emphasis needs to be given to ensure that for structures, adequate provision is made for extreme snow and wind loads, and for earthquakes.] However, there was no clear chain to ensure that the design (as checked) was that which was actually implemented. Although difficult to firmly correlate, it did seem that there were instances where adequate designs were compromised by 
poor construction - indeed there was at least one case where it appeared that steel reinforcement in a retaining wall had been omitted to save money.

In general, there was also a good understanding of the need for an operations and maintenance plan; however, there were mixed responses on how this should be done - not always was someone nominated and trained for responsibility, and rarely was there a contingency or succession plan in case of incapacity or unavailability of anyone nominated. Ongoing costs were a big factor (especially for projects that would perpetually rely on an imported fuel supply) and, whereas most CDCs had simple physical/financial plans, their biggest concern was whether the community savings box would remain adequately filled in the longer-term. A range of recommendations follow for the enhancement of engineering projects.

\section{Recommendation 43}

The need for mitigation measures against natural hazards (particularly earthquakes, landslides and floods) should be given a higher profile. General requirements for all projects (whether by avoidance or mitigation of risk) should be highlighted at the specification stage, and all infrastructure projects should be vetted for adequate compliance by an appropriately qualified engineer.

\section{Recommendation 44}

A Block Grant fund needs to be made available to the NSP to mitigate the affects of disasters and terrorist attacks that damage/destroy NSP initiatives. The availability of such a fund would be extremely useful in building social solidarity in times of crisis. A proposal should be made to NSP donors to set up a Disaster Mitigation Fund for these purposes.

\section{Recommendation $\mathbf{4 5}$}

A more tangible link should be established between those who design projects and those who construct them. There should be a mandatory requirement for an engineer from the designer's organization to visit projects under constru ction at appropriate times, to ensure that respective designs are being followed and that no shortcuts are being taken in respect of materials and standards that might compromise the integrity of the structures concerned. Auditable records of these inspections should be maintained. It is recognized that there appears to be a shortage of suitably qualified engineers in Afghanistan - unsurprising given the scale of reconstruction and development. Therefore, those projects where non-adherence to design requirements could lead to catastrophic failure should receive the highest priorities for inspections.

\section{Recommendation 46 \\ CDCs should be encouraged to identify clearly who is responsible for: \\ - Project selection and subsequent direction (normally the whole $\mathrm{CDC}$ ); \\ - Project management (normally a bespoke trained team within the $\mathrm{CDC}$ ); \\ $\checkmark$ Site management (normally an adequately trained individual (plus reserve) who is probably not in the $C D C$ ).}

\section{Recommendation 47}

$\mathrm{CDC}$ members should not receive remuneration for their activities. However, CDC members or local residents working in project management or site management should be rewarded - so if they are also CDC members, it should be noted that it is for their enablement roles, not their empowerment roles, for which they are being compensated.

\section{Recommendation $\mathbf{4 8}$}

A major initiative should be established to encourage the introduction of formal training in all the key construction skills, underpinned by the award of appropriate qualifications. The training should be village-based with instructors visiting at regular intervals. Formal instruction need not be very long (and could be conducted for groups of villages in collective sessions) but should be substantial enough to allow for follow-up on-the-job training. For each skill set, a required standard should be defined and a method of testing the standard required should be established. Initially, this standard should be applied nationally by MRRD and its agencies to all
N SP AFGHAN ISTAN Mid-term EVALUATION REPO RT 
those working within NSP. In time, this should be integrated into agreed national construction training and testing standards. An important element of the initiative in order to promote portability of acquired skills would be the award (and registration) of appropriate certificates (suitably designed to militate against fraudulent use). A similar initiative is needed for training and qualifying site managers, though in this case a longer period of formal instruction will be required (say two weeks), and there would be considerable reliance on the individual's past experience when being formally assessed for the appropriate qualification.

\section{NSP Financial O perations}

Four main obstacles to effective and efficient NSP financial management have been identified in our survey: disbursement, procurement, liquidity and limited evidence of corruption. The NSP-OC's failure to meet its roll-out targets for December 2004 to August 2006 was partly attributable to prolonged delays that occurred in: the procurement process for securing critical goods (the responsibility of the MRRD); 6 in the disbursement process due to the absence of Block Grant funds (the responsibility of the WB); and in the inefficient transfer of funds from $D A B$ to CDC bank accounts. A further bottle-neck emerged in December 2005 due to the lack of liquidity in the Block Grant fund. Block Grant disbursements started to slow down in December 2005, reaching a complete halt in February 2006. The absence of Block Grant funds for disbursement further undermined the ability of the $\mathrm{OC}$ to meet its roll-out targets. It is also noteworthy that

6 For example, 40 generators requested by FPs in 0 ctober 2004 were not delivered until December 2005, and 20 four-wheel drive vehicles were requested in January 2005 by the PO $\mathrm{OC}$ but were not ready for use until June 2005.

7 N SP/OC (2006), Analysis of Experiences and Lessons Learned in Program Implementation, 2003-6, Kabul.

EXECUTIVE SUMMARY payments to FPs are also seriously behind schedule - 93 per cent of invoices received from FPs for services rendered in the second half of 2005 are yet to be reimbursed (the responsibility of the MRRD). been very little 'political' help forthcoming from the MRRD or the donor community to help the NSP/OC deal with these high level bottle-necks in the disbursement and other financial processes. It is therefore unsurprising that targets have not been met. However, the OC has been able to develop a Memorandum of Understanding ( $M O U$ ) from $D A B$ to transfer grants to the provinces within two weeks. The situation needs to be
It is evident from our survey that there has carefully monitored and contingency plans for alternative disbursement mechanisms put into place. While it is important to build the capacity of Da Afghanistan Bank (DAB) to play a disbursement role, efficient disbursement processes are axiomatic to the operational delivery of the NSP. As we noted in Section 5, improvements have also been made with regard to the introduction of a streamlined disbursement process to deal with the problems emanating from the initial policy of requiring three instalments per sub-project.

Our surveys picked up on very few instances of corruption committed by members of CDCs. Indeed, the evidence from our research is that where you have effective CDCs corruption does not occur. Indeed, the NSP provides an outstanding opportunity to learn about how and why corruption takes place, and what mechanisms lead to or prevent corruption. It is therefore observed that corruption can be minimized through trust management, capacity development, and social audit. There is evidence, however, that the capacity of CDCs to provide effective reporting to the community and to the NSP on project progress and the use of funds could be improved.

\section{Recommendation $\mathbf{4 9}$}

In accordance with the recommendations outlined by the $\mathrm{OC}^{7}$ - improvement needs to be made to operating processes at the national level in relation to the processing of FP contracts, the replen ishment of Block Grant funds and the payment of invoices. This would be best managed through one office under the auspices of the NSP.

\footnotetext{
Recommendation $\mathbf{5 0}$

A further capacity development deficit can be identified in relation to the manage ment of NSP finances. A strategic plan needs to be devised by the MRRD in order for its finance team to assume the role of the $\mathrm{OC}$ in the disbursement process. This must involve a significant capacity development dimension. MRRD staff will need to play a greater role in NSP auditing, disbursement and other financial processes by the end of the Programme.
} 


\section{Recommendation $\mathbf{5 1}$}

Further training needs to be provided to CDCs on auditing, transparency and financial reporting processes.

\section{Recommendation 52}

The NSP provides an outstanding opportunity to learn about how and why corruption takes place and what mechanisms lead to or prevent corruption. Research should be supported by the World Bank in this a rea.

\section{Community Development Councils and future governance in Afghanistan}

We propose a constitutional role with statutory responsibilities for CDCs at the village level, 8 and the extension of the public administrative system from the district to the CDC level through the establishment of an elite of CDSOs. The role of the CDSO will be to provide technical support to the CDC in all of its core competences. The establishment of this technocratic elite, with attractive conditions of service, is central to the long-term sustainability of CDCs and should be a key component of the NSP's consolidation strategy. This proposal will also require a long-term capacity development strategy which should be integrated with broader processes of civil service reform.

It is therefore recommended that:

\section{Recommendation 53}

CDCs be institutionalized into the system of governance.

\section{Recommendation $\mathbf{5 4}$}

CDC By-laws are extended to include cyclical elections.

\section{Recommendation $\mathbf{5 5}$}

CDCs are given statutory powers in relation to community development planning and programming in core programme areas (education, health, water, energy, sanitation and basic infrastructure).

\section{Recommendation $\mathbf{5 6}$}

Federated structures are created at the district level in order for communities to interface with government agencies and development programmes.

\section{Recommendation $\mathbf{5 7}$}

Community Development Officers are recruited and trained to support and promote human capital development activities in rural development.

\section{Recommendation $\mathbf{5 8}$}

We therefore recommend that where a ppropriate certain projects should have a component which should specifically benefit the poorest of the poor and encourage pro-poor growth. In the future, due to donor mandates, it is likely that more emphasis will need to be placed on poverty reduction initiatives that focus on livelihoods rather than physical infrastructure. Our research findings suggest that there is a desire to consolidate community gains made through the NSP, with related initiatives for employment, income generation and further skills training.

\section{Recommendation 59}

The NSP should foster linkages between sub-projects. For example, the provision of electricity generators would be much more effective if the generators were to power mills, small manufacturing, or refrigerated storage rather than focussing purely on the provision of light and the encoura gement of a consumer life style.
8 See Recommendation 31.

N SP AFG HAN ISTAN 


\section{Linkages with the evaluation of other community-driven development programmes}

The findings of this evaluation and several of its recommendations concur with the Independent Evaluation Group's evaluation of the effectiveness of World Bank support for CDD. Please consider the following.

\section{The strengths of community driven development interventions}

- Borrower officials believe that a participatory approach can contribute to poverty alleviation.

- CDD projects help to reduce the cost to government of delivering infrastructure.

- They have increased access to remote communities to service-delivery infra-structure.

- Capacity-enhancement efforts are likely to be more successful when a bank project supports indigenously matured efforts or provides sustained, long-term support to communities beyond a sub-project cycle.

- CDD projects have enhanced government capacity to implement participatory interventions.

\section{Weaknesses of community driven development interventions}

- Much more success is achieved in CDD projects in relation to quantitative goals (such as the construction of infrastructure) than on qualitative goals (such as capacity enhancement or quality of training).

- M\&E systems do not allow systematic assessment of the capacity-enhancing impact of CDD interventions. It is often assumed that meeting the quantitative goals will automatically fulfil the qualitative goal; for example, holding a certain number of training courses is expected to enhance capacity.

${ }^{9}$ See Sections 3, 4, 5 \& 6 .
The poorest may not always benefit from CDD projects.

The sub-project cycle is too short to sustainably enhance community capacity where it is weak or does not exist.

More changes are needed to improve fiduciary and safeguard compliance in CDD projects.

This evaluation lends further support to the Independent Evaluation Group's recommendations of the need to ensure that:

base-line surveys are conducted in CDD projects;

the costs and benefits of undertaking CDD interventions are systematically calculated; and

CDD programmes are integrated into overall country assistance strategies.

Indeed, the evaluation advances CDD knowledge in all three respects.

\section{Programme costs, expectations and impact}

In an ideal rational-type evaluation a programme should be strictly evaluated against the achievement of its aims and objectives. However, it is evident from this analysis of the obstacles to programme delivery that: a) a significant range of obstacles have been confronted by the NSP which have constrained its capacity to meet ambitious targets; b) although some of these have been the product of the absence of strategic thinking, the vast majority are outside the control of the NSP/OC and its FPs, and are generally typical of post-war reconstruction development programming; and c) despite these constraints significant achievements have been made. This evaluation has found evidence of at least 11 sets of benefits which have been derived from the NSP:

1. increased public perceptions of national solidarity achieved through state-building - e.g. the creation of new institutional architecture at the central (NSP-OC, DAB), provincial (Provincial Office [PO], OC), and village (CDCs) levels; 9 
2. improved state-civil society relations as a consequence of improvements in national solidarity; ${ }^{10}$

3. greater awareness of the activities of government as a consequence of the work of the PCU; 11

4. the empowerment of rural communities through the establishment of a new legitimate form of community governance; ${ }^{12}$

5. heightened perceptions of community solidarity achieved through processes of community governance; 13

6. delivery of governmental capacity development (provincial and district level MRRD, NSP/OC, PO OC, DAB and Ministry of Finance staff); 14

7. delivery of FP capacity development (training); 15

8. delivery of community capacity devel opment (training); 16

9. direct forms of economic development through improved productive capacity and the provision of work in relation to certain NSP projects; 17

10. indirect forms of economic development facilitated by: a) increased economic activity arising from improved infrastructure, and b) savings derived from lower costs of production; 18 and

11. improvements in the quality of rural life. 19

As stated in the technical proposal for this mid-term evaluation, it was premature to attempt to determine the impact of the Programme either in terms of achieving its stated objectives (laying the foundations for improved community level governance and poverty reduction), or in terms of the overarching aim of strengthening national solidarity. Nevertheless, as the evaluators expected, it has been possible to identify the above qualitative trends that can be attributed with some confidence to the interaction of the Programme with the objective socio-economic conditions in the communities and these, if sustained, would be capable of delivering the intended impact. No evidence was found of negative impact, although a number of threats to the sustainability of the positive gains were identified.

This inclusive approach to evaluating NSP Programme costs and benefits reveals significant gains to the Afghan people in relation to institution-building (limited democratization) and capacity development (mainly in skills development) and social solidarity at the national and community levels, and to a lesser degree at the provincial and district levels. Impressive benefits have also been derived economically by: creating livelihood opportunities and direct forms of economic development through improved productive capacity and the provision of work in relation to certain NSP projects; and the provision of indirect forms of economic development facilitated by increased economic activity arising from improved infrastructure, and savings derived from lower costs of production. Important gains in gender equality have also been achieved in certain regions.

These benefits justify the overhead costs of the Programme, particularly in years 1 and 2 of the Programme. Moreover, overhead costs should diminish dramatically as a consequence of: a) lesson-learning from Phase 1 ; b) elimination of unnecessary bureaucracy through the simplification of delivery systems; and c), the gradual development of a new institutional venue for the delivery of the Programme. However, these achievements will need to be consolidated in the ways suggested above in order to ensure the long-term future of what may be deemed a development programme of outstanding potential.
10 See Section 4.

$11_{\text {See Section } 2}$

12 See Section 4

13 |bid.

14 See Section 2.

15 Training in relation to delivering aspects of the N SP. See Sections 2 \& 3.

16 See Section 4

17 See Section 7.3.

18 Ibid.

$19_{\text {Ibid. }}$ 


\section{Findings and Recommendations}

\section{Programme Design}

\section{and Rationale}

The NSP has provided Afghanistan with the best chance it has had for real development in its modern history.

It is our responsibility to seize this opportunity and to make it work. (Minister, Islamic Republic of Afghanistan)

We are very happy with the NSP; sure there are problems that need looking at for the second phase, but there have been some very significant achievements. (NSP donor stakeholder)

The NSP is an outstanding success. It is managed well, funds are delivered to the villages, money is disbursed effectively and good programme outputs are achieved.

(NSP donor stakeholder)

The principles underpinning the NSP participation, pro-poor poverty reduction and government ownership - are the first principles of development. The NSP deserves our support because it is the best chance that Afghanistan has of getting real development. (NSP donor stakeholder)

The rapid expansion of the NSP has been a success but the pace of implementation creates inevitable problems. The capacity to deliver the NSP to 6,800 villages is simply not there. More implementation problems will emerge... we need a more incremental approach. (OC representative)

The NSP is a success, no rational person would say otherwise, but it needs to belong to the whole government and not one ministry. It can't be right for
50 per cent of the annual government budget to be distributed through programmes in one ministry. (Minister, Islamic Republic of Afghanistan)

NSP was the only programme that had any real impact so far. The best aspect was the CDC which enabled communities to solve their own problems. (Deputy Governor)

They came together in happiness and sadness and talking with each other

to solve problems.

(Woman householder

in Shah Qadam CDC, Bamyan)

\subsection{Analysis}

It is self-evident that the Afghan communities, their government and the aid community are facing a formidable task in reconstructing Afghanistan. The basic needs are great, and the developmental needs include the immense task of recovering years of lost opportunities while responding to an ever-increasing level of expectations brought about by the country's relative stability. At the same time reconstruction is taking place at a time when there has been a shift in the way aid to Afghanistan is being considered, the attitude of 'any help is worthwhile' is changing to recognizing that the future stability of the country relies on appropriate and sustainable systems of governance and economic recovery. In this context, the NSP represents the flagship post-war reconstruction initiative of the Islamic Republic of Afghanistan. It is a distinctive programme because of the 
emphasis placed on deploying the rapid disbursement of Block Grants to rural communities as a policy instrument for both 'bottom-up' institution building, through the creation of directly elected CDCs at the village level, and pro-poor economic growth. The Programme is also distinctive in that it is implemented through the government and has nation-wide coverage. It is designed both to help the rural communities rebuild their lives and their nation, and to demonstrate that the Afghan government, with assistance, could develop the inclusive governance structures required to sustain a stable government. These are all important qualities for empowering institutions and sustaining development outcomes.

Considering the transitional context in which the Programme was designed, the rationale behind supporting a governmentled national programme (thus extending the visibility and influence of central government in the provinces) is a commendable one. It is important to remind ourselves that this occurred at the same time when MRRD, with its limited resources and capacities, was rightly being re-oriented to directing policy and implementing programmes through partners in the non-governmental and private sector rather than implementing directly. The responsibilities of the Ministry include: the formulation of rural development policies, strategies and guidelines; the coordination and monitoring of other implementing agencies working in rural development as well as mobilizing the resources for it. The employment of the NSP/OC was particularly important for the speedy implementation of the Programme, and in our opinion can be credited with much of the achievements so far. Equally critical for the comprehensive progress of the Programme has been the contracting of FPs, many of whom have had extensive experience in community mobilization and the implementation of development programmes.

The initial design of the NSP recognized that in an operating environment of chronic emergencies and media-led donor support, community participation is the key to the sustainable and effective rehabilitation of the service sector. It reflects the view that local communities and institutions bear a key responsibility for the rebuilding of their own services and infrastructure, and are therefore the real owners of the overall process of post-war rehabilitation. By placing the communities at the centre of the rehabilitation process NSP potentially offers the government and other development agencies the opportunity to adapt their responses to the complex dynamics of longterm recovery. This is a major shift from the traditional tendency to rely on quick fixes through 'top-down' project-driven relief programmes with a misguided emphasis on short-term indicators (for example, the number of projects delivered, people helped, expenditure targets met, etc.), and the habitual excuse of 'context constraints' and the 'lack of resources', that prevent governments and agencies alike from harnessing longer-term developmental potential and building a stable and peaceful recovery. The real challenge for post-war reconstruction is to develop local institutional capacities for providing assistance to recovery processes, in a manner that reinforces rather than undermines the dynamic of recovery at the local level. This is something that NSP has the potential to deliver.

However, when it came to implementing the Programme, the NSP faced a combination of some common implementation problems such as: 1) poor problem and context definition; 2) ambiguous and inconsistent objectives; 3) inadequate policy design, particularly in terms of capacity development and sustainability; 4) certain recalcitrant implementing actors; 5) lack of initial support from some affected communities as well as some ministries; and finally 6) unstable and uncertain socio-economic and security contexts in a number of the provinces. Of course, some of these factors played a greater role in impeding successful policy implementation than others. Similarly, with the national coverage of the Programme and the sheer size of the enterprise, unprecedented in the Afghan context, it was inevitable that some projects would be more successful than others and some facilitating partners more efficient than others.

Nevertheless, the main tension between the rationale of the NSP and its implementation is derived from the limited time-frame established for its implementation, which has had a major knock-on effect on the successful achievement of the original goal of the Programme. It is evident that what is fundamentally a development programme has been rolled-out with a relief mindset, leading the MRRD to emphasize increased coverage and rapid disbursement of Block Grants to communities. This emphasis on
FIN DIN GSAN D RECOMMENDATIONS 
$1_{\text {In our assessment, the World }}$ Bank's April 2005 Supervision Mission played an important role in reinvigorating the process.

2 A number of FPs have expressed concern over the constant change of the $0 \mathrm{M}$.

3 See N SP/O C, 'N SP 1: Lessons Learned', 2005. disbursement may have been a rational response to the political climate of the time and have reflected the critical need to provide a visible governmental presence in the provinces, districts and villages of Afghanistan. It was a conscious political act of state building, seeking to build public confidence in an infant government. Nor was this relief mindset confined to the national level. Many of the people forming CDCs were returning refugees, mostly from Pakistan and Iran, where their situation was helped by relief efforts. According to many NSP FP stakeholders, understandably many people still have this relief mentality and have difficulty making the transition to identifying longer-term community development priorities. However, from the outset certain rudimentary components of programme design, formulation, implementation and management were lost in the rush to delivery. For example, the NSP/OC was recruited after six months of operation and was expected to disburse Block Grants immediately. There was therefore no time for a phasing-in strategy during which: a) a rational Operational Manual could be finalized; b) consistent performance indicators could be identified and effective monitoring systems established; c) coherent and consistent community profiles completed; d) an effective capacity development strategy for MRRD staff could be developed; and e) a rational NSP/OC exit strategy devised. Moreover, many of the traditional nuts and bolts of organizational management, such as the development of a human resources strategy and logical frameworks to guide programme management, took a back seat in the drive for CDC creation and the rapid disbursement of Block Grants to support NSP projects.

The NSP was designed on the hoof in response to political priorities and until recently was deficient with regard to its operational, monitoring, quality assurance and capacity development activities. While the NSP/OC has made concerted efforts over the past 6 months to work on these deficiencies, at present the base-line field data does not exist to conduct a 'scientific evaluation' of the achievements of the Programme (however significant they may be). ${ }^{1}$ Moreover, the political/security driven choice of first wave communities for disbursement led to the rapid roll-out of the Programme, an over reliance on expatriate expertise and the failure to engage in effective capacity development at the national and provincial levels.
These problems are reflected in the constant changing of NSP objectives and key performance indicators in the Operational Manual in response to new political priorities. ${ }^{2}$ For example, NSP's focus shifted from local governance to rural infrastructure but the MRRD, NSP facilitating partners and the OC lacked the technical engineering expertise needed to support communities. ${ }^{3}$ In order to ensure effective monitoring and evaluation, it is now crucial to have a settled understanding of programme objectives in order to achieve desired inputs.

At the same time new realities have emerged that prompt the need for some marginal adjustments to the programme design for Phase 2. These include:

- the importance of a greater emphasis on quality programming in order to ensure sustainable programming - NSPs need to make development sense;

the implementation of NSP through one ministry was a necessity in Phase 1 but now a 'whole government approach' and greater resource sharing is required in order to maintain stable government, build governmental capacity and to deliver on broader national development goals;

$\checkmark$ communities now have an expectation of the development of NSP income enhancing projects, but most projects are infrastructural that only provide for short-term employment opportunities and therefore provide a modest contribution to poverty reduction there needs to be a greater focus on livelihood enhancing projects in Phase 2 (e.g. alternatives to poppy cultivation).

Understandably the NSP was formulated in a very short period of time (two to three months). In its formation, it benefited from transferring community development policy from elsewhere. However, the short period of time allowed for the design of the NSP meant that there simply was not enough time to pay sufficient attention to investigating international exemplars of post-conflict transition, and therefore the international comparisons work that was conducted focussed on convenient examples (e.g. Cambodia, Indonesia). The international case study evidence suggests that a number of factors may act as constraints to successful programme learning in community development planning and programming. Some of these factors are evident in the NSP context, and need to be investigated further, 
including: 1) limited search for successful and compatible exemplars, particularly in relation to capacity development of government departments; 2) multiple goals (declared and undeclared), increasing the Programme's complexity; 3) little or no compatibility with existing policy systems; 4) resource constraints, including political, bureaucratic, technological and economic resources; and 5) the initial cultural and ideological incompatibility between donor policy and the dominant value system amongst MRRD employees.

\subsection{Summary and recommendations for programme design and rationale}

Overall, Phase 1 of the NSP has undoubtedly been a success, given the difficult environment in which it has operated. Indeed, only a small minority of our respondents questioned the success of the Programme given the extraordinary constraints under which it has operated. Nonetheless, several problems can be identified in terms of policy formulation, implementation and monitoring and evaluation arising from problems in the process of programme formulation and inception, which have created operational obstacles that need to be surmounted in Phase 2.

\section{Recommendation 1}

The political objectives of the NSP (e.g. the establishment of CDCs within the formal system of local governance) need to be expressed more overtly within the Programme objectives.

\section{Recommendation 2}

New 'simplified', 'realizable' and publicly 'knowable' programme objectives and a 'simplified' and 'realizable' set of performance indicators need to be drawn for NSP Phase 2 which express the governance, capacity development and economic growth objectives of the NSP more explicitly so that they can be measured over time.

Monitoring systems should be simplified to focus on developing time series data around a simplified set of performance indicators. A coherent and consistent representative sample of community profiles drawn to common criteria needs to be completed for comparative and evaluative purposes.

\section{Recommendation 3}

NSP Phase 2 should be a period of consolidation rather than expansion. The aim of rolling out the NSP to 6,800 communities in Year 3, despite the considerable backlog of Year 1 and 2 projects, is not tenable. There should be a greater focus on quality rather than quantity to allow for effective social mobilization and institution-building to take root, and for projects to be sustained through high quality community development planning. A twin track process of consolidation and expansion should be devised. A Phase 2 Consolidation Strand should be aimed at CDCs who have successfully completed sub projects. An action zone approach should be deployed where appropriate within this strand whereby CDCs sharing common CDP goals should be encouraged to engage in joint programming to meet community priorities and achieve economies of scale. The Phase 2 Expansion Strand should focus on the strategic roll-out of the NSP to ensure nation-wide covera ge of the NSP, but with a bias towards integrating vulnerable communities.

\section{Recommendation 4}

NSP Phase 2 needs to embrace a 'whole government approach' both in order to gain greater political legitimacy in the eyes of political elites, and to coordinate national development planning and programming more effectively to gain economies of scale and to a void waste and duplication.

\section{Recommendation 5}

An International Comparisons and Lessons Learnt Unit should be established in the MRRD to help support effective policy learning both in Phase 2 of the NSP and the Ministry's other major development programmes.

The Unit could start by working through the institutional memory of the OC. It should ideally be linked to an independent academic body, such as Kabul University, to ensure objectivity. 


\section{Recommendation 6}

Phase 2 needs to place a greater emphasis on increasing the direct economic benefits of the NSP through both incentivizing CDCS and encouraging income-generating programmes to meet its economic growth strategy.

\section{Recommendation 7}

NSP Phase 2 requires more effective donor coordination. Donors should be aware of the consequences of action when they pick and choose where their NSP funding goes. An integrated approach should be adopted by the donor community, both to ensure that international funding helps to support national development priorities and to provide for better coverage. 


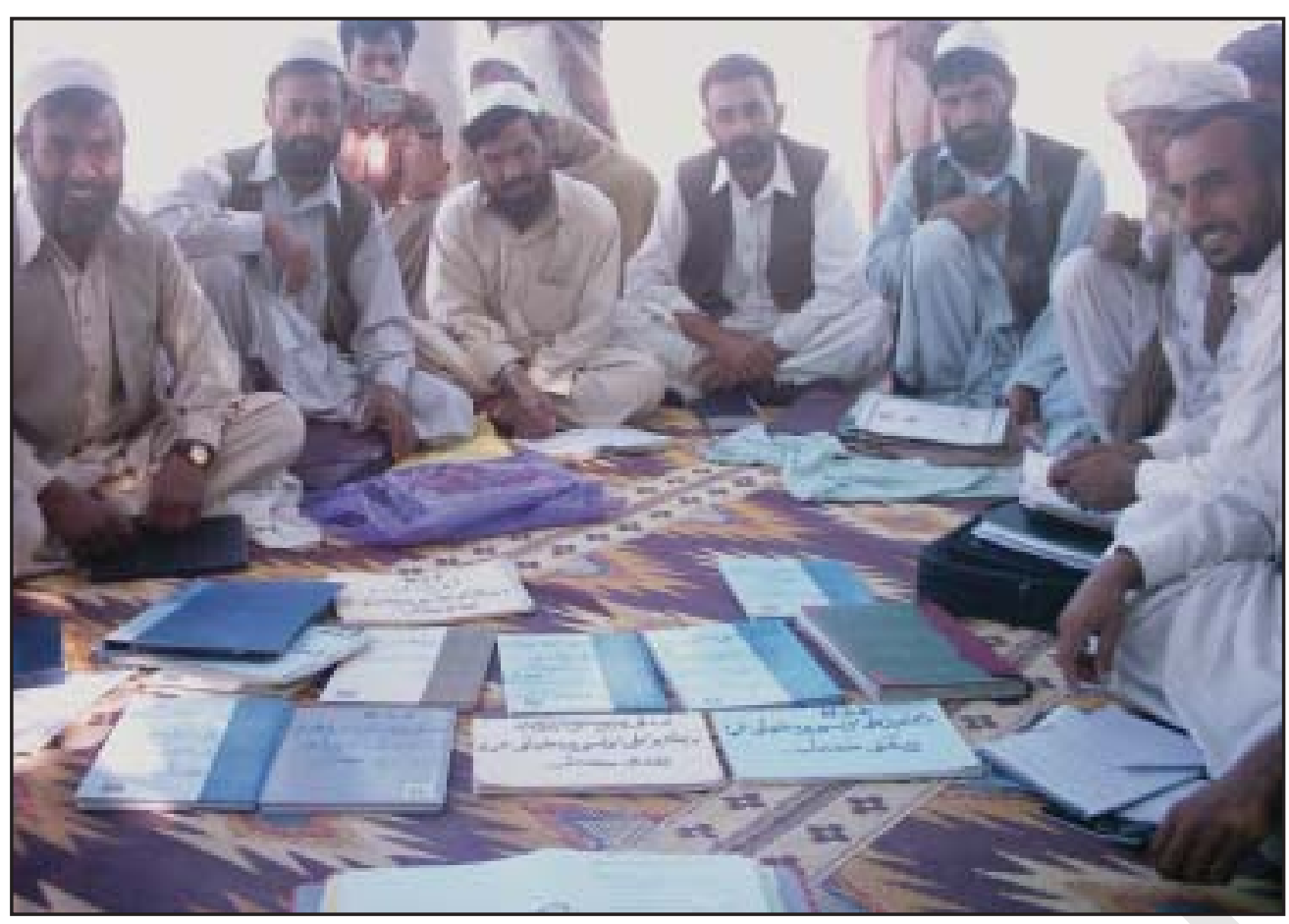

FIN DIN GS AN D

RECO MMEN D ATIO NS 


\section{Findings and Recommendations}

\section{National Level}

\section{Programme Management}

and Coordination

This section of the report focusses on the management and coordination of the NSP at the centre of the Afghan political system, focussing on the work of national level coordination committees, the MRRD and the NSP OC. The analysis draws mainly on qualitative data derived from extensive nationallevel interviews and two workshops held with NSP stakeholders, including representatives from: all the core ministries involved with the NSP; MRRD and NSP/Oversight Consultant $(\mathrm{OC})$ staff; Facilitating Partners (FPs) and all the participating donors (Canadian International Development Agency, Department for International Development, European Union, US Agency for International Development, Japan International Cooperation Agency).

\subsection{National level coordination committees}

The NSP at the national level is in theory coordinated through two committees - the External Review Committee and the Interministerial Committee. The External Review Committee is comprised of NSP donors, UN agencies (UNAMIR, UNICEF, UNHCR) and the Ministry of Finance. It is mandated to meet every three months. While the donor community is unanimous in its support for the NSP it is less flattering on the work of the Committee:

The NSP needs to institutionalize donors into the deliberative process.

At the moment we are simply not geared to support the NSP effectively.

(NSP donor stakeholder)
The External Review Committee needs

to be more proactive; it should be a problem-solving committee but we are not asked to play this role.

(NSP donor stakeholder)

We need to be organized;

the present committee is a talking shop no more, no less.

(NSP donor stakeholder)

We can be an important source of support for the MRRD especially in their battle with other ministries.

(NSP donor stakeholder)

The donor community thus calls for an action oriented coordination committee aimed at providing support for the NSP both in its strategic thinking on broader development issues and in providing political pressure to remove bottle necks at different levels of the delivery system.

The Inter-ministerial Committee includes the ministries of Finance, Public Works, Women's Affairs, Public Health, Agricultural Affairs, Education, and Water and Energy. Once again it is mandated to meet every six months with the aim of ensuring that the NSP is linked into the work of the respective ministries. For example, the construction of a NSP school has to comply with the Ministry of Education's own national plans and building regulations, and Memorandums of Understanding (MoUs) have been set up between the respective ministries to achieve this. In practice, this Committee functions in a very limited way. Indeed, three key ministries were not aware of its existence: 
I can't recall being involved in any Inter-ministerial Committee meeting.

We've discussed the NSP in Cabinet but that's as far as it goes.

(Minister, Islamic Republic of Afghanistan)

What Inter-ministerial Committee? (Minister, Islamic Republic of Afghanistan)

We would like to be involved but have never been asked. (Minister, Islamic Republic of Afghanistan)

Nor did they recognize the importance of the NSP's work:

We already have our own community structures; why do we need new ones? (Minister, Islamic Republic of Afghanistan)

All the NSP does is complicate matters. (Minister, Islamic Republic of Afghanistan)

The NSP makes no effort to communicate with ministries working in similar areas... this is leading to poor planning and waste.

(Minister, Islamic Republic of Afghanistan)

The NSP needs to recognize that we need to be able to do our jobs; the MRRD gets all the money and we sit here twiddling our thumbs. (Minister, Islamic Republic of Afghanistan)

However, ministerial perceptions of the NSP differ markedly in accordance with the Ministry's involvement in the Programme. There follows a selection of narratives from ministries involved with the NSP:

CDCs are the best community structures to work through.

(Minister, Islamic Republic of Afghanistan)

Community-based development is the future for Afghanistan and this is why CDCs are important; they hold the key to its future.

(Minister, Islamic Republic of Afghanistan)

CDCs need to be properly integrated into the local system of government because it is the only community structure that works.

(Minister, Islamic Republic of Afghanistan)

Despite the initial indifference of certain ministries towards the NSP, it is noteworthy that by end of the research process these same ministries had become NSP enthusiasts:
As long as there is greater

inter-ministerial cooperation

the NSP will be of great importance

to the future of Afghanistan.

(Minister, Islamic Republic of Afghanistan)

This change in perception coincided with the London conference in February 2006.

Our interviews also revealed that the NSP suffers from poor coordination of its largescale development projects. For example, there is insufficient integration of strategic thinking with regard to the relationship between the NSP and the National Areabased Development Programme (NABDP). Consideration should be given to providing Oversight Teams that can look at NSP (at community level) and NABDP projects (at the provincial level), rather than each programme having its own teams. This could yield both significant savings in time and money and a more comprehensive understanding of development needs, problems and their resolution. Under a 'whole government' approach the same concept could be extended to include the ASP (Afghanistan Stabilization Programme under the auspices of the Ministers for the Interior and Communications) which operates at district level.

Collaboration between the various programmes has been minimal so far (even within the same offices in MRRD), but if there were efforts towards developing cooperation then the quality of the programmes will improve along with staff satisfaction as well as increased efficiency.

Poor donor and inter-ministerial coordination has clearly presented the NSP with some steering problems. While certain of these problems are self-inflicted (e.g. the inactive coordination committees and lack of strategic thinking across its key development programmes), others are the product of its success in bidding for external funding, such as petty inter-ministerial jealousy resulting in the deliberate engineering of bottle-necks in the delivery process (e.g. financial disbursement processes). These problems can only be dealt with effectively through the establishment of a 'whole government' approach.

\section{An integrated approach to donor support}

The MRRD needs to integrate donors into the deliberative process more effectively. In
FIN DINGSAND

RECOMMENDATIONS 
terms of donor coordination, here we can see a policy of dividing and ruling donors. The donors themselves help this process by poor coordination of their activities. The External Review Committee is a case in point. There is a need for a formal quarterly meeting:

We would also like to have a formal quarterly meeting with the MRRD

in which we discuss the MRRD development programmes and assess efficiency issues and share good practice. (NSP donor stakeholder)

All the donor stakeholders we have interviewed argued for more effective donor coordination with regard to development programming in general, and the NSP in particular. They argued that this would allow them to: support the work of the NSP more effectively; and avoid duplication and waste and ensure economies of scale in development programming. As a case in point, during a workshop activity which we convened to discuss this mid-term evaluation with NSP stakeholders, it was brought to our attention that 4 donors had simultaneously commissioned mini-evaluations of the NSP, at considerable expense.

\section{A 'whole government' approach}

There is a profound problem in terms of the inter-ministerial coordination of the NSP. The MRRD is a very effective ministry and needs to help develop the capacity of other ministries. There is a great deal of jealousy in weaker ministries; 'they believe that the MRRD monopolizes the large development programmes' (NSP donor stakeholder).

The MRRD is a victim of its own success. It is too efficient; too effective at talking donor-speak and attracting resources and therefore prone to attracting enemies and arousing petty jealousies. The position of the President's Office does cause some confusion, the consequence of which is a political environment where accusations, misperceptions and counter accusations abound. The President's Office 'needs to intervene more directly in supporting the NSP and broadening it out to a greater number of ministries' (NSP donor stakeholder).

All the ministries consulted recognized the importance of establishing a 'whole government' approach to the NSP in Phase 2. This would necessitate more effective inter-min- isterial coordination. In Phase 1 of the NSP it was necessary to focus on an outputdriven strategy (i.e. the rapid creation of CDCs and disbursement of Block Grants) in order for the NSP to gain a national profile and to build credibility. It was therefore impossible to develop effective inter-ministerial partnering arrangements at this juncture. However, for both political and sustainability reasons it will be important to develop a more collaborative approach in Phase 2. This could be achieved through:

the MRRD developing strong collaborations with indicative ministries (Education, Public Health, Water and Energy, Agriculture, Women's Affairs and Interior) in specific areas of NSP programming involving national and provincial level steering committees;

$\checkmark$ the establishment of an NSP unit in each indicative ministry with the responsibility of coordinating joint programming; and

$\checkmark$ ministerial membership of an NSP Steering Committee.

\subsection{The role of the NSP $O$ versight Consultant in programme management and coordination}

GTZ/DAI were given the OC role after the NSP was already up and running... 'deliver, deliver, deliver' they were told; well it has done that very well but a lot of other things have gone undone in the process and they have only started sorting them out in the last six months. (NSP FP Stakeholder)

Lots of outputs, lots of good things achieved (which in the circumstances is a miracle) but from the perspective of performance management and assessment the NSP is a dog's dinner.

The strange thing is that despite all the problems it works. (NSP donor stakeholder)

Considering what it has been asked to do, the pressures that it has been under and the obstacles it has faced, its achievements have been incredible. (NSP donor stakeholder)

The evaluation of the role of the Oversight Consultant in NSP programme management rests on an assessment of its ability to deliver on its core responsibilities to: 
1. contribute to institution-building in local governance through the establishment of CDCs;

2. supervise partnership management with FPs;

3. engage in FP contract screening;

4. prepare and implement sub-projects with the support of FPs via CDCs and disburse Block Grants to support their development needs;

5. provide informal and formal training for MRRD (central, regional and provincial), $O C$ and FP staff;

6. provide training for members of CDCS;

7. deliver NSP information and awareness campaigns provided by the NSP's Public Communication Department;

8. monitor NSP projects; and

9. prepare for the hand-over of NSP OC functions to the MRRD.

GTZ/DAl was contracted by the MRRD as the OC of NSP to to provide Programme oversight for the first three years after the Programme had already been running for six months. The entire MRRD NSP staff was integrated within the $O C$ structure when the NSP began. The Ministry, through the NSP coordination office, retained its leadership in the areas of policy and programme development, local governance, fund management, inter-ministerial relationships, interactions with NSP donors, as well as dealing with community complaints and petitions. The organizational structure of the NSP OC (as of October 2005) is presented above. The $O C$ is comprised of 530 staff working in 34 provincial offices and 5 regional offices, and with a headquarters in Kabul.

The overall performance of the $O C$ was evaluated as 'highly satisfactory' by the WB supervisory mission of October/November 2006. While this evaluation concurs with the general tenor of this assessment, it identifies the key obstacles to Programme delivery in NSP Phase 1, and provides a set of recommendations for programme enhancement in Phase 2 of the Programme. There follows a snapshot of the survey findings which are analysed in greater detail in other sections of this report.

\section{Box 1. The organizational structure of the NSP O versight Consultant, GTZ-DAI}

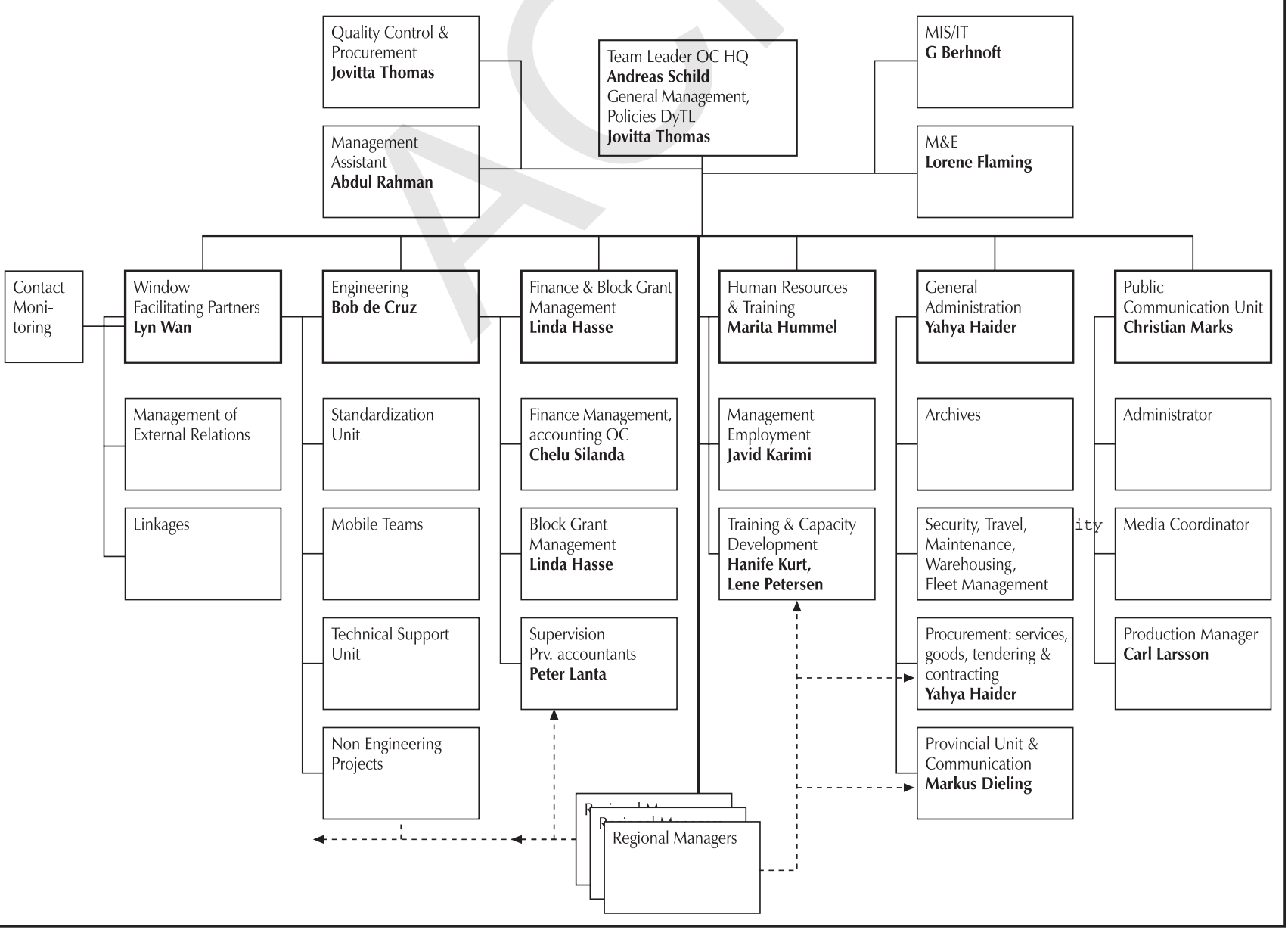




\section{Institution-building and preparation and implementation of sub-projects}

We've got to get real a bout community governance. They're asking us to do in a few months what it has taken the West decades to achieve.

(NSP FP stakeholder)

Yes, policy is made and remade in the process of delivery. Good practices arise from trial and error during the delivery process and it takes time to disseminate those practices across the deliver y system. As the delivery mechanisms mature so will our ability to mobilize communities efficiently and effectively.

(OC staff member)

It is important to keep things simple; to focus on what matters. But this proceeds from the assumption that there is a general understanding of what matters. Unfortunately this has not been the case until quite recently.

The best conditions for development arise from all stakeholders having a common view on what matters and focussing on achieving it. (OC staff member)

While the NSP-OC has been unable to meet the targets for December 2004 to August 2006 established in its contract with the MRRD, its achievements have nonetheless been remarkable. Since its involvement in September 2003:

the NSP has encompassed 193 districts in all 34 provinces in Afghanistan;

the NSP has reached 22,500 rural communities covering 38,000 rural settlements;

- the NSP has benefited 10.5 million people and established $10,000 \mathrm{CDCs}$;

14,000 projects in 8,000 communities have been financed with Block Grant disbursements amounting to US \$166.1 million and total Block Grant

4 See N SP OC (2006), Analysis of the Experiences and Lessons Learned in Program Implementation, GTZ-IS, Kabul, March 2006, pp. 3-5.

5 See Section 2.3 for a more detailed exposition.

SECTION 2: N ATIO N AL LEVEL commitments of US $\$ 214.6$ million;

- more than 4,000 sub-projects have been completed successfully. ${ }^{4}$

In addition, this survey identifies significant evidence of:

$\checkmark$ increased public faith in the system of government;

- improved community relations;

- improved state-civil society relations; and

the empowerment of CDCs.
The main obstacles to effective delivery in this area have been 'at least' four-fold. First, the targets for 2004- 6 were not developed with a rational understanding of how much time community mobilization and subproject implementation takes. Secondly, several bottle-necks emerged in the process of programme implementation, which have undermined the ability of the $\mathrm{OC}$ to meet targets. Prolonged delays occurred in: the procurement process for securing critical goods; in the disbursement process due to the absence of Block Grant funds, and in the inefficient transfer of funds from $\mathrm{Da}$ Afghanistan Bank to CDC bank accounts. Thirdly, long delays have also occurred in the approval of extension contracts for existing FPs and the contracting of additional FPs. Fourthly, it is also evident from our survey that there has been very little 'political' help forthcoming from the MRRD or the donor community to help the $\mathrm{NSP} / \mathrm{OC}$ deal with these bottle-necks in the disbursement process. It is therefore unsurprising that targets have not been met.

\section{FP management}

In general the $O C$ and the FPs enjoy good working relations, underpinned by regular meetings and a collaborative approach to problem-solving. It is evident from respondents that this relationship has improved significantly in recent times. Six further obstacles (in addition to the underestimation of how much time community mobilization and sub-project implementation takes) to effective FP management were identified by our sample of respondents. ${ }^{5}$

First, the relationship between FPs and the $O C$ has often been undermined by shifting expectations of the role of FPs in accordance with MRRD or donor priorities:

From the beginning the NSP was about governance. It was never about economic growth or pro-poor economic growth or poverty reduction or gender inclusion. These objectives have been parachuted in without any real reflection on how they can be achieved. Some FPs have the experience to make progress on these issues but others don't. This clearly puts pressure on the OC-FP relationship. (NSP FP stakeholder)

There is a tendency for donors to think that they can use CDCs as a 'cure-all' to deliver on all their in-country priorities; what they need to remember is that this is 
Afghanistan we're talking about and not the US, Japan, Canada or elsewhere... (NSP FP stakeholder)

This problem has been compounded by the absence of joined-up thinking across development programmes and the failure to develop effective processes of crossprogramme learning:

There has been a clear lack of strategic thinking between ministries on rural development and this is reflected in the rural communities themselves.

(NSP FP stakeholder)

The MRRD needs to reach out to a chieve a 'whole government' approach and there is no evidence that it is doing so.

(NSP FP stakeholder)

Thirdly, there has been insufficient lessondrawing across FPs:

In this rush to roll-out the NSP to more and more communities we don't have time to do enough learning from each other's experiences. (NSP FP stakeholder)

Hence, the $\mathrm{OC}$ needs to play a greater role in generating collaboration between FPs.

Fourthly, bottlenecks in the coordination of NSP disbursement and procurement processes have heightened tensions between FPs and communities:

The NSP has created too many ga tekeepers who are unwilling to accept responsibility but have to demonstrate their power to obstruct.

(NSP FP stakeholder)

Fifthly, FPs contend that they are placed under significant pressure to implement rather than facilitate the NSP. This ultimately limits the benefits that CDCs can derive from the NSP in terms of capacity development:

The new imperative is sub-project completion, when building the capacity of CDCs is much more important and was the original purpose of the NSP. (NSP FP stakeholder)

Finally, there is also evidence that the very act of developing westernized formal processes to ensure transparent and accountable delivery systems erodes trust systems between NSP stakeholders and communities. As one FP stakeholder argues:

A fundamental premise in the Technical Annex of the NSP is that communities are trustworthy... as long as communities go through the process you don't need the engineering verification as this should happen in the evaluation process... there needs to be an effective balance between the need for a paper trail and expedience. Trust management is crucial to the efficient delivery of the NSP.

The counter claim to this view is of course that the very act of creating formal processes is a form of capacity development in itself.

\section{Training 6}

The NSP provides:

- Informal 'on the job' training with an estimated total of 50,000 person training days for MRRD (central, regional and provincial), OC and FP staff;

- Formal training with approximately 9,000 person days for the same target groups;

- Members of approximately 10,000 CDCs and communities participate in the training provided by the FPs;

- Information and awareness campaigns are provided by the Public Communications Unit (PCU) to underpin the training activities; and

FPs also provide training for CDCs in key areas of institutional and community development.

Hence, the capacity development dimension of the NSP is really quite considerable and should be considered as one of the most important outputs of the NSP.

\section{OC understanding of capacity-building}

The emphasis on roll-out and the sheer effort that that has involved has meant that the focus has been on CDCS and FPs and the OC-MRRD 'people' issues have been neglected. We are now working hard to catch-up. (OC staff member)

The concept of capacity-building employed by the $O C$ focusses on 'skills and knowledge transfer' (OC staff member). This rather narrow understanding reflects the 'relief' rather than 'developmental' mentality that
6 See Section 2.2 for further observations on N SP training.

FINDINGSAN D RECOMMENDATIONS 
underpinned the operation of NSP Phase 1, and is reflected in the absence of the development of a strategic approach to capacity development. On its own admission the OC has neglected the human resource management aspect of the NSP but it must be noted that the $O C$ is presently recruiting a human resource development specialist to design a human resource strategy. ${ }^{7}$ There are other areas that were also neglected at the strategic level:

- A change management strategy wasn't developed to deal with the problems of cultural change inherent in transforming old administrative systems;

- A needs assessment wasn't conducted to identify the skills gaps in MRRD staff;

$\checkmark$ A logical framework to guide programme management around the achievement of milestones was not developed; and

- the OC's capacity-building strategy, such as it was, did not have linkages with the broader process of civil service reform in Afghanistan.

This third observation is particularly important as a large part of the NSP's training activities involve building the skills of civil servants in the MRRD. However, it has not proved possible to integrate NSP thinking with MRRD thinking in terms of identifying the type of civil servant the Afghan government would like to produce, i.e. the range of skills required to assume a full role in the operational delivery of the NSP. Concerted efforts will need to be taken in all of these areas in NSP Phase 2.

\section{Policy instruments}

The training strategy deployed by the OC has focussed mainly on providing training packages to underpin the main areas of the NSP's activities (e.g. accounting, procurement, CDC institution and capacity-building etc.). Effective work and training plans are provided for each aspect of the Programme. The OC has used a cascade system whereby 'trainers train trainees who become trainers' in a virtuous circle of capacity development. However, the OC has recently decided that this approach is not working satisfactorily, '... the problem with the cascade system is that a certain amount of knowledge is lost between the layers' (OC staff member). The OC has therefore proposed a modular approach (i.e. the development of modules linked to key skills development) to capacity development which will increase its function in terms of facilitating and coordi- nating training. It is envisaged that the amount of training delivered at the provincial level will increase accordingly. ${ }^{8}$

The OC provides high quality training for CDC members. Indeed, it is our view that the training packages delivered at this level provide examples of international best practice. The packages themselves are carefully crafted using culturally sensitive role play, team building exercises, and lesson-drawing exercises. The central reason for the success of the training is that it has evolved from participatory processes and is genuinely Afghan in design and approach. With regard to CDC training conducted by FPs, it is evident from our survey that the best CDC training is spread throughout the programme cycle and should not be front-loaded.

How is the impact of training on performance (i.e. programme outcomes) evaluated? The OC uses a testing tool to evaluate the impact of training on output. For example, there is significant evidence to demonstrate that engineering training has improved the quality of build.

Three main gaps can be identified in the training repertoire: strategic capacity development training packages for MRRD staff; the absence of effective training in management and leadership skills; and general office skills:

In Phase 2 of the NSP, capacity-building will become increasingly prescient because of the impending hand-over to the MRRD.

(OC staff member)

The $O C$ is now planning management training for unit and provincial heads and team building training for provincial management. A management consultant is being contracted to advise on the issue. As one OC staff member put it, 'the initial emphasis was on getting things going; now the focus is on the development of management skills' (OC staff member).

\section{O bstacles to capacity development}

The obstacles to capacity development identified by respondents can be organized into two main categories - problems of bureaucracy and problems of cultural change. The first set of obstacles include: the problem of high staff turnover; the existence of too many forms; constant changes to the NSP Operational Manual 
requiring additional training support; civil service tenure providing disincentives for MRRD staff to engage fully in training activities or to take initiative in the workplace. Issues of cultural change include: the need for MRRD staff to move away from a planned system mindset; the problem of low rates of literacy in CDCs (including social organizers); limited female involvement in training; and maintaining the interest of CDCs in lengthy processes of training. However, the most serious obstacle to effective capacity development lies in the poor integration of MRRD staff into NSP work. As one OC staff member put it:

We were just given a list of MRRD staff and told to integrate them; no consultation, no nothing. Integration has not been well planned. For example, it hasn't been linked to the development of the core skills necessary to deliver core NSP functions. We've done our best but without cooperation we can't move forward very quickly.

\section{Summary}

Three main conclusions can be drawn from this sub-section. First, the $O C$ needs to complete its work at the strategic level with regard to the completion of its human resources strategy, change management strategy, needs assessment for MRRD staff, logical framework to guide programme management around the achievement of milestones, and capacity development strategy with linkages into the broader process of civil service reform in Afghanistan. This will help to remove certain of the obstacles to capacity development. Secondly, it is evident that the $O C$ is extremely reflexive on training issues and delivers best practice in relation to $C D C$ capacity development. Thirdly, it is evident that sufficient numbers of MRRD staff do not presently possess the skills necessary to assume the operational delivery of the NSP or, as an OC staff member put it, 'they can only do it if they recruit existing Afghan OC and international staff'.

\section{Public relations}

While the Public Communication Unit (PCU) plays an important role in reinforcing key messages in CDC training, its main role is to promote the work of the NSP. It does this in five ways - via the radio, television, Internet, print and NSP events. The PCU has its own press agency with 20 full-time reporters working in the field and three editors, and it produces its own television programmes, including an NSP soap opera. Television coverage is considered central to the PCU's work and it has been successful in securing agreements with all the major Afghan channels to air NSP programmes on a regular basis. The PCU also coordinates and stage manages the monthly NSP 'Roadshow' which has proved highly effective in raising public awareness of the NSP. The impact of the work of the PCU is monitored using sophisticated content analysis techniques. The evaluation team has found significant evidence from these sources of the important work that the PCU has played in both promoting and maintaining public interest in the NSP. Indeed, this is a further area in which international best practices are being delivered.

The only area of concern which should be raised in relation to the work of the PCU lies in its capacity development strategy for MRRD staff. It has proved very difficult for the PCU to integrate MRRD staff into the work of the PCU and build their capacity to assume its functions. This has largely been due to the recalcitrance of MRRD staff. Better lines of communication between the $O C$ and the MRRD must be established in this area to ease tensions.

\section{Information system management}

The OC possesses highly effective information systems which are extremely well managed and are a model of good practice. It is, however, a victim of its own success in the sense that the capacity of the MIS Unit to provide high quality reports is often called upon by MRRD staff which takes OC staff away from their core responsibilities and creates excessive workload demands. The staffing costs for the MIS are linked to the Unit's core NSP functions, so any additional tasks should be funded from other sources.

Future terms of reference for the MIS should therefore focus on the functions it performs in managing and reporting essential and relevant NSP information. In addition, the possibility of decentralizing certain areas of data entry, archiving and management to OC PO should be explored to assist with the capacity development of MRRD staff, to ease the workload burden on the centre, and to make for more efficient programme delivery. It is also worth noting that as well as the development of highly efficient information systems, there is also
FIN DIN GSAN D RECOMMENDATIONS 
evidence in this area of effective capacity development of Afghan staff through shadowing. The Unit's good practices in capacity development should be diffused to other units within the OC.

\section{Programme monitoring}

The OC did not develop a logical framework for the programme, nor did it develop a coherent monitoring and evaluation framework... the right data does not a ppear to have been collected in relation to the key performance indicators... in spite of this the outputs have been significant and the role of FPs has been pretty good. (MRRD representative)

It is universally recognized that 'progress' should be measured over the life of any development programme. This is significant to all investors in managing the Programme from the donor community, to the MRRD, to provincial and district authorities, to facilitating partners, to the NSP/OC responsible for maximizing the cost effectiveness of interventions of this kind and, most significantly, to people living in rural areas. Relevant and practicable indicators should therefore have been identified at the outset and their values monitored as the Programme unfolded. Unfortunately, this was not the case during Phase 1 Programme, although there is significant evidence to suggest that major improvements have now been achieved in this area thanks to the recruitment of a highly effective unit head in spring 2005.

Monitoring of the NSP has had a chequered history. The original view was that, 'effective monitoring could be achieved on the basis of quarterly reports from the FPs' (former OC staff member), and did not require elaborate systems. Indeed, the argument was that detailed evaluation should be conducted by independent evaluators on a cyclical basis and that the role of monitoring should purely focus on whether CDCs were making progress. It did not prove possible to develop an accurate community base-line to monitor progress and indeed compare progress across communities. This is because community profiles were not drawn up to common criteria as the Programme rolled-out. The current Operational Manual observes that the communities are defined:
... on the basis of existing available information from government records (e.g. the list of registered villages from the 1970s, or the list of villages prepared for the nomination of the members of the 2002 Loya Jirga). However, since the reliability of the available official data on villages was inconsistent when the records were established, and since it is by now outdated due to population increase and/or displacements, the identification of communities for the purpose of the NSP would have to reflect the ground realities existing today. ${ }^{9}$

While the NSP/OC has made concerted efforts over the past six months to work on these deficiencies through the improvement of forms and the strengthening of post implementation monitoring processes, at present the base-line field data does not exist to conduct a 'scientific evaluation' of the achievements of the Programme (however significant they may be). These problems have been exacerbated by the constant changing of NSP objectives and key performance indicators in the Operational Manual in response to new political priorities. ${ }^{10}$

In order to ensure effective monitoring and evaluation, it is now crucial to have: a settled understanding of programme objectives in order to achieve desired outputs; the establishment of a rational NSP Phase 2 Operational Manual; the establishment of a simple set of key performance indicators for monitoring progress in relation to the achievement of these objectives, which can be measured over time; and the completion of coherent and consistent community profiles of all CDCs for comparative and evaluative purposes. This latter task could be completed by the large cohort of MRRD monitors (approximately 108).

Monitoring and evaluation is a further area where the MRRD lacks the capacity at present to assume the $\mathrm{OC}^{\prime}$ 's role, and significant thinking needs to be paid to capacity development issues. This is likely to require more effective integration of the monitoring and evaluation units in the $O C$ and the MRRD, and increased responsibility for the Rural Rehabilitation and Development PO.

\section{Exit strategy}

It is evident from our investigations that in the short-term the MRRD will not have the capacity to take over the NSP without a 
continued role for the OC. The Exit Strategy has been devised too late. This should have been considered from the beginning of the Programme. Moreover, the Exit Strategy options should have been reviewed by an independent party (i.e. not the $\mathrm{OC}$ or the MRRD). Although the MRRD has some highly effective staff at the senior management level, there is not sufficient talent in depth to assume the OC role in 2006.

We also noted that there continues to be a high level of political uncertainty regarding the future of the NSP and the handover from the $O C$ to the MRRD. This uncertainty has started to affect the morale of the FPs. It is widely acknowledged that $\mathrm{HE}$ Haneef Atmar is not only a strong supporter of the NSP but the creative force behind it, and there are worries that if he moves to another ministry, political support for the NSP may well wane.

\subsection{Summary and recommendations for national level coordination}

From the outset, it was impossible for the OC to adopt a 'rational' approach to programme management for at least 3 main reasons: the obligation to deliver on outputdriven objectives has meant that they had to hit the ground running to establish the delivery system for the rapid creation of CDCs and the disbursement of Block Grants; the absence of clear programme objectives has meant that they have always been engaged in institutional 'catch-up' in relation to new priority settings identified by the MRRD and donors; and the lack of a settled understanding of the role of the OC by the MRRD and the donors has meant that they have had to shift human and institutional resources to support non-core NSP activities in response to changing political expectations (e.g. MIS).

Hence, the OC was not provided with the time to initiate a phasing-in strategy during which: a) a rational Operational Manual could be finalized with clear programme objectives; b) consistent performance indicators could be identified and effective monitoring systems established; c) coherent and consistent community profiles completed; d) a capacity development strategy for MRRD staff could be developed; e) a human resource management strategy could be devised for NSP OC staff; f) a rational NSP/OC exit strategy devised; and g) a logical framework for implementation completed.

All of these areas of 'rational' programme management are now being attended to, but this does mean that much of the institution-building and the capacity development work that needed to be completed to allow for a hand-over to the MRRD in July 2006 is in the process of completion.

There is currently significant debate within the MRRD and the NSP/OC over the most suitable institutional venue for the delivery of the NSP in Phase 2 once the MRRD has taken over the management of the Programme. Three options have been debated: full integration; re-tender for a new OC; or create a 'not for profit' semiautonomous organization as a special project under the Ministry. The third option is being proposed by the MRRD as it provides the Ministry with the ability to secure the services of high quality, experienced staff in the field of rural community development who demand high salaries, while simultaneously developing the capacity of national staff. However, we believe that these aspirations can be met through a fourth option; the creation of an executive agency for NSP delivery.

\section{A 'whole government' approach - reforming decision structures}

\section{Recommendation 8}

A new institutional structure is recommended for the national level coordination of the NSP. The dysfunctional External Review Committee and the Inter-ministerial Committee should be replaced with three new committees - an NSP Steering Committee, a donor Support Group and an Inter-ministerial Committee.

The NSP Steering Committee should meet every two months, it should be chaired by the Ministry with oversight of local governance matters, and be comprised of the NSP Coordinator, the first and deputy Minister of the MRRD, the OC, the NSP Coordinator, representatives from partnering ministries, five $C D C$ representatives from NSP regions, and a representative of the facilitating partners.

The donor Support Group should meet quarterly; it should be chaired by a presidential nominee, and be comprised of all
FIN DIN GSAN D RECO MMEN D ATIONS 
the donor stakeholders, the First and Deputy Minister of the MRRD, and the NSP Coordinator. In addition to ensuring donor accountability, the role of the group will be to convene 'action-oriented' meetings with minutes in order to support the work of the NSP more effectively.

The Inter-ministerial Committee should meet quarterly and be chaired by a presidential nominee and include representation from all partnering ministries. Its key role will be to identify areas of duplication and waste, potential areas of joint working, and NSP input into ministerial development plans and vice versa. Day to day management of the NSP would remain with the NSP/OC.

This institutional design would provide the architecture for a 'whole government' approach to the national coordination of the NSP, foster greater inter-ministerial and presidential collaboration, and provide for more proactive donor support. A 'whole government' approach should be integrated at all levels of programme delivery in appropriate areas of programming.

\section{Recommendation 9}

We also recommend that the MRRD develops a strategic plan to integrate the NSP with other national programmes such as: the Water and Sanitation Programme (WATSAN); emergency employment (NEEPRA), mostly for labour-intensive road building; the Microfinance Programme (MISFA); the Emergency Response Programme (in Badghis, Bamyan, Herat, Kabul, Kundoz, Nangarhar, Paktia, and Paktika), and, in particular, NABDP. It is crucial to adopt a strategic approach to large-scale development programming to ensure that a joined-up approach is taken that avoids duplication and waste, and meets broader national development goals.

\section{Recommendation 10}

We recommend the establishment of: a rational NSP Phase 2 Operational Manual with a coherent set of programme objectives which can be measured over time, and a simple set of key performance indicators for monitoring progress in relation to the a chievement of these objectives.

\section{Recommendation $\mathbf{1 1}$}

While we recognize that excellent work is being conducted in these areas, the OC needs to complete its work at the strategic level with regard to the completion of its: human resources strategy; change management strategy; logical framework to guide programme management around the achievement of milestones; needs assessment for MRRD staff; capacity development strategy with linkages into the broader process of civil service reform in Afghanistan; a quality assurance strategy to ensure sustainable programming; and a final NSP/OC exit strategy.

\section{Recommendation $\mathbf{1 2}$}

We recommend the creation of an executive agency as a new institutional venue for the delivery of the NSP; a model of operational service delivery currently deployed in most OECD member states (see Section 7 for more detail). 


$$
\text { or }
$$




\title{
Findings and Recommendations
}

\section{Sub-national Level Coordination}

\section{and $O$ perational Delivery}

\author{
of the NSP
}

The MRRD at the provincial level does not have the capacity to deliver the NSP... so much work needs to be done to bring them up to speed... there is enthusiasm but no hard skills. (NSP FP Stakeholder)

This section of the report focusses on the role of 3 further groups of stakeholders in the coordination and operational delivery of the NSP - sub-national governments (DRRD provincial and district levels), provincial OCs and their teams, and FPs.

\subsection{Sub-national level coordination and operational delivery of the NSP - the MRRD and provincial and district government}

The main challenge for the MRRD in ensuring the sustainability of the NSP is to maintain and improve its capacity to manage the delivery of the Programme's aims and objectives. This involves using its horizontal and vertical institutional linkages within the provincial and district levels of government, and employing sufficiently qualified staff to tackle the technical aspects of community development. The aim of this analysis is to separate some of the salient aspects of this challenge.

This analysis of the provincial and district DRRD staff is divided into three main subsections. Firstly, it is important to review the improved relationship between the NSP participating communities and the Afghan government. The second sub-section establishes the entry point for further staff capacity development and the last sub- section addresses the entry point for longterm institutional capacity development. This analysis concludes by identifying the main achievements and strengths in addition to deficiencies and threats to the management of the NSP. The latter are matched by a set of specific recommendations.

It should be stated at the outset that this analysis is partly based on a self-evaluation by provincial and district DRRD staff and is therefore particularly relevant since it articulates their views on potential areas of programme enhancement. Furthermore, it is proposed that these views are representative of the wider national dimension because all relevant levels of DRRD staff (provincial, district, NSP Unit managers and field staff) were interviewed across 10 provinces. Some of the findings from the interviews with provincial governors and/or deputy governors are also included because of their insight into the management of the NSP at the sub-national level.

\section{Sub-national bureaucratic elite perceptions of the impact of the NSP on rural communities}

Provincial and district level DRRD employees, and provincial governors observed that the NSP was making a positive contribution to the development of national solidarity. This is manifested in three interrelated areas: an improved relationship between the NSP communities and the Afghan government; stronger community relations; and evidence of the limited empowerment of CDCs. 


\section{The relationship between}

\section{NSP communities and government}

All provincial and district level staff interviewed for this evaluation have perceived a significant improvement in the relationship between the participating communities and government. There is general agreement that this shift has been a direct result of the NSP and its activities. The improved relationship with the communities is connected to both levels of government: provincial and district. The sources of this improved relationship are considered to be four-fold.

Firstly, it is defined in terms of the quality of the contact; i.e. DRRD staff have a clear understanding of the nature and purpose of the relationship and thus the rationale of the Programme. In Balkh, the DRRD officials described 'visiting, advising and directing them [CDCs] though not interfering nor controlling'. In Paktika, working relations with the CDCs are described as 'friendly and cooperative'. In Herat, there is particular importance attached to the presence of the Director or Deputy Director of the DRRD during the inauguration of projects. However, in Balkh it was noted that 10 per cent of the people are not satisfied because the NSP is 'a very new concept and therefore difficult to implement completely'. This is compounded by the people's 'very high' expectations of largescale development projects.

The second feature of the improved relationship is the frequent interaction between government and communities. The DRRD representatives in Takhar describe how 'NSP staff together with the OC team regularly visits the CDCs and discuss issues related to [the] NSP projects'.

A third characteristic of this improved relationship is the provision of incentives for the communities to participate in the NSP. Respondents believe that the fundamental attraction for communities is the opportunity to play a major and direct role in the local decision-making process and their acceptance of the ensuing responsibilities of legitimate authority while building upon the traditional shura system. At a more basic level, the Programme is considered to have enlightened those involved in Herat, thereby causing more activity within the communities. Similarly, in Kundoz, an increase in awareness and interaction was noted. In sum, incentives stem from the widespread recognition that the government is interested in the communities, which is considered unprecedented in Nangarhar. In other provinces, some respondents also point to knock-on linkages between the State and civil society in general.

Fourthly, it is argued that the establishment of a complaints procedure is a key element of this maturing relationship. Whether used or not, government respondents asserted that the communities respected the provision for redress and found it effective (Badhgis, Balkh, and Herat). In Balkh and Herat, complaints were divided into 'direct complaints from the CDC and the shura or via the FP', by the FP, or from miscellaneous community actors. For each type, the initial approach was to hold a meeting with all those concerned (CDC, FP, DRRD and NSP staff) and the provincial DRRD held a 'weekly meeting every Tuesday for two hours'. If unsuccessful, then a case would be sent up the chain of authority within the MRRD (district - provincial - national).

The provision for addressing complaints also acted as an important conflict prevention mechanism. For example, in Kabul, the DRRD staff recalled how they conducted transparent investigations into the implementation of a project's budget, which successfully resolved the only two community registered complaints. The latter example reflected both the establishment of a process of growing trust in the DRRD as impartial public servants, but also demonstration of the barriers to establishing transparency and accountability for an uneducated and often socially marginalized population. Of course, a degree of suspicion within a community is natural and can also form a last line of defence against corruption and malpractice. Interestingly, in Paktika, respondents believed that there was 'no standard complaints procedure' but emphasized that written complaints were received, which were either tackled immediately or sent to the MRRD if necessary.

\section{Inter- and intra-community relations}

The NSP is considered to have directly strengthened inter and intra-community relations, and has thus furthered progress towards greater national solidarity. In particular, it is claimed that both types of community relations benefited from the binding nature of the CDCs and the projects.

Intra-community relations have been augmented because the NSP encourages
FIN DIN GSAN D RECOMMENDATIONS 
communities to unify through a democratically elected and organized CDC, which enjoys constitutional status. Respondents in Paktia emphasized the significance of the latter. Furthermore, group cohesion is fostered through the common goal of the project. Respondents in Kabul were not alone in recalling instances of CDCs resolving tribal, clan and familial tensions even where higher authorities proved ineffective. At the same time, the Nangarhar case also reveals incidences of power struggles between community elites, arising when community expectations are not met (in time) and where a traditional shura feels marginalized by changes in local governance. Government respondents were particularly impressed by examples of multiethnic CDCs, as exemplified in Kabul and Kundoz. Conversely, ethnic tensions were not completely resolved in Balkh, where the Provincial Governor acknowledged, and of course rejected, the criticism from Hazaras in the province that he had manipulated the selection of NSP villages in response to ethno-political allegiances.

The survey also revealed several examples of strengthened inter-community relations. Three insightful cases in Balkh Province demonstrated the centripetal drive of the NSP, which encouraged villages of different ethnic groups in Dawlatabad, Charbolak and Kishendeh Districts to cooperate through joint projects involving the building of a school, a well and a road, respectively. Similarly, in Herat, DRRD staff noted the greater interconnectedness between 'surrounding villages'. However, there is also some evidence of smaller communities being prevented from institution building because of their geographical isolation.

\section{Evidence of Community Empowerment}

The extent of the empowerment of CDCs is perhaps the most crucial indicator of the NSP's impact, as perceived by the DRRD. This has five key components: the capacity of CDCs to play the central role in community level governance; the legitimacy of CDCs as institutions of community level governance; the longer-term prospects for the NSP; the process of community mobilization; and issues of gender mainstreaming.

With regard to the first component, all DRRD representatives (except in Takhar) considered the CDCs to be largely well managed and to possess the capacity to become permanent institutions. The DRRD in Takhar felt that the FP had prevented the CDCs from becoming a durable institution. It was suggested that although some CDCs had the ability to become independent and self-sustaining, the majority still required funding and technical support and training from the NSP (Badghis, Balkh, Bamyan, Herat, Kundoz, and Paktia). Estimates ranged from a further two to three years in Paktia, to 8 to 10 years in Balkh. In Herat, it was felt that further credibility and sustainability was also dependent on the recognition of CDCs as the key instrument of community development by all government departments.

In relation to the second component of empowerment - the foundational values of self-determined community development: community support (as demonstrated by the widespread use of the community savings boxes) and legitimate authority and responsibility (based on the principle of equality and fair representation) were observed by the vast majority of government representatives.

Thirdly, with regard to the long-term sustainability of CDCs, some of the provincial governors also stated their belief in the long-term prospects of the NSP. For example, Governor Atta believed that the NSP would achieve long-term acceptance in Balkh because of the nature of the projects and the transference of responsibility to the communities. In particular, Governor Atta and the Deputy Governor of Nangarhar focussed on the communities' involvement in the decision-making process, needs assessment, and the setting of priorities.

Fourthly, in reference to issues of community mobilization, as Balkh and Kabul DRRD staff noted, unlike the previous donor-driven approach, it was empowering that the NSP first surveyed needs, with NGOs and donors acting as subcontractors and with the government required at all stages in the process. It was felt that this developed the capacity of the CDCs to approach other organizations and agencies for 'top-up' funding, and even for non-NSP development projects. As stated in the Goal and Objectives of the NSP (I.B and I.B. (ii)), it was designed to create an entry point or environment for poverty reduction through community empowerment and by creating projects to build infrastructure. It was agreed by all respondents in Kundoz and Paktia that the community projects are helpful in creating job opportunities. The 
DRRD Director in Bamyan also thought that the NSP would enable poverty reduction and thus constituted a significant development programme.

Finally, approximately half of the beneficiaries, some DRRD staff and the Governor of Balkh emphasized the need for improvements in the empowerment of women. It was proposed that this should occur by women gaining a more equal role in the decision-making and implementation processes, in addition to ensuring that delivered projects were responsive to their development needs.

This sub-section has provided a detailed assessment of the scope and intensity of the NSP's impact, as perceived by DRRD representatives. The direct emergence of microconflict resolution processes was a crucial cross-cutting theme (within the community and between the community and the state). However, three main concerns were also articulated: the operation of an effective though inconsistent complaints procedure; the emergence of intra-community power struggles; and gaps in the achievement of principles for sustainable development, in particular, the exclusion of women.

\section{The potential sources for long-term 'staff' capacity development}

This sub-section investigates the potential for long-term DRRD staff capacity development with the goal of improving the management of the NSP. Accordingly, it compares DRRD staff assessment of: general community development experience; NSP community development experience; and NSP training. It then highlights the potential sources for improving capacity, which stem from the DRRD's experience of managing development projects within the Afghan national policy framework and advancements in training.

\section{General community \\ development experience}

The DRRD's community development experience mainly stems from the concurrent implementation of five national community development programmes: the Water and Sanitation Programme (WATSAN); emergency employment, mostly for labourintensive road building (NEEPRA); the National Area-Based Development Programme (NABDP); Microfinance Programme (MISFA); and the Emergency Response Programme (ERP) in Badghis,
Bamyan, Herat, Kabul, Kundoz, Nangarhar, Paktia, and Paktika. The DRRD in Herat provided examples of substantive overlaps between the programmes. Furthermore, several senior management staff noted important relevant experience gained from outside the policy framework. For example, the DRRD Director in Paktia had worked for 15 years in community development during and after the war.

However, two caveats must also be noted. Firstly, the DRRD Director in Bamyan acknowledged that the NSP complemented the other programmes, but emphasized that it was qualitatively different. Secondly, the DRRD Director in Kundoz added that most of the other five programmes are implemented directly by NGOs and not by the DRRD, whose role remained 'minor and mostly superficial'.

\section{NSP community development experience}

As a significant institutional indicator, the Community-led Development Departments commenced their activities in 2002-3, with the latest starting in 2004. Staff could therefore rely to a certain degree on strong institutional expertise and awareness. This was reflected by the number of projects and the coverage of the Programme. For example, 400 of the 611 projects were completed in Bamyan, with 324 ongoing projects in 7 districts in Kabul. Furthermore, all MRRD staff had an extremely positive perspective on the management and performance of the NSP, and there was a common drive to cover other communities and districts (for instance, in Bamyan and Balkh). This was an important indicator of confident management although it was circumscribed by resources.

In addition to the general supervisory role prescribed by the NSP, some provincial DRRDs emphasized the need for a contexttailored approach. For example, DRRD staff in Kabul believed their preparatory peacebuilding work was an important foundation for the subsequent programme activities conducted by the FP. The NSP Manager and staff in Badhgis claimed to have spent most of their time in the field supervising the projects. Nangarhar was an exception, where DRRD staff could only recall a more symbolic involvement in the Programme; for example, the inauguration of projects and the distribution of certificates. The Deputy Governor of the Province suggested that this was simply a problem stemming from weak capacity.
FIN DIN GSAN D RECOMMENDATIONS 
For the majority of the provinces (including each level of staff) interviewed, the quality (effectiveness) of work was prioritized before the efficiency (number of projects). This was best encapsulated by staff in Balkh when they stated that they 'emphasize the capacity development of communities rather than spending money'. Other similar qualitative indicators included the benefit to the community (Paktia), the sustainability of the projects (Paktika) and the honesty and dedication of the FP (Kabul). Staff in Nangarhar also stated these factors while admitting the number and location of projects were equally important. ${ }^{11}$

\section{NSP training}

All the members of the NSP teams within the DRRD had received specific training on managing the Programme. However, the nature (scope, length, and style), and thus standard, of the training varied considerably.

As a minimum, all respondents were trained in the use of the official Operational Manual. Staff in Nangarhar claimed their training was restricted to the latter. Alternatively, there was greater scope in Badghis, with instruction on community mobilization, while the DRRD Director in Bamyan was trained in monitoring and community development. Those in Kabul and Paktika received a more general NSP orientation and training. The DRRD Director and staff in Balkh and Paktia seemed to receive more specific guidance on activity training for procurement, programme management, monitoring and evaluation and financial duties.

11 In Herat, DRRD respondents were unable to answer this question.

12 As a possible explanation for the variation, training might have been tailored to the existing level of experience of each director and staff, with the aim of reaching a healthy balance in each DRRD. For example, the Balkh DRRD Director received two months of training whereas his provincial and district staff claimed three days, but also acknowledged continuous cascading training from the Director once he returned from Kabul.

months for the DRRD directors in Paktik and Balkh, respectively; and from three days to one year for provincial and district staff in Balkh and Kundoz, respectively. 12 Paktika was in the middle, with two weeks of orientation. For provincial and district staff, in Badghis and Kundoz the training was on-site and informal (see Box 2 below), whereas formal workshops and meetings in addition to the cascading technique from the DRDD director were observed in Balkh, Herat, Kabul, Paktia, and Paktika. Balkh district staff felt that the FPs' experiences and resources provided the best opportunities for improvement and thus, 'met with FPs regularly, sometimes daily or weekly, if not monthly'. However, they also felt that not all the FP community mobilizers were ade- quately qualified, which 'limited the transfer of knowledge to the CDCs'. Naturally, the variation in training meant it was difficult to discern which one was most useful overall. Apart from the DRRD directors' cascading technique, training was generally delivered by the OCs and FPs (Balkh, Kabul, Kundoz, and Paktia).

\section{Box 2. \\ The training of DRRD staff in Kundoz}

The only training the DRRD received from the NSP was the sending of 3 employees to work with the FP to receive on-the-job training. This started 7 months prior to the research and was expected to last for one year. The respondent did not think that there had been any corresponding increase in the capacity of the individuals.

Finally, two other main weaknesses in training were noted. The Provincial Governor of Kabul (based on NSP experience in Nangarhar) concluded that the management of the Programme was too expensive. While the Deputy Governor of Bamyan disagreed (compared to conventional reconstruction programmes by contractors and NGOs), both senior representatives concurred that the best solution was increased capacity development of Afghan/DRRD staff and institutions.

Secondly, particular emphasis was placed on improving technical (engineering and monitoring and evaluation) and computer skills in addition to English language training, to allow for the provision of more sophisticated management courses by international organizations and agencies.
In sum, the DRRD representatives relied on three types of relevant development experience. Overall, training was effective in building capacities but it suffered from an uneven application, with a resultant fluctuation in the experiences and training of staff. Therefore, long-term improvements in staff capacity development ought to focus on greater consistency; that is, across the provincial DRRDs and down to the district level. Similar trends, in addition to separate strengths and weaknesses, are found in an analysis of the institutional capacity development. 


\section{The potential sources for long-term 'institutional' capacity development}

An analysis of the key strengths and weaknesses or strains in programme management, as perceived by the DRRD representatives, uncovers the potential sources for long-term institutional capacity development. While strengths or opportunities for capacity development are noted, there were four main strains in programme management. The first strain observed arises from a significant shortfall in human and physical resources. Weaknesses in institutional structures represent the second strain and the need to improve cooperation with other ministries, and institutional learning is the third. The last strain encompasses five key programme design flaws.

\section{Insufficient human \\ and operational resources}

In each province, the problem of insufficient staff was a recurring complaint, both in terms of number and relevant technical proficiency. Engineers were specifically and repeatedly highlighted in this respect. Respondents believed that these quantitative and qualitative deficits in human resources significantly reduced institutional capacity, and these gaps were particularly obvious when working alongside the MRRD, OC, FPs, and other international NGOs. For example, Balkh district staff stated that there are 'only four of us with the capacity to carry out the NSP' and that some districts did not have DRRD staff. The Director of the DRRD in Kabul stressed that the 'MRRD has the leading role in implementing NSP without it the $\mathrm{OC}$ and the FP could not implement the programme.' Accordingly, he highlighted the insufficient human resources of the indigenous institution compared to the supporting agencies. A key source of this problem was the perception of poor wage-levels in a competitive market, which caused more qualified staff to move to international organizations. This was exemplified by the DRRD Director in Paktia who emphasized the difficulty in recruiting qualified staff, while employees in Kabul estimated that the $O C$ does the same job but earns 'five times their salary'. ${ }^{13}$ In addition to these human resource problems, there was consensus that the high number of projects had reduced the quality of the work, as emphasized in Paktika and Balkh.

Inadequate operational resources were also a recurring complaint and considered a direct constraint on capacity. This included
Box 3.

Transportation stress in Bamyan

DRRD officials in Bamyan noted that they had only two vehicles and a limited budget for running costs to cover 6 districts: one was allocated to the central office and one was for monitoring all the ongoing national programmes.

not having enough vehicles and mobile phones to visit and keep in contact with communities. For example, the DRRD Director in Kabul noted that his fuel allowance lasted only for half the month, after which he relies on lifts to carry out supervision. Herat DRRD staff were unique in not having operational problems, for example, transportation. However, it should be noted that they received assistance from the FP and OC.

\section{Tensions in the institutional structure}

Some tensions in the institutional structure of the NSP were raised by DRRD representatives. The Provincial Governor in Kabul (based on his experience in Nangarhar) recommended that the conflicting models for community and district governance (traditional shuras of elders versus proposals for elected district councils) should be resolved by creating one inclusive structure.

Secondly, the provincial DRRD Director in Balkh preferred that CDCs were not granted complete authority because they tended to lack adequate experience. He used the example of a CDC insisting on (and creating the expectation for) an electricity project, but not appreciating that the government was unable to provide the service.

A third weakness, as raised in Balkh, Badghis, Kundoz, and Takhar was institutional jealousy. For DRRD staff, this arose from the frustration of wanting, though being unable, to manage the Programme alone. For example, DRRD staff praised the FPs but often felt sidelined and unappreciated by the communities. The latter was particularly acute in Kundoz, where the DRRD department felt excluded by both the OC and the FP.

\section{Cooperation with} other government departments

Cooperation with other government departments was consistently valued as an important strength. Hence building on
13 The N SP U nit in each province typically consisted of two staff in addition to DRRD staff. For example, the DRRD in Bamyan had 40 staff of which 28 were in permanent posts. They included: 5 engineers, 1 advisor, programme staff, computer operators, and radio operator. In Badghis, the D epartment was supposed to have 40 staff but only had 31 . Herat had 40 staff out of 41 available full-time positions, with 20 others paid on a daily basis. Kabul and Paktika both had 28 established staff each as well as contracted staff. This included: 1 construction engineer, 2 water supply engineers and 1 hygiene specialist.

FIN DIN GSAND RECOMMEN DATIONS 
existing horizontal and vertical institutional linkages should be considered an opportunity to further capacity and alleviate strains in the delivery system. In demonstrating the former, Badghis recalled attempts to cooperate with the departments of Agriculture and Health by conducting joint site visits. Similar stories were told in Balkh and Herat (Education and Health for needs assessments; and Energy for project approval, respectively). The sharing of transport and sectoral coordination meetings with the departments of Education and Agriculture were described in Kabul and Paktia. In Kundoz, respondents pointed to a 'joint commission for emergency response', which was considered to have a positive impact on the NSP. In demonstrating the vertical element, the DRRD in Nangarhar was also keen to integrate programme initiatives further, since it appreciated the already improved contact between the provincial and district levels of government.

However, inter-departmental coordination was clearly undeveloped, especially in terms of improving project implementation. Despite the optimism in Nangarhar, the FP, $O C$ and CDCs reported a pattern of DRRD inertia. Some of the DRRDs' perceived inaction of other government departments, as voiced in Paktika, forms a second obstacle to cooperation. Thirdly, it was claimed that delays and misunderstandings emerged from clashes in departmental bureaucracies and procedures, as exemplified by the failed attempts to work with the Department of Energy in Balkh and Kabul.

\section{Institutional learning}

Institutional learning and monitoring and evaluation are essential to consolidating and furthering the NSP's progress, and together they form an important provision within the Programme. For example, staff in Bamyan described how they and the FP undertook the documentary process to select projects before being processed by the OC. NSP and DRRD staff also referred to the use of joint monitoring programmes, quarterly reviews and transparency checks on CDC financial management with the $\mathrm{OC}$ and FP. Bamyan and Kabul staff listed election observation, and regular meetings and workshops to promote community participation in maintenance. In Kundoz, it was asserted that issues and problems raised during the implementation of the projects were always referred to the district government and, if not solved, to the provincial and central governments. This process was claimed to produce closer interaction and better understanding and working relations between communities and the different layers of the government.

Nevertheless, DRRD respondents overwhelmingly stated that institutional learning was severely restricted. This deficiency stemmed from the shortfalls in resources (number of staff and level of qualified training, in addition to physical resources), as detailed above. While claiming to do their best, district DRRD staff in Balk noted that 'although the NSP projects involve construction we do not have full engineers, only an assistant engineer, an economist and an agriculturalist'. NSP staff in Kabul thought that even the combined DRRD/OC team was not sufficient to monitor the existing 324 projects, never mind the further 608 just passed. Similarly, it was claimed that only two out of the 41 DRRD staff assisted in monitoring the projects and checking the proposals. Similar difficulties were relayed in Paktika.

\section{Flaws in programme design}

Firstly, (provincial and district) staff in Balkh and Kabul, in addition to the Provincial Governor of Balkh, emphasized the need to review the restriction in the budget allocation of US $\$ 60,000$ for 300 families. This was because in practice projects with a budget allocation for 300 families were being used by more beneficiaries. This was deemed to occur for two reasons - large villages were prevented from splitting into two or more by the NSP, and villages where original estimates of population made by the NSP subsequently increased through the return of IDPs and refugees. In particular, some feared that strains on projects would prove a catalyst to intra-community conflict.

Secondly, DRRD representatives in Balkh, Kabul, Paktia and Paktika all raised the significant operational problem of delays in the transfer and release of NSP instalments. Most seriously, the delays were blamed for damage caused to the quality of projects; for example, where the building of infrastructure could not be completed before winter.

Thirdly, in Balkh and Nangarhar, there was strong support for an increase in the coverage of the NSP in each province.

Fourthly, as a weakness in the NSP's aims and objectives, the Provincial Governor in Kabul asserted that the sustainability of projects was not given enough consideration. 
Finally, the Provincial Director of the NSP advocated the urgency for the DRRD to explain more about the goals of the second phase of the Programme.

This sub-section identified two main opportunities for long-term capacity development: the practice of harnessing the combined resources from horizontal and vertical institutional linkages; and the inherent scope for institutional learning. However, long-term institutional capacity development will also face several barriers, which are all characterized by two types of discord: between Programme expectations or institutional ambitions and actual resources; and between government and community approaches to governance and development.

\section{Summary}

The fundamental strength of the above findings is that they provide a frank assessment of progress in NSP management by those responsible for delivering the Programme. We must begin this summary by firstly recognizing the achievements of the NSP. According to the DRRD respondents and the provincial governors, the NSP has significantly improved the relationship between the participating communities and the government, in addition to creating stronger intra and inter-community relations to the extent that cases of conflict management emerged. There was also evidence of initial steps being taken towards community empowerment. In explaining these developments, the government representatives overall could rely on development experience from the NSP and within the wider national policy framework. Furthermore, there were several instances of institutional cooperation and some evidence of institutional learning in practice.

However, the following significant deficiencies and threats also emerged from the analysis, which in turn prompt some recommendations at the end of Section 3:

- The cap on the budget allocation ('regardless of the number of real beneficiaries') was causing significant distress within the Programme and risks causing rivalry and grievance.

- There was considerable frustration with delays in the transference of funds from the $\mathrm{OC}$ to the communities, which needs to be continuously reviewed.
While the official complaints procedure was used, the approach to its implementation varied considerably, to the extent that it risked disappearing in some provinces. This is especially worrying considering the natural barriers to establishing transparency and accountability in the context of a war-ravaged State.

- There is a need to reconcile conflicting models of governance, both at the community and programme design level.

Similarly, the question of sustainability (CDCs and projects) should also be addressed at both levels. Regardless of previously stated aims and objectives and as a minimum, it is essential to recognize that the NSP (to its credit) is progressively creating an expectation for sustainable development in villages. This expectation was voiced above by government representatives and is echoed by other relevant actors down to the communities. This expectation needs to be addressed and tackled either as a matter of defence but, more preferably, as a pragmatic step towards greater poverty reduction.

- In recognizing the values of fair representation, inclusion and legitimate authority, the role of women in the decision-making processes needs to be advanced to ensure that their development needs are protected.

- Greater efficiency and effectiveness would be gained by improving cooperation between government departments with a focus on coordination. This would create a complementary dimension to the NSP, consisting of a more strategic set of interrelationships between the programme and other national programmes, with the goal of large-scale development programming. This dimension would need to avoid duplication and address the different financing and implementation modalities that might hamper close cooperation in order to meet broader development goals. As a minimum, it is important for government departments to have accurate information concerning the responsibilities and operational tasks of their counterparts to avoid confusion or jealousy.

- Operational and human resources proved weak and uneven. The recommendations above would help to alleviate such strains.
FIN DINGSAN D

RECOMMENDATIONS 
- Institutional learning and monitoring and evaluation also proved uneven.

While this stemmed from weaknesses in resources and training (see below), there was also the need to instil a standardized set of procedures and checks and to ensure these are adhered to.

- NSP training was equally patchy in its nature and style. Greater efforts should be made to ensure greater consistency and effectiveness, with particular emphasis on making technical skills training more widely available.

\subsection{Sub-national level coordination and operational delivery of the NSP - the provincial OCs and teams}

The main challenge for the provincial OCS and teams, in protecting and strengthening the advancement of the NSP, is to supervise the management of the Programme while simultaneously developing the capacity of DRRD staff to assume operational delivery responsibilities. While these two tasks are laudable and have achieved some progress, there is an inherent tension between them. That is, the first task concentrates on making sure that short-term targets are met efficiently, while the latter involves longerterm aspirations. The main aim of this analysis is to highlight some of the salient outcomes from this tension.

This analysis of the provincial OCs and teams first reviews the improved relationship between the NSP participating communities and the Afghan government. The second sub-section establishes the potential sources for long-term staff and institutional capacity development. This analysis concludes by identifying the main achievements and strengths, in addition to deficiencies and threats to the role of the OC. The latter are matched by a set of specific recommendations.

In keeping with the previous section, this analysis is partly based on a self-evaluation by provincial OCs and teams, and is therefore particularly relevant since it articulates their views on potential areas of programme enhancement. It is further argued that these views are representative of the wider national dimension because OCs in nine provinces were interviewed. In general, the provincial OCs and teams shared the same concerns and assessments of NSP management as the provincial and district DRRD staff.

\section{Perceptions of the impact of the NSP on rural communities}

The nature of the NSP impact on rural communities was assessed to be generally positive and largely rests on the perception of an increase in national solidarity. An improved relationship between the NSP communities and the Afghan government, arising from the attractive values ascribed to the NSP process, is observed although both organized and ad hoc opposition was also noted. Similarly, respondents identified a shift towards stronger community relations through the incentives provided by NSP projects. Nevertheless, this positive impact may prove ephemeral, depending on the NSP's ability to meet the challenges to the empowerment of CDCs in general, and the particular problems experienced by women's CDCs.

\section{The relationship between NSP communities and government}

The OCs and teams asserted that the NSP had improved the relationship between the participating communities and the government considerably. It was believed that this effect stemmed from the opportunity for communities to assume local authority and responsibility. In particular, practical incentives involved the participatory, bottom-up and democratic process of defining needs and deciding priorities (Herat, Nangarhar, and Paktika etc). For example, in Badghis and Kabul, the popular enthusiasm to implement projects was noted, and it was asserted that people sometimes contributed more than the basic 10 per cent. The OCs in Balkh and Kundoz concurred and further claimed an improvement in the standard of living for some communities.

In addition, the common perception that the CDCs were democratic was held as the key reason for their legitimacy. The OCs also found that the CDCs complemented the traditional shuras' local governance in general, while introducing welcomed values such as transparency, accountability and representative leadership. The CDC was similarly welcomed in Bamyam, but because there was no traditional shura.

However, opposition to the NSP was noted and this can be understood in two ways. Firstly, in Badghis there was deliberate or direct opposition from armed groups 
because the NSP threatened vested interests. In another case, a mullah preached that the NSP was 'unlslamic'. Secondly, there was accidental or indirect opposition stemming from weaknesses in security through the ongoing low-intensity conflict and the sensitivity surrounding the poppy industry. Nangarhar, especially its more mountainous areas, exemplified this type of opposition.

\section{Inter- and intra-community relations}

The provincial OCs and teams described stronger community relations within participating communities, which was commonly characterized by the perception of greater unity. There were also some examples of conflict resolution, from between families in Herat to between armed groups in Kabul.

In addition, the OCs found evidence of some solidarity between villages where joint projects had pulled people together based on tangible incentives (Box 4 below illustrates how and why this occurred).

\section{Box 4. \\ Villages unified in Balkh}

The Balkh OC and team referred to the example of the village(s) of 'Kashanda Chakinah, where 13 CDCs reconstructed a $50 \mathrm{~km}$ road costing US $\$ 240,000^{\prime}$. There were two significant impacts: the project was decided and implemented ('in a proper way') by the community itself not an NGO. This was crucial as it meant, 'the CDCs represented a break from the traditional shura - a time when village elders and warlords were all-powerful.' Key to this development was the 'secret voting system, which lets people make their own choices', thereby granting 'authority with responsibilities to the elected representatives'. For example, it was believed that 'the $C D C$ and its subcommittees can now try to solve the problems of families'. Secondly, it meant the travelling time from Mazar was reduced from 21 to 7 hours (OC and Team, 26 October 2005).

Not all of the provincial OCs reported stronger intra and inter-community relations in their respective provinces. Furthermore, it was reported in Nangarhar that envy between non-participating and NSP villages had resulted in conflict in some districts.

\section{Evidence of community empowerment}

The NSP's determined drive for capacity development was seen as the central opportunity for the empowerment of communities. The OCs perceived this development and the Programme's long-term potential to be based on its new approach to funding, the people's increase in knowledge and skills through participation, and the official recognition of the CDCs (Balkh, Herat, Kabul, and Nangarhar). Nevertheless, the inability to ameliorate weak capacities at the community level created significant obstacles to empowerment (see Box 5).

\section{Box 5. \\ Weak community capacities in Nangarhar}

The OC in Nangarhar emphasized fundamental weaknesses in the capacities of the $\mathrm{CDC}$ members and communities in general as a crucial challenge to the process of empowerment. Accordingly, and as echoed by the OC in Paktika, illiteracy, other shortfalls in education and tight timeframes typically resulted in a weak grasp of the Programme's purpose and procedures, and cast doubt on the levels of substantive participation in terms of identifying priorities and submitting a CDP. It was also attributed to the creation of confusion and false hope. Moreover, it was felt that the insufficient capacities and their implications for empowerment were not addressed by the NSP. Consequently, the OC believed it was common for the FP to shift from facilitating to implementing. Specific recommendations included the need for more livelihood projects, payment for CDC members and improving the linkages between the actors in the community empowerment process.

Building gender-equal capacities forms one of the most crucial elements of empowerment. Progress was classified as slow overall based on the assessment of the provincial OCs and teams (for example, see Badghis and Kabul provincial field reports). The two main areas of concern were insufficient participation in the processes of community decision-making and project implementation, and the limited allocation of project funds for women. Despite the targets prescribed by the Operational Manual, slow progress was attributed either to cultural opposition and suspicion from communities (Nangarhar) and/or insufficient impetus from the NSP actors (Balkh). In the latter
FIN DIN GSAN D RECOMMENDATIONS 
province, the OC estimated that only the small (under US \$3000) and non-sustainable projects for women were accepted by the communities. Based on these challenges, the OCs commonly referred to using a gradualist approach towards greater inclusion. However, there was equal concern that this approach was at odds with the time constraints of the Programme.

Whether women and men's CDCs ought to be mixed or remain separate was a recurring dilemma for the OCs. Since the underlying theme of the NSP is cooperation, interaction and the building of social capital, then the integration of CDCs may be the ideal arrangement. Of course, the main conclusion is that approaches to integration and such targets must be tailored to the cultural mores and capacity levels within each province, district and community. For example, the OC in Balkh was confident that the integration of rural-based CDCs would occur in 4-5 years, with evidence of some already mixed. ${ }^{14}$ Conversely, the Nangarhar OC was less optimistic and deemed equal participation to be impossible in the eastern areas of the Province. Moreover, it can be argued that integration is important and may be necessary, but this dilemma should not mask the real need: building the actual capacities and skills of women in the communities to enable proper participation in decision-making and project implementation in addition to access to project funds. It is prudent to consider that the latter represent more reliable indicators for empowerment rather than the integration of CDCS, which can be easily feigned for the outsider.

In sum, the OCs and teams attributed a positive impact on the communities participating in the NSP. However, opposition to the NSP was also a cross-cutting concern. Evidence for this already existed in deliberate and accidental forms, including the instances of conflict from envious non-participating villages. Furthermore, the inability to respond to the low levels of skills and capacities prevented empowerment, and risked creating confusion and false hope. In compounding this, the failure to ensure the satisfactory inclusion of women represented additional resistance, if not obstruction, of the Programme's core aim and objectives. It is now appropriate to establish the OC's assessment of the DRRD's management capacity.

\section{The potential sources for long-term DRRD staff and institutional capacity development}

An analysis of the key strengths and weaknesses in programme management, as perceived by the OCs and teams, reveals the potential sources for long-term staff and institutional capacity-development. In addition, the analysis presents the strengths and weaknesses of the OC's supervisory and capacity-development role. The weaknesses included the tendency for some OCs to adopt a more managerial function: the lack of systematic capacity development; the inadequate capacity of the DRRDs, especially in terms of coordination; and the unrealistic timeframe for the OCs' exit strategy. Despite the positive response to the eligibility criteria, two key programme design flaws were noted.

\section{Inconsistent perception of the role of the provincial $\mathrm{OC}$}

While the OCs and teams conveyed a confident understanding of their role in the NSP, this role varied significantly between provinces in two main ways. Often the division appeared blurred between supervising the management of the Programme and actual management. For example, the Balkh OC and team defined their role as, 'giving technical advice, transferring money to the $C D C^{\prime}$ ', in addition to 'controlling the management of the overall programme' (OC and Team, 26 October 2005). The OCs in Bamyan and Kundoz also described a more involved role and, in Badghis, the $\mathrm{OC}$ and team presented their role in terms of direct implementation to the point of making themselves indispensable to the continuation of the NSP in the province.

Conversely, in Herat, Nangarhar, Paktika, and Takhar, the OCs denied any involvement in the management of the Programme, and each described their role as monitoring the projects, providing technical advice, advising other stakeholders, and ensuring there is coordination and cooperation. Similarly, the Kabul OC believed the management of the NSP was well coordinated between the three implementing agencies (DRRD, FP and OC), which worked as a team. Accordingly, the supervisory role consisted of regular field visits involving scrutiny of the documentation and project proposals before being forwarded to central office. However, it was thought that this level of supervision had decreased as the number of projects and proposals increased. 
The second function of the OCs' role was to develop the institutional and staff capacities of the DRRDs. In Balkh, Herat, Kabul, Kundoz, Nangarhar, Paktika, and Takhar there was evidence of clear cooperation between each $O C$ and DRRD, with a deliberate effort to build capacities (see Box 6 below). For example, in Balkh, the respondents noted the principle of always having 'two-way communication during training' and during the weekly meetings. Key themes were finance, $M \& E$ and engineering. The Takhar OC had developed an evaluation form to assess the training needs of the staff and followed this with workshops, but little progress was noted. In Nangarhar, a longterm training programme had been introduced for the DRRD to focus on all aspects of the NSP. However, it was felt that there was too much emphasis on the technical aspects and on rural infrastructure at the expense of community development, income generation, microfinance and livelihood development. Despite claiming a close relationship, the Badghis OC did not mention any involvement in the capacity development of the DRRD. Therefore, the prospect of the DRRD assuming even an equal role was remote. While the Bamyan OC worked closely with the DRRD there was no evidence that it had provided such training.

\section{Limited capacity of DRRD}

The majority of the OCS and teams overwhelmingly asserted that the capacity of their respective DRRD was inadequate because of the number of staff and level of expertise, especially in terms of technical staff to supervise projects in the field. This assessment was relevant in provinces, whether the role of the $O C$ was managerial or supervisory, a builder of capacities or not. For example, the Badghis OC emphasized the DRRD's lack of professional, qualified staff and the NSP Manager's inadequate level of education. In completing the vicious circle, this OC blamed the DRRD's lack of capacity as the reason for not being able to develop capacity systematically.

In turn this was also the OC's justification for assuming full operational control of the Programme, although importance was given to developing the capacity of the FP through training and direct supervision and to empowering and developing the capacity of the CDC. While the DRRD was perhaps informed, it was effectively marginalized because the arrangements failed to produce a productive capacity-developing partnership.
Box 6.

An integrated approach to DRRD capacity development in Kabul

There was a conscious effort to build the capacity of DRRD staff in Kabul by the OC through the joint supervision and monitoring of the projects. The FP (SDF) also contributed crucial peacebuilding and problem analysis methodologies, as well as an understanding (as a national NGO) of the culture and moral beliefs of the communities. This enabled greater inclusion of interest groups, with the harnessing of preexisting leadership as an important feature. These efforts were further complemented by the provision of practical and political support by district governors. Overall, it was asserted that all parties shared a common understanding and enthusiasm for the NSP aims and concept, which included the active involvement of the DRRD Director. This unified approach was credited with the creation of tangible results in terms of governance and community development. For the latter, this consisted of the quality of the projects in terms of their design, relevance and construction, as well as their sustainability in terms of maintenance. In sum, capacitybuilding was described as central to the role of oversight consultant and as the core activity of the Programme as a whole.

In Nangarhar, the $O C$ noted that the staff management capacity varied, but overall there was willingness at the provincial level but little capacity to manage the NSP, while the district level was nonexistent in this sense. The $\mathrm{OC}$ and team in Balkh and Herat were satisfied with the management capacity of the DRRD, and the former believed they were engaged in an active learning process involving 'engineers gaining field practice in the NSP, especially in terms of monitoring and evaluation'. ${ }^{15}$ However, it was noted that the lack of technical staff was a crucial restriction. The Bamyan and Takhar OCs pinpointed a similar lack of resources in addition to inadequate development expertise. The main outcome of this weakness was poor coordination of the provincial NSP actors (see Balkh, Herat, Nangarhar, and Takhar provincial reports). However, it must be recognized that the pressure on the $\mathrm{OC}$ to meet the Programme's quantitative targets and deadlines was also a restricting factor.
15 Based on the data collected, the $\mathrm{OC}$ teams in each province varied between 4-7 staff. For example, in Balkh, the team consisted of an engineer, N SP/OC clerk, a data handler (woman), a monitor (woman), an $M \& E$ specialist, an accountant and two other local staff. In Kabul, the operational team consisted of 1 engineer, 2 monitors, and 1 documentation clerk. 0 ne of these staff was a woman.

FIN DIN GS AN D RECOMMEN DATIONS 
All of the OCs (except Kabul) believed that the proposed timeframe for the exit strategy of the OC was unrealistic. However, alternative timeframes varied from two years in Paktika, to 8-10 years in Balkh. Kabul was the exception although the $\mathrm{OC}$ emphasized the precondition of needing more staff in order to match the expectation for expansion. Moreover, the OCs in Kabul and Nangarhar asserted that this deadline reflected the lack of long-term planning and direction within the Programme. Both perceived this to stunt performance, for example, towards the capacity development of communities and DRRDs.

\section{Programme design}

All the OCs and teams considered the application of the eligibility criteria to be a positive feature of the Programme and believed that most projects complied. Nevertheless, the first flaw was the delays in the transfer and disbursement of funds, which was experienced by all the OCs except in Kundoz, and to a degree in Paktika. Four weaknesses of varying impact were defined: the DAB for late disbursement; the OC headquarters for their failure to renew proposals efficiently; the FP for sometimes sending late requests for second instalments; and miscellaneous bureaucratic errors. However, there was optimism that this set of flaws would be corrected by the new electronic tracking system.

The second flaw was the project budget cap of US $\$ 60,000 / 300$ families, which meant that project budgets sometimes did not reflect the actual number of beneficiaries. Consequently, projects were susceptible to overuse and needs were not adequately met (see Balkh and Nangarhar provincial field reports).

In sum, further staff and institutional capacity development centres on the practical limitations of the OCs' role of having to supervise NSP management and build the capacities of the managers. Both roles could not be performed effectively. Moreover, the capacity of the DRRD (staff and quality of staff) was clearly not benefiting from this level of capacity development. As a consequence, the timeframe for the exit strategy of the $\mathrm{OC}$ was judged unrealistic. Last, there was a positive reaction to the eligibility criteria but the Programme was flawed in releasing the funds to the CDCs, and the budget restriction meant some projects were disproportionate to needs.

\section{Summary}

The fundamental strength of these findings is that they provide an honest and open assessment of progress in NSP management by those responsible for delivering the Programme. We must once again begin this summary by firstly recognizing the achievements of the NSP. According to the respondents, the NSP has significantly improved the relationship between the participating communities and the government, in addition to creating stronger intra- and inter-community relations. However, the findings also identify some concerns:

the skills and capacities of community members were lower than the level assumed by the Programme to reach its targets;

$\checkmark$ progress was slow in gender-equal participation and the debate concerning $\mathrm{CDC}$ integration risked the masking of real needs;

there was a risk of institutional dependency because the OCs struggled both to develop the capacity of the DRRDs (which was particularly weak in terms of staff numbers and expertise) while ensuring that the Programme advanced. In sum, capacity development needed to be made relevant to the implementation environment and the rationale of the NSP; and

- the budget cap remained a significant and unaddressed programme flaw. While this demanded specific attention from the NSP, budget shortfalls for projects might be tackled by links to other international donor programmes.

\subsection{The role of the Facilitating Partners in NSP coordination and operational delivery}

FPs and NSP/OC lack qualified staff to support income gen erating a ctivities. We believe that such activities should be encouraged in Phase 2 and that suitably qualified staff should be appointed, i.e. this will need an HR strategy. (FP Stakeholder)

FPs were selected and in some cases operational before NSP/OC was contracted by the government... this has severely hampered NSP/OC's ability to monitor the performance of FPs. (OC Stakeholder) 
Table 1. The operations of NSP Facilitating Partners

\begin{tabular}{|c|c|c|c|c|}
\hline FP & Province & $\begin{array}{l}\text { Sub-Projects } \\
\text { Completed }\end{array}$ & $\begin{array}{l}\text { Block Grant } \\
\text { Disbursements } \\
\text { (Afs) }\end{array}$ & $\begin{array}{l}\text { Research } \\
\text { for the } \\
\text { Evaluation }\end{array}$ \\
\hline AKDN, ACTED, Afghan Aid & Badakhshan & 0 & $107,255,946$ & \\
\hline BRAC, DACAAR & Badghis & 20 & $132,139,511$ & $x$ \\
\hline ACTED, AKDN & Baghlan & 33 & $114,826,805$ & \\
\hline CHA, UN-HABITAT & Balkh & 40 & $277,588,719$ & $x$ \\
\hline AKDN, UN-HABITAT & Bamyan & 47 & $261,527,097$ & $x$ \\
\hline Oxfam & Day Kundi & 23 & $101,752,908$ & \\
\hline UN-HABITAT & Farah & 193 & $287,673,313$ & \\
\hline ACTED & Faryab & 24 & $94,294,658$ & \\
\hline CARE, DACAAR & Ghazni & 119 & $241,782,469$ & \\
\hline Afghan Aid & Ghor & 40 & $118,775,568$ & \\
\hline BRAC & Hilmand & 170 & $228,368,554$ & 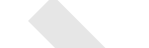 \\
\hline UN-HABITAT, DACAAR & Hirat & 166 & $338,380,889$ & $x$ \\
\hline ActionAid*, GAA & Jawzjan & 88 & $156,614,846$ & \\
\hline SDF & Kabul & 81 & $333,524,864$ & $x$ \\
\hline UN-HABITAT & Kandahar & 179 & $283,918,559$ & \\
\hline UN-HABITAT & Kapisa & 66 & 276,484451 & \\
\hline IRC & Khost & 89 & $188,129,127$ & \\
\hline Madera & Kunar & 0 & $168,147,988$ & \\
\hline ACTED, GRSP & Kunduz & 51 & $220,574,538$ & $x$ \\
\hline Madera, DACAAR & Laghman & 66 & $150,631,502$ & $x$ \\
\hline IRC & Logar & 70 & $221,848,526$ & \\
\hline BRAC & Nangarhar & 103 & $207,739,408$ & $x$ \\
\hline O ckenden International & Nimroz & 148 & $66,081,563$ & \\
\hline Afghan Aid, Madera & Nuristan & 0 & $39,877,079$ & \\
\hline BRAC & Paktika & 326 & $258,658,970$ & $x$ \\
\hline DACAAR, PIN, CARE* & Pakyta & 57 & $189,829,632$ & \\
\hline UN-HABITAT & Panjsher & 16 & $164,586,986$ & \\
\hline UN-HABITAT, AKDN & Parwan & 107 & $226,442,956$ & \\
\hline Afghan Aid, BRAC & Samangan & 78 & $201,875,668$ & \\
\hline GAA, ACTED, CO NCERN & Sari Pul & 6 & $192,901,367$ & \\
\hline ACTED, CONCERN & Takhar & 68 & $167,372,847$ & $x$ \\
\hline ADA & Uruzgan & 0 & 0 & \\
\hline SCA & Wardak & 52 & $259,861,025$ & \\
\hline ADA & Zabul & 69 & $34,439,190$ & \\
\hline Totals & & 2,617 & $6,314,007,527$ & \\
\hline
\end{tabular}


The Afghanistan Ministry of Rural Rehabilitation and Development (MRRD) has currently contracted 19 non-governmental organizations (NGOs) to facilitate the delivery of the National Solidarity Programme in selected districts/provinces of Afghanistan. The NGOs are the Facilitating Partners (FPs) of the NSP. Table 1 shows the FPs, their provinces of operation, the number of sub-projects completed and the amount of Block Grant disbursements as of 30 September 2005.

The research for the evaluation was undertaken with 11 FPs in 13 different areas across Afghanistan. Six teams, consisting of 4 members each, carried out the research amongst the FPs in the following locations: Kabul (SDF), Bamyan (AKDN and UNHABITAT), Herat, (UN-HABITAT), Balkh (CHA), Nangahar (BRAC), Badghis (BRAC), Paktika (BRAC), Laghman (DACAAR and Maderia), Kundoz (GRSP) and Takhar (Concern). In addition Kabul level research was undertaken for CARE and ActionAid. A list of the stakeholders interviewed can be found in Annex C.

Following the agreed Terms of Reference, this section sets out to evaluate: the role of the FPs within the NSP; FP capacity and the NSP; community participation; and the effectiveness, efficiency and relevance of the FPs' work. The Altai Assessment of the FPs (Common Final Report II, August 2004) will be used as a source of comparative evaluation on the work of FPs. ${ }^{16}$ However, this is not an evaluation of individual FPs; it would be unrealistic to compare relative 'successes' or 'failures' across such a diverse and challenging setting as Afghanistan. Hence Table 1 does not break down individual targets attained by various FPs. This section on the role of FPs in NSP coordination inevitably has many linkages with the analysis of the MRRD/OC and the CDCs. Hence many of the implications of these findings are discussed in greater detail in other parts of the report.

This evaluation attempts to give more weight to the qualitative aspects of the FPs' work which helps to contextualize their operating environment and give indications as to the capacity and sustainability of CDCs. The findings presented here will go some way towards mitigating the fact that 'many FPs currently fear that MRRD only check their data and thus does not sufficiently consider the qualitative and long term aspects they try to implement' (NSP FP stakeholder). Furthermore, the quantitative figures do not provide a clear and fair appreciation of the field work conducted by FPs as well as the sustainability of the CDC projects delivered. Nor do they inform our understanding of the strengths and weaknesses, best practices, and issues to be addressed. This qualitative information is also essential for the OC/MRRC when it comes to preparing the next steps of the Programme. ${ }^{17}$

This evaluation provides further confirmation of a common observation throughout our surveys that the absence of consistent and coherent NSP methodology and documentation creates serious delays in the process of operational delivery. ${ }^{18}$ Many of the FPs complain of the ever-changing requirements and their difficulty in keeping up with the changes. Hence it is crucial that any changes to the NSP Operational Manual factors in the costs of implementation. Indeed, a risk assessment should be concluded before deciding to introduce changes. The eligibility criteria and flexibility of projects was not found to be as rigid as reported in the Altai study. However, FPs still feel constrained by the amount of paperwork required for multi-CDC projects, and there is a general feeling that the OCs do not appreciate the specific local dynamics of their operations.

As identified in other sections of this report, programme coordination with other governmental bodies at the national, provincial and local levels is essential to the long-term sustainability of the NSP. This would enable the FPs to operate with more confidence and certainty and to integrate their work with other initiatives being undertaken. 19 Moreover, in keeping with the Altai findings $(2004,10)$, there exists a strong view that the long term strategy of NSP should be shared with FPs. Indeed, there continues to be a high level of uncertainty regarding the direction of NSP. The above points are discussed in further detail in the ensuing sub-sections of the report.

\section{The role of the FPs within the NSP - the 'bridge' between the government and the community}

Research with the FPs and amongst the CDCs highlights that the FPs understand their role within the NSP as identified in the Manual.

All the FPs see their role as facilitating different aspects of community development, by enabling people to come together 
to identify priorities, develop proposals and then implement the projects. As the Director of BRAC states '[W]e help the people to develop capacity within their communities to help them get to a position where a project can be implemented and sustained. 20 Whilst the Provincial Director of UN-HABITAT described their role 'as a bridge between the government and the people to explain the NSP system to the community, conduct training, bring the hardware, guide the identification of needs and priorities and help the CDCs prepare their CDPs'. ${ }^{21}$ The Executive Director of SDF referred to his role as, 'the promotion of advocacy from people to government and from government to people and capacity development.'22

These perceptions of the NSP and the role of the FP within the Programme were not just held by those in the higher echelons of the FPs, but seemed to transcend to the district level. For example, $\mathrm{CHA}$ Provincial staff in Balkh described the role of their NGO as a:

... bridge for relations between the shura and government, since through them the community can contact the government and vice versa and that the [newly created] CDCs were very happy the first time we came and they think of us as their advisor. ${ }^{23}$

District managers of BRAC in Badghis 24 highlighted how they continually explained their role as facilitators of a government programme to the communities. However, all the FPs, without exception, confirmed that at first it was difficult to win the trust of the communities until they began to see visible changes as a result of the projects. Their experience therefore confirms the observations of the $\mathrm{OC}$ that the social developments of the Programme are achieved through participation in the projects. Some of the FPs (such as UN-HABITAT) saw their role in a more transitional sense and directed towards a situation where facilitation between the CDCs and the government was no longer necessary. It is also worth noting that some of the FPs also view the NSP as an entry point and institutional framework for expanding their own community development work

All the research indicated that the communities know that the FPs work on behalf of the government. The FPs use social mobilizers to explain the NSP and their role within it to ensure that people are clear that it is a government programme. Feedback from some FPs, notably BRAC in Nangarhar, and Paktika and GRSP in Kundoz, highlighted that at first people did not believe that the government was working for them through the NGOs because in the past any developmental work was implemented by NGOs and did not involve the government. In some project sites visited there are signs and NSP literature emphasizing and promoting the role of the government as distinct from that of the FP.

The role of the FP as a facilitator of a government programme is also highlighted when government officials periodically visit the communities to reinforce the government's overall role within the Programme. In addition the projects are inaugurated and training certificates are always distributed by government officials and not the FPs.

The 'NSP Awareness' recommendations from the Altai Assessment have a relevance for improving the role of the FPs. Altai (2004, 3-10) found that the FPs must be given clear objectives in terms of training and communication to make sure that the communities know about the role of the FP within the NSP. All the research undertaken by the PRDU indicates that both the FPs and the communities were clear that the NSP was a government programme. In addition, the recommendation for a 'simple and clear message emphasizing the government's role in NSP to be disseminated to all levels' also appears to be working. The need for 'basic communication tools (posters, information boards) to better brand the NSP at the village level and thus present the FP accordingly, i.e. a partner helping the communities to access a governmental, national programme', has certainly been implemented in the majority of the communities visited.

However, other Altai recommendations are yet to be fully realized. For example, there was little evidence that, 'CDCs were being encouraged to create linkages with other programmes and/or local initiatives'. Moreover, whilst the NSP/MRRD-inspired CDC Jirga in August 2005 was highly successful, there is still room for greater initiative sharing amongst the CDCs as enabled through the FPs. The MRRD and other government departments also have a responsibility to ensure better linkages between the CDCs and other development initiatives, and there is only limited evidence of "joint field sessions amongst the FPs and the MRRD teams to transfer know-how'.
20 Director, BRAC, 220 ctober 2005, Kabul.

21 UN - HABITAT Provincial Director, 1 N ovember 2005, Mes.

22 Executive Director SD F, Mohammed Raz Dilili, Kabul.

23 CHA D istrict Staff, 27 0 ctober 2005, MeS.

24 D istrict Managers BRAC, Baghis.

FIN DIN GSAN D RECOMMENDATIONS 

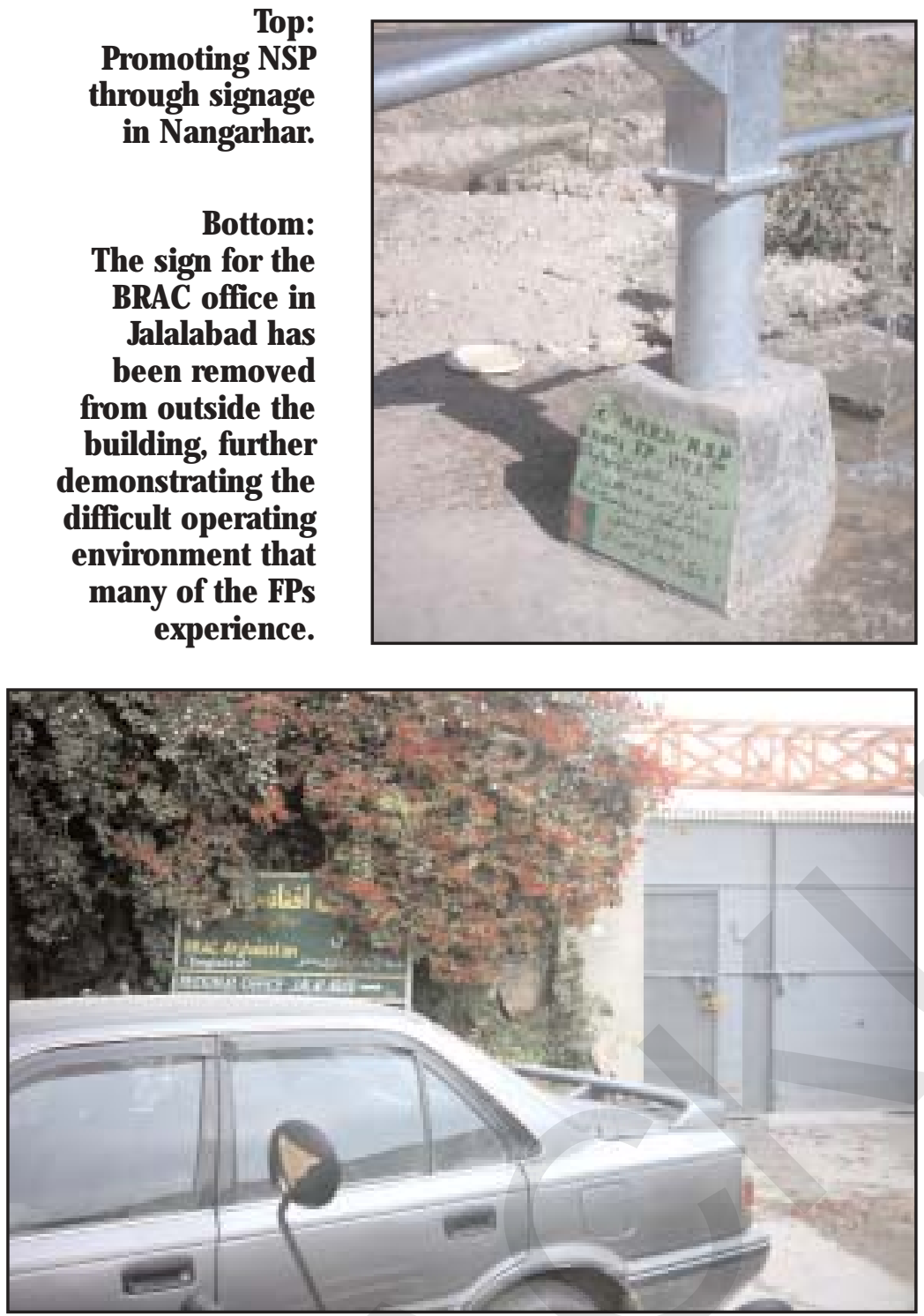

The FPs interviewed have played a major role in the CDC elections which appeared to be an easier process than many had anticipated. However, there is a major question mark as to what extent this has altered the power balance in the villages. A determining factor for the election, facilitation, training, the need for technical assistance and ability to monitor is: a) the number of literate in the village and their level of education, and b) facilitation and technical skills among FP staff. In both cases the challenge increases with the remoteness of the NSP project from major cities as literacy levels decrease, and it is extremely difficult to recruit and keep staff in these locations. In addition, in some areas the factual project period is only the summer season as the areas are not accessible during the winter, increasing the challenge. FPs generally maintained that the NSP system is based on a rather inflexible approach menu - written in English - where possibly English skills become more important to demonstrate towards the OC than the FPs' technical skills.
The end result is frequently that the FPs actually have to 'do too much on behalf of the communities' to be able to meet the project requirements. It is not so much a question of having the choice of playing the right role as to being forced into a wrong role.

In some of the areas researched, such as Nangarhar, Pakita and Laghman, the FPs are working in extremely trying conditions and are acutely vulnerable to events beyond their control. ${ }^{25}$ In Nangarhar, for example, communities in Chaparhar, Achin and Badakot Districts have accused BRAC of informing ISAF where poppies are grown, or spying on behalf of the CIA. BRAC also have to deal with night letters in Sorkhrod district. In May 2005, the BRAC offices in Jalalabad were attacked following the US soldiers' desecration of the Koran in Guantanamo Bay, and staff have come under attack in the districts from IEDs. Although relations with the majority of the communities are good BRAC, like other FPs, feel acutely vulnerable to any external occurrence involving ISAF, and especially America. 26

\section{FP relations with MRRD/OC}

The research highlighted an uneven pattern of relations with the MRRD/OC. Many of the FPs and also the MRRD emphasized the need to build up the MRRD presence at the district level, not least to be able to continue the capacity development of the CDCs and to undertake monitoring. However, this should not mean that, a) another layer should be added to the project approval and disbursement (and corruption) chain, and b) that capacity development should be viewed from a political angle, especially from the other ministries who lack funding for establishing 'their' district representation. In addition, the local woluswals might see their power eroded, and thus care should be taken when the system is established and presented to other parts of the government. As highlighted elsewhere, one of the main concerns from this evaluation is that the provincial and district MRRD have little grasp of the practical aspects of the NSP and the problems and prescriptions required to ensure its effective day-to-day running.

At the Kabul level relations between the FP and the $\mathrm{OC}$ are good. The FP Windows Dept oversees the contracting of the FPs and is seen by many of the FPs as the initial department to which issues of concern are 
brought. The $\mathrm{OC}$ in general is aware of all the problems that the FPs have, and acknowledge that many of the problems are structural and due to the political nature of the Programme, with its emphasis on rollout.

At the provincial level, relations between the FP and the DRRD are generally positive. The DRRD/OC/FP usually meet on a weekly basis to solve problems and make collective decisions. However the FPs, without exception, consider the capacity of the provincial level MRRD to be weak. Although they have more resources than any other provincial ministry there remain significant shortages of technical and physical resources. GRSP for example highlight that, 'If we talk about the $\mathrm{OC}$ as part of the MRRD in Kundoz then one can say that their capacity is good, but without the OC, MRRD capacity is like the other government departments - weak.' 27

At the district level, the FPs also consider the MRRD to be weak. The MRRD often does not have an office at the district level and therefore contact between the community and local government is limited. In some districts, the district personnel have inadequate access to transport and a shortage of skilled staff. In Nangahar, for example, there are only two engineers to cover 5 districts. In addition, some FPs complain that 'new district governors require a great deal of time to be brought up to speed with the NSP.'28 This comment from GRSP in Takhar was typical: 'the capacity of the MRRD at the district is weak, there is just one vehicle and that is for the director. The rest of the staff are not allowed to use it to travel to project areas.' In some provinces feedback from the FPs (which was also confirmed by the CDCs), suggest that district administrators are more concerned with security than development. Some of the FPs, notably BRAC and Maderia, cite this as being a structural problem within all Afghanistan, and as such supports the rationale for the newly created CDCs becoming the local government at the district level. Some of the FPs, such as BRAC in Nangahar and Maderia in Laghman, are frustrated that when the district MRRD does deal with the $C D C$-elected representatives within $\mathrm{CDC}$ communities, rather they only consult the maliks and not CDC representatives. The experience of SDF is slightly different as their proximity to the MRRD and the $\mathrm{OC}$ has meant that they 'have not experienced the problems we have heard about outside Kabul'.29
In general, relations between the regional and provincial OCs and FPs were good, with the FPs seeing themselves as part of a coordinated team dedicated to delivering the Programme in often difficult circumstances. Most of the FPs appreciated the work of the $O C$ and did not feel overly pressured by the OCs in terms of the actual day-to-day decisions. However, some FPs are upset when comparisons are made between their work and that of other FPS. BRAC for example, concede that Nangarhar is not comparing favourably to other provinces in terms of the NSP; this they claim is because of poor security and the low receptive capacity of the beneficiaries. In such circumstances some of the FPs feel that more practical support should be forthcoming in terms of a more flexible timetable and extra allowances.

The gap remains between the community and local district government, but the contact between the community and provincial government has increased due to the NSP. Never before have the government been so visible in communities, with physical reminders through projects, signs, workshops and meetings, etc that strengthen the link between communities and provincial/national government.

\section{FP capacity to deliver the NSP}

Many of the FPs are international NGOs with a proven track record of managing community development in different contexts, and many were already active in Afghanistan and implement other programmes as well as the NSP. BRAC for example manage a health care programme across their areas of operation, AKDN manage rural development and education programmes, whilst Concern has an extensive rural development programme, mainly in the north. The research amongst the national FPs such as GRSP, CHA and SDF highlight how useful local knowledge was to implement NSP based on their ongoing involvement with other programmes across Afghanistan.

The research found that to varying degrees the FPs possessed the capacity to manage the NSP. Some FPs already possessed the capacity to incorporate NSP into their portfolio of activities. BRAC, for example, did not have to increase its capacity as such to cope with the demands of the NSP, but had to tailor its resources from existing programmes. It did not have to recruit more
27 Director, GRSP,

N ovember 2005, Kundoz.

28 Regional Manager, BRAC $\mathrm{O}$ ctober 28th, $\mathrm{N}$ angarhar.

29 Team Leader, SD F, O ctober 20th 2005, Kabul.

FIN DIN GSAN D RECO MMEN D ATIO NS 
30 However, it is noted that the $O C$ s recommend that BRAC increase their staff capacity in order to implement the N SP more efficiently; it is too soon to say if this has been undertaken.

31 They are in fact waiting for government approval to establish 35 more shuras in Shibar, covering the most remote communities, and have started some surveys.

$32 \mathrm{CHA}$ Provincial Management Team, 260 ctober 2005, MeS.

33 UN - HABITAT Provincial Director, 1 N ovember 2005, Balkh.

34 CHA District Staff, 270 ctober 2005; CHA District Staff, 8 N ovember 2005; and UN - H ABITAT D istrict Staff, 10 N ovember 2005

SECTION 3: SUB-N ATIO N AL LEVEL staff as they already had specific expertise in relevant areas, e.g. engineering, livelihoods and project management. ${ }^{30}$ However, some of the FPs had to recruit additional staff. In order to take on the NSP in Bamyan, AKDN for example had to advertise and select SO (Social Organizers) and CF (Community Facilitators) in each district. AKDN is clearly well resourced and pays a great deal of attention to staff recruitment and training, including a comparatively high number of women field staff. In the two AKDN districts there are 9 women to 16 men. The 4 women SOs working in Shibar were returned refugees from Iran, where they had some experience of community work. If the number of projects increases AKDN have the capacity to expand and train the staff. 31 AKDN's field staff believe that their training and experience of completing one phase of the Programme (in Surkpasa District) has equipped them with the skills they need to tackle the second phase with confidence. The key skills they cited were: establishing relations with the community with cultural and social sensitivity, and knowledge of development. They had received training on: NSP awareness, community mobilization and clustering the communities. Other training related to identifying priorities for a development plan, and aspects of project development, proposal implementation and monitoring were also considered to be useful.

The consequences of local staff training can be problematic for some of the FPs. As the BRAC NSP Manager states, 'We have often found that we spend a great deal of time and money on training local staff who then promptly leave for better paid jobs within the NGO sector. We are philosophical about this and acknowledge that at least our training is having a trickle-down effect so that in some way the country is benefiting'. Even though GRSP in Kunduz experience similar dilemmas they always try to ensure that there are experienced staff on the projects by ensuring teams are mixed with newly trained personnel.

Other FPs, such as $\mathrm{CHA}$, acknowledge that they have had to develop their capacity, knowledge and skills through various training sessions and workshops conducted by themselves, OC and MRRD. 32 District staff concur that they 'had to learn more skills, use more social mobilizers and facilitators, and hire a technician to ensure we kept to the regulations since it is a new programme'. This was particularly crucial 'to maintain efficiency when the number of projects was high'. There was also a test for all staff on applying the Operational Manual.

UN-HABITAT'S history of developing the CFDO and in providing training material for the NSP meant that they started working on the NSP with extensive experience. ${ }^{33} \mathrm{CHA}$ and UN-HABITAT district staff listed training/workshops on the Operational Manual, proposal writing, monitoring, book-keeping, finance, human rights, children's rights, mine awareness, community development and the rule of law/constitution. The staff felt that the training had been very useful. ${ }^{34}$ As an example, a social mobilizer for UN-HABITAT explained how he was trained to gain proper access to a village for the first time:

First, we contact the district head and ask them to invite the village leader to a meeting in the district office to explain the NSP and our aims. If necessary, we will also move down the line of authority to find other key persons to secure permission. When we enter, we visit the elders at a small meeting and then we have a community-wide gathering.

(UN-HABITAT District Staff, 10 November 2005)

SDF has a Capacity-Building Department which designs and develops training and capacity-building for the communities. NSP staff are then trained in these methods before working with the communities. SDF acknowledge that they are fortunate, in Kabul, in being able to recruit staff with at least secondary education and often relevant experience. For many FPs, the capacity development aspect of NSP is seen as the most important: '[W]e believe everything we do with them (the CDCs) is a form of capacity building'. It focusses on two areas: participatory governance and being able to manage their projects. Implicit in this belief is the need for trained and capable staff to implement the Programme.

\section{CDC training}

The training of the CDCs is essential for the success of the NSP. There is a basic common approach to training given by the FPs. The problems are first identified and different training is then given to develop capacity as necessary for the election of the CDC, formulation of the CDP and then the management of the project. In the case of some 
remote communities it has proved necessary for FPs like AKDN and BRAC to organize and pay for exposure visits to take the $\mathrm{CDC}$ members to neighbouring projects (in one case to Kabul) to broaden their appreciation of NSP.

All the FPs echoed the belief of SDF that 'training and capacity-building are first of all essential to the process of establishing the CDC. Peacebuilding, based on Islamic principles, is key to opening the way for the Programme.' This aspect of SDF's and other FPs' approach was referred to by all the other stakeholders from MRRD to the CDC members and householders. It is clear that this CDC training groundwork is an important factor in the success of the FPs work.

SDF provides a good example of effective training for CDCS. SDF gives training in all aspects of CDC functions, record keeping, book-keeping and project management, as outlined in the Operational Manual. These functional aspects had clearly been thoroughly transferred to the CDC members in the case of Kabul, where all the CDCs visited had a good understanding of the functions of the CDC, the NSP Programme and the management of their projects. Documentation of their activities and financial transactions was also of a very high standard. The process was no doubt helped by the good standard of education of the CDC members compared to other areas of the country.

SDF, like AKDN, have added other training programmes to the basic NSP requirements, which they think are relevant and help the $C D C$ to function effectively. These include: education, health, literacy, Islamic education and human rights awareness. Again it was clear from the respondents in the communities that they had been exposed to these courses and found them relevant. Problem analysis using a problem tree to discuss the communities' needs and project options is another capacity development exercise that was seen to be effective in Godara and other CDCs.

Other FPs such as CHA and UN-HABITAT emphasized their efforts to deliver adequate training and believed that this proved effective for most CDC members. Such capacity development initiatives ranged from teaching the general objectives of the Programme to more specific instructions like budgeting, book-keeping and filing, procurement, children's rights awareness, mine awareness and natural disaster management. Training was also specific to suit the particular functions of the CDC subcommittees (for example, the role of chairmen, secretary etc) and followed the 5 NSP phases. Where possible, in Balkh, training was supplemented by the provision of satellite radios for the CDC to listen and learn from capacity development programmes. 35

The challenges for many FPs in training the CDCs vary between different places, hence it is unfair to compare FPs with SDF or UNHABITAT. Many of the FPs complain that many of the CDC were unable to show a sufficiently in-depth grasp of key aspects of the NSP process such as purchasing, accounting, completing forms and accounting without the help of the FP. This is not necessarily due to poor training on the FP's behalf. Without exception these other FPs cited that the main barriers to effective training are lack of time, especially when introducing new ideas and skills to less educated people. ${ }^{36}$ As established, the NSP timeframe is very short for the FP to achieve their objectives. The community members also have limited time as they have their own business to attend to. So although FPs think, with justification, that their training programmes have been very successful, some have not been able to carry out the whole of their training plan. This is to the detriment of the CDCs' capacity to manage NSP and survive in the future without the FP. Altai $(2004,8 / 10)$ also recommend that proper training on accounting needs to be longer than previously forecast; several training sessions have to be considered with longer in-field mentorship.

The Altai Assessment $(2004,5 / 10)$ makes a number of training recommendations which stipulate that the training should be completed in a timely manner and that FPs should provide CDCs with refresher training sessions at regular intervals. Although not specifically referred to as 'refresher' courses, there was evidence from many FPs that retraining was conducted as the need dictated. However, this is done on an informal ad hoc basis and assumes that: a) the CDCs have acknowledged that they need training, and $b$ ) the FP can give it. The capacity of some FPs is so low that many CDC members think they can process NSP, but in reality they cannot.

Altai $(2004,5 / 10)$ recommends that the most important training for CDC members
$35 \mathrm{CHA}$ Provincial Management Team, 260 ctober 2005; CHA D istrict Staff, 270 cto ber 2005; and UN -HABITAT Provincial Director, 1 N ovember 2005

36 The lack of time becomes even more critical when training is taking place towards the end of the allocated time FPs have been accorded to reach their target numbers of CDCs.

FIN DIN GSAN D RECO MMEN D ATIONS 


\section{Box 7. \\ BRAC in Nangarhar}

The experience of BRAC bears testament to many of the issues identified. BRAC have organized training for NSP orientation (which clarifies the NSP, the role of the FPS, community representatives, etc), book-keeping, accountancy, procurement and project proposal writing. BRAC uses master trainers who receive their training from the resource centre in Kabul. The master trainers then train social organizers who in turn train the CDCs. This CDC training also includes operation and maintenance. Training on the whole is successful, but BRAC complain that often people ignore the training and do what they want. For example, BRAC will inform the people of the main characteristics that make a good CDC representative (honesty, functional literacy, etc) yet the community still 'choose' an illiterate warlord or former commander as CDC representative.

In terms of the skills required by BRAC employees working on the NSP, knowledge about NSP, communication skills, a positive attitude and a good technical grasp are all essential. Although BRAC acknowledge their weaknesses, especially the inadequate number of engineers, their difficulty understanding the Technical Manual and the confusing technical guidelines for engineers (form 7), they nonetheless feel they have the capacity to run the NSP, but would appreciate greater technical training input for specific NSP projects.

BRAC originally received NSP training from UN-HABITAT and the $O C$ training department. The training mainly concerned the five steps to NSP, engineering and irrigation principles, interpretation of the Technical Manual and other NSP guidelines such as procurement and proposal writing. All this training has proved very useful for BRAC to facilitate the NSP. However, much of the training does not benefit all the people who require training. The $O C$ only allow two people from the FP to be trained, yet BRAC is operating in 5 provinces across the country and does not have the time to train others whilst simultaneously rolling out projects. In addition a BRAC engineer stated: '[T] he main training problem for us is that the procurement policy is designed in Washington and bears no reality to conditions here in Nangarhar. Even BRAC with all our expertise and resources find it extremely difficult to get CDCs to understand the procurement policy and accounting guidelines!' Regardless of where the procurement guidelines originate, it remains a complex procedure with which BRAC struggle. In addition, training the CDCs to complete sub-project proposal forms is also very difficult, as one member of BRAC stated: 'the CDCs are constantly asking for our help with the sub-project completion form, we show them, yet still they ask because their capacity is so low, what will happen when we (BRAC) leave? They will not be able to cope.'

is on accounting and book-keeping. This should be completed before the disbursement of Block Grants and refreshed at each phase of the implementation. This evaluation endorses Altai's recommendation but adds that whilst training for book-keeping and accounting is conducted before the disbursement of the Block Grant, it is not always refreshed at the other stages for the reasons highlighted above. This evaluation also agrees with Altais' $(2004,5 / 10)$ recommendation that intensive $\mathrm{CDC}$ training should start after project approval as this will ensure better assimilation considering the existence of direct practices of training points. However, in some cases CDC training has begun, the projects approval has been delayed and there is no practical application for recently trained $C D C$ members to apply themselves, and the training and momentum is lost.
Altai $(2004,7 / 10)$ also recommended that in order to solve the engineering shortage various possibilities, including recruitment from Tajikistan, the creation of an 'NSP University' and a loyalty grant on top of the engineers' salary, should be pursued. This research has not seen any evidence of these initiatives being undertaken.

\section{Community participation}

Arguably the most essential role of the FPs is to generate a representative level of community participation; this firstly includes community sensitization to the NSP, and then mobilization to enable the community to vote for CDCs. The challenges inherent in this process are many high levels of illiteracy, cultural barriers, geographical constraints etc. This subsection will outline the role of FPs in 
encouraging general participation, and the participation of women in particular.

In the majority of cases there was initial resistance to participation in the NSP; some FPs ascribed this to people's 'low level of education' (awareness?). In some areas, Badghis for example, different groups found it difficult to participate in the CDC because of long-standing enmities and conflicts, until proportional representation was negotiated. Influential individuals whose power was challenged by elected CDC also tried to ensure these divisions remained. In Jawand, religious leaders also resisted the Programme as 'infidel' and 'anti-Islam'. In Paktika, there were participation problems experienced at the beginning in 2003. Community members thought that the NSP was 'an American trick to trap them'.

The management at the $\mathrm{CHA}$ admitted there were three barriers to participation across Balkh Province, with the 12 per cent literacy rate in general representing the most significant. District staff claimed that '80-85 per cent of members find it difficult to understand completely all the forms and they should be in very simple/local language to be made accessible'. It was therefore recommended that the skills of the CDC members needed to be improved and that there needed to be an increase in the distribution of 'working' satellite radios.

Management staff hoped that this barrier was alleviated by their methodology and approach to training; that is, by starting at the elite level within the CDC and then moving down gradually. Using the local language also helped the people understand. ${ }^{37}$ UN-HABITAT 'anticipated that illiteracy would be a barrier' and joined the NSP to prepare instructive pictures/cartoon magazines. Accordingly, 'each phase has a cartoon handbook, in particular, for the election of the CDCs, and this has proved useful for the educated and the uneducated'. 38

The time of the year formed the second, though variable, barrier. That is, people were typically 'too busy with farming during the spring and summer months to participate in the NSP'. Implementation can thus be limited when the men are unable to conduct large meetings. Conversely, winter is more conducive for such community participation but access to communities more difficult. The third barrier to participation was that CDC positions were not salaried. 39
Many of the FPs used innovative salutations in 'marketing' the NSP to communities. SDF in Kabul set up peacebuilding workshops as the first step in establishing the CDC to ensure that all sections of the community participated from the start. The field staff and CDC members interviewed explained that the former traditional council leaders are generally included in the CDC in some way (on committees etc.), if not actually elected. Occasionally a CDC head proves unacceptable to one part of the community and the conflict has to be resolved in another workshop.

The participation of vulnerable groups (excluding women - see section below) is mixed. In Nangarhar, for example, most of the projects have a component for a percentage of vulnerable people who must benefit (whilst this was fixed in the past at 10 per cent, now it is left up to the community to decide). There was evidence through the research to show how, for example, widows, orphans and the disabled were specific beneficiaries of some initiatives - e.g. sheep rearing in Sholana.

The recommendations from the Altai Assessment (2004, 4/10) cover various aspects of community participation. In the first instance, Altai $(2004,4 / 10)$ recommend using PRA tools in order to facilitate census. There was evidence from this research to suggest that formal PRA methods were in use, with each FP facilitating consensus as the situation dictated. Some FPs, such as SDF, used a 'problem tree analysis' but no social mapping or resource mapping exercises appeared to be employed. Altai (2004, 4/10) also presented recommendations for improving community mobilization:

- FPs should be selected on a basis of an historical presence in the area or, as a minimum, on its experience in rural development and community mobilization;

$\checkmark$ Local leaders should be used to champion the NSP;

- Close contact with the communities on the status of their project must be ensured; and

- The presence of other development programmes and the involvement of CDCs in these programmes (project identification and management) can be a real asset to strengthen the role of CDCs and keep the level of motivation high.
37 CHA Provincial Management Team, 260 ctober 2005: and CHA District Team, 310 ctober 2005

38 The FP Director noted that in general the treasurer and the secretary have to be literate and educated and this is a prerequisite for these posts in the election. Alternatively, it was asserted that "most chairmen tend to be uneducated". (UN -HABITAT Provincial Director, 1 N ovember 2005).

39 UN - HABITAT Provincial Director, 1 N ovember 2005, Balkh.

FIN DIN GSAN D RECO MMEN D ATIONS 
Although the NSP is more advanced than when Altai undertook the evaluation, some of their recommendations have yet to be fully integrated. All of the FPs we worked with had either an historical association with an area or a high level of expertise in rural development and community mobilization. Even though, for example, GRSP had not worked in Kundoz before the NSP they are highly experienced in rural development. GRSP ran a number of training workshops in preparation for the rollout in Kundoz. However, this evaluation has highlighted that 'success' is dependent upon many external factors beyond an FP's own experience. DACAAR, for example, have relevant experience in Laghman and rural development but their work is nonetheless affected by external factors beyond their control. Certainly the use of local leaders can be positive from the FP's viewpoint; however, care should be taken over just how much influence these local leaders have - do they rule by fear? The household surveys showed that in some areas people are still cowed by local warlords who are now on the CDC. Again this research shows that communities are reasonably content that communication between the FP and the $C D C$ is adequate. However, feedback from the FPs indicates that they often find themselves in a difficult position when delays occur because they are held personally responsible for disbursement problems. In some areas CDCs are being used by other programmes (e.g. USAID's Alternative Livelihoods Programme in Nangarhar), and feedback suggests that as more developmental programmes evolve and the capacity of CDCs increase the linkages will become greater.

\section{Women's participation}

There remain significant cultural barriers to women's participation in many of the southern provinces of Afghanistan. However, gradual change is occurring. The experience of BRAC in the Achin District of Nangarhar was typical, where men were refusing to let their wives/female relatives even be considered on the survey sheet for the NSP preparation, but this is slowly changing, as the NSP gains acceptance. However, there is no occurrence of men and women sitting together to formulate the CDP. Without exception, all members of the senior CDCs are male. Women have formed their own CDCs (as specified by the Manual). However, the women give their votes to their male relatives, who vote for the all-male members of the senior $C D C$ on their behalf. This process is universally accepted by the women in the sites visited. Women do not have a direct say in the process of prioritization and project selection. Feedback from the women suggests that their male relatives inform them as the decision is being made. This was also universally accepted by the women in the sites visited. However, women do have their own sets of priorities for genderspecific initiatives - health training, micro enterprise and literacy, which remain largely unaddressed.

In Paktika, the FP encountered similar problems; the men were not ready to register the names of their women for the Programme. For instance, once the thenDeputy Governor of Paktika learned that the names of some women were registered, he complained to the FP that 'they would report (the women) to Americans who will make them come out of their houses and go to schools'. The situation is now different and there is more willingness amongst the population to allow women to be registered for the NSP

In Kabul, SDF confirmed that although the initial NSP concept was to have mixed CDCs, it didn't work. SDF now have a women-only CDC with their own projects, but there is cooperation between the two. The women are assisted by the men's CDC on the logistics, such as purchase of goods. The women's CDC for their part often contribute financially to the projects of general community benefit run by the men (see again Godara women's (DC). In Kabul, at least, after initial scepticism the men have accepted the concept, especially when they saw the money coming in and projects being implemented. This seems to be further evidence of the importance of the projects as vehicles for promoting social change.

Even in the more conservative areas in the south where women are allowed to register for the NSP, they experience one key benefit. Until the female-only CDCs were established, women were not allowed to mix outside of their household. Now, through the $\mathrm{CDC}$, women can meet to discuss NSP matters. The female-only CDCs have become a forum for discussion on other relevant issues (health, domestic violence, literacy, etc) that women could not discuss before for want of a reason; this is a direct result of NSP. A common observation from many of the FPs and this research was 
that the more people see the benefit of the $C D C$ and what it can bring, the more both men and women want to join.

The Altai $(2004,5 / 10)$ women's participation recommendations highlight several key areas that should be addressed to improve women's participation. Altai recognize that it is best if men and women meet separately before convening at a common consultation, as this is more respectful of the cultural separation between men and women, and it allows women to raise a louder voice and to express more freely than when mixed with men.

Women's groups for selection of projects, women's committees with separate budget, and the increased use of women's staff, are all concepts that appear to be accepted by the FPs, and in broad terms it certainly seems that where possible the FPs are following this advice. The exceptions remain in the more conservative areas of the south. Here it is recommended that the gradual approach to women's participation is maintained; clearly anything that is seen to be 'imposed' will only be met with hostility.

\section{The efficiency, effectiveness and relevance of the FPs work}

The research findings observe that from the viewpoint of the FPs there are several key factors which impact upon the efficiency, effectiveness and relevance of their work. The approach to identifying the projects as community priorities, the eligibility criteria, delays, problems associated with the high number of projects, allocation of staff and skills shortfalls, appropriate design and construction, the project relevance and maintenance and sustainability all have their strategic and operational basis in the MRRD/OC rubric, but nonetheless are central to FP's operations.

Central to the role of the FPs is the Operational Manual. All the FPs believe that the Manual is a clear working document. However, the majority of FPs complained that the manual is changed too frequently, which in the past has meant that work has been initiated on the basis of guidelines that are then altered or cancelled. For example, SDF undertook a great deal of work preparing communities for income generation projects that were then stopped. This created great disappointment. FPs felt that changes to the Manual do not take place in a consultative way.
Identifying projects as community priorities The projects are identified through a PRAtype process with focus groups identifying problems and ranking priorities for subproject proposal. As many of the FPs acknowledge, and the household surveys indicate, in some instances traditional elites such as warlords still dominate proceedings. In such cases some FPs get people to write or draw their priorities on paper so they will not be directly influenced by the elites. Often though, people are too cowed to respond independently. Conflicts of interest can also occur when a decision on a community priority is evenly split, i.e. where there is a substantial minority who have not got what they want.

The project will only proceed if it is: a) technically acceptable; b) costed within the defined budget; and c) if there is adequate attention given to issues of future maintenance. It is often necessary for FPs and sometimes the Provincial OCs to assess for mine risks, undue political pressure, and environment factors other than the ones identified during the feasibility study. For example, in 2005 a CDC in Nangahar wanted to initiate a project to generate income through the construction of kilns used for firing bricks. After an environmental assessment the project was turned down because of the negative impact associated with increased incidences of land slides, and the exacerbation of soil erosion due to the need for wood to fire the kilns. In addition, relatively intense fires in the arid conditions of Nangarhar are not appropriate.

\section{Eligibility criteria}

FPs found that whilst it is easy to apply the eligibility criteria to the intrinsic project it is not always easy to present this criteria to the community. In Balkh, for example, the $\mathrm{CHA}$ management team and the UN-HABITAT Provincial Director felt there was no problem in applying the criteria to the needs of the communities. CHA district staff agreed but admitted it was difficult at the start presenting it to the community. In Nangarhar, the first project people often want is a mosque. As a BRAC community mobilizer related: 'We tell the communities to work together and identify priorities, to listen to each other and they tell us they want a mosque, even though we have said from the start that we cannot give them a mosque, and they ask us where is the 'democracy' in our thinking, denying them something they all agree upon to be a priority. We are then accused of trying to impose Christianity!'
FIN DIN GSAN D

RECOMMENDATIONS 


\section{Box 8 \\ Identifying community priorities through project selection - examples from CHA and UN-HABITAT}

In Markaz-e-Dawlatabad, CHA recalled that the community originally wanted a generator for electricity but the people realized they could not raise the additional US $\$ 40,000$ to meet the US $\$ 100,000$ total costs (Dawlatabad is the size of a small town although is classified as a village). Although there was already a school in the community, the people opted for an additional school as their second priority because there was need for more space. The present school had only 16 classrooms. Nevertheless, the new school would only have 8 classrooms, which meant "the number of rooms was still an issue" (CHA District Team, 31 October 2005).

In Choba Temorak Karni Khail, CHA noted that their first task was consulting the CDC and to encourage them to prioritize the needs of the community. The people then gave their input on the list and the CDC made the final decision: "[ $t]$ he people sat and thought, 'we have a school and road but we need a community centre'. The technical engineer estimated the cost and detailed a budget." (CHA District Staff, 27 October 2005). In Yakdan, similar processes of consultation were noted (CHA District Staff, 8 November 2005).

For Aliseena, UN-HABITAT described the first phase as 'identifying the priorities of the communities, categorizing the problems, and deciding which projects can be done'. Unlike Markaz-e-Dawlatabad, Aliseena were able to choose their first priority, followed by a school and then electricity. The district staff recalled that, 'as soon as the community reached their conclusion, we had a large gathering and some problems were raised by CDC members concerning the identification of their priorities'. In Alichopan, the people rejected the CDC's original proposal and asked for water supply instead (UN-HABITAT District Staff, 10 November 2005).

It was estimated that 16 villages would use the school in Markaz-e-Dawlatabad; 900 people to use the community centre in Choba Temorak Karni Khail; all 218 families benefited from the bridges and aqueducts and expected to receive electricity in Yakhdan; and it was hoped that all the residents in Alichopan ( 306 families) and Aliseena ( 426 families) would benefit from the water supply projects (CHA District Staff, 27 October 2005; CHA District Team, 31 October 2005; CHA District Staff, 8 November 2005; and UN-HABITAT District Staff, 10 November 2005).

All the district staff for both CHA and UN-HABITAT admitted it was likely that the projects would pull people in from outside the community - new residents and/or returnees ( $\mathrm{CHA}$ District Team, 31 October 2005; and CHA District Staff, 27 October 2005). For Yakhdan, CHA acknowledged that the electricity 'will have high impact, the people will be more civilized and since most left their houses originally because there was no electricity, they will come back' (CHA District Staff, 8 November 2005). UN-HABITAT developed this point further by raising two interlinked barriers: 'no one can prevent people from coming in and we have received no guidance although we have already told the MRRD and the World Bank, and donors know about it'. Furthermore, strains could emerge since the project budget was based on the original community profile and there were no provisions for re-adjustment (UN-HABITAT District Staff, 10 November 2005). The respondents could not suggest possible solutions based on the strict guidelines of the NSP. For example, it may be possible to ensure that water supply is restricted to the original beneficiaries by piping the water into their homes. However, this option would be very expensive to construct and maintain (UNHABITAT District Staff, 10 November 2005).

\section{Attempts to be inclusive}

The school in Markaz-e-Dawlatabad could not be completely inclusive because there were only 8 classrooms to accommodate the children of more than 1000 families. Poor roads would also have hampered access for those on the outskirts (CHA District Team, 31 October 2005). Conversely, the community centre in Choba Temorak Karni Khail, the bridges and electricity project in Yakhdan and Aliseena's and Alichopan's water supply projects had the potential to be inclusive (CHA District Staff, 27 October 2005; and CHA District Staff, 8 November 2005). 
In terms of gender equality, the NSP clearly promoted men's and women's CDCS and both FPs had encouraged women's CDCs from the start. However, power and influence in the project process was typically limited to the men. There were two approaches to this imbalance - mixing or continuing the segregation of the CDCs. For the former, CHA was optimistic that CDCs would merge in the future but assured the researchers that this was completely impossible at the start of the NSP and for villages initially. Instead, the FP's approach was to start small and encourage integration, and staff believed that there was the potential for this to increase (CHA Management Team, 8 November 2005).

Assessment of political, economic, sociological and technological factors The non-budgetary reason for choosing the school in Dawlatabad was the lack of access to proper schooling outside of the home and mosque (CHA District Team, 31 October 2005). Before proposing the centre in Choba Temorak Karni Khail, the community valued a tangible presence of the government (CHA District Staff, 27 October 2005). In Yakhdan, it was believed that the projects would increase people's general awareness and improve basic access (CHA District Staff, 8 November 2005).

The researchers were assured that the construction of the community centre in Choba Temorak Karni Khail would enjoy similar checks in addition to the support and interest of the people (CHA District Staff, 27 October 2005). Yakhdan also had two monitoring teams consisting of $\mathrm{CHA}$ staff (technician and evaluator) and the community (engineer and foreman) (CHA District Staff, 8 November 2005). UN-HABITAT stated the projects in Aliseena and Alichopan would have "three sub-committees for procurement, finances and monitoring". Monitoring would be supplemented by the OC, MRRD and UN-HABITAT, but the researchers raised the weakness in the $M \& E$ capacity of the MRRD. The respondents argued that capacity had improved but accepted the limitations overall and added that probably 'the best way was for the people to monitor' (UN-HABITAT District Staff, 10 November 2005).

FPs found the eligibility criteria to be most useful in determining limits and clarifying specifications of more technical projects. Some CDCs want large-scale infrastructure projects such as dams which, due to cost and scale, fall outside the remit of the NSP (US $\$ 60,000$ ). Many people ask for carpetweaving projects but these have proved to be very difficult to bring forth a positive change because, whilst the intrinsic carpetweaving is straightforward, the marketing and distribution of the carpets is far from easy. FPs clarified that the eligibility criteria is most relevant to the micro hydro and diesel generation projects, as are cross sectoral projects such as health initiatives which need to be sanctioned by the Ministry of Health and not the NSP.

\section{Delays}

There are many reasons for delays - delivery of materials, security problems, weather, geography, problems of disbursement and poor CDC/FP management.

The most common source of delays is the disbursement process. Once a sub-project proposal is submitted, the OC check the proposal in order to make a decision on whether the project should be sanctioned. The prime reason for delay is due to the excessive length of time it takes for the Block Grant to be processed by the OCS, and the protracted process of dispersal of funds through the DAB. However, many FPs like $\mathrm{CHA}$ and UN-HABITAT in Balkh commented that the delays in disbursement were becoming less; however, they recommended that 100 per cent of the funds should be transferred once the project is approved. Other FPs such as BRAC in Nangahar maintain that over the last 6 months these delays have worsened, but this is due to the worsening security situation in the Eastern region and the uncertainty that surrounded the election process. On occasions BRAC has to wait up to 6 months for the Block Grant to arrive; these delays cause tension between the CDC and BRAC. For example, the increment for the intake project in Sholana was delayed by 6 months, during which time the community was again flooded because the protection had only been partially constructed.

The period of time between identification of the project and project completion varies considerably between FPs. For BRAC in Nangarhar and GRSP in Kunduz the time between project identification and implementation is typically around 3 months, and in Herat UN-HABITAT the period of time
FIN DIN GSAN D RECOMMEN D ATIONS 
between identification and implementation is 5 months. According to the NSP-OC, the average time from implementation to completion is meant to be 2-3 months, but the process can take considerably longer. In the case of the school in Dawlatabad, 9 months lapsed between identification of the project and the start of implementation. Implementation started on 24 April 2005 and the first instalment was spent. Construction had stopped as the CDC had been waiting 3 months (at the time of research) for the second instalment. The MRRD in Kabul were initially blamed for this delay but it then transpired that $\mathrm{CHA}$ had made an administrative error, which apparently had been recently corrected. ${ }^{40}$ SDF maintain that the 'centralization of decisionmaking on project proposals and the dispersal of the second and third Block Grant instalments costs too much time and effort. It would be more efficient to decentralize the decision-making authority.

\section{Problems associated with processing the high number of projects}

Some of the FPs experienced problems in processing the high number of projects; these problems were not intrinsically linked to the number of projects but, rather, FPs felt that due to pressures to implement projects it was difficult to ensure that the CDCs had sufficient capacity to act without the influence of the FP. For example, CHA district staff noted that there are many difficulties at the beginning of the implementation, especially during the elections of the CDCs and the writing of the CDPs. ${ }^{41}$ UNHABITAT was reaching this busy stage and was thus concerned about 'the next three to four months'. The Director also noted problems at the start when the communities found it difficult to understand the procedures of the NSP. He estimated that '40-45 per cent of the 13,000 projects are of good quality, but for the others there is concern that the quality will not be as good because the CDCs have insufficient capacity'. He therefore recommended that 'it is better to start with two to three projects with the CDCs and with a small grant of US $\$ 20,000$ maximum so that they can learn the necessary skills gradually'. Alternatively, he thought it was better for the government and/or the UN agencies to implement the US $\$ 60,000$ projects. The two problems were the 'delays in instalments and weak monitoring'. 42

Other FPs felt that there are significant problems associated with processing the high number of projects. Although both organizations feel they have the capacity to administer and implement the intrinsic NSP, they find it difficult to keep up with the rollout pressure. This causes them to work quickly with the $C D C s$ to make sure the proper OC procedures are followed; FPs acknowledge that this often means that in the long-term the CDCs will not have the capacity to cope in a future without the FP.

\section{Allocation of staff and skill shortfalls}

The FPs allocate their staff in the most efficient way possible; however, due to the general shortage of engineers there are inevitably increased pressures on some staff members. Some of the FPs, especially at the district level, felt that their 'relevant skills were weak at the start of the NSP'. While this gradually improved, they still desired more skills training, 'for example, in community development monitoring and methodology'. In particular, the staff suggested that 'social organizers need more training about women's rights and mine clearance/awareness' (CHA District Staff, 27 October 2005).

CHA and UN-HABITAT provide a good example of staff allocation. For Charbolak District, CHA allocated 6 core staff for the NSP consisting of finance, administration, engineering (junior and senior) personnel and a senior supervisor/manager. Only one of these core staff was female. In addition, there were 16 social organizers. Each project typically had 6 staff, 4 salaried (engineer, storekeeper, finance and foreman) and 2 from the CDC with no salary. Projects in Dawlatabad District had 1 senior and 1 junior engineer, 1 facilitator, and a district officer. UN-HABITAT claimed 18 staff were allocated to the NSP, including managers, engineers, social mobilizers, reporting officers, and administration and finance. Eight staff members were female. ${ }^{43}$ The Director's account conflicted with this total, noting that, 'for $18 \mathrm{CDCs}$, we have 1 engineer in addition to 23 field and support staff. The Director estimated that they assigned " 1 social organizer to $12 \mathrm{CDCs}$, who would cover $2 \mathrm{CDCs}$ each day and all 12 CDCs each 6-day working week'. Nevertheless, he admitted candidly that 'we, like all FPs, have problems'. 44

CHA provided the following description of the main project skills needed; these were echoed by other FPs:

- Social Organizer - community development, working with the community, knowledge about the 5 phases of the NSP and the culture of the community. 
- Senior Engineer - to check the proposal and the NSP Programme methods.

- Engineer - to know about the NSP, engineering issues and construction.

- District Officer - to know all about the NSP, management, finance, administration, and methodology of establishing elections.

- Monitor - to be skilled in the approach to monitoring, proposal writing, feedback, relations between the district office and the district government.

- Community Development Officer - how to develop the community, get a full picture of the community and check the community proposal.

NSP Manager - full responsibility, knows about all the programmes, the methodology of NSP, relations between the $O C$ and the office and how to resolve problems.

- Office Manager - to manage and assist the NSP Manager. 45

UN-HABITAT provided a similar overview, noting orientation training, how to mobilize the community, how to select the CDCs and prepare the elections, CDP training, project management, evaluation, implementation, procurement and accounting. 46

The SDF field staff thought that the main requirements for the job were: that all except the drivers and guards should have a secondary school certificate (baccalaureate); staff need a good understanding of the society and should know and respect the culture and traditions of the communities; they should have good communication skills, including knowing the local dialect or at least understanding it; conflict resolution skills are also necessary.

Before going to work in the field they received orientation on the NSP concept and training in community mobilization, communication, problem analysis, conflict resolution and peacebuilding. Of these, community mobilization and conflict resolution had proved most useful. For example, they have been called on by communities to resolve conflicts because their expertise is known.

\section{Appropriate design and construction}

The appropriateness of the design and method of construction are essential to the efficiency of the project. Examples are used from Balkh and Nangarhar to illustrate the experience of the FPs.

\section{Box 9.}

\section{Examples of the issue of appropriate design and construction} - CHA District Team in Balkh

First, the school in Dawlatabad was built strategically at the centre of the community. Second, technical engineers were hired to complete the design. This was 'approved by Kabul and is based on normal standards although we also have a Safety Standards Theory'. The Department of Public Health also issued a code. Following this, the relevant CDC subcommittees discussed the need for skilled labour and then found skilled labourers, foremen and extra monitors within the community. They had purchased the materials from the local market (CHA District Team, 31 October 2005). Despite the efforts of the community and all the NSP actors, the construction of the school was flawed; in particular, there was insufficient mortar used between the bricks, nor were the structures of the three buildings strengthened. However, it was unclear if this was the result of poor construction or the effect of the CDC trying to save money in anticipation of the delay. Regardless of blame and the delays (past and future), it was certain that the construction would not be able to continue until after winter (CHA District Staff, 8 November 2005).

The construction of the school in Markaz-e-Dawlatabad had reached a midway point. $\mathrm{CHA}$ noted that they had 'technical monitors, engineers and a monitoring team (members of the $C D C$ ) to check the quality and management of the project during weekly visits'. (CHA District Team, 31 October 2005).

Pre-construction, for the community centre in Choba Temorak Karni Khail, the CHA district staff could only refer to 'having our own engineering standards and public health norms and standards'. While CHA had already found skilled labour, they were trying to find more from the community and to give them cost-effective training. The community also planned to utilize the procurement subcommittee to purchase the materials locally. The community and CHA believed it was unnecessary to consider mitigation/defensive measures against natural disasters as there were no previous similar disasters in this area (CHA District Staff, 27 October 2005).

In Yakhdan, the community worked with the $\mathrm{CHA}$ and the Department of Public Health to design the 13 bridges and aqueducts. The relevant government standard was used and technical experts from the $\mathrm{OC}$ and the MRRD also had input on site. In particular, the CHA designed the aqueducts and obviously assessed the natural supply of water. There was a monitoring schedule (for quality and quantity) for both organized by the $O C$ and the NSP. The procurement committee within the CDC purchased the material and hired the engineers. The community and $\mathrm{CHA}$ also believed mitigation/defensive measures against natural disasters were relevant (CHA District Staff, 8 November 2005).

The extensive interviews with three levels of the FPs clearly uncovered a range of salient design and operational issues. Several positive features were noted, including a clear understanding of their role and function with the NSP, a resultant increase in capacity and instances of cooperation with the OC and RRD. However, the most fundamental weakness concerned the projects. This included widespread inefficient implementation and instances of poor design. Moreover, it was concluded overwhelmingly that the sustainability of the projects was not envisaged by the relevant actors. 


\section{Box 10. \\ Issues of appropriate design and construction - the BRAC Team in Nangarhar}

To ensure efficiency within the actual design and construction of the facility, BRAC always undertake a feasibility study to clarify if the proposed project is appropriate and sound. A BRAC engineer, working on occasions with OC/MRRD representatives, will carry out the feasibility study to survey the design, implementation and maintenance of the project in accordance with the Technical Manual. BRAC acknowledge that this process requires qualified engineers who are in short supply. Local capacities are assessed, but due to the shortage of engineers not all people are up to the task, hence the role of BRAC as the overseer working through a technical checklist takes on an increased importance. Once the project has received sanction, purchasing of materials takes place in three key ways: direct (>Afs 500), quotation (>Afs 5000-250,000) and bidding (>Afs 250,000).

Mitigation measures for earthquakes and floods are incorporated in both the architectural and engineering aspects of the design. For example on a $300 \mathrm{~m}$ protective wall in Sholana expansion joints are placed every $15 \mathrm{~m}$ to allow for seismic movement, and buildings tend to be low and wide. Problems during construction include strict supervision for mixing/timing of the cement, as one BRAC engineer complained, 'Engineers in Afghanistan do not allow for curing because of the lack of water; this causes problems such as weak cement, flaking and cracking etc.'

BRAC feel that to increase the project efficiency the training needs to be more comprehensive and include more NSP-specific projects. Currently there is flexibility for BRAC engineers with autocad experience to design projects that are not covered in the Technical Manual but have nonetheless been chosen by communities and received sanction from the OC.

The usual considerations of quality, costs and time are of course relevant to the efficiency of the project. The delays in disbursement causes costs to increase. For example in one site at Dago, Chaparhar, an original estimate for the price of a bag of cement doubled during the period of time from project submission to first disbursement. Fortunately there is provision for such occurrences within the incremental process that enables increased amounts for the second and third instalments. However the Provincial NSP Manager of BRAC summed up, 'The real problem is that the BRAC is involved with 348 projects and the OC/MRRD at the Provincial level only have 2 engineers to visit all the projects and give feedback; the OC/MRRD at the provincial level simply do not have the capacity to check the number of projects.'

On larger projects there is some effort made for safety of workers, but there are few concessions; no helmets, basic site safety etc.

45 CHA District Staff,

270 ctober 2005, MeS.

46 UN - HABITAT District Staff,

$10 \mathrm{~N}$ ovember 2005, Balkh.
Altai $(2004,8-10)$ recommend that standardized designs should be created to avoid the great loss of time, due to the fact that the engineers of each FP are making almost the same technical design for a school, bridge or well. Providing simple engineering software, along with adequate training, would hasten dramatically the feasibility studies. This research would certainly endorse these recommendations; however, whilst there is evidence of standardization of design within the FP, it is too early to say whether these recommendations have been fully implemented.

\section{Relevance}

SDF staff thought that judging the FP performance (or efficiency) on the quantity of projects completed does not value their quality. Rather, quality issues such as relevance/utility to the community, appropriate design and sustainability are more important. To this extent the research showed that all the FPs facilitate a range of projects including irrigation, water intake, diesel generator, protective walls, roads, boring wells, culverts, sheep rearing, school construction, community centre construction and self-help.

The projects have a direct relevance to community needs although some FPs such as BRAC acknowledge that projects such as water intake are more universally beneficial than others. The most relevant projects demonstrate clear linkages between the newly created CDC and its capacity for community development, and the intrinsic project with other forms of community development.

There is a problem of understanding in many of the communities. For example, people want light but many have no appreciation of how the light appears, and how the generation of light needs to be maintained/sustained, and for the poorest power is not a priority. In the experience of some of the FPs the poorest communities are more likely to ask for an economic activity rather than an infrastructure facility, but the same communities often feel deluded when tangible results do not happen overnight.

Although as yet there is no country development document like a PRSP, the intrinsic projects are broadly integrated and relevant to national development plans of reducing poverty and improving infrastructure. 


\section{Maintenance and sustainability}

The research with the FPs highlighted the importance of the initiation of several measures to ensure that NSP projects can be maintained. The cost of the maintenance, as well as the depreciation of the asset, should be included within the project cost. The community (per household that benefits) pay a fee either in cash or in kind once a month to enable appointed technicians to maintain the facility, provide for fuel for the project if necessary and to cover depreciation costs. These costs typically account for 20 per cent of the overall investment.

In theory, local technicians and not professional personnel maintain the facility, and the money saved up through the monthly payments scheme ensures that when the facility is beyond repair a new facility can be purchased. However, at this relatively early stage many FPs are not optimistic that this system will work, fearing that even if funds are collected, the cash will be spent elsewhere and the facility will fall into disrepair. Unfortunately, this is also testament to the limited capacity of certain CDCs.

Sustainability is also an important factor in relation to economic activities, but much more difficult to measure than infrastructural projects. Even BRAC, with its tremendous experiences of working in rural communities, is unsure how microfinance initiatives implemented through the CDCs can help to reduce poverty.

\section{Summary}

All of the FPs have serious doubts whether the CDCs will be able to function without further capacity development and direct external support. The future role of the FPs rests on whether the NSP remains purely a development programme or whether the governance component of the Programme assumes a greater role in NSP Phase 2 . If the former applies then their engagement will be concluded at the end of the project, but if the governance dimension is emphasized they will a) need to undertake further training to prepare the CDCs for taking on such a governance role, and $b$ ) be funded to maintain contact with the CDCs over a period of time to organize re-elections and then undertake further training of the newly elected members.

\subsection{Recommendations for sub-national venues for the coordination and the operational delivery of the NSP 47}

\section{The role of the provincial MRRD}

\section{Recommendation 13 \\ A strategic plan needs to be devised by the MRRD in order for the provincial level administration to ultimately assume a long- term NSP delivery role. This must involve a significant capacity development dimen- sion. Provincial DRRD staff will need to play a greater role in NSP quality control, enhancement and disbursement processes by the end of the Programme.}

However, due to the absence of a culture of sub-national government in modern Afghanistan, it is crucial that the decentralization of operational delivery functions to DRRD provincial and district officers is carefully phased in. Indeed, it should only occur when it is clearly demonstrable that DRRD officers have the capacity to assume the role. In the meantime there is an urgent need to build DRRD management and operational delivery capacity at the provincial level and to extend it down to the district level through a phasing strategy. Until then the continued presence of an OC-type organization would be prudent to insulate the NSP against political pressure and corruption, and to ensure independent quality control and monitoring and reporting to donors.

\section{Recommendation 14}

The cap on budget allocation ('regardless of the number of real beneficiaries') is causing significant distress within the Programme and risks precipitating conflict. The problem of budget caps based on poor population surveys needs to be looked at and acted upon by central MRRD as a matter of urgency.

\author{
47 Please note that the \\ consideration of these courses \\ of action should take into \\ consideration the costs of \\ change, which should be \\ calculated on: a) their capacity \\ to improve qualitative rather \\ than quantitative output and \\ b) the likelihood that they will \\ survive for a considerable time.
}




\section{Recommendation 15}

While the official CDC complaints procedure is used, the approach to its implementation varies considerably, to the extent that it risks disappearing in some provinces. This is especially worrying considering the natural barriers to establishing transparency and accountability in the context of a warravaged state. The complaints procedure therefore needs to be standardized and entrenched.

\section{Recommendation 16}

There is a need to reconcile conflicting models of governance, both at the community and programme design level. Similarly, the question of sustainability (CDCs and projects) should also be addressed at both levels.

\section{Recommendation 17}

Greater efficiency and effectiveness would be gained by improving cooperation between government departments at the provincial and district levels, with a focus on coordination. As a minimum requirement, it is important for government departments to have accurate information concerning the responsibilities and operational tasks of their counterparts to avoid confusion or jealousy.

\section{Recommendation 18}

Sufficient operational and human resources need to be provided by the MRRD in the field in order to maintain levels of community confidence in government.

\section{Recommendation 19}

Processes of institutional learning need to be standardized and monitored.

\section{Recommendation 20}

The nature and style of training demands consistency and effectiveness, with special emphasis on improving the provision of technical skills training.

\section{The role of the provincial $\mathrm{OCs}$ and teams}

\section{Recommendation 21}

The capacity development of the DRRDs by the OCs needs to be made relevant to the implementation environment and the rationale of the NSP in order to avoid institutional dependency while ensuring the Programme advances.

\section{Recommendation 22}

The level of skills and capacities of community members required by the Programme to reach its targets needs to reflect the actual skills and capacities of the community members. The advancement of targets would demand training to address the gaps and weaknesses in these areas, as identified by the $\mathrm{OC}$ in consultation with each CDC, DRRD and FP.

\section{Recommendation 23}

As a particular concern within the recommendation above, the skills and capacities of women CDC members need to be improved towards ensuring gender-equal participation and decision-making at the community level.

\section{Recommendation 24}

The cap on budget allocation ('regardless of the number of real beneficiaries') is causing significant distress within the Programme and risks precipitating conflict. The problem of budget caps based on poor population surveys needs to be looked at and acted upon by provincial OCs and teams as a matter of urgency. Connected to this, in overcoming project budget shortfalls, further action is required to form links to other international donor programmes. 
The role of Facilitating Partners

\section{Recommendation 25}

Processes of lesson-learning across FPs should be improved, particularly in areas where certain FPs possess significant expertise e.g. UN-HABITAT and economic development activity or gender-oriented development programming or BRAC and working in areas with security problems.

\section{Recommendation 26}

A community-based programme requires a high degree of trust between the communities, the FPs and the government - this is easier to achieve if the FPs have previous rural development experience in Afghanistan. FPs therefore need to be carefully selected; a criteria is suggested below. A national NGO with prior engagement in rural development and a professional administration and monitoring capacity is the ideal choice as they don't carry overhead costs for expatriate staff, establishing new offices or costly lines of communication, and they do have a tested system for community development that can be further improved. In second place would be international FPs with considerable experience working in Afghanistan, a majority of Afghan staff at all levels, offices and experience of working in different parts of the country with rural development projects. These two categories of FPs are also better prepared to handle and mitigate security risks and have the necessary degree of trust within the communities to evoke community protection. The least 'cost effective' FPs would be those who are new to Afghanistan, overly reliant on expatriate staff that has a tremendous challenge to gain the trust of communities and government.

\section{Recommendation $\mathbf{2 8}$}

The definition of 'project completion' should be reviewed in consultation with FPs in order to incorporate an appreciation of the intangible outcomes of the NSP (e.g. community empowerment, ability to maintain facilities, etc).

\section{Recommendation 29}

The Operational Manual should be changed as little as practicable; this would ease the pressure on the national OC and allow all other stakeholders time to consolidate practice. 48

\section{Recommendation $\mathbf{3 0}$}

Some of the administrative forms that require completion by the $\mathrm{CDC}$ are too complex for barely literate people to complete. There needs to be a balance between transparency and expediency, particularly for the CDCs. This is especially the case for accounting and procurement forms and the sub-project proposal completion form. A failure to adopt a more realistic approach to capacity development and community empowerment will continue to ensure that FPs remain 'Implementing Partners'.

\section{Recommendation 31}

NABDP and NSP thinking needs to be harmonized in order to join-up ProvincialDistrict-CDC coordination of development programming to avoid waste and duplication.

\section{Recommendation 27}

For some FPs the constant comparison to others working in less difficult areas is disheartening, and in some circumstances has led to a feeling of a lack of appreciation. Extra support and allowances should be given to FPs working in problematic areas, particularly in terms of a more flexible timetable and a reaffirmation of the generally good work they are doing in such trying circumstances.
48 This recommendation has been adopted post publication of the PRDU's Inception Report, N ovember 2005

FINDINGSAND RECOMMENDATIONS 


\section{Findings and Recommendations}

\section{4}

\section{The Role of Community Development Councils in Representative Governance and Community Development}

CDCs a re gen erally viewed as an effective mechanism for reaching the people, targeting development and producing quick, tangible results. The coverage of the NSP is outstanding. (NSP donor stakeholder)

We want to see NSP move mainly to the governance side... CDCs are a vehicle for local governance... people have very high expectations and we need to see the creation of sustainable structures.

(NSP donor stakeholder)

The CDC is our representative. It is our government.

(Male and female householders in Shah Q adam CDC, Bamyan)

We have improved in terms of security, but other improvements will take a long time. In my opinion, reconstruction in a 25-years war-ravaged country won't be a simple task. We have lost our national constitution, our army, our police, our education system and the most important, our national unity all over the country and trust in each other; therefore I can't

say that our lives have improved in a short period of three years.

(Male householder, Bardowlet Khil CDC, Paktia)

\subsection{The strategy for evaluating Community Development Councils}

The following observations about the role of CDCs in the NSP are drawn from two sources - a community power survey and a household survey. The community power survey was conducted with the principal aim of assessing the extent to which CDCs had been able to assume the two key roles assigned to them by the Programme: representative governance and community development. In practical terms this involved assessing their capacity to function independently as a democratic leadership of their communities and their ability to select, plan and manage development projects. The household survey was designed both to assess the impact of the NSP in respect of its goal and objectives, and to provide evidence of progress in developing inclusive community governance as a means of empowering communities to improve their lives, as well as detecting changes in public perceptions of government.

In the absence of baseline data, community leaders and householders in matched communities not participating in the NSP were interviewed, with a view to corroborating the retrospective accounts of the CDC of governance before the NSP, and in order to distinguish between general post-war trends and changes directly induced by the Programme. It is envisaged that this research strategy will continue to be useful for the NSP until adequate baseline data is generated by the Programme, through the compilation of enhanced community profiles and statistical records. A detailed presentation of the methodology employed can be found in Annex A. 


\subsection{The Community Development Council Community Power Survey}

\section{Sample and key indicators for evaluation}

Comprehensive interviews with either the principal office holders or, in some cases, all the members of the CDC, were conducted in $18 \mathrm{CDCs}$ in 9 provinces. Of these 3 were mixed shura in Bamyan, Balkh and Kundoz, while 4 were divided into separate men's and women's shura (3 CDCs in Balkh and 1 in Kabul). In 3 of these both men's and women's shura were surveyed, and in one community in Balkh only the women's shura. In 12 other communities in Badghis, Balkh, Herat, Kundoz, Nangarhar, Paktika and Takhar men only CDCs were surveyed.

The majority ethnic groups in the $C D C$ communities visited were Arab, Pashtun, Tajik and Hazara. In Badghis, Balkh, Kundoz, Nangarhar, Paktika and Takhar two CDCs in the same area and working with the same FP, but at different stages of development, were surveyed for comparative purposes. In Bamyan, Herat and Kabul only one CDC was surveyed in depth.

A further 4 CDCs were visited and briefly interviewed in the course of the engineering specialist's fieldwork in Kabul. Additional CDCs were also visited in Nangarhar (8) and Laghman (8). In addition, for comparative purposes, leaders of 6 communities not included in the NSP were interviewed, and household surveys were conducted in the same communities. These were in the same geographical areas as CDCs where interviews and household surveys were conducted, and matched as far as possible in relation to common indicators of socio-economic conditions and ethnic composition. The communities were located in Badghis, Balkh, Herat, Kabul, Kundoz and Nangarhar, and had either Tajik or Pashtun majority populations.

The key indicators that were operationalized in order to provide an overall assessment of CDC capacity were:

$\checkmark$ the capacity of CDCs to exercise community leadership;

the capacity of CDCs to represent the community as a whole;

$\checkmark$ the commitment of CDCs to the enhancement of democratic governance;

$\Delta$ the quality of the role of CDCs in project management:
- the capacity of CDCs to process NSP documentation and maintain accounting and reporting systems;

the ability of CDCs to forge effective relations with governmental organizations;

- the ability of CDCs to forge effective relations with Facilitating Partners; and

$\checkmark$ the capacity of CDCs to be engaged in gender mainstreaming.

\section{Principal findings}

\section{On leadership of the community}

Eight of the 18 CDCs surveyed appeared to be, as they said, the sole leadership of their communities. In the case of the 3 majority Hazara communities in Bamyan and Balkh, the CDCs were not otherwise well established, for example, in terms of project implementation, but there appeared to be no pre-existing formal institutions of governance. In Kundoz and Nangarhar, two established CDCs felt that they were fully in charge, but they had clearly had to negotiate with pre-existing authority figures. In the majority Arab community in Balkh, the traditional shura had disbanded when the village joined the NSP, and this was also the pattern in Kabul where the peacebuilding exercises in preparation for the elections to the CDC had involved negotiating the inclusion of traditional leaders in the $C D C$, which then became the sole institution.

\section{Contested leadership - the role of women in Community Development Councils}

In all of the communities with established CDC leadership except in Nangarhar (discussed below), women CDC members clearly had a leadership role for the women in the community and were able to discuss and represent women's interests. However, they clearly did not have a role as leaders of the whole community, even when they sat in a mixed shura. Cultural limitations to the acceptance of women in such a role were evident in all communities (apart from factors such as relative lack of education and knowledge, discussed below). For example in Kundoz, the two women CDC members, for cultural reasons, could not participate in CDC meetings but made representations on behalf of women individually to elders or male relatives on the CDC. In Bamyan, although formally the deputy leader of the CDC is a woman who participates fully in
FIN DIN GS AN D RECOMMENDATIONS 
the meetings, householders only referred to the male office holders as leaders.

In Nangarhar at the other extreme, no practical role was ceded to women. They were were kept informed of CDC business but excluded from it, including even from voting directly for its members, being obliged to transfer their vote to a male relative.

Nevertheless, the NSP had created the opportunity for women (especially younger women) to meet and discuss their concerns. As the women in Kabul also pointed out, previously women had no contacts outside their own homes.

These cultural realities were the reason given by the rather capable women in a women's shura in Balkh for wishing to remain separate, 'It would be very difficult to sit with the men...then they are superior and we would have no voice in decision making. For now it is better to work separately.'

\section{Shared and contested community leadership}

In a further 8 communities in Badghis, Balkh, Nangarhar, Paktika and Takhar, a transitional phase of shared leadership with the pre-existing traditional councils or leaders (arbabs/maliks and mullahs) was evident. In these villages there was clearly a process of negotiation and cooperation, with some individuals belonging to both authorities. On the whole, the CDC authority was fully recognized in the area of democratic participation in community development, while traditional figures retained the political leadership (representation to government and arbitration of disputes). However, CDC members described how they were increasingly called on to fulfil these roles because they often enjoyed more trust from the villagers. Some of these CDC thought it was simply a matter of time before the CDC assumed a complete leadership role. Others thought the two authorities were complementary.

In a recently formed $\mathrm{CDC}$ in Kundoz, the process was more conflictual. The CDC clearly enjoyed a good deal of acceptance by the general population, but its authority to represent the community was contested by some influential individuals with close (and allegedly corrupt) links to the district administration. However, the CDC members were prepared to be patient and work for change. As they put it, 'Some people try to exert their influence but we hope things will change gradually.'

In another CDC in Takhar, which claimed to be the sole form of government in the village, the researchers nevertheless observed that, 'Despite the absence of any other form of government in the village, the $\mathrm{CDC}$ members are under the influence of other elders and the mullah of the mosque.' The CDC members themselves said nothing could be decided without consulting them.

\section{The exclusion of women from leadership}

In these communities the leadership role of women had little or no recognition. In the Takhar community cited above, for example, there was little evidence of women's participation and the separate women's CDC appeared not to have any influence in decision making. In two CDC in Balkh the women's CDC, though with clear ideas of their own on village issues, had clearly been excluded from the decision-making process. In one case they said they did not have access to the documentation of the CDC which nevertheless was maintained to the required NSP standards by the men. In other communities where only men were interviewed it was difficult to detect any activity by women's leaders in the CDC.

\section{On representative governance}

Setting aside the issue of the full representation of women discussed above, in almost all cases (16 of the 18 interviewed as well as the majority of those visited) the CDCs were found to be representative of their community, often bringing together different family and tribal groups that had previously been antagonistic, by means of the cluster of representatives and negotiated sharing of the leadership roles.

The evaluation team was doubtful in only two cases about the inclusiveness of the CDCs. A community of 375 households in a remote area of Badghis had apparently excluded 75 families from the CDC in order to comply with NSP guidelines. Although it was otherwise representative of the 300 households included, it was not clear from the CDC or the FP how the 75 households were selected for exclusion, or how the community had reacted. A CDC surveyed in Paktika failed to demonstrate exactly how it had been constituted and since no household survey was conducted, there was no other means of verification. 
Although the evaluation team was satisfied in the majority of cases, on the basis of observation and testimony, that the CDC was not only representative but perceived as such by the villagers, there were only 8 cases where the election process had certainly met the criteria set out in the NSP guidelines; that is, by secret ballot monitored by external scrutineers (FP, OC, DRRD). In at least 5 cases, due to the illiteracy of the majority of voters, various strategies for assisting the voters had been adopted, such as instructing another member of the community, an FP staff member or some other person to vote for them. In Nangarhar, as already stated, women were required to instruct a male relative to vote for them. In Bamyan, women (who were almost all illiterate) were given assistance in the electoral process by their shura by assigning a separate ballot box to each candidate, who identified it by standing beside it. In the remaining cases, the CDC itself or the householders if surveyed, gave only vague accounts of the election.

\section{On the commitment of Community Development Councils to enhancing community 'democratic' governance}

The extent to which the CDC are developing into truly democratic institutions of community governance has to be judged by their ability to communicate with, and promote participation by, the whole community, as well as the transparency of their decision-making processes and transactions on behalf of the community. The evidence from the household survey outlined in Section 3.4 below shows that the NSP has had a significant impact in this regard, but that further consolidation is needed. The Community Power survey sought to establish to what extent council members see participatory governance as an essential aspect of the CDC concept that they will need to sustain after facilitation is withdrawn.

\section{Participation}

Fifty per cent of the CDCs surveyed demonstrated an understanding of and a commitment to the democratic governance model involving participation and accountability to the whole community, as introduced by the NSP. Others appeared to be committed to serving their whole community honestly and accounting for their decisions as elected representatives, but did not see the need for general participation. A small number ( 5 per cent) seemed to have little understanding of the CDC concept, regarding themselves as more of a project management committee. The women's shuras that were surveyed had successfully involved and communicated with other women in their communities by creating forums for discussion of community issues, but as discussed above were not fully empowered.

Only one of the CDCs interviewed (in Paktika), adopted a traditional approach to decision-making by deciding the priorities within the $C D C$ without reference to the general population, on the basis of their 'expertise in issues relating to the community'. However, the vast majority of CDCs showed, through their descriptions of how they worked in the community, that they thought that they should act with the consent of the whole community. However, for a minority of CDCs the process of community involvement in setting priorities was seen as a consultative rather than an actively participatory process. One CDC in Kabul consulted residents through their representatives about their problems, then established the priorities in a problem tree exercise in the $C D C$, and reported back to the residents. One CDC in Badghis also 'consulted everyone' and then set the priorities in the CDC. However, they recognized that in the future decisions might be challenged and they would have to decide in the community on 'a majority-minority basis'. As already noted, the participation of women outside their own shura did not occur in CDC in provinces such as Nangarhar, Kundoz and Takhar, but men in these communities were actively involved in the discussion of priorities for projects and in implementing the projects. In other communities in Kabul, Bamyan, and Balkh, women had varying degrees of participation in setting community priorities, but not in the work of the projects.

CDCs in the early stages of development might still be fully conscious of the importance of promoting inclusion and participation, but had not yet fully established regular meetings and other means of sustaining participation (for example the recently constituted CDC in Badghis). When it came to participation in and benefit from the projects, most CDCs at this stage were consciously trying to allocate paid labour on an equitable basis, and had complied with the guidance to select projects that would benefit the whole community. There 
appeared in most cases to be a genuine commitment to this aspect of the NSP concept.

\section{Communication and transparency}

The understanding of the need for transparency by keeping clear records of meetings, decisions and financial transactions was clear in all but three of the CDCs, but (see below) not all were able to fulfil this task or if they were, the majority of their constituents were unable to read or fully understand the records. Often no conscious effort was made to overcome this problem.

However, in those CDCs fully committed to transparency, various oral methods of accountability were also in practice. For example, in the largely illiterate community visited in Bamyan, communication with the villagers was both through their cluster representatives and by briefings at monthly meetings attended by most householders. In other communities, CDC announcements are made in the mosque, as well as (in those communities with higher levels of literacy, such as Kabul and Nangarhar) by using public notice boards. Nevertheless, as the household survey also reveals, even with the best intentions it can prove difficult to communicate adequately with dispersed and poorly educated villagers who are extremely busy getting on with their daily lives.

\section{On the quality of project management}

Seven CDCs (in Badghis, Balkh, Herat, Kabul and Kundoz) were found to have developed the necessary competences to manage projects: planning relevant projects involving the whole community; organizing and supervising the work of implementation; managing paid and voluntary labour from the community; raising monetary contributions from the community; managing and accounting for the project budget (negotiating and recording purchases etc.); forward planning for maintenance and working towards future projects. Two recently established CDCs in Balkh and Kundoz, that had planned but not implemented a project, also seemed likely to develop the necessary management skills within the project timeframe.

As in the case of democratic governance, not all CDCs nearing the completion of projects had achieved this level of competence, while others in the earlier stages of implementation were already competent. The reasons for this go beyond the quality of the facilitation, though this is clearly one factor. While project management capacity is clearly developed as a result of the NSP experience and CDC members frequently described this, the level of existing skills and experience in the community (educational level, former work experience etc.), as well as the level of economic development and proximity or ease of access to urban markets, were also seen to be significant factors.

For example, three of the CDCs with good project management capabilities (in Badghis, Kabul and Kundoz) were able to draw on the skills and management experience of community members, as well as a higher than average educational level amongst CDC members. They were also in reasonable proximity to their provincial capitals. In contrast, longer established CDC in remote areas of Badghis and Bamyan had much greater difficulties with project management, and were clearly going to find it difficult to pursue further projects without some assistance.

\section{On processing NSP documentation and maintaining accounting and reporting systems}

One area of competence that is critical both for purposes of transparency within the community and in order to satisfy accountability requirements of any future governmental, donor or NGO partners, is that of recording the decisions, agreements, and resolutions of the $\mathrm{CDC}$ as well as financial book-keeping to an acceptable standard.

Nine CDCs maintain records to at least the standards set by the NSP. In some cases (such as in Kabul) land deals negotiated for the purposes of project implementation and minutes of all meetings with outside bodies, or in other cases (such as in Kundoz) agreements reached in the arbitration of disputes, were also meticulously recorded. In addition, two CDCs yet to implement projects did not have a complete set of records, but on the basis of the records kept to date and their educational level, were likely to meet the required standard.

However, in the other $7 \mathrm{CDCs}$ and the women's shura either very little was recorded or the records were clearly kept by the FP staff. In most cases, this was directly related to the level of education of $C D C$ 
members. In the CDC in Bamyan, for example, only 5 members ( 4 men and 1 woman) are literate, and have little further schooling. They acknowledged that they needed help. The women's shura in Kabul, unlike their well-educated male counterparts discussed above, have only two literate members. One of these, the treasurer, is receiving help from the men's treasurer and the FP's social organizer keeps some brief notes on the meetings. In a CDC in Takhar the evaluation team observed well kept records but realized that they were the work of the FP staff, because the CDC members' level of literacy was very low.

In other cases the lack of records was due to issues of governance and negotiated leadership. In one CDC in Badghis, educated members of the council had accepted the election of a poorly educated member as secretary in the interests of unity and respect for democracy. This meant accepting for the time being less than adequate documentation. In Balkh, as already discussed, women's lack of empowerment was a factor.

\section{On Community Development Council - Government relations}

Improving relations between the communities and government is both an objective of the Programme and a necessary condition for the successful functioning of the CDC. The critical relationship as far as the CDCs are concerned is that with their nearest level of government - district administration (where it functions) or the provincial government. In one CDC in Balkh and one in Kabul, both the men's and women's CDCs felt that they had good relations with the district administration. The Kabul women also described contacting the provincial health authority over staffing of a maternity clinic. However, in two other CDCs in Balkh, though the men were satisfied with their relations with government, the women thought that they did not get enough support, though one $C D C$ said relations were improved. Both CDCs in Paktika characterized their relations with district administration as good.

Five CDCs in Badghis, Balkh, Bamyan and Herat observed that their relations with government had greatly improved as a result of the NSP. However, in Badghis, they thought the government should give community relations more attention, and one $C D C$ had made a complaint to the Minister on his visit to the Province. Similarly, one CDC in Herat and one CDC in Balkh felt that relations, though good, could be improved by better coordination and more frequent contact as there was a lot that the communities were prepared to do to support the government.

Relations between the CDC and district administrations in Kundoz, Nangarhar and Takhar, were clearly poor and characterized by lack of trust and accusations of lack of recognition, corruption and nepotism. In Kundoz, in particular, this was clearly creating difficulties for the development of the CDC. In Takhar, apart from lack of trust there appeared to be very little contact or knowledge even of the DRRD.

\section{On Community Development Council - Facilitating Partner relations}

The relationship with the FP was considered from two perspectives by most of the CDCs: the FPs commitment and ability to form good community relations, and their capacity to facilitate the Programme. In 9 CDCs these criteria were deemed to have been met. All the CDCs visited in Kabul, for example, commented on the commitment and competence of the FP. However, other CDCs, often working with the same FPs that other CDCs viewed as highly effective, had some reservations. For example, in Badghis both CDCs were satisfied with their relations with the FP but one detected that their engineering capability was not adequate. In Balkh, the men's CDCs were very satisfied, but the women thought that they could have done more for them. A further 9 CDCs made this kind of assessment of their FP. In several of these cases, it seemed that this was as much an indication of the CDC's growing knowledge and capacity for management as of deficits in the performance of FPs.

In Takhar, however, in addition to the lack of contact with the government, the two CDCs surveyed did not seem to have adequate support from the FP. The relationship was essentially mutually cooperative, but very little time was being given to training and capacity-building. Visits from FPs were brief and informal and directed at implementing the projects. It is evident that the staff to community ratio in these FPs are very low compared to others. One CDC did not criticize this situation but the other was dissatisfied. It is noteworthy that the more aware CDC expressed criticism.
FIN DIN GSAN D RECOMMENDATIONS 


\section{On gender relations}

The evidence suggests that where the CDC has assumed a full leadership role in the community, women's leadership of women is more commonly recognized, though they still have a subordinate role in regard to general decision-making. Where leadership is shared with traditional authority figures, and in spite of the existence of formal arrangements for women's representation, they have little influence and may be specifically excluded from participation in community decision-making. Women's ability to overcome these cultural constraints are further hampered by their relative lack of education and knowledge of public affairs.

\section{The findings of the survey of leaders of matched communities in non-NSP communities}

These communities were found to share many post-war development needs with their CDC counterparts and to be seeking to meet them, through various forms of traditional and ad hoc governance. Their discussions of governance were particularly useful in shedding light on attitudes and expectations that were still evident, as their CDC neighbours negotiated new forms of governance while seeking to avoid a confrontation with traditional authority and powerful individuals.

\section{Community governance}

While governance in all the communities was strongly shaped by traditional concepts, it was clear that war experiences had also modified it in some cases. A Tajik community in Badghis had the most formally constituted and probably longstanding form of governance: a council of arbabs and elders meeting to deal with general issues affecting the community, and a council of clerics responsible for hearing legal cases. In Herat, another Tajik community also had a council of elders but it was led by the Qaria Dar (headman) who was their spokesperson to government.

At the other extreme, a Pashtun community in Nangarhar had no regular council meetings but the Imam and elders met when problems had to be dealt with. Similarly a community of Pashtun-returned refugees in Kundoz had no formal governance but the elders of the extended families who, as the household survey revealed, were highly respected, met to discuss and resolve community problems.
This community showed an unusual degree of internal cohesion, forged by their shared life in exile and close kinship.

Mixed but majority Pashtun and Tajik communities in Balkh and Kabul had obviously convened a number of traditional leadership figures and other influential figures when re-establishing civil governance after the war. In Balkh, they included 'elders of the camps, mullahs, respected persons'. In Kabul the District Governor of Kalakan had convened a council made up of members of various district and local committees (village committees, scholars' council, health and education councils). They included elders, teachers, a mullah and a former commander.

\section{Development needs and assistance}

Since the communities were matched with neighbouring CDCs, they defined their development needs in very similar terms. Most communities lacked basic amenities such as clean drinking water and housing, social infrastructure and viable livelihoods. The leaders had all made attempts to attract assistance, but only the community in Herat had obtained significant assistance from DACAAR and USAID. Most described receiving insignificant amounts of relief aid, or said they had received no assistance since the end of the war. The community in Nangarhar attributed this to their location in the dangerous border area with Pakistan; others in Kabul and Kundoz felt discriminated against by government.

\section{Relations with government and perceptions of national solidarity}

The leaders of most of these communities had come to expect little from government. In Nangarhar they said that they had adequate relations in that the district government informed them of important policies, such as poppy eradication, and they got a response if they contacted them, but they knew government could not help them in any other way as it was fully occupied with security. Other communities in Badghis and Balkh described relations as good, but governmental contact as insignificant. In Kabul and Kundoz they felt they had been unfairly excluded from the NSP. Only in Herat did they speak of a partnership with government.

In a similar vein to the $C D C s$, their perception of government was naturally influenced by their experience of local government. In Kundoz, as with their CDC neighbours, this 
had been negative: '...we do not expect them to be supportive. There is no partnership between government and the community.' In other communities such as Balkh, Badghis and Nangarhar the government was simply perceived as weak. The response seemed to be to expect more from NGOs than government and to try to resolve problems themselves within the community.

Nevertheless, the majority clearly thought that a closer and more supportive relationship with government should be the norm. In Badghis they said 'government and people should be constantly in contact...government should know about our needs.' This translated in most cases into a desire to be included in the NSP.

\section{Community perceptions of the National Solidarity Programme without Community Development Councils}

All the leaders except those in Nangarhar were aware of the NSP, and those in Kabul and Kundoz were actively seeking to be included. The project funding aspect of the NSP was clearly very attractive, given their failure to get other assistance. This was probably uppermost in the minds of the Kabul leaders, most of whom showed little interest in the changes in governance involved. In Kundoz, community leaders were also interested primarily in development assistance but recognized that by channelling funding through a representative council in the community itself, NSP provided a means of implementing projects without corruption. In Badghis, the concept of a council was welcome but it was assumed it would complement, not replace, the existing councils. Similarly in Nangarhar, when NSP was explained to them, the leaders were attracted to it but also had doubts about it replacing their leadership. In Balkh on the other hand, the leaders expressed interest in NSP both for its development potential and the contribution to national solidarity. They were also prepared to consider new forms of governance, including participation by women. In Herat they fully understood the NSP and were ready to sign up to it.

Although this was a small and therefore unrepresentative sample, the responses indicate a broadly positive attitude to improving relations with government and to the NSP (in part due to observing its progress in neighbouring communities), but a reluctance to see it replace current arrangements for community governance, not only out of self interest (many would be likely to be elected to a CDC) but also due to the strength of traditional custom which has held communities together in the absence of any national cohesion.

\section{In summary - \\ On the general capacity of Community Development Councils}

Capacity is a product of the interaction between the Programme and the objective circumstances of each community. Hence capacity in some aspects of CDC functions may be successfully developed while others continue to need support. As a result it is not always the case that the longest established CDCs are the most developed. The more disadvantaged or politically or socially contested CDCs take longer to achieve full capacity in every aspect of community development and governance. Nevertheless, there was clear evidence in every case of progress towards both representative governance and community development.

Five of the CDCs interviewed (in Badghis, Balkh, Herat, Kabul and Kundoz) were assessed as able to function without facilitation by the end of the project. Three of the 5 were established CDCs nearing completion of a project. These CDCs nevertheless had outstanding issues to tackle on the inclusion of women, communication with the whole community, final transfer of full leadership and some minor administrative matters. They will also continue to need technical assistance for complex engineering projects. Seventy-five per cent of the CDCs visited in the course of the engineering survey in Kabul were also judged to have achieved this level of capacity, as well as a CDC visited in a rapid appraisal in Laghman.

The majority of the CDCs interviewed (13 including one women's shura in Balkh), were assessed as 'able to function but with difficulty' due to their own lack of management and leadership skills, lack of women's participation and/or external political and economic constraints. They were therefore thought likely to require at least some further facilitation beyond the conclusion of the current project. The CDC visited in the rapid appraisals in Nangarhar also fall into this category.

The four remaining women's shura that it was possible to assess were deemed not
FINDINGSAND

RECOMMENDATIONS 
able to function as envisaged in the Manual, due to lack of knowledge (as in Kabul) or exclusion (as in two CDCs in Balkh and one in Kundoz). Indications from the rapid appraisal in Laghman are that women's CDCs have a similar potential to those in Balkh. However, women's shura in other locations, such as Nangarhar, were even less empowered. This is in no way an indication of lack of progress, rather an indication of the scale of the social impediments to their inclusion. As discussed below, continuing facilitation in support of women's role in the CDC is necessary across the whole programme.

These findings support the view that separate women's groups with separate project budgets are necessary in the shortterm to develop women's capacity. At the same time this should not be used as a mechanism for institutionalizing their exclusion from decision-making in the general CDC.

The findings from interviews with leaders of matched communities with no CDCs reinforce the evidence from the CDCS and householders that traditional forms of governance, though in some cases manipulated by self-interested individuals, also commonly embody important aspects of community identity and traditional knowledge that need to be incorporated in the new governance. For this reason the gradualist and negotiated approach to establishing the CDC, adopted in most cases by the FP, is most appropriate.

\subsection{The Household Survey}

\section{Sample and key indicators for evaluation}

The household survey was designed both to assess the impact of the NSP in respect of its goal and objectives, and to provide evidence of progress in developing inclusive community governance as a means of empowering communities to improve their lives. To this end the interview schedule sought responses from a sample of householders on a number of key issues:

- their experiences in the war and the immediate post-war period including economic conditions and forms of governance (the baseline from which the Programme had to work); how they had experienced the process of setting up the CDC and the choice of projects;

$\checkmark$ the extent of their participation in governance and project implementation today;

$\checkmark$ their perceptions of the wider national governance including recovery and development plans; and

$\checkmark$ their outlook on the future.

Since there is no comprehensive baseline data for the NSP, as well as the retrospective enquiry in the CDC communities and use of information provided by the FP, a sample of householders in matched neighbouring communities not participating in the NSP were interviewed to provide another means of distinguishing the impact of the NSP from general trends towards recovery.

Random sampling was not feasible due to the lack of accurate sampling frames for the communities visited and the time constraints of the evaluation. The strategy adopted was first of all to develop a community profile from the testimony of the staff of the Facilitating Partner working with the community, and then refine it in the light of the description given by the CDC (or community leaders in the case of a matched community without $(D C)$. These were then asked to arrange for contacts with representatives of households to reflect the different economic, social and ethnic groups in the different clusters making up the community. A comparison of the actual samples with the recorded profiles after the conclusion of the fieldwork showed this method to have been broadly successful. In all the samples the 'typical households' made up the majority, but minority groups were also represented.

As regards representation of ethnic diversity, respondents from the following ethnic groups were interviewed: Pashtun, Hazara and Tajik majorities in their communities; Pashtun, Arab, Tajik and Uzbek minorities in their communities. However, in one respect, the survey suffered an unavoidable bias. It was not possible, due to local cultural factors, to interview men and women householders in equal numbers. The first limitation was the number of women researchers it was possible to take to the field, which was constrained by the limited locations where it would have been possible for them to work at all, and the cultural constraints on them working in a mixed team without either an accompany- 
ing escort or another female researcher. As a result one team of two women and one man worked in Bamyan and Kabul and was able to interview a sample of equal numbers of men and women representing different households, and a second team of two women and one man in Balkh interviewed men and women from the same households. All-male teams in Badghis and Kundoz found that they were able to interview widows if they were heads of household, but in Herat, Nangarhar and Paktia only men were interviewed.

The resulting sample was as follows: 73 men and 13 women representing households in communities with a $C D C$ were interviewed individually in 7 of the provinces and in the eighth province (Balkh) men and women in 30 households were interviewed. In addition, 33 men and 7 women representing households in matched communities without CDCs were interviewed in the 7 provinces and 6 households in a matched community in Balkh. In all, the sample represents 162 households.

The principal findings of the household survey are presented below in accordance with the key indicators of evaluation outlined above: the communities' experience of the war and immediate post-war period, including economic conditions and forms of governance; how the communities experienced the process of setting up a CDC and the process of community development planning; the extent of community participation in governance and project implementation; community perceptions of wider national governance, including recovery and development plans; and community outlooks on the future.

\section{The communities' \\ experience of the war}

Communities in different areas of the country and in different locations in the same province experienced the war differently. Two main observations can be drawn here. In the first place, their pre-war conditions were also different. Remote rural areas in Badghis or Bamyan, for example, had experienced little development before the war and are still poor and under-developed today. Householders in rural Kabul, however, remember being prosperous and having access to education and urban markets before they were affected by war, and are striving to recover the lives they once had.
Secondly, different ethnic groups, depending on their location, suffered most in different phases of the war. Pashtun residents in Nangarhar remember the attacks by Soviet forces as the time when they were under most threat, while the period of Taliban rule, though harsh socially and economically, was relatively stable. Other ethnic groups, such as Tajiks in Kabul and Hazara in Bamyan, experienced ethnic cleansing at the hands of the Taliban during the war with the Northern Alliance.

I have heard with my own ears from

Taliban that we should go to Tajikistan.

(Householder, Godara CDC, Kabul)

Most communities were sporadically affected throughout the war by direct violence, looting and destruction of property, as well as intimidation or forced recruitment to local militias. However, some stated that they were only indirectly affected on the grounds that no one in their family had been killed. The indirect effects can be summarized as chronic insecurity and impoverishment. Many responded to the violence and/or economic hardship by migrating but these experiences also varied: from hiding in the mountains for short or prolonged periods, migrating to other safer villages and the urban areas, to emigrating for all or most of the war to Iran or Pakistan.

During the war against the Soviet invasion, one Pashtun community in Kundoz was 'oppressed by the Soviets and the Mujahideen' and abandoned their homes; and bombing, violence and looting affected two Pashtun communities in Nangarhar, so that some were driven to migrate. In the war between the Taliban and the Northern Alliance, two Tajik communities in Kabul, a Hazara community in Bamyan and a mixed Pashtun, Usbeck and Tajik community in Kundoz were violently driven from their homes, which were destroyed. Six Pashtun communities in Balkh, Kundoz, Nangarhar and Paktia, and 4 mixed communities in Balkh said they were affected throughout the war by sporadic violence, looting and intimidation. Three Tajik communities in Badghis, and 1 Pashtun community in Nangarhar described being affected indirectly throughout the war.

These different experiences have clearly resulted in wide variations in the capacity of both individuals and communities to recover from the war, and consequently the extent to which they have been able to par-
FIN DIN GSAN D RECOMMENDATIONS 
ticipate in and benefit from the NSP. One of the strengths of NSP has been the ability of the local management teams (DRRD, FP and OC) to adapt the NSP concept to these different levels of capacity.

\section{The communities' post-war experience}

The communities' post-war experience has been conditioned by how the war affected them as well as the present conditions in their area. For example, communities in Kabul and a community of returned refugees in Kundoz had returned so recently that they were still experiencing problems of shelter. Communities in Nangarhar whose homes were destroyed in the earlier phase of the war had been able to rebuild their homes, though not recover livelihoods, during the Taliban rule. Others in Badghis who had not migrated had experienced little change other than improved security. However, the overwhelming majority ( 88 per cent) of householders did think that their lives had improved since the end of the war. The remaining householders said that their personal (usually economic) circumstances were unchanged and only a few said things were worse. Those in communities without CDCs were as likely as those with CDCs to say that their lives had improved.

\section{Security}

We have improved in terms of security, but other improvements will take a long time. In my opinion, reconstruction in a 25-years war-ravaged country won't be a simple task. We have lost our national constitution, our army, our police, our education system and, the most important, our national unity all over the country and trust in each other. Therefore I can't say that our lives have improved in a short period of three years. (Householder, Bardowlet Khil CDC, Paktia)

The majority of all householders cited greater security/peace/stability as the main improvement in their lives. However, those communities without CDCs commonly cited very little else that had improved. Sixty per cent of households in CDCs and 76 per cent of those not in CDCs cited improved security as the main improvement. Fifteen per cent in CDC communities and 36 per cent in non-CDC communities said this was the only improvement. In Nangarhar (reflecting the current level of insecurity) only 4 householders, all in a community without a CDC, thought security had improved. Others in that community and the CDC communities argued that security was worse. However, in the three communities in Nangarhar and two in Kundoz, a total of 11 householders said that they were now free to lead their lives without interference or bullying by warlords, or in other cases the Taliban.

\section{Economic opportunity}

The next most commonly cited improvement (though the majority stressed that conditions are still poor) was the increase in opportunities for work and economic activity, largely due to freedom to circulate or work free from threat. Thirty-five per cent of the CDC householders made this point but only two householders in a nonCDC community (4 per cent). In the CDC communities, 8 householders specifically mentioned the NSP as having materially improved their lives. Seven referred to the NSP projects in their village and two to infrastructure projects elsewhere as evidence of economic improvement. Eight householders in both $C D C$ and non-CDC communities noted increased international assistance to the country as a whole or in their personal experience.

\section{Changes in governance}

In the CDC communities, 2 men (in Badghis and Nangarhar) and 4 women (all in Bamyan) cited the creation of a democratic shura as leading to an improvement in their lives. Three householders in non-CDC communities in Kabul and Nangarhar, and 1 in a CDC in Badghis, cited having an elected national government as an improvement in their lives.

\section{Other improvements}

Other improvements cited were clearly influenced by the householders' particular circumstances. The 20 householders in both CDC and non-CDC communities in Kabul unanimously said that just being able to return home was the first improvement for them. A single householder in Nangarhar expressed the same sentiment. Four householders in non-CDC communities, 2 of them teachers, mentioned that schools are functioning. Householders (including women) in one CDC in Balkh welcomed freedom for women. 


\section{The establishment of Community Development Councils}

The CDC is our representative. It is our government.

(Men and women householders in Shah Qadam CDC, Bamyan)

Our National Solidarity Council. It is there to help us build our village with our own hands and make sure that we don't go back to the times of war and

devastation. It helps us stay united. (Householder in Hoftoi Sofla CDC, Herat)

\section{CDC is NSP and the NSP means projects.}

(Men and women householders in Yakhdan CDC, Balkh)

Sixty-nine per cent of the householders in CDC communities had a good general understanding of the development purpose and representative nature of the CDC. A further 17 per cent had a vague or partial understanding, often seeing it as simply a project management committee, or 'some sort of council'. Nine per cent did not know what it was exactly, though they were aware of its existence. Estimates as to how long the $C D C$ had been operating tended to vary, suggesting that different people became aware of the process at different times, or dated the CDC's establishment from their first contact with it or from the inception of elections. Where separate samples of individual interviews with men and women were possible, women were found to be as likely as men to have a good understanding of the purpose and principles of the $C D C$, and often showed considerably more enthusiasm for the democratic nature of the process. Elderly widows were the least engaged.

There was a high level of participation in the elections. Eighty-three per cent said they had voted and many added that their whole family had voted, men and women. Women in the sample participated in the elections in the same proportion as men. Of the 17 per cent who did not vote, most were prevented by absence or sickness or the fact that they had only returned to the community after the election. Several of these respondents also mentioned relatives who had voted and were aware of how the election had been carried out. However, there were a few cases of people who chose not to vote, or believed they had been consciously excluded, or were simply unaware of the electoral process.
A full understanding of the purpose of the election was much less common. Only 30 per cent understood not only the election itself but how it had been set up, including the selection of the electoral commission, and/or the scrutiny role performed by FPs and DRRDs. A further 30 per cent had a partial understanding of the process, but a belief in its legitimacy. Twenty-three per cent had no understanding of how the election was run or, even if they had voted, exactly what it was for.

\section{Pre-existing community power structures}

When asked about the pre-existing decisionmaking bodies in their communities, 58 per cent described various forms of traditional council or community leaders (elders, maliks, arbabs, mullahs):

We had a traditional council that was responsible for decision-making at the community level, but definitely it was not as organized as the NSP one.

(Woman head of household, Dour Robat CDC, Kundoz)

A small number (4 per cent) thought that decisions were referred to the district administration or the governor. It was evident that in a number of communities this traditional leadership was still in place and often still representing the community to the district government. In some of the most disrupted communities, particularly those that had abandoned their villages for a number of years, traditional leadership was not acknowledged. Fifteen per cent of respondents said that there was no means of decision-making before the $C D C$, while 7 per cent stated that warlords or commanders had controlled them. For example, all the community members interviewed in Bamyan who were driven from their homes into the mountains said there was no leadership before the $C D C$, though some women said the men had 'discussed things' but they were not party to it. The CDC members also said there had been no formal governance and that anyone with any means (the class that are often leaders elsewhere) had not bothered to return after the war.

In Kabul, on the other hand, residents in the $C D C$ village visited either said there was no leadership or said that warlords had dominated them. Nevertheless, this CDC, like all the others visited in the Province, included elected or co-opted elders who had at some time in the past formed a tradi-
FIN DIN GSAN D

RECOMMEN DATIONS 
tional council, though they said several had died. It seems clear that after the forced abandonment and return several years later, the traditional leadership was no longer in charge and military figures had dominated.

\section{Community perceptions of the role of Community Development Councils}

In this section we report community attitudes on the legitimacy of CDCs, community awareness of the work of CDCS, community participation in NSP projects, community understanding of the financial management of NSP projects and community perceptions of the impact of CDCs.

\section{Issues of Legitimacy}

It is evident from the householders' responses that CDCs were on the whole considered beneficial to the community and were gaining community standing. Sixty-five per cent (including several traditional leaders) expressed general satisfaction with the CDC. In some cases (9 per cent) criticisms of the CDC were couched in terms of its need to prove itself in the long term. However, there were only 3 respondents who expressed actual hostility to it. A larger group (33 per cent) avoided giving an opinion, either because they wanted to 'wait and see' or claiming that they did not know. Although many of these responses can be taken at face value, some undoubtedly indicated a degree of dissent or unease. When the householders were asked directly who now constituted the formal leadership of the community, this ambiguity became more apparent:

They all represent and manage our community. There is no one outside the CDC who represents the community to the outside Afghanistan.

49 The role of the N SP management teams, particularly the FP is clearly critical in this process, some such as SDF in Kabul prepare for the introduction of the CDC with peace building exercises. See also the recognition by non-CDC communities that existing leaders are likely to feel threatened by a CDC and seek to prevent it.

The household survey provided no evidence to suggest that there was a clear relationship between unanimous acceptance of the $C D C$ and the length of time it had been functioning. Other critical factors that emerged during the interview process included: the nature of the particular community and its particular geographic, economic and political context; and the success of the NSP facilitation in responding to these factors when establishing the CDC.

Eighteen per cent of respondents (in one CDC in Badghis, Balkh, Kundoz and in Paktia) stated unequivocally that the community was led by traditional leaders, though on the whole they also welcomed the $C D C$ as a development council:

$$
\begin{gathered}
\text { Our tribal leader leads. } \\
\text { He is not a CDC member. } \\
\text { (Householder in } \\
\text { Bar Dawlet Khil CDC, Paktia) }
\end{gathered}
$$

However, the CDC in Paktia was the only one where all respondents expressed this view. A further 11 per cent of respondents in these communities described various collaborative arrangements between the CDC and the traditional councils, with some members sitting on both:

In the past, local warlords and elites used to run the affairs for us, but now the members of $C D C$, with the hel $p$ of

some other community leaders, lead the community here. (Householder in Dai Zangi CDC, Badghis)

From this perspective they ascribed a continuing political role (representation and arbitration) to the traditional councils, and a development role to the CDC. A similar number of respondents in these same communities also chose not to give an opinion on the matter. These responses confirm the evidence from the CDC, district and provincial government, and FPs that where traditional leadership is not only entrenched but is also still respected by communities (particularly those composed of relatively cohesive kinship groups), a gradual transfer of authority is being negotiated with a degree of goodwill on both sides. A number of traditional leaders have also clearly recognized that it will be in their interests to accept the CDC and find a role in it. 49

\section{Community awareness of the work of Community Development Councils}

Seventy-eight per cent of householders were aware of the meetings of the CDC, though not always the exact timetable. In a number of cases this seems in any case to 
have been variable. There were suggestions from some that they felt excluded or deliberately uninformed. Others thought, since they were not members that they did not need to know exactly when it met:

The CDC knows, not me. (Householder in Dai Zangi CDC, Badghis)

More significantly, however, the majority had little idea of what was done in CDC meetings or how the CDC works. Fortyseven per cent had no idea and 33 per cent only gave quite a vague explanation. Only 19 per cent seemed to be actually following the work of the CDC. Nevertheless, most believed it was working in their interests:

I am mostly at home and do not have information about the CDC.

The members are good people and wholeheartedly work for the benefit of the community. (Severely disabled young man in Godara CDC, Kabul)

In only 5 CDC communities did the respondents refer to any public meetings of the CDC. In Bamyan 90 per cent of those interviewed and all those in Herat said they attended monthly meetings where the CDC reported on what it was doing. In Kabul 20 per cent mentioned monthly meetings. Respondents in the most established of the two CDCs in Kundoz all spoke of meetings where they participated with the CDC and in Paktia 4 out of 6 respondents mentioned attending meetings. However, there were comments in several communities suggesting a perception of exclusion:

They don't listen to us when planning. (Householder in

Bar Dawlet Khil CDC, Paktia)

They don't let the poor participate. (Householder in Mobarak Shah CDC, Badghis)

In any case there was no obvious correlation between the mention of meetings and the level of awareness of CDC business. In some cases where meetings are held most respondents did feel informed. In other cases, such as the CDC in Paktia, noted above, they did not. Meanwhile, communities in Balkh, for example, did not mention public meetings, but were generally well informed.

Community awareness of the future plans of the $C D C$ was higher, suggesting some understanding of a development plan or participation in priority setting. Forty-two per cent seemed well-informed and 19 per cent vaguely aware of plans. There were two exceptions to this trend - a recently formed CDC in Kudoz, where it was perhaps too soon to expect long-term plans, and the CDC in Kabul, where householders were not informed beyond the two projects already in hand, although the CDC was already negotiating further projects. In 5 communities the householders all said that the $C D C$ was not making contact for further project funding, and overall only a quarter of the respondents were aware of such approaches.

The majority of householders, however, were observing and being informed of the contact between their leaders and government. In those CDCs where the leadership was making these contacts, 80 per cent of the respondents were aware of it. In the community with the most recently formed CDC in Kundoz, and one of the CDC communities in Nangarhar, the respondents were all aware that the traditional leaders continued to be the ones to do business with district government. In a second CDC community, the majority said that the CDC worked with government but one dissenter said it was the malik. In Paktia, they were equally certain that the CDC had no contact but the malik might.

On all of these aspects of the functioning of the $C D C$ women were more likely than men to be amongst the least informed.

\section{Community participation in NSP projects}

As described above, direct community participation in planning the projects and their implementation is clearly happening in some communities; in others they were consulted by the CDC and then informed of decisions. A minority of householders felt that they had not been involved. Where householders had been actively involved in planning a project that had yet to be implemented (4 CDCs in Balkh, Bamyan, Kundoz and Nangarhar) there was a high expectation that respondents themselves and all the community would participate in the implementation, though in Balkh two households expect to be excluded.

The level of actual participation by those interviewed and their fellow villagers where projects were under way varied from $C D C$ to $C D C$. In one CDC in Balkh half the households interviewed were not participating.
FIN DIN GSAN D RECOMMENDATIONS 
Two respondents in Paktia said they were not available to participate and one respondent in a third CDC in Balkh, and one in an established CDC in Kundoz, simply said they had not participated. However, the majority of villagers were participating in the work: 56 per cent were participating with paid labour (mostly also contributing some voluntary days or repaying some wages as a cash contribution); 12 per cent, mostly the better off, were contributing voluntary labour or, in the case of one disabled and one elderly respondent, voluntary supervision; 18 per cent said they were contributing 10 per cent (in one case 20 per cent), that is, to the community contribution to project costs. Most had no complaints about how the work was allocated, though two in Paktia said it was difficult to make time for voluntary work, and one in Kabul thought he had been unfairly treated when the foreman had to reduce the paid labour force.

All the women interviewed individually in communities implementing projects adopted by the general CDC (all infrastructure projects) said they, as women, were not able to participate themselves but referred to male relatives who were. Women in Kabul said they expected to participate in women's projects when these were set up. When it came to discussing the level of participation by the community as a whole, only two CDCs (in Badghis and Herat) were said to have had no problems with participation. In all the other communities, respondents described problems in getting a minority of residents to participate. Barriers to participation were identified as: lack of time and poverty/needing to give priority to main livelihood, objections to paying contributions, illiteracy and lack of awareness:

Some people are not a ware. They use the bridges every day but never think who built them or how they were built. (Householder in Yakhdan DC, Balkh)

In Kabul and one of the CDCs in Kundoz, participation from some segments of the village community was limited. One respondent in Kabul said he would not work on the current project because it did not benefit his part of the village, but would participate on the next one. In Balkh one householder stressed the fact that women were discriminated against.
Public understanding of the financial management of NSP Projects

In the recently formed CDC of Dour Robat in Kundoz, householders did not know the source of the funding for community development projects, and since the money had not yet been received, they could not say how it was managed, though one knew that a treasurer had been chosen by the CDC. Another said, '[W]e have many illiterate people in the community and would ask the $C D C$ to give time and verbally explain how the grant is spent and give a chance to the poor people to work and get daily labour.' Of the remaining respondents, 54 per cent of men and 41 per cent of women interviewed individually understood that the money came from international aid and was channelled by government through the FP to the CDC. All the male and female householders interviewed in the longestestablished CDC in Balkh also understood this to be the case. Most of the other householders ( 42 per cent of men, 41 per cent of women and 56 per cent of households in Balkh) understood that the money came in some way from government. Ten per cent of men, 17 per cent of women and 10 per cent of the Balkh households did not know where the money came from. One man in Yakhdan, Balkh, said it was 'because no one tells me'.

When it came to understanding the financial processes, such as procurement and allocation of the Block Grants few householders, and particularly very few women, felt able to follow the work of the CDC. Only one woman, a member of the CDC in Bamyan, though illiterate said:

I am sitting in the shura and making the decisions with the men.

(We) all sit together to make the decision on how to spend the money. The treasurer tells us how it has been spent.

Two other women in Bamyan thought they were informed as much as they could be in the monthly meetings. The 10 other women interviewed (77 per cent) said they had no understanding of how the finances were managed. Only 19 per cent of the men felt able to follow the transactions, either in the account books or from the treasurers' reports. However, nearly half (42 per cent) had some idea of how the money was being handled, while 36 per cent had no idea: 
AKDN ... helpsus a lot because we are

unfamiliar people and don't know anything a bout city issues.

(Male householder

in Shah Qadam CDC, Bamyan)

In Balkh, 7 per cent of households were able to explain the financial management, 46 per cent had some knowledge, and 14 had none. Forty-seven per cent of all respondents said they left it to the $C D C$ and its treasurer to manage the finances, which they themselves could not follow in detail:

Well, they gave us reports on the expen ditures; even if we ask them about it every day. I don't know how they manage it a mongst themselves though. Do I need to know?

(Male householder in Dai Zangi CDC, Badghis)

More than half the women expressed this view. However, the expression of sentiments of distrust was rare, but those that expressed it also said they had no knowledge of how the CDC works:

I know that the money is given to those who do some job but only Allah knows

of what happens behind the curtain. (Male householder in Godara CDC, Kabul)

This lack of capacity has implications for ensuring accountability to the general public, which clearly has in most cases to be by oral communication, and for accountability to funding agencies which relies on written records that only a minority can handle. This is the key area in which there is virtually no capacity amongst women, which in turn (see Godara CDC) limits not only their general participation, but the capacity of those elected as CDC representatives to function effectively.

\section{Community perceptions of the impact of Community Development Councils}

They came together in happiness and sadness and talking with each other to solve problems.

(Woman householder in Shah Q adam CDC, Bamyan)

It is a body that has united three villages. (Male householder in Chogha-e-Sofla CDC, Kundoz)
The NSP has helped a lot, we are more united as a community and have a project that gives us hope and I can grow more wheat.

(Male householder

in Sholana CDC, Nangarhar)

In this section we present the findings of the household survey with regard to community perceptions of the impact of CDCs on enhancing community governance, deriving material benefits for community members, providing new learning opportunities, building national solidarity and improving community perceptions of government.

\section{Community attitudes on the impact of Community Development Councils in community governance}

The impact of the NSP on community governance was remarked on by a large majority of the householders. This was most commonly expressed as 'unity', 'solidarity', or 'working together'. Eighty-six per cent of the respondents ( 90 per cent of women) volunteered this description of the impact of the CDC on their lives. Notably, in Godara CDC in Kabul, the women said they had not even known each other, though neighbours, until they were able to meet in the women's shura. A further 8 householders ( 7 per cent), when asked directly, agreed that there is more unity as a result of setting up the CDC. Six respondents in Badghis, Herat, Kabul and Kudoz specifically noted that the creation of the CDC had reduced the influence of the warlords:

$$
\begin{gathered}
\text { No more use of the gun! } \\
\text { (Male householder } \\
\text { in Mobarak Shah CDC, Badghis) } \\
\text { We are no longer vulnerable } \\
\text { to those who want us to fight. } \\
\text { (Male Householder } \\
\text { in Hoftoi Sofla CDC, Herat) }
\end{gathered}
$$

A smaller majority (56 per cent) spoke of the CDC as a new system of community governance that is transforming decisionmaking. Twenty-eight of these (24 per cent) also referred to the project management role of the CDC. However, only a minority (15 per cent) saw the CDC only in terms of its project management role. An even smaller minority of 11 per cent, some of them in the more recently formed CDC, were unable to say what the NSP/CDC meant to them.
FIN DIN GSAN D RECO MMEN D ATIO NS 
Community attitudes on

material benefits derived from

the National Solidarity Programme

Sixty-five per cent of householders in all the communities (except the recently established Dour Robat CDC in Kundoz, where nothing was said on this issue) said that they had received some material benefits from the NSP or were confident that projects in progress would benefit them kin the future:

Everybody uses the road without discrimination, even the poorest. (Male householder in Balla Dehe CDC, Nangarhar)

However, 8 respondents in 5 of the CDC communities said that the CDC had not changed their lives materially. One of these in Balkh specifically stated that the CDC had not benefited women:

The NSP just built the wall but it has not changed my personal situation.

(Chogha-e-Sofla CDC, Kundoz)

Six respondents in the more recently formed CDC in Balkh and Kundoz, as well as the more established CDC in Bamyan and Nangarhar, mentioned that the NSP had increased learning opportunities:

We have seen what we can do as a community.

(Male householder

in Balla Dehe CDC, Nangarhar)

Skills and knowledge acquired through the CDC work and through literacy and increased interest in education including women's enrolments. Electricity projects were expected to help both children and adults study.

\section{Community attitudes on issues of national solidarity}

Building our country, building our village through our own people. (Male Householder in Hoftoi Sofla CDC, Herat)

NSP works to unite people and remove anarchy in Afghanistan.

(Male Householder

in Dour Robat, Kundoz)

Fifteen per cent of respondents saw the NSP as contributing to national peace and solidarity. Very few respondents (three) had any detailed knowledge of even one other government development plan. One of these respondents from Nangarhar was alarmed that the government planned to eradicate poppy cultivation; his main source of labouring work. The other two in Badghis and Kundoz provided details of several reconstruction projects in their province.

Nevertheless, nearly half of the sample (49 per cent) had a general impression that the government was working to rehabilitate the country, although 4 respondents in Nangarhar suggested that it did not have the capacity to implement its plans. Three other members of the same community were adamant that the government had no plans:

Government is busy arranging security for the people and it has no time to think about other aspects of life. (Male householder in Sholana CDC, Nangarhar)

The remaining 47 per cent of respondents simply said that they had no knowledge of government plans, often saying they were illiterate, to o poor or too busy. Women were particularly likely to give such responses.

\section{Community attitudes towards Government}

A much larger number (77 per cent) asserted that the government is interested in their community. A quarter of these cited the NSP work in the village as evidence of that interest. Others cited other infrastructure projects such as roads or surveys as evidence:

If it were not interested, you would not have been asked to interview me

(Male householder

in Dour Robat CDC, Kundoz)

Nine other respondents were unsure of the government's interest, particularly those who were not fully aware of the government's role in NSP:

We hope it is. It seems to be We receive promises but nothing is done. (Male householder in Chogha-e-Sofla CDC, Kundoz)

A total of 10 respondents said the government had no interest in their community. They were all from the two CDCs in Kundoz, the most recently formed $C D C$ in Nangarhar, and the CDC in Paktia. It was clear from their other responses that this attitude was associated with ignorance of 
the government role in NSP or lack of understanding of the Programme, and deep distrust of government due to bad past experiences of government, particularly, local government:

\section{Whoever started NSP it can't be government, otherwise the money would have gone to warlords or district administration. (Male householders in Dour Robat CDC, Kundoz)}

For example, 7 respondents in the recently formed Dour Robat CDC had a very negative view of the district government, which they accused of extorting bribes and other forms of corruption. Three respondents said that the government had no interest in their community. However, 4 respondents distinguished between the local government and national government, which had demonstrated some interest. If work starts in the village they will be convinced of government interest.

\section{Prospects and plans for the future}

When asked what would most improve their lives, 89 per cent of respondents cited developments that would affect them directly in their daily lives. Various types of infrastructure were the most commonly mentioned. Highest on the list were first schools and then clinics. Clean drinking water schemes were also very commonly mentioned. Respondents in 4 communities also mentioned irrigation schemes and roads. Electricity was mentioned by a few. One or two respondents in the poorest communities mentioned food aid.

The need for work was another priority. In one CDC in Nangarhar it was the primary need. In the communities where women were interviewed the need for work for both women and men was stressed:

Work for men and women.

(Woman householder

in Godara CDC, Kabul)

Others identified livelihoods for both men and women, such as agriculture and carpetweaving as priorities. The one social need identified as a priority in more than half the communities was education, including schooling, literacy and skills training, especially for women and girls:
If government found vocational training courses for women, especially widows, the women in this community can be self-sufficient in the next few years.

(Woman householder

in Dour Robat CDC, Kundoz)

In one community in Balkh all the respondents identified schooling as a priority. A small number of respondents (8) looked to the wider picture, seeing improvements in security, economic growth and governance at the national level as offering the best hope of future prosperity:

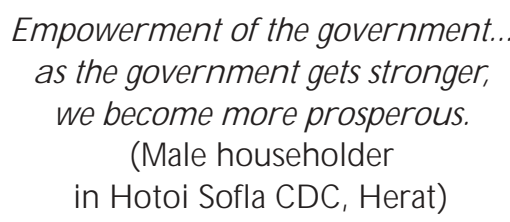

Fifty-nine per cent of the householders in the CDC communities declared themselves optimistic about the future:

I am very optimistic about the future because what I have today is beyond my wildest dreams. I even didn't imagine I would be back in my own birthplace one day. I pray Allah almighty for listening to our prayers. I always tell my sons and grandsons to work for our country and not let it be destroyed again. (Male householder in Godara CDC, Kabul)

While for a few (11 per cent) this was mostly a matter of faith in God, the others advanced some objective reasons for their confidence:

God knows better about the future. (Male householder in Shah Qadam CDC, Bamyan)

I think people are tired of war and want to live in peace and construct their country. (Male householder in Godara CDC, Kabul)

About a third ( 29 per cent) said that things were generally beginning to improve. Twenty-eight were optimistic as a direct result of the NSP Programme in their community. Twenty-two per cent thought the whole recovery process, economic recovery, reconstruction, security, government and international commitment, was working: 
The mechanism appears to be working. (Male householder

in Mobarak Shah CDC, Badghis)

Others were much less enthusiastic; 18 per cent said they were confident that at least there would not be a return to war, and a further 18 per cent cited improved security as the main reason why they could get on with their lives:

We hope that the government changes for the better and we pray for its stability.

People are satisfied with their lives

today and hopeful about the future.

(Householders

in Shah Qadam CDC, Bamyan)

A further 30 per cent said they were hopeful or conditionally optimistic about the future, still clearly fearful that the improvements they have experienced could be reversed:

\section{I don't know but I am happy our village should be supported. (Woman householder in Shah Qadam CDC, Bamyan)}

The 7 per cent who expressed pessimism about the future gave quite specific reasons for their opinion. For a widow in Badghis, the economic prospects for her and her children were so bleak she could only fear for the future. One respondent in Herat said the future now depended on the government and how strong it could be. Four respondents in Nangarhar and Paktia thought that the power of the warlords would prevent any improvement. A householder in Kundoz could see no prospect of a better future as long as the local government was ruled by corrupt individuals. Another householder in the same village feared that the CDC might also be taken over by corrupt maliks:

I am not very confident because the government offices particularly at the district level are filled with the corrupt and illiterate Jehadi people. (Male householder in Dour Robat CDC, Kundoz)

I can predict that while the warlords are in power, our country can't improve. (Male householder in Bar Dawlet Khil CDC, Paktia)
The findings of the Household Survey of non-NSP matched communities

The purpose of including these communities in the evaluation was to compare them with the $\mathrm{CDC}$ communities in relation to a common set of indicators, in order to disentangle changes observed by the CDC communities which can be ascribed to the impact of the NSP from those which are attributable to general post-war trends. This required that communities should be selected that matched as far as possible the geographic location, ethnic mix and socioeconomic conditions of at least one of the two CDC communities researched in the same region. Moreover, it was also important, for purposes of impact assessment, that the communities should also share similar experiences of the war and immediate post-war period, including economic conditions and forms of governance.

The following analysis therefore examines those aspects of community life and perceptions that the NSP aims to transform, and compares the responses in these communities with those of the CDC communities discussed above.

\section{Pre-existing community power structures}

Descriptions of the character of community leadership in these communities were similar to their CDC counterparts. Fortythree per cent of respondents (all men or mixed household groups) said that a council of elders or of elders and clerics governed the community. In some cases, such as Kalakan in Kabul, these had recently re-established a council after the end of Taliban rule. They were described as:

Talented custodians, honest and sincere. (Male householder in Mangal Abad, Kundoz describing the 3 leaders of the community interviewed by the research team)

Mosque lea ders, commanders and now they call themselves representatives. (Widow in Kalakan Centre, Kabul)

Fifty per cent of respondents, including all the women interviewed, referred not to a council but to one or two powerful individuals, with titles such as 'malik' or 'arbab' (though notably members of the same community did not always name the same leaders). For example, in the community visited in Nangarhar, where 5 men named leaders in this way, others said that there 
was no formal leadership, and later others described the existence of conflict over community leadership. This lack of consensus, together with the evidence of disputed leadership, supports the contention that this is the failed character of Afghan governance that CDC community members believe needs to be overcome through the NSP.

\section{Community participation in community governance}

When describing how priorities were decided in the community, 43 per cent said the leaders decided and only 13 (28 per cent) mentioned any form of consultation. Eight of these were in a community consisting of a single kinship group. This is in contrast to levels of participation in CDC communities that ranged from 50 to 90 per cent:

The arbab gathers people and people agree with him.

(Male householder in Yaka Dokan, Herat)

$$
\begin{aligned}
& \text { Our elders take decisions and all the } \\
& \text { people sit together in the mosque } \\
& \text { and focus on the problems. } \\
& \text { (Woman householder } \\
& \text { in Kalkan Centre, Kabul) }
\end{aligned}
$$

Thirty-nine per cent of householders (all men or in mixed household groups) said they had participated in community work. Fifteen per cent said they had not participated. Another 15 per cent said they were willing but had not been asked. A third of the respondents did not answer this question. Participation in community projects in the $\mathrm{CDC}$, in contrast, was found to be over 80 per cent.

\section{Community-Governmental Relations}

Fifty-six per cent of householders in the non-CDC communities said that their leaders contacted government as representatives of the community:

Of course they work with government.

That is their job, but we don't have to know about it.

(Male householder in Yaka Dokan, Herat)

However, two women in Kabul suggested that it was aimed at serving their own interests, while 13 per cent were unsure if there was any contact:

How should I know?

(Widow in Kalakan Centre, Kabul)
The community in Kundoz, like their CDC counterparts, deeply mistrusted the district administration, and 6 respondents stated that their leaders did not work with government. Three householders in Nangarhar also said that their leaders did not work with government. Again the level of contact with government, or at least the level of transparency about the nature of contact, is in stark contrast with the CDC communities where it was 80 per cent. When it came to awareness of their leaders' representations to funding agencies for assistance, 28 per cent (all men and mixed household groups) were aware of these invariably unsuccessful efforts. One man in Nangarhar, however, also said that they were just pursuing their own interests. Seventy-one per cent (including all the women) said that they were not aware of any approaches to funding agencies for assistance, did not know, or were certain there were none. Again, although awareness of these activities in the CDCs was not universal, it was much higher: 42 per cent of respondents were aware of specific approaches and 19 per cent were vaguely aware.

\section{Community perceptions \\ of community solidarity}

The majority of householders (73 per cent) described their communities as united:

By the grace of God, Kalakan is united.

(Male householder

in Kalakan Centre, Kabul)

However, this has to be seen in the light of the fact that 50 per cent said they all belonged to the same kinship group and were therefore naturally united. If there were any disagreements they were clearly unlikely to discuss them with strangers. In a mixed community in Kabul, opinions were divided. Men associated with the council of elders declared the community united, while poor women denied any unity:

No there is no unity. If they receive anything they keep it for themselves, not for poor families to address their problems.

(Woman householder in Kalakan Centre, Kabul)

Other women spoke only of social solidarity. Six men in an ethnically homogeneous community in Nangarhar nevertheless saw their community as deeply divided, politically and socially.
FINDINGSAND RECOMMENDATIONS 
The elections divided us into small pieces. The elders say they unify us but they do not. Too many people think they are in charge. (Householders in Bahsawal, Nangarhar)

Seventeen per cent of the respondents said that their community was not united and a further 10 per cent said nothing on the subject. In contrast, CDC members were almost unanimous in describing their communities as united or more united as a direct result of setting up the CDC. In only one case did a respondent say that they were already united because they were one kin.

\section{Community perceptions of Government}

Only 13 per cent of respondents had any detailed knowledge of government plans (in several cases because they owned a radio). A further 17 per cent of respondents (including one woman) had vague ideas about government policies. A large majority (69 per cent) either said they had no knowledge of government plans or thought the government had no plans for the country. Thus, while the level of knowledge of government plans and policies is similar to that in the CDC communities, the perception of government is clearly different. In the CDCs, the majority believe that the government has plans for reconstruction, while in the matched communities most respondents had no belief in government:

The government has no plan for us. Throughout our history the government has never helped us. (Male householder in Bahsawal, Nagarhar)

Government is not interested in our affairs, the seniors are good people,

but all juniorsare corrupt in the present government. (Male householder in Mangal Abad, Kundoz)

Not surprisingly, 26 per cent of the respondents in matched communities thought that the government had an interest in their communities. Fifty-two per cent thought the government had little or no interest and a further 19 per cent (including 2 women) either gave no reply or said they did not know if the government is interested. In contrast, 77 per cent of respondents in CDC communities believe that the government cares.

\section{Community awareness of the NSP}

Thirty-five per cent of the respondents had heard of the NSP and understood its basic purpose. All of the respondents thought the community would welcome the NSP and many were keen to be included in the Programme:

Yes, we would be happy to have CDC/NSP in our community to improve like Shakardara, Estalef and the others. (Woman householder in Kalakan Centre, Kabul)

Twenty-eight per cent had heard of it but said they did not really know what it is for or had misunderstood its purpose. In some cases this lack of knowledge was perhaps more a case of not wanting to know. Eight members of this group (all men) were doubtful that a CDC would be welcomed in their community because they foresaw a conflict of interest with the existing community leadership:

It would be difficult to convince the malik and elders...if there was a CDC with ever ything transparent (they) would lose their lucrative positions.

(Male householder in Mangal Abad, Kundoz)

Thirty-nine per cent had not heard of the NSP. After it was explained to them, 6 households in Balkh and two women in Kabul said they would certainly welcome it.

\section{Prospects and Plans for the Future}

When asked what would most improve their lives, like their counterparts in the CDC communities, the respondents in matched communities identified mainly material inputs and their priorities were also broadly similar: clean drinking water (54 per cent); irrigation schemes (34 per cent); social infrastructure such as schools and clinics (32 per cent); employment and support for livelihoods - notably mentioned by half the women ( 28 per cent); and roads ( 8 per cent). Two communities of recent returnees, however, felt that there was still a need for basic relief assistance to help them rebuild their houses. A much smaller proportion than in the CDC communities (8 per cent), spoke strongly of the need for education, especially for women. 
If our children were educated, they would be able to help us. If I were educated, I would have responded (to the survey) from the top of the mountain.

(Widow in Chaar Sangi, Badghis)

Women's vocational training and literacy.... would help the population which is deprived and unaware of their rights. (Male householder in Mangal Abad, Kundoz)

Only two men spoke in terms of the broader national political and economic context. Significantly, 11 per cent said that getting the NSP into their community would make the most impact.

Yes, I am optimistic.

We are developing as a nation.

I am in my home country now.

I didn't have anything to enjoy in exile.

(Male householder in Yaka Dokan, Herat)

Yes, because I believe in my god and have never been disappointed whatever has happened to me in my life.

(Male householder in Mangal Abad, Kundoz)

\section{If the government focusses on our community we will be optimistic, otherwise no. \\ (Woman householder in Kalkan Centre, Kabul)}

I am optimistic as long as our government continues to work as it has in the last 3 years otherwise things can reverse and Afghanistan will again be a place of war.

(Male householder, Mangal Abad, Kundoz)

Forty-eight per cent of the respondents said they were optimistic about the future. A further 32 per cent (including 5 women) said they were hopeful or conditionally optimistic. The main reason for expressing optimism or cautious hope was the feeling that things were generally improving. Twenty-eight per cent ( 5 women) expressed this view. Another common reason for hope was the belief that at least there would not be a return to war (21 per cent gave this response). A rather higher proportion than in the CDC communities (19 per cent), and all the men were optimistic solely on the basis of their faith. As in the CDCs (17 per cent), some respondents were confident for the future as a result of their assessment of the general process of recovery.
I think we have a bright future

because we have a powerful state now. The NGOs help us and so does the international community. The parliament is being established. We will certainly live a better life after this. (Male householder in Kalakan Centre, Kabul)

I don't see any light.

(Male householder

in Bahsawal, Nangarhar)

The proportion expressing pessimism about the future (15 per cent), though a minority, was twice that in the CDC communities. Personal circumstances were the reason for this view in several cases. Widows in two Balkh households saw their economic prospects as bleak, and one returned refugee in Kundoz had obviously not been ready to return when compulsorily repatriated. The political context was the other reason for pessimism.

Afghanistan's political situation is not stable. I returned because I was forced by the Pakistani authorities to leave.

Those who work in the higher positions are living out of the country and ask

and deceive the poor to return. (Male householder in Mangal Abad, Kundoz)

Altogether, these communities shared some of the optimism created by the end of the war and signs of general recovery with their CDC neighbours, but they were less likely to view the future with confidence. Many fewer were prepared to express optimism for the future based on a positive assessment of their current circumstances (rather than on faith alone or the absence of war) and more were uncompromisingly pessimistic.

In sum, the evidence from the matched non-NSP communities suggests that the NSP bridges a vacuum in community governance in the sense that it provides for greater community participation, public legitimacy, faith in the system of government and confidence in the future. 


\subsection{Conclusions}

In this section summary, general conclusions are drawn regarding: the public acceptance and institutional legitimacy of CDCs; gender inclusion in CDCs; project implementation, monitoring and sustainability; perceived benefits of the NSP, and the relationship between CDCs and FPs and government.

\section{The institutional legitimacy of Community Development Councils}

The CDC have the trust and acceptance of the majority of the community members, in most cases (58 per cent of those questioned), as their sole representatives and means of internal governance.

Nevertheless, although establishing the legitimacy and acceptance of the CDC is a process that begins with the first contacts with the NSP Programme and continues through the election of the council, the definition of community priorities and the implementation of successful projects, it is not the NSP process by itself, or the skill of the facilitators alone that determine the point at which a full leadership role is assumed. The research evidence suggests that it is the interaction between the NSP intervention and very specific local conditions (of geography, development, social, cultural, economic and political realities) that determines the rate of progress towards fully representative governance. Above all it is a process of negotiation between different interest groups in the community. Thus, for example, some CDC achieve legitimacy within their community at an early stage of the process, while others may still share the leadership with traditional authority figures in the final stages of successful project implementation.

In the communities where the CDC have taken over as the primary community decision-making units they are widely accepted as a positive agent for change by all groups, and often incorporate respected traditional leaders. In the communities where the NSP concept has not been fully taken up the tendency is for the CDC to be seen as responsible for the implementation of a community development plan, while traditional leaders (arbab, malik, clan elders) and religious leaders continue to represent the community to government and arbitrate disputes. In some cases this is a negotiated and collaborative arrangement; in others it is conflictual.
The following observations on the character of community governance are central to our considerations on the efficacy of the NSP as a mechanism of institution-building:

elites inevitably tend to dominate the CDCs - traditional leaders remain influential, the new leaders are chosen from the well educated and articulate, men predominate over women.

Nevertheless the NSP process is seen by the public to be reducing the power of warlords and corrupt elites over the communities and establishing a form of governance that they trust to represent their interests.

- all the established CDCs could explain the NSP process with reasonable confidence, and understood the importance of documentation and for transparency and accountability. However, though many were able to maintain excellent records, the extent to which all the communities could undertake such an exercise in the future without an effective FP is highly questionable.

- Participation in decision-making and collective effort for the community is greatly increased by creation of the CDC (participation in discussing community priorities ranged between 50 and 90 per cent in CDC communities, compared to the matched communities where 28 per cent described limited consultation only, and the majority had no participation. Eighty per cent in CDC communities participated in project implementation, but only half that number (all men) did any community work in the matched communities. Nevertheless, whilst at the moment voluntarism is accepted, many CDC members wanted some form of future financial incentive to compensate for the time taken from their main livelihood activities.

$\checkmark$ the recent CDC Jirga in Kabul (August 2005) was cited by many CDC members to be a defining factor that influenced their perception of the NSP. People were encouraged by hearing the Minister and the President talking about the NSP.

\section{Gender Inclusion}

The NSP has undoubtedly strengthened the role of women in governance, with the election of some mixed CDCs and separate CDCs. However, even in the most progres- 
sive areas there is a gap in capacity between men and women, both in terms of personal skills and empowerment. The inclusion of women in the NSP in some of the conservative areas is not as advanced as other areas. For example in the Province of Nangarhar all members of the CDCs are male. Women have formed their own CDCs (as specified by the Manual). However, the women give their votes to their male relatives who vote for the all male members of the CDC on their behalf. The women in the sites visited universally accepted this process. Please consider the following observations:

- Women often do not have a direct say in the process of prioritization and project selection. It appears that their male relatives inform them as the decision is being made, but feedback from women in Balkh, for example, suggests that this process of exclusion is probably causing latent resentment. 50

Women do have their own sets of priorities for gender specific initiatives - health training, micro enterprise and literacy.

The NSP gives one key benefit to women. Until the female-only CDCs were established women were not allowed to mix outside of their household. Now, through the CDC, women can meet to discuss both the NSP and other matters. The femaleonly CDCs have become a forum for discussion on other relevant issues (health, domestic violence, literacy, etc) that women could not discuss before for want of a reason; this is a direct result of NSP.

Nevertheless women are in most cases excluded from direct participation in the general $C D C$, or have only a weak voice within it. The situation in Achin, for example, is even more extreme; women are not even part of the NSP process. For the men of Achin this is simply unacceptable.

\section{Project implementation}

In general the CDCs are satisfied with the commitment and performance of the FP. However, a minority had reservations about some aspects of their technical competence. The vast majority of CDCs provided contributions towards the project, either in cash or in kind. However, in all cases there was excessive optimism regarding what the community could contribute, and in some cases individuals have reneged on their promises and this has caused some division. The delays in disbursement are considered by the CDCs to be the major problem experienced. When the projects are delayed costs rise since the original estimates were undertaken, and momentum is lost.

\section{Project monitoring}

In all the field sites visited there was evidence of a monitoring procedure as defined in the Manual. However, FPs play the main monitoring role. In some locations, the community's monitoring is complemented by whiteboards at the key construction site, showing all literate community members an updated cost, community contribution, instalment number and targets. This reinforces ownership and transparency.

\section{Project sustainability}

CDCs appreciate the need for maintenance and have in a number of locations planned a community levee either in cash or in kind (asher) to pay for one person to oversee the maintenance of the facility. However, FPs and the OC have doubts if this system can be maintained in the long run. The sustainability of diesel generators appears to be particularly problematic as fuel costs have risen substantially since the generators were installed. It is noteworthy that in several $\mathrm{CDCs}$, the project was complete but a 'Project Completion Certificate' was not forthcoming. The $\mathrm{OC}$ definition of completion does not correspond to that of the FPs. This, in the view of some of the FPs, accounts for the slow progress in terms of completion. It is also noteworthy that several communities have developed further initiatives as a result of the NSP project.

\section{The relationship between Community Development Councils and the Government}

The District Administration in most cases has practically no capacity to work with the NSP. In addition the research from the CDCs, comments from the $O C$ and FPs, confirm that the District Administration focusses more on security than 'development'. In some cases the findings suggest that the District Administration is unwilling to work with the $\mathrm{CDC}$, preferring to
50 Note that in Paktia, women were originally consulted by FP (CARE) but that is about as far as inclusion went.

FIN DIN GSAN D RECOMMENDATIONS 
continue to work through the traditional elites. This has led to disillusionment within the CDCs that their potential authority is already being undermined by a traditional system that in some cases they believe to be corrupt.

The relationship between CDCs and the provincial government is better, with fairly regular contact, especially when certificates are presented and projects inaugurated. The perception that the NSP is a government programme is reinforced with NSP/MRRD signs at key construction sites throughout the communities.

There is significant evidence from our fieldwork that there has never been greater contact between those communities with CDCs and the provincial government. This is true of even very remote communities that previously had virtually no contact.

\section{The relationship between the Community Development Councils and the Facilitating Partners}

In general the CDC thought they had good working relationships with their FP. They found the FP staff committed, cooperative and honest. All the NSP communities visited deemed the training provided by FPs to be relevant and useful. However, in some cases, they were also aware that the FP lacked technical capacity or gave insufficient time to training and capacity-building.

FPs are under pressure to complete projects; this inevitably means that there is some degree of fast tracking in the process of creating the $C D C$, which is often at the expense of ensuring that effective and sustainable institution-building takes place, despite the fact that many FPs have the necessary community development expertise.

For example, even many of the CDCs whose members are literate find the forms (procurement, accounting, and sub-project completion forms) too complicated, and are content to rely on FPs to ensure their completion, in some cases just signing already completed forms. In districts where the vast majority of all CDC are illiterate, there is little option but for FPs to complete all the forms. This inevitably means that CDCs are not equipped to face a future without FPs.

\section{The benefits of the National Solidarity Programme}

The key benefits that the NSP brings to rural communities have been identified in discussions with them as:

- the formation of the CDC as a fully representative council has brought unity and collective purpose to previously divided and dispersed communities;

$\checkmark$ the CDC provides them with a voice to government;

$\checkmark$ NSP has enabled the establishment of community priorities and the development of a Community Development Plan;

- The collective implementation of projects has developed community skills, improved living conditions and built community self-esteem.

The joint implementation of projects has given rural communities with NSPs a huge boost of collective confidence and esteem. Such communities are more optimistic about the future than those communities where there is no NSP. Without exception all the communities we have visited so far knew that the NSP is a government programme. The communities also understand the connection between community empowerment, collaborative decisionmaking and enhancement of rural infrastructure, improved livelihoods and a greater feeling of local and national unity. Simply put, rural people believe that for the first time in decades the government is listening and responding to community needs. The following additional benefits can also be identified:

- The NSP process has introduced new skills to the community, which certainly need to be consolidated, but nonetheless contribute to community confidence building, especially when it comes to approaching other donors for assistance and using the CDC as a problem-solving forum.

The intrinsic projects in the sites visited were generally well designed and constructed appropriately. In particular, those projects which bring multiple benefits are especially noteworthy, such as the culvert/road, protection wall/intake, boring well projects, and tended to benefit the most number of people regardless of economic status or participation in the CDC process. 
- The NSP facilitates other communityled initiatives that could not otherwise have been undertaken. Additional infrastructure is often added to the NSP project which enhances the value of the NSP, demonstrates community ownership and initiative, and to an extent augurs well for the sustainability of the project in the future.

There is also some evidence of neighbouring CDCs combining available resources in order to be able to facilitate a bigger project (such as a through road).

- The link between NSP projects and poverty reduction at a community level varies from one community to another. For example, some of the NSP sites visited were associated with several discernible poverty reduction benefits which included the ability to: grow more produce, especially cash crops such as sugar and cotton, and sell the surplus; adopt year round cultivation; and generate more income which is spent within the community.

- The communities also benefit from cheaper goods because of improved transport; a reduction in transport costs; greater levels of protection against natural disasters; better levels of communication; and higher levels of education.

Direct benefits can also be perceived in relation to poppy eradication objectives at the local level through alternative livelihood NSPs. However, it is recognized that the effects in this regard are fairly limited and poppy cultivation is still deemed to be lucrative.

In summary then, the NSP must be viewed as a long-term process; the NSP is a radical programme in the context of Afghanistan and it is unrealistic to expect lasting change within a short time frame. For example, female participation is highly problematic in the Eastern Region, and Nangarhar in particular. The east is a very conservative area and FPs and the OC acknowledge that an increase in female participation will only occur gradually, a point certainly borne out by this research. Nonetheless, NSP communities have far more tools than non-NSP communities for envisaging problems, linking priorities and planning. NSP com- munities are therefore less reactive and more proactive, and have a significantly more favourable opinion of the government. This is underpinned by optimism for the future that non-NSP communities do not share. The non-NSP communities have a strong distrust for government and little faith in its ability to address their problems. Indeed, there are many misplaced perceptions about the government and Afghanistan in general, because there has not been any formal contact with governmental organizations to clarify the facts. As one villager put it in a non-NSP community, 'the government has done nothing for us'.

\subsection{Recommendations for Community Development Councils}

We suggest a broad range of recommendations for CDCs aimed at improving project delivery through simplification of bureaucratic processes, and enhancing genderbalanced institution-building and capacity development at the local level through processes of consolidation.

\section{Simplification}

\section{Recommendation 32}

The Disbursement system is too onerous and should be made in one instalment. 51

Recommendation 33
While the fund transfer mechanism system
has improved through the delegation of
approval to the Provincial OC, and by
reducing the number of instalments, we
still believe that much could still be done to
speed up the approval process and dis-
bursement process through, for example: a
less bureaucratic CDC and project formu-
lation processes; allowing villagers to
establish a bank account where the money
might be deposited, rather than having to
bring the money to the village and, not
least, by giving the villagers a fixed date
when the funding will be available.

51 This recommendation has been adopted post-publication of the PRDU's Inception Report, N ovember 2005. 
Consolidation

\section{Recommendation 34}

A greater focus should be placed on effective social mobilization, capacity development and institution-building. This is especially relevant in CDCs where the vast majority of people are illiterate. Again, a failure to adopt a more realistic perspective will mean that the FPs will continue to be 'Implementing Partners', placing the longterm sustainability of CDCs at risk. A twin track process of consolidation and expansion should be devised. A Phase 2 Consolidation Strand should be aimed at CDCs who have successfully completed subprojects. An action zone approach should be deployed where appropriate within this strand whereby CDCs sharing common CDP goals should be encouraged to engage in joint programming to meet community priorities and achieve economies of scale. The Phase 2 Expansion Strand should focus on the strategic roll-out of the NSP to ensure nation-wide coverage of the NSP, but with a bias towards integrating vulnerable communities.

\section{Recommendation 35}

In order to ensure the long-term survival of CDCs, the NSP process needs to be incentivized. We recommend the use of 'top-up' grants and 'matching funds' to reward CDC initiatives on NSP priority areas such as gender based and alternative livelihood programming.

\section{Recommendation 36}

Where appropriate, certain projects should have a component which should specifically benefit the poorest of the poor and encourage pro-poor growth. In the future there will need to be more emphasis on poverty reduction initiatives that focus on livelihoods rather than physical infrastructure. Our research findings suggest that there is a desire to consolidate community gains made through the NSP with related initiatives for employment, income generation and further skills training. However, there needs to be a careful balance between institution-building objectives and the establishment of programmes that have a genuine impact on pro-poor growth. Indeed, in the medium term pro-poor growth programmes should only be rolled out on a strategic basis in areas where CDCs have become socially embedded and are capable of acting benevolently.

\section{Recommendation 37}

Continued support should be given to women-only CDCs. The gradualist approach to more significant women participation within the NSP process should also continue, and where possible womenonly priorities should be addressed as a priority. A separate NSP fund for projects targeting women and children should be created and bids encouraged, but this needs to be accompanied by the strengthening of women's capacities within the CDC. These findings support the view that separate women's groups with separate project budgets are necessary in the shortterm to develop women's capacity. At the same time this should not be used as a mechanism for institutionalizing their exclusion from decision-making in the general CDC.

\section{Recommendation 38}

There is significant concern about the longterm sustainability of CDCs once NSP projects have been completed. It is therefore recommended that CDCs should assume a broader range of responsibilities with community development planning and programming to provide them with an ongoing role in community governance. This should be introduced through a phasing process linked to the attainment of certain levels of capacity. The new responsibilities could include: resolving internal community disputes (e.g. land, water rights); bargaining with traders; sharing lending risk; bargaining for better share cropping arrangements; bargaining between CDCs and developing district plans and projects, thus achieving economies of scale; and the registration of births, marriages and deaths. A more ambitious and longer term task, which is nonetheless worthy of consideration, is to use CDCs to collect local taxes on the basis that they would retain the large part of the levy for community development activities, while transferring the remaining part to government. 


\section{Lesson-learning \\ and capacity development}

See above recommendations 22 and 23

\section{Recommendation 39}

In relation to engineering projects there is a need for a formalized system of appointment for 'site managers' by CDCs. Focussed training is required for those appointed. CDCs should provide overall project direction but a separate project management team should be appointed. CDC members should remain unpaid (to show commitment to the community) but the project management team should be paid allowances.

\section{Recommendation $\mathbf{4 0}$}

The recent CDC jirga was very well received by rural communities and helped to convince the cynics that the NSP was a positive step forward. Regional and national CDC jirgas should be arranged on a regular basis to reinforce the government's position, consolidate the perceptions of existing CDC members and demonstrate the government's support for newly created CDCs.

\section{Recommendation 41}

CDC members have benefited from 'exposure visits' to other local CDCs. In the spirit of a national programmeadvocating solidarity, provision should be made for regional or national 'exposure visits' to enable lessons to be learned and relationships to be formed - both of which would directly contribute to state building.

\section{Recommendation $\mathbf{4 2}$}

At the community level, training in clerical skills is good (to the literate), but training in artisan trades is patchy and inadequate (to the illiterate). Skills a cquired should be rendered portable by issuance of commonly-recognized certificates for management, clerical and artisan skills. 


\title{
Findings and Recommendations
}

\author{
An Analysis of
}

National Solidarity Programme

Engineering Projects

52 Figures obtained from ISAF indicate that wide variations in each province exist in the application of N SP between rural and urban villages, from $98 / 02$ to $35 / 65$ percentage splits.
This section evaluates the quality of NSP engineering projects. It is organised into six parts: analytical methodology; project relevance; project quality and sustainability; project management; intangible benefits; and key recommendations.

\subsection{Methodology}

Sets of data have been extracted from all the reports submitted by the Regional Assessment Teams (RATs) during the first survey period in late October/early November 2005. Additionally, the Engineering Consultant made personal visits to 4 villages in Kabul Province and 3 villages in Paktia Province in order to be able to calibrate and finalize questionnaires to be used by RATs, and subsequently to be able to cross-reference their collated data.

In selecting the areas to be surveyed, an attempt has been made to use a representative sample of provinces, districts and villages (the term 'village' applies to rural and urban villages). 52 However, it is only a sample and it is to be expected that in the country as a whole there will be wide variances in the practical application of NSP as far as engineering is concerned. Additionally, because of the high number of variables in each location, much of the analysis is inevitably qualitative by nature.

\subsection{Project relevance}

In theory, the projects prioritized from those identified by each community will be representative of the majority views of every adult member of the community. In general, most of the projects lay in the infrastructure sector; this was especially true in provinces where women traditionally have little or no voice. However, in some of the poorest communities microeconomic projects were chosen as they were seen to be of more immediate and direct value.

Perhaps not surprisingly, power generation projects predominated for villages without any system of distributed electricity, and irrigation/water supply projects where there were severe water deficiencies. Some excellent examples of 'clean' power (in the form of micro-hydropower) were under construction or had been completed. These contrasted with diesel-generated power schemes that were utilized where gravity water feeds were not available - with all the disadvantages of requiring regular fuel supply and ongoing heavy maintenance, as well as being environmentally unfriendly. Road/bridge construction or improvement projects were common where a village's ability to tap satisfactorily into area markets was being hampered.

There can be particular limitations in generating electricity locally and harnessing water locally. For the former, it can be difficult to generate enough power to support significant local business activity. For the latter, local reservoirs are likely to freeze up in winter.

Project cost was clearly a defining factor in limiting choice or scope. In a few cases, villages came up with imaginative ways of achieving synergetic benefits when combining potential resources with neigh- 
bouring villages. The $O C$ quoted school, road and micro-hydropower projects where two or three neighbouring CDCs had successfully managed cooperative projects from which the communities shared inputs and outputs. These ventures perhaps indicate a natural propensity to find economies of scale, at least in cases where the alternative is failure. In the cases of highways and electricity provision, this is moving into the grey area of network establishment and how that is best managed. Here, it can still just be done from the bottom-up, but there comes a time when some kind of area or regional overwatch becomes necessary. It is also an interesting example of local governance extending upwards rather than being imposed downwards - the former arguably being more sustainable.

\subsection{Project quality and sustainability}

NSP carries an obligation for stakeholders to consider most aspects that make projects sustainable. However, much is implied through various procedures outlined in the Operational Manual rather than spelt out definitively. The only indicator listed is the requirement for an operations and maintenance plan. The need for project quality is, by definition, essential for sustainability; this includes adequate/appropriate specification, design and construction. The Technical Manual provides adequate guidelines for specification and design. However, just as important is the level of emphasis given to process as compared to physical outcome. What was very noticeable from the received data was that process had been given a high priority as far as CDC empowerment and enablement was concerned, but in terms of local management of projects there was little guidance. This had an effect on project quality and sustainability, and satisfactory durability therefore relied almost entirely on the diligence or otherwise of CDCs. The more intangible benefits of good process at project level were also underemphasized by NSP. All of this is discussed more extensively in following sections of this report.

Mitigation/defensive measures against natural disasters were sometimes specified only where there was a history of such events. If they were not specified, then they surely would not be designed into the structure. In the case of earthquakes, much of Afghanistan could be said to be at significant risk. In terms of floods and landslides, a more local appraisal would be necessary in every case - in general, preference was to reject potentially unsafe sites rather than mitigate at additional cost.

Standards of project design and construction varied to extremes, although most were appropriate and adequate. At one end of the scale one could cite the impressive microhydropower project at the village of Salakhail, Skakardar District (Kabul Province) where relevance, specification, design, construction and sustainability were all covered very well, resulting in an excellent project all-round. At the other end of the scale one could mention the school at Markaz-e-Dawlatabad, Dawlatabad District (Balkh Province) where relevance was inadequate, specification and design were suboptimal (in terms of school size and earthquake mitigation) and construction standards were sometimes poor.

There appear to be satisfactory processes for checking engineering designs, particularly for infrastructure where failure could lead to human casualties. Particular emphasis needs to be given to ensure that for structures, adequate provision is made for extreme snow and wind loads. However, there was no clear chain to ensure that the design (as checked) was that which was actually implemented. Although difficult to firmly correlate, it did seem that there were instances where adequate designs were compromised by poor construction indeed, there was at least one case where it appeared that steel reinforcement in a retaining wall had been omitted to save money.

Generally, there was a good understanding of the need for an operations and maintenance plan; however, there were mixed responses on how this should be done - not always was someone nominated and trained for responsibility, and rarely was there a contingency or succession plan in case of incapacity or unavailability of anyone nominated. Ongoing costs were a big factor (especially for projects that would perpetually rely on an imported fuel supply) and whereas most CDCs had simple physical/financial plans, their biggest concern was whether the community savings box would remain adequately filled in the longer-term.
FIN DINGSAND

RECOMMENDATIONS 


\subsection{Project management}

In general, management and decisionmaking has been focussed, quite sensibly, at $C D C$ level with accountability to the village population. CDCs are responsible for organizing and executing all projects for which they receive funding through NSP. Training in management and clerical skills has been provided as necessary to CDC members. This has enabled the CDCs to be more effective in some areas of project management. However, little training appears to have been provided in site management. At many of the sites visited, there was no obvious person-in-charge; indeed, the CDCs would either rotate people to take nominal charge or even manage by consensus. Where there was a site manager or foreman, he was usually selected because of some distant experience in construction, either locally or in Iran/Pakistan, but he rarely had any formal training or qualification - in some cases he would also be a CDC member, in other cases he would not.

For a project to come to a successful conclusion, there are three areas of significant administration (in the Operational Manual these are only loosely described, with no specific reference to site management):

- Project selection and subsequent direction - empowerment

- Project management - enablement

Site management - enablement

At present, CDCs attempt to cope with all three, but somewhat haphazardly and with varying degrees of success.

There was also very little evidence of training in artisan skills (such as carpentry, masonry, plumbing and electrical skills). In some cases, unskilled labourers were learning on the job from a small corps of skilled workers, and then successfully taking their newly-acquired skills further afield. However, although there can be considerable merit in learning on the job, when it is not accompanied by formal training the following shortcomings can arise:

- Good and bad practice is passed on, but rarely best practice alone;

$\checkmark$ Little possibility of basic new technology being introduced in a sustainable way;

$\checkmark$ Unfavoured can get left behind;

- Skill standards are not established,

EN GIN EERIN G PRO JECTS

SECTION 5: tested and monitored; and

- No formal recognition of skills acquired and therefore skills can be less portable.
The majority of village projects were undertaken using local direct labour (rather than by contract). This provides an excellent opportunity for simple structured training at artisan level and would provide an essential ingredient of community enablement, a key component of NSP.

\subsection{Intangible benefits}

There is always a danger with infrastructure projects that the degree of success is assessed solely by the utility of the physical output. The great strengths of NSP lie in its attention to process, but the benefits from this are often intangible and difficult to measure.

In prioritizing projects, it was not always apparent that communities had identified and measured the wider benefits (or disbenefits) as well as the more obvious focussed ones. Some of the questions that might be asked at the project selection stage include:

$\checkmark$ Does the project have some benefit to everyone in the community, directly or indirectly?

$\checkmark$ Does the project enhance the microeconomy of the community?

- Does the project provide a means by which the capacities of the community can be enlarged?

$\checkmark$ Does the project improve the opportunities for trading with other communities?

There are points within these questions that are crucial to the continuance and sustainability of the NSP philosophy within every village. For as communities grow in respect of self-governance and economy, so the need to have structures to support these must continue. NSP has facilitated the formation of these structures, but the communities will need the means to accelerate their economic growth through further development programmes. These will rely on the availability of an increasing pool of skilled labour. Failure to address this will not only jeopardise many of the successful features of NSP, but ironically it will also widen the gap between the literate and illiterate, as the former will gain new skills and the latter will not.

A view might be taken that many people with newly acquired skills will locate further 
afield as they search for higher wages, and will thus denude their home communities of the very skills that are needed. With portable skills this will happen, but the effect will be to encourage trade between communities and there should be a net benefit for the country as a whole.

One of the key intangible benefits of NSP is that the concepts within it are relatively simple and easily understood by most members of every community (although the bureaucracy that goes with it sometimes may be overprescribed, as discussed elsewhere in the report). All governance, economic and engineering parameters discussed above will benefit if it is kept that way. Parallel programmes should be minimized, and for this to happen ministries, IOs, NGOs and other agencies that work in these fields at community level should be encouraged to add volume to NSP, rather than add complexity through different implementation methodologies.

\subsection{Key recommendations for the enhancement of NSP engineering projects}

Recommendation $\mathbf{4 3}$
The need for mitigation measures against
natural hazards (particularly earth-
quakes, landslides and floods) should be
given a higher profile. General require-
ments for all projects (whether by
avoidance or mitigation of risk) should be
highlighted at the specification stage, and
all infrastructure projects should be vetted
for adequate compliance by an appropri-
ately qualified engineer.

\section{Recommendation 44}

A Block Grant fund needs to be made available to the NSP to mitigate the affects of disasters and terrorist attacks that damage/destroy NSP initiatives. The availability of such a fund would be extremely useful in building social solidarity in times of crisis. A proposal should be made to NSP donors to set up a Disaster Mitigation Fund for these purposes.

\section{Recommendation $\mathbf{4 5}$}

A more tangible link should be established between those who design projects and those who construct them. There should be a mandatory requirement for an engineer from the designer's organization to visit projects under construction at appropriate times, to ensure that respective designs are being followed and that no shortcuts are being taken in respect of materials and standards that might compromise the integrity of the structures concerned. Auditable records of these inspections should be maintained. It is recognized that there appears to be a shortage of suitably qualified engineers in Afghanistan - unsurprising given the scale of reconstruction and development. Therefore, those projects where non-adherence to design requirements could lead to catastrophic failure should receive the highest priorities for inspections.

\section{Recommendation 46}

CDCs should be encouraged to identify clearly who is responsible for:

- Project selection and subsequent direction (normally the whole $\mathrm{CDC}$ );

Project management (normally a bespoke trained team within the $\mathrm{CDC}$ );

- Site management (normally an adequately trained individual (plus reserve) who is probably not in the $C D C$ ).

\section{Recommendation 47}

CDC members should not receive remuneration for their activities. However, CDC members or local residents working in project management or site management should be rewarded - so if they are also CDC members, it should be noted that it is for their enablement roles, not their empowerment roles, for which they are being compensated. 


\section{Recommendation 48}

A major initiative should be established to encourage the introduction of formal training in all the key construction skills, underpinned by the award of appropriate qualifications. The training should be village-based with instructors visiting at regular intervals. Formal instruction need not be very long (and could be conducted for groups of villages in collective sessions) but should be substantial enough to allow for follow-up on-the-job training. For each skill set, a required standard should be defined and a method of testing the standard required should be established. Initially, this standard should be applied nationally by MRRD and its agencies to all those working within NSP. In time, this should be integrated into agreed national construction training and testing standards. An important element of the initiative in order to promote portability of acquired skills would be the award (and registration) of appropriate certificates (suitably designed to militate against fraudulent use). A similar initiative is needed for training and qualifying site managers, though in this case a longer period of formal instruction will be required (say two weeks), and there would be considerable reliance on the individual's past experience when being formally assessed for the appropriate qualification. 


$$
\text { or }
$$




\section{Findings and Recommendations}

\section{National Solidarity Programme}

\section{Financial 0 perations}

Building the capacity of national level staff is the first priority... we should play a role in the disbursement process to help build capacity in the disbursement process and to develop an institutional memory.

(MRRD staff member)

Corruption is not a significant problem in the NSP but where it rears its ugly head it does so because the CDC is not functioning properly and local warlords are abusing the process.

(NSP FP stakeholder)

There are bottlenecks in the disbursement, procurement and various approval processes which have a very damaging impact on the ability of the OC to meet its targets; they could all be removed if there was the political will.

(NSP donor stakeholder)
This brief evaluation of NSP financial processes is organized into three parts. It begins by outlining the financial process that underpins programme development; it then identifies the main obstacles that have confronted the delivery of efficient and effective financial management focussing on issues of disbursement, procurement, liquidity and limited evidence of corruption. The section concludes with a short set of recommendations.

\subsection{Financial processes}

As Table 2 illustrates, the disbursement process for the NSP - the period encompassing the stages of programme development, from the selection of a community to the receipt of the fund transfer - is

Table 2. The disbursement process in the context of programme development

\begin{tabular}{|l|l|}
\hline Stage in programme development & Milestone \\
\hline FP contracting & Contract signed, FP staff mobilized, community selected \\
\hline Community Mobilization & CDC elected, CDC registered, bank account opened \\
\hline Planning & CDP completed, sub-projects identified \\
\hline Design & Proposal of first sub-project and instalment request \\
\hline Approval & $\begin{array}{l}\text { Submission of proposal by FP, approval by OC PO } \\
\text { Forward to Kabul HQ, data entry of forms }\end{array}$ \\
\hline Disbursement & Fund instalment received by the CDC \\
\hline Implementation & Completion of two sub-projects on average \\
\hline Evaluation & Post-implementation evaluation, certificate of completion \\
\hline \multicolumn{2}{|c|}{ Analysis of Experiences and Lessons Learned in Program Implementation, 2003-6, Kabul, p.31. } \\
\hline
\end{tabular}


organized into various stages, from the inception of community mobilization to sub-project implementation.

As Table 2 illustrates, if we track the process of programme development from the 'bottom-up' we begin with the contracting of a FP, and the selection and then election of a CDC. The CDC is responsible for overseeing the preparation of the CDP, and the preparation and implementation of individual sub-projects. The CDC is normally comprised of a chairperson, a treasurer and a secretary. It is the responsibility of the $\mathrm{CDC}$ to obtain community endorsement through community forums regarding:

$\checkmark$ decisions on rehabilitation or development priorities, and the final selection of project proposals developed on the basis of agreed priorities;

$\checkmark$ the size and composition of community contributions, and use of project funds;

$\checkmark$ transparency arrangements; and

$\checkmark$ the arrangements for the maintenance of completed projects.

The Operational Manual provides a detailed description of the key aspects of the disbursement process from the perspective of rural communities:

The CDC signs an overall Tripartite Agreement (Disbursement Form 8) with NSP and the Facilitating Partner on behalf of the community. Depending on the number of sub-projects to be managed, smaller Community Project Management Committees may be established to prepare and manage individual sub-projects, but they will report to the Community Development Council and the community-wide meetings. On the other hand, if a community chooses to implement only one or two sub-projects, the Development Council may manage implementation of those projects. These representative

Development Councils must be registered with NSP as a condition for receiving assistance and over seeing the management of communally owned property (Disbursement Form 5). A Community Project Management Committee (which can be identical with the Development Council and should comprise at least a chairperson, secretary, treasurer, and storekeeper) nominated by a community-wide assembly will be able to withdraw funds and procure goods and services for implementation of the project after being registered with the NSP (Disbursement Form 4).
The CDC is therefore responsible for:

$\checkmark$ overseeing preparation of the community development plan;

$\checkmark$ convening community-wide meetings;

$\checkmark$ overseeing planning and preparation of individual sub-projects through the community project management committees;

- mobilizing community contributions;

$\checkmark$ ensuring community participation during all phases;

$\checkmark$ presenting the sub-project plans at appraisal; and

$\checkmark$ managing and supervising sub-project implementation.

Its key role in financial matters focusses on overseeing (or directly handling) procurement and financial management at the community level; and reporting to the community and to the NSP on project progress and the use of funds.

CDCs submit sub-project proposals via the FP for approval by the OC PO. Once this has been negotiated the forms are forwarded to the $\mathrm{OC}$ in Kabul for data entry, and a request for the disbursement of funds is made to the NSP MRRD's office for Block Grant disbursement. However, it should be noted that this is purely for reporting reasons. The MRRD is not directly involved in decisionmaking regarding the disbursement process, or indeed in the auditing of the disbursement process. The paperwork is then forwarded to the Ministry of Finance which has access to a World Bank spatial bank account. The grant is then released via $\mathrm{Da}$ Afghanistan Bank (DAB) and deposited into a CDC bank account held at the provincial level. Each community with an elected CDC and a completed CDP is entitled to receive a Block Grant of up to US $\$ 200$ per family, with a ceiling of US $\$ 60,000$ per community. The average Block Grant disbursed per community is US $\$ 30,000$.

\subsection{0 bstacles to effective operational delivery}

Four main obstacles to effective and efficient NSP financial management have been identified in our survey: disbursement, procurement, liquidity and limited evidence of corruption.

As we noted in Section 2.2, the NSP-OC failure to meet its roll-out targets for December 2004 to August 2006 was partly
FIN DIN GSAN D RECOMMENDATIONS 
$1_{\text {For example, } 40 \text { generators }}$ requested by FPs in 0 ctober 2004 were not delivered until December 2005, and 20 four-wheel drive vehicles were requested in January 2005 by the PO OC but were not ready for use until June 2005.

2 N SP/OC (2006), Analysis of Experiences and Lessons Learned in Program Implementation, 2003-6, Kabul.

SECTION 6: FIN AN CIAL O PERATIONS attributable to prolonged delays that occurred in: the procurement process for securing critical goods (the responsibility of the MRRD); ${ }^{1}$ in the disbursement process due to the absence of Block Grant funds (the responsibility of the WB); and in the inefficient transfer of funds from $D A B$ to CDC bank accounts. A further bottle-neck emerged in December 2005 due to the lack of liquidity in the Block Grant fund. Block Grant disbursements started to slow down in December 2005, reaching a complete halt in February 2006. The absence of Block Grant funds for disbursement further undermined the ability of the $\mathrm{OC}$ to meet its roll-out targets. It is also noteworthy that payments to FPs are also seriously behind schedule - 93 per cent of invoices received from FPs for services rendered in the second half of 2005 are yet to be reimbursed (the responsibility of the MRRD).

It is evident from our survey that there has been very little 'political' help forthcoming from the MRRD or the donor community to help the NSP/OC deal with these high level bottle-necks in the disbursement and other financial processes. It is therefore unsurprising that targets have not been met. However, the OC has been able to develop a Memorandum of Understanding (MoU) from $D A B$ to transfer grants to the provinces within two weeks. The situation needs to be carefully monitored and contingency plans for alternative disbursement mechanisms put into place. While it is important to build the capacity of DAB to play a disbursement role, efficient disbursement processes are axiomatic to the operational delivery of the NSP. As we noted in Section 5, improvements have also been made with regard to the introduction of a streamlined disbursement process to deal with the problems emanating from the initial policy of requiring three instalments per sub-project.

Our surveys picked up on very few instances of corruption committed by members of CDCs. Indeed, the evidence from our research is that where you have effective CDCs corruption does not occur:

Corruption is greater where traditional shuras play a more significant role. (NSP FP stakeholder)

Indeed, the NSP provides an outstanding opportunity to learn about how and why corruption takes place, and what mechanisms lead to or prevent corruption. As Section 5 illustrates, corruption can be minimized through trust management, capacity-building and social audit. There is evidence, however, that the capacity of CDCs to provide effective reporting to the community and to the NSP on project progress and the use of funds could be improved.

\subsection{Key recommendations for financial operations}

\section{Recommendation 49}

In accordance with the recommendations outlined by the $O \mathrm{C}^{2}$ - improvement needs to be made to operating processes at the national level in relation to the processing of FP contracts, the replenishment of Block Grant funds and the payment of invoices. This would be best managed through one office under the a uspices of the NSP.

\section{Recommendation $\mathbf{5 0}$}

A further capacity devel opment deficit can be identified in relation to the manage ment of NSP finances. A strategic plan needs to be devised by the MRRD in order for its finance team to assume the role of the $\mathrm{OC}$ in the disbursement process. This must involve a significant capacity development dimension. MRRD staff will need to play a greater role in NSP auditing, disbursement and other financial processes by the end of the Programme.

\section{Recommendation 51}

Further training needs to be provided to CDCs on auditing, transparency and financial reporting processes.

\section{Recommendation $\mathbf{5 2}$}

The NSP provides an outstanding opportunity to learn about how and why corruption takes place and what mechanisms lead to or prevent corruption. Research should be supported by the World Bank in this area. 


$$
\text { or }
$$




\section{Findings and Recommendations}

\section{Programme}

\section{Enhancement}

3 The PRDU can provide further details on this proposal if required.

4 This is a detailed exposition of Recommendation 10.
This section focusses on providing greater elaboration on our key recommendations for programme enhancement in the second phase of the NSP. Further details are provided with regard to: the proposed new institutional venue for the NSP; the potential role of CDCs in future governance in Afghanistan; the putative role of the NSP in poverty reduction; the nature of measuring the performance of the NSP; the character of government capacity development required in NSP Phase 2; strategic issues with regard to the management of cultural change during the transformation of administrative systems; and gender issues for NSP Phase 2. It must be noted, however, that the purpose of this section is to signal possible ways forward and not to provide highly detailed prescriptions. ${ }^{3}$ Effective lesson-drawing requires decision-makers to engage in a rational search for ideas and this would involve a much more rigorous process of policy-oriented learning.

\subsection{A new institutional venue for the National Solidarity Programme}

There is currently significant debate within the MRRD and the NSP/OC over the most suitable institutional venue for the delivery of the NSP in Phase 2 once the MRRD has taken over the management of the Programme. Three options have been debated: full integration; re-tender for a new OC; or create a 'not for profit' semiautonomous organization as a special project under the Ministry. The third option is being proposed by the MRRD as it provides the Ministry with the ability to secure the services of high quality, experi- enced staff in the field of rural community development who demand high salaries, while simultaneously developing the capacity of national staff. However, we believe that these aspirations can be met through a fourth option; the creation of an executive agency for the operational delivery of the NSP.

We recommend the creation of an executive agency, a model of service delivery currently deployed in most OECD member states and pioneered in the UK context in the late 1980s. ${ }^{4}$ The key features of an executive agency fit with the MRRD's institutional and human resource needs:

1. An executive agency is semi-detached from its parent department (MRRD), with its own budget, freedom from some aspects of departmental regulation (particularly in relation to recruitment), with the organization under the direction of a chief executive and other unit managers often recruited through open competition.

2. Executive agencies are accountable for the performance of specific operational tasks as a corporate unit, including output-focussed performance targets set by the parent department (in this case the MRRD), and the personal accountability of the chief executive for meeting performance targets.

3. Executive agencies are established through a Framework Document issued by the minister of the parent department (MRRD). Although the Framework Document is an official document, it is not a law. Hence 
agencies are not legally distinct from the departments that supervise them and, of course, all of the employees are public servants even though the managerial élan is often recruited from outside the public sector.

The advantages of deploying an executive agency model of service delivery for the NSP are at least 6-fold:

Firstly, the arms-length quasi nongovernmental character of this form of organization will allow the MRRD to retain expert staff from within the NSP$O C$, as it would have the flexibility to pay internationally competitive salaries.

Secondly, the executive agency would remain accountable for the performance of specific operational tasks as a corporate unit, including outputfocussed performance targets set by the parent department, the MRRD.

- Thirdly, the chief executive would remain personally accountable to the Minister of the MRRD for meeting performance targets.

Fourthly, through retaining expert and highly skilled staff, the executive agency would play a key role in helping to devise and deliver MRRD capacity development.

Fifthly, an executive agency model is more appropriate in the context of a 'whole government' approach as it allows the agency greater freedom of movement to develop strategic partnerships with indicative ministries and development programmes.

Finally, the NSP executive agency would provide an institutional archive for institutional memory on best practices in community based and community-driven development, and take as one of its fundamental roles the diffusion of best practice to other Afghan public organizations.

It should be noted, however, that this proposal is geared towards meeting the particular needs of the MRRD for a form of organization that will allow it to retain specialist staff on internationally competitive salaries to deliver the NSP. This is not to say that executive agencies are not without their problems - lines of accountability can become blurred, and separating policy from administration can lead to the emergence of implementation gaps.

For a more detailed elaboration of the executive agency model see James (2003), James (2001), Ibbs (1988), OECD (1998), OECD (2002), and Peters (1997).

For a contextual analysis of new public management see: Barzealy (2000), Hogwood and McVicar (2000), Hood (1991), Hood (1995), Hood (2000), Kettl (2000) and Kettl (2002).

For new approaches to public management, see: Moore (1995), Rhodes (2000), and Stoker (2005)

\subsection{Community Development Councils and future governance in Afghanistan}

CDCs can only be sustained if they are given 'statutory' responsibilities. (NSP donor stakeholder)

We want to see the NSP move mainly to the governance side... CDCs are a vehicle for local governance... people have very high expectations and we need to see the creation of sustainable structures. (NSP donor stakeholder)

With the exception of three ministries, all the ministries included in this survey have recognized the potential of CDCs as delivery/consultative mechanisms for development programming. A majority of ministries were also in favour of CDCs becoming a formal part of the system of governance (i.e. afforded constitutional status as the lowest tier of elected government); others felt it important that CDCs remained independent from government in order to maintain the trust of local people. All the ministries consulted argued for greater coherence across the system of local governance, and the need to establish clear constitutional relationships and operating protocols between districts and CDCs. PRTs also appeared keen to use NSP-type processes. International experience of post-war reconstruction tells us that this can work, but only as long as it does not result in producing parallel programmes instruments of development must remain relatively simple at the community level,
FIN DIN GSAN D

RECOMMEN D ATIO NS 
i.e. there is no need for more than one delivery system (the NSP). Programme volume can be increa sed, but not complexity.

We also received a range of reports from different ministries about the existence of several competing forms of institutions of community governance at the village level. These included: parents-teachers' associations, teachers' associations, farmers associations, women's committees, maliks, imam etc. Our fieldwork suggests that with the exception of the malik and imam in certain villages, such organizations are largely mythical. However, where they do exist they need to be integrated more effectively into the system of local governance.

Table 3 provides a rudimentary sketch of the domain of governance in the Islamic Republic of Afghanistan which proposes a constitutional role with statutory responsibilities for CDCs at the village level, ${ }^{5}$ and the extension of the public administrative system from the district to the CDC level through the establishment of an elite of Community Development Support Officers (CDSOs). The role of the CDSO will be to provide technical support to the CDC in all of its core competences. The establishment of this technocratic elite, with attractive conditions of service, is central to the long-term sustainability of CDCs and should be a key component of the NSP's consolidation strategy. This proposal will also require a long-term capacity development strategy which should be integrated with broader processes of civil service reform.

We are not in a position at this juncture, nor is it part of our mandate, to suggest future directions for the Afghan judicial system, but a role for CDCs in legal affairs would appear sensible and wholly legitimate.

It is therefore recommended that:

\section{Recommendation 53}

CDCs be institutionalized into the system of governance.

\section{Recommendation $\mathbf{5 4}$}

CDC By-laws are extended to include cyclical elections.

\section{Recommendation $\mathbf{5 5}$}

CDCs are given statutory powers in relation to community development planning and programming in core programme areas (education, health, water, energy, sanitation and basic infrastructure).
5 See Recommendation 31.
Table 3. Governance in the Islamic Republic of Afghanistan

\begin{tabular}{|c|c|c|c|}
\hline Level of Governance & Administrative System & Representative System & Judiciary \\
\hline National & $\begin{array}{l}\text { Presidential Core } \\
\text { Executive territory }\end{array}$ & $\begin{array}{l}\text { Two-chamber } \\
\text { National Assembly - } \\
\text { House of Elders } \\
\text { (M eshrano Jirga) and } \\
\text { House of the People } \\
\text { (Wolesi Jirga) }\end{array}$ & $\begin{array}{l}\text { Supreme Court plus } \\
\text { High Court system }\end{array}$ \\
\hline Provincial & $\begin{array}{l}\text { Governor's O ffice } \\
\text { plus M inistry } \\
\text { departments }\end{array}$ & $\begin{array}{l}\text { Elected Provincial } \\
\text { Council }\end{array}$ & $\begin{array}{l}\text { High Court system } \\
\text { barely functioning }\end{array}$ \\
\hline District & District Administration & Elected District Councils & No formal system \\
\hline Village & $\begin{array}{l}\text { malik, } \\
\text { Community } \\
\text { Development Support } \\
\text { Officer }\end{array}$ & $\begin{array}{l}\text { Community } \\
\text { Development Councils }\end{array}$ & No formal system \\
\hline
\end{tabular}




\section{Recommendation $\mathbf{5 6}$}

Federated structures are created at the district level in order for communities to interface with government agencies and development programmes.

\section{Recommendation $\mathbf{5 7}$}

Community Development Officers are recruited and trained to support and promote human capital development activities in rural development.

\subsection{The role of the National Solidarity Programme in poverty reduction}

Poverty reduction is central to the reconstruction of rural communities and the establishment of national solidarity in Afghanistan. The instability that the country has suffered over the last three decades has led to increased rates of poverty which in turn represents a continuing threat to the long-term stability of the infant nation state. 6 Without improvements in people's livelihoods that address their economic, social and physical well being, national solidarity, peace and security will not occur.

Containing and reversing poverty must involve reconstruction that tackles root causes, not merely the symptoms of war. It is also not appropriate to think in terms of merely restoring the pre-war economy, as the original source of conflict is often aggravated by the pre-war economic conditions. Simple economic recovery does not inevitably lead to poverty reduction.

If a return to violence is to be avoided, postwar poverty reduction must be seen as a development process directed at preventing the onset of new processes of impoverishment. Fundamental changes are often required which not only reflect the multidimensional nature of poverty but address the structural causes of poverty. These approaches include linking poverty reduction with: sustainable economic growth, good governance and community empowerment. The NSP has directly impacted on such approaches.

Table 4 demonstrates that the NSP has a number of direct and indirect affects on community poverty, depending on the type of project involved. Whilst it is unrealistic to quantitatively define the microeconomic impact of the NSP, this research has shown that the crucial microeconomic relationship between income earning opportunities and households interacting to determine relative prices of goods and factors of production benefits from the NSP. Projects such as road construction, culverts, intakes and irrigation have a direct positive impact on the ability of farmers to grow and sell more produce. Moreover, savings from such ventures are then reinvested back into the community, usually through improvements to houses and family welfare. More produce is available locally and transport costs for goods and services reduced. For example, in Sholana in Chaparhar District, Nangahar farmers could only grow $50 \mathrm{~kg}$ of wheat annually, but after the NSP protective wall and intake was constructed farmers are now able to grow $450 \mathrm{~kg}$ of wheat. Due to these economies of scale, farmers can now afford to hire a truck to transport and sell the wheat in Jalalabad. In Kahoo and Chinnar Kali in Laghman, the new road created by the NSP has caused the cost of transport to decrease substantially. Prior to the project local people had to hire a donkey to carry produce to and from Kahoo to Chinnar Kali at a cost of Afs 400 per journey. Since the road was built the same amount of produce can be taken in a car for only Afs 80 . Indeed, the cost of all produce has dramatically reduced due to the decrease in transport costs, and people are able to transport and sell more produce accordingly. These types of interventions have undoubtedly contributed to an increase in the productive capacity of the community.

It is also important that the indirect affects of the NSP on poverty within the community are considered. The projects help people to travel further, broaden their horizons, and gain a better understanding of life outside their community. Most significantly, the increased level of interaction increases solidarity. In the vast majority of the rural communities that we visited respondents cited that not only has the NSP improved people's lives physically through the intrinsic project, but the empowerment of the community has led to greater communal solidarity. The social confidence that is derived from stability is the key to poverty reduction; so as long as a period of CDC consolidation is initiated then the NSP promises much.

Although the impact of the NSP has been
6 UNDP, Human Development Report for Afghanistan, 2005.

FIN DIN GSAN D RECOMMEN D ATIONS 
Table 4. The impact of the NSP on community poverty

\begin{tabular}{|c|c|c|c|}
\hline Project Intervention & Direct Impact on Poverty & Indirect Impact on Poverty & Negative Impact $*$ \\
\hline $\begin{array}{l}\text { Culvert/ } \\
\text { irrigation system }\end{array}$ & $\begin{array}{l}\text { Increased number of crops can } \\
\text { be grown and sold in local and } \\
\text { regional markets; } \\
\text { It is more economically viable to } \\
\text { sell produce in regional towns; } \\
\text { Economies of scale; } \\
\text { Growing season is longer; } \\
\text { Price of produce can decrease. }\end{array}$ & $\begin{array}{l}\text { Modest effect on poppy growing } \\
\text { as other forms of growing are } \\
\text { seen to be viable; } \\
\text { Increased savings from trading is } \\
\text { invested back in the community } \\
\text { usually through housing } \\
\text { improvements and children's } \\
\text { education. }\end{array}$ & $\begin{array}{l}\text { Arguments can occur } \\
\text { over water rights. }\end{array}$ \\
\hline $\begin{array}{l}\text { Road improvement/ } \\
\text { construction }\end{array}$ & $\begin{array}{l}\text { Communities benefit from } \\
\text { cheaper goods and services } \\
\text { coming into the village; } \\
\text { Transport of people, goods and } \\
\text { services are cheaper; } \\
\text { New markets are created for } \\
\text { traders; } \\
\text { Properties and/or land by the } \\
\text { road increases in value. }\end{array}$ & $\begin{array}{l}\text { As accessibility improves people } \\
\text { can travel further; } \\
\text { People can get to hospital } \\
\text { quicker; } \\
\text { Savings from cheaper transport } \\
\text { are invested in other areas; } \\
\text { Greater cohesion and solidarity } \\
\text { between hitherto isolated } \\
\text { communities. }\end{array}$ & $\begin{array}{l}\text { Arguments can occur over } \\
\text { where exactly the road } \\
\text { should run. }\end{array}$ \\
\hline MHP & $\begin{array}{l}\text { The productive capacity } \\
\text { of some light industries } \\
\text { are increased (e.g. milling). }\end{array}$ & $\begin{array}{l}\text { People get a greater appreciation } \\
\text { of life outside their communities } \\
\text { through television/radio; } \\
\text { Accidents involving unstable } \\
\text { kerosene lamps decrease; } \\
\text { Many communities made a } \\
\text { direct link between better } \\
\text { lighting and enhanced literacy } \\
\text { levels. }\end{array}$ & $\begin{array}{l}\text { Arguments can occur over which } \\
\text { households benefit from the } \\
\text { MHP; } \\
\text { Household payment for the } \\
\text { MHP is sometimes problematic, } \\
\text { resulting in ill feeling; } \\
\text { It is not yet practically clear how } \\
\text { the facility will be sustained. }\end{array}$ \\
\hline $\begin{array}{l}\text { Boreholes/ } \\
\text { Wells }\end{array}$ & $\begin{array}{l}\text { People do not have to spend so } \\
\text { much time travelling to the far } \\
\text { away wells, their time is used } \\
\text { more productively; } \\
\text { As illnesses decrease savings are } \\
\text { made as medicines do not need } \\
\text { to be purchased as often. }\end{array}$ & $\begin{array}{l}\text { There are fewer conflicts over } \\
\text { accessing boreholes in other } \\
\text { villages. }\end{array}$ & $\begin{array}{l}\text { It is still unclear how the facility } \\
\text { will be maintained. }\end{array}$ \\
\hline Protective wall & $\begin{array}{l}\text { More land (hitherto subject to } \\
\text { regular flooding) is available for } \\
\text { production; } \\
\text { Culverts and intakes are often } \\
\text { added to the protection walls } \\
\text { (see above). }\end{array}$ & $\begin{array}{l}\text { There is more confidence and } \\
\text { optimism in the prospect of a } \\
\text { decent harvest. }\end{array}$ & $\begin{array}{l}\text { It is still unclear how the facility } \\
\text { will be maintained. }\end{array}$ \\
\hline Diesel generators & $\begin{array}{l}\text { The productive capacity } \\
\text { of some light industries } \\
\text { are increased (e.g. milling). }\end{array}$ & $\begin{array}{l}\text { People get a greater appreciation } \\
\text { of life outside their communities } \\
\text { through television/radio; } \\
\text { Accidents involving unstable } \\
\text { kerosene lamps decrease. }\end{array}$ & $\begin{array}{l}\text { The difference between the } \\
\text { estimated cost of fuel and the } \\
\text { current cost has on occasions } \\
\text { rendered the diesel generator } \\
\text { impotent. }\end{array}$ \\
\hline
\end{tabular}


overwhelmingly positive, it has had some negative effects on rural communities in relation to relatively few instances of intracommunity conflict. These have mainly involved petty arguments over the location of the project and payments for the maintenance of the project. At times these disagreements have undermined the stability in the community so vital to longer term development. In many cases it is unclear how the facility will be practically maintained. The research found limited evidence of the community paying for the facility to be maintained either in cash or in kind; this could cause problems in the future and undermine the long-term benefits of the project.

Our field research found that projects such as protective walls/intakes, and roads/ culverts benefited the most number of people regardless of status or the degree of participation in the NSP process. Such projects had the most significant impact on the general level of community poverty. A villager in Nangarhar illustrated this observation to us most cogently, '[W]e who are poor have always lived without electricity, it makes little difference to us, yet protection against the elements helps us greatly'.

Finally, the field research also enabled us to clarify the perception of rural communities that the most important benefit of the NSP was improved community governance, which was consolidated through the project, and which in turn was making a positive contribution to local and national unity and stability.

\section{Recommendation $\mathbf{5 8}$}

We therefore recommend that where appropriate certain projects should have a component which should specifically benefit the poorest of the poor and encourage pro-poor growth. In the future, due to donor mandates, it is likely that more emphasis will need to be placed on poverty reduction initiatives that focus on livelihoods rather than physical infrastructure. Our research findings suggest that there is a desire to consolidate community gains made through the NSP, with related initiatives for employment, income generation and further skills training.

\subsection{Measuring the performance of the National Solidarity Programme}

The research has shown that one of the main problems that the NSP is experiencing is the lack of accurate base-line data on the NSP process which undermines the subsequent ability to plan and meet targets. In addition, a number of implementation gaps have been identified by FPs and other stakeholders which impact on the FPs' capacity to deliver:

- Delays in the disbursement of Block Grants. If there are three instalments, the average time is 9 months (three months for each instalment). There is now only one instalment, with just a three month delay. This means that there has to be some form of check and balance, so that if the community do one project well they will get money to do more.

$\checkmark$ The operation and maintenance of infrastructure. In many CDCs there is not the capacity to operate and maintain the project, especially MHPs.

- FP payment. FPs should be paid on the basis of performance, especially in terms of building institutional capacity of the $C D C$, not on the basis of the number of CDPs or CDCs created. FPs manage by indicator and not by objectives; a completed project is not a complete CDC!

- Relationship building. There is a lack of trust within communities and between NSP stakeholders. How do we build that trust? We should admit our weaknesses.

On the basis of the need for more accurate data collection, accurate identification of areas requiring more attention, the need for realistic targets and these implementation gaps, a number of key performance indicators (KPIs) can be devised which would be of benefit to the Ocs, and FPs in particular.

\section{Criteria for designing performance indicators}

The following criteria serve as guidelines for the construction of effective NSP performance indicators.

1. Indicators should measure changes in specifically those social and economic conditions that the NSP is attempting
FIN DIN GSAN D RECO MMEN D ATIO NS 
to improve - bearing in mind that according to the MRRD, NSP projects should be as 'community-led' as possible.

2. The measurement of progress in any endeavour must relate closely to the aims agreed upon.

3. It follow from items 1 and 2 that the process of selecting indicators should be a participatory one in which all NSP stakeholders and a representative sample of $C D C$ representatives should be involved.

4. All indicators selected must be simple, knowable by all (i.e. all NSP stakeholders and $\mathrm{CDCs}$ ), and easy to monitor.

5. They should be precisely specified and capable of accurate measurement in quantitative or qualitative terms.

6. Data relating to them must be available, or capable of being produced, for all NSP communities regardless of whether a 'standard' data collection community or not.

7. Movement up and down the value of any indicator should have an unambiguous positive or negative meaning in relation to the NSP's intentions.

8. The movement should, so far as possible, reflect changes brought about by the activities initiated under the NSP programme rather than changes stemming from other policy interventions or from non-policy related factors.

9. The information produced on some indicators may have a 'downside risk' in the sense that it may feed negative perceptions and prejudices and must therefore be carefully managed.

7 P. Ambrose (2005)

'U rban Regeneration,' in D. Taylor and S. Balloch (eds.), The Politics of Evaluation, Bristol, the Policy Press, p.49.

8 These measures have been themes throughout the research.

SECTION 6: PRO GRAMME EN HAN CEMEN T
10.Given the range of objectives that the NSP is attempting to achieve, in the selection process there should be a clear understanding of the difference between 'structure', 'process' and 'outcome' indicators, and of the usefulness of certain proxy indicators in some circumstances.

'Structure' (S) indicators refer to formal, written or legal structures. 'Process' (P) indicators refer to working practices and norms. 'Outcome' (O) indicators measure the outcomes of the NSP.

It is important to keep S, P and $\mathrm{O}$ indicators separate, because it may well be that although the NSP Operating Manual - the rules (S) - specifies the importance of gender inclusion, the 'process' (P) may not implement the rules very well, nor may the 'outcome' (O) reflect their apparent intention. As Peter Ambrose puts it:

The three types of indicator can be understood by analogy with making a pudding. The $\mathrm{S}$ is the recipe, the $P$ is the making of the pudding and the $\mathrm{O}$ is the eating.

Proverbially, the proof of the matter lies in the 0, not in the other two. 7

However, in the case of the NSP, $P$ is also vitally important because it is the NSP operational delivery stakeholders and CDC members who carry out the process of delivery in communities, exchange ideas, trust or distrust each other, form and destroy friendships and store grievances. In short, policy is often made and remade in the process of implementation.

\section{What needs to be measured?}

We would suggest that there are 6 separable qualities associated with the NSP that require time series measurement: community empowerment; community governance; community capacity; economic development; community solidarity; and national solidarity. ${ }^{8}$

Given the six qualities of the NSP that we are trying to measure, indicators may be required in at least 18 categories:

CE (S) Community empowerment (structure)

CE (P) Community empowerment (process)

CE (O) Community empowerment (outcomes according to NSP stakeholders and beneficiaries)

CG (S) Community governance (structure)

CG (P) Community governance (process)

CG (O) Community governance (outcomes according to NSP stakeholders and beneficiaries)

CC (S) Community capacity (structure)

CC (P) Community capacity (process)

CC (O) Community capacity (outcomes according to NSP stakeholders and beneficiaries) 
ED (S) Economic development (structure)

ED (P) Economic development (process)

ED (O) Economic development (outcomes according to NSP stakeholders and beneficiaries)

CS (S) Community solidarity (structure)

CS (P) Community solidarity (process)

CS (O) Community solidarity (outcomes according to NSP stakeholders and beneficiaries)

NS (S) National solidarity (structure)

NS (P) National solidarity (process)

NS (0) National solidarity (outcomes according to NSP stakeholders and beneficiaries)

It is likely that the indicators selected to measure these 6 qualities will move in the same direction but this is not inevitable. For example, while a gain in CS should, all things being equal, lead to a gain in NS it is not beyond the boundaries of possibility that the local community could unite in opposition to government. Moreover, a gain in NS may be the product of other actions (e.g. popular national leadership).

The indicators to measure change in these 6 qualities need to be chosen in the light of the criteria outlined above, or a similar approach. By way of illustration, the indicators for measuring change in CG could involve the following:

\section{Community governance - structure}

1. What is formally laid down about the role of CDCs in the Operational Manual? In other words, what do 'the rules' specify?

2. How far is appointment to CDCs made on the basis of open competition, universal suffrage and secret ballot?

3. How free from intimidation and bribery is the process of election itself?

4. To what extent do the votes of all electors carry equal weight and how far is there equal opportunity to stand for office, regardless of which social group a person belongs to?

5. How much consultation took place, and with whom, in defining this set of rules?

\section{Community governance - process}

6. The opinion of NSP operational delivery stakeholders' on the degree to which these formal arrangements for the operation of CDCs work out in practice.
7. The opinion of local residents on the degree to which these formal arrangements for the operation of CDCs work out in practice.

8. Attendance/participation rate of CDC members at meetings, project steering groups, etc.

9. Assessment of the ways in which meeting agendas are drawn up and chaired.

10. Participation rate of non-CDC members in project steering groups, etc.

11. How systematic and open to community scrutiny are CDC decision-making processes?

12. How accessible are CDC members to their electors and how effectively do they represent electors' interests?

13. How systematic and open to community scrutiny are CDC accounts and reporting processes?

14. How publicly accountable are elected CDC members for their private interests and sources of income that are relevant to the performance of their public office?

15. How readily can community members gain access to redress in the event of maladministration or the failure of CDCs to meet their responsibilities; and how effective are the means of redress available?

\section{Community governance - outcomes}

16. The opinion of NSP operational delivery stakeholders on the quality of the work of CDCs in relation to its core responsibilities as defined by the Operational Manual.

17. The opinion of local residents on the quality of the work of CDCs in relation to its core responsibilities as defined by the Operational Manual.

18. What percentage of residents can name their $\mathrm{CDC}$ representatives?

19. What percentage of the community actually votes?

20. How closely does the composition of the CDC and its community development plan reflect the choices made by the community as a whole?

21. The opinion of participating residents on the positive/negative effects for them of being active participants in NSP projects.

22. The analysis of specific key decisions made in a formally participatory context to see the extent to which the voice of community representatives was: a) decisive and b) reflective of the choices made by the community as a whole? $^{9}$
9 See D. Beetham (ed.), (1994), Defining and Measuring Democracy, London, Sage, for an extremely detailed discussion on how to develop indices for measuring the quality of community governance.

FIN DIN GSAN D RECO MMENDATIONS 
The process of arriving at an agreed set of indicators needs to be fully participative, including NSP operational delivery stakeholders and a representative sample of CDC representatives. Thus far the absence of such a process has constituted a fault line in the NSP. Following this there needs to be a more technical consideration of all the indicators selected from the perspective of measurability and the availability of data at the community level. An arithmetic value should be attributed to each indicator, even if it is just a binary 0/1 (for 'absent' or 'present'). This calibration is necessary to ensure that trends can be measured over time as objectively as possible. All of the indicators above can be expressed arithmetically or, in the case of attitudinal indicators, as values on a scale of possible responses. 10 The opinion of NSP operational stakeholders on various delivery issues should be sought through a periodic survey of a structured sample of officers working at various levels of the organizations involved, including different tiers of management and front-line staff. The opinion of CDC members and local residents could be evaluated using the same approach deployed in Section 4 - a community power survey and a household survey. Indeed, the findings in Section 4 could provide the first year of time series data on this issue.

\subsection{Government capacity development in National Solidarity Programme Phase 2}

The NSP urgently requires a capacity development strategy for MRRD staff that has linkages with broader processes of civil service reform in Afghanistan. The focus of the capacity development should be placed on developing high quality managers who are capable of managing significant processes of cultural change, involving:

- The move away from command and control forms of management.

- The need to be more sensitive to external forces and influences.

10 A scale of ' $1-4$ ' is useful because it doesn't allow for a 'mid point' response.

SECTION 6: PRO GRAMME EN HAN CEMEN T
At the same time, the NSP has revealed the key skills which all modern civil servants require in order to discharge their duties effectively:

- Policy analysis and planning

- formulation, implementation, evaluation skills.

Delivery skills.

Risk assessment skills.

- Programme management skills.

- Financial management skills.

- Change management skills.

- Technological management skills.

$\checkmark$ Better business planning from top to bottom.

- Partnering skills and the capacity to manage systems of collaborative governance with international NGOs and donors.

- The development of a service more open to people and ideas, which brings on talent.

In order to meet these challenges a Professional Skills for Government Agenda (PSG) has to be introduced, geared to bridging skills gaps for managers and civil servants at all levels in response to the changing environment. The NSP could kickstart this process by developing its own PSG framework which would require MRRD staff to demonstrate skills and expertise in 4 areas at the appropriate level in relation to their job and chosen career path - policy, operational delivery or corporate services. These skills would be tested at the key career gateways. As Figure 1 illustrates, the four areas would be: people management; financial management; programme and project management; and analysis and use of evidence. In addition, those in or aspiring to management positions would also need to demonstrate skills in strategic thinking, communications and marketing.

This PSG framework would provide common skills training for managers and aspiring managers in policy, operational delivery and corporate services. We argue that the delivery of this common core is crucial for general skills development. As policy is made and remade in the process of implementation, it is of critical importance that managers in all the career families understand each others' roles, organizational environment and challenges.

So, for example, policy-makers need to be attentive to the problems of implementing as well as drafting their initiatives. While a variety of approaches to implementation 


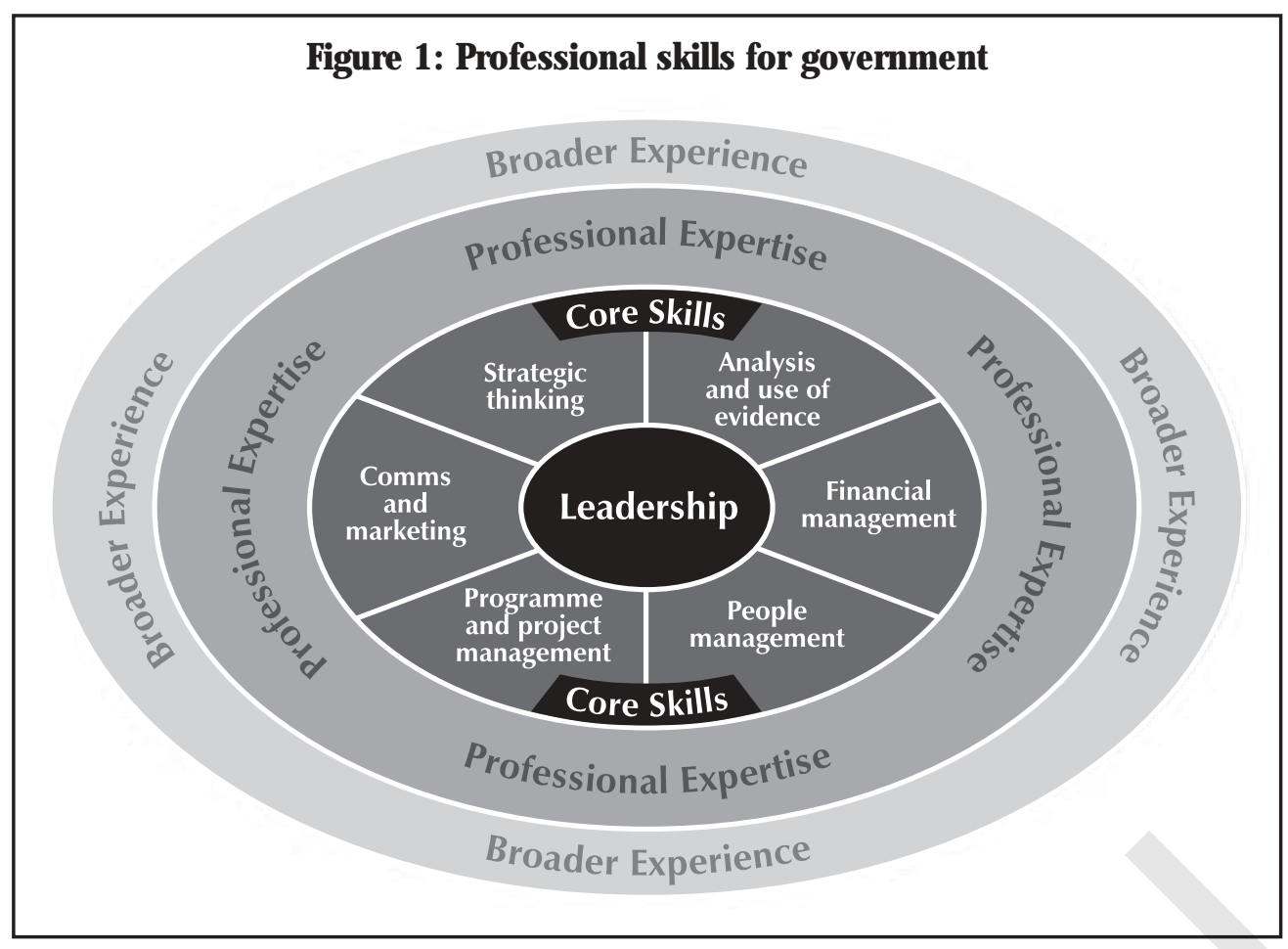

can be used, all contain dangers of significant slippage between the goals and values of the policy-makers who supposedly set policy, and of the managers charged with implementing it. Implementation often involves a broad range of public, private and external actors in the production of public services, and by implication requires negotiation as policy is not always clearly and precisely expressed, and there are often steering difficulties. All of these factors suggest that policies are made and remade in a process of implementation, and that implementation frameworks must be flexible in order to cope with unintended consequences of action. Hence, a broad understanding of the rudiments of policy, operational delivery and corporate services is essential to the development of effective public managers in Afghanistan.

In sum, capacity development in Phase 2 of the NSP needs to contribute to the creation of civil servants who have the skills necessary to manage, deliver and sustain complex programmes such as the NSP, and the initiation of a PSG framework will go some way towards achieving this aim.

\subsection{The management of cultural change in the National Solidarity Programme Phase 2}

One of the central challenges confronting the NSP-OC in NSP Phase 2, as identified in Section 2, is to provide a management of strategy aimed at reculturing the MRRD from a command and control administrative system to a modern administrative system. The aim of this section is to provide an insight into the management of change in Afghan public administration. The section will be organized around a consideration of: the drivers of administrative change and their implications for change management; comparative evidence on why organizational change fails; the ingredients of managing planned organizational change; and the identification of guidelines to 'good learning practice' in change management.

\section{The drivers of administrative change}

Two main sets of pressures impact on Afghan public organizations - domestic pressures and external pressures. The domestic pressures range from: the need for greater responsibility for initiative and leadership at all levels of public administration due to the pervasiveness of performance targets; the need to move from a shorttermist 'relief' organization to a learning 'development' organization; skills shortages within the civil service and limited capacity to act; coping with resistance to reform;
FIN DIN GSAN D RECOMMEN D ATIONS 
getting best value from scarce resources; and managing high workloads, poor working conditions and fear for job security. These internal problems have been exposed by increased external pressure to engage in international understandings of best administrative practices, or what in modern parlance is referred to as 'good governance'. Good governance is commonly exhorted as an essential component of development. However, it is a deeply contested and politicized term, reflecting competing conceptions of the role of the nation state in a globalizing world.

The following meanings of governance associated with different international organizations illustrate how politically nuanced the term is in practice:

'Good governance including effective policies and administration, respect for human rights, the rule of law and participatory development, is widely regarded as important for sustainable and equitable development'.

(The Simons Report)

Hence good governance is linked with both top-down and bottom-up democratization.

'Effective governance means competent management of a country's resources in a manner that is open, accountable, equitable and responsive to people's needs'.

(Aus Aid)

Hence good governance is a problem of efficient, effective and economic management of resources in accordance with national priorities.

'Good governance refers to the complex mechanisms through which citizens and groups articulate their interests, exercise their legal rights and obligations, and mediate their differences'.

(UNDP)

Hence good governance is linked with bottom-up democratization through civil society.

'The manner in which power is exercised in the management of a country's economic and social resources for development'.

(World Bank)
In theory, the World Bank's mandate prevents it from dealing directly with political issues. However, in practice it is wholly political in the sense that it makes a distinction between governance as an analytical framework and as an operational framework leading it to identify three aspects of governance: (1) the form of the political regime; (2) the process by which authority is exercised in the management of the country's economic and social resources for development; (3) the capacity of governments to design, formulate and implement policies and discharge functions. A nation state's credit rating is thus based on these criteria.

Good governance is an ideal which is difficult to achieve in its totality. Very few countries and societies have come close to achieving good governance. Good governance can be seen to have at least 8 major characteristics. It is participatory and thus consensus oriented, accountable, transparent, responsive, effective and efficient, equitable and inclusive, and is underpinned by the rule of law. It assures that corruption is minimized, the views of minorities are taken into account, and that the voices of the most vulnerable in society are articulated in decision-making.

In sum, external pressure to conform to international standards of good governance as predicated by international organizations has created significant challenges for Afghan public administration. This pressure to conform has been compounded by the significant changes which have occurred in public administration on a global scale over the last two decades. These global trends can be organized into three main categories of administrative reform that relate to two main factors: the adoption of certain private sector organizational methods, and the move towards governance and away from government.

Market inspired reforms which have included:

- The creation of internal markets - separating purchasers from providers within the public sector to create quasi-markets;

- Performance Contracts - establishing performance targets for public employees, especially senior executives, rather than relying on traditional hierarchical management;

- Programme review - systematic analysis of costs and benefits of individual programmes; 
- The privatization of state assets, and certain services;

- Co-provision - services delivered in partnership;

Outsourcing of public services to private contractors;

- The creation of 'one-stop-shops' - coordination of programmes through one delivery system to eliminate duplication for regulatory and/or social service programmes; and

- Pay-for-performance - replacement of standard pay scales of civil service system with individualized pay based on performance.

Participatory reforms, which have included: $\checkmark$ The introduction of quality management - applying principles of quality management, e.g. circles, and/or implementation of quality standards;

- The decentralization of delivery systems - moving responsibility for programmes from central government to provincial or local governments; and

- Consumer or citizen rights - statement of the rights of citizens (or consumers) to expect certain quality levels for the services rendered by public organizations.

Deregulatory reforms, which include:

- Personnel deregulation

- open competition in recruitment, performance-related pay, performance targets, elimination of civil service controls over hiring, firing, promotion, etc., and

- Purchasing Deregulation - permitting individual organizations to make decisions about procurement, rather than using centralized purchasing organizations.

In addition, technological innovation is impacting on all aspects of public administration, from service delivery to public participation in decision-making. Much of the reform in this area has focussed on the introduction of new information systems for citizens through E-governance or front-line delivery (e.g. booking driving tests on-line). Attempts to provide cash-till based single delivery systems for the payment of benefits have also been explored but remain politically sensitive in many states.

\section{Implications for change management}

These internal and domestic pressures increasingly inform the operating environ- ment of Afghan public administration and have significant implications for change management. The most serious challenges have been the need: to move away from command and control forms of management; develop negotiating skills to be sensitive to external forces and influences as a condition for aid; to manage a system of governance involving state, non-state and international actors; to be more committed to high performance due to donor accountability processes; to exercise leadership that mobilizes and energizes others; and to anticipate, initiate and respond to change.

\section{Why does organizational change and development programming fail?}

Comparative evidence suggests that organizational change and development programming fails when: managers do not know the fundamental principles of change management; when there is internal resistance to change; when managers resort to 'quick-fix' and 'simple solutions' and do not fully appreciate the significance of the leadership and cultural aspects of change. These problems are normally compounded by a lack of urgency in confronting organizational problems, the absence of committed agents of change, and a vision to direct change or poor communication of the vision and the failure to remove obstacles to the vision. Essentially, poor change management occurs when managers do not appreciate the people issues and make no attempt to develop a strategic approach to human resource development. Matters are often made worse when trainers and developers lack organizational credibility or are given limited political support.

\section{Managing planned organizational change}

These obstacles to organizational change and development programming suggest that an effective strategic approach to human resource development requires:

- Developing a common vision of the future to establish an overarching objective for strategic development;

- Becoming a reflexive, learning organization open to new ideas;

$\checkmark$ Ensuring that others in the organization understand and share the vision through individual and group work (away days, training, establishment of working groups);

- Planning the change strategy through detailed individual and group plans;
FIN DIN GSAN D

RECO MMEN D ATIONS 
- Securing ownership, commitment and involvement through the delegation of authority for aspects of the change strategy and the creation of work incentives;

- Project managing the implementation of the change strategy and sustaining momentum through ongoing processes of support and training; and

- Monitoring, reviewing and consolidating the change strategy to ensure that the change becomes organizationally embedded.

Ten principles of change management In sum then, it is possible from the above discussion to extrapolate 10 principles to inform an effective change management strategy. Good change management involves:

1. developing a shared vision ('bring allies close and enemies closer still');

2. being proactive and innovative - the most effective managers always lead from the front;

3. always having a duty of care for all staff, irrespective of how difficult some individuals may be;

4. playing to the strengths of the team;

5. providing a broad range of incentives to improve performance;

6. providing continuous support and guidance;

7. developing new skills;

8. being firm in the prevention of 'free riding';

9. persuading through argument rather than coercion; and

10. always being honest with staff about the state of the organization and their role in it.

For further reading on change management and principles of organizational change see: Burnes (2004), Carnall (2002), Darwin et al (2002), Dawson (2003), Drucker (1995), Heffron (1989), Hamlin, Keep and Ash (2001), Hood (2000), Isaac-Henry et al (1997), Mintzberg and Quinn (2003) and Senior (2002).

\subsection{Gender issues for Phase 2 of the National Solidarity Programme}

Throughout this report gender relations, the role of women in the NSP and the impact of the NSP on women living in rural communities, have been discussed as an integral part of the mainstream discussion, because it is the view of the evaluators that gender is a mainstream issue that needs to be consciously addressed when evaluating every aspect of the Programme and its implementation.

Progress towards women's participation and empowerment for governance and development is viewed as a key indicator of the success of the NSP in achieving its goals and objectives. While women in Afghan society are uniquely disadvantaged compared to men, as the household surveys reveal they share many of the same basic needs and aspirations. Both men and women in the rural communities, for example, define their needs in terms of the needs of the family. One successful outcome of the Programme in some communities (in Kabul, for example) has been to demonstrate the economic and social advantages that can flow to the family and the community if women are empowered to assume a more active role in decisionmaking and economic activity.

Nevertheless, progress towards women's full participation in the NSP and beyond it in the wider society is necessarily a gradual and negotiated process, and needs to be constantly and consciously promoted, not just by means of programme milestones and objectives, but by the way the Programme is implemented at every level.

A first objective for the enhancement of the Programme in addressing gender inequality should be to improve the recruitment of women to work at all levels of the Programme. The work with women in the communities is restricted in many areas by the lack of female staff. This is obviously due to the same cultural factors that restrict women's participation in general, and many FPs therefore have difficulty recruiting female staff. Even fewer women work in the provincial or district level MRRD or with the $\mathrm{OC}$. It is necessary to tackle this problem strategically through national level programme management rather than leaving it to the initiative of local actors.

Experience in other societies has shown that appointing women to local and national management positions can have a significant influence in galvanizing women's participation at the community level. This works in two ways - by providing a role model for women and by demonstrating to 
men that women can assume responsible roles. While the evaluation team could not research this fully in the Afghan context, it was certainly the view of several informants in Bamyan (the province where women's participation and recruitment as staff was highest) that the appointment of a woman as a provincial governor has had a crucial impact on promoting women's participation in the $C D C$

If the NSP wants to promote women's participation and recruitment at the community level, a key strategy would be to achieve a visible female presence in its provincial and national management.

Another important factor for the recruitment of women to work in the communities is the recognition that special attention (usually involving additional cost) has to be given to ensuring that they have appropriate living and working conditions to ensure their safety and acceptance in the communities where they work. Cultural norms in different areas of the country have so far dictated different measures to ensure this. In some areas, women can only work if accompanied by a male relative. In others women can live and work together in the field in small groups supported by male staff. The Programme needs to consider special measures to ensure that FPs recruit and adequately support more women.

Within the CDC framework, women have not achieved full equality in terms of participation and empowerment. Afghan women identify two factors that are holding them back: their relative lack of education, knowledge and experience outside the home; the lack of effective support in some areas from NSP management and local government.

The first of these problems needs to be tackled through specific capacity development programmes for women. As regards the second, recruitment of women to NSP management may give rural women more confidence to assume a role in the $\mathrm{CDC}$, but their recognition in decision-making and leadership roles in the community needs to be consciously affirmed by all NSP staff, men as well as women. We did identify examples of good practice in both gender capacity development and the promotion of women's responsibilities by some provincial teams, and examples of gender awareness but less effective practice in others. These examples of good practice should be disseminated throughout the Programme.
Given the extent of the gender gap, in terms of capacity as well as empowerment, women themselves and their facilitators see a need at the present time for separate women's shura or groups within the general shura, as well as separate budgets and projects managed by and for women. This would enable the FP and relevant government departments to deliver targeted education and skills training to women, and allow them to acquire project management capacity and leadership skills independently of men before seeking to find a role for themselves in the general CDC.

From a cultural perspective, this represents a less confrontational approach to changing the status of women in rural communities, and affords the opportunity for women to eventually negotiate a genuine role in the $C D C$, with confidence in their own capacity to contribute. However, this tactic runs the risk of becoming institutionalized, reinforcing existing gender cleavages and permanently excluding women from fully participating as elected CDC representatives.

Our household survey reveals that the ability of the majority of community members to participate in the scrutiny of project implementation is limited by both lack of knowledge and basic education. For example, 77 per cent of women householders and 36 per cent of men had no idea how CDC finances were being managed. Others had a general idea, but only 19 per cent, all men, could explain the financial arrangements. This suggests that the long-term consolidation of the CDC as fully democratic institutions will require formal linkages between the NSP and national programmes for adult education, as well as its continuing cooperation with the Ministry of Education in extending the school network.

While arrangements for the institutional inclusion of women in the CDC apparatus have been negotiated in most places, and high levels of awareness of women's rights to participation have been achieved, effective participation in decision-making and project management remains extremely limited due both to a lack of exposure to information as well as basic education. Further progress in women's participation will depend on access to specific programmes of adult education and skills training (for example, through the Ministry of Women's Affairs).
FIN DINGSAND

RECOMMENDATIONS 


\section{Findings and Recommendations}

\section{In Conclusion}

8

- Programme Costs, Expectations and Impact

\subsection{Approach}

There are three common approaches to evaluating programme impact in postconflict environments: the scientific approach, the deductive/inductive approach, and the participatory approach. The scientific approach tends to be used by those wishing to generate quantitative measures of impact, for which there is a strong demand, as such information is more easily analysed, packaged and presented than qualitative information, and is a politically potent resource for those who need to show donors and parliaments that interventions are having an impact. Furthermore, quantitative measures of impact (presenting information on the costs of interventions) are needed to calculate the 'cost-per-unit of impact' (the cost-effectiveness) of an intervention - important for managers having to decide where to allocate scarce resources to ensure maximum impact. However, the key techniques of quantitative analysis demand such enormous data sets that such an approach is normally ruled out in the evaluation of post-war reconstruction programmes except in the most exceptional circumstances. Such an approach was ruled out during the tendering process for this evaluation due to the high costs of developing a statistically significant sample in a country characterized by serious security problems.

Another quantitative method, commonly used in many research fields, involves the creation of control groups, in which beforeand-after comparisons can be made of the same group. Ideally, this requires the collection of base-line data, so that conditions before the intervention can be compared with conditions afterwards. In the case of the NSP such base-line data has not been available. Moreover, where communities have undergone great changes, such as during a war or where populations uproot and flee to another area, there will generally be too much uncertainty to attribute impact to an intervention whether before-and-after data exists or not.

The inductive/deductive approach involves a more anthropological and socio-economic approach to determining impact. The approach relies heavily on qualitative interviews with key informants, participatory observation, and the drawing of lessons from other cases that are similar or comparable. It seeks to provide a narrative interpretation of the links between an intervention and any impacts that occur. It understands that there are often several ways of interpreting impact, and that interpretation requires a balanced approach based on building a preponderance of evidence in support of a particular interpretation.

In practice evaluators use a mixture of approaches, and the method(s) one chooses will also be informed by the nature of the data available and the questions you are posing. We are no exception in this regard. This evaluation of the NSP has drawn on qualitative data derived from: extensive national-level interviews; two workshops held with all NSP stakeholders; a community power survey; a household survey; an engineering analysis; and documentary and institutional analysis. An inclusive approach to evaluating programme costs and benefits is deployed in this final section to provide a final assessment of the overall impact, efficiency and 
effectiveness of the NSP, drawing on the empirical evidence presented in Sections 1-7. It is inclusive in three respects: first, it presents a brief overview of programme costs; secondly, an assessment is made of programme expectations given the significant operating constraints that the programme has confronted; and thirdly, in the absence of reliable base-line socioeconomic data on rural communities, it identifies a range of 'indirect' as well as 'direct' benefits of the NSP. It then proceeds to an overall assessment of the impact, efficiency and effectiveness of the NSP.

\subsection{Programme costs}

This analysis of the programme costs of the NSP is drawn from data provided by the OC. ${ }^{11}$ Figure 2 shows the initial composition of total NSP cost commitments for the second phase of the Programme. This was projected on the basis that it was expected that by this time the NSP would have reached a plateau in its performance levels. Block Grants are calculated at 63 per cent of total costs, and delivery activities at 37 per cent of total costs. Figure 3 reveals the composition of the delivery costs. It identifies the main delivery costs of the NSP as:

$\checkmark$ the cost of FPs (61.1 per cent);

$\checkmark$ OC costs (27.8 per cent); and

$\rightarrow$ MRRD costs in relation to consultancy

( 0.5 per cent) and incremental costs

(2.2 per cent) - i.e. the overhead costs

of the National Coordination Office

responsible for overall management.

The OC has rightly observed that these MRRD costs are core functions of the Ministry and should not be included as NSP programme delivery costs. Nor should: a) the costs of consultancies (3.5 per cent) which relate to external evaluation and support for the management, rather than operational delivery function of the NSP; and $b$ ) the costs of goods which will become MRRD property at the end of the Programme. As the OC observes:

After deducting these cost items the net programme delivery costs make up 34.3 per cent of the total NSP costs including Block Grant disbursements. The ratio of net programme delivery costs to the Block Grant disbursement is 52.2 per cent. The share of the costs of the OC within programme delivery costs is 31.5 per cent; the share of the FPs is 68.5 per cent. 12

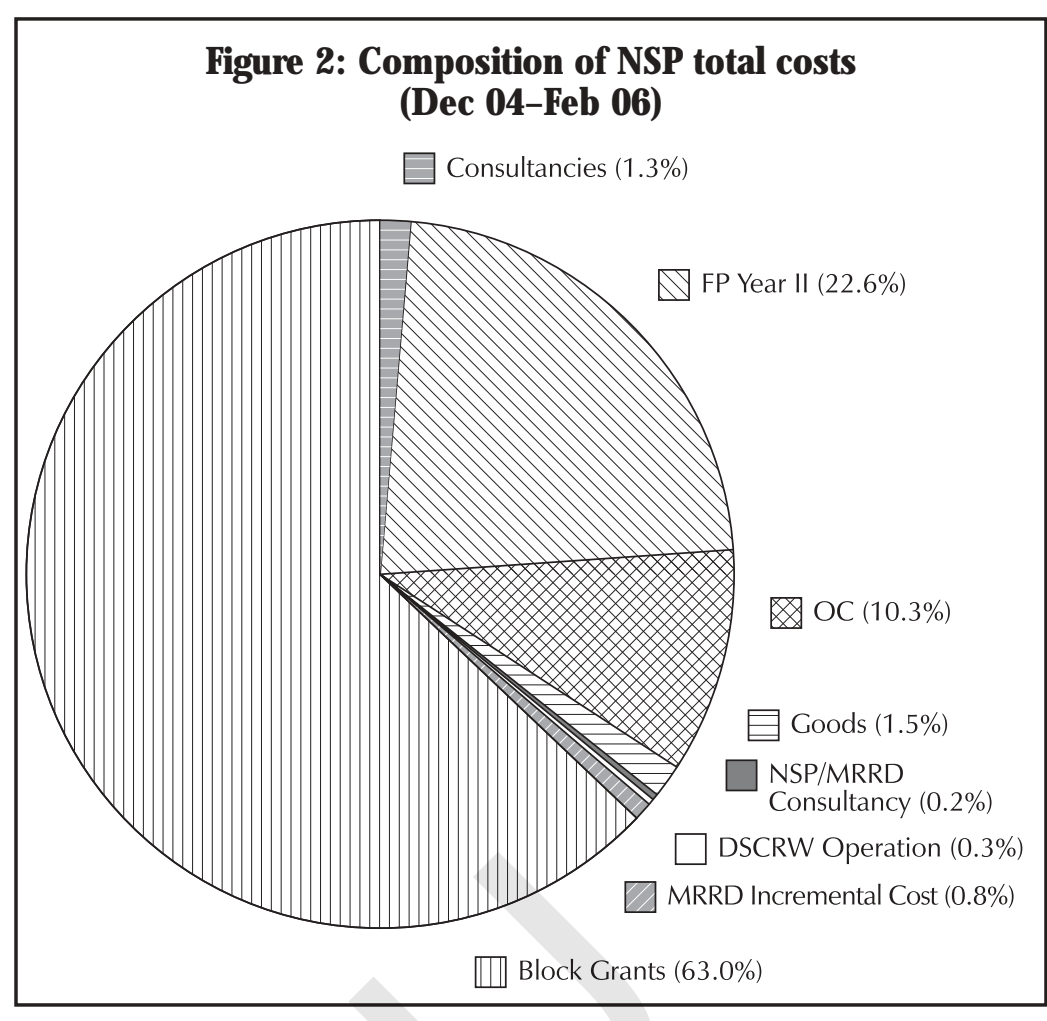

Figure 3: Composition of NSP programme delivery costs (Dec 04-Feb 06)

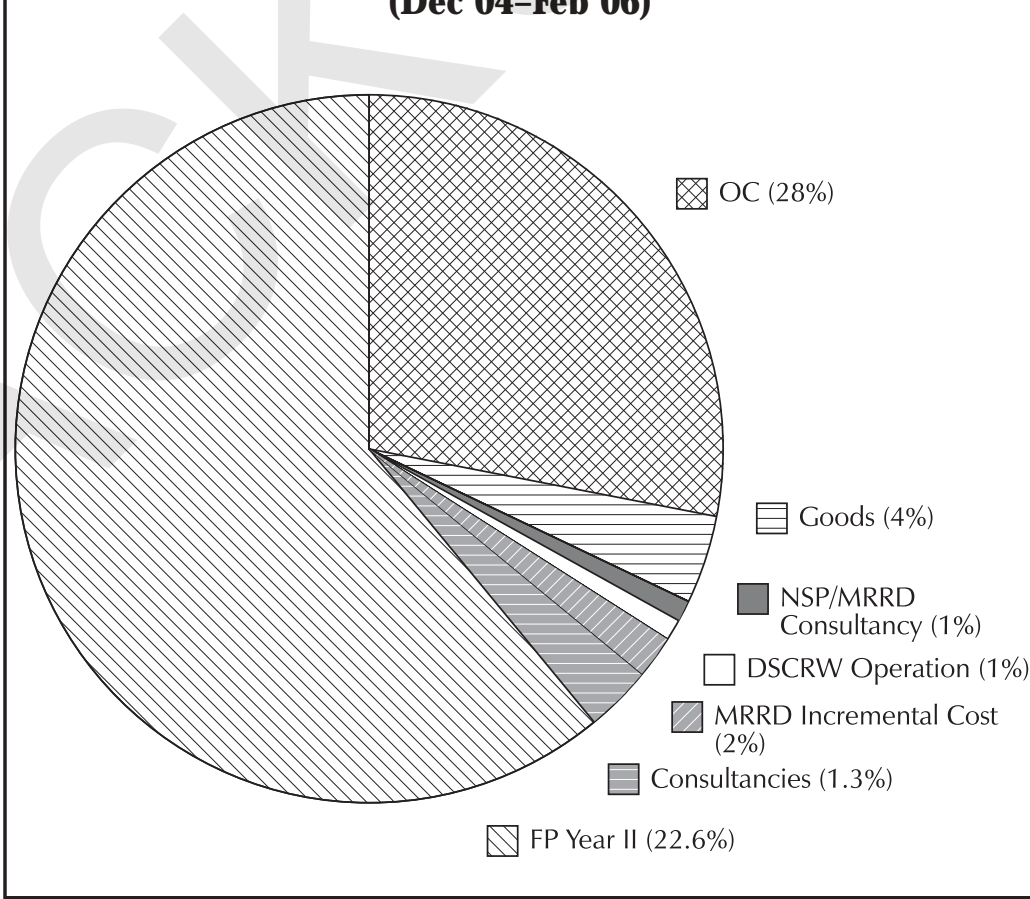

11 See N SP O C (2006),

Analysis of the Experiences and Lessons Learned in Program Implementation, GTZ-IS, Kabul, March 2006, pp. 21-26.

12 Ibid., p. 22. 
We have already identified a broad range of initiatives that could be introduced to achieve efficiency savings in the operational delivery of the NSP; 13 so we proceed here from the assumption that improvements can be made to reduce bottlenecks in the implementation process as long as the $O C$ is provided with sufficient institutional and political support. Hence, the key question that arises in relation to programme costs is: do the outputs justify the high overheads? The following sections seek to address this question.

\subsection{Programme expectations}

Table 5 presents an overview of the obstacles to effective programming identified in the course of this evaluation, and a reference to the recommendations that we have identified for surmounting them. A column is also presented which provides indications on the progress that is being made on these issues since the publication of our Inception Report in November 2005 which drew attention to many of these problems.

Table 5. Programme obstacles

Obstacle Recommendations Progress

Programme Design and Rationale

1. Inconsistent programme objectives

2. Poor population surveys exacerbate the ability to plan

3. Poorly drawn performance indicators

4. Absence of community base-line data

5. Limited monitoring systems

6. Dominance of a 'relief' rather than a 'development' mentality

7. Narrow programme ownership

8. Insufficient lesson-drawing on programme successes and failures
Recs $1 \& 10$

Limited progress

Rec 14

$\operatorname{Rec} 2$

$\operatorname{Rec} 2$

Rec 2

$\operatorname{Rec} 3$

Recs $3 \& 8$

$\operatorname{Rec} 5$
No progress

Significant progress Significant progress Significant progress

Limited progress Limited progress

Limited progress

\section{National level Coordination}

9. Ineffective donor coordination

10. Poor inter-ministerial coordination

11. Poor integration of national level development programming

12. Limited capacity development of central N SP/M RRD staff

13. Absence of exit strategy

14. Absence of logical framework for programme management

15. Limited human resource development

16. Limited strategic thinking regarding the management of change

17. Limited strategic thinking regarding quality assurance issues
Recs $4 \& 7$

Recs $4 \& 7$

$\operatorname{Rec} 9$

Rec 11

Rec 11

$\operatorname{Rec} 11$

Rec 11

Rec 11

Rec 11
Limited progress Limited progress Evidence of progress

Evidence of progress

Evidence of progress Evidence of progress

Evidence of progress Evidence of progress

Significant progress

13 See Recommendations $1-2,6,9-10,10,13-14$ 25-28, 36-38. 
Sub national Coordination and O perational Delivery Issues

18. Limited capacity at the provincial and district level M RRD

19. Variability in the use of the $C D C$ complaints procedure

20. Limited evidence of conflict between CDCs and traditional community organizations

21. Poor inter-ministerial coordination at the provincial and local levels

22. Inadequate governmental operational and human resources at the field level

23. Insufficient programme learning across $P O$ $O C S$ and MRRD

24. Capacity development of DRD s by O Cs not relevant Rec 21 to implementation environment and N SP rationale

25. Nature and style of training demands consistency and effectiveness with the emphasis on technical skills training

26. Skills and capacities of women CDC members are insufficient

27. Insufficient programme learning across FPs

28. The need for trust building between the communities, FPs and the government

29. Implementation delays; ineffectual programme instruments

30. The need for improved partnering relations between the $O C$ and FPs
$\operatorname{Rec} 13$

No evidence of progress

Rec 15

$\operatorname{Rec} 16$

No evidence of progress

Evidence of progress

Rec 17

No evidence of progress

Rec 18

No evidence of progress

Recs 19, $22 \quad$ No evidence of progress No evidence of progress

Recs 20, $22 \quad$ No evidence of progress Limited evidence of progress

No evidence of progress Evidence of progress

$\operatorname{Rec} 26$

Recs 27, 28, 29, 30 Evidence of progress

Rec 31 progress

The Role of Community Development Councils in Project Formulation, Management and Delivery

31. Implementation delays through ineffectual

$\operatorname{Rec} 32$

Significant progress programme instruments; the onerous disbursement system

32. Implementation delays through ineffectual programme instruments; the fund transfer mechanism

33. The long-term sustainability of CDCs

34. The limited capacity of CDCS

35. The limited role and capacity of women in CDCs

$\operatorname{Rec} 33$

Evidence of progress

Recs 34, 35, 36, 38, Evidence of 47, 51, 53-57, 59 progress Recs 34, 35, 36, 39, Evidence of $40,41,42,48 \quad$ progress Rec 37 Evidence of progress

36. O ver-emphasis on infrastructural projects

Recs 6, $36 \& 58 \quad$ No evidence of progress

14 In addition to the building of technical capacity outlined in the previous section. 
NSP Financial Processes

40. Implementation delays through ineffectual programme instruments; FP contracting

$\operatorname{Rec} 49$

No evidence

. Implementation delays through ineffectual programme instruments; maintenance of Block Grant Fund

42. Implementation delays through ineffectual programme instruments; payment of invoices to FPs

43. Limited attempts to build MRRD capacity with Rec 50 regard to NSP financial processes of progress

No evidence of progress No evidence of progress No evidence of progress

As Figure 4 (below) illustrates, these obstacles can be divided into 3 broad sets of variables: 'conceptual', 'operational delivery' and 'environmental'.

The 'conceptual' obstacles to the NSP refer to: the legitimacy of the international actors involved in the intervention; overcoming the entrenched culture of relief that has continued into the post-conflict era; the clash between traditional and modern organizational cultures in the system of collaborative governance which has been created to deliver the Programme; and the absence of a 'whole government' approach to the NSP reflected in a narrow conception of programme ownership. The following quotations indicate the scale of the challenge at this level:

Everybody is focussed on getting through the day and meeting short-term goals.

Thinking about development is impossible as long as this mentality persists (Senior Officer, International NGO, Afghanistan).

Figure 4: Mapping obstacles to NSP success/failure

\section{O bstacles to operational delivery}

1. Inconsistent programme objectives and performance indicators

2. Poor inter-ministerial programme coordination

3. Gaps in strategic thinking in relation to human resource development and programme management and enhancement

4. Limited capacity of MRRD staff

5. Inappropriate programme instruments

6. Limited base-line socio-economic data

7. Limited programme learning

8. CDC sustainability issues

9. Natural hazards

\section{Conceptual obstacles}

1. Legitimacy of external actors

2. Relief mindset

3. Command and control culture

4. Narrow programme ownership

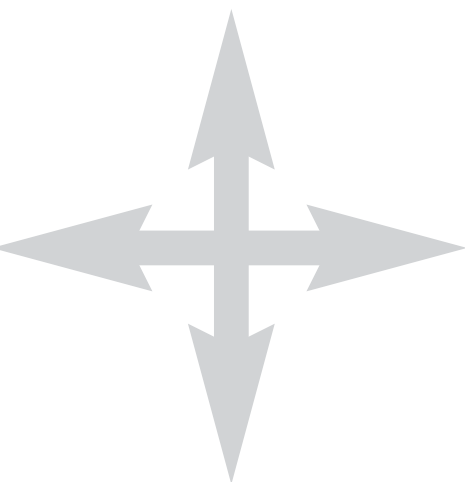

\section{Environmental obstacles}

1. Security

2. Political support

3. Ineffectual donor coordination

4. Weak local state institutions

5. Intra- and inter-community conflict

6. Inequitable growth

7. Unrealistic expectations of changes to cultural norms and values

8. Prevailing social and economic conditions

\section{The National Solidarity Programme}

Programme outputs of implementing agencies
Assimilation of programme outputs with target groups
Actual impact of programme outputs
Perceived impact of programme outputs
Revisions in the NSP $O$ perational Manual 
A psychology of short-termism is

all pervasive. Bureaucrats live from

day to day. There is no sense of collective responsibility.

(Minister,

Islamic Republic of Afghanistan)

Effective reconstruction is about effective partnership building.

Few post-conflict states can go it a lone

in the short- to medium-term. They

are reliant on us for delivering basic

services and mobilizing the resources

they need for reconstruction.

(Senior Officer, International NGO, Afghanistan)

The main obstacles to 'operational delivery' are identified as: inconsistent programme objectives and performance indicators; poor inter-ministerial programme coordination; gaps in strategic thinking in relation to human resource development and programme management and enhancement; the limited capacity of MRRD staff; the use of inappropriate programme instruments which have impacted adversely on the ability of the NSP to meet its targets; limited base-line socio-economic data which has undermined the development of effective monitoring systems and limited programme learning between NSP stakeholders; obstacles relating to the long-term future of $C D C s$; and coping with natural hazards. These problems are dramatized in the following narratives:

I've been a civil servant under the Soviets, the Mujahideen, the Taliban and now under... and I've never been able to do my job properly because we've never had the right organizational structures, resources or power.

(Senior Civil Servant, Islamic Republic of Afghanistan)

After 23 years of war we no longer possess the expertise to do our jobs properly. (Senior Civil Servant, Islamic Republic of Afghanistan)

We spend all our time tackling logistical issues due to the closed nature of the bureaucracy; until the system changes the NSP will never be efficient because there will always be someone somewhere deliberately holding things up. (Senior Civil Servant, Islamic Republic of Afghanistan)
Finally, the environmental obstacles confronting the NSP encompass: continued problems with security; the lack of political support due to petty jealousies between ministries; ineffectual donor coordination in support of the NSP; weak local state institutions; problems of sporadic intra and inter community conflict; inequitable growth between regions; unrealistic expectations of changes to cultural norms and values, particularly in relation to gender mainstreaming targets and prevailing social and economic conditions. The following narratives indicate the scope of these challenges:

The rule of law needs to replace the rule of violence; until it does we cannot function as a government because we can't do simple things like collect taxes. (Minister, Islamic Republic of Afghanistan)

The key problem here (Afghanistan) is the distance between government and the people, especially outside Kabul. There is very little government outside Kabul. (Minister, Islamic Republic of Afghanistan)

We have become too reliant on foreigners as we lack knowledge about reconstruction programming. We are also very vulnerable to the World Bank and the IMF as we don't have the ability to argue with them on their own terms. (Minister, Islamic Republic of Afghanistan)

The international community will soon forget us. It always does.

It is my job to ensure that it doesn't. (Minister, Islamic Republic of Afghanistan)

These variables have evidently interacted in complex and often unexpected ways and have informed the context and challenges of programme delivery. Hence, they must be clearly understood in order to develop an appropriate strategy for programme management and enhancement.

In an ideal rational-type evaluation a programme should be strictly evaluated against the achievement of its aims and objectives. However, it is evident from this analysis of the obstacles to programme delivery that: a) a significant range of obstacles have been confronted by the NSP which have constrained its capacity to meet ambitious targets; b) although some of these have been the product of the absence of strategic thinking, the vast majority are outwith the control of the NSP/OC and its FPs, and are generally typical of post-war
FIN DINGSAND

RECOMMEN DATIONS 
reconstruction development programming; ${ }^{15}$ and c) despite these constraints significant achievements have been made. Let's turn our attention now to an assessment of those achievements.

\subsection{Programme benefits}

This evaluation has found evidence of at least 11 sets of benefits which have been derived from the NSP:

1. increased public perceptions of national solidarity achieved through state-building - e.g. the creation of new institutional architecture at the central (NSP-OC, DAB), provincial (PO OC), and village (CDCs) levels; 16

2. improved state-civil society relations as a consequence of improvements in national solidarity; 17

3. greater awareness of the activities of government as a consequence of the work of the PCU; 18

4. the empowerment of rural communities through the establishment of a new legitimate

15 See S. Barakat (ed.), (2005), After the Conflict: Reconstruction and Development in the Aftermath of War London, I.B. Tauris.

16 See Sections 3, 4, $5 \& 6$.

17 See Section 4.

18 See Section 2.

19 See Section 4.

20 lbid.

21 See Section 2.

22 Training in relation to delivering aspects of the NSP. See Sections $2 \& 3$.

23 See Section 4.

24 See Section 7.3.

25 Ibid.

$26_{\text {Ibid. }}$

SECTION 8: IN CONCLUSION form of community governance; 19

5. heightened perceptions of community solidarity achieved through processes of community governance; 20

6. delivery of governmental capacity development (provincial and district level MRRD, NSP/OC, PO OC, DAB and Ministry of Finance staff); 21

7. delivery of FP capacity development (training); 22

8. delivery of community capacity development (training); 23

9. direct forms of economic development through improved productive capacity and the provision of work in relation to certain NSP projects; 24

10. indirect forms of economic development facilitated by:

a) increased economic activity arising from improved infrastructure, and b) savings derived from lower costs of production; 25 and

11. improvements in the quality of rural life. 26

As stated in the technical proposal for this mid-term evaluation, it was premature to attempt to determine the impact of the Programme either in terms of achieving its stated objectives (laying the foundations for improved community level governance and poverty reduction) or in terms of the overarching aim of strengthening national soli- darity. Nevertheless, as the evaluators expected, it has been possible to identify the above qualitative trends that can be attributed with some confidence to the interaction of the Programme with the objective socio-economic conditions in the communities and these, if sustained, would be capable of delivering the intended impact. No evidence was found of negative impact although a number of threats to the sustainability of the positive gains were identified. Let's review the evidence here on community impact in a little more detail.

\section{Community governance}

Positive trends in establishing representative and participatory governance were observed in all communities which had established a CDC. By comparing this state of governance with their own accounts of governance prior to the $C D C$, and with the current governance in neighbouring matched communities without CDCs, these trends were found to be directly attributable to the process of establishing the CDC. Progress towards improved community governance was observed in three key aspects of the functioning of the CDC:

\section{Leadership}

The CDCs were clearly gaining the trust and acceptance of their communities. They were capable of uniting previously antagonistic social groups and were becoming recognized as representatives of the whole community. While this general trend could be observed in all the CDCs surveyed, the rate of development is conditioned by local factors. There are two key constraints to CDCs achieving the leadership role envisaged in the NSP Programme design: in more than half the communities, leadership is still shared (and in a minority contested), with traditional institutions of community governance; women have not achieved a leadership role in the general $C D C$, or in some cases even in relation to the women in their community. However, there has been a trend in both these areas towards an enhanced role for inclusive CDCs by means of a gradual and negotiated process.

\section{Threats to leadership}

The main threats to this process are external: collusion between corrupt district administrations and powerful individuals in the community; weak facilitation, by an inexperienced FP without local knowledge; and lack of political support for CDCs (including women's CDC) from district MRRD and the provincial government. 
Capacity for democratic governance

A high degree of inclusion of different social groups has been achieved by the CDCs. Women's inclusion in governance has also been negotiated to a limited extent (they voted in most CDC elections and had some say in defining project priorities) but this still remains to be consolidated in practice. The principle of including the whole community in the benefits of the projects has been adopted and put into practice. In most cases this has involved direct participation in defining development priorities and choosing projects. The majority of householders, since they are also beneficiaries, participate in the NSP projects through paid and voluntary work and contributions. This is in marked contrast to levels of participation in community work in non-NSP communities.

The need for accountability and transparency is recognized by the majority of the CDC members and their communities, but on the whole they have confidence in their probity and integrity. However, there are problems in finding effective ways to report back to a largely illiterate population, and very few villagers are capable of scrutinizing the work of the CDC.

It can be observed that the NSP has now enabled communities to experience democratic governance for the first time, and most community members consider it a positive experience. The main challenge in the next stage of the Programme will be to enhance and institutionalize democratic culture and practice.

\section{Threats to democratic governance}

The main threats to sustaining democratic governance through CDCs would include: traditional elites reasserting themselves and precipitating intra-community conflict; the failure to afford constitutional and statutory authority to the CDCs; institutionalize periodic and fair elections to the CDCs and increase its competences; and the absence of greater public involvement in, and scrutiny of, the CDCs.

\section{Capacity for planning and managing development projects}

There is evidence of the transfer of project management skills from the FPs to the CDCs through the NSP process. A significant number of CDCs, after completing an NSP project, were found to be capable of planning and implementing projects through a community participation approach underpinned by transparent accounting. Some CDCs were already developing new projects on their own initiative.

However, success in achieving this skills transfer is also conditioned by local levels of development, especially education and professional skills. Women's capacity to run projects independently is particularly limited in this respect. For this reason many CDCs will not have the capacity to manage projects without technical assistance after completing a first project. This is not an indication of failure but characteristic of the observation that the time frame for social mobilization and facilitation remains far too short in many communities. Moreover, the opportunity to apply the skills which have been acquired is dependent on the local economy and ease of access to urban and commercial centres. Even capable CDCs in areas of low economic activity, in remote or insecure areas where few NGOs or aid programmes operate, may find they are unable to initiate new projects without assistance.

\section{Threats to future}

project management capacity

Many CDCs without continuing access to technical support, facilitation and advice are likely to fail to consolidate and sustain their project management capability. This in turn will compromise their credibility as community leaders.

\section{Living conditions in the communities}

The NSP is making a positive contribution to the quality of life in rural communities. In some cases this is demonstrably supporting poverty reduction by creating livelihood opportunities and direct forms of economic development through improved productive capacity and the provision of work in relation to certain NSP projects. 27 In other cases it provides for indirect forms of economic development facilitated by: a) increased economic activity arising from improved infrastructure, and b) savings derived from lower costs of production.

Community priorities in both the NSP and non-NSP communities were similar and focussed on basic services, livelihoods and access. As a result of the participatory selection of priorities, the NSP projects are in general meeting these needs. Most contribute to one or more of the following:
27 See Section 7.3.

FIN DINGSAND RECOMMENDATIONS 
- Improved health - most notably through clean water projects, also clinics and access to health care from road improvements clinics.

- Improved knowledge and skills/education - through schools, literacy and skills training courses but also by knowledge and skills transfer through the implementation process. Electricity projects were expected to facilitate learning by extending the time for study.

- Improved access and communication - most notably through road projects which increase access to markets and services, reduce the cost of goods brought into the villages, and facilitate contact with government and other external agencies.

- Direct contributions to livelihoods - through short-term paid labour in the projects and sustained livelihood development through irrigation schemes, flour mills, home industry (carpet-weaving etc).

- Environmental protection - against floods and drought through the construction of floodwalls and reservoirs, which creates the space for productive work.

Nevertheless, NSP funding limits and conditions often mean that communities cannot tackle their main priorities. Hence, for pragmatic reasons they often opt for meeting one of their lesser priorities. While there is some advantage in this in the shortterm in terms of gaining expertise and some immediate benefit through these lesser projects, expectations are then raised that they will ultimately be able to get funding to implement their first priority.

\section{Threats to CDC credibility and future governance}

Although householders more commonly cited representative governance than material benefits as the main gain from the NSP, their main preoccupation is with improving their living conditions, and they expect the CDCs to represent them to governmental and non-governmental agencies in order to secure support for further community development projects. This is likely to pose a threat to the credibility of the CDCs and their capacity for representative governance if such expectations are not realized. For this reason, channelling future development programmes, whether governmental or non-governmental, through the CDCs is crucial for the sustainability of the process of democratic community governance generated by the NSP.

\section{National solidarity}

The rationale behind the NSP is that by contributing to the establishment of both community governance and poverty reduction through a clear government initiative (though with non-governmental and international partners), the Programme would strengthen national solidarity in the aftermath of many years of conflict and weak government. The evidence from the field survey suggests that this rationale is correct. The indications are that the NSP, by improving community governance and materially benefiting poor communities, is also contributing to a greater sense of community solidarity both within and between communities, and between communities and government. Nevertheless, this increased trust, after decades of disillusionment, is fragile.

\section{Community solidarity}

A large majority of householders interviewed in $C D C$ communities thought that greater unity, solidarity and cooperation between different groups and families within their communities was the most important aspect of the NSP.

\section{Threats to community solidarity}

Some householders indicated that despite gains in community unity, there are continuing sources of friction and individuals who might cause trouble. A minority of those interviewed were also reticent on this subject, indicating either unease or dissent. If future projects and the functioning of the CDCs are not perceived to be fully inclusive, conflict could be re-ignited.

\section{National solidarity}

Although few householders spoke in terms of national solidarity, over half of the householders in the CDC communities had a general awareness that the government was working to rehabilitate the whole country, and considerably more believed that the government had demonstrated its interest in their community. In contrast, the majority of respondents in matched non-CDC communities had little or no faith in government 


\section{Threats to rural perceptions of national solidarity}

Positive perceptions of government are closely linked to the delivery of tangible benefits in the community and therefore subject to disillusionment if expectations are not fulfilled. Villagers have very little actual knowledge of government policy and programmes beyond their own communities. In the non-NSP communities this led them to assume that nothing was being done. The same ignorance in the NSP communities could also easily feed negative perceptions of government.

The main point of contact between the communities and the wider nation is at the district and provincial government levels. The NSP has improved this relationship but it is still very weak. The lack of adequate response and moral support for the CDCs from local government could undermine public perceptions of national solidarity. In some districts the administration is corrupt and deeply resented by villagers. This detracts from any sense of solidarity, although some were able to differentiate between good governance at the national level and poor local governance. In communities neighbouring the $\mathrm{CDC}$ communities, there is evidence both of growing demand to be included in the ambit of the NSP and the perception by some that they are being unfairly excluded. The lack of inclusion constitutes a real threat to national solidarity.

\subsection{Programme efficiency and effectiveness}

At the outset of this evaluation the $O C$ was especially keen that our methodology should take into consideration issues of cost-effectiveness which they could then highlight to donors, and in particular the World Bank. Cost-effectiveness is currently calculated by taking the total cost of delivering the programme against the total amount given through Block Grants. At the same time, the Ministry of Finance and the Ministry of the Economy measure the costeffectiveness of the NSP through comparing the total cost of individual projects against the income generated from those projects. Not only is this approach too simplistic, it leads them to the conclusion that the NSP is very cost-inefficient at providing rural infrastructure, because they fail to take into account the training and building of capacity for local governance that have enabled the infrastructure project in the first place.
Neither of these forms of measurement are appropriate because they both fail to take into consideration that the NSP is more than just about the disbursement of Block Grants to meet the costs of individual projects. The essential focus of the NSP is concerned with improving rural community governance, capacity development and training, and galvanizing state-civil society relations. As we noted in Section 7, these objectives present profound challenges for quantification and indicator development. Key performance indicators need to be developed that show how local governance and rural infrastructure development can make progress towards poverty reduction. As we noted in Section 8.2, the cost of the NSP is a major issue and must be shown to be good value for money. Let's consider the evidence.

Overall our findings confirm that the output and outcomes of NSP are serving effectively the original objectives of the Programme: the empowerment of rural communities through the establishment of a new legitimate form of community governance; increased public faith in the system of government and national solidarity; enhanced intra community relations and state-civil society relations; and direct and indirect forms of economic development. However, given the size of the Programme and its diverse geographical location, as well as the variable levels of stability in the country, it is not surprising to find that the Programme has been more effective in some areas than in others.

Table 6 provides an insight into the outputs of the NSP from September 2003 to February 2006. It demonstrates that despite problems in the programme design stage of policy development, the NSP has proved remarkably successful at 'muddling

\begin{tabular}{|lr|}
\hline \multicolumn{2}{|c|}{$\begin{array}{c}\text { Table 6: NSP outputs - } \\
\text { September 2003 to February }\end{array}$} \\
\hline Communities selected & 10,817 \\
CDCs elected & 10,514 \\
CD Ps completed & 10,360 \\
Sub-project proposals submitted & 17,254 \\
Sub-project proposals approved & 16,946 \\
Sub-project disbursed & 14,809 \\
Sub-projects completed & 4,190 \\
\hline
\end{tabular}

FIN DINGSAND RECOMMENDATIONS 


\begin{tabular}{|ll|}
\hline \multicolumn{2}{|c|}{ Table 7: NSP capacity development } \\
\hline $\begin{array}{l}\text { Form of training } \\
\text { Informal 'on the job' training }\end{array}$ & $\begin{array}{l}\text { An estimated total of } 50,000 \text { person training } \\
\text { days for M RRD (central, regional and } \\
\text { provincial), OC and FP staff. }\end{array}$ \\
Formal training & $\begin{array}{l}9,000 \text { person days for the same target groups. } \\
\text { CDC training }\end{array}$ \\
\hline
\end{tabular}

\begin{tabular}{|lr|}
\hline \multicolumn{2}{|c|}{ Table 8: NSP projects } \\
\hline Project type & Number \\
Drinking water & 2,933 \\
Education & 548 \\
Energy related & 2,094 \\
Irrigation projects & 2,419 \\
Livelihood & 1,235 \\
Transport related projects & 2,319 \\
O thers & 154 \\
\hline
\end{tabular}

through' and achieving significant rates of social mobilization, project proposal processing, and grant disbursement.

However, although Table 7 provides evidence of significant capacity development of FP and OC employees as well as CDC members, our respondents identify the absence of effective capacity development as a key area of concern for Phase 2 of the Programme, particularly when it comes to developing the capacity of MRRD itself:

It would be disastrous to hand over the NSP to the MRRD at this juncture; they simply do not have the skills to deliver the Programme. They have the people at the top, but scratch below the surface and the skill levels aren't there.

(NSP donor stakeholder)

The capacity development deficit can be traced back to the original definition of the term in project documents or, in truth, the lack of such a definition. The general understanding of the term is confined to conflating the provision of infrastructure (computers, telecommunications facilities, etc.), with technical assistance and training. These all have an important role to play in capacity development but they are distinct from one another and do not encompass the scope of the activity. What seems to be lacking is a clear strategy for MRRD capacity development to 'own' the NSP. While it is evident that the MRRD has worked hard (in line with the Cabinet's plans as set out in the National Development Framework) to obtain outside assistance without forfeiting national ownership, much of the capacity associated with the NSP is either owned by the $\mathrm{OC}$ or has been procured in ways that have inevitably distorted public sector employment, and is therefore very difficult and expensive to maintain.

A second factor leading to compromise over indigenous civil service capacity development has obviously been the limited amount of time defined for the completion of the Programme. In a context where there is a shortage of people with relevant education and training, combined with an employment market inflated by international agencies and the private sector, the pressure to complete current work leads to outsourcing rather than internal capacity development. There is therefore a tension between imperatives for rapid completion and the need to allow people to develop skills over time by learning both on and off the job. As one $\mathrm{OC}$ representative puts it, '[I]n the rush to disburse Block Grants something has had to give and that something has been building-up governmental capacity at the national and provincial levels'.

A further concern for the long-term sustainability of the NSP is the tendency to invest too heavily in infrastructural rather than livelihood enhancing projects (see Table 8). This suggests the need for a change in emphasis in Phase 2 if the NSP is to deliver on its aims for economic growth. A final recommendation is therefore posed here:

\section{Recommendation $\mathbf{5 9}$}

The NSP should foster linkages between sub-projects. For example, the provision of electricity generators would be much more effective if the generators were to power mills, small manufacturing, or refrigerated storage rather than focussing purely on the provision of light and the encouragement of a consumer life style.

Nonetheless, this inclusive approach to evaluating NSP programme costs and benefits reveals significant gains to the Afghan 
people in relation to institution-building (limited democratization) and capacity development (mainly in skills development) and social solidarity at the national and community levels, and to a lesser degree at the provincial and district levels. Impressive benefits have also been derived economically by: creating livelihood opportunities and direct forms of economic development through improved productive capacity and the provision of work in relation to certain NSP projects; and the provision of indirect forms of economic development facilitated by increased economic activity arising from improved infrastructure and savings derived from lower costs of production. Important gains in gender equality have also been achieved in certain regions.

These benefits justify the overhead costs of the Programme, particularly in years 1 and 2 of the Programme. Moreover, overhead costs should diminish dramatically as a consequence of: a) lesson-learning from Phase 1 ; b) elimination of unnecessary bureaucracy through the simplification of delivery systems; and c) the gradual development of a new institutional venue for the delivery of the Programme. However, these achievements will need to be consolidated in the ways suggested above in order to ensure the long-term future of what may be deemed a development programme of outstanding potential. 


\section{Contents}

\section{Annex A}

page

A1. General Introduction

A2. Methodology

\section{Field Research Findings:}

A3. Badghis Province

A4. Balkh Province

A5. Bamyan Province

A6. Herat Province

A7. Kabul Province

A8. Kundoz Province

A9. Nangarhar Province Annex 1. Laghman Province

A10. Paktia Province

A11. Paktika Province

A12. Takhar Province

\section{Annex B}

B1. Terms of Reference

\section{Annex C}

C1. Stakeholders Consulted

\section{Annex D}

D1. References 


$$
\text { or }
$$




\section{A1 General Introduction}

Annex A contains the individual reports prepared by the 5 research teams on the work they completed in 11 provinces and 23 districts between 20 October and 12 November. The general findings and evaluative conclusions from the comparative analysis of the provincial surveys have already been reported in the Main Report. Annex $A$ is published with the purpose of making the basic data from local contexts available to operational staff and other interested parties, such as researchers and future evaluators.

As described in the methodology section, the teams worked together for a week prior to the fieldwork to validate a common set of interview guidelines and agree on the general approach to the research and its key objectives.

Once in the field each team was autonomous and had to find the most practical way to implement the research strategy within the particular constraints of time and access that they faced. Some teams were delayed by transport problems or had to wait for key informants to be available, while others were able to visit additional sites or collect secondary data in addition to the core research framework based on the common research questions.

Each team completed the essential core research strategy in one province: interviews with representatives of the NSP provincial and district management teams $\mathrm{DRRD}, \mathrm{OC}$ and $\mathrm{FP}$; interviews and project visits to one established and one recently formed CDC; surveys of householders in each CDC; an interview with the leaders of a matched community without a $\mathrm{CDC}$; a survey of householders in the community without a CDC. These full surveys are reported in the findings from Badghis, Balkh, Kabul, Kundoz and Nangarhar. The Balkh and Nangarhar teams also carried out additional visits, interviews and data collection.

As time and opportunity allowed, the teams also conducted partial surveys in other provinces and districts, in order to sample a wider area for comparative purposes, but always applying the same methodology. The 5 other provincial reports, Bamyan, Herat, Paktia, Paktika and Takhar cover these partial surveys. In addition the team in Nangarhar made a rapid appraisal visit to Laghman. 


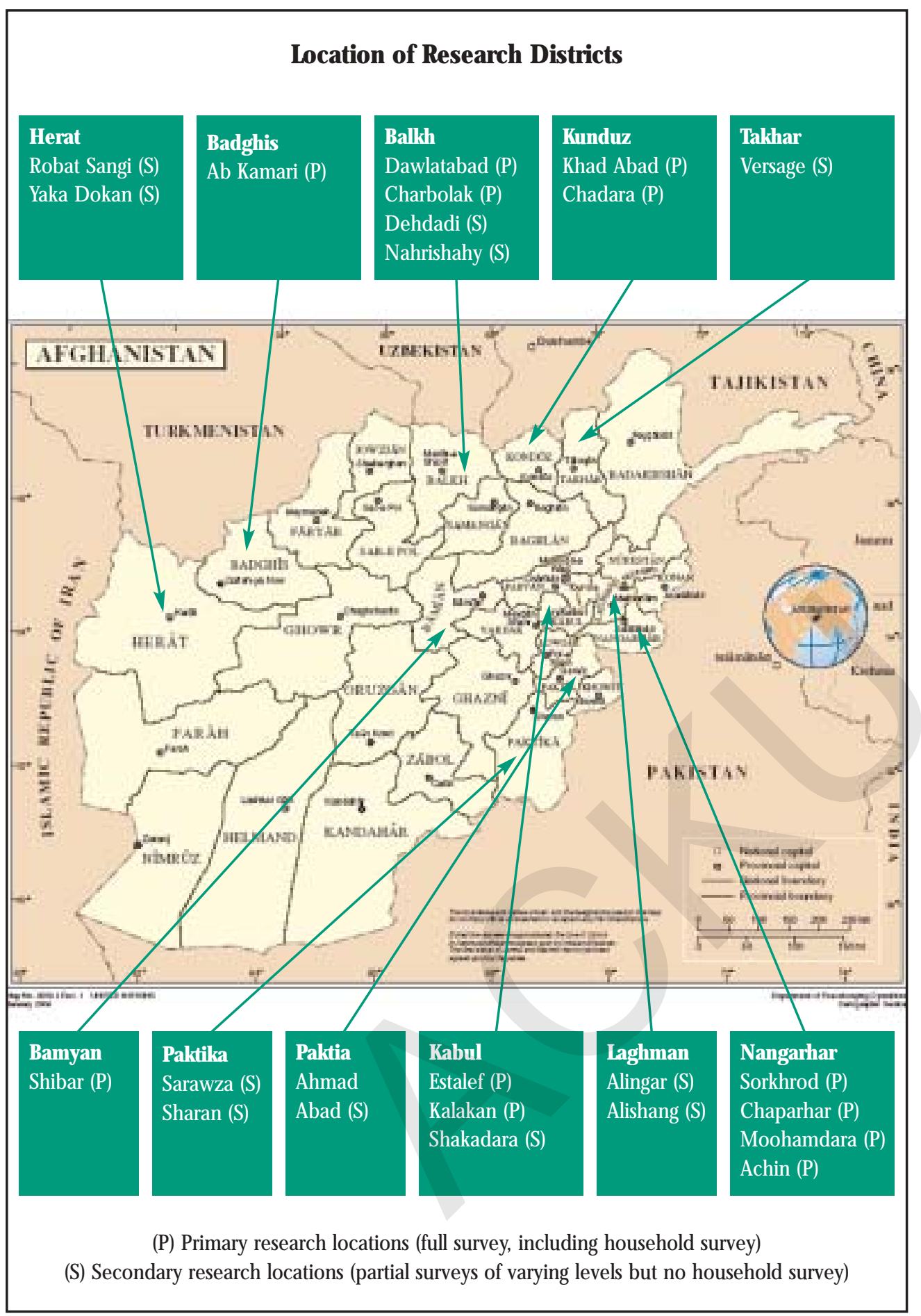




\section{A2 Meluation}

This evaluation methodology is divided into seven sections: the review of the literature; the scope of the field research; the approach to gaining access in Afghanistan; the data gathering techniques; the selection of the samples and their representativeness; the main practical constraints to the field research; and the analyses of the field data.

\section{Review of the literature}

This evaluation started with reviews of the academic literature and the grey literature (field reports, policy documents and other reliable internet-based data) on the wider policy roots of the NSP; that is, the World Bank's Social Funds Development Policy.

This was followed by a more focussed review of the grey literature on the NSP, which consisted of policy documents and statistical data (some internal and confidential) from the World Bank, MRRD, NSP Oversight Consultants team, in addition to independent reports from NGOs, think tanks and research institutes with specialized expertise in Afghanistan. Further secondary data pertaining to the coverage and performance of the NSP was collected during and after the field research.

$1_{A}$ detailed list of the stakeholders interviewed, workshop attendees and stakeholders from the Provincial research can be found in Annex $C$.

\section{Scope of the field research 1}

\section{Kabul}

over 30 people to validate our approach and discuss our findings. The stakeholders held senior positions within the NSP OC Team, the Ministry of Rural Rehabilitation and Development, FPs and the World Bank. Ministers/senior ministerial representatives from the Ministries of Finance, Agriculture, Education, Water and Energy and Women's Affairs were also consulted, in addition to senior representatives from NABDP, AREU and UNDP.

The donors that were consulted included: DfID, JICA, USAID, EU and the Embassies of Norway, Germany and Canada.

\section{The provinces}

Between October and November 2005, 5 teams of 3 researchers conducted the field research in 11 provinces (Badghis, Balkh, Bamyan, Herat, Kabul, Kundoz, Laghman, Nangarhar, Paktia, Paktika, and Takhar). Two of the Research Assessment Teams (RATs) were led by Afghan team leaders, and the other 3 were led by British Research Fellows from the PRDU. Therefore, each team had at least two Afghan researchers.

Across the 9 provinces visited, 18 CDCs and the leaders of 6 matched communities not participating in the NSP were interviewed. Household surveys were conducted in all but 4 of these communities, in addition to one community in Paktia visited by the PRDU's engineering specialist (total 21).

Between October 2005 and February 2006 over 50 interviews were conducted with various national level stakeholders, as well as two participatory workshops attended by
The mode of carrying out the surveys depended on local cultural factors, which particularly determined where women researchers could work or researchers could interview women. In Herat, Nangarhar and Paktia the all-male research 
teams could only interview men. Nevertheless, the extensive inclusion of Afghan women's voices represents one of the key achievements of this evaluation. Using a mixed research team in Balkh meant it was possible to interview men and women in the same households. The other mixed research team working in Bamyan and Kabul interviewed men and women representing different households. Furthermore, in Kundoz and Badghis, the all-male teams were sometimes able to interview widow heads of households.

As a result, 73 men and 13 women were interviewed individually within the CDC communities in 8 of the provinces, in addition to men and women in 30 households within CDC communities in Balkh. Furthermore, 33 men and 7 women were interviewed individually in communities without a $\mathrm{CDC}$, in addition to men and women in 6 households in Balkh. In all, representatives of 162 households were surveyed.

Additional visits were made to 4 CDCs in Kabul, 8 in Laghman and 8 in Nangarhar. However, full household surveys were not carried out in all provinces, due to constraints of time and access (see below).

The DRRD NSP management teams were interviewed in every province visited except Laghman (10 provinces), and the OCs in all except Paktia and Laghman (9 provinces). Interviews were also conducted with provincial governors or their deputies where possible.

A total of 13 FP provincial teams were interviewed or visited. Full interviews were conducted with the management teams of the FPs facilitating the CDCs visited in 8 provinces: AKDN in Bamyan; BRAC in Badghis, Nangarhar and Paktika; $\mathrm{CHA}$ and UN-HABITAT in Balkh; Concern in Takhar; GRSP in Kundoz; and SDF in Kabul. FPs working in neighbouring areas were more briefly interviewed or visited: UN-HABITAT in Bamyan; Madeira and DACAAR in Laghman; and ACTED in Kundoz.

As detailed in their respective provincial reports, the research teams based in Balkh and Nangarhar were able to conduct additional background and comparative research.

\section{Approach to gaining access}

All interviews were arranged through the proper and official channels, and with informed consent. ${ }^{2}$ Before each interview, there were tailored introductions to inform the interviewee of the nature of the questions and the purpose of the evaluation. Confidentiality and anonymity were ensured and the researcher was proactive in being sensitive to the respondents' needs.

First, a focussing approach was employed, with interviews conducted with respondents from the elite level of the NSP in Kabul, and moved down through two further levels before finishing with the selection of households within the provinces (see Figure 1 below).

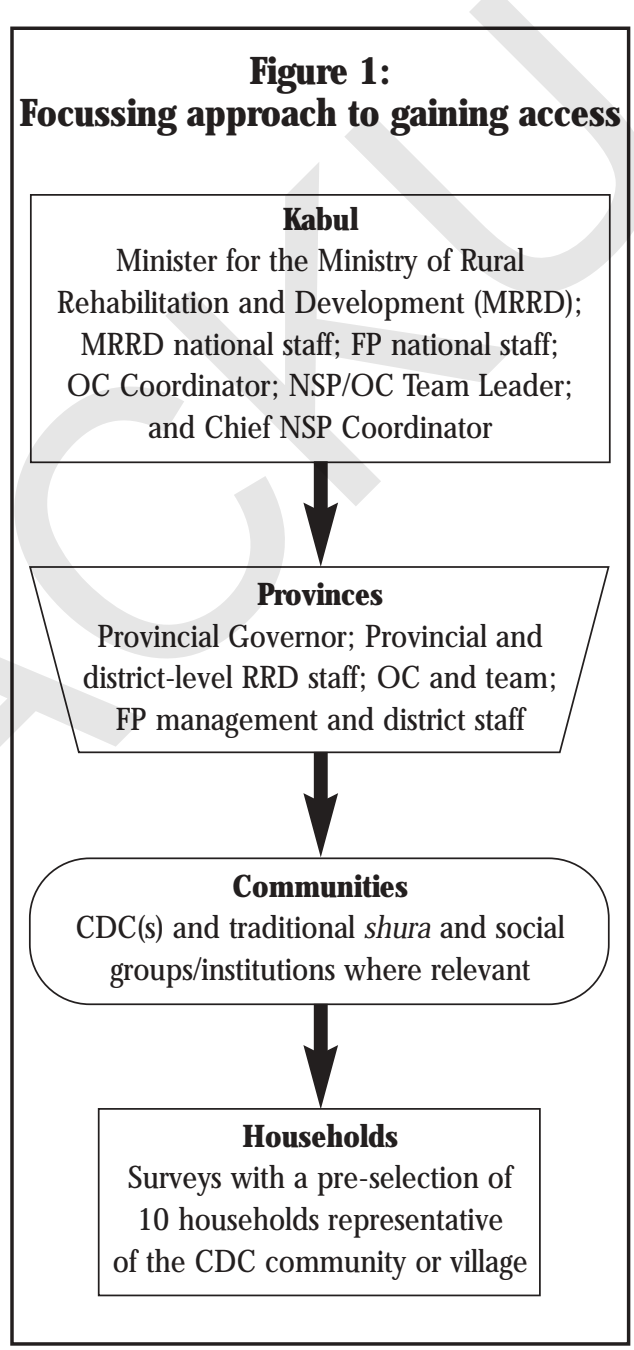

Access to the communities was gained ultimately through their leaders, which granted the research credibility and respect. However, in order to overcome diplomatic biases it was essential to insist politely on exploring other areas and talking to other
2 In order to gain and maintain access within the provinces, each RAT met with the Provincial Governor or deputy and/or the Provincial Director of the MRRD. At this meeting, an official letter of introduction from the Minister of the MRRD was presented, in addition to a brief overview of the evaluation: the main aims or purpose of the research, the type of interviewees and the districts targeted.

THE PRO VIN CIAL FIELD SU RVEY REPO RTS 
people. For the latter, interviews with households living beyond the obvious areas of community activity and marginalized subgroups provided a more complete understanding of each community. This also demonstrated awareness of active, present and living biases by including and showing sensitivity to issues involving the sick or dead of the communities. To control male bias, it was important to try and establish interviewees and responses that were gender-equal by seeking a representation of female respondents and raising gender issues as part of the research aims. ${ }^{3}$ To overcome seasonal bias, respondents were asked to consider the long-term (past and future) when answering relevant questions. Bias overall was acknowledged, but controlled by discussing and sharing knowledge at several intervals before and during the collection of data.

Although there were notable achievements in gaining and maintaining access, it is prudent to assume the research inevitably had positive and negative impacts. Barakat et al and Goodhand emphasize the impossibility of a researcher remaining neutral, especially during conflict. Similarly, Jacobsen and Landau raise the issue of "reactivity", where a researcher's presence potentially influences the behaviour and responses of informants (Jacobsen and Landau, 2003: 102). This includes the possibility that the research may have unwittingly supported vested interests; for example, Pratt and Lozios remind that research can empower, which can make others hostile (Pratt and Lozios, 1992: 17-19). Where possible, this was alleviated and controlled by making the aims of the research clear and by using the guidance of key respondents and gatekeepers. While reactivity is inevitable, it is also important to give respondents some credit in their ability to listen, understand, form realistic expectations and to differentiate among types of outsiders. Furthermore, there may be potential benefits for interviewees, "[k]nowing they are contributing to a worthwhile endeavour can be gratifying; it may increase confidence." (Arksey and Knight, 1999: 127).

3 As noted above, most of the RATs were able to interview women householders and members of CDCs. sentatives and groups of staff. Second, a survey was conducted with households participating and not participating in the NSP. Structured observations were important, especially when visiting the communities and evaluating the projects. The collection of quantitative data was also crucial, especially in evaluating NSP coverage and performance, and it was gained through the grey literature collected before, during and after the field research. In addition, the PRDU collected primary quantitative data through the profiles of the communities and households surveyed.

The questions for the semi-structured interviews and the household surveys stemmed from the PRDU's initial conceptualization of this mid-term evaluation and the literatures reviews. The sets of questions were then piloted in Kabul during exploratory research in August 2005, and refined further during the intensive training workshop with the Afghan researchers in October 2005. In particular, this workshop refined the engineering questions based on the insight gained from the engineering expert's prior evaluation of four completed projects in and around Kabul.

Using the example of the CDC interviews, the questions principally aimed to assess the ability of the CDCs to assume the two key roles assigned to them by the NSP: representative governance and community development. In practical terms, this involved assessing their capacity to function independently as a democratic leadership of their communities and their ability to select, plan and manage development projects. Accordingly, group interviews with the CDCs and observation of their work focussed on a number of key indicators: legitimacy and acceptance; participation, transparency and communication with the whole community; project management skills; record keeping; relations with government and outside bodies; and their relationship with the FP.

As another example, the household survey was the principal tool for assessing the impact of the NSP in respect of its goal and objectives. It was designed to provide evidence of progress in developing community governance and project management capacity as a means of empowering communities to improve their lives. To this end the survey sought responses from a sample of householders on a number of key issues: their experiences in the war and the 
immediate post-war period including economic conditions and forms of governance (the baseline from which the Programme had to work); how they had experienced the process of setting up the CDC and the choice of projects; the extent of their participation in governance and project implementation today; their perceptions of the wider national governance, including recovery and development plans; and their outlook on the future.

All interview and household questions followed a strategic structure of clusters linked to specific themes, which was important for several reasons. The order reflected the degree of potential sensitivity, from an initial request for straightforward information to socio-economic data as the last cluster. The strategic structuring strategy was used to develop trust before more personal questions were asked, and allowed the researcher to proceed through the questions in a logical manner which made sense to the respondents (Arksey and Knight, 1999: 39). The questions that, in subject matter, were relevant to two question clusters, were placed at the end of a section to provide a logical lead question to the next one. Reflecting the overall strategy, the more basic and less sensitive questions within each cluster were placed before questions of a sensitive or opinion/ value-based composition.

To initiate trust and rapport prior to each interview and survey, a uniform method was employed to briefly and informally introduce the reasons for the research and how information would be used, while stressing and demonstrating confidentiality. 4 Each interview and survey was concluded by asking for further comments and questions, and our gratitude was repeated. On some occasions, interviewees asked to be informed of our findings and this was facilitated where possible. In particular, the shura or CDC was debriefed in a general way before exiting the community.

It was also important to consider the possibility of bias in the interviews and surveys, since respondents may have been motivated by the perceived intentions of the researchers, mistrusted the aims and credibility of the process or "used it for their own purpose", thereby resulting in "false or incomplete" information (Barakat et al, 2002: 993-994). Alternatively, the time taken by semi-structured interviews can also reveal inconsistencies and instil more trust
(Barakat et al, 2002: 993). Pratt and Lozios draw attention to the danger of specialists attaching too much causal weight or interest because of their own 'specialism'. This bias was balanced by asking household heads to prioritise and explain the major problems facing their community, which itself generated insightful observations (Pratt and Lozios, 1992: 2 and 6). ${ }^{5}$

\section{Selection of samples and representativeness}

There were 5 main sets of samples for analysis: the NSP actors (national, provincial and district levels); the provinces; the districts; the communities and their leaders; and the households.

First, the field research aimed to reach a cross-section of key respondents who were representative of the range of actors within the NSP; that is, senior representatives from the relevant government ministries and departments, and the NSP Oversight Consultants team in Kabul. Based on the selection of the provinces (see below), senior representatives of the $O C$ and DRRD were then interviewed at the provincial level, in addition to representatives of the latter at the district level. Similarly, representatives of a wide range of FPs were interviewed at each of the three main levels, which consisted of indigenous and international NGOs, and a UN agency (see above). Overall, the final selection of the NSP actors stemmed from the consultation and triangulation of two fundamental sources of information to ensure representativeness: policy documents (as listed above); and data gathered during the interviews in Kabul. ${ }^{6}$ Care was also taken to interview actors who had both short- and long-term engagements. The continuity of interviewees and the subsequent analysis of commonalities and shifts in perception ensured the respondents' credibility.

Second, the selection of the provinces was based fundamentally on addressing those with the critical mass of projects within the NSP, followed by security considerations. While we would have preferred to visit every province, this was prevented by security.

Third, the selection of the districts within each province was mainly decided by the selection of the communities (see below).
4 The researchers/interpreters also received guidelines for during, and closing, the interview (Arksey \& Knight, 1999: 102). These guidelines were presented and discussed during the 3-day training workshop in Kabul in 0 ctober 2005. The household surveys lasted for 20 minutes (approx.) with an average of 45 to 60 minutes for the semi-structured interviews.

5 Validity depended on the skill of the interviewer, the time available and the rapport that allowed respondents to be as informative as possible (Arksey and Knight, 1999: 16).

6 For example, the FPs were selected from the comprehensive list of $\mathrm{FPs}$ within the N SP O versight Consultants 'Implementation Progress Report' from 30 September 2005.

THE PRO VIN CIAL FIELD SU RVEY REPO RTS 
Nevertheless, the appropriateness (representativeness and security constraints) of the districts was confirmed by consulting three other crucial sources: the updated and comprehensive list of districts provided by the National OC in Kabul; each FP in Kabul and the FP at the provincial level; and checking with the general background knowledge of our Afghan researchers who had expertise in the NSP.

Fourth, within each province the selection of the communities was based on three cluster types: those with a well established $\mathrm{CDC}(\mathrm{s})$, project approved and at the stage of project implementation; one with a recently established $\mathrm{CDC}(\mathrm{s})$ and at the stage of drawing up a project plan; and one nonparticipating community. The first two clusters were receiving or expected to receive the physical and non-tangible benefits of the NSP. The third, non-participating community shared a similar profile to the other two clusters of communities, which permitted a comparative analysis. The latter small sample was necessary because there was no baseline data on the nature of governance and development in the rural communities prior to joining the NSP.

In selecting the three clusters, relevant information and profiles of the communities were attained and then verified at three levels: hard data from the FP in Kabul; background knowledge and hard data from FP staff at the provincial and district levels; and from the $\operatorname{CDC}(\mathrm{s})$. Each profile was based on the size of households, the proportion of rich, middle and poor incomes, sources of livelihoods, ethnicity, the number of vulnerable sub-groups or dependent/semidependent adults (elderly and/or sick, disabled, widows and widowers, $\mathrm{FHH}$ with dependent children, returnees and IDPs), and the age of adulthood. The presence and type of social groups and institutions were also explored.

Accordingly, a complete list was drawn up for all communities within the first two clusters, and the average communities were randomly selected after rating each community in terms of their NSP performance. Where possible, the three communities were located in the same or at least similar districts, which allowed useful comparisons and provided insight into the varying progress of CDCs.
As the last sample set, a representative quota of 10 households was drawn from each community profile. In general, 5 to 7 typical households were interviewed with 5 to 3 households representing vulnerable subgroups, depending on the profile of each community. As above, since there was no comprehensive baseline data for the NSP, the sample of householders in matched neighbouring communities not participating in the NSP provided another means of distinguishing the impact of the NSP from general trends towards recovery.

Last, it is important to note two deliberate exceptions, which widened the scope of the investigation. Some CDCs were interviewed, but without household surveys completed in their communities. This was to compare established and newly formed CDCs and with non-CDC communities. As the second exception, some CDCs were visited and interviewed with specific focus on the engineering of their projects.

\section{Practical constraints to field research}

As detailed above, it was essential to identify and manage the more academic challenges to the field research. However, there were also two main practical constraints: the Eid holiday period, and security restrictions as advised by the UN guidelines. Although the timeframe of the field research was significantly reduced by these two factors, the teams managed to research more communities, CDCs and FPs than originally expected. This stemmed from effective time management, accurate planning and the cooperation of the interviewees. In particular, the cooperation of all the FPs proved invaluable. Furthermore, the RAT leaders used the Eid period as a timely mid-way interval to review and consolidate the data gathered, which made the final week of field research more focussed.

\section{Analyses of field data}

The field data was analysed progressively during three main stages. Using the same evaluative headings or themes, the findings from the national-level interviews in Kabul were collated parallel to the completion of the field reports by the RAT leaders. These two strands of enquiry formed the preliminary analysis and this initial stage closed with the submission of the Inception and 
First Draft Report of the NSP mid-term Evaluation (PRDU, 2005).

The second stage of analysis was composed of two main parts. This involved the research team tightening the preliminary analysis in light of requested feedback on the Inception Report from the MRRD and the OC Oversight Consultant team. The second part consisted of comparative analyses of the provincial field data for the DRRDs, OCs, FPs, CDCs, NSP households, and the non-participating community leaders and households, using the same evaluative themes. This second stage closed by gaining important feedback on the updated findings through a workshop presentation in Kabul in February 2006, with senior representatives of the key NSP stakeholders (MRRD, FPs, OC team, international and indigenous NGOs, and donors).

The last stage focussed on drawing together the final conclusions and recommendations, as presented within this final report.

Finally, throughout the three stages of analyses, the field data was cross-checked within and, where possible, against the grey literature collected on the NSP. This was to ensure consistency in the opinions of each interviewee and to identify inconsistencies. For example, the household surveys and the CDC interviews focussed on similar issues but came from two different perspectives, and thus permitted insightful comparisons. 


\section{A3 Badghis Province \\ Provincial Field Research Findings}

\section{Timing and scope of the research}

The research team ${ }^{1}$ worked with the NSP programme in Badghis between 25-31 October 2005. They interviewed the management teams of the DRRD, the OC and one of the FPs, BRAC in Qala-e-now. They then visited three communities in $A b$ Kamari district: two participating in NSP and one matched community not involved with the NSP.

\section{Persons interviewed}

The Provincial Director of DRRD

- The DRRD Manager of NSP and a member of the monitoring team

- The Provincial Head of OC

- The Provincial Manager of BRAC

- The District Managers of BRAC Ab Kamari and BRAC Jawand

- The BRAC engineering team (Central Office Project Engineer, Provincial and District Engineers (seven) and a monitoring officer

- Chairman and members of the Mobarak Shah CDC

- Chairman and members of the Dai Zangi CDC

- Nine householders (8 men and one woman) in Mobarak Shah

$\checkmark$ Eight householders ( 7 men and one woman) in Dai Zangi

$\checkmark$ Community leaders of Charsangi

$\checkmark$ Nine householders ( 7 men and two women) in Charsangi

$1_{\text {Waheed } 0 \text { mer (Team Leader) }}$ with Malaiz D oud and Roydar Q utabuddin.

\section{The DRRD at the provincial and district level}

The Director, NSP Manager and a member of the monitoring team were interviewed at the Directorate in Qalae-now. The Director responded to general questions and then left his staff to continue the interview.

\subsection{Badghis DRRD}

The Department is supposed to have a staff of 40 but currently has 31 . They are currently running a number of programmes directed at community development: WATSAN; Hygiene and health awareness programmes; NEPRA (for road construction in central Badghis); area-based development projects; micro-finance; vulnerability assessment; emergency preparedness and response etc.

\subsection{Experience of community development with the NSP}

The Director said the NSP department had been established three years ago and started work in Qades District. Since then the NSP manager and staff spend most of their time in the field supervising the projects. The OC was established a year ago and the DRRD have been cooperating with them since then.

\subsection{Training and capacity of the DRRD}

The two members of the NSP team said they had received training on the basics of NSP and how to use the Operational Manual. They had also been trained in community mobilization. However, all this training had been on-site, not in workshops or formal training. They found the community mobilization training most useful.

They felt that they had the professional capacity not only to carry out the current programmes but to run more programmes, 
except that they are constrained by lack of resources (vehicles and mobile phones, for example.)

\subsubsection{Constraints due to the NSP structure/procedures/workload}

The number of staff processing the large number of projects had proved inadequate and the Director had allocated two extra staff to it. As to other aspects of the NSP management, the Manager said his 25 years' experience working in the province meant that he was more than capable of handling it on his own. However, he now feels confused about his status. Since the OC came he is required to work from the OC's office, and has been told he is paid by both DRRD and the OC. He can't see how he can be an employee of both and would like clarification as to which is his boss.

\subsubsection{Coordination with other ministries}

They attempt to keep the directorates of agriculture and health informed of what they are doing by taking them to visit the projects. However, there is little being done in these sectors with which to coordinate.

\subsubsection{Community relations}

They thought they had good working relations with the CDC because they always discussed things with them and had a good understanding. They had also received and discussed complaints from the people. Any they were unable to handle were passed on to Kabul.

\subsection{The role and impact of NSP/CDC}

They did not think there was much prospect of the CDC surviving for very long without the funding support from the MRRD because in the final analysis politics is determined by the economy. However, the NSP has brought people close to government, which is a strong sign of national solidarity. Without it 'people will get involved in harmful things in the villages'.

\section{The provincial NSP O versight Consultant (OC)}

The Oversight Consultant was interviewed on his own.

\subsection{General comments on the strengths and weaknesses of the NSP}

The strengths of NSP are that it has given authority to people to decide their priorities for themselves. It has generated a sense of responsibility and inspired enthusiasm to carry out large construction projects, in some cases contributing, not just the required 10 per cent of the cost, but as much as 50 per cent. People now refer to NSP frequently after defining their needs (comments by some householders interviewed support these claims).

Another achievement, often in the face of opposition from elders and former commanders, has been to establish the legitimacy of democratically elected councils (also supported by the experience of the two CDC visited; see discussion, 7.1 below)

The OC was reluctant at first to discuss weaknesses, saying he had told the Minister about them. However, he described some of the constraints.

The first of these, in a remote and underresourced province like Badghis, is the difficulty in publicising the programme to the public without local newspapers, radio or other means. It also affects the bidding process once projects are approved.

The next problem is the transfer of funds through $D A B$. The Badghis branch is run by two people (one is also a Mullah) who do not have the capacity to manage the volume of work. As a result the CDC wait a very long time for their money.

The third problem, already mentioned, is the opposition of commanders and elites, who have tried to block the process in order to protect their vested interests. In one case a Mullah preached against NSP as unIslamic. Rounds of discussions were necessary to convince him and the people that it is a government initiative to support them, not run by the Americans.

\subsection{The role of the $\mathrm{OC}$}

The OC described his role as taken up with disseminating information about the
THE PRO VIN CIAL FIELD SU RVEY REPO RTS 
programme. In particular it was necessary to explain that it is a government programme, not the initiative of the FPs, who are only partners (two FP are operating in the Province: BRAC and DACAAR). The FP had initially failed to make this clear.

Another task is processing and approving proposals, managing fund transfers and supervising the FPs. The $O C$ engineer, for example, makes frequent site visits. He did not mention any involvement with or capacity-building of the DRRD as part of his essential role at this stage. In fact he described his role in terms of direct implementation: 'We observe the activities of the FP and CDC and give them direct feed back. We are the sole authority to approve and disapprove projects. We are involved in all the process.'

\subsubsection{The capacity of the DRRD (and BRAC)} When asked directly about the capacity of the NSP staff in the DRRD, he said 'The Director is a good guy, but he does not have professional staff.' His view of the NSP Manager was that his lack of education (a grade six graduate only) meant he cannot handle NSP work. He grudgingly acknowledged his experience in the communities that made him 'good for monitoring'.

When asked about specific capacity-building measures, he said that since the government has no capacity they have to do the work directly themselves. They do take the Director with them on most of their missions and brief the DRRD on their activities weekly and they 'hope all this will help the DRRD develop its capacity'.

He did think they were improving but said it would be impossible to hand over to them in the proposed timeframe. In fact the only way to hand over to DRRD would be for them to hire qualified staff and pay them proper salaries. (Note above that the DRRD has not been able to appoint a full complement of staff.)

He added that BRAC had also hired very unqualified staff despite the money they have. (The CDC in Dai Zangi also noted this while saying their contribution was on the whole good.) The OC suggested that the money saved went back to Bangladesh.

(Another explanation might be difficulty recruiting to this remote province, but the FP said they had no recruitment problems.)

\subsection{The supervisory role of the $\mathrm{OC}$}

Despite his low opinion of the FP, he confirmed that they explained the eligibility criteria effectively to the communities before they drew up their projects. As a result most proposals comply with the criteria.

When asked how the NSP management ensures delivery of funds he described the difficulties created by various other actors in the process: the $\mathrm{OC}$ headquarters fails to review proposals and transfer funds on time; the DAB adds further delay; the FPs are 'sometimes lazy in sending us their requests for second instalments'.

Representations to $\mathrm{HQ}$ had mitigated the problems over time and a new information system had been introduced which will enable electronic tracking of proposals and Block Grant disbursement. Talks with DAB resulted in them being asked to send all three disbursements together, so that the money is available as needed.

He said the average waiting time for communities to receive project funds is two months, but it can be as short as 28 days; in some cases it has taken over a year.

\section{The facilitating partner (BRAC)}

Members of the provincial and district management teams were interviewed together in the BRAC office in Qala-e-now.

\subsection{Programme management}

\subsubsection{General Information on BRAC's NSP operations}

The management team provided the following information about their NSP programme.

Two districts of Badghis, Ab Kamari and Jawand, are targeted through NSP. Seventytwo villages of each district have been covered by the programme - 144 villages in both districts. An additional 54 villages have been surveyed in Ab Kamari District, taking the total to 198 .

Two hundred and thirty-five sub-projects have been approved so far. One hundred and twenty-seven projects are ongoing. A total of US $\$ 1,536,000$ has been received so far. The CDCs have received US $\$ 1,380,000$ altogether as of now. 
Currently, BRAC/NSP has 68 field staff, 8 of whom are female. The female staff are always accompanied by male escorts from the family. For some specific tasks, some women are hired on short-term contracts. The FP is trying to get more women on board. There is a shortage of women both interested and educated enough to be able to work. One hundred and eleven BRAC staff and 998 CDC members have benefited from a number of training activities. BRAC has 68 field staff for NSP.

Delays and impediments to implementation The programme has suffered some setbacks which have resulted in delaying the programme. Since May 2004, BRAC had to relocate its staff four times to Herat and Kabul from Jawand, and there was no proper work for four months because of security constraints.

The province saw unprecedented snowfall last winter which hadn't been witnessed in over a decade. Consequently there was virtually no work from December to March. Jawand was, in particular, troubling the FP for a variety of reasons; the villages are very scattered. Most of the villages are on high mountains while others are located in low river beds, which can be up to $1,800 \mathrm{~m}$ lower than main communication roads. To reach most of these villages, it can easily take 2-3 days. Animals, donkeys mostly, are the main means of transport.

Jawand is also $150 \mathrm{~km}$ from Qala-e-Naw, the provincial capital. The road is harsh, especially the Darzak Pass, which has a 90-degree slope. The other way into the district is along a canal which is, however, full of water at all times during the winter.

Another reason for delay in the programme has been the migrations. Many nomads and farmers shift to mountain slopes from June to September since the slopes are green and fit for grazing of animals.

The habit of wanting to change projects is another problem. The projects are finalized but not approved since mostly changes are required. One $C D C$, even after getting the money, wanted to change the project.

Some projects were approved later than they should have been. Around 40-45 projects were delayed for almost eight months until three months ago. One of the projects was delayed for one year. Some projects were sent to NSP HQ for approval but they were lost in NSP HQ and the OC had to submit copies of them again.

\subsubsection{The role of FP}

The FP team described their role, starting with their liaison with local government, OC, DRRD, 'commanders and influential people at community level' and aid agencies. They then spoke of staff recruitment and training, planning and implementation of projects as 'our responsibility' but saying that they ensure the implementation of projects through their staff and communities.

They then emphasized that they are only facilitators and provide technical assistance and that they always emphasize that it is a government programme and 'we are only facilitating community organization, formation of CDCs, elections and prioritizing their needs.'

They were sure communities understood this role because they explained it repeatedly to them in both CDC and monthly community meetings. (The household survey confirmed that the villagers did understand that the programme was initiated by government and most did not mention BRAC.)

\subsubsection{Working relations with the DRRD/O C}

They described their working relations with DRRD as good. The two FP (BRAC and DACAAR) meet weekly with the DRRD and they make joint project visits. There are also regular exchanges of visits and information so that they are informed of problems arising and can be called on to help when necessary. They share the same community development aims.

They also described their relations with the OC as 'good from the very beginning.'

They particularly mentioned technical assistance and help with staff training and capacity-building and that they work closely with them on project planning and supervision.

Their view is that FP, DRRD and OC work as a team and discuss things frankly which results in improvements. If here are differences of opinion, the problems are always 'interrelated' so they work together to solve them. This suggests a commitment to team work but relations that are sometimes difficult.
THE PRO VIN CIAL

FIELD SU RVEY REPO RTS 


\subsubsection{Capacity of DRRD}

They recognized that the DRRD lacks capacity but believed they were in 'a continuous process of capacity-building' including recruitment from both inside and outside the province so that their capacity 'increases day by day'. At present they do not have the capacity 'to manage huge projects', but they have great strength in solving problems in the community.

\subsubsection{The impact of NSP on relations between communities and government}

They said there is ' 100 per cent contact' between people and government through their representation by the CDC. Because people feel they have been given the authority to take decisions this has weakened the local warlords. People go to the $C D C$ to resolve problems. One of the engineers said they can now work without fear in Jawand because of this. He added:

\section{'The NSP has formed the very first and fundamental pillar of government in far and remote areas where no government existed.'}

\subsubsection{Training and capacity-building in the communities}

The first training in the communities is orientation on NSP. They also provide training necessary for project management such as accounting and procurement and use of the NSP Operational Manual (presumably by CDC members?). Specific skills training for particular projects is also given. For example, widows and the disabled were given training in livestock rearing.

\subsubsection{Participation}

There was initial resistance to participation in the programme, which they ascribed to people's 'low level of education' (awareness?). Different groups found it difficult to participate in the CDC because of long-standing enmities and conflicts, until proportional representation was negotiated. Influential individuals whose power was challenged by elected $C D C$ also tried to keep these divisions going. In Jawand religious leaders also resisted the programme as 'infidel' and anti-Islam. They were hostile to both government and NGOs but came to realize that it was to their benefit to accept it.

Inclusiveness was not discussed/not recorded (see below) but in the large community of Mobarak Shah, with over 300 families, 75 were left out of the CDC. Since these communities considered themselves as all related, this seems unsatisfactory and there were indications of resentment in the household responses. It was also unclear if all would benefit equally from the projects visited.

Participation of women

The FP did show a commitment to promoting women's involvement, but this is still culturally difficult (see discussion of recruitment above). There are now women's CDC in Jawand, but apparently not in Ab Kamari. Women's participation seemed minimal in Mobarak Shah and limited in Dai Zangi.

\subsubsection{The FP's capability in relation to the programme demands}

BRAC was already running a health programme in Badghis when it took on the NSP and it would aim to continue working in the province if NSP does not continue.

It was necessary to recruit 64 extra staff for NSP but they did not mention any particular difficulty with recruitment of qualified staff or with training (but see comments by the $O C$ and one $C D C$ ). They said that they are able to meet the current demand of the programme in terms of preparing and following through project proposals because they have the budget and enough staff to manage it. For example, they had no problems in explaining and applying the eligibility criteria.

\subsection{Management at district and project level}

Staff capacity-building and training The field staff were not interviewed but the district management team said that they had had a workshop on the basic NSP programme, technical training on proposals, training in monitoring and evaluation and in accounting and procurement procedures. They thought all were useful. Different members of staff found different parts of the training of particular use to them.

Project relevance, sustainability and efficiency NOTE: questions $17-23$ missing from the transcript

\section{Relevance}

The FP's views on this are not known (see above). The CDC and household interviews 
give an indication of relevance in their particular cases. Access to clean drinking water was a high priority in Mobarak Shah, but the project will only supply 30 per cent of the village's need. Projects to address other problems may well have gone beyond the budget of the NSP. In Dai Zangi, the CDC thought the electricity project would have advantages for children to study (they are getting a school built under another MRRD programme) and enable carpet-weavers (mainly women) to increase production. However the main community priority seemed to be a clinic. None of the householders interviewed mentioned looking forward to having electric light, though most earned income from carpet-weaving.

As in communities elsewhere, they appear to have chosen what they could afford and easily implement with the NSP budget.

\section{Sustainability}

The FP's views on maintenance and use of facilities and economic benefit etc. are not known (see above). CDC comments suggest it was not being adequately addressed in these cases.

The CDC in Mobarak Shah was going to appoint one volunteer to maintain the reservoirs and had no budget plan for maintenance. In Dai Zangi, the CDC said they had been advised at an early stage by the FP to consider this and had made a budget plan to hire someone to look after the machine on a full-time basis. The budget would also cover the cost of fuel. They did not say how this budget was to be sustained in the longterm, especially as householders find it difficult to afford fuel for lanterns at present.

As regards the quality of infrastructure, project design and construction, the engineers and operational staff described a number of ways in which this was assured:

They are first of all guided by the NSP technical manual. If this does not cover any problem they consult the OC or use other guidelines such as the International Code of Conduct, American Concrete Institute, Afghanistan Construction Norms.

The design is then cross-checked amongst the staff and sometimes checked by the engineering specialist from $\mathrm{HQ}$, who makes frequent visits (present in this interview).

They also regularly check the quality of the materials procured by the $C D C$, who have been trained both in the accounting and procurement procedures of the NSP and to be aware of how they can ensure that they buy the right quality.

(However, both the CDC in Dai Zangi and the $O C$ thought the BRAC engineers lacked qualification, though the above accounts suggests they are tackling this weakness.)

\section{Efficiency and effectiveness}

The operational staff, including the engineers, described the normal timeframe for project completion as: one month for identification; project start after one and a half months; completion (of large projects) in three months.

However they also said that projects could be delayed and take as much as 6 months. Delays were attributed to delays in Block Grant transfers and also in the initial approval process. They had noted an improvement in the month prior to the interview and thought the system is now working better. (Dai Zangi CDC noted that the FP itself completed its work on schedule.)

It was clear from the responses that the FP team had no knowledge of appropriate safety measures and therefore did not include these in their training for project implementation by the communities.

The effectiveness of the projects was not discussed and it was too soon to assess this at the two communities visited.

District profile of Ab Kamari

(Provided by the BRAC management team)

The population of Ab Kamari are mostly Tajiks. There are some 30-35 khels (subtribes) of nomads. People in this district are poor. They are dependent on rain-fed land and livestock as the main source of their livelihoods. The district has also benefited from very limited emergency interventions but no development projects have been implemented in the district.

Those with some livestock and some land with adequate water, warlords and ex-commanders are well-off. Their houses are visible in the villages as noticeably better than the majority. Normally, one will find a car in front of their houses too.

Poor people have neither land nor livestock and it is hard to find employment in the
THE PRO VIN CIAL FIELD SU RVEY REPO RTS 
district. There is also up to 5 per cent of widows in the district. No exact figure of disabled people can be indicated as yet, but there are disabled people in all villages of the district.

The communities are mostly led by religious clerics, the Mullahs. Until very recently, commanders of different warring factions and warlords functioned as leaders of communities though.

Some of the community representatives to the NGOs for emergency programmes have functioned as linkages between the communities and aid agencies which have been widely accused of widespread corruption. Many of those people are now enjoying an economically prosperous life.

\section{General comments on the management of NSP in Badghis}

\subsection{Strengths/successful implementation}

Given the difficulties of operating in a remote and underdeveloped province, continuing security problems, such as Badghis, the NSP achievements so far, though falling short of the results in other provinces have to be considered a success. In particular, negotiating a gradual transition to CDC governance in traditional kinship-based communities represents successful adaptation of the NSP to local conditions. It appears from the FP's and community members' comments that the experience of the DRRD staff contributed to these successful community relations. The favourable attitude to NSP of the leaders of the so far non-participating community also seems to have resulted from contact with DRRD. It should be noted that the DRRD and FP worked together for two years before the appointment of the $\mathrm{OC}$, although the present head was at the time also working for an NGO in the province.

It was evident from the FP's approach and the two districts they cover that the NSP in Badghis is also making significant, though slow progress in involving women in community governance, by the same gradualist approach.

\subsection{Limitations}

However, as noted by the OC, both the FP and the DRRD staff lacked professional and technical competence. The DRRD is also generally short-staffed though it has given priority to NSP staffing. In this situation the OC saw his role as taking full operational control of the programme while giving importance to building the capacity of the FP through training and direct supervision, and to empowering and building the capacity of the CDC. However, he seemed to marginalize or substitute, rather than support the DRRD team though he kept them informed. In particular this approach did not build on those community relations skills they undoubtedly possess.

The arrangement described above represents a failure of partnership and team building, but was probably induced by the perception that it was essential to ensure the implementation of the programme to the expected targets within the time frame. The capacity-building of the DRRD, in the difficult circumstances of the province with a weak facilitating partner, was a task too many for the OC.

Threats to further implementation However, the result of the OC approach is that the $O C$ team has made itself indispensable to the continuation of the NSP in the province and the prospect of DRRD assuming even an equal role, despite their growing capacity, is remote.

\section{The CDCs}

\subsection{Mobarak Shah}

- Ab Kamari District

The Research team interviewed the Chairman of the CDC at his home with some of the other members of the CDC (all men).

\subsubsection{Community profile}

The village is situated at $40 \mathrm{~km}$ from the centre of province. The road is dusty with many passes. It is narrow at places, only accommodating one vehicle at a time. The road also passes through a river at some places.

The village is dry, remote and threatened by possible demolition by the floodwater of a small river that flows from the middle of the village.

There isn't a single vehicle available in the entire village of 375 families. To transport seriously sick people, the villagers have to 
go to Dai Zangi Village, which is at a distance of $30 \mathrm{~km}$, to find a vehicle.

The inhabitants of the villages are mainly Tajiks. People are dependent on farming and livestock for livelihood. Those with 150-200 animals are considered rich, whereas poor people have only one animal.

The nearest source of drinking water is four hours away from the village, as river and underground water is salty and not suitable for human and animal use.

There are around 35 widows in the village.

Seventy-five families have been left out of the NSP.

\subsubsection{Legitimacy and acceptance of the CDC} When asked about the leadership of the council, the $C D C$ members unhesitatingly said it was the tribal council made up of 30 elders and clerics. When asked about the relationship between the two councils, they said there was collaboration and consultation between the tribal council and the CDC. However, they thought that there was more trust in the $C D C$ than the tribal council and (probably for that reason) they were sometimes involved in resolving community conflicts. This suggests a growing legitimacy despite the fact that they and the householders interviewed still recognized the leadership of the traditional council.

\subsubsection{Functioning of the CDC in relation to the whole community}

The community had been made aware of NSP by BRAC and (see below) the DRRD held a meeting with the elders (traditional council) before the CDC was set up. (This confirms the FP's assessment of the importance of the DRRD experience in dealing with local communities, which was downplayed by the OC.)

The CDC members did not give any more details of the actual process of setting it up and the householders interviewed (see below) also did not elaborate. As explained in the profile, 75 families are not included in the CDC. However, the other groups in this large community are represented by 15 active CDC members. They discuss the issues, exchanging views in order to reach a consensus, and tasks are allocated to individual members.They take notes of important matters as well as minuting their meetings.

\subsubsection{The Project}

The community was implementing a project to build reservoirs of clean drinking water.

The members said the process for selecting the project started with the CDC identifying the problems; they then 'consulted everyone' and set the priorities. (This description and the fact that no householder described being actively involved in the decision-making suggests that it was not actively participatory.)

They said there had been no differences of opinion so far (the need for drinking water is clearly acute and affects everyone) but said if differences do arise they would decide 'on a majority-minority basis'.

Once the decision was taken the CDC started implementation with the guidance of the FP. They did not respond when asked if there had been any disagreements over the implementation.

As regards participation they claimed that those in executive positions in the $C D C$ spent 80 per cent of their time on the project and the other members 50 per cent. One member of the CDC monitored the implementation on a daily basis. (That is the work being done by the other villagers as paid labour, but they did not mention this.)

They said that a volunteer would be responsible for the maintenance of the reservoirs when complete, but had obviously not thought out exactly what might be involved or any possible costs.

They estimated that completion of the project, while generally beneficial, would only contribute 30 per cent of the villagers' need for drinking water. It would reduce but not remove the need to use briny water. (It was not clear if the location of the reservoirs was going to give equal access to all the villagers.)

\subsubsection{Activities beyond the NSP}

The CDC has so far not thought of other projects or approached any organization. (They are still implementing a first project and are remote from any such contacts.)

\subsubsection{Relationship between the CDC and government}

The CDC members said that they contact government whenever they have a problem and the District Administrator had also visited the village once. The community
THE PRO VIN CIAL FIELD SU RVEY REPO RTS 
elders had held a meeting with the DRRD before the setting up of the CDC.

They described the relationship as mutually beneficial but thought that more attention to it on the part of government would improve the partnership, since the people were more than ready to cooperate.

However, they said they take complaints to the FP in the first instance, followed by the $O C$ if there was no result. DRRD would only be contacted if the $\mathrm{OC}$ failed to respond.

(This reflects the way in which the DRRD appears to be marginalized in the management of the NSP even though, in this area of community relations, it does have experience and competence.)

\subsubsection{Relationship between the CDC and the FP}

The CDC thought that the FP had given them good guidance on the process. They had overseen the work on the project for which their engineers had designed the structures, while on site the CDC leads the project. They had received orientation on the NSP and training in accounting and procurement, both of which they found useful. At another point in the interview they expressed what appears to be genuine satisfaction with the work of the FP: 'They listen to us. They have been guiding and facilitating the process well.'

\subsubsection{The capacity of the CDC}

In relation to the criteria in the Operational Manual for a fully functioning CDC, the CDC in Mobarak Shah still lacks full capacity. In the first place although elected, the household survey indicates that at least some of the residents did not vote and most householders had no understanding of it as an institution of governance rather than a project management committee. There was also no evidence of the participation of women in the $\mathrm{CDC}$. The authority of the CDC as the sole representative of the community is also not established, although there is a collaborative rather than confrontational relationship with the traditional leadership, which suggests mature judgement on both sides.

As regards the planning and implementation of the project, the process of deciding on the priorities for community development did not involve active participation by the community and there was no evidence of a community development plan (though some project ideas were mentioned by householders). Consequently there was no view as to next steps after the initial project. They also did not yet have adequate plans for maintenance.

However, they were actively engaged in managing the project, apparently to the satisfaction of the villagers, who have contributed in labour and money as envisaged in the manual (see Household Survey below). They were recording important decisions and minutes of their meetings (as well as their financial transactions; see Household Survey) in the interests of transparency. A minority of householders interviewed were able to follow this and all the householders had been informed about the government funding though no account was given, as in other communities, of regular meetings to update the villagers on the use of the funds and they had little awareness of how and when the CDC works.

In the light of this evidence, this CDC could be classified as 'able with difficulty' to fulfil its role and needing continuing facilitation and support. As the FP pointed out, the remoteness and general lack of awareness and capacity of this community are likely to have influenced the time required to establish a fully functioning CDC.

\subsection{Dai Zangi - Abkamari District}

Eight members of the CDC (all men) were interviewed in the Chairman's house.

\subsubsection{Community profile}

There are 295 families in the focussed community. Main sources of livelihood are farming, livestock, and carpet-weaving women are the main producers of carpets.

Rich people can be determined from the number of animals they have and the land they own. There are some people in the community who have up to 100 animals and five jeribs of land who are the best off of all. The families with a middle status have 2-3 men who are physically able to work and earn. Eighty per cent of families are poor, a number of which are women-headed.

There are twenty women-headed families in the villages. There are 56 families which have either a widow or disabled people. The community demand is a clinic. They didn't have a school building, which they will have through another MRRD programme called 'school window'. 
6.2.2 Legitimacy and acceptance of the CDC The CDC explained that the community is still led by a council of elders, but that the $C D C$ is in the process of replacing it. For the time being there is good cooperation between the two councils, especially as two members belong to both councils.

The $C D C$ has only been able to change the way the community is governed in some aspects. At present it deals mainly with economic development while the other council still 'takes care of political aspects'. (The householders interviewed were also aware of this compromise.)

\subsubsection{Functioning of the CDC}

\section{in relation to the whole community}

BRAC had informed the community about the NSP, though (see below) DRRD was also involved. The CDC has 13 members but only considered 11 'active', saying that the two who could not give time to the CDC would be replaced.

They meet weekly to discuss matters and try to reach a consensus. If they can't agree they then get the rest of the community involved.

They are not able to document much of their work, but showed some records. The problem is that the member elected by the people to be secretary is illiterate, but they feel they must respect his election because it ensured the equal participation of different sub-tribes. (Unity and peacebuilding were the main benefits that the householders interviewed attributed to the $C D C$ in their community.)

\subsubsection{Projects}

The CDC members described how, with the help of the FP, they started discussing priorities within the $C D C$ but were split between an electricity project and a school project. At this point they put the matter to the community and a majority opted for the electricity project. (It seems they were asked to choose between these two options only, rather than being asked to list their suggestions at the beginning of the process, as in CDC processes elsewhere. The householders, for example, mentioned a number of ideas, especially a clinic. However, this would depend not just on their choice but the ability of the health ministry to allocate staff. Since they are now to have a school anyway, this was presumably already contemplated by that ministry.)
The CDC were able to implement the project themselves, providing both skilled and unskilled labour from the community. They already had an electrician, a good mason and two mechanics in the community and said the project had been 'a learning opportunity'. Skills such as these are also normally transferred where they are needed in the neighbouring villages.

CDC members all participated and key members, especially the Chairman, were fully occupied with it, spending a lot of time monitoring it on site. (The householders interviewed also described a high level of paid and voluntary participation by the community and CDC members.)

The main benefits they envisaged from the project were that their children would be able to study and the women would be able to see better for weaving and increase their carpet production. They also seemed to think that it would be cheaper than buying oil for lamps.

The FP had made them aware of the need to plan for maintenance and they had decided to hire someone to look after the machine on a full-time basis. They talked of 'putting together a fund' to pay for this and the cost of fuel. However, they had not yet worked out how this money would be raised.

\subsubsection{Projects beyond the NSP}

The CDC was already discussing a school project with the DRRD that would be funded through a different programme (school window). While the 'other' council of elders was generally taking care of other issues in the community, the CDC does sometimes try to resolve disputes, referring them to the tribal council if they fail to resolve them.

They also said that they had now learnt enough from the initial project to be able to spot the 'mistakes made by the engineers' in any future projects.

\subsubsection{Relationship between the CDC and government}

They said they support the government because they elected it. Their main contact with government is now through the NSP, and the provincial director of DRRD has visited them three times.

They said 'of course' the relationship is good. They described it as a 'people's government' and thought the partnership
THE PRO VIN CIAL FIELD SU RVEY REPO RTS 
would improve with more cooperation. They could even cooperate over security. Nevertheless the NSP had already improved it a lot through 'the trust the government has put in the people to have the power to decide'.

They had however had some complaints and they had put these to the Minister when he was in Badghis. Apart from that they normally complain, if they need to, to DRRD, the FP and the OC.

\subsubsection{Relationship between the CDC and the FP}

They said that the FP 'over all' had been good. They were always accessible, complete their part of the work on time and had given useful guidance. However they have some 'shortfalls'; for example, lack of professional staff. From other comments, it seems that the engineering input was unsatisfactory.

Apart from the facilitation by the FP, already described, they had been on exposure visits to other communities implementing NSP projects. This convinced them that projects carried out directly by communities were of a higher standard than those implemented by contractors.

\subsubsection{The capacity of the CDC}

This CDC, while still negotiating its position with the traditional authority, had established its legitimacy and involved the community in its activities. The involvement of women was not evident in the CDC itself (no women's shura was mentioned) but the women had voted in the CDC elections and the first project was aimed at enhancing their earning capacity (a benefit for example to the female headed households and those with many women members, including widows).

CDC members were fully aware of all the requirements in the Operational Manual and the council was complying with them within the constraints imposed by the need to negotiate inclusion of all stakeholders.

They had acquired the capacity to manage projects, building on existing capacity and proactively learning from this first experience. They were already looking to further development activities. On this basis, this CDC can be described as 'able', even though it has not yet achieved the model of governance envisaged by the NSP.

\section{The Household Survey \\ - CDC communities}

\subsection{Mobarak Shah}

- Ab Kamari District

A community with a CDC and a project being implemented.

\section{Summary of results}

\subsubsection{The sample}

Representatives of 9 households ( 8 men and one woman, a widow) were interviewed. The smallest household had 6 members and the largest 32 (average 14) but all the households seemed to have adults of more than one generation, or siblings and their families together.

One family was headed by a widow and two by war-disabled men, one of whom had a sick wife. Several families had other dependents: one with three disabled adults, one blind woman and two paralysed men; one with a paralysed man and another sick person; one supporting a widow and a sick woman; one with a disabled man. Poverty, lack of a water supply and distance from any medical assistance (see the CDC community profile) leading to poor health, seem to have been the factors leading to dependence in the majority of cases, not war injury.

Three households were farmers of their own land. Two of these described themselves as of 'middle' income in the village; one had two cows. The third, one of the larger families, also kept $70-80$ head of livestock and harvested pistachio. They considered themselves 'rich'. Another large family with only 4 male members (including the disabled head) to 16 female, were nevertheless 'rich' because they kept a shop. Four families lived from paid labour (in two cases on the NSP project); in one case combined with some cultivation. Three of these considered themselves 'poor' and one 'middle'. Another 'poor' household made a living from 'a donkey for transport'. (This householder became uncooperative with the enquiry and refused eventually to respond. However, since he claimed that his life was worse after the war, he may have been making money in some way from the war.)

All those interviewed were Tajik, which is the predominant ethnic group in the area.

When compared to the community profile 
given by the CDC and the district profile from the FP, the sample seems to provide a representative cross-section, though the sick and disabled may be over-represented.

\subsubsection{War experience/post-war}

All the families remained in the village during the war and did not seem to have been under constant threat in their homes. One family said they were unaffected by the war. The shopkeeper was shot and disabled and his house was looted. One of the farmers also had his house looted. Another had been injured, but not otherwise affected. The widow said her husband was injured once, but he died later of illness. (These may have been fighters or just unlucky.) Three families spoke of men from the family who were 'martyred', one saying the family were 'in the Jehad'. These cases clearly refer to fighters.

Nevertheless, the main improvement in their lives since the end of the war (cited by seven of the nine) is peace and greater security. Three mentioned the assistance through the NSP and others referred to the wider context: democracy (one), reconstruction (one), more employment (one), greater national unity and international support (one).

One householder simply said his life had not improved: it was worse.

\subsubsection{The history of the CDC}

Three householders described the CDC as an elected council for implementing the NSP and its projects or, as one said, to 'streamline' the delivery of assistance from government. One of these said that BRAC had explained the whole process to them. Two others were less specific, saying it was to 'serve and help the people' and to tell them 'how to work'. One respondent gave a very detailed reply: 'The CDC is for NSP. It is a very important programme. It is linking the people to the government. The best practice of the programme is the fact that people have been given the decisionmaking authority. This certainly has a very positive effect. People are very interested in CDC since they know it is in their interest.'

However, 3 respondents, the widow, one of the severely disabled and the respondent who eventually refused to answer questions, said they did not know what the CDC is, though the disabled man said he knew someone who is a member. They also didn't know how long it had been function- ing, though the widow thought it was since the year before. None of these had voted in the election.

Five respondents, who all voted in the elections, suggested periods from 4 months to two years. (As in other communities these answers probably relate to different stages in the process. The respondent who said two years was the one who knew most about it and probably followed the process from the start.)

One disabled householder, who was clearly following the work of the $C D C$, knew that the project had started 3 months ago, but could not say when the council had started. He had also not voted.

As regards community decision-making before the $C D C$, the widow and the severely disabled householder said they did not know. Three others said a council of elders and Mullahs determined the priorities. Another 3 said 'another council' of representatives decided, and one said there was 'no organized effort.'

\subsubsection{General understanding and awareness} There seems to be a compromise and informal separation of spheres of interest between the new $\mathrm{CDC}$ and the existing council of elders: the CDC dealing with project development and the elders retaining the role of representation to government. The majority of householders therefore saw the CDC only in its role as an implementer of development projects and valued it for its practical impact on their lives.

As in other communities, the most disadvantaged had very little involvement in or knowledge of the functioning of the CDC.

The majority of householders could not say anything about the financial management, but those who were able to follow it were satisfied that it was transparent and competent.

However, the majority did understand that the money was being delivered to them by government. Some were also aware of other government initiatives for reconstruction. As a result the majority did think the government is interested in their community, and two cited this as a reason for optimism for the future. The implementation of the project had therefore encouraged some feeling of national solidarity.
THE PRO VIN CIAL FIELD SU RVEY REPO RTS 
The majority did not recognize any impact on community solidarity, but 4 did see that there was less conflict as a result of the CDC and two of these perceived its political role.

\subsubsection{The CDC today}

\section{Functioning/legitimacy}

Five respondents could not say how often the CDC meets. The other 4 all said it meets weekly, one saying on a Thursday. Only 3 expressed any opinion about how it works. One simply said it meets to 'discuss what it is best to do'. Another, who had said he doesn't know when it meets, also said he didn't know how it works because, 'they don't let the poor participate'.

The most prosperous member of the group and a traditional leader, however, said it works well and there is more understanding as a result of the CDC. In response to the next question he said he is the chairman of the council, which leads the community. According to 3 others who answered this question, this is not the $\mathrm{CDC}$ but the preexisting council composed of elders and Mullahs. Two other respondents suggested that the CDC and the traditional council led the community. (These responses confirm the statements of the CDC about the current [transitional] collaborative arrangement between the two councils: see also below the chairman's enthusiasm for NSP.)

The severely disabled householder and the elderly widow found it difficult to answer this and most of the other questions about the CDC. The respondent who eventually refused to answer any questions gave no response to this one.

The chair of the traditional council said it was working closely with the government and from time to time visited the district administrator. Two other respondents thought that maybe sometimes the leaders worked with government. Two said no they did not, and the rest said they did not know.

\section{Projects}

The respondents were more forthcoming on the subject of the project. Five, including the Chair of the traditional council, had no doubt that the money came from the government through a government programme. The elderly widow and one of the farmers also thought it might be government. Only one described it as a partnership of the CDC, the FP and the government using government money. Three others said it was the community's initiative in deciding on the project and asking (one said 'demanding') money from government. There were two non-responses.

Five respondents did not know if the community had applied to any other organizations for funding in the past and one was certain they never had. However, the chair of the traditional council said they had applied to both NGOs and government and had been surveyed by WFP and a Norwegian NGO but without success. Two other respondents were aware of these unsuccessful efforts.

Despite their lack of knowledge of the functioning of the $C D C$, all 7 respondents (except the severely disabled and the elderly widow), had participated in the project: three as paid labourers; two (including the respondent who answered no further questions) had contributed 10 per cent to the community fund and one day of voluntary labour every 10 days; an elderly farmer had contributed 20 per cent and his grandsons had worked; the chair of the traditional council had worked voluntarily.

The traditional chairman said the council and the villages had participated and there had been only 'limited' difficulty in getting this participation. Four others simply said the villagers participated and there had been no problems. Four could not or did not answer.

On the subject of future projects, 3 mentioned a road project, one a livestock project for widows and one clinics. Another simply said they let the CDC know their needs so they could find resources and ask the government for assistance. Four did not know.

Financial management

Four respondents had nothing to say on this subject. One said the elders knew about it and another said he knew about it 'to some extent'. Three were confident they knew about it: one said that they made the CDC accountable (perhaps orally?); another that they were able to 'trace' the procurement and expenditure; the chair of the traditional council said it was recorded in the registers of the CDC.

\subsubsection{Impact of NSP/CDC}

By this point 3 respondents had clearly tired of the interview. One said he had given a 
page of information and that was enough. The widow and the severely disabled householder probably found most of the questions irrelevant or beyond them.

Two others found it difficult to give a general assessment of what NSP/CDC meant to them. Three associated it with development and progress, bringing work and better lives. The traditional chairman also called it 'a very positive step' and said the $C D C$ was the best entity for the implementation of development projects. (Reserving other roles to the elders). However, one respondent (the shopkeeper) stressed the political role: its promotion of 'equal participation' and an end to 'dominance and manipulation' by a few - 'no more use of the gun'. (This matches statements from other communities that CDC helps to reduce the influence of warlords and former fighters.)

Thinking about how it had affected their lives, some were able to see some practical impact, or the prospect of it: work, the means to get food and access to clean drinking water in the village were mentioned by 4 respondents who had not commented on the general impact. No one could think of anything else that had helped the community.

Five were silent on the subject of village unity. Four thought there was less conflict and more unity, peace and harmony. The traditional leader spoke at some length:

\section{'Continuous meetings give the chance to people to know each other better resulting in reducing the hatred and conflicts. The inclusive participation has proved to be ver y useful in promoting unity.'}

On the subject of government plans, 3 spoke of reconstruction of roads, the provincial capital and the surrounding villages. One said they were helping widows and orphans. The researchers noted that the traditional leader, a former district administrator, spoke at length showing detailed knowledge of government plans.

Six respondents had no doubt that government is interested in the community. One said 'Yes, 100 per cent'. Another said since they backed NSP they might help again.

\subsubsection{Confidence in the future}

Thinking of what might improve their lives most, two referred again to the prospect of clean drinking water in the village, 3 mentioned retaining walls to contain the stream in the village and 4 also mentioned roads. Two respondents (not themselves disadvantaged) started by saying assistance for the poor and needy, such as disabled and widowed. The widow thought a clinic and food were her priorities after the drinking water. The rich farmer and traditional leader wanted help for agriculture and livestock as well as electricity. Another farmer first said, 'more peace' then thought of wells, tractors and electricity.

Three had no comment on the future. However, the widow and the severely disabled householder both responded to this question and said they supposed there would be no more war. Another thought things were getting better because the conflict is over and there are 'no more guns in public'.

One felt optimistic because of the reconstruction in the country and the assistance being given. Another said simply, 'The mechanism seems to be working.'

The traditional leader again spoke at length:

'I am very optimistic. There is justice. The rule of law helps to develop.

There is less interference from our neighbouring countries. The

international community has been on our side and making many

sacrifices - even sacrificing their lives.

The in vestment made in Afghanistan is making us further optimistic.'

\subsection{Dai Zangi - Ab Kamari District}

A community with a CDC and a project being implemented.

\section{Summary of results}

\subsubsection{The sample}

One woman and 7 men representing 8 households were interviewed in their homes. There were no nuclear families. All households included at least 4 adults, of different generations or siblings. The average family size was 11-12 with 5-6 children, the largest having 20 members, 10 of whom were children. Four said they had no dependents although one of these was himself disabled. Another disabled householder was responsible for his blind mother and sick wife. One householder had a mentally ill daughter, one a disabled son
THE PRO VIN CIAL FIELD SU RVEY REPO RTS 
and one cared for two elderly relatives. None seemed to have been injured or impaired as a result of war.

The woman householder made a living from carpet-weaving and owned a donkey. Carpet-weaving was one of the economic activities (probably of women) in 6 other households. Five also had land (in two cases at least, rain-fed only). Four of these had livestock, but in some cases only a few animals. The head of one of these families was the Mullah who had 20 sheep and more land than the rest. He also received contributions from the villagers for leading prayers in the Mosque. Pistachio nuts were collected for sale by 5 households (including the landless) and one kept a shop. Three families received some remittances from a brother working as a labourer in Iran. One landless family earned from day labour on others' land and from the NSP project.

Five families described themselves as 'middle' income (though in some cases this clearly only meant they are not the poorest of the poor). The shopkeeper, who also had land and livestock and carpet-weavers in his household of 20 , said he was rich. The elderly woman and the other landless householder described themselves as poor.

All the householders were Tajik, which is the ethnicity of almost all the population in the area.

The sample is broadly representative of the community as described in the $C D C$ community profile and consistent with the FP's description of the general population in the district.

\subsubsection{War experiences/post-war}

Five households were displaced during the war, the woman to the mountains and two to neighbouring villages. Two did not say where they went. One of these left when a relative was killed, but his house was not looted. The other said a relative was martyred.

The other 3 households said they were not much affected by the war, one because he had already left to work in Iran. All thought things were better since the war ended. Five said there was more security and peace. One of these, the Mullah, dated this increase in security from when the Soviets left. Another related it to the demobilization. Two said there is now more stability.
One of these thought things were generally 'moving'. One householder, the shopkeeper, thought there is more employment but two others that there was no economic improvement and the Mullah said they had had more drought.

7.2.3 General understanding and awareness The householders were generally aware of the aspirations of the NSP and knew that it is a government programme. Most did not mention BRAC, or ascribed a secondary role to it. The exact status of the OC was not known, but he was mentioned by name. They also understood, in general terms, the purpose and functions of the CDC and in most cases saw it as providing a better representation than the traditional council, particularly by representing all the tribal groups and including everyone in the project. Some recognized that the tribal elders were still part of the decision-making process, some at least as CDC members. Some hinted that there were still differences.

The majority did not know about the detailed working of the finances or what went on in the CDC meetings, but knew when it met, felt they were informed about purchases or were free to ask information. It seems that they felt no need to be further involved. One did understand the Block Grant system and how it was being used.

They had a similar confidence that the government was acting in the interests of the country, without having any detailed knowledge of its policy or programmes. Their opinion was apparently influenced more by what they were now seeing on the ground, especially NSP. Their aspirations for the future were concerned with material improvement, employment and economic growth and the continuing stability made them hopeful that things would get better.

\subsubsection{The history of the CDC}

The majority of the householders (5) described the CDC as their national solidarity council, two adding that it 'encourages peace and unity' and 'brings resources and funds to the village'. The woman was unsure but thought it was a council. Two householders described it as a council set up by BRAC. One of these added that it 'encourages cooperation between people.. The Mullah, however, said he was too busy to know much about it. (He was probably a member of the traditional shura, see below.)

The estimates of how long the CDC had 
been functioning ranged from 6 months to two years. While all had participated in the election (two stressed that everyone, men and women voted, the Mullah said he had been 'consulted.'), there was little knowledge of how the electoral commission was chosen. Most did not know, the Mullah gave no answer, two said the people had chosen them at a meeting and one said BRAC had chosen them.

When asked about decision-making prior to the $C D C$, the woman said she did not know and another householder said this kind of exercise had never been done before. The other 6 all described traditional arrangements: a shura of elders and clerics; named Arbabs; a monthy shura of representatives from 16 villages. One of these added that it was for conflict resolution and had never been like the CDC. One later also mentioned the power of warlords which had now been replaced by the rule of elders and the CDC.

\subsubsection{The CDC today}

Functioning and legitimacy

Six of the respondents thought the CDC met once or twice a week. The woman said she was too old a woman to know, the Mullah said he was to o busy. (In fact he had to cut short the interview at this point to go and lead prayers.)

Four respondents could not say how the CDC works, though one had heard that it works well. Another said, 'The CDC knows, not me.' Another said it meets to talk and make decisions, but as he was not a member he couldn't say more. Two respondents gave an explanation: one said it 'belongs' to the DRRD and implements projects; the other said it works democratically and well and the finances are made public.

When asked about the leadership of the community 4, including the woman householder, said unequivocally, the CDC; 3 described an accommodation between the traditional leaders and the CDC; one said the elders led the community but some are in the CDC; two said the community was led by the CDC and some elders; one respondent gave no answer.

As regards contact with government, apart from the woman, who did not know, the respondents said the $C D C$ was certainly in contact. Two said they had been to see both the District and Provincial Governors and one said government representatives had been at the CDC opening ceremony.

\section{Projects}

When asked who initiated the project and where the money came from, 3 said that it was BRAC with money from government; 3 said it was the government or MRRD for government, and one said it was the DRRD and the OC (named) with government money.

Four said they had approached government and NGOs in the past whenever there was an opportunity but nothing had come of it. The others were not aware of any approaches.

The woman and one of the disabled householders had not participated in the project but all the others had: another disabled man as overseer; one with paid labour; one with paid labour and voluntary days; one with (voluntary) labour; one by paying the 10 per cent contribution. They all said the other villagers including the CDC members had also participated and there had been no problems in getting them to join in.

They were also aware that the CDC had other projects in mind: a bath house (Hamaan) and a project to assist widows and the disabled were mentioned. The elderly woman did not know of anything but said 'Karsai has helped so far' and no other 'king' had done that before.

\section{Financial management}

The woman did not know about the finances and one other respondent said he did not know and then gave a figure for the money received. Five others said either that they were given information whenever they asked or that those responsible reported or were accountable to the villagers for any procurement. Two said they did not know the details of what was done in the CDC, one of whom asked, 'Do I need to know?'.

Three could not say how the Block Grant was spent (or did not understand the question?) and one said it was handled by the procurement team. Three knew it was being spent on a generator. One of these explained that the first instalment was used to build the generator house and to purchase the wiring and that the second instalment would buy the generator.

\subsubsection{Impact of NSP/CDC}

Five respondents described the NSP/CDC as
THE PRO VIN CIAL

FIELD SU RVEY REPO RTS 
'unity', 'solidarity', 'mutuality', 'being together'. 'Peace', 'peaceful progress' and 'strength' were added by 3 of these. One other respondent associated NSP with poverty eradication and 'better lives'. The elderly woman had no answer.

One respondent had to go shopping and did not answer any of the following questions. Five thought the NSP/CDC had improved their lives or would do so. One said the electric light would help with the carpet-weaving; the others could not explain why things were better and one pointed out that the price of oil was more than they had expected.

Most said they had had no other help, but one mentioned World Vision and a Norwegian NGO as having helped, as well as naming the OC. (It was not clear if this was when he worked for an NGO or now that he is OC.)

The 5 who had described the CDC as 'unity' naturally agreed that there was greater unity as a result of its creation in the village. However, the respondent who first described the NSP as for poverty eradication, at this point said that the $C D C$, by including representatives of all the tribes in the village, had created greater unity. Another made the same point and said the fact that they all participated in the project was a sign of unity, but warned that 'there are problems'.

Most did not note any other changes, except one who mentioned 'progress and work' and one who thought the existence of a representative council to guide the affairs of the village was significant.

None of the respondents had any detailed knowledge of government plans. The woman simply said people are happy with the government. Two others were confident that the government has long-term development plans (like NSP as one said) and one thought there were plans for roads. Two others had no answer.

All except the woman, who did not know, thought the government is interested in their community, citing in two cases NSP and paved roads as evidence.

\subsubsection{Confidence in the future}

Asked what would most improve their lives, most thought in terms of material assistance. The woman householder thought any assistance would be useful while another said they needed everything (schools, clinics, roads etc.). Clean drinking water, schools, clinics and roads were also mentioned and one farmer said 'help with livestock'. Two respondents thought more in terms of underlying conditions: economic growth, security and employment opportunities for all.

The respondents were hopeful rather than optimistic about the future, saying that things were improving. One said better security allowed them to concentrate on their work. Another felt more confident since the affairs of the village were run by the CDC. The woman householder expressed no opinion.

\section{Matched community without a CDC}

\section{Charsangi - Ab Kamari District}

This Tajik community shared many of the problems of Mobarak Shah: lack of clean drinking water, remoteness and lack of transport preventing access to health care, inadequate schooling. Four elders of the community, Arbabs, were interviewed in an open space in the centre of the village.

\subsection{Existing governance}

The Arbabs explained that the community is governed by a council of elders who represent the different sub-villages. They deal with all issues arising in the village except legal matters. These are dealt with by another council of clerics. They therefore considered that the leaders of the community are both elders and clerics.

\subsection{Development needs and assistance}

They felt that they were unable to meet their basic needs. They need wells to be dug. Many villagers die for lack of health care. Like Mobaak Shah they have no vehicle to take anyone to a clinic. The village school does not provide education beyond grade 3 .

They had received virtually no assistance so far except from World Vision which had given some assistance for clean water; first by supplying clean water in a tanker, and secondly by constructing some reservoirs. However, these measures seem to have alleviated rather than solved the problem. 


\subsection{Relations with government and perceptions of national solidarity}

The leaders do contact different government entities and the district administrator does visit the village. However, this falls short of what they think ought to happen, namely that 'government and people should be constantly in contact'. There should be solidarity between the two and 'government should know about our needs'.

\subsection{View of NSP}

They had heard of the NSP as an MRRD programme and knew that it provided Afs 10,000 per family towards development projects. They therefore welcomed the idea of a CDC. However, like their counterparts in Mobarak Shah and Dai Zangi, they expected it to complement not replace other forms of governance in the community and that they would all cooperate with each other. (As the two existing councils apparently do.)

\section{Household survey of communities without CDC: Charsangi - Ab Kamari District}

\section{Summary of results}

\subsection{The sample}

Seven men and two women (widows) representing households were approached for interviews. One of the widows almost immediately felt she was not able manage the interview, saying, 'My head is not working. I don't know what I say.' The others all completed the interview.

The average household size was 12 , the smallest had 8 members and the largest 24 . Only one was a nuclear family of a husband, wife and 7 children. The others all had 5 or more adults and between two and 16 children. The widow who completed an interview was vague about her family, but it seemed to consist of herself and her widowed daughter and a number of children, some of whom may have been of working age, but there was certainly no male breadwinner.

Four of those interviewed were themselves disabled or sick, and one had mental problems. Only one said his disability was due to the war. Four said their wives were sick or elderly and one was supporting elderly parents.

Four households described themselves as poor. The widow's family were landless and lived by paid domestic work and making quilts for sale. Another landless family relied on paid farm labour. One disabled householder said he had no source of income. The war-disabled householder had a small plot of land and a donkey.

The other 4 householders all had land and livestock. Those with less land and fewer animals described themselves as of 'middle' income. One of these (a former commander) also earned additional income as a teacher. Two householders had quite extensive land and more livestock. They both made additional income from collecting pistachios. One of these described himself as 'rich' but the other, with a household of 8 adults and 16 children, as 'middle'.

All the householders were Tajiks.

The sample is consistent with the general description of the poor farming communities in the district given by the FP, and closely matches the two communities with CDC, particularly Mobarak Shah.

\subsection{War experience/post-war}

Five respondents thought they had not suffered much in the war, because there had been little fighting in the village. One of these was a former commander. Another, since no one in his family was killed or displaced, said he suffered 'indirectly'. Two of this group were displaced, but one said he took refuge in the mountains for short periods only.

Three other householders were more directly affected. The 'rich' householder had a relative killed and was displaced to another village. One simply said he was disabled in the war. The widow said her brother-in-law was 'martyred', her house was looted and she was displaced to the mountains.

Seven householders thought things were now better because there was more security, an end to fighting and peace. One said it was better because they had received some aid. The widow said things were no better because she had no donkey and no cows.
THE PRO VIN CIAL FIELD SURVEY REPO RTS 
When asked about what assistance they had received, two said they had never had any. The other 6 said they had had some food aid from a Norwegian NGO (the widow said it was from government).

\subsection{General understanding and awareness}

This community felt itself to be very remote from national government, but generally united under a traditional leadership, which they thought was working with the local government when necessary. One respondent suggested that this council was newly empowered since the warlords no longer dominated.

Although the villagers recognized this leadership, and were willing to participate in community work if asked, they seemed to take no part in decision-making or discussion of community issues and were not informed about actions taken on their behalf.

As they were already in touch with the FP, BRAC with a view to joining the NSP, they had some idea of what was involved. They understood that the CDC is an elected representative council, that would give them access to funding and assistance they had so far failed to get. However, the most disadvantaged seemed to understand nothing about either NSP or government.

On the whole, they did think the government might be interested in their community, especially as a result of recent delegations and voter registration, but several were sceptical. Most were prepared to say they were hopeful for the future. This view seems mainly influenced by improved security rather than any material improvements.

Responding to a survey was obviously an unfamiliar experience to several respondents, but less daunting for the men than the women who both lacked confidence, to the extent that one dropped out of the interview. This might be due in part to being interviewed by men, but was also clearly due to their self-consciousness about their lack of education and knowledge.

\subsection{The community today}

Three of the four individuals interviewed by the research team as community leaders, were all named by at least two of the respondents, so there seems little doubt that they are the leading figures in the village.

The former commander said that the warlords were no longer in control, so the community is led by the elders and religious scholars and named one of the three as the head of this council. Two other respondents named the same individual as head, but one also mentioned one of the others. Two described the third man as Arbab and leader. The widow named this man and one of the others as leaders. Two gave no names but spoke of a representative council. One of these, the 'rich' householder, said he was a member of this 15 member council.

All the respondents said the village is united. Three said 'very united' and two that it had always been united. However, when asked how priorities were determined, only the council member said this was discussed in the shura. Two said priorities had never been discussed and the rest had no answer.

Apart from the widow who could not answer, they all expressed willingness to participate in community work when needed, though two said they had never been asked. The former commander/ teacher said he had been called on to represent the village on several occasions and had been happy to do it.

The head of the shura (who also works for the Department for $\mathrm{Haji}$ and Religious affairs) was said to be in regular contact with government by 3 respondents. Two others were certain that the leaders contacted government when necessary. Two others were unsure but thought they probably were in contact. The widow gave no answer.

The majority of the respondents did not know of any attempts that the community had made to get assistance from NGOs or government before being in contact with BRAC about NSP. The council member and former commander were aware of many applications that produced little response.

Since the village was already in contact with BRAC about joining the NSP, the majority (6) said they had heard about it recently. They understood it to be about electing a representative council, as a means of making their needs known and getting assistance. Two spoke of it as promoting unity and one added that it is one of the government's good recovery strategies. These six naturally 
said that a CDC would be welcome in the village.

The widow and one other householder confused the $C D C$ process with the voter registration for the general election (which they clearly did not fully understand) and so could not say if it would be welcome.

\subsection{Perception of national solidarity}

The majority of the householders had little knowledge of government plans or activity. Five said they knew little or nothing. The widow was one of these and said she did not even know 'the new king'. Another said he thought the government was soliciting aid. Two were aware of government schemes elsewhere but saw no visible evidence of government working in Badghis, as it is doing in Herat and/or like what they hear on the radio.

Only the former commander/teacher had a positive view. He said the government had brought security and set up a parliament and he was looking forward to it. $\mathrm{He}$ also thought the government is 'very interested' in their community.

Three others thought that the presence of the researchers or previous delegations for vote registration etc. meant that government is interested. The shura member thought it is not much interested and another said it was not interested otherwise it would have done something. Two (including the widow) could not say.

\subsection{Confidence in the future}

When asked what would most improve their lives, water projects for both clean drinking water and to enhance the rain-fed agriculture (wells and reservoirs) were the top priority for 4 respondents; roads and a clinic were other choices. The representative of the largest household said simply, 'employment'. One elderly householder was perhaps rather weary of the interview and said, 'You know better'.

Not surprisingly, the former commander and teacher had a more strategic view, citing security and stability as the first requirements, followed by education and economic growth. Interestingly, his view of the importance of education was also strongly advocated by the elderly widow, who included schools in her comprehensive wish list:
'If our children were educated, they would be able to help us.

If I were educated, I would have responded from the top of mountain.'

(Dari idiom meaning, I would have given you very good answers)

Four respondents said they were hopeful or optimistic about the future without giving any reason. Two said only God knows. The representative of the largest family said only if there is paid work. Only the 'rich' man declared himself '100 per cent' optimistic because now weapons had been collected (from the fighters) this would allow the destroyed economy to recover. 


\section{Balkh Province \\ Provincial Field Research Findings}

$1_{\text {D avid Connolly (Team Leader) }}$ with Lida Rahimi and Asila Wardak.

2 Districts were selected based on vulnerability factors (level of poverty and risk of drought or food insecurity), the number of returnees or internally displaced persons (ID Ps), and security conditions. 0 ther criteria may also have applied. Each year FPs were invited to submit proposals to the MRRD to mobilize communities in new target districts and complete N SP activities in previously-targeted districts. FP proposals included a preliminary list of target communities. Individual FP contracts were awarded by province, to allow them to focus on a specific geographic area. The Government of Afghanistan intended to eventually offer N SP to all eligible rural communities (www.nspafghanistan.org and www.cha.org).

3 www.nspafghanistan.org
Timing and scope of the research

The research team ${ }^{1}$ conducted interviews and collected data in the Province between 25 October and 11 November 2005. Overall, the research strove to interview the main National Solidarity Programme (NSP) actors at all levels within the Province, from the household to the Provincial Governor (as listed below). The overriding aim was to achieve representativeness, and thereby to establish if there was a trend towards greater perception of national solidarity at the most crucial levels of the NSP, and among Afghans in general within Balkh.

The main research findings for Balkh Province are structured in 10 main sections. This provincial report starts with an introductory analysis of the NSP coverage and performance in Balkh based on secondary data. The second section reviews the methodological approach of the research team. The subsequent main analysis is separated into the roles of: the government as represented by the Department for Rural Rehabilitation and Development (DRRD) at the provincial and district levels; the provincial NSP Oversight Consultants $(\mathrm{OC})$ and team; and the two Facilitating Partners (FPs) in Balkh. This is then followed by an analysis of the findings from the sample of Community Development Councils (CDCs); households within these CDC communities; the selected community leaders without a CDC; and households within this non-CDC community. This report closes with some lessons drawn from an interview with the Community Forum Development Organization (CFDO) in Mazar, which is interpreted as the indigenous roots to the NSP and the CDCs.

\section{NSP coverage and performance}

In Balkh Province, 6 (42.86 per cent) of the 14 districts were engaged in the NSP. The Afghan non-governmental organization (NGO), the Co-ordination of Humanitarian Assistance (CHA), started as an FP in August 2003 and had extended the NSP within four districts (CHA Provincial Management Team, 26 October 2005). The second FP, UNHABITAT, started its programme in February 2004 and had extended it within two districts (UN-HABITAT Provincial Director, 1 November 2005).

\subsection{Charbolak, Chemtal/Alboraz, Dawlatatbad and Keshendeh Districts}

Table 1 below details the coverage and performance of the NSP as facilitated by the $\mathrm{CHA}$ in the 4 districts of Charbolak, Chemtal IAlboraz, Dawlatatbad and Keshendeh.

Table 1 demonstrates clearly the strategy of the NSP and the CHA to engage and then saturate districts with the creation of CDCs and the implementation of projects. For example, all the villages in Dawlatabad District were engaged in the NSP and all but one of the villages in Charbolak District had CDCs (CHA Provincial Management Team, 26 October 2005). Of course, this strategy is based on the Ministry for Rural Rehabilitation and Development's (MRRD) RollOut Plan, which identified target districts and established the total number of communities within each district to be mobilized. ${ }^{2}$ Overall, based on the aims of the NSP to reach 20,000 rural communities between June 2003 and June 2007,3 Table 1 demonstrates that the NSP was on track in Balkh Province. 
Table 1: Performance of NSP

\begin{tabular}{|c|c|c|c|c|c|c|}
\hline & $\begin{array}{l}\text { Charbolak } \\
\text { (District } \\
\text { No. 1607) }\end{array}$ & $\begin{array}{l}\text { Chemtal/ } \\
\text { Alboraz } \\
\text { (District } \\
\text { No. 1608) }\end{array}$ & $\begin{array}{l}\text { Dawlatatbad } \\
\text { (District } \\
\text { No. 1605) }\end{array}$ & $\begin{array}{l}\text { Keshendeh } \\
\text { (District } \\
\text { No. 1610) }\end{array}$ & Total & $\begin{array}{l}\text { National } \\
\text { Totals }\end{array}$ \\
\hline No. villages received NSP information & 50 & 79 & 60 & 77 & $266(336)$ & $(10,789)$ \\
\hline No. of CDCs received training & 50 & 79 & 60 & 77 & $266(317)$ & $(10,110)$ \\
\hline No. of established/elected CDCs & 50 & 79 & 60 & 77 & $266(317)$ & $(9785)$ \\
\hline No. of CDPs made & $50(48)$ & 79 & 60 & 77 & $266(315)$ & $(9230)$ \\
\hline No. of submitted sub-project proposals to OC & $27(24)$ & 144 & 147 & 160 & $478(480)$ & $(13,437)$ \\
\hline No. of (1a) project proposals prepared & 25 & 79 & 60 & 77 & 241 & Unknown \\
\hline No. of (1b) project proposals prepared & 2 & 55 & 55 & 53 & 165 & Unknown \\
\hline No. of (1c) project proposals prepared & 0 & 8 & 26 & 24 & 58 & Unknown \\
\hline No. of (1d) project proposals prepared & 0 & 2 & 6 & 6 & 14 & Unknown \\
\hline No. of instalments transferred to bank & 0 & $124(126)$ & $118(127)$ & 144 & $386(401)$ & $(12,022)$ \\
\hline Total no. of projects under implementation & 0 & 109 & 99 & 130 & 338 & Unknown \\
\hline No. of (1a) projects under implementation & 0 & 75 & 60 & 77 & 212 & Unknown \\
\hline No. of (1b) projects under implementation & 0 & 34 & 30 & 53 & 117 & Unknown \\
\hline No. of (1c) projects under implementation & 0 & 0 & 9 & 0 & 9 & Unknown \\
\hline No. of $(1 d)$ projects under implementation & 0 & 0 & 0 & 0 & 0 & Unknown \\
\hline No. of CDCs received 2 nd instalment & 0 & 72 & 54 & 46 & 172 & Unknown \\
\hline No. of women sub-projects & 0 & 9 & 22 & 5 & 36 & Unknown \\
\hline Pending sub-projects & 0 & 1 & 14 & 18 & 33 & Unknown \\
\hline Completed sub-projects & 0 & $20(11)$ & $21(18)$ & $14(11)$ & $55(40)$ & $(2,617)$ \\
\hline No. of all FP staff & 28 & 20 & 20 & 20 & 108 & (4185) \\
\hline Block Grant disbursed (Afs) & $133,460,000$ & $106,372,483$ & $94,514,309$ & $76,701,927$ & $277,588,719$ & $6,314,007,527$ \\
\hline & \multicolumn{6}{|c|}{$\begin{array}{l}\text { Compiled from statistical information from the National OC (up to } \\
30 \text { September 2005) and the CHA in Mazar (up to } 250 \text { ctober 2005) } 4\end{array}$} \\
\hline
\end{tabular}




\footnotetext{
4 Figures in brackets are from the $O C$ 's document. Where the figure is lower, this can be explained by the more updated information from the CHA's document. It cannot be explained where the figure is higher.

5 www.nspafghanistan.org

6 www.nspafghanistan.org

7 Through the impact of the latter on survival rates, the number of disabled Afghans was actually quite low.
}

It is important first to analyse the four districts as a whole, as a more in-depth comparative analysis of the two sampled districts is provided below. On the surface, there was a perfect success rate for the establishment and training of CDCs and the drafting of Community Development Proposals (CDPs). Furthermore, 1(a)-type projects formed the majority of the CDPs across the four districts. Apart from the district of Charbolak (as explored in more detail below), 84 per cent (approx.) of the total proposals submitted to the $\mathrm{OC}$ had received their first instalment of project funds, and this was typical of the performance in each of the three other districts.

There was a similar success rate in terms of the total projects under implementation. Within this, all or most of the 1(a)-type projects and 50 per cent (approx.) of 1 (bs) were under construction, while there were few 1 (cs) and 1 (ds). Just over two-thirds of the CDCs had received a second instalment, with Chemtal/Alboraz and Dawlatabad Districts representing the highest in this regard. Women's projects represented just over 10 per cent of the 338 projects under implementation.

Most significantly, only 10 per cent (approx.) of the project proposals submitted to the OC were completed, and therefore the field research attempted to explore the reasons for this weakness in addition to the other main facets of the NSP performance. Nevertheless, based on Table 1, it is clear that the communities appeared to be accepting NSP once they were engaged.

\subsection{Dehdadi and Nahrishahy Districts} UN-HABITAT had started 50 men's CDCs and 50 women's CDCs in Balkh from February 2004. The original plan was to create 70 each, with 34 CDCs in the district of Nahrishahy (suburbs which encircle Mazar) and 36 CDCs in Dehdadi (outside Mazar) (UN-HABITAT Provincial Director, 1 November 2005).

Regrettably, it was not possible to gain access to statistical data from UN-HABITAT. Nevertheless, such data would have been limited in insight because the CDCs were relatively new creations.

\subsection{Positive inclusion}

It appeared to be positive that the NSP encouraged villages to unite in order to secure funds for a project. That is, the NSP worked with rural communities of at least 25 families. Villages with less than 25 families could join with nearby villages to become eligible to participate in the NSP. ${ }^{5}$

\subsection{Limited inclusion}

Perhaps the most significant constraint of the NSP in terms of reaching the most vulnerable was the capping of funds for subprojects to 300 families. ${ }^{6}$ Primarily this limited the nature of projects. Furthermore, in practice it was found that more than 300 families were using the projects because of the needs of communities. This latter point was illustrated best by the example of the school in Markaz-e-Dawlatabad, which was being constructed using the funds for 300 families but was really going to be used by the children of more than 1000 families (detailed further below).

A second important limitation was the concern that the NSP was not accommodating the disabled, who represent 10 per cent of the total population and form one of the most vulnerable subgroups. The $\mathrm{CHA}$ 's technical advisor had worked extensively with the disabled in Afghanistan as a special needs teacher before joining the $\mathrm{CHA}$. $\mathrm{He}$ had worked for eight years with deaf, blind and mentally retarded persons. He asserted that the NSP did not do enough to include the disabled within communities; that is, did not make special provisions in terms of representation within the CDCs and, for example, in access for the disabled when constructing new schools and community centres. Although some of the 10 per cent were disabled from the protracted conflict, a significant number stemmed from inadequate health and sanitation and stretched social services (CHA Technical Advisor, 31 October 2003). This further emphasized the need for the state to make special provisions within its national programmes. ${ }^{7}$

The same informant stated that the NSP did not include the Kuchis and felt that such inclusion was difficult, based on the nomadic existence of the group. However, the informant agreed that the group did have important needs relevant to the NSP and that the Kuchis were staying for longer periods of time in certain communities. For the latter, the example of Chimental District was provided, where a group of Kuchis had asked the Ministry of Education for a school and clinic (CHA Technical Advisor, 31 October 2003). 
This section first used statistical data to provide a brief overview of the NSP performance in Balkh Province by focussing on the work of CHA in four districts. The NSP appeared to be on track in terms of coverage and financial instalments but only 10 per cent of the projects were deemed completed. In particular, the data for Charbolak District suggested deeper weaknesses in performance, and women's projects across the four districts represented only 10 per cent of the total under implementation. Alternatively, it was not possible to review statistical data for UNHABITAT, which meant the findings from the field research below were especially insightful. Last, the brief analysis of inclusion asserted that the NSP was a crucial unifying force for villages but three weaknesses were suggested: exclusion of the disabled; exclusion of the Kuchis; and the capping of funds to 300 families. Overall, this analysis proved the need for closer inspection. Before examining the main findings, it is important to review the main aspects of the methodological approach to the field research in Balkh.

\section{Methodology}

The field research in Balkh followed the methodology of the overall PRDU evaluation, as detailed in the final report. Therefore, this provincial report will not include a summary of the data-gathering techniques, the structure of the interview questions and the analysis of the data. Instead, it is important to reflect on the data collection process within the specific dynamics of the provincial context. Accordingly, this section addresses: the approach to gaining access; the selection of the samples; and the constraints to the field research.

\subsection{Approach to gaining access}

The field research aimed to reach a crosssection of key respondents that were representative of the range of actors within (or relevant to) the NSP in Balkh; that is, governmental, non-governmental indigenous and international organizations, in addition to $C D C s$, households and social institutions and groups. Accordingly, the Provincial Governor, the Provincial Director of the NSP, provincial-level staff and district staff for Charbolak District, in addition to the OC and $O C$ team were interviewed, with some participating in follow up sessions. For $\mathrm{CHA}$, senior management and all district staff relevant to each community were interviewed. For UN-HABITAT, the Director, Finance/Administration Head, and two social mobilizers were interviewed. The research also tapped into the experience of two senior representatives from the CFDO. Figure 1 below illustrates this focussing approach.

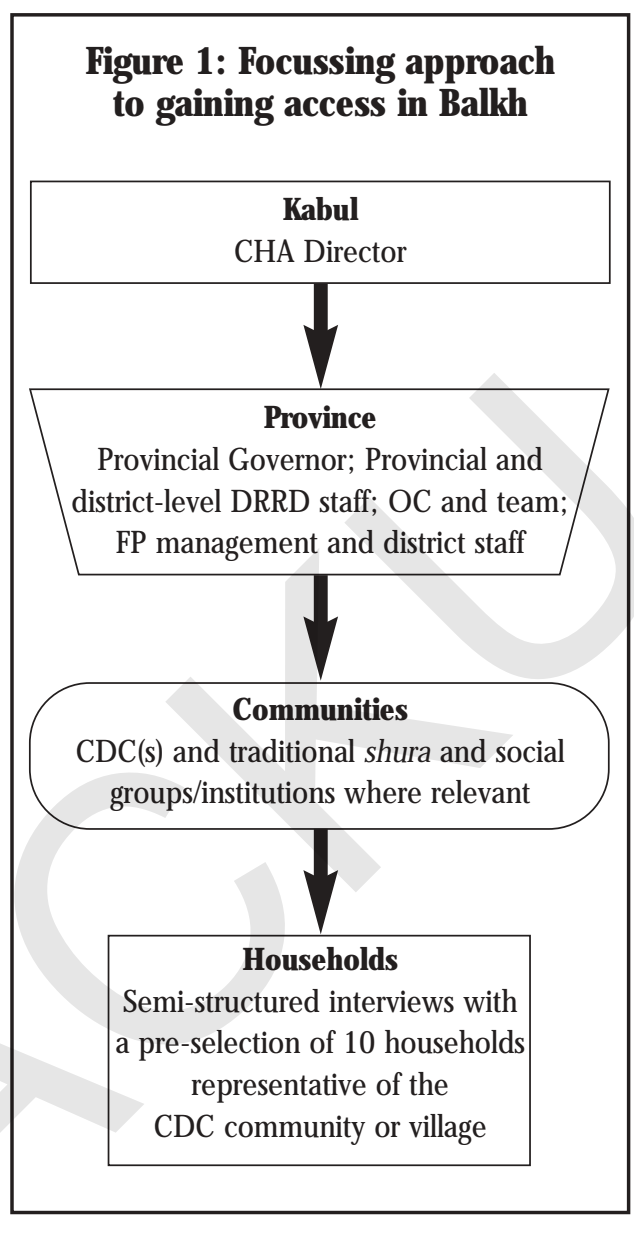

Access for the empirical research was based on consent, which resided at the four levels of authority: national, provincial and district (State), followed by local (community) and household (individual). For the latter two in particular, the "acceptance by local communities and their leadership" was gained by carefully negotiating consent from those in control by making the research objectives clear (Barakat et al, 2002: 1001). Furthermore, for research in the communities, the risks (for interviewees, local guides and the research team members) and the overall security situation were assessed and monitored, based on the advice of the FP and community leaders to determine if and when access should occur and then if the research should continue (Goodhand, 2000: 13-14).
THE PRO VIN CIAL FIELD SU RVEY REPO RTS 
Access to key respondents from $\mathrm{CHA}$ and UN-HABITAT in Mazar and in the districts was fundamental to identifying and then gaining and maintaining access to the gatekeepers within each community. This in turn facilitated access to the sample of households in each community. This focussing approach demonstrated "ways to mitigate and compensate for" the "severe limitations to access" (Barakat et al, 2002: 992; and Goodhand, 2000: 12-13). It also helped the research team display a greater "sensitivity to the local culture" (Barakat and Strand, 2000: 135-136). For example, interviews were conducted to suit the religious and work obligations of the respondents. ${ }^{8}$ Linked to this issue was the consideration given to researchers' selfpresentation, that is, respecting the Muslim code of attire and the cultural emphasis on politeness and ceremony.

Notwithstanding the benefits, it was also important to maintain a distance from the FP representatives to avoid bias in responses. For example, despite making the purpose of the research clear before every interview, it was crucial that the CDC and household members did not colour their answers based on a perceived association between the research and the operations of the FP.

It is important to identify some of the challenges related to identifying the relevant gatekeepers, and gaining and maintaining access, which proved either difficult to control or insurmountable. First, gathering basic statistical information was difficult, although it was alleviated by building trust, triangulation and in some cases multiple cross-checking. One of the main challenges with interviewing the $\mathrm{CDC}$ was making sure the right members were interviewed. This was addressed by constantly cross-checking names throughout the focussing approach to gaining access. There was also the unavoidable problem of writing down respondents' responses, which may have caused suspicion. This was countered by remaining aware of the respondent's reactions, explaining the aims of the research, ensuring anonymity and by getting introduced by the gatekeepers (in line with local custom) at collective and individual levels (Pratt and Lozios, 1992: 53-54).

In justifying the selection of the FPs and districts/communities the work of both FPs was researched, but the research team focussed on $\mathrm{CHA}$ because it was the more established. Furthermore, in reflecting the aims of the NSP to empower Afghan actors, it was decided that it would be more insightful to focus on this indigenous organization. UN-HABITAT was interviewed but had only recently facilitated $\mathrm{CDCs}$, while $\mathrm{CHA}$ had identified, mobilized and formed many CDCs with ongoing projects.

\subsection{Selection of sampled districts, communities and households}

The selection of the districts was made after consulting three crucial sources: the updated and comprehensive list of districts provided by the National OC in Kabul; consultation with each FP in Kabul and the FP at the provincial level; and checking with the general background knowledge of the Afghan researchers. First, as Table 2 illustrates, three districts were visited in Balkh and this formed the only non-random
8 This included always inquiring if permission was needed from the husband if an interview was to be conducted with his wife alone; being flexible in the time taken to introduce the purpose of the interviews; adopting customs and respecting cultural and religious traditions, in particular, either refraining from or limiting the interviews on a Friday, the most important day in the mosque for the men, and during Ramadan and Eid.

\section{Table 2: O verview of Samples}

\begin{tabular}{|l|l|l|l|l|l|l|}
\hline $\begin{array}{l}\text { Communities } \\
\text { Visited }\end{array}$ & Type & District & $\begin{array}{l}\text { Facilitating } \\
\text { Partner }\end{array}$ & $\begin{array}{l}\text { No. of CDCs } \\
\text { interviewed }\end{array}$ & $\begin{array}{l}\text { No. of social } \\
\text { groups in } \\
\text { community }\end{array}$ & $\begin{array}{l}\text { No. of } \\
\text { households } \\
\text { interviewed }\end{array}$ \\
\hline Markaz-e-Dawlatabad & 1 & Dawlatabad & CHA & 2 of 2 & 0 & 10 \\
\hline $\begin{array}{l}\text { Choba Temorak } \\
\text { Karni Khail }\end{array}$ & 2 & Charbolak & CHA & 2 of 2 & 0 & 10 \\
\hline Taimorak & 3 & Charbolak & Non-N SP & $\begin{array}{l}\text { Traditional } \\
\text { shura }\end{array}$ & 0 & 6 \\
\hline Yakhdan & 1 & Dawlatabad & CHA & 1 of 1 & 0 & 10 \\
\hline Alichopan & 2 & Dehdadi & UN-HABITAT & 1 of 2 & 0 & 0 \\
\hline Aliseena & 2 & Nahrishahy & UN-HABITAT & 1 of 2 & 0 & 0 \\
\hline
\end{tabular}




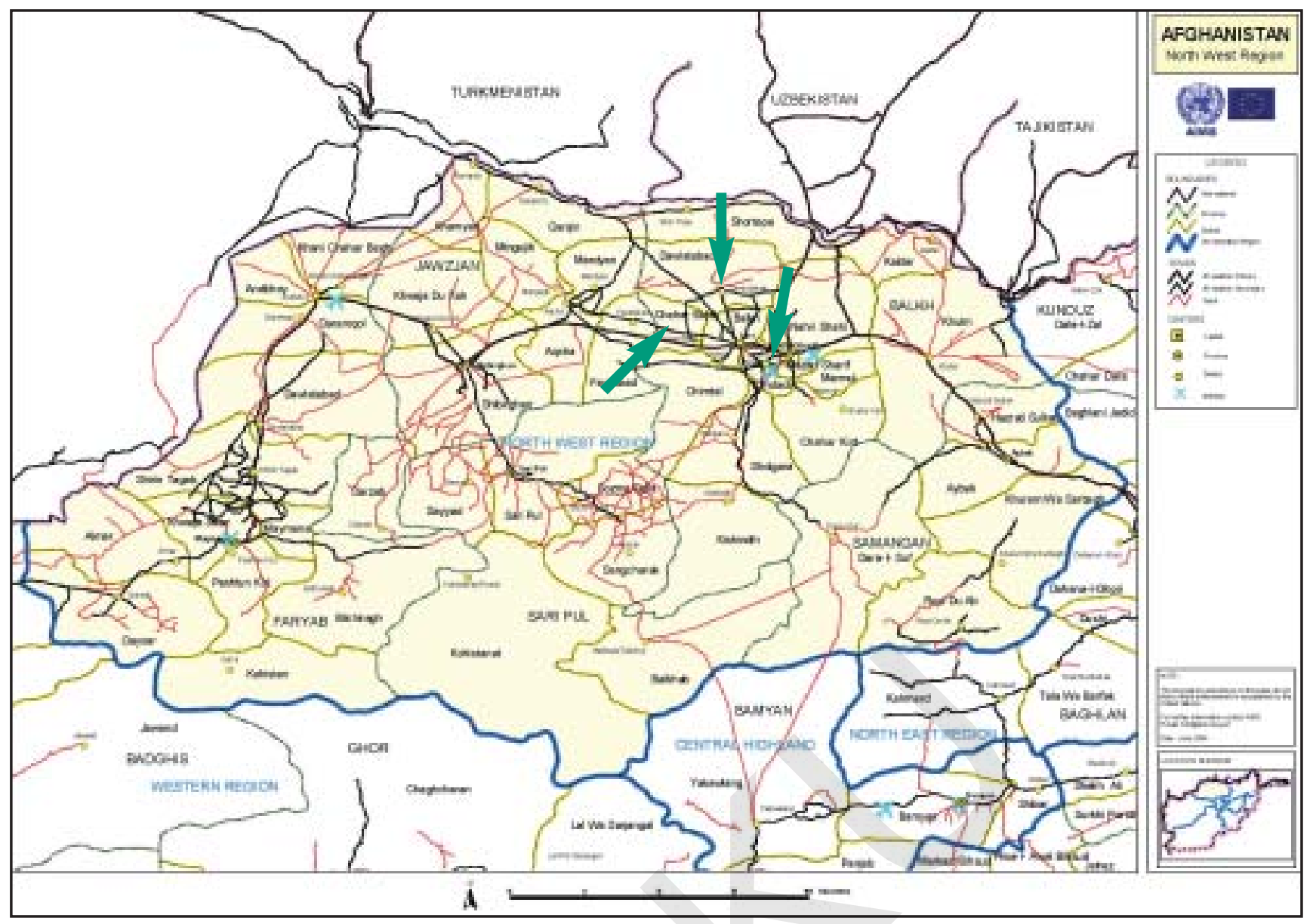

selection. Based on the time restrictions in Balkh and other constraints (see below), the distance of the districts from Mazar was a determinant. The districts of Chemtal/ Alboraz and Keshendeh were ruled out since they were at least six- and four-hours away by car, respectively. Security was considered although did not affect the selection process. Furthermore, as found in the analysis of Table 1 above, Charbolak was chosen because of apparent weaknesses in getting the proposals to the $\mathrm{OC}$ and thus getting funds. Dehdadi and Nahrishahy Districts were selected in order to provide findings from urban CDCs near the city of Mazar-e-Shariff.

Figure 2 illustrates the location of the 3 districts within Balkh Province.

In keeping with the PRDU evaluation, the selection of the communities was based on three cluster types: those with a well established $\mathrm{CDC}(\mathrm{s})$, project approved and at the stage of project implementation; one with a recently established $C D C(s)$ and at the stage of drawing up a project plan; and one nonparticipating community. The first two clusters were receiving or expected to receive the physical and non-tangible benefits of the NSP. The third community, the non-participating, shared a similar profile to the other two clusters of communities, to permit a comparative analysis.

In selecting the three clusters, relevant information and profiles of the communities were attained and then verified at the sources named above. This was then checked with the $\operatorname{CDC}(\mathrm{s}) \cdot{ }^{9}$ A complete list was drawn up for all communities within the first two clusters, and after rating each community in terms of their NSP performance the average communities were randomly selected. ${ }^{10}$ As Table 2 shows, it was not possible to locate the three community types in the same district, but this did not preclude comparative analysis.

A representative quota of 10 households was drawn from each of the 3 NSP-participating communities. As an approximate guide, 5 to 7 typical households were interviewed with 5 to 3 households with vulnerable subgroups, depending on the profile of each community. ${ }^{11}$ Six households were selected for interview within the non-participating NSP community.
Figure 2:

Location of Charbolak, Dawlatabad, Dehdadi and Nahrishahy Districts, Balkh Province

\footnotetext{
9 Each profile was based on the size of households, the proportion of rich, middle and poor incomes, sources of livelihoods, ethnicity, and the number of vulnerable sub-groups or dependent/semi-dependent adults (elderly and/or sick, disabled, widows and widowers, $\mathrm{FHH}$ with dependent children, returnees and IDPs), and the age of adulthood. The presence and type of social groups and institutions were also explored.
}

THE PRO VIN CIAL FIELD SU RVEY REPO RTS 


\section{Figure 3: Location of 6 communities}

10 For example, Markaz-eD awlatabad and Yakhdan were selected randomly from 144 available communities in Daw latabad D istrict.

Coincidentally, the former represented the centre of the district. The community of Choba Temorak Karni Khail was selected randomly from the two available communities in Charbolak. The other was Ahmad, which was one hour from the Charbolak district office of $\mathrm{CHA}$. It was in the middle of drafting a proposal to build a school (Choba Temorak Karni Khail Men's and Women's CDCs, 270 ctober 2005; and CH A D istrict Staff, 270 ctober 2005). The non-participating village, Tiamorak, was selected randomly from 31 non-N SP villages in Charbolak District.

$11_{\text {For example, in Markaz-e- }}$ D awlatabad the quota was 7 typical households and 3 households of vulnerable subgroups. The households were mainly Tajik with Arab, Pashtun and Turkman. The CDC and $\mathrm{CHA}$ stated there were no social groups (Markaz-e-D awlatabad Men's and Women's CDCs, 310 ctober 2005; and CHA District Team, 310 ctober 2005). For all the communities, there was a balance in interviewed households located at the centre, mid-way and on outskirts of communities.

AN NEX A4: BALKH PROVINCE

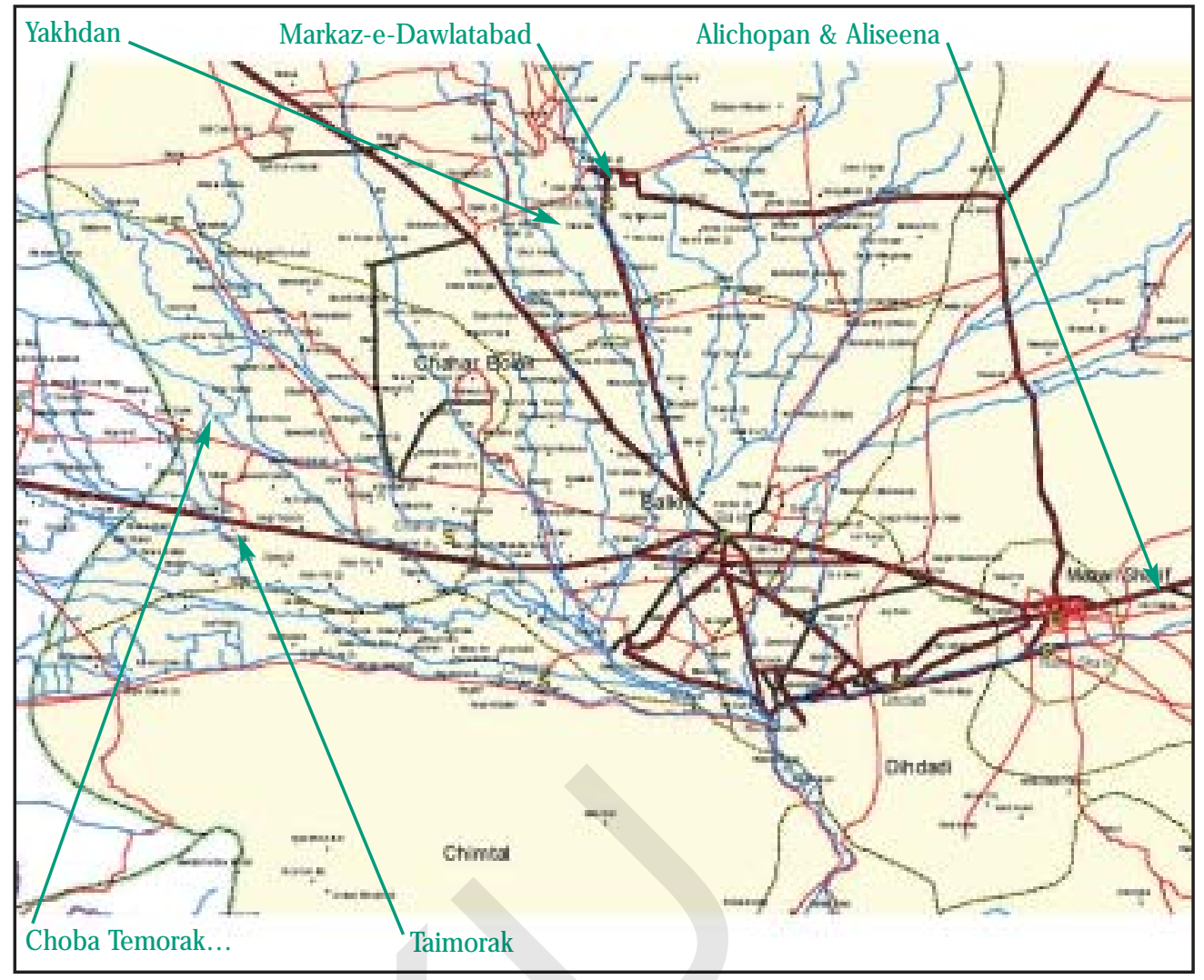

\subsection{Constraints to field research}

The main constraint to the field research was time. In particular, Ramadan, the Eid holiday period, and security restrictions set by the UN guidelines significantly reduced the timeframe. In Balkh, Friday was a day off for everyone and Thursday was meant to be a half day during Ramadan, although for the latter the research team managed to reach compromises. In particular, Ramadan meant that interviews were not possible after 4 pm (at the latest) and this was compounded by a restriction on travel one hour before dusk. In addition, the Eid holiday meant that interviews were not possible between the 2-6 November (inclusive), as these were public holidays and the Afghan researchers were travelling to and from Kabul. The week prior to Eid also proved difficult, though not insurmountable, with people leaving the communities for the day to travel to the bazaar in preparation for Eid. On Sunday 30 October, Mazar was also raised to 'white city' security status after the shooting of ISAF soldiers in the city the day before. This meant there were 10 full days to conduct the research with the full research team. The team leader was able to complete a further day of research alone, with one interviewee who spoke English.

However, these obstacles were unavoidable and, moreover, did not interfere with the original aims and scope of the research due to accurate planning, the expertise of the Afghan researchers and the cooperation of the FPs. The flexibility of all the interviewees also ensured all necessary access. In fact, the provincial research team managed to research more communities, CDCs and FPs than originally expected while not compromising the qualitative focus. Furthermore, the team leader used the Eid period as a timely mid-way interval to review and consolidate the data gathered, which made the final week of field research more focussed.

In conclusion, the PRDU's methodological approach to the NSP evaluation was well suited to gathering the necessary data within the contextual dynamics of Balkh. Overall, the research claims to be representative of the NSP's performance within the Province. First, while not every district could be visited, the research team focussed on rural communities far from Mazar in addition to researching a sample of urban CDCs. Furthermore, insight into the NSP's performance in Balkh stemmed from interviews with all the relevant NSP actors: Governor, DRRD, FP and OC and OC team. These elite-level interviews were in turn complemented by the random selection of communities based on strategic types. Last, the random selection of households, based on the profile of each community, ensured a 
more accurate understanding of the NSP. It is now appropriate to present the main findings from the research.

\section{The government DRRD (provincial and district levels)}

The analysis of the findings from the interviews with the provincial and district levels of the government are divided into programme management, and the experience of the staff. The main positive element to programme management included the wide acceptance of the NSP as a programme for positive change. Significant benefits for DRRD staff involved improved co-relationships within the various levels of the State and between the State and communities; intra-governmental co-operation; the prioritization of project quality over quantity; familiarity with the official complaints procedure; and the development of the $\mathrm{CDC}$ as a permanent institution. Accordingly, there was consensus that the NSP was contributing to nation building. Nevertheless, programme management was experiencing some teething problems. One example was the slow expansion of the NSP and this added to the other strains in capacity: limited (physical, human and technical) resources; delays in the release of instalments; and some institutional jealousy between the DRRD and the FPs. Last, it is important to note the emergence of criticism of the Provincial Governor's role in the NSP and of course to include his defence.

\subsection{Programme management - positive on the surface}

The Provincial Director of the DRRD was positive regarding the management and performance of the NSP since the inception of the Community-led Development Department in 2003. At this time, the NSP was the biggest of the six national programmes. ${ }^{12}$ The senior DRRD official stated that the programme was "welcomed by the people from the beginning" because "it tried to reach and involve them directly".

However, he appreciated that, "10 per cent of the people are not satisfied" because "it is a very new concept and therefore difficult to implement completely". Second, it was difficult as, "the expectations of the people are very high, for example, small shuras want big projects". Last, it was noted that, "at the beginning, people were not contacting us and gave up when some donors did not fulfil their promises." (Director of the Balkh DRRD, 25 October 2005).

The Provincial Director made the following recommendations to improve future programme management:

- "The MRRD should explain more about the second phase of the NSP since now there is a delay and a gap in the first phase."

- "The CDCs should not be granted 100 per cent authority because they lack adequate experience and do not fully understand the impact of their authority. For example, a CDC can insist on an electricity project but the government cannot provide this service so the CDC is using their authority to create conflict with the government."13

- On a similar note, he advised that "CDCs should not have the authority to sign contracts for small projects without the involvement of the NSP." (Director of the Balkh DRRD, 25 October 2005).

The DRRD district staff strongly recommended that, "the budget of US $\$ 60,000$ should not be restricted to 300 families." For example, "in some villages the totals were calculated before IDPS and refugees returned", which naturally leads to the stretching of projects and/or the potential for intra-community conflict (District DRRD staff, 9 November 2005). The provincial staff concurred, noting that there were "cases of 2000 families using a project based on the maximum funding allocation of 300 families", which were then not allowed to split into smaller CDCs. This problem, stemming from the "rule created by the MRRD/NSP", was described as a "big source of conflict" (Provincial DRRD staff, 25 October 2005). Governor Atta also raised this concern and advised that "a responsible committee should come from Kabul and divide and accept them into two or 3 normal villages ... since the allocation of money is not fair." (Balk Provincial Governor, 10 November 2005).

\subsection{Mixed experience of provincial and district DRRD staff 14}

\section{Adequate training}

The provincial staff had received "only a 3day workshop (activity training programme) on the Operational Manual from the OC
12 The N SP U nit had two staff in Mazar and four in the field, with an additional 9 staff on the $O C$ team (D irector of the Balkh DRRD, 250 ctober 2005).

13 UN - HABITAT also raise this example below but as a criticism of the government.

14 This consisted of a group interview with operation staff from both levels. There were 4 provincial DRRD staff and one from the N SP U nit present. All were engineers and male. At the district level, there were also 4 participants; all were male and from Charbolak D istrict.

THE PRO VIN CIAL FIELD SU RVEY REPO RTS 
15 Therefore, it is important to note that the district staff referred to more training and guidance than their colleagues in Mazar. 0 verall, the former proved more voluble on this topic and explained, for example, that the "guidelines had 5 levels and 15 steps for implementation" and that they had "nearly finished Level 4" (D istrict D RRD staff, $9 \mathrm{~N}$ ovember 2005).

\section{The provincial staff further explained that: In the past, all the warlords and drug dealers ruined everything. N ow communities are involved in the decision- making process, setting the priorities and want to get responsibility. In the past, people always blamed the system, N GO s and international NGO s as corrupt. Now, people are do ing it themselves and are trying to get it right (Provincial DRRD staff, 250 ctober 2005).}

office and 4 staff from the $\mathrm{CHA}$ ", with "no other training and guidance" (Provincial DRRD staff, 25 October 2005). The district staff also attended this workshop, "on procurement, programme management, $M \& E$ and financial duties", and added that the "DRRD director had two months of NSP training in the NSP in Kabul and was then able to return and train us." 15 Both levels emphasized the usefulness of the Operational Manual and the cascading impact of the activity training programme, which allows them "to transfer to" and "train others, especially the CDCs" (Provincial DRRD staff, 25 October 2005; and District DRRD staff, 9 November 2005).

\section{Improved co-relationships}

The provincial and district staff overwhelmingly believed that the NSP had improved the co-relationships between the three levels of government. The respondents also extended the "improved linkages" to between government and civil society. There was a similar impact noted in the relationship between the government and the communities; for example, "it is very good that the government is very interested and available to work with the communities" and "the people are getting involved" (Provincial DRRD staff, 25 October 2005; and District DRRD staff, 9 November 2005). 16

Governor Atta also welcomed the NSP, thought it would achieve long-term acceptance, and would form good relations between the government and the communities. He praised the nature of the projects, which aimed to be cost effective with little or no administration costs. Furthermore, he was glad the communities would be getting responsibility:

"The people should be involved in all the decision-making, needs assessment and setting the priorities.

This involvement in the decision-making avoids corruption and it means the NSP is based solely on the needs of the people. In the past, it was a donordriven approach but now the needs are surveyed first. It is also positive that NGOs and donors will act as sub-contractors and the involvement of the government is required in all the projects."

(Balk Provincial Governor, 25 October 2005)
Quality as the main indicator of success Both levels of the DRRD prioritized the quality (effectiveness) of work before the efficiency (number of projects). This was best encapsulated by the provincial staffs' comment that, "[w]e emphasize the capacity-building of communities rather than spending money." (Provincial DRRD staff, 25 October 2005; and District DRRD staff, 9 November 2005).

While the district staff praised the FPs for their "monitoring, commitment and work ethic", the provincial representatives criticized the FPs for "always talking about themselves, ignoring the government and the MRRD" instead of "explaining more about the government and the MRRD since we are funding it all." (Provincial DRRD staff, 25 October 2005; and District DRRD staff, 9 November 2005).

\section{Strained capacity}

Institutional capacity was evidently weak and the respondents' comments were grounded in the context of "the huge number of obstacles"; and framed by appropriate comparisons. For resources, it was noted that, "compared to the staff of the MRRD, we do not have enough transport and communication to visit communities", while there is "very limited technical staff" in the field and at "MRRD headquarters". These gaps were perceived to be wider still when juxtaposed with "people from donor communities and international NGOs" (Provincial DRRD staff, 25 October 2005). The district staff echoed these strains ("only four of us with the capacity to carry out the NSP") and thus welcomed "more capacitybuilding, training, $M \& E$ and technical/engineering skills". The district level respondents emphasized that some districts did not have DRRD staff and noted that, "we are not monitors but we are here to learn". For the latter, they felt that the FPs' experiences and resources provided the best opportunities for improvement and thus, "met with FPs regularly; sometimes daily or weekly if not monthly".

As an exception, the district staff felt that not all the FPs' community mobilizers were adequately qualified, which "limited the transfer of knowledge to the CDCs". In compounding the strains above, there was no doubt that the high number of projects had reduced the quality of the work. However, the district DRRD staff appreciated that there needed to be "increased coverage of the NSP so the more needy villages are 
included, and where there are conflicts." (District DRRD staff, 9 November 2005). Similarly, Governor Atta recommended expansion "to all villages, because only 6 out of 14 districts" were covered (Balk Provincial Governor, 25 October 2005).

The provincial DRRD were satisfied with the quality of "current staff" who "do their best, especially in monitoring" (Provincial DRRD staff, 25 October 2005). However, this natural assertion was contradicted at the district level where it was noted that, "although the NSP projects involve construction we do not have full engineers, only an assistant engineer, an economist, and an agriculturalist." (Provincial DRRD staff, 25 October 2005; and District DRRD staff, 9 November 2005).

In addition to the restrictions in transportation and financial resources, the other main operational problem was "delays" in the transfer and release of instalments, which also affected the quality of projects. The provincial staff recalled various scenarios: for example, "If a community is building a well and there is a delay of three months after the first or second instalment, which prevents installing the water pump, then sand can seep in and dirty the well." Furthermore, "If a community does not receive the second or third instalment then engineers will not stay on, so the community has to hire guards to protect the site." In demonstrating the widespread and systemic nature of the delays, the respondents noted that communities had tried to pre-empt this problem by saving money from the beginning, but this means the "quality risks being cut" (Provincial DRRD staff, 25 October 2005; and District DRRD staff, 9 November 2005).

There were 3 main strengths, which could act as opportunities in alleviating the strains in capacity. First, both provincial and district staff noted positive co-ordination among all the relevant ministries/ departments, although it seemed that this was an emerging development (towards improving project implementation). ${ }^{17}$ The Ministry of Education and the Ministry of Health were highlighted; for example, "Whenever we have needed to do a needs-assessment of a clinic or school the relevant departments have supported us" (Provincial DRRD staff, 25 October 2005; and District DRRD staff, 9 November 2005).
Second, the state representatives were familiar with the NSP's complaints procedure and claimed its usage was positive as it acted as a "proper system". Both confirmed that potential or actual types of conflict were divided into "direct complaints from the CDC and the shura or via the FP", by the FP and then from miscellaneous actors. For each type, the initial approach was to hold a meeting with all those concerned (CDC, FP, DRRD and NSP) and the provincial DRRD held a "weekly meeting every Tuesday for two hours". If unsuccessful, then a case would be sent up the chain of authority within the MRRD (district - provincial - national) (Provincial DRRD staff, 25 October 2005; and District DRRD staff, 9 November 2005).

Third, the DRRD officials looked to the CDCs as a permanent institution for communities to cooperate with the government because: they enjoyed a formal function (legitimate authority and responsibility through official registration to having proper letterheads and stamps); united previously divided ethnic groups through the projects (by their type and through using the community saving boxes) and by instilling the principle of equality and fair representation; and finally they made the people more determined to reconstruct and develop (Provincial DRRD staff, 25 October 2005; and District DRRD staff, 9 November 2005).

In considering the last strength, the DRRD officials seemed clear in their understanding of the relationship with the CDCs, "The relations are very good, very positive through visiting, advising and directing them, though not interfering, nor controlling." They also liked the development of the CDC, with provincial level staff providing the example of a village where the WFP came and directly consulted and worked with the CDC in order to distribute aid "rather than having to get an NGO to do it". In sum, "the NSP through the CDC provides a way in for all other projects" (Provincial DRRD staff, 25 October 2005; and District DRRD staff, 9 November 2005).

\section{National solidarity}

The provincial and district representatives affirmed that the NSP was contributing to the broad goal of national solidarity based on the binding nature of the CDPs and the projects. Three insightful examples were provided:

\section{The researchers believed these opinions, that is, the possibility of bias, was considered. Nevertheless, co-ordination was described as nascent since there were no tangible benefits visible to the researchers.}

THE PRO VIN CIAL FIELD SU RVEY REPO RTS 
... if there are three villages of different ethnic groups cooperating, the shura and the NSP want to address one project to crea te solidarity among all three. In Dawlatabad District, there is a school for 3-4 villa ges of different ethnic groups. In another village, Aornagha, Charbolak District, they are digging a well among 4-5 ethnic groups and this has had some positive effects on their relations. In Kishendeh District, the money for each village was low (because the number of families in each village was less than the 300 qu ota), so they merged the funds and built a road for these three villages and were very happy about this project. As individuals they are worth nothing but together they are fulfilling their priorities. (Provincial DRRD staff, 25 October 2005)

This centripetal drive is commendable in terms of physical and psychological nation building. However, important, widespread limitations are detailed below; in particular, where small communities were restricted by geographical isolation.

Regardless of communities merging, the district DRRD staff argued that it was "a good indicator of solidarity if [ for instance] the treasurer is Pashtun, the head is Tajik and the deputy is Arab. We recommend that the only way forward is for the communities to sit and work together as one group." (District DRRD staff, 9 November 2005).

As detailed further in this provincial report, Governor Atta had received criticism from some communities, in particular Hazaras, for interfering in the selection of NSP villages to fulfil ethno-political allegiances. In response, the Governor denied wielding such discriminating influence and asserted that, "the NSP decides by itself... the plan is already fixed at the centre... I do not have the right to tell the NSP to choose the villages." He explained that, "the Hazaras have a political problem with me and they blame me, especially Muhaqiq's people." In illustrating the NSP's drive for equality, he noted that "In Charbolak, they are mostly Pashtuns and come under the NSP and the NSP will now focus on multi-ethnic Sholgra". Governor Atta also claimed that this was propaganda for a wider campaign because of his "opposition to the federalism proposed by the Hazaras, Uzbeks and others" (Balk Provincial Governor, 10 November 2005).
Finally, although pursued later, the Balk Provincial Governor was the only state actor who raised the need for improved gender equality, noting, "[w]omen should be given more chance to be part of the NSP at the decision-making level and during the implementation of projects, for example, getting small micro finance projects would be good for their empowerment." (Balk Provincial Governor, 10 November 2005). Of course, the more challenging goal was to make these aims achievable in the communities.

This section established some of the positive aspects of programme management for DRRD staff (provincial and district) in Balkh, though highlighted some deep concerns. Similarly, a review of the staff's experience pointed to significant direct benefits from the NSP while revealing crucial strains in capacity. It is therefore appropriate to consider the support from the $\mathrm{OC}$ and team.

\section{Provincial NSP OC and team ${ }^{18}$}

These findings are presented based on a general self-assessment by the $\mathrm{OC}$ and team, which highlight the strengths of: popular acceptance, empowerment, improved standards of living and relationship between the people and the government. However, weaknesses included the capping of funds to 300 families, the limited allocation of funds to women, and weak coordination among the NSP actors during implementation. The main opportunity was the approach to, and goal of, capacity-building. The $O C$ and team understood their capacity-building role and were satisfied with the management. Accordingly, they perceived a development in institutional and staff capacities but noted the lack of technical staff among the DRRD personnel. Therefore, they believed an 8-10 year exit strategy was more accurate. Despite an initial positive account of the OC supervisory role, a follow up interview uncovered important explanations for delays.

\subsection{General}

Strengths, Weaknesses,

Opportunities and Threats

As strengths, the $\mathrm{OC}$ and team confirmed that, "we are welcomed and accepted by all the people because the money is going directly to the communities." They provided 
the example of the village(s) of Kashanda Chakinah, where 13 CDCs reconstructed a $50 \mathrm{~km}$ road costing US $\$ 240,000$. There were three significant impacts: the project was decided and implemented ("in a proper way") by the community itself, not an NGO. This was crucial as it meant, "the CDCs represented a break from the traditional shura - a time when village elders and warlords were all-powerful." Key to this development was the "secret voting system, which lets people make their own choices", thereby granting "authority with responsibilities to the elected representatives".19 For example, it was believed that "the CDC and its subcommittees can now try to solve the problems of families" (OC and Team, 26 October 2005). Second, it meant the travelling time from Mazar was reduced from 21 hours to 7 hours. Last, it was considered "a good approach by our government to think about and address the problems", which formed "a good bridge for relations and created good publicity for the government and the MRRD." (OC and Team, 26 October 2005).

The main weakness noted, in echoing one of the provincial and district DRRD's concerns, was the maximum budget cap of 300 families, which made it difficult to select, for instance, "300 out of 1000 families" to use a project. Moreover, in reality "it means that 1000 use the project, especially when it is a road or a school". In sum, they argued that "the projects must have the capacity to be inclusive" (OC and Team, 26 October 2005).

The second flaw was the "limited allocation of money for women" (in practise and against the Operational Manual). It was claimed that "95 per cent of projects for women are rejected", with only the small proposals (under US \$3000) accepted. For example, "Carpet-weaving may need a budget of US $\$ 10,000$ to be sustainable, but this is not possible under the NSP [or hard for the community to justify] when the maximum budget for the community is US $\$ 60,000$." In sum: "women may contribute 10-15 per cent to the decision-making process but in practical terms their needs are not given priority." (OC and Team, 26 October 2005). Towards resolving this, the OC estimated that it would take 4-5 years for the more rural-based CDCs to mix men and women members. ${ }^{20} \mathrm{~A}$ third weakness was inadequate co-ordination during implementation.
The OC and team could not think of specific threats and defined the central opportunity as "capacity-building for communities because of the new approach to donors" (OC and Team, 26 October 2005).

\subsection{Capacity-building role of the $\mathrm{OC}$}

Definition of role and management of NSP

The OC and team defined their role as "giving technical advice, transferring money to the $C D C$, controlling the management of the overall programme and capacitybuilding of the FP and DRRD." They claimed "100 per cent involvement in the management of the NSP." They were also "satisfied with the management capacity of the NSP staff in the MRRD [at all three levels]" and noted that they always "shared information" (OC and Team, 26 October 2005).

\section{Developing institutional and} staff capacities and the exit strategy

In using the programme to develop the institutional and individual staff capacities within the DRRD, the respondents noted the principle of always having "two-way communication during training" and during the weekly meetings. As promoted by the NSP, the key themes are finance, $M \& E$ and engineering. However, the last two were particularly problematic as the "DRRD do not have complete staff". Nevertheless, the $O C$ and team believed that the DRRD staff were engaged in an active learning process involving "engineers gaining field practice in the NSP, especially in terms of $M \& E$ ".

However, it was asserted that it would be "very difficult" to transfer full management responsibility to the DRRD within the proposed timeframe as "only M\&E staff and engineers have been trained". Therefore, sustainability would require "the other staff to be trained, with a timeframe of 8- 10 years rather than the current 2-3 years" (OC and Team, 26 October 2005).

\subsection{Supervisory role of the $O C$}

\section{Eligibility criteria}

The OC and team stated that "80-90 per cent of the project appraisals for construction complied with the eligibility criteria, especially because of strict monitoring by the MRRD." However, as noted throughout the findings, this assertion was weak consid-
19 The respondents added that there was evidence of some intimidation and interference at the beginning, but the process was transparent and fair overall (OC and Team, 260 ctober 2005).

20 The respondent noted that the villages close to Mazar had more mixed $C D C s(O C$ and Team, $9 \mathrm{~N}$ ovember 2005).

THE PRO VIN CIAL FIELD SU RVEY REPO RTS 
ering the limited capacity of the DRRD. The respondents believed that "60-80 per cent of the proposals for capacity-building and social development were successful". In general, they were familiar with the criteria.

\section{Delivery of resources}

In ensuring the proper delivery of resources, there were "four persons from the CDC and one from the FP". The OC officers maintained there was "no problem within the NSP in distributing the funds as long as a report has been completed on time." Then, once a project is approved, " 50 per cent goes to the bank and is ready for the communities, followed by 30 per cent, and 20 per cent upon completion of further satisfactory reports". The OC also asserted that communities had to wait "a minimum of 14-17 or 18 days" for the transfer of funds from Kabul (OC and Team, 26 October 2005).

Of course, the positive account above conflicts with the clear prevalence of delays, as examined above and below. Therefore, during follow up questions and a final interview, the $O C$ admitted to the slow delivery of resources and identified five problem areas and recommendations.

- It was argued that "administrative delays stemmed from the processing of CDPs in Kabul", which partly explained the low number in Charbolak District, for example.

- The OC said he had "received CDPs from 50 villages in Charbolak, which had all been processed and checked. The MRRD has only approved some of them and some were sent back to the CDCs for further information." (OC and Team, 9 November 2005).

- In addressing a third "gap", the OC recommended that the "FP should submit its report after 40 per cent of the first instalment is spent, as opposed to the current rule of waiting until 80 per cent is spent", which would speed up the process (OC and Team, 26 October 2005).

- The delay in the second instalment for the Dawlatabad school (see below) was because of an unfortunate "bureaucratic mess", which was subsequently corrected (OC and Team, 9 November 2005).

- Last, it was noted that the cap of 300 families (see above and below) "was raised several times by all the relevant actors within the Province up to the
MRRD Minister and it is up to Kabul now to find a solution." (OC and Team, 9 November 2005).

Overall, the findings from the $O C$ and team interviews concurred with the consensus that the NSP had created crucial benefits, especially in terms of the drive to empower communities, and the respondents clearly understood their tasks and role. However, the interviews also reiterated common concerns; in particular, the limited involvement/benefits for women within the communities, the budget constraint for each project, bureaucratic delays in the instalments, and the lack of technical capabilities within the DRRD. The latter was a special concern in planning for the transfer of full management responsibility to the DRRD.

\section{FPs (National, Provincial and District Levels)}

The two FPs researched were $\mathrm{CHA}$ and UNHABITAT. The National Director of the former emphasized the need for a more bottom-up approach and to allow the imported concepts behind the NSP enough time to evolve. Second, both FPs' (provincial and district levels) interpretation of their roles reflected the programme concept. However, there were varying relations with the DRRD, which was characterized overall by limited capacity. In addition, strong cooperation with the $O C$ and team was noted by all. It was also felt that the communities in general understood the role of the FPs and government in the NSP, and there was some evidence of CDCs working directly with donors. Training in the communities was described as successful, although illiteracy was a barrier to participation despite the use of cartoon booklets. It was clear that the engagement with the NSP had caused the FPs to increase capacity, which had been stretched at the start. The respondents claimed the training had compensated, with staff possessing the right skills.

The projects in the selected communities involved social infrastructure, water supply and electricity. Selection seemed to be based on processes of community consultation with leadership from the $C D C$; however, few of the communities implemented their first choice. Four other concerns involved project inefficiency, challenges to maintaining the projects, the lack 
of women's power and influence in the implementation process, and there were no measures to protect the usage of the projects. The FPs maintained that the necessary quality control mechanisms were in place for all the projects, but some fundamental design weaknesses were uncovered.

\subsection{CHA at the national level 21}

CHA was formed in 1987 in Afghanistan and focussed on four sectors: education, health, engineering, and agriculture. The NSP ran across all four sectors but was primarily grounded in their education sector. $\mathrm{CHA}$ started operations in Mazar in 2000. Accordingly, the National Director raised a number of salient points and recommendations.

Achieving balances: development, time and strategy, and funding

For community empowerment, the Director urged the government "to not just use the CDCs as a tool but as part of civil society because Afghan development demands strong government and strong civil society they are good for each other." Instead, the respondent perceived an imbalance with the "government getting all the benefits at the expense of civil society". In particular, it was asserted that:

... the CDCs' and communities' plans for development are limited to the MRRD but plans need to come from the bottom-up and not just from Kabul.

Top-down is not good. Let the communities think about strategies but of course they need support. Let them experience successes and failures.

The most critical decision is for policy makers.

(CHA National Director, 20 October 2005)

This was deemed particularly significant as "people are questioning parliament: who was elected? Do they have the capacity? After 25 years of war, standards are low."

A second necessary balance was allowing the useful though "perfect and imported concepts of democracy and civil society development the time to evolve here, as they did originally in Western Europe and the US". In sum, "expectations should be tailored to the context". Therefore, the two interlinked factors of time and strategy were of "central importance". The respondent thought the uncertainty surrounding the latter (in particular, the lack of an exit strategy for NGOs as the main implementers) was conditioned by the rushed timeframe imposed by the international community: "The World Bank's expectations were too high at the beginning, therefore, now is not the time to phase out. We are not at the point yet where we were 25 years ago." Also, it is important to remember that, "across the country, the CDCs are at very different stages of development."22

Third, the CHA National Director stated that, "The future sustainability of the CDCs depends on lots of money; for example, 16 per cent of the Health Department is from the Afghan government and the rest is from outside." (CHA National Director, 20 October 2005).

\subsection{Accurate interpretations of roles within NSP: provincial and district levels 23}

The FPs' interpretations of their roles in the NSP were consistent with the programme concept.

Facilitation at the community level $\mathrm{CHA}$ and UN-HABITAT understood that their role was to act as facilitators at the community level and this was grounded in the NSP Operational Manual. CHA provincial staff ordered their duties as, "The first time we had to select, facilitate and then mobilize the community. We then explained the elections and started the election process." District staff added that "we were very neutral during the elections and provided information so they could choose their own people". Following this, they "facilitated the registration of the shura $C D C$, their account number and then started the CDP." Responsibilities after this included "advising the people to help them select the project and helped them write the proposal." While this required the "participation of the people we were kept in the loop about the proposal." Once the "CDC agreed on the project, the CDP was signed and sent to the $\mathrm{OC} . "$

CHA stated that they "emphasized it was better that the CDCs and projects were started by the community, which could then subcontract an NGO or construction company." Once a start date was set, it was the responsibility of the FP to ensure the $C D C$ received the necessary forms for pro-
21 This consisted of an interview with the $\mathrm{CHA}$ $\mathrm{N}$ ational Director in Kabul, 200 ctober 2005

22 The respondent believed that this misplaced urgency reflected the Afghan $\mathrm{N}$ ational D evelo pment Strategy, with its "short-term perspective" and its insufficient involvement of the communities.

23 This consisted of a primary and follow up interview with the $\mathrm{CHA}$ Provincial Management Team (Provincial Director, Chief Technical Advisor and the Education 0 fficer), 260 cto ber 2005 and 8 November 2005. The Provincial Director of UN HABITAT was interviewed in Mazar, 1 N ovember 2005. For the selected communities of Dawlatabad, Charna Choba Karna Khail, Yakhdan, Aliseena and Alichopan, the relevant FP district teams were interviewed on 310 ctober 2005, 27 0 ctober 2005, 8 N ovember 2005, and $10 \mathrm{~N}$ ovember 2005. For the third-type (non-N SP) community, Taimorak, the 'would be' district team was interviewed, 8 N ovember 2005. D istrict teams included the engineers, social mobilizers and finance specialists/administrators.

THE PRO VIN CIAL FIELD SU RVEY REPO RTS 
curement etc, learnt about the procedures for each phase (for example, bookkeeping), and to "facilitate the fundraising and check the budget." (CHA Provincial Management Team, 26 October 2005 and 8 November 2005)

UN-HABITAT outlined a similar role of facilitation: "explaining the NSP system to the community, conducting training, bringing the handbooks, guiding the identification of needs and priorities and helping the CDCs prepare their CDPs." The Director admitted the UN agency's initial scepticism but the communities were able to "participate and complete the relevant NSP tasks and follow the steps with regular training and guidance" (UN-HABITAT Provincial Director, 1 November 2005).

The common positive perception CHA provincial staff described their NGO as a "bridge for relations between the shura and government, since through them the community can contact the government" and vice versa (CHA Provincial Management Team, 26 October 2005). District staff concurred, noting that the people "were very happy the first time we came and they think of us as their advisors" (CHA District Staff, 27 October 2005).

UN-HABITAT's Director believed this organization's "very good reputation in Mazar" (from their experience with the CFDO, as outlined below) was an important influence in gaining the people's "trust" and enthusiasm (UN-HABITAT Provincial Director, 1 November 2005).

Varying working relations with the MRRD and their limited capacity CHA district and provincial staff described joint relations as "very good" and cooperative (CHA Provincial Management Team, 26 October 2005 and District Staff, 27 October 2005). It was the same for UN-HABITAT but the Director added that the DRRD staff were "easier to reach and talk with". There were further problems working with the other government ministries and there was ongoing disagreement over electrical power in Mazar. It was reported that 20 CDCs had been promised power from the city after submitting proposals. Despite conducting a survey and collecting the money from the people, the respondent asserted that the government then indicated it would take two years for electricity to be distributed. It was asserted that the CDCs perceived this as corruption at worst, or destabilizing at best.
There were also problems working with the Department of Education but these were resolved after several meetings (UNHABITAT Provincial Director, 1 November 2005). As mentioned above, one of the main weaknesses in the NSP was matching needs with the budget available. While smaller communities could merge under a larger project, UN-HABITAT staff raised the exceptions to this. For example, "There was an isolated village of 92 families that wanted a school but their budget was too small, even though it was their greatest need." (UNHABITAT District Staff, 10 November 2005).

CHA management stated that the MRRD's capacity was good, especially "at transferring knowledge" (CHA Provincial Management Team, 26 October 2005). Conversely, UN-HABITAT thought "the government does not have the capacity and the FPs are filling for this. Perhaps in 3-4 years the MRRD can manage the CDCs, but until then the OC has a lot of work to do." (UNHABITAT Provincial Director, 1 November 2005). CHA district staff were more critical and described the capacity of the MRRD staff as "very low in terms of monitoring...not technical and not professional, especially when compared to the OC". There was also a fundamental problem with the "MRRD staffs' preference for poverty reduction which conflicted with the NSP". In addition, the attitude of the MRRD field staff was also perceived as, "never encouraging when visiting communities" and this was contrasted with the "always positive role of the MRRD Minister because of his NGO background". More widely, the district staff criticized the staff from other ministries, which are "sometimes very slow in their procedures, for example, the releasing of instalments and cannot check reports because of weak skills, which all cause delays." (CHA District Staff, 27 October 2005).

Positive working relations with the $\mathrm{OC}$ CHA provincial and district staff were "very happy with the work of the OC, who is always advising and providing technical support". It seemed that problems were always addressed by joint meetings (Provincial Management Team, 26 October 2005 and CHA District Staff, 27 October 2005). UN-HABITAT relayed similar experiences (UN-HABITAT Provincial Director, 1 November 2005).

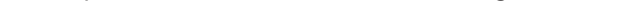




\subsection{The strengthening of dialogue between communities and national government through the Programme structure}

$\mathrm{CHA}$ believed that the communities understood clearly and trusted the role of the FPs and the government in the NSP (CHA Provincial Management Team, 26 October 2005). First, there was evidence of a greater acceptance of legitimate state authority:

For example, before the NSP, in a subdistrict in Dawlatabad there was an informal Governor and all the people used to go to him when they needed help. However, after the CDCs, the people went to the formal government, so the NSP in this example 'collected all the people' (CHA District Staff, 27 October 2005)

Second, towards increased local authority and responsibility, the district staff added that where the government was unable to act, the communities felt secure in their own role within the programme structure to "ask the CDC to solve problems and conflict" (CHA District Staff, 27 October 2005). As an extension of this point, UNHABITAT noted the communities' positive acceptance of the procedure to ensure the government and the FPs, "have to consult the CDCs and sign an agreement concerning engagement". The Director also noted that the, "FPs form the link between the two" but the CDCs are, "solving many local problems and are official organizations". He explained:

Our CDCs now have rights, have an ID card, can raise problems with the government and agencies etc and write their independent proposals. For example, JICA has approved proposals in two villages and will start in two weeks. Although this is the first time for this development, the NSP said the CDCs will be introduced to other agencies (UN-HABITAT Provincial Director, 1 November 2005).

Although the FP reminded that "the NSP is solving 1-2 problems but not all" (UNHABITAT Provincial Director, 1 November 2005). Third, all the FP respondents agreed that the contact between the communities and local government had increased under the NSP alone because this was the first time for such coordination (CHA Provincial Management Team, 26 October 2005; CHA District Staff, 27 October 2005; and UNHABITAT Provincial Director, 1 November 2005).
Successful training but

barriers to participation

CHA and UN-HABITAT emphasized their efforts to deliver adequate training and believed that this proved effective for most CDC members. Such capacity-building initiatives ranged from teaching the general objectives of the programme to more specific instructions like budgeting, bookkeeping and filing, procurement, children's rights awareness, mine awareness and natural disaster management. Training was also specific to suit the particular functions of the CDC sub-committees (for example, the role of chairmen, secretary etc) and followed the 5 NSP phases. Where possible, training was supplemented by the provision of satellite radios for the CDC to listen and learn from capacity-building programmes (CHA Provincial Management Team, 26 October 2005; CHA District Staff, 27 October 2005; and UN-HABITAT Provincial Director, 1 November 2005).

The management at the $\mathrm{CHA}$ admitted there were barriers to participation across Balkh Province, with the 12 per cent literacy rate in general representing the most significant. This was especially problematic at the beginning. District staff claimed that "80-85 per cent of members find it difficult to understand completely all the forms, and they should be in very simple/local language to be made accessible." Therefore, it was recommended that the skills of the $C D C$ members needed to be improved and with an increase in the distribution of "working" satellite radios. Management staff hoped that this barrier was alleviated by their methodology and approach to training; that is, by starting at the elite level within the CDC and then moving down gradually. Using the local language was also attributed with helping the people understand $(\mathrm{CHA}$ Provincial Management Team, 26 October 2005; and CHA District Team, 31 October 2005). UN-HABITAT "anticipated that illiteracy would be a barrier" and joined the NSP to prepare instructive pictures/cartoon magazines. Accordingly, "each phase has a cartoon handbook, in particular, for the election of the CDCs, and this has proved useful for the educated and the uneducated."24

The time of the year formed the second, though variable, barrier. That is, people were typically "too busy with farming during the spring and summer months to participate in the NSP." Implementation can thus be limited when the men are unable to
24 The FP Director noted that in general the treasurer and the secretary have to be literate and educated and this is a prerequisite for these posts in the election. Alternatively, it was asserted that "most chairmen tend to be uneducated". (UN - HABITAT Provincial Director, $1 \mathrm{~N}$ ovember 2005).

THE PRO VIN CIAL FIELD SU RVEY REPO RTS 
conduct large meetings. Conversely, winter is more conducive for such community participation. The third barrier to participation was that $C D C$ positions were not salaried (UN-HABITAT Provincial Director, 1 November 2005).

\subsection{The FPs' capability and limitations in relation to the programme demands}

Increasing capacity to cope with the NSP (Management level)

$\mathrm{CHA}$ argued they had to build their capacity, knowledge and skills through various training sessions and workshops conducted by themselves, $\mathrm{OC}$ and MRRD ( $\mathrm{CHA}$ Provincial Management Team, 26 October 2005). District staff concurred that they "had to learn more skills, use more social mobilizers and facilitators, and hire a technician to ensure we kept to the regulations since it is a new programme." This was particularly crucial "to maintain efficiency when the number of projects was high". There was also a test for all staff on applying the Operational Manual (CHA District Staff, 27 October 2005). UN-HABITAT's history of developing the CFDO and in providing training material for the NSP meant they started with extensive experience (UNHABITAT Provincial Director, 1 November 2005).

Post-NSP plans

The CHA management team were optimistic because the election of the CDC members was an important principle towards sustainability. Therefore, "even if there is no NSP in the future, the system should still be there in addition because there was training on how to approach donors." (CHA Provincial Management Team, 26 October 2005). The district staff were confident as long as the "government supports and funds the CDCs for another 4-5 years; if this lasts for another two years then the projects will die". In sum, "the CDCs do not have good sustainable capacity." (CHA District Staff, 27 October 2005). UN-HABITAT stated a similar timeframe to enable sustainability (UNHABITAT Provincial Director, 1 November 2005).

Problems associated with processing the high number of projects CHA district staff perceived no current problems but noted there were many difficulties at the beginning of the implementation, especially during the elections of the
CDCs and the writing of the CDPs ( $\mathrm{CHA}$ District Staff, 27 October 2005). UNHABITAT was reaching this busy stage and was thus concerned about "the next 3-4 months". The Director also noted problems at the start when the communities found it difficult to understand the procedures of the NSP. He estimated that "40-45 per cent of the 13,000 projects are of good quality, but for the others there is concern that the quality will not be as good because the CD Cs have insufficient capacity." Therefore, he recommended that "it is better to start with 2-3 projects with the CDCs and with a small grant of US $\$ 20,000$ maximum so that they can learn the necessary skills gradually." Alternatively, he thought it was better for the government and/or the UN agencies to implement the US $\$ 60,000$ projects. The two problems were the "delays in instalments and monitoring is very weak." (UN-HABITAT Provincial Director, 1 November 2005).

\section{Eligibility Criteria}

The CHA management team and the UNHABITAT Provincial Director felt there was no problem in applying the criteria to the needs of the communities. CHA district staff agreed, but admitted it was difficult at the start (CHA Provincial Management Team, 26 October 2005; CHA District Staff, 27 October 2005; and UN-HABITAT Provincial Director, 1 November 2005).

Allocation of staff and skills shortfall For Charbolak District, CHA allocated 6 core staff for the NSP, consisting of finance, administration, engineering (junior and senior), personnel, and a senior supervisor/manager. Only one of these core staff was female. In addition, there were 16 social organizers. Each project typically had six staff, 4 salaried (engineer, storekeeper, finance and foreman) and two from the CDC with no salary. Projects in Dawlatabad District had one senior and one junior engineer, one facilitator, and a district officer (CHA District Staff, 27 October 2005; and CHA District Team, 31 October 2005). UN-HABITAT claimed 18 staff were allocated to the NSP, including managers, engineers, social mobilizers, reporting officers, and administration and finance. Eight staff members were female (UN-HABITAT District Staff, 10 November 2005). The Director's account conflicted with this total, noting that, "for $18 \mathrm{CDCS}$, we have one engineer in addition to 23 field and support staff. The Director estimated that they assigned "one social organizer to $12 \mathrm{CDCS}$, 
who would cover two CDCs each day and all 12 CDCs each 6-day working week." Nevertheless, he admitted candidly that "we, like all FPs, have problems" (UNHABITAT Provincial Director, 1 November 2005).

CHA provided the following description of the main project skills needed:

- Social Organizer: community development, working with the community, knowledge about the 5 phases of the NSP and the culture of the community.

$\checkmark$ Senior Engineer: to check the proposal and the NSP programme methods.

- Engineer: knows about the NSP, engineering issues and construction.

- District Officer: to know all about the NSP, management, finance, administration, and methodology of establishing elections.

- Monitor: the approach to monitoring, proposal writing, feedback, relations between the district office and the district government.

$\checkmark$ Community Development Officer: how to develop the community, get a full picture of the community and check the community proposal.

NSP Manager: full responsibility, knows about all the programmes, the methodology of NSP, relations between the $O C$ and the office and how to resolve problems.

- Office Manager: to manage and assist the NSP Manager (CHA District Staff, 27 October 2005).

UN-HABITAT provided a similar overview, noting orientation training, how to mobilize the community, how to select the CDCs and prepare the elections, CDP training, project management, evaluation, implementation, procurement and accounting (UN-HABITAT District Staff, 10 November 2005).

All but one of the groups of the two FPs thought there were no skills shortfalls ( $\mathrm{CHA}$ District Team, 31 October 2005; CHA District Staff, 8 November 2005; UNHABITAT District Staff, 10 November 2005). $\mathrm{CHA}$ staff in one district thought their "relevant skills were weak at the start of the NSP". While this gradually improved, they still desired more skills training, "for example, in community development monitoring and methodology". In particular, the staff suggested that "social organizers need more training about women's rights and mine clearance/awareness." (CHA District Staff, 27 October 2005).

\section{Training}

CHA and UN-HABITAT district staff listed training/workshops on the Operational Manual, proposal writing, monitoring, book-keeping, finance, human rights, children's rights, mine awareness, community development and the rule of law/constitution. The staff felt that all had a good impact and effect (CHA District Staff, 27 October 2005; CHA District Staff, 8 November 2005; and UN-HABITAT District Staff, 10 November 2005). As an example, a social mobilizer for UN-HABITAT explained how he was trained to gain proper access to a village for the first time:

First, we contact the district head and ask them to invite the village leader to a meeting in the district office to explain the NSP and our aims. If necessary, we will also move down the line of authority to find other key persons to secure permission.

When we enter, we visit the elders at a small meeting and then we have a community-wide gathering (UN-HABITAT District Staff, 10 November 2005)

\subsection{Project relevance}

Nature of the projects 25

Markaz-e-Dawlatabad, Dawlatabad District, (Type 1 Community) a school (social infrastructure), and engaged in Phase 3 (implementation of project) of the NSP;

- Choba Temorak Karni Khail, Charbolak District, (Type 2 Community) community centre (social infrastructure);

- Taimorak, Charbolak District, (Type 3 Community) non-participating NSP;

- Yakhdan, Dawlatabad District, (Type 1 Community) small bridges and aqueduct system completed, and electricity system ongoing (social infrastructure and services);

- Alichopan, Dehdadi District, (Type 2 Community) water supply, deep well (services); and

- Aliseena, Nahrishahy District, (Type 2 Community) probably water supply, deep well (services) (CHA District Teams, 27 October 2005; 31 October 2005; 8 November 2005; and UNHABITAT District Staff, 10 November 2005).
25 The nature of the projects, if quantity was prio ritized over quality, and the opportunities for capacity-building and empowerment, are detailed in Section 1.6.

THE PRO VIN CIAL FIELD SU RVEY REPO RTS 
Approach to identifying the

projects as community priorities

In Markaz-e-Dawlatabad, CHA recalled that the community originally wanted a generator for electricity but the people realized they could not raise the additional US $\$ 40,000$ to meet the US $\$ 100,000$ total costs (Dawlatabad is the size of a small town although it is classified as a village). Although there was already a school in the community, the people opted for an additional school as their second priority because there was need for more space. The present school had only 16 classrooms. Nevertheless, the new school would only have 8 classrooms, which meant "the number of rooms was still an issue" (CHA District Team, 31 October 2005).

In Choba Temorak Karni Khail, CHA noted that their first task was consulting the $C D C$ and to encourage them to prioritise the needs of the community. The people then gave their input on the list and the CDC made the final decision: "[t]he people sat and thought, 'we have a school and road but we need a community centre'. The Technical Engineer estimated the cost and detailed a budget." (CHA District Staff, 27 October 2005). In Yakdan, similar processes of consultation were noted (CHA District Staff, 8 November 2005).

For Aliseena, UN-HABITAT described the first phase as "identifying the priorities of the communities, categorizing the problems, and deciding which projects can be done." Unlike Markaz-e-Dawlatabad, Aliseena were able to choose their first priority, followed by a school and then electricity. The district staff recalled that, "as soon as the community reached their conclusion, we had a large gathering and some problems were raised by $C D C$ members concerning the identification of their priorities." In Alichopan, the people rejected the CDC's original proposal and asked for water supply instead (UN-HABITAT District Staff, 10 November 2005).

Estimating immediate beneficiaries and the wider impact

It was estimated that 16 villages would use the school in Markaz-e-Dawlatabad; 900 people to use the community centre in Choba Temorak Karni Khail; all 218 families benefited from the bridges and aqueducts and expected to receive electricity in Yakhdan; and it was hoped that all the residents in Alichopan (306 families) and Aliseena (426 families) would benefit from the water supply projects (CHA District Staff, 27 October 2005; CHA District Team, 31 October 2005; CHA District Staff, 8 November 2005; and UN-HABITAT District Staff, 10 November 2005).

All the district staff for both FPs admitted it was likely that the projects would pull people in from outside the community new residents and/or returnees (CHA District Team, 31 October 2005; and CHA District Staff, 27 October 2005). For Yakhdan, CHA acknowledged the electricity "will have high impact, the people will be more civilized and since most left their houses originally because there was no electricity, they will come back." (CHA District Staff, 8 November 2005). UN-HABITAT furthered this point, raising two interlinked barriers, "No one can prevent people from coming in and we have received no guidance, although we have already told the MRRD and the World Bank, and donors know about it." Furthermore, strains could emerge since the project budget was based on the original community profile and there were no provisions for re-adjustment (UNHABITAT District Staff, 10 November 2005). The respondents could not suggest possible solutions based on the strict guidelines of the NSP. For example, it may be possible to ensure that water supply is restricted to the original beneficiaries by piping the water into their homes. However, this option would be very expensive to construct and maintain (UN-HABITAT District Staff, 10 November 2005).

\section{Attempts to be inclusive}

The school in Markaz-e-Dawlatabad could not be completely inclusive because there were only 8 classrooms to accommodate the children of more than 1000 families. Poor roads would also have hampered access for those on the outskirts (CHA District Team, 31 October 2005). Conversely, the community centre in Choba Temorak Karni Khail, the bridges and electricity project in Yakhdan, and Aliseena's and Alichopan's water supply projects, had the potential to be inclusive (CHA District Staff, 27 October 2005; and CHA District Staff, 8 November 2005).

In terms of gender equality, the NSP clearly promoted men's and women's CDCs, and both FPs had encouraged women's CDCs from the start. However, as detailed below, actual power and influence in the project process was typically limited to the men. There were two approaches to this 
imbalance: mixing or continuing the segregation of the CDCs. For the former, $\mathrm{CHA}$ was optimistic that CDCs would merge in the future, but assured the researchers that this was completely impossible at the start of the NSP and for villages initially. Instead, the FP's approach was to start small and encourage integration. Staff believed there was the potential for more ( $\mathrm{CHA}$ Management Team, 8 November 2005).

Assessment of political, economic, sociological and technological factors

The non-budgetary reason for choosing the school in Dawlatabad was the lack of access to proper schooling outside of the home and mosque (CHA District Team, 31 October 2005). Before proposing the centre in Choba Temorak Karni Khail, the community valued a tangible presence of the government (CHA District Staff, 27 October 2005). In Yakhdan, it was believed that the projects would increase people's general awareness and improve basic access (CHA District Staff, 8 November 2005).

Controlling the quality of

construction on site

The construction of the school in Markaz-eDawlatabad had reached a mid-way point. $\mathrm{CHA}$ noted that they had "technical monitors, engineers and a monitoring team (members of the CDC) to check the quality and management of the project during weekly visits." (CHA District Team, 31 October 2005).

The researchers were assured that the construction of the community centre in Choba Temorak Karni Khail would enjoy similar checks, in addition to the support and interest of the people (CHA District Staff, 27 October 2005). Yakhdan also had two monitoring teams consisting of $\mathrm{CHA}$ staff (technician and evaluator) and the community (engineer and foreman) (CHA District Staff, 8 November 2005). UN-HABITAT stated the projects in Aliseena and Alichopan would have "three sub-committees for procurement, finances and monitoring". Monitoring would be supplemented by the OC, MRRD and UN-HABITAT, but the researchers raised the weakness in the $M \& E$ capacity of the MRRD. The respondents argued that this capacity had improved but accepted the limitation overall and added that probably "the best way was for the people to monitor". (UN-HABITAT District Staff, 10 November 2005).

\subsection{Project sustainability}

Measures to maintain the project

For each project, the approach to cost management was the community savings box (thereby furthering the original contribution of 10 per cent) and having the appropriate oversight or observation committees/sector groups, which were encouraged and trained from the start. For example, the Markaz-e-Dawlatabad CDC also planned to manage the supervision and costs of the school with the Department of Education (CHA District Team, 31 October 2005; CHA District Staff, 27 October 2005; CHA District Staff, 8 November 2005; and CHA Management Team, 8 November 2005). In Mazar, UN-HABITAT hoped that a member of the community would be in charge of maintaining the equipment for the wells once they were trained by the Water Supply Department. Nevertheless, the respondents admitted that the people taking responsibility was the crucial point.

It seems likely that a person(s) can be appointed to take charge of, for example, a well so they can arrange for a mechanic to come and repair a broken part when necessary. However, the more significant concern was the community's ability to have the budget to pay the mechanic and for the parts each time the well breaks. UNHABITAT estimated that it could cost US $\$ 300$ dollars a year to maintain a well, especially when this resource is used frequently by many families. Therefore, it seemed unlikely that the community saving box was sufficient to cover all the maintenance costs, especially when there were no planned economic activities connected to the projects researched (UN-HABITAT District Staff, 10 November 2005).

There was no evidence of plans to further the technical skills for maintenance staff. Apart from the example of the school, there were no other examples of coordination with the other ministries and it was unclear if there were the required professional staff to run the services in the long-term $(\mathrm{CHA}$ District Team, 31 October 2005; CHA District Staff, 27 October 2005; CHA District Staff, 8 November 2005; and UN-HABITAT District Staff, 10 November 2005).

Furthermore, 4 of the communities had no plans to ensure that the projects would be functioning in 10 years' time apart from 'hope and enthusiasm' (CHA District Team, 31 October 2005; and CHA District Staff, 27
THE PRO VIN CIAL FIELD SU RVEY REPO RTS 
October 2005). Yakhdan was the exception and there was some attempt to make the electricity system sustainable:

Now each house is using $300 \mathrm{~W}$ electricity and this provides 3 light bulbs/lights. They will pay Afs $80-120$ per month as a bill to the CDC, and then they will calculate after 5 years if they will be able to buy a nother generator of a similar standard. (CHA District Staff, 8 November 2005)

Nevertheless, none of the projects had identifiable direct economic activities (CHA District Team, 31 October 2005; UNHABITAT District Staff, 10 November 2005; and CHA District Staff, 8 November 2005). For example, in explaining the rationale for the community centre in Choba Temorak Karni Khail, CHA district staff only "hoped to have a small library and resource centre" and that it "would be a space for people to gather and could be sustainable by providing a place for donors to come and meet" (CHA District Staff, 27 October 2005). In Yakhdan, the link between electricity and handicrafts or weaving was tentative if not an afterthought (CHA District Staff, 8 November 2005). Also, in Aliseena and Alichopan, the water supply would have limited economic impact since there were no farmers (UN-HABITAT District Staff, 10 November 2005).

As outlined in the NSP, one approach towards sustainability was for the CDCs to apply to donors for small projects. However, the $\mathrm{CHA}$ had only facilitated three so far. The Markaz-e-Dawlatabad CDC had sent a proposal to JICA for a US $\$ 12,000$ poultry project, and two other communities in Chimental were being processed ( $\mathrm{CHA}$ Management Team, 8 November 2005). UNHABITAT claimed to have integrated this approach more with their recent CDCs, based on their experience with the CFDO and in response to the delays in the NSP grants (UN-HABITAT Provincial Director, 1 November 2005).

\subsection{Project efficiency}

Time from identification to implementation and reasons for delays For the school in Dawlatabad, there were nine months between identification of the project and the start of implementation. Implementation started on 24 April 2005 (6 months ago at the time of the research) and the first instalment was spent. Construction had stopped as the CDC had been waiting three months (at the time of research) for the second instalment. The MRRD in Kabul were initially blamed for this delay but it then transpired that $\mathrm{CHA}$ had made an administrative error, which apparently had been recently corrected (CHA District Team, 31 October 2005).

For the community centre in Choba Temorak Karni Khail, the CHA optimistically anticipated a further period of six months until completion but appreciated that there could be delays in receiving the instalments (CHA District Staff, 27 October 2005).

Completion of the electricity project in Yakhdan was expected to take five months from identification to completion. However, the district staff anticipated a delay in the second instalment and hoped it would arrive between 1-30 December (CHA District Staff, 8 November 2005).

It was too soon for UN-HABITAT to predict the timeframe of the water supply projects in Aliseena and Alichopan.

CHA and UN-HABITAT believed the delays were decreasing but still remained a barrier (CHA District Team, 31 October 2005; CHA District Staff, 27 October 2005; and CHA District Staff, 8 November 2005). It was recommended that 100 per cent of the funds should be transferred once the project is approved (CHA District Staff, 8 November 2005).

Ensuring appropriate design and construction of the projects

First, the school in Dawlatabad was built strategically at the centre of the community. Second, technical engineers were hired to complete the design. This was "approved by Kabul and is based on normal standards although we also have a Safety Standards Theory". The Department of Public Health also issued a code. Following this, the relevant CDC subcommittees discussed the need for skilled labour and then found skilled labourers, foremen and extra monitors within the community. They had purchased the materials from the local market (CHA District Team, 31 October 2005).

Despite the efforts of the community and all the NSP actors, the construction of the school was flawed; in particular, there was insufficient mortar used between the bricks 
and the structures of the three buildings had not been strengthened (see Figures 4, 5 and 6 below). However, it was unclear if this was the result of poor construction or the effect of the CDC trying to save money in anticipation of the delay. Regardless of blame and the delays (past and future), it was certain that the construction would not be able to continue until after winter ( $\mathrm{CHA}$ District Staff, 8 November 2005).

Pre-construction, for the community centre in Choba Temorak Karni Khail, the CHA district staff could only refer to "having our own engineering standards and public health norms and standards". While CHA had already found skilled labour, they were trying to find more from the community and to give them cost-effective training. The community also planned to utilise the procurement subcommittee to purchase the materials locally. The community and $\mathrm{CHA}$ believed it was unnecessary to consider mitigation/defensive measures against natural disasters as there were no previous similar disasters in this area (CHA District Staff, 27 October 2005).

In Yakhdan, the community worked with the $\mathrm{CHA}$ and the Department of Public Health to design the 13 bridges and aqueducts. It was claimed that the relevant government standard was used and that technical experts from the $O C$ and the MRRD had input on site. It was also stressed that $\mathrm{CHA}$ had designed the aqueducts and assessed the natural supply of water. There was a monitoring schedule (for quality and quantity) for both, organized by the $\mathrm{OC}$ and the NSP. The procurement committee within the $\mathrm{CDC}$ purchased the material and hired the engineers. The community and $\mathrm{CHA}$ also believed mitigation/defensive measures against natural disasters were relevant (CHA District Staff, 8 November 2005).

It was too early to ask or adapt the engineering-related questions to the water supply projects in Aliseena and Alichopan. However, UN-HABITAT stated that they provided training for natural disaster management (CHA District Team, 31 October 2005).

The extensive interviews with three levels of the FPs clearly uncovered a range of salient design and operational issues. Several positive features were noted, including a clear understanding of their role and function with the NSP, a resultant increase in
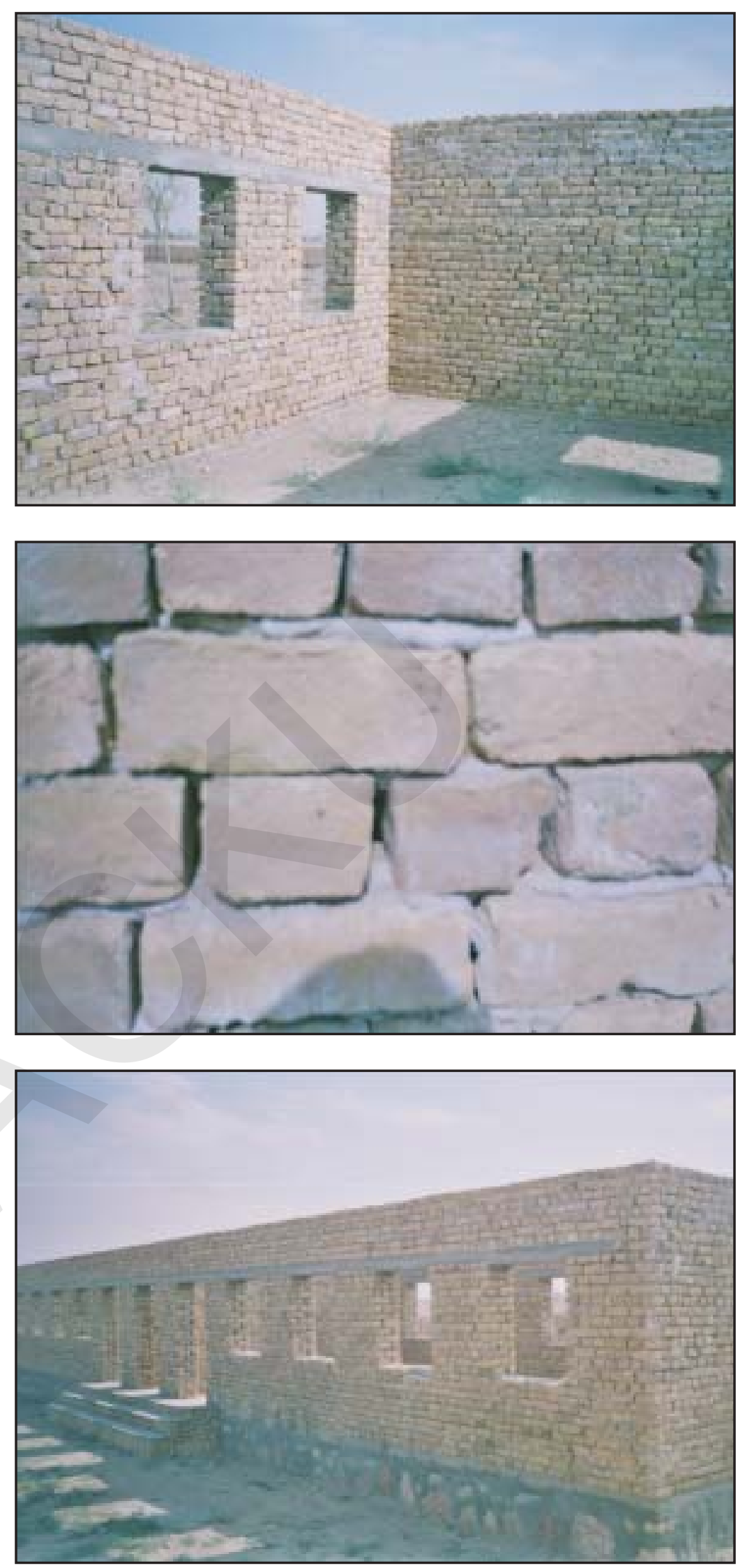

Markaz-e-Dawlatabad school

\section{Figure 4: Inside}

Figure 5: Close-up

Figure 6: The front
THE PRO VIN CIAL

FIELD SU RVEY REPO RTS 
capacity, and instances of co-operation with the OC and DRRD. However, the most fundamental weakness was the projects. This included widespread inefficient implementation, and instances of poor design. Moreover, it was concluded overwhelmingly that the relevant actors had not envisaged the sustainability of the projects. 26

\section{The CDCs}

This section first presents a general profile for each of the five communities participating in the NSP in Balkh. Markaz-eDawlatabad, Choba Temorak Karni Khail and Alichopan were multi-ethnic communities compared to the predominately Arab Yakhdan and Aliseena, which was mainly Hazara. All the communities were clearly deeply affected by the war, with poverty and displacement as two recurring characteristics. Yakhdan was the most advanced in terms of project implementation while Aliseena was the newest NSP member. Markaz-e-Dawlatabad, Choba Temorak Karni Khail and Alichopan encountered significant challenges: disproportionate budget to actual number of beneficiaries; not enough families/budget to allow main needs to be prioritised; and delays in instalments, respectively. Nevertheless, all the CDCs affirmed that the NSP had created (or at least expected it to) positive changes to community governance. Two concerns were noted by two of the women's CDCs: unelected persons were still dominant in Markaz-e-Dawlatabad; and in Alichopan, the women's CDC preferred not to integrate with the men's.

Overall, the CDCs functioned well in relation to the whole community, which they attributed to the work of the FPs. The CDCs claimed the elections were fair and well supported, which was complemented by the identification of community needs based on consensus (within CDC and the community). All had the relevant documentation based on their stage within the NSP. However, the women's CDC in Choba Temorak Karni Khail stated that it did not have access to the documents. Sub-committees all appeared to be in place. Although the communities could identify important benefits from the projects, there were insufficient plans for maintenance, and economic activities were mainly not considered. The women's CDC in Alichopan was an exception but had encountered major obstacles. This CDC and Aliseena's also did not have a meeting place. All but one of the CDCs praised their relationship with the government. Alichopan expected a good relationship but complained that the Governor had manipulated the selection of NSP villages. The women's CDCs in Markaze-Dawlatabad and Choba Temorak Karni Khail yearned for direct contact with the government. All the CDCs were aware of the official NSP complaints procedure.

All the CDCs valued (and Aliseena expected to) their relationship with the FP and emphasized the usefulness of the training. However, the women's CDCs in Markaz-eDawlatabad and Choba Temorak Karni Khail considered the training insufficient to their needs. The bridges/aqueduct project in Yakhdan displayed notable engineering design and implementation strengths.

\subsection{0 verview of the communities and their CDCs}

General community profile

Markaz-e-Dawlatabad was $50 \mathrm{~km}$ north of Mazar (1.5 hours by car). The multi-ethnic community of 1688 families consisted of mainly Tajik with some Pashtun, Turkman, Uzbek, Hazara, Baducch and Arab ethnic groups. Livelihoods depended on farming, teaching and an assortment of daily wage work. CHA asserted that the war had a significant impact on the community. In particular, inter-ethnic fighting had left deep psychological scars and livelihoods were fractured. Consequently, all the families were described as poor, with 353 widows, 128 IDP families, and 209 disabled persons. There were 7-8 members in each household. The district head of the police, the head of the district government and the traditional shura were named as the only other influential figures apart from the CDC members. The age of adulthood was 18 years for men and 14 years for women (Markaz-e-Dawlatabad Men's and Women's CDCs, 31 October 2005; and CHA District Team, 31 October 2005).

Choba Temorak Karni Khail was 54 km west of Mazar ( 40 minutes by car on the main road from Mazar, followed by a further 10 minutes off-road driving). The community of 126 families consisted of mainly Pashtun, with some Tajik and Arab ethnic groups. Their livelihoods depended on trying to grow wheat but there had been drought for two years. None of the families were rich 
and the majority were described as poor, with some of middle income. Most of the households (between 4-15 family members in one compound) had several dependents - widows, elderly and/or sick. Many of the families had been displaced during the war. Only the CDC members were identified as influential figures. However, the wife of the CDC head was also head of the female shura, and the deputy of the female CDC was wife of the traditional shura head, and these connections could have easily influenced/restricted the women's CDC.

The researchers observed some larger and better-built homes in the centre of the community - spacious, two levels, glass windows, and some had one or more tractors. The owner of the largest house was the uncle of the CDC leader. The age of adulthood was 14 years for women and 18 years for men. Fifty per cent of the adults were literate. An estimated 40 per cent participated in the $C D C$ elections winter (Choba Temorak Karni Khail Men's and Women's CDCs, 27 October 2005; and CHA District Staff, 27 October 2005).

Yakhdan (2500 jarebs) was $50 \mathrm{~km}$ north of Mazar ( 1.5 hours by car), 6 km (15 minutes by car) from Markaz-e-Dawlatabad. Of the 218 families, Arab was the main ethnic group, with some Pashtun and Uzbek. Their livelihoods depended on manual labour. Most of the families were described as poor, with some of middle class. There were 3-4 persons in each family; many had disabled and/or widows and there were 80 displaced families. Named influential figures included the head of the district, the elders and the CDCs. The age of adulthood was 17 years (Yakhdan CDC, 7 November 2005).

Alichopan was located $5 \mathrm{~km}$ from Mazar. Of 306 families, the main ethnic group was Hazara with some Sayed and Pashtun. The people worked as labourers or shop keepers. Most were described as poor. There were 2-3 families in each compound and the CDC identified 37 widows as heads of households, 7 disabled, and most of the community were returnees. Influential figures consisted of the elders of the community (Alichopan CDC, 10 November 2005).

Aliseena was located in the suburbs of Mazar. The community of 425 families/2500 persons was all Hazara, worked mainly as labourers, and were poor. Typically, 3-4 families lived together and there were many widows and disabled. Fifty per cent were returnees and IDPs. The shura and the women's CDC were described as the only influential people (Aliseena CDC, 10 November 2005).

Basic NSP related information

In Markaz-e-Dawlatabad, there were 15 members each on the men's and women's CDCs. Both were formed two years prior and met once a month. There were 1688 families but they would receive the maximum budget of US $\$ 60,000$, which was for 300 families in theory (Markaz-eDawlatabad Men's and Women's CDCs, 31 October 2005).

In Choba Temorak Karni Khail, there were 15 members each on the men's and women's CDCs. They had been established three to four months prior and met once a week. Although there were several wells, the quality of the water was described as "poor, salty and unpredictable in supply". The CDC wanted a new well but the budget allocated was too small because there were only 126 families. Instead, the community opted for a community centre (US $\$ 25,200 /$ Afs $1,260,000$ allocated) and the pre-construction site measured $56 \mathrm{~m} \times 65$ $\mathrm{m}$. There were 200 school children (first, second and third years), who could use a school ( $5 \mathrm{~km}$ away) outside of winter (Choba Temorak Karni Khail Men's and Women's CDCs, 27 October 2005; and CHA District Staff, 27 October 2005).

In Yakhdan, there were 11 men and one woman on the $C D C$ and they met regularly. The CDC had submitted two sub-project proposals, with one completed and one under construction (Yakhdan CDC, 7 November 2005).

In Alichopan, there were 6 members on the women's CDC and they met regularly. The CDC had been waiting for their first instalment for 3 months, and had become frustrated as they had started to lose the trust and faith of the community (Alichopan CDC, 10 November 2005).

In Aliseena, there were nine members of the men's CDC, as a representative was elected from each of the nine neighbourhoods. The CDC had held many meetings together and with the FP, even though the CDC was created three months prior. They intended to apply for a water supply project. It was noted that there had been no assistance, not even for the IDPs and returnees (Aliseena CDC, 10 November 2005).
THE PRO VIN CIAL FIELD SU RVEY REPO RTS 


\subsection{Legitimacy and acceptance of the CDC}

Community governance and leaders In Markaz-e-Dawlatabad, the men's CDC stated that the traditional shura and the head of the district governed the community. For the women's CDC, the community was governed by influential figures, in particular, the district head of the police. Both CDCs described how the FP introduced the NSP. Both CDCs identified the traditional shura as the only other community committee. Both CDCs thought they had changed the way the community was governed and complemented other forms of governance through co-ordination (Markaz-e-Dawlatabad Men's and Women's CDCs, 31 October 2005).

In Choba Temorak Karni Khail, both CDCs stated that the traditional shura governed the community. The men's CDC was introduced to the NSP through information from other villages while the women's CDC described how the FP arrived and conducted the needs assessment. Both CDCs identified the traditional shura as the only other community committee. Both CDCs considered their work to have changed community governance, with several examples of conflict resolution. Accordingly they believed the CDCs to have complemented other forms of community governance through coordination and the creation of better relations (Choba Temorak Karni Khail Men's and Women's CDCs, 27 October 2005).

In Yakhdan, the CDC described themselves as the leaders, since the traditional shura disbanded when the NSP started. The FP introduced the NSP to the community. The CDCs were the only other community committees. The CDC felt they had improved community governance by making their objectives clear and involving the community in the decision-making process (Yakhdan CDC, 7 November 2005).

In Alichopan, the $C D C$ was described as the leaders. The community had a network with UN-HABITAT in the past and that is how they discovered the NSP. The CDCs were the only other community committees. The CDC did not perceive a major change in community governance but thought it would complement other forms of community governance in the future. The Alichopan women's CDC did not want to mix with the men's CDC "as it would be very difficult to sit with the men. Also, if we sit with the men then they are superior and we would have no voice in the decisionmaking. For now, it is better to work separate." (Alichopan CDC, 10 November 2005).

In Aliseena, the CDC was described as the leaders. They heard about the NSP from other neighbourhoods and then asked to join. The CDCs were the only other community committees. Significant changes in community governance by the CDC were noted. It was also thought that it complemented other forms of community governance. It was claimed that over 50 per cent voted in the election (Aliseena CDC, 10 November 2005).

\subsection{Functioning of the $C D C$ in relation to the whole community}

\section{General}

In Markaz-e-Dawlatabad, the men's CDC met to plan how to "rehabilitate the village and the district, and advised the role of the NGOs". The women's CDC met to "advise on and solve women's problems". Both CDCs stated that the election of the 15 members on each CDC was based on secret voting and that some were elected from the traditional shura. All the relevant documentation (for example, minutes, procurement forms, and observations) was checked by the researchers, and the CDCs knew these tasks belonged to the secretary. Their first priority was a generator but it was too expensive so they decided on the school. The men's CDC had sub-committees for buying the material and for monitoring. The women's CDC stated that the school was a prime need and it was important that boys and girls could benefit from the project (Markaz-e-Dawlatabad Men's and Women's CDCs, 31 October 2005).

In Choba Temorak Karni Khail, the men's $\mathrm{CDC}$ aimed to "improve the relationship between the community and the government and work on sub-project proposals". The latter consisted of reconstructing the road, establishing a tailoring course for women and then the building of a school. They met once a week and their main responsibilities were to set an agenda, share out the tasks, discuss the announcements from the district level and decide how to resolve problems with the government. The women's CDC defined their main function as holding weekly meetings to discuss and 
advise on important issues within the community. Both CDCs agreed that they had been elected based on secret voting three months prior. The men's CDC stated that 70 per cent of the community voted. All the relevant documentation (for example, minutes, procurement forms, observations) for both CDCs was checked by the researchers. Financial forms relating to the CDP were not filled out as the project had not yet started. The women's CDC claimed not to have (access to) the documentation. 27 The men's CDC stated that they had discussed the needs of the community and decided on a community centre during a meeting. They thought it would be useful for doctors and NGOs, while providing a communal meeting place for the community. The women's CDC agreed but also stated that they could not afford their first choice of a school (Choba Temorak Karni Khail Men's and Women's CDCs, 27 October 2005). The DRRD staff thought the community centre was "appropriate to the needs of the community and a good idea from a social point of view because the community could hold gatherings. Now, there is no such hall or room so it is a way to be more civilized." (District DRRD staff, 9 November 2005).

In Yakhdan, the CDC met regularly to discuss and plan the sub-project proposals. The CDC stated that secret voting was used in the election, which took place in the mosque. It was claimed that 400 people voted. The CDC had all the relevant documentation and the secretary kept the relevant records. Using the same approach to deciding the bridges and aqueducts project, the $\mathrm{CDC}$ members recalled that they held a community meeting and finally decided on a generator/electricity project. They had found it difficult to find paid skilled labour and needed to hire from outside the village. This had caused delays, especially during Ramadan (Yakhdan CD C, 7 November 2005). They had received two instalments for the generator (Afs 572,390 and Afs 228,956) (OC and Team, 9 November 2005). They stated that there were no major disagreements from the community. However, they had originally planned to build a school but were discouraged by the requirement for the Ministry of Education's approval. They managed to save money from the bridge project by getting high quality material at a low price and built two wells with this money (Yakhdan CDC, 7 November 2005).
For the Alichopan $C D C$, the main obstacle was not having a place for meetings and to keep documents. The 6 CDC members stated that they were elected based on a secret vote. The $C D C$ had all the relevant forms and the official certificate etc. They approached the community first to discuss and prioritise needs since they had received the relevant technical training, and encouraged the people to vote (Alichopan CDC, 10 November 2005).

In Aliseena, the CDC conducted regular meetings and spent 20 days preparing for the CDC elections. Unfortunately, they did not have a CDC building for meetings and used the house of one of the members. Secret voting was also used and the community was instructed that anyone could nominate themselves. The recently created CDC had not yet received all the forms and documentation and members were finding them difficult to understand. They believed that it was the responsibility of the whole community to prioritise their needs, and noted that a well was needed (Aliseena CDC, 10 November 2005).

Implementation of project/s

In Markaz-e-Dawlatabad, the CDCs agreed that the FP was able to facilitate the community's request(s). They did not face disagreements within the CDC or with other community groups concerning the implementation of the project. To this end, the community contributed 12 per cent of the costs and provided physical assistance. The two CDCs also conferred on the best approach to implementation. The men's CDC recalled that 4 families who disagreed with the project were invited to the school during the implementation to view the progress. In terms of benefits, both CDCs hoped the children of the community would have definite access to education. The main long-term benefit was the education of the next generation. The CDCs referred to the community savings box (for repairs) and the possible employment of locals as teachers, as the main arrangements for maintaining the school. The quality and quantity of the construction was monitored by the CDC members regularly. The men's CDC discussed their plans to install electricity and to continue consulting with the NSP. The women's CDC wanted to have direct contact with the donors (Markaz-eDawlatabad Men's and Women's CDCs, 31 October 2005). The CDCs had spent half of the NSP money (Afs 2,979,428, then Afs $1,489,762$ on 2 April 2005). The DRRD had
27 The leader produced the following forms: 0 bjective and Goals of the N SP, Long and Short-term goals, Rules and Regulations of the NSP, Constitution of the $C D C$, Job Responsibility of the CDC, Procurement Policy and Manual, Manual of Children's Copy of Subcontractors forms, Q uotation forms, Purchasing form, Building form, Evaluation of the CDC form, Manual for Microfinance, Leisure Books, Cash Book, Finance Summary sheet, Advance form, Bank Deposit form, Financial Expenditure form, Committee Account form, Received form, and Recording forms.

THE PRO VIN CIAL FIELD SU RVEY REPO RTS 
not visited the school but the $\mathrm{OC}$ and team had made at least one site inspection (District DRRD staff, 9 November 2005; and OC and Team, 9 November 2005).

In Choba Temorak Karni Khail, the CDCs agreed that the FP was able to facilitate the community's request(s) by always "consulting and advising when asked". They did not expect to face disagreements within the CDC or with other community groups concerning the implementation of the project. Both CDCs were optimistic and motivated about the implementation, and planned to focus on the selection of builders and the quality of the monitoring. The CDCs had not faced opposition from within the community. In terms of benefits, the men's CDC valued the project as a communal meeting place, which could also be used to house a library, resource centre and perhaps a day care centre. The women's CDC linked it directly to empowerment. No direct economic activity was attributed but there was limited potential. The main potential long-term benefits were an improved standard of living and empowerment.

The CDCs referred to the community savings box for repairs and establishing linkages outside the community as the main arrangements for maintaining the community centre. It was planned that the community would monitor the implementation of the project. Both CDCs wanted to implement more projects and to try focussing on a school with assistance from the Department of Education (Choba Temorak Karni Khail Men's and Women's CDCs, 27 October 2005).

In Yahkdan, the CDC agreed that the FP was able to facilitate the community's request(s). They did not face disagreements within the CDC or with other community groups concerning the implementation of the project, except one issue, which was resolved through discussion. The community contributed 10 per cent of the costs and "were very enthusiastic to participate". The FP was also involved by giving instructions in terms of capacity-building, bringing staff, and by finding an engineer in the village. The CDC got involved in the procurement of materials and the monitoring. In terms of benefits, the bridges project had improved general access in the community and to the outside, which was important for commerce and medical emergencies. The electricity project would also allow the people to access radio and televi- sion for news and leisure. No direct economic activity was attributed to either project. The main potential long-term benefit was a better standard of living. The $\mathrm{CDC}$ referred to the community savings box for repairs and employing locals (as guards and engineers) as the main arrangements for maintaining the community centre. It was also proposed that each family could have their own electricity metre. Informants claimed that a group of evaluators and monitors played a key role in choosing and criticizing the projects, especially for the bridges. They reported to the $\mathrm{CDC}$ from the beginning and especially checked the quality of the materials, for example, the cement etc. The CDC was working on a carpet-weaving project and animal husbandry. It also resolved a serious conflict between two brothers in early 2005 (Yakhdan CDC, 7 November 2005).

In Alichopan, the CDC agreed that the FP was able to facilitate the community's request(s) but admitted that it had "difficult tasks to fulfil". They did not face disagreements within the CDC or with other community groups concerning the implementation of the project. The community planned to contribute 10 per cent and help dig the wells. They expected to benefit from clean drinking water. No economic activity was attributed apart from those involved in the construction. The main potential longterm benefit was a better standard of living. The CDC did not know how to maintain the project and admitted the community savings box might be inadequate for repairs. However, they hoped the people would act responsibly when using the wells, and planned to apply for small grants once they the capacity and skills. There was a monitoring sub-committee for the project. The group's main recommendation was "that instalments should be on time". Despite the challenges, the women's CDC desperately wanted "job opportunities", and had started by planning a project for embroidery. They showed the research team a sample of embroidery and stated that they wanted to sell it but found there was no market because they were being undercut by Chinese imports. Instead, they planned to sell lace work but needed "money for raw material and machines". In addition, they had tried to establish a mathematics course for girls but were without budget, and managed by charging people a small fee (Alichopan CDC, 10 November 2005).

In Aliseena, the CDC hoped that the FP 
would facilitate the community's request(s). They did not expect to face disagreements within the CDC or with other community groups concerning the implementation of the project because of the complete support. The CDC planned to find qualified engineers and to control the quality of the work. It expected to benefit from clean drinking water but there was no economic activity attributed. The main potential longterm benefit was a better standard of living. The CDC had not planned for maintenance but expected to discuss it with the community and to focus on applying to the government and donors for small grants. Monitoring had not been planned at the time of the research (Aliseena CDC, 10 November 2005).

\subsection{Relationship between the CDC and government}

In Markaz-e-Dawlatabad, the men's CDC claimed to have "very good" relations with the district government but the women's $\mathrm{CDC}$ had not been in recent contact. Both CDCs thought the partnership was good. Nevertheless, the women's CDC wanted more women to be part of the decisionmaking system and to have direct contact. Both CDCs were aware of and had used the NSP complaints procedure (written and verbal), and had received feedback through meetings with the NSP and the FP (Markaze-Dawlatabad Men's and Women's CDCs, 31 October 2005).

In Choba Temorak Karni Khail, both CDCs agreed they wanted to address and solve, or reduce, the problems first before visiting the government offices. Both CDCs thought the partnership was good. The men's CDC thought it was their responsibility to improve the partnership while the women's CDC wanted direct contact. Both CDCs knew about the complaints procedure but had not used it (Choba Temorak Karni Khail Men's and Women's CDCs, 27 October 2005).

In Yakhdan, the CDC had a coordinating meeting with the Head of District and relevant government departments at the beginning of the NSP and reassured them they would solve any problems. The CDC thought the partnership was good, though believed it could be improved through more unity and coordination. The CDC was aware of the complaints procedure but so far the FP had managed all their problems (Yakhdan CDC, 7 November 2005).
In Alichopan, the CDC had been introduced to the District Head and government departments and felt they could contact them when necessary. The CDC thought the partnership was good. The group had a copy of the NSP Operational Manual but did not know about the complaints procedure (Alichopan CDC, 10 November 2005).

The CDC in Aliseena had not been introduced officially to the government but expected the partnership to be good once they registered. The CDC had not yet received information on the complaints procedure. However, the community group was concerned that more than 300 families would use the wells. Furthermore, they complained that the Provincial Governor was pushing for another village to have a CDC even though it had no families. It was claimed that this was an attempt by the Governor to encourage people to return. At the centre of these two issues was the complaint that the government did "not want to focus on Hazaras, whether inside or outside Mazar". The CDC claimed that the target groups were limited to "Pashtun, Arab, Uzbek and Turkmen". (Aliseena CDC, 10 November 2005).

\subsection{Relationship between the CDC and the FP}

In Markaz-e-Dawlatabad, both CDCs thought the training was good but the women's group felt it was insufficient. Additional support for the men's CDC included meetings at the district level among all the CDCs, which was a good opportunity to share information and transfer knowledge. The main problem was the delay of the second instalment by 3 months (at the time of research). It was expected that this would affect the quality of the work directly, and then indirectly since winter was fast approaching, which would delay the work further. The women's CDC was not aware of problems because it was prevented from managing the project (Markaz-e-Dawlatabad Men's and Women's CDCs, 31 October 2005).

In Choba Temorak Karni Khail, both CDCs valued the workshop training because it was empowering and informative. The women's CDC had not received additional support but then men were given satellite radios to listen and learn from weekly training programmes. One member was also being trained in monitoring (Choba Temorak
THE PRO VIN CIAL FIELD SU RVEY REPO RTS 
Karni Khail Men's and Women's CDCs, 27 October 2005).

In Yakhdan, the CDC valued the training on human rights, conflict resolution and banking. The group claimed that help and support were always available (Yakhdan CDC, 7 November 2005).

In Alichopan, the CDC thought the training was useful in addressing problems and resolving conflict, and that these skills were transferable. No other support had been provided (Alichopan CDC, 10 November 2005).

The Aliseena CDC had not yet received training but expected to work closely with the FP's Technical Engineer when writing the CDP (Aliseena CDC, 10 November 2005).

\subsection{Capacity of the CDC}

Based on the above enquiries, the household surveys and the FP's assessment, the men's CDCs in Markaz-e-Dawlatabad, Choba Temorak Karni Khail and Alichopan can be classified as 'able with difficulty'. It was difficult to judge the women's CDCs, as they were clearly excluded from the decision-making processes. In comparison, Yakhdan and Aliseena were 'able'.

\subsection{Engineering questions 28}

Appropriate standards, Monitoring For Markaz-e-Dawlatabad and Yakhdan, please see sub-sections 5.5, 5.6, 5.7, 6.3, and 6.5 above.

Project leadership on site

For Markaz-e-Dawlatabad and Yakhdan, the research team did not identify project leadership on site.

Skills in the community pre-project For Markaz-e-Dawlatabad and Yakhdan, please see sub-sections 5.3, 5.4, 6.1, 6.2, and 6.5 .

28 These questions were not applicable to Choba Temorak Karni Khail, Alichopan and Aliseena.
Long-term budgeting and maintenance

For Markaz-e-Dawlatabad and Yakhdan, please see sub-sections 5.5 and 5.6, and 5.7.

Technical details of projects

The school in Markaz-e-Dawlatabad was constructed to hold 8 classrooms, with two administration buildings in front. The height was originally $2.20 \mathrm{~m}$, which was changed to $2.80 \mathrm{~m}$. The size of the stones also changed from $15 \mathrm{~cm}$ to $65 \mathrm{~cm}$. The adjacent building/school was built by an NGO, but it was claimed that there were some construction problems since the foundations were weak.

In Yakhdan, electricity poles were erected throughout the village and the CDCs had purchased but not erected or installed the cables (see Figure 7). The 13 small bridges seemed to be good structures, although some had developed cracks (see Figures 8 and 9). The CDC and FP indicated that it took one week to build each bridge. The two aqueducts appeared to be well constructed - solid and with deep foundations - and were built by the CDC (see Figure 10). There was a water divider between the two villages, which agreed to take the water on alternate weeks. Two rivers flowed into Yakhdan (see Figures 11 and 12).

Therefore, as set out in the NSP Operational Manual, the CDCs claimed to have been elected based on the guidelines, met regularly and had established sub-committees and a CDP for relevant sub-projects. This demonstrated legitimacy and capacity to plan and manage development projects that benefited the community. In sum, the CDCs had achieved a positive transformation of community governance (successfully

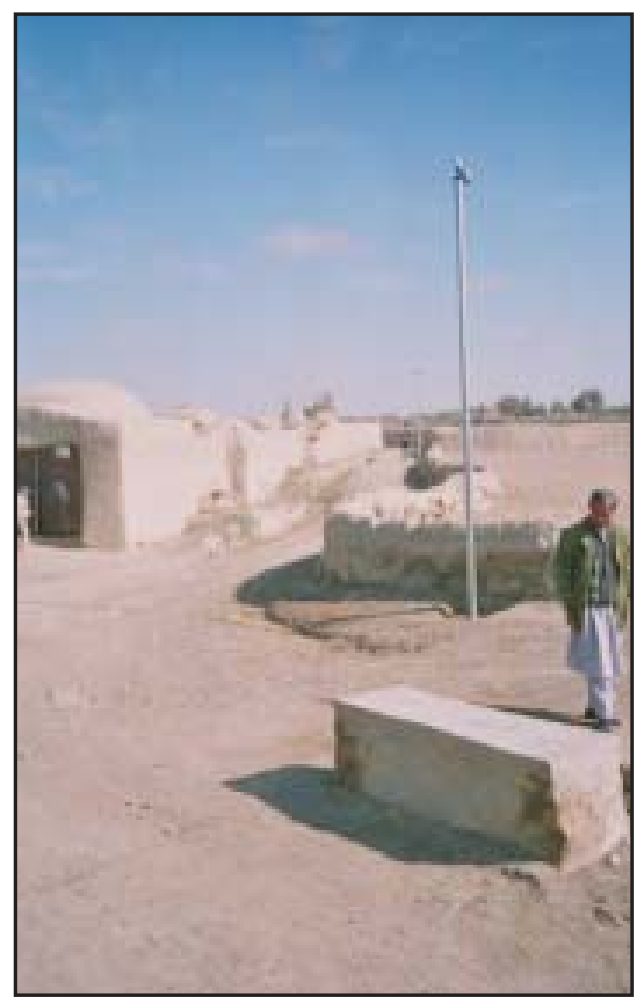

Figure 7: Electricity poles, Yakhdan 

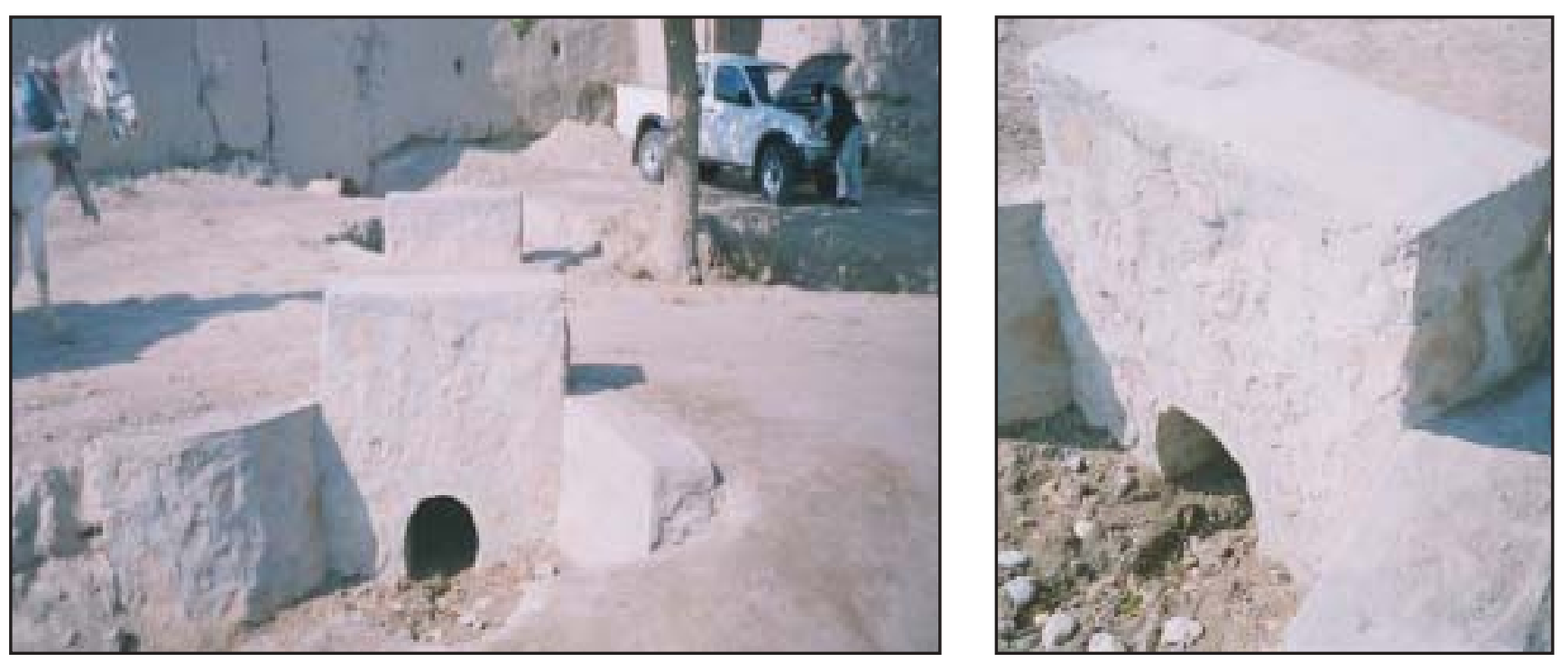

Figures $8 \& 9$ : Small bridge, Yakhdan \& Close-up

Figure 10: An aqueduct, Yakhdan

Figures $11 \& 12$ : River dividers, Yakhdan
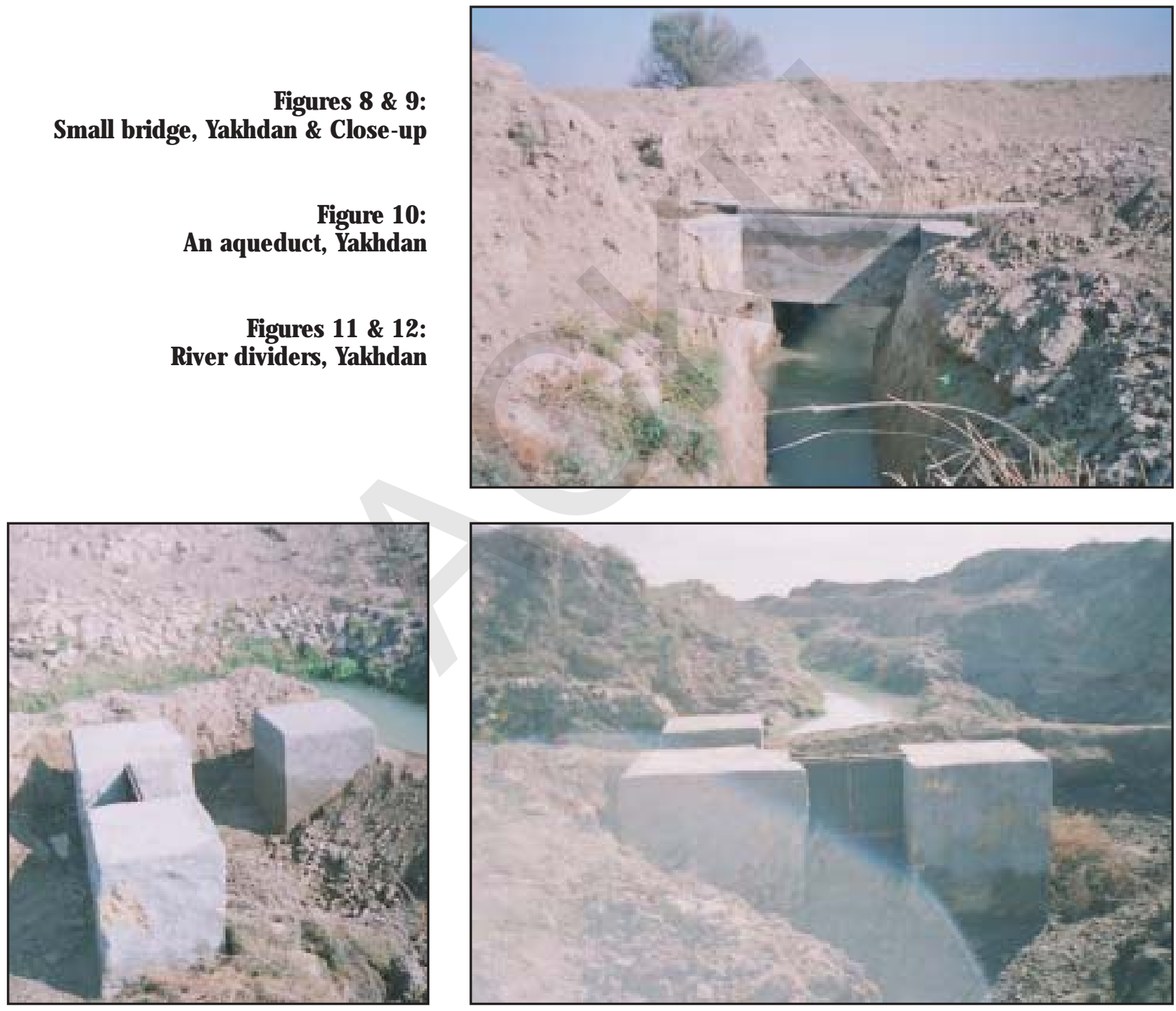
replacing or working in tandem with traditional community governance) and displayed the potential to become genuine partners with the government. However, budget constraints meant that the toppriority in each community was not always addressed. In particular, women's CDCs complained of a limited role. Moreover, they were excluded from power and the decision-making process. Overall, the assessment of the CDCs questioned whether it was right that community priorities came before economic development.

\section{Households with a CDC}

This section demonstrates how the sampled households were representative of their respective NSP community in terms of household composition: livelihoods; income level; and ethnicity. The profiles also yield two main conclusions: each community was deeply affected by the war (although to varying degrees); and the majority of households perceived a post-war improvement in their lives. Overall, the households had a good grasp of their CDC's role (social, local governance and projects) and claimed sound awareness of the election process. Households also generally believed the CDCs were performing well, had contributed (physically and financially) to the projects, and were aware of the main NSP actors and the need for applying for funding outside the Programme. Nevertheless, illiteracy and a lack of social cohesion were two recurring barriers to wider participation. This section closes with four crucial and interlinked findings: half of the households (approx.) in each community perceived the NSP to be about governance and representation; all identified specific service-based projects as the key to improved lives; all believed their government was interested; and all were optimistic about the future.

\subsection{Household profiles}

Basic data

In Markaz-e-Dawlatabad, the 10 households interviewed each consisted mainly of two men and two women. Some had 3-4 men and 3-4 women while one had 8 men and 7 women. There was an average of 13 children in each household. Three households had no dependents, one had a widow and the rest had a mixture of widows and/or disabled. There were several sources of livelihoods listed, including office and government work, teaching, basic labour, shopkeeping and farming. One household head was a Mullah and another was a NGO worker. There was an even split in middle income and poor households. Eight households were Tajik, with one Pashtun and one Uzbek.

In Choba Temorak Karni Khail, the 10 households interviewed each consisted mainly of 2-3 men and 2-3 women. One had 8 men and 10 women, one had 10 men and 5 women, and another had one man and 12 women. There was an average of 15.4 children in each household. Two households had no dependents, and the rest had a mixture of widows, sick and/or elderly and one of these households was also displaced. Field labour and farming formed the most common sources of livelihood. Four households defined themselves as middle income, with the other six classed as poor. Five households were Tajik, 4 were Pashtun and one couple were of mixed ethnicity.

In Yakhdan, the 10 households interviewed consisted mainly of 4 men and 4 women while one household had 7 men and 3 women. There was an average of 8.6 children in each household. Three households had no dependents and the others had a mixture of widows, sick and/or elderly. The members of one of these households were also returnees. Similar to Markaz-eDawlatabad, there was a wide range of livelihoods, consisting of farmers, labourers, a shop-keeper and a Mullah. Three houses were of middle income and the other 7 were poor. Eight households were Arab and two were Pashtun.

Impact of the war and after In Markaz-e-Dawlatabad, only one household claimed not to have experienced impact from the war. For the other 9 households, the most common (and often combined) effects were displacement, the destruction of homes and the killing of immediate family members. All but one household asserted that their lives had improved since the war ended, especially in terms of security, employment opportunities and the freedom of women.

In Choba Temorak Karni Khail, the most common (and often combined) effects were displacement, the destruction of homes and the killing of immediate family members. As a respondent described: 
Our village was close to the road so we saw and heard rockets and bombs explode. One of my brothers died, we lost two women during pregnancy and all the women were traumatized. We were not displaced.

(Household Survey, 27 October 2005)

Eight households argued there was an improvement in their lives after the war, with several focussing on safety. Two households agreed that security had eased, but this alone was not sufficient in creating improvement in their lives. Other barriers included drought and inadequate social services.

In Yakhdan, the households were especially affected by the killing of family members and displacement, for example: "Four uncles and one brother killed and we were displaced", "One brother killed and we were displaced to another province", and "we lost three members and were displaced to several villages" (Household Surveys, 31 October 2005). Seven households believed their lives had improved because security was better, opportunities created, and infrastructure improved. For example, a respondent stated, "we have wells, bridges and we will have electricity". Two households thought the change was negligible and one argued their "lives were still the same" (Household Surveys, 31 October 2005).

\subsection{History of the CDCs}

In Markaz-e-Dawlatabad, 3 households claimed to have no substantive knowledge of the two CDCs. Another also did not know the objectives but hoped to attend a meeting soon. The other 7 households perceived the role of the CDCs to include "rehabilitation ... conflict resolution ... achieving solidarity and cooperation within the community ... talking about and sharing ideas on development" (Household Surveys, October 2005). All respondents knew the CDCs had started two years prior, even those who did not know what they were. All but one respondent knew the Election Commission was chosen by secret voting/election. Eight households (men and women) voted while two did not because they were not present. Before the CDC, village priorities were identified by the elders of the village ( 8 households), the head of the district (one household) and one household did not know.

In Choba Temorak Karni Khail, the house- holds expected the two CDCs to gather people together and address, advise and solve the problems faced by the community. Such problems involved providing services, including a school, and resolving conflict. The majority of respondents knew the CDCs had started 3 months before. Seven households knew the Election Commission was chosen by secret voting/election, while two did not know. Half (men and women) the households voted. Before the CDC, village priorities were identified by the elders of the village ( 6 households), and 4 households did not know.

In Yakhdan, respondents understood the CDC to bring people together, coordinate, make decisions and provide electricity, the bridges and other future projects. In sum: "CDC is NSP and the NSP means projects" (Household Surveys, November 2005). There was slight variation in the respondents' knowledge of the CDC's history. While most knew it had been one year, one thought it was 3 months, while another stated two years. All respondents knew the election commission was selected using secret voting/election. Eight households (men and women) voted, one did not vote through choice, and the other was not in the village. Before the $C D C$, village priorities were identified by the elders of the village ( 4 households), the head of the district (one household), the military commanders and the Taliban (two households) and 3 households said priorities were not set by anyone.

\subsection{CDCs today}

\section{General}

In Markaz-e-Dawlatabad, 5 households thought their CDCs met twice a month, 3 thought once a month and two did not know. Seven households considered the CDCs to work well, and provided examples, while 3 did not know. Seven households thought the elders led their community and, of these, one linked them with the CDCs while the other 6 did not. One household perceived the government, elders and the CDCs to be the joint leaders and two households answered the CDCs. Eight households thought their community leaders were working with the district government, one stated no, and another did not know.

In Choba Temorak Karni Khail, 5 households thought their CDCs met once a week,
THE PRO VIN CIAL FIELD SU RVEY REPO RTS 
3 thought once a month and one said "once a week at the start, now twice a month because of the harvest." (Household survey, October 2005). Four households considered the CDCs to be working well and some provided examples, one thought it was too slow while four did not know. All households agreed that the CDCs led the community. Four households believed their community leaders were working with the government, 4 did not know and two said no.

In Yakhdan, 6 households thought their CDCs met twice a month, two stated once a month and two did not know. Seven knew how the CDC functioned and thought it was working well. Three households did not know and had not received any benefits. All households agreed that the CDC led the community. Nine households believed their community leaders were working with the government and one did not know.

Management of the projects

In Markaz-e-Dawlatabad, all 10 households knew some or all of the relevant actors that initiated the project and the source of the funding; that is, the NSP, the government, CDCs, MRRD, DRRD, World Bank, and/or $\mathrm{CHA}$. Six households knew that the Treasurer or CDC members managed the finances; however, four did not know. Four households did not know how the Block Grant/money was spent. Four knew some of the details of the spending (hiring builders and engineers and purchasing raw materials) while two simply knew that it was spent on building the school. Four households believed the CDCs had not approached other organizations/institutions for funding, three recalled that the community had already contacted the Swedish Committee for Afghanistan, the EU, the WFP and the PRTs, and two households did not know.

Half the households claimed to have assisted the project either as labourers, as part of the procurement and CDP drafting committees, through the community savings box, or giving towards the community contribution of 10 per cent. Six households did not know who else participated and 4 provided the community as their answer. Interestingly, two respondents emphasized that women were excluded from participating. Nine households considered illiteracy as the main barrier to increased participation and the remainder blamed the lack of time and awareness.
Seven households believed the CDCs were planning new projects, which would bring benefits. These consisted of "vocational training for women, carpet-weaving, tailoring, electricity, digging wells and husbandry." Three households did not know of any plans.

In Choba Temorak Karni Khail, 8 households knew some or all of the relevant actors that initiated the project and the source of the funding; that is, the NSP, the government, and CHA. However, two households did not know. The CDC had not received instalments, so it seemed normal that 7 households did not know who managed the finances. Nevertheless, 3 households understood that the $\mathrm{CHA}$ would train the CDC members to manage the funding. None of the households knew that the Block Grant would be spent on building the community centre. Seven had no idea and 3 trusted the CDCs to spend it on the community. All of the respondents believed neither the community nor the CDCs had asked for non-NSP funding.

Once construction started, 8 households hoped to participate in the process although two thought that they would not be asked by the CDC. Seven households expected that everyone in the community would participate while two did not know. Five households perceived illiteracy and lack of other relevant skills as the main obstacles to participation, two thought it was the lack of time, one blamed the lack of awareness, one focussed on discrimination against women, and one household did not know. Six households did not know of future projects, and 4 listed livelihood and agriculture, bridges, electricity and wells.

In Yakhdan, 9 households knew some or all of the relevant actors that initiated the project and the source of the funding; that is, the government, MRRD, and CHA. One household had no idea "because no one tells me" (Household Surveys, November 2005). Eight households knew that the Treasurer of the CDC managed the money and two did not know. Seven households knew the Block Grant was spent on the community projects and two of these were able to provide details, for example, purchasing raw materials. However, 3 households did not know, even though the bridges and aqueducts were completed and the electricity was mid-way through construction. Four households believed the $\mathrm{CDC}$ and the community had not asked for 
non-NSP funding, 3 did not know and three mentioned approaches to the EU, the government and other NGOs. One of these households knew an NGO had recently completed a survey and the outcome was uncertain.

All but one of the households had assisted in the construction of the two projects and this involved mainly working as labourers. Five stated that only men and boys participated in building the projects, 3 households stated that the whole community participated, and two did not know. Four thought there were no difficulties regarding participation but 3 households perceived the lack of time as the main barrier. One household provided the answer of general exclusion and two blamed illiteracy and the lack of education; for example, "some people are not aware. They use the bridges every day but never think who built them or how they were built." (Household Surveys, November 2005). Half the households thought the $\mathrm{CDC}$ was planning future projects which could involve: carpet-weaving, husbandry, livestock, tailoring for women, a school, and a deep well.

\subsection{Impact of NSP/CDC}

\section{Perception of the NSP}

In Markaz-e-Dawlatabad, the answers of 6 households reflected governance and representation as their first response. Specific examples included "solving problems... linking, coordinating and building trust between the government with local community... and social justice" (Household Surveys, October 2005). Two households perceived the NSP to be more about the projects and resultant services. Two households did not know the meaning of NSP. Half of the households claimed the NSP had brought, or hoped it would bring, a noticeable improvement to their lives. These answers varied between the planned completion of the school, talking with people in the community and being consulted, and conflict resolution among the ethnic groups. Only 50 per cent were positive, perhaps since the school remained incomplete due to the delay in the instalments. All respondents claimed that no one else had helped them. Seven households believed their village was more united as a result of the CDCs because it was representative of the community (ethnicity was particularly important) and from the increase in consultation and communal activities. One household was unsure and two saw no impact in this respect.

A range of other changes from the $C D C$ were listed, including: the transference in knowledge and experience between the CDCs and the community, closer relations with the government, and better security. However, one of these households believed the changes were enjoyed only by the men. The 4 other households did not perceive any other changes but one of these was confident that their children would benefit. Six households had not heard about government plans for Afghanistan. The other 4 mentioned general reconstruction or the specific improvement of the main Dawlatabad road, and more development projects in Mazar. Nevertheless, all households felt the government was interested in their community.

In Choba Temorak Karni Khail, the answers of 5 households reflected governance issues and representation as their first response; for example, unity/solidarity, coordination, support and peacebuilding/conflict resolution. Five households did not understand the meaning of the NSP. Seven households either experienced already or hoped the NSP would improve their lives. The latter depended on the completion of the community centre whereas the former stemmed from the increased participation and training. Three households claimed there was no improvement. Nine respondents claimed no one else had helped them, with one household referring to the World Food Programme and NGOs. All the households thought the NSP had improved their lives through coordination and unity. Eight households did not perceive any other changes from the CDC (past or future). The other households hoped livelihoods, transport, unity, and coordination would improve through building the community centre. Six households were not aware of the government's national plans, and the other 4 could only provide very vague information. Nevertheless, all households believed the government was interested in their community.

In Yakhdan, the answers of 5 households ranked representation, governance and the projects as equally important. Two households perceived the NSP to mean governance and representation, two households did not understand the meaning of the NSP and one household pointed solely to projects. Nine households argued that the
THE PRO VIN CIAL FIELD SU RVEY REPO RTS 
NSP had improved their lives through empowerment, solidarity, the building of the bridges and the hope that electricity would be installed. For example:

Now we can cross (vehicles and animals) easily, which has facilitated better relations between us and the district and the government. If we get electricity then we will have the privilege to communicate more and the chance to listen to radio and watch TV. (Household Survey, November 2005)

Nine households claimed no one else had helped them and one set of respondents remembered that the UN cleaned the drainage once a year. All respondents believed the NSP had improved their lives through unity, better community relations (especially between ethnic groups) and freedom of thought. Half the households could not think of other changes caused by the $C D C$ because they were satisfied already with the projects and felt it was too soon to experience more changes, but remained optimistic. However, the other half pointed to increased awareness of development and conflict resolution. Eight households did not know about the government's national plans and only vague information was provided by the other two households. Eight households felt the government was interested in their community.

\section{The future}

In Markaz-e-Dawlatabad, 3 households focussed on specific projects (literacy and factories) for women in order to improve their lives. The other households suggested many different ideas: bridges, clinic, wells and irrigation, electricity, more schools and the building of roads. All but one household was optimistic for the future because of the government and the NSP, the rule of law, security and the commitment of the international community. However, two households wanted to see more people involved in the decision-making of the NSP, in particular for women and the disabled. One of the households was pessimistic because she was a widow, had no job security and no one could guarantee her children's future.

In Choba Temorak Karni Khail, 7 households prioritized the building of a school. These households also, in addition to the other 3, wanted clean drinking water and a clinic. All households were optimistic because the government and the international community were committed and security had improved.
In Yakhdan, all respondents mentioned several projects that would improve their lives in the future. The most popular were a school, clean drinking water and a clinic. All respondents were optimistic and positive about the future because of the NSP projects which reflected their needs, their strong Muslim faith, and the improved security.

The findings from the 3 communities demonstrated the significant though varying impact of the NSP. Despite some important weaknesses, the programme had also created crucial connections between the three main levels of government and the people. Perhaps the most important lesson was the ability of the NSP to instil strong optimism and solidarity within the communities. It is therefore appropriate to contrast the sampled non-participating community.

\section{Leaders of community without a CDC}

This section provides the findings from the interview with the leaders of Tiamorak, Charbolak District. This village of 1000 Pashtun families enjoyed a relatively higher standard of living through stable agriculture. Nevertheless, the community was poor and deeply affected by the war. The group of elders had limited contact with the government, which was perceived as weak, with NGOs deemed the only potential providers of basic services. Crucially, the group claimed that such assistance had not been provided for 6 years. Consequently, the leaders were eager to join the NSP.

\subsection{0 verview of the community}

\section{General}

The village of Tiamorak, like the 31 other villages in Charbolak District, was not selected for the NSP based on the programme's criteria. Compared to the nearby community of Choba Temorak Karni Khail (see above), Tiamorak had better irrigation and cultivation and more (shallow) wells. The $\mathrm{CHA}$ claimed these advantages stemmed from their closer proximity to the road (CHA comments, 9 November 2005).

Tiamorak was one hour 15 minutes (approx.) by road from Mazar and located 5 minutes from the main road. The area of the village covered 6200 jareb/640 hectares. All 
1000 families were Pashtun, depended on farming (husbandry, cotton, apples, wheat, peas, barley and watermelon) for their livelihoods (and for consumption) and were mostly poor. The leaders stated that 10-12 per cent of the population were widows and 15 per cent were disabled since "this was of the war-affected and mined areas". 29 There was an average of 3 to 5 families in each compound or household. The village elders were the only influential figures listed. The age of adulthood was 15-16 years. Ten-fifteen per cent of the community were literate (CHA comments, and Community Leaders, 9 November 2005).

Infrastructure and education

The village had its own community building, which was spacious and in good condition. Girls could attend a school nearby up to fourth year only. Boys were able to attend school up to Grade 10 and then continue their education in Mazar. The school was twenty minutes' walk from the centre of Tiamorak and schooled 1282 pupils from 12 villages. In 2004, ESSAR had reconstructed the previous building under the 'Rehabilitation Agency Foundation Project Badaky School Rehabilitation' by the Ministry of Education, UNICEF, UNOPS and the Government of Japan. JICA had also supplied some desks. The 30 teachers delivered a range of subjects (geography, English etc) but there were scarce resources and no books visible to the researcher

\subsection{Existing traditional forms of governance}

Leadership and meeting needs Community governance came from "a form of commission involving elders of the camps, Mullahs and respected people".

The community was meeting needs using 150 shallow wells but still needed clean drinking water. There were 7 families to one well, which were $5 \mathrm{~m}$ deep. UNICEF and the Swedish Committee for Afghanistan provided 2-3 wells 6 years ago. However, the leaders claimed that they "never had a clinic or doctor or medical facilities" and have to go to Mazar using rented vehicles when someone is sick (Community Leaders, 9 November 2005).

\subsection{Relationship between community leadership and government}

Insignificant contact

One of the five community leaders had close contact with the District Head and this was the point of contact for the government. This approach was also used in an emergency. The group felt they had a "very good relationship with the government" but considered the capacity and facilities of the government to be "weak". Instead, they saw the NGOs as the providers (Community Leaders, 9 November 2005).

\section{NSP enthusiasm}

The leaders had "heard about the NSP" and knew that it encouraged "people to make their own decisions and contribution". Naturally, the group welcomed the NSP and noted that they did not have a savings box. The group also said that it would introduce women representatives. The leaders were extremely disappointed with not being included in the NSP, especially when other villages nearby were given projects and CDCs. Therefore, they urged the government to make them part of the NSP (Community Leaders, 9 November 2005).

In sum, the findings from Tiamorak provided a significant contrast to the 4 other NSP communities. There was a clear fracture between community and state and a grass-roots enthusiasm to repair the tradition of a weak and uninterested government. Although development and economic growth were important tangible incentives, the Tiamorak leaders also conveyed their eagerness to experience the psychological benefits of nation building. As the next section shows, these conclusions were substantiated by the findings from the households interviewed in Tiamorak.

\section{Households without a CDC}

This section demonstrates how the 6 sampled households were representative of their community in terms of household composition: livelihoods; income level; and ethnicity. First, the profile details that the households were deeply affected by the war (although to varying degrees). However, the majority of households perceived a post-war improvement in security and general stability at the local level. Informants were satisfied with the performance of their traditional shura but realized two barriers to
29 This point was not central to the research and was therefore not explored in detail. However, it is relevant to note that it conflicted with information from one of the other communities nearby. Second, unlike other communities there were no chalked markings from mine clearance teams, for example, Halo Trust.

THE PRO VIN CIAL FIELD SU RVEY REPO RTS 
development: weak relationship with the and donors. Consequently, all professed the urgent need for clean drinking water and half of the households were not optimistic for the future.

\subsection{Household profile}

Basic data

The 6 households interviewed consisted mainly of 2-3 men and 2-3 women. One household had one man and 6 women and another had 7 men and 13 women. There was an average of 13.5 children in each household. All households had dependents and 5 had multiple dependents - widows, sick and elderly. None were displaced. Half the households were farmers, two relied on labouring and one worked for an NGO. All but one of the households was poor and none were rich. All households were Pashtun.

\section{Impact of the war and after}

All households were affected by the war. The most common and combined impacts were the killing of immediate family members, houses destroyed and families displaced. Two households claimed their lives had not improved since the end of the war and the other 4 stated significant improvements in security and general stability. All households claimed that they had not received assistance.

\subsection{Community today}

\section{Governance}

All households defined the community leadership as the traditional shura/commission or elders, identified them as the decisionmakers, considered the community united, and all participated in community work. Five households thought their community leaders worked with the district government and one did not know.

30 This section is based on two interviews with the Director, Education 0 fficer and Social Worker of the CFDO, and the Provincial Director of UN HABITAT.

Prospects for funding

Four households thought that the community had not been able to approach organizations/institutions for funding (other than NSP, FPs and MRRD). One household thought UNICEF were approached, without success, and one did not know. Only two households had heard of the NSP and only one knew that it created projects. All households thought their leaders would welcome the creation of a CDC and some thought it government and international organizations

would directly improve community governance.

Perception of national solidarity

None of the households had heard about the government plans for the country because either they were uneducated or excluded as women. Four households believed the government was not interested in their community, one disagreed and one did not know.

The future

Clean drinking water was the most common need for improving lives, followed by a school, clinic and electricity. An informant pinpointed the primary problem:

... ever ybody is sick and has stomach problems. When we go to the doctor they say it is because of the dirty water and they advise us to boil it but we do not have enough fuel to boil the water. (Household Survey, 9 November 2005)

Three households were unconditionally optimistic about the future because of their faith in Islam. One respondent felt the NSP was needed to improve their lives and two households were pessimistic because they were widowed or had lost most of their adult family members, and were now responsible for several children.

The findings from the households in Tiamorak highlighted two crucial gaps towards establishing sustainable development: inadequate constructive contact with the government, and third party provision of assistance. Despite having agriculture as a reliable source of livelihoods (relative to the local context), households in Tiamorak were not able to fulfil the basic need of clean drinking water. Moreover, there was no mechanism to ensure the fulfilment of this need in the future.

\section{Lessons from the CFDO 30}

This section taps into the experience of the CFDO in Mazar and focusses on their insight into establishing strong community governance and sustainable poverty reduction projects. From this, several lessons are identified for the NSP. The CFDO also provided direct advice for the programme. First, it is appropriate to identify the relevance and links. 


\subsection{The indigenous roots of the NSP}

In 1995, UN-HABITAT started its own Community Development Programme, which was run by Community Forums in six provinces. In 2001/2002, the UN agency phased out from the programme, but the Community Forums in Mazar decided to retain the established system of community governance, and came together to be registered as an umbrella NGO called the CFDO. Mazar is the only former Forum still functioning and is "working well" as a local NGO.

The city of Mazar is divided into 10 districts/199 streets and each district has its own Community Forum. The latter is composed of 5 neighbourhoods and each neighbourhood has a Forum with an office. Each neighbourhood is divided into clusters, which elect a representative to sit at the district level. The neighbourhood Forums feed into district Forums, which in turn feed into the CFDO (UN-HABITAT Provincial Director, 1 November 2005). Interestingly, the CFDO pointed out that, "the NSP was established based on us." (CFDO Staff, 10 November 2005).

\subsection{Governance}

The CFDO had a committee, manager and treasurer etc. Throughout this structure, UN-HABITAT noted, "that men and women work together, secret voting is used, elections are held every year and this is all managed by the CFDO." The members claimed to have "not changed the State's system of governance" but just have "members of districts coming together". There seemed to be a strong relationship with the government as the CFDO was registered with the Department of Planning, and worked with the Department of Women's Affairs, the Department of Refugees and Returnees, and the Department of Education (UN-HABITAT Provincial Director, 1 November 2005). UNHABITAT stated that neither the CFDO nor the Community Forums wanted to join the NSP and would not meet the criteria (UNHABITAT Provincial Director, 1 November 2005).

\subsection{Sustainability}

The CFDO claimed to manage the funding process by mainly drafting development proposals and sending them to international NGOs and UN agencies. There was also coordination between the shuras and government and the CFDO, for example, in getting technical support when drafting proposals for donors and government departments (UN-HABITAT Provincial Director, 1 November 2005).

Activities were divided into 4 sectors: Education (200 teachers delivering different courses for 3000 students in the community, for example, language, maths, arts, sports and theatre); Protection Unit (finding and creating jobs for men and women, with 200 poverty reduction and vocational training projects completed, and ongoing involving embroidery, weaving and livestock); Women's Empowerment; and Social Services (health, kindergartens and sanitation). There was no construction of physical infrastructure.

UN-HABITAT noted that the CFDO was particularly strong and transparent when managing their budget. For example, when it submitted a proposal to aid agencies it included all the expenses and the CFDO salaries. However, with each proposal they saved the administration costs (based on UN guidelines) and then used this to expand their programmes. For example, from saving the administration costs from an income-generation project, they could move this funding to another sector. In 2004/2005, the CFDO received nine grants totalling US $\$ 140,000-150,000$ from USAID, the PRTS, IOM, WHO, WFP and UNHCR (UNHABITAT Provincial Director, 1 November 2005).

The CFDO emphasized that remaining sustainable was easier for them compared to rural CDCs because their members in Mazar were typically better educated. Second, the CFDO felt that the NSP did not explain its objectives completely when it first started, and "did not pass on sufficient skills or information". Instead, there was simply a "need to have projects". They provided the example of an "NSP project in Kishindeh District that did not maintain the lining of a generator from house-to-house". Consequently, the project finished with "some having power and some not, but they and the FP have spent all the money." The CFDO felt that a proper survey had not been completed and the community was not included in the original estimation. As an alternative, the CFDO members advised:

When implementing projects you need to discuss ownership and sustainability from the beginning - how to take care and use the money to do the repairs.
THE PRO VIN CIAL FIELD SU RVEY REPO RTS 
Our recommendation is not just to have projects but to ensure there is technical support.

(CFDO Staff, 10 November 2005)

Third, in ensuring its projects helped people gain an economic activity, the CFDO always conducted a needs assessment, and then prioritized the projects according to the one which gave more privileges to all of/the majority in the community. The community voted where there was more than one option.

Fourth, the CFDO prevented corruption in three ways: accountability, reporting and transparency. The latter was emphasized a lot in principle and in practice during implementation of a project. For example:

... we ask our members that if they see corruption to discuss and share it with the community and this provides good lessons for others and tea ches them to be careful not to get a bad name. We have monthly meetings among the Forums, sharing lessons and getting feedback on problems. (CFDO Staff, 10 November 2005)

The last key to sustainability was encouraging cooperation between men and women in the Forums and the CFDO. It was argued that the mixing of men and women at the decision-making levels became possible after the fall of the Taliban but had its roots in co-ed schools, which influenced present and future generations. The Manager of the CFDO, a woman, thought it was better for CDCs to be mixed because "men and women provide good input, which creates a healthy balance". Nevertheless, the Manager added that it was difficult to expect change in some areas, so the overriding principle was to encourage but ultimately let the communities decide.

\subsection{The NSP}

The CFDO found that the NSP "had a very good impact on the mentality and spirit of the people". While believing the CDCs could be effective, the respondents thought that their performance varied considerably as they really "depended on the quality of the FPs' technical support" (CFDO Staff, 10 November 2005).

Four important lessons for the NSP and the $\mathrm{CDCs}$ can be drawn from the insight into and from the CFDO. Strong organizational structure was crucial. Second, sustainability required innovative projects, grounded in priority local needs and the creation of economic activities, in addition to accountability and transparency. Third, staff needed adequate skills. Last, the mixing of men and women's CDCs was deemed preferable though cooperation was essential. 


$$
\text { or }
$$




\section{A6 Bamyan Province \\ Provincial Field Research Findings}

\section{Timing and scope of the research}

The research team ${ }^{1}$ visited Bamyan from 27-31 October. The scope of the research was therefore limited by the time available. Since the team was mainly working in Kabul Province, one week was allocated to the research in Bamyan. However, this was further reduced by the fact that the FP staff were all to be on leave for the week leading up to Eid. With the help of the $O C$ and goodwill and flexibility on the part of all those involved in the programme, the researchers were able to complete the original research plan in 4 days but this necessarily left little time for any secondary investigation beyond the basic research plan. It had been decided to work mainly with one facilitating partner (AKDN) which was not covered by any other research team, and to visit one established CDC in the second district it has taken on, Shibar. This was carried out successfully by adapting the household survey methodology so that it could be completed in one day. It was also possible to complete interviews with government, DRRD and $O C$, and to hold an informal meeting with the Director and Programme Engineer of UNHABITAT, the longest-serving FP in the Province, but whose work in Balkh was to be covered by another team.

Persons interviewed:

- The Deputy Governor

1 Margaret Chard (Team Leader) with Marina $\mathrm{N}$ awabi and Jawed $N$ ader. $\checkmark$ The Director of DRRD

- The NSP OC consultant and team (including two DRRD staff)

$\checkmark$ The DRRD NSP Administrator

- The Director of AKDN (NSP FP)

$\checkmark$ The AKDN Regional Manager of NSP

- The AKDN Finance Manager
- The AKDN/NSP Director for Shibar District

- AKDN/NSP District Field staff

- The CDC of Shah Qadam (Shibar District)

- Representatives of 10 households in Shah Qadam

- The Director of UN-HABITAT /NSP and Programme Engineer.

\section{General observation of conditions in the Province}

There was visible evidence of widespread destruction of homes, bazaars, and monuments and only slow recovery (compared for example to neighbouring Parwan).

Many settlements appear to have remained deserted. The main route between Kabul and Herat passes through the Shibar Pass and Bamyan but is slow and difficult, so is not much used by commercial transport that might stimulate the local economy, though there are some local truckers. It also makes marketing of produce outside the Province difficult.

\section{Provincial government}

The Deputy Governor, who was interviewed, worked in the NSP prior to his present appointment and so understands it well. He said that NSP is the only programme that has had any real impact so far in the Province. The best aspect is the $C D C$, which enables communities to solve their own problems. 
He saw the programme as much more costeffective than conventional reconstruction programmes of contractors or NGOs (comparing the costs of road building as an example) and believed it could be even more effective if the MDRRD had the capacity to run it directly. Therefore his view is that donors should concentrate on building government capacity.

\section{The DRRD at the provincial and district level}

\subsection{Bamyan DRRD}

The DRRD in Bamyan has 40 staff of which 28 are in permanent posts. They include: 5 engineers, one advisor, programme staff, computer operators (they have 5 computers), radio operator etc. However they have only two vehicles and a limited budget for running costs, to cover 6 districts: one is allocated to the central office and one is for monitoring the 7 programmes they run, including NSP.

In addition to NSP which has 611 projects (400 completed) they are responsible for WATSAN, Area Base, MISFA (micro-finance) Quick Response, Capacity-building, and NEEPR (emergency employment - mostly labour-intensive road building).

\subsection{NSP management}

The DRRD Director is strongly in favour of the NSP, which he said is qualitatively different from the other programmes they run though it overlaps with them. His view is that NSP will enable them to reduce poverty and move towards development. They would like to be able to expand the NSP to the only district not yet covered.

He claimed that the DRRD, with enough staff and resources and consultancy (by that he meant retaining a technical advisor but not FP and OC operational staff ), could run the programme directly. However, their role is limited at present with only two full-time NSP staff and limited resources, especially transport.

Despite its limited resources the DRRD (including the Director himself) seems to be directly involved on a day-to-day basis in the management and supervision of the NSP and to give it high priority.
He described how the documentary process is undertaken and projects selected with the help of the FP before being processed by the OC. Apart from their own monitoring teams, which involve other DRRD staff besides the NSP staff, including the Director himself, they run joint monitoring programmes, quarterly reviews and transparency checks on CDC financial management with the $O C$ and FP. The researchers also learnt from the CDC in Shibar and the household survey that DRRD staff also observe CDC elections.

Every three months they have a meeting with the FP and $O C$ to review the programme. They also aim to hold a maintenance workshop to promote community participation in maintenance.

\subsection{Experience of the DRRD NSP staff}

The DRRD NSP staff, an administrator and an engineer participated in the group interview with the OC team, but the administrator interviewed individually added some further comments.

Asked about the performance of the FP he said that it can be judged on the success of the CDCs and the people. His assessment of the CDC was that 80 per cent are well managed and should become permanent institutions.

As regards his own capacity he said he had received appropriate training in monitoring and community development.

\subsection{Role and impact of NSP}

In the administrator's view, contact between government at different levels and the communities has increased by $80-100$ per cent but mainly as a result of the new laws and government structures. He thought NSP had contributed to this change but was not the main factor.

Nevertheless he, like the Director, thought that it is important that NSP should continue and shared the Director's view of the capacity of the DRRD to run the programme if it had the necessary resources, suggesting that the government should be given resources to hire experienced staff and cover fuel and expenses costs for district visits.
THE PRO VIN CIAL FIELD SU RVEY REPO RTS 


\section{The 0 versight Consultant at the provincial level}

The Oversight Consultant was interviewed with his team, which included the DRRD NSP Administrator and Engineer. It was clear that they all work together on a daily basis.

\subsection{General comments on the strengths and weaknesses of the NSP}

They considered the strength of the programme is that it concentrates on people and developing their capacity to solve problems. It is bottom-up, the opposite of previous top-down programmes, and since there were no traditional shura in Bamyan, it was readily accepted by the people. The main concern is for its sustainability - whether the programme will continue to support the process that has been started.

\subsection{The capacity-building role of the $\mathrm{OC}$}

They thought the $O C$ has a leadership/consultancy role (two teams are close in Dari) and works to advise both the FP and CDC. The OC team also works closely with DRRD (see above: in fact the two DRRD/NSP staff were present as part of the OC's team).

They had all received many training workshops in Kabul on all aspects of the programme and these had proved useful in the field. However they did not mention any further training or systematic capacitybuilding locally, though everyone said (in his presence and at other times) the $\mathrm{OC}$ was 'very helpful'.

The OC expressed the view that the DRRD could take over the programme 'after more training' but it would be difficult without the current facilitation. He presumably meant that they could develop the expertise but would probably lack the resources.

\subsection{The supervisory role of the $\mathrm{OC}$}

The OC thought that there were no difficulties in supervising some areas of the work. There are no problems in ensuring that the eligibility criteria are understood and applied and the money transfer system works well unless there are bank delays. This is because they prepare applications once 80 per cent of the first instalment is used.
Working with two FP was also not a problem. They each had their particular strengths: UN-HABITAT has more experience but AKDN has more resources, and complemented each other (cooperation between the FP themselves was also noted later in the field visit).

The main problems occur in ensuring the supervision of engineering projects. The $\mathrm{OC}$ considered that the FP do not hire enough engineers but claim they are meeting their contractual obligations. Since the $\mathrm{OC}$ has no access to the terms of these contracts he cannot contest their claims.

Another problem is that Bamyan has a very high number of projects (he claimed the second-highest in the country) but only the same $O C$ resources as provinces with fewer projects. They also only have 4 months clear of winter conditions in which to get round the projects.

The OC felt strongly that local conditions, such as the winter weather and resource levels, should be taken into account when assessing performance.

\section{The facilitating partners at the provincial level}

Two facilitating partners are operating in Bamyan. UN-HABITAT started the programme and AKDN (who facilitated our community visit) started more recently. Both were interviewed at the management level.

\subsection{UN-HABITAT}

Informal interview with the Director. The Programme Engineer was also present and responded to the short questionnaire framed by the engineering consultant.

\subsubsection{The role of the FP}

The Director described the NSP as making a bridge between government and community. At present the FP is the bridge between the community and MMRD but eventually will be phased out and the CDC will make their own contacts with MDRRD other ministries, and the donors. He saw this beginning to happen but believed there is a lot of capacity-building still to do. For that reason he felt that it is important that NSP continues and stressed that it is premature to withdraw it. 
He thought NSP is having a profound effect in transforming the communities that were disunited and had no leadership for development. They now have 5-year development plans, and they are able to make good choices for projects within the NSP budget while deferring other projects in the development plan till later.

In 95 per cent of the communities in the programme there had been no difficulties in getting all groups to join in the CDC. In a few there were some who were unwilling to get involved, mostly because at first they didn't think it was going to be important.

\subsubsection{Training in the communities}

The Director described the 5 phases of training which they follow as in the manual and said that after the fifth phase they start project implementation. They have also started literacy classes in $24 \mathrm{CDC}$ (one male/one female class in each) over the last 18 months. It was not planned initially but they found that it was very necessary and will now generalize it.

\subsubsection{The capacity of the FP to respond to the demands of the programme}

In assessing UN-HABITAT's capacity to respond to the demands of the programme he explained that the expansion of the staff and resources is planned (centrally) on the basis of expected expansion of the work, so it presents no problem. In other words they have the capacity to expand their work if required.

\subsection{AKDN programme management}

Interview with senior management: Director and Regional NSP Manager. Joined later by the District NSP Director for Shibar and the Finance Manager

\subsubsection{The role of the FP}

The Director explained, 'AKDN has a longterm development plan in Afghanistan. NSP is our first step as a community development programme. We have found it a strong way to get into the community. We see ourselves as facilitators.' His emphasis was on this development agenda based on a comprehensive community development plan, rather than issues of governance and national solidarity.

Although he commented that they see the CDC 'as a permanent structure for local governance' he did not, like UN-HABITAT, see any role for the FP in building links between community and government.
AKDN in fact also runs its own projects in the communities where it is running NSP, which either complement it or tackle other development issues. The other management team members were confident that the communities perceived the NSP as a government programme. This was not clear in the beginning and many thought it would not cover their villages. They saw it as their role to set this right and facilitate understanding of the programme.

\subsubsection{Relations with DRRD/ capacity of DRRD}

They said relations with DRRD were extremely good. They are in 'continuous dialogue'. They also use them to troubleshoot any problems with the community. They thought DRRD lacked capacity in community development work that would prevent it from moving beyond a monitoring and supervision role and suggested they should be given this experience, because without it the quality of supervision will also not be useful.

\subsubsection{N SP management structure}

They expressed some impatience with the NSP management structure. 'There are a lot of duplications of effort happening, a lot of human resources engaged and many checks and balances.' They would rather send proposals direct to Kabul for example instead of going through the local processing first.

They also suggested there could be more flexibility in the management of the Block Grants. Because of the budget limit for all communities regardless of size, 'in some CDCs one cluster comes up with a road project and the other with drinking water. Ignoring the urgency of the water project they reach a consensus on a third project such as solar electricity.'(The field staff, CDC members and householders later described why such a compromise was agreed in Shah Qadam.)

The NSP in this respect clearly contradicts their normal community development approach. However, the Regional NSP Manager said that the communities understood that some things in their development plan would not be covered by NSP and they would have to look for other funding. In general, he was more sympathetic to the NSP concept than the Director.

\subsubsection{Training in the community}

The problems of the people are first identified and different training is then given to
THE PRO VIN CIAL

FIELD SU RVEY REPO RTS 
build capacity as necessary (purchasing, accountancy and procurement, costs etc.) for managing their project and development plan. The preparation of the development plan is also clearly a capacity-building exercise, which involves the exercise in listing priorities as in the NSP guidelines and later described by Shah Qadam community.

In the case of remote communities it has proved necessary to take the CDC members to neighbouring projects (in one case to Kabul) to see what they are like. These are called exposure visits and are funded by AKDN, not the NSP budget.

$$
\begin{aligned}
& \text { '....at the beginning they didn't believe } \\
& \text { the government would provide money } \\
& \text { - once they sa w it happened } \\
& \text { they got interested.' }
\end{aligned}
$$

AKDN is also providing literacy classes, especially for women.

\subsubsection{Capacity of the FP to respond to the programme demands}

In order to take on the NSP in Bamyan they had had to advertise and select SO (social organizers) and CF (community facilitators) in each district They structure their work using the manual but 4 staff also went to India to be exposed to functioning CDC programmes and brought back this expertise.

AKDN central management plans staff and resources in advance of expected requirements so it can respond as needed in this way.

AKDN is clearly well resourced and pays a lot of attention to staff recruitment and training, including a comparatively high number of women field staff. In the two districts there are 9 women to 16 men (see below 6.3). The 4 women so working in Shibar were returned refugees from Iran, where they seem to have had some experience of community work.

If the number of projects increases they can expand and train the staff. They are in fact waiting for government approval to establish 35 more shuras in Shibar, covering the most remote communities, and have started some surveys.

\subsection{AKDN District and project management}

Interviews with the field staff: an interview with women staff from two districts and a second interview with men and women staff (FC and SO) in Shibar District after the CDC visit. It was not possible to interview any of the engineers.

\subsubsection{Staff capacity and training}

The field staff felt that their training and experience of completing one phase of the programme (in Surkpasa District) meant that they now had all the skills they needed to tackle the second phase with confidence. The key skills they cited were for establishing relations with the community with cultural and social sensitivity; knowledge of development. They had received training on: NSP awareness, community mobilization and clustering the communities. Other training related to identifying priorities for a development plan and aspects of project development, proposal implementation and monitoring. They did not mention any specific training for organizing the elections or capacity-building of the CDC, though this may have been included in NSP awareness. They thought the project training was the most useful.

\subsubsection{Project relevance, sustainability and efficiency}

The field staff described how projects are selected. They were aware that the choice is often a compromise because the primary need of the community (eg irrigation as in the case of Shah Qadam) is beyond the NSP budget.

They also said certain project proposals, such as solar energy and roads, are normally dealt with quickly while others (involving other ministries for example) are delayed beyond the average time of 6 months from identification to the start of implementation. This demoralizes the communities and the delays are getting worse.

It may be that this is another reason for encouraging the communities to start with a project they can complete quickly and within budget - from a capacity-building and community-building point of view this makes sense. Electricity projects also seem to be popular and it also makes the FP look more efficient.

As regards sustainability, they said they took necessary steps to select equipment that is guaranteed (or to carry out necessary engi- 
neering supervision/quality checks) and to ensure maintenance training and budgeting is in place (this was planned for the Shah Qadam project).

The impact of the project is also monitored after completion.

\subsubsection{District profile of NSP in Shibar based on information given by the district staff and an AKDN data sheet on the election of the CDC.}

\section{NSP Staff}

In Shibar District there are 15 programme staff: One NSP manager; 6 community facilitators, CF (all men); 4 social organizers SO, (all women); 4 engineers and 7 support staff: one logistics officer; 3 drivers; 3 guards.

In Surkpasa District (which has already completed phase one) there are 20 programme staff: one NSP manager; 13 CF (of which 3 are women); two SO (both women); 4 engineers and 7 support staff as in Shibar.

\section{The CDC in Shibar}

- Thirty-five general shura (mixed shura) with 35 special shura for women are established and there are 31 shura still to mobilize.

- The number of CDC members depends on the number of clusters but a typical CDC would have 5 members and there would also be 5 members of the women's shura, which is constituted in the same way as the main shura.

$\checkmark$ When no women are elected to the main CDC shura, two representatives from the women's shura join the main CDC, making a shura of 7 members.

- The data sheet shows that in all 18 women were elected directly to the general shuras in 10 communities. In the majority the women are co-opted as described.

- Five shura have women deputies.

- The populations represented by each $C D C$ vary from 25 families (in very inaccessible places) to 270 families.

- Widows and disabled: average 3-5 widows in a community.

The rich minority have land, cars and trucks. They are powerful gunmen and former commanders. Most families are poor and it is the middle poor or most poor who are in the CDC.
Projects

Ten general projects have been implemented/are being implemented so far: for hydro-electricity and solar electricity.

Nineteen have been proposed for women: 14 for animal husbandry and 4 for carpetweaving have been submitted for approval.

The above account suggests they start with electricity projects (which are from environmentally sustainable sources) as a) simple to organize b) inclusive of the whole community. Carpet-weaving and animal husbandry seem to be promoted for women - this suggests some manipulation of the choice of priorities.

\section{General comments on the management of NSP in Bamyan}

\subsection{Implementation and future implementation}

There was clear evidence of effective cooperation between DRRD, OC and FP from them and from the community respondents, which undoubtedly contributes to the operational effectiveness of the programme in the Province at this stage. However, it is not clear how the management can progress from this stage to one in which the facilitation functions of $F P$ and OC are phased out.

The DRRD, despite protestations, clearly would not have the capacity in the short term to take over sole management, not only in terms of staff numbers but community development expertise. The present set up also affords little opportunity to build that expertise beyond their current (highly committed but under resourced) monitoring and supervisory role, though they could be given field experience by the FP as suggested by AKDN (and as practised by SDF Kabul).

In fact there is no conscious attempt to build the capacity of the DRRD to run NSP The OC has adopted a coordinating and operational, rather than a capacity-building role. As such and with the resource constraints on DRRD recruitment, it is unclear how the OC could be phased out at this stage.

The other necessary development would be the capacity of the $\mathrm{CDC}$ to initiate and
THE PRO VIN CIAL FIELD SU RVEY REPO RTS 
manage their own projects in direct negotiation with NGOs, government ministries and contractors, thus requiring only technical assistance and regulatory management from DRRD.

This means that the FP should also have an exit strategy from their facilitating role so that they can then continue to offer services to the $C D C$ in competition with other providers. However, (see 8. below) the CDC are still not at this level of capacity and there is some question about how some of the remoter communities could independently attract investment.

\subsection{The role of the FP}

The heads of the two FP had very different concepts of the relationship between their organization and the NSP. UN-HABITAT did see their role as transitional and directed towards a situation where facilitation between the $C D C$ and government was no longer necessary. AKDN sees the NSP as an entry point and institutional framework for expanding their own community development work. It is true that at the operational level under their Afghan NSP management they were promoting the programme as a government initiative and understood the NSP concept. However, at the same time they are implementing other projects of their own and there was also a tendency for some staff to emphasize to the community that it is AKDN that delivers the projects. (Nevertheless the villagers in Shah Qadam were clear that NSP is a government programme and AKDN are 'the contractors'.)

Both FPs (like SDF in Kabul) had the capacity to expand their cover by recruiting and training effective staff. They also have a proven expertise in community development work and could be required to give field training to DRRD staff (as occurred in Kabul). This means that in the current situation they have the capacity to respond to the demands of the programme and their participation is necessary for the next phase of the programme. However, their greater facility should not be allowed to take the form of competing with DRRD for development staff (such as engineers) and community development work outside NSP should be complementary to it and enhance its impact rather than using it as a vehicle for NGO privileged access to communities.

\subsection{Potential threats to further implementation}

The existing close relationship between the $O C$ and both FP and DRRD staff (also observed in Kabul) which is operationally effective at this stage also carries some negative potential. There is first of all little incentive for either OC or FP to move towards the envisaged end state in which DRRD and CDC become independent. In the present set up the arrangement is also incompatible with exercising independent control of the management of the programme for accountability purposes. Despite the ever-growing mountain of form filling etc., the scope for corruption therefore exists at all levels which is not yet counter-balanced by effective public scrutiny at the community level, or by independent government audit.

\section{Community with a CDC}

\subsection{Shah Q adam, Shibar District}

The community was selected because it is typical in terms of social economic and geographic conditions, of average size, with a mixed shura running a women's project (distribution of sheep) and a solar electricity project.

Data provided by the FP field staff There are 90 families with a population of 432. Fourteen sheep were purchased as a women's project for distribution to widows. (In fact they were not specifically allocated to widows in the village - see Household Survey.]

Livelihoods (income-generating activities):

- The majority are general farmers and income is from cash crops (wheat and potatoes) and animal husbandry.

- Minority occupations are:

* Truck drivers

* Shop keepers.

General observation by the research team This Hazara community is situated at the furthest point of a road usable by car. The terrain is steep hillsides, which provide pasture and a very restricted area of arable cultivation, which could be enhanced by an irrigation scheme. There are no shops. The Secretary of the $C D C$, who is a truck driver, and the shopkeepers work outside the village. 
The villagers were driven from their homes, lost their possessions, and hid in caves in the mountains during the Taliban rule. Any wealthier members of the community have settled permanently in Kabul and there have been no returnees. The community is generally poor and all but a few are illiterate. They now have a school for boys and can get to a clinic in summer months. AKDN runs literacy classes in which only women are enrolled (30).

\subsection{Legitimacy and acceptance of the CDC}

$\checkmark$ The CDC has been functioning for one year

- It sits as a mixed shura, though the women's group was elected separately and has chosen projects specifically for women

$\checkmark$ Three leaders of the shura (Head, Secretary and Treasurer) are men; the Deputy is a woman. They were elected by the shura members after the general election

- Eight men and 9 women members were interviewed together by the researchers.

\subsubsection{The Elections}

Due to the illiteracy levels the election process had to be assisted. Illiterate voters asked literate members of the community (rather than the AKDN and DRRD representatives who were present) to write the names for them, trusting their honesty. The women's shura was elected by having a box for each candidate who stood by her box to identify it.

The household survey suggests that this process was regarded as a free election and the shura is accepted as the representative of the village. One elderly woman would have preferred a different leader but recognized she was outvoted.

Although this was apparently a satisfactory democratic process, without periodic elections it could entrench a CDC which may have lost the trust of the community and is no longer democratic.

\subsection{Functioning in relation to the whole community}

The CDC involved the whole community in discussing the options for projects and then made the final decision.

It reports orally to the community through the representatives for each locality (cluster) and has an open meeting once a month to report on progress and for the treasurer to explain the finances. Householders said all but those in the most distant locations participate. However, the survey revealed that householders, especially women do not have a complete grasp of the programme but rely on the shura to decide.

Apart from a development plan, a well-maintained cashbook and copies of contracts, the CDC activities were not documented. (Only 5 members of the CDC, 4 men and one woman, and very few in the community are literate.)

\subsubsection{Projects}

The CDC has produced a development plan, which includes a number of projects. Of these it has implemented one (women's) project, to distribute sheep to the poorest women (widows and others). Some of this target group obviously received a sheep but others apparently didn't or at least the basis for selection was not transparent, especially to the women, and we saw no documentation of purchases although the CDC leaders told us the price they bargained so they could buy extra sheep. This may account for some, other than poor women, who received sheep?

A second project is about to be completed and is a general project that will benefit every household: a solar energy project. Information about this project was much better organized and the contracts for supply and installation were there. A charge is to be made for each light bulb to raise funds for other projects and for maintenance. Householders will be trained to maintain their equipment and one community member will be trained for general maintenance. After it had been selected, AKDN arranged for the men from the shura to see a similar installation with a UN-HABITAT project. The project has general acceptance but it is not clear how much detail the householders understand.

The decision to opt for this project took place after heated debate followed by a vote. The issue was that the main need of the village is for irrigation but this was going to cost much more than the NSP grant. The solar electricity was also going to benefit everyone equally. Since all work in agriculture (landowners and labourers), irrigation would benefit all, but some more than
THE PRO VIN CIAL FIELD SU RVEY REPO RTS 
others. It seems likely that AKDN suggested the solar project as an affordable compromise?

\subsection{Relationship between the CDC and Government}

'Before we didn't have contact and communication with government and now it is very good from every aspect. After the Taliban collapsed our lives took a turn for the better and we are hopeful.

Before government collected from us

- now they are contributing to us.'

They were fully aware that the programme was a government programme and that the money came from the World Bank and donors.

They also said if they had any complaints that they could not solve they would take it to the district government though they were not aware of any formal complaints procedure, but obviously expected to be heard.

\subsection{Relationship between the CDC and the FP}

'They played a great role in NSP which was essential to provide us with guidance.'

CDC leaders received formal training in purchasing and procurement and advice on getting the best prices, which was much appreciated. However, as with the election, they insisted on their autonomy:

'We did bargain and do this project by ourselves and AKDN is only helping us.'

They understood AKDN's role as a facilitator of NSP for government and in referring to other AKDN projects (seed distribution, training health workers), understood they were outside the NSP.

The literacy classes were particularly mentioned by the women and will be crucial for the long-term success of the CDC. However, we did not understand why there were no literacy courses for men. We also felt there was a tendency to be manipulative rather than facilitating of community needs. Hence the defensiveness of the CDC members?

\subsection{The capacity of the CDC}

Assessment of the general CDC based on the criteria in the manual: Able to function with difficulty. That is, still needing support and capacity-building, including literacy and understanding of accounts.

Assessment of the women's shura: Not able. That is, needing specific capacitybuilding, especially literacy and accounting.

The CDC still has many limitations with regard to documentation and procedures and therefore for accountability, but is applying the principles of CDC as a community representative body and has general acceptance and trust. The implementation of the first (sheep) project was not transparent and most CDC members (as well as the community at large) were vague about what was planned and what was actually done. Cash was accounted for and the price of the sheep but no receipts shown. The solar project is likely to be better organized and increase capacity and confidence. As more CDC and community members become literate, understanding and accountability could grow.

Key issues for sustainability

There are 3 key issues for the continuity of the CDC as a democratic institution for community governance and development:

1. The capacity of the majority to understand and monitor the work of the CDC - this requires literacy, understanding of simple accounting and, especially for the women, greater awareness of the wider society.

2. Periodic renewal of the mandate of the CDC members - i.e. elections. The honesty of the $\mathrm{CDC}$ and the trust of the community can be compromised by exclusion and /or corruption, if the elections do not happen periodically.

3. The further assistance of the government in encouraging the NGOs and donors to cover these remote areas. 


\section{Household Survey: Shah Q adam, Shibar District}

\section{Summary of results:}

\subsection{The sample}

Representatives of 10 households ( 5 women and 5 men) were interviewed (though two are father and son). Due to time constraints and the dispersed settlement in very steep terrain without roads, they were contacted in advance and gathered in two meeting places. Under the circumstances the sample was considered as representative as possible given that a random sample was not possible. The villagers applied the guidelines we gave as best they could with the following result:

Respondents came from 3 areas of the community.

- Their ages ranged from 35-70 (average 49).

$\checkmark$ The CDC already explained that the whole community is poor but within that the respondents assessed themselves as 'poor': (5) mostly due to lack of land or other vulnerability; middle/average (4); and one household with 3 sources of income as 'rich'.

- The average household size was 11 and consisted of 5 two-, and 5 threegeneration families. (parents and children, grandchildren).

- Four households had disabled, sick or elderly dependents (including the husband in one family) and there was one household headed by an elderly widow with only one working man (son). They had an average of 5 children below working age.

$\checkmark$ One man was literate. None of the women.

- Nine are Hazara and one an Arab displaced during the war.

- The main livelihood in every family is agriculture, either on their own land or as labourers for others (or both). Four families had other sources of income: one as a small trader; one from sons street trading in Kabul; one is a teacher; in the 'rich' family the husband is a guard for the school and the wife trained as a community health worker (AKDN funded).

\subsection{War experience/post-war}

The majority (7) fled the village and hid in the mountains, where they suffered hunger.
The Taliban meanwhile robbed their houses. One was at first forced to work for the Taliban and fled later. The Arab who was already displaced moved again to a different district but lost a child frozen to death on the way. One stayed in the village but was robbed by the Taliban. All fled under threat of violence; two women's husbands experienced extreme violence, one was permanently disabled. Another lost a son and a daughter in the war.

After the fall of the Taliban all returned. One, the widow, to the same poverty as before. All the others saw a better life. The 5 men cited security as the main gain, 3 had experienced economic improvement and two cited international assistance and one government support. The women said things got better 'day by day' and two mentioned the coming of the shura.

\subsection{General understanding and awareness}

The respondents' replies to questions about the CDC and the NSP and government suggest that there is a significant gap between men and women (even though one is CDC deputy and one a CDC member) in their understanding of the NSP programme and the functioning of the CDC.

The 5 male respondents had either adequate (2) or a high (3) level of understanding of the CDC functions, project details etc., and general awareness of the relationship with government and the FP and their respective roles was at a similar level.

Three of the women respondents had a good understanding of the purpose of the CDC but incomplete understanding of how it works, especially the management of the finances and the criteria for the distribution of sheep, which was said to be a women's project. Two of these had a fair degree of awareness of the national programme (though they did not know the name) and the role of government and FP. The other women, including the widow, said themselves that they understood very little about it and were uncertain when they did offer an answer.

'I don't know what NSP means. $\mathrm{CDC}$ is that men and women come together for working and meetings but we don't have the literacy to know.'
THE PRO VIN CIAL FIELD SU RVEY REPO RTS 


\subsection{The history of the CDC}

When asked what the CDC is, all except one (elderly widow) had an answer: two men described the national solidarity concept clearly; one woman and two men described it as a form of representation/governance: 'It is our representative', 'CDC is our government'; problem solving and community cooperation/unity were cited by 3 men and one woman; two women thought it meant security; only one woman mentioned the project benefits as part of its 'good effect on our lives'. All were aware that it had been started one year previously.

All but two women were able to give an account of the election process, in most cases especially the men, describing the role of AKDN and government scrutiny. All had voted. No dissatisfaction was expressed and two men specifically said it was properly conducted. 'There was no offence and the elections went well.' 'It was a fair and free election.'

The women said there was no shura before: 'We had problems but no one asked about that'. Two said the men discussed things but women knew nothing, 'were blind'. One said problems were discussed individually and then referred to the district. One described how the village had got assistance for a water channel this way.

In response to this question the men described how they set priorities now in the CDC (see below).

\subsection{The CDC today}

\subsubsection{Projects/ priorities}

"We will make many plans and will do it ourselves, we don't want to be a burden in this country."

All the men insisted that the options were identified by them, then put to AKDN. Two described the listing on forms provided by the FP. One hinted that there were other serious problems that were set aside in favour of the solar project. (Four out of 5 women mentioned water for agriculture as one of these.)

One woman and one man said the villagers as a whole were consulted to identify the problems. The two shura members described discussions in the shura to reach agreement on the priorities (one specifically said she participated in the decision with the men). A fourth (not a shura member) said these decisions were taken by the shura.

All the respondents knew about the solar electricity project and knew it was going to include everyone. This seemed to be part of its appeal.

The project for distributing sheep to poor women, which has been implemented, was less well understood, especially the criteria for distribution. In fact in practice the distribution seems not to have been transparent, though no one suggested it was dishonest. Two women who described their families as 'middle' and 'poor' had received sheep but didn't know why. The other 3, from 'rich', 'middle' and 'poor' families had not received sheep and did not know the criteria for distribution, except one knew they were for women.

'Up to now we don't know, just some people got sheep and others didn't.'

(shura Deputy)

Two men of 'middle' income knew that the sheep were for the poor - one had received one and one hadn't but thought he might later. The Arab, who is clearly poor, had not received one 'yet'. The teacher made no mention of sheep. His father said his family (i.e the women) had received one.

The majority of men and women were confident the shura would go on to develop other projects. A woman member of the shura described it as: 'Working to bring electricity and when that is finished they work on another problem to solve, focussing on the problems of the village.'

The women are keen to start carpet manufacture (which could be helped by the solar lighting). Extending the water channels for irrigation to increase agricultural yield is also seen as important by men and women. It would require more funding than the NSP grant and may not benefit all equally, as not all own much land, but all the villagers participated in the last project.

They had so far not approached other funding agents, but assumed they could do so. They have had experience in the past with Solidarity and AKDN assistance outside the NSP. 


\subsubsection{Functioning of the shura}

Four women and two men thought the CDC met once a week (or every 10 days). Two men (father and son) said the meeting was monthly but could be more frequent when necessary (see 8. CDC above - the shura reports monthly to the whole population but meets more frequently). It seems they were all aware of the meetings taking place and agreed that everyone attended except for those living a long way away. Only the elderly widow claimed not to know about it.

On the subject of what it did and how, there was much less clarity. Two women couldn't say, the others said it was about discussing projects or solving problems. The men also mentioned problem solving and projects but also described the office holders (omitting the woman deputy, though one mentioned the women's shura).

In answer to the question, 'Who leads your community?, two women said all the CDC members, one man implied the same (others were not asked). The elderly widow gave the name of a man she thought was the real leader ('not the $C D C^{\prime}$ ') but no one had voted for him because he is illiterate. Two women thought the leader of the $C D C$ was the leader but gave the name of the treasurer and another name, not of an office holder.

\subsubsection{Financial management}

The majority rely on the Treasurer and [male] shura heads to manage on their behalf. Two men said they had confidence in the way the money was handled by the Treasurer and the others implied the same. A woman shura member said the members decided what to spend the money on, then 'the Treasurer tells us how it has been spent'. One man said they relied on the advice of AKDN 'who helps us a lot because we are unfamiliar people and don't know anything about city issues.' Two men and one woman were aware of the Block Grant instalments.

The majority were aware of the origin of the money to some degree. The teacher knew that the money came from World Bank to government and was delivered through AKDN. Three men and two women said it was government money delivered by AKDN. Two women knew it was collected from the bank in Bamyan but were unsure if it was government or AKDN money. The other man and woman indicated that they knew it was the government that supported them.

\subsection{Impact of NSP/CDC (after one year )}

As one woman said, the CDC is only 'recently established' but it has clearly had a significant impact on the community. The respondents' remarks suggest that the main impact has been on the governance and social cohesion of the community. All the respondents thought the community was more united as a result of the programme.

'They came together in happiness and sadness, and talking with each other to solve problems.'

(woman)

'People are more united and they feel that we will have more credit to the NGOs and government, but if we are disunited we can do nothing.

So people are very close to each other now.' (man)

'People are very united now. And they are very calm now.'

(man)

Their capacity for inclusive governance has been greatly increased by the election of CDC representatives and the fact that it includes women. However, full participation by the majority is hampered by illiteracy and lack of knowledge, especially amongst the women.

They have contacted government and NGOs for assistance in the past but now feel they have a legitimate body to represent them. They also recognize the programme as a sign that the government is supporting them.

All of the above suggests a significant contribution to national solidarity at all levels.

The economic impact of the programme is not yet significant. The sheep distribution was intended as poverty alleviation but it is not clear how much it helped the very poor. The solar energy project will benefit all equally, but will not initially make an economic impact and has to be maintained by contributions. There will be obvious social value during the long winters, enabling school children to study, literacy classes etc. and it may enable craft work in the home by women. However, it does not directly address the issue of improving livelihoods.
THE PRO VIN CIAL FIELD SU RVEY REPO RTS 


\subsection{Confidence in the future}

The projects were not a totally new experience to the villagers, but the process of assuming responsibility for its management was clearly a new experience in which they still have a lot to learn. Nevertheless, as a result they feel confident to tackle further projects and these are likely to be economically significant: irrigation and carpet manufacture. Water for irrigation, work and a clinic were the main needs mentioned.

The villagers are cautiously optimistic for the future:
"'God knows better about the future" but I hope people's economy will develop in future.' (man)

'We hope that the government changes for better and we pray for its stability.' (man)

'People are satisfied with their today and are hopeful about the future.' (man)

'I don't know but I am happy our village should be supported.' (woman)

'Yes, for example if something comes to the community then we will be happy.' (woman) 

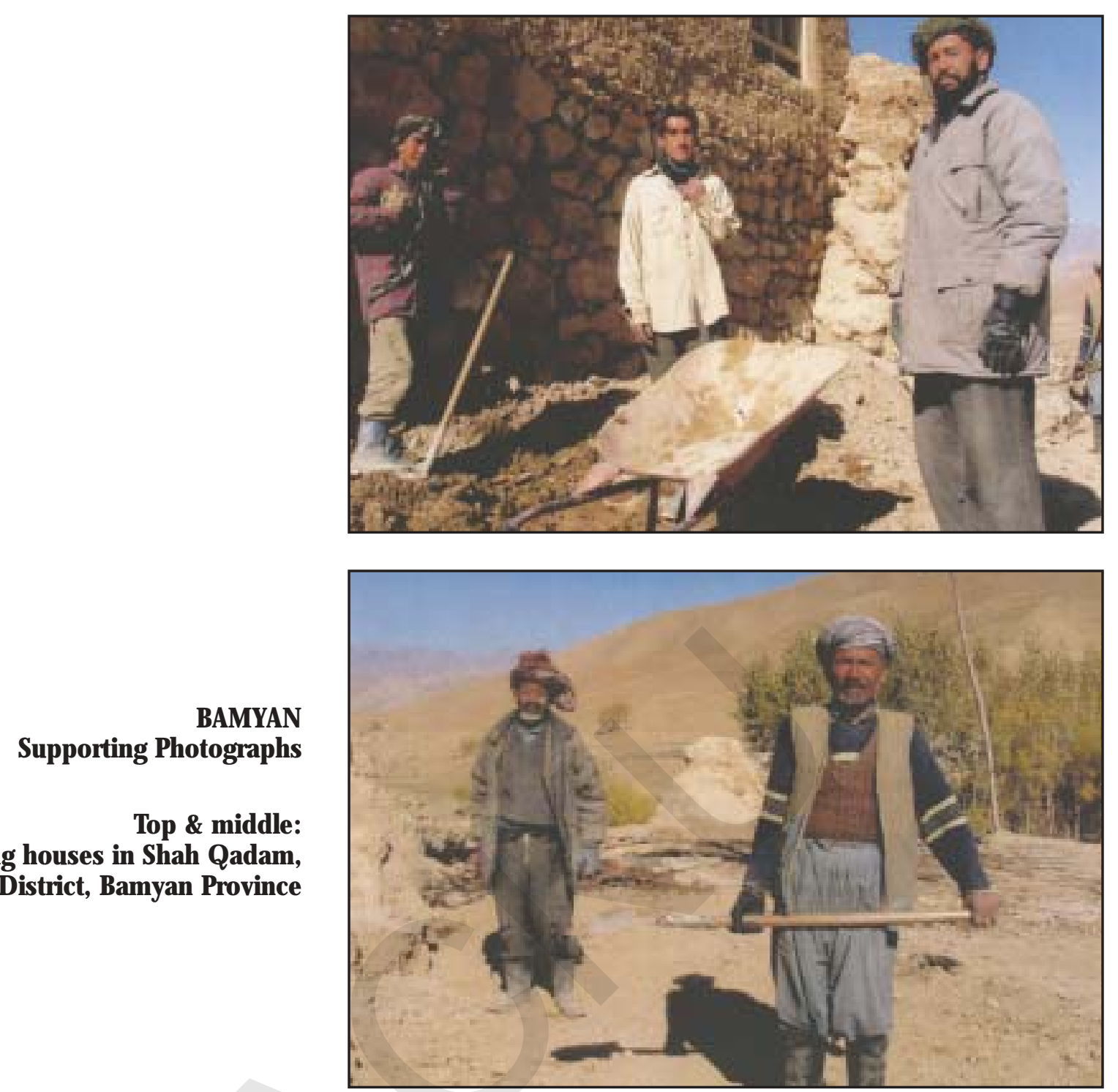

Bottom:

Fields and pasture in Shah Q adam, Shibar District, Bamyan Province

(All photos by Jawed Nadir)

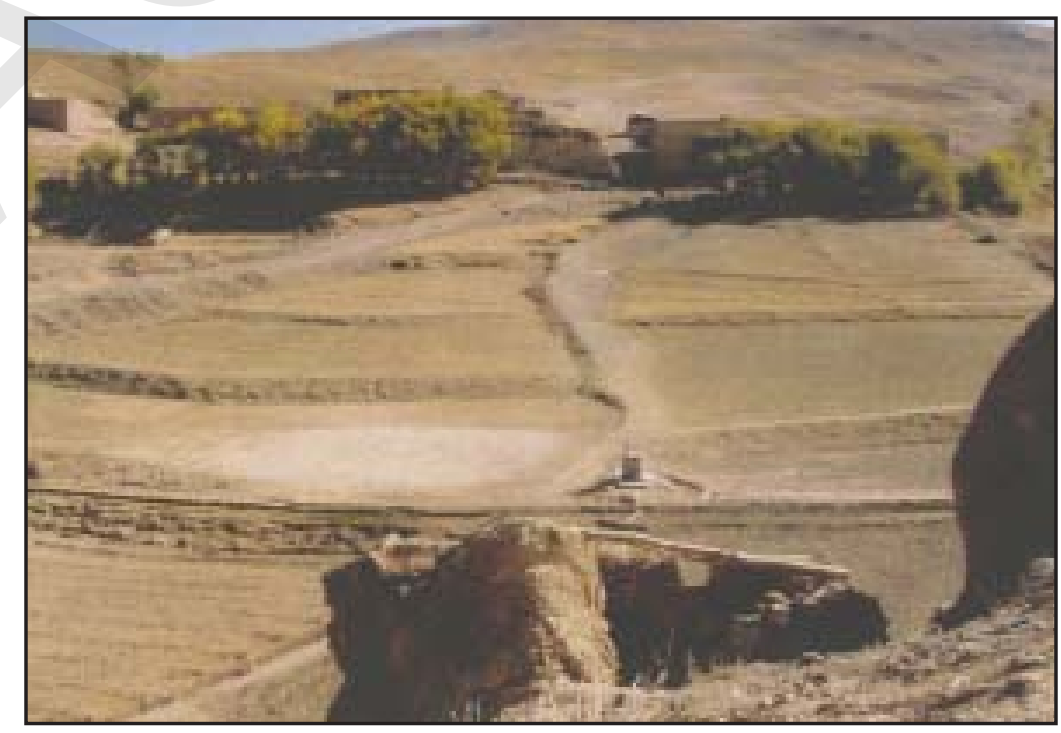




\section{$\Lambda 6$ Herat Province Provincial Field Research Findings}

Timing and scope of the research A rapid survey was conducted in Herat by the research team working in Badghis ${ }^{1}$ from 6-9 November. Interviews were conducted with DRRD, FP and OC. One CDC was interviewed and the leaders of a community without a CDC.

\section{Department of Rural Rehabilitation and Development (DRRD)}

Meeting Profile

Interviewee/s: Director of Directorate of Rural Rehabilitation and Development, and Assistant in the NSP Section. The NSP Manager was unable to attend the interview due to illness.

\subsection{Training and capacity of the DRRD}

The interviewees framed their experience by the six nationwide programmes: a) Roadbuilding Programme (formerly called NEEP), b) National Solidarity Programme, c) Water and Sanitation Programme, d) Microfinance Programme, e) Emergency Response Programme and f) Area-based Development Programme. The DRRD in Herat also claimed to have implemented projects streamlined under the abovementioned programmes. Five examples were provided: under the Area-based Development Programme, the offices of DRRD and OC were rehabilitated and refurbished; and through the Road-building Programme, $15 \mathrm{~km}$ of road was paved and 20 engineering structures were undertaken. Third, under the Water and Sanitation Programme, 100 wells were dug and hand pumps installed in addition to 185 wells ongoing, and 136 toilets. Fourth, under the Microfinance Programme, it was stated that FINCA, BRAC and the Agha Khan Foundation, had become important partners in successfully executing the programme. Last, the Herat-Ghor Road was cleared from snow last winter through the Emergency Response Programme.

In Herat, the Community-led Development Department was established two and a half years prior to the field research. Forty staff of the 41 staff positions were filled with 20 others paid on a daily basis.

In terms of training and guidance from the NSP, staff claimed to have received only orientation on NSP in Kabul and training sessions conducted by the FP and the $O C$ for their staff and the CDCs.

It was found that the NSP "really enlightened people" since "they are more active now and are vigorously seeking contact with the government at all levels." The respondents argued that "95 per cent of the CDCs are fully in contact with the government."

The question concerning the main indicator of success used for the FPs was not answered properly by the informants. However, it was noted that all the actors were working hard. In terms of capacity, the respondents felt that they did not have enough staff "to effectively and practically be responsive to our duties. However, in terms of knowledge, we feel we have the capacity."

The DRRD staff claimed that they had no other operational problems; in particular, they noted that transportation was good because of assistance from the FP and $\mathrm{OC}$. 


\subsection{Coordination with other ministries}

The DRRD staff concluded that coordination was good with other government departments. For example, they noted that school construction projects could not be implemented unless there was prior approval by the Department of Education; and generator-related projects were always coordinated with the Department of Energy to prevent a duplication of efforts. A noted exception was the building of clinics through the NSP. It was alleged that the Department of Public Health had promised, yet failed, to provide staff and resources.

\subsection{Community relations}

The DRRD's relationship with the communities was described as "good" and for example, the director or deputy director of the DRRD was always present at the inauguration of projects.

Regarding the complaints procedure, the DRRD staff stated that complaints were registered and either tackled by the DRRD alone, jointly by the DRRD, the FP and the $O C$, or sent to the MRRD in Kabul if higher authority was needed.

The respondents believed that the CDCS would remain permanent institutions as long as there were projects or resources for projects. They also felt that the CDCs would enjoy more credibility if they were recognized by all the government departments.

\subsection{The role and impact of NSP/CDC}

The respondents affirmed that a "strong foundation has been laid for national solidarity" since "[p]eople's attitudes have been changed by the programme", which has allowed people to be connected "with their surrounding villages and throughout the province and the country".

\section{The Provincial NSP O versight Consultant $(\mathrm{OC})$}

Interviewee/s: Provincial Head of OC Venue: OC Office in Herat

\subsection{General comments on the strengths and weaknesses of the NSP}

The OC claimed that the NSP allowed the government to reach out to the people; increased the knowledge of the people and helped in their capacity-building; gave the communities a structure recognized by the government; and that the CDCs were instrumental in solving problems and defusing conflicts in their communities. Consequently, the OC had received many demands from the communities without the NSP.

The OC claimed that there were no specific problems but emphasized that the selection of areas should be done in a balanced way to ensure equality in allocation of resources. The OC advocated greater cooperation and coordination among the government departments.

The OC described his role as monitoring the projects, advising other stakeholders, and coordinating and bridge-building between the FP and the government.

The OC claimed to be not involved at all in the management of the programme.

\subsection{The capacity-building role of the $\mathrm{OC}$}

Towards developing the institutional and individual staff capacities, the OC claimed to have organized a workshop and provided training in using computers and the Internet, and filing. The OC stated that the joint visits were useful in learning more about monitoring and evaluation. Overall, he thought that there was a good process of learning.

\subsubsection{The capacity of the DRRD}

The OC believed that the DRRD of Herat was working well, especially compared to other provinces. It was noted that the NSP manager was an experienced person who had worked in the MRRD for 25 years.

It was argued that the possibility of transferring full management responsibility to the (M)RRD within the proposed timeframe depended on the magnitude of the NSP. The need for more staff was deemed essential.

\subsection{The supervisory role of the $O C$}

The OC noted that the eligibility criteria were explained to people to prevent the suggestion of projects outside of the criteria.

Management ensured that resources were delivered to the community on time since it
THE PRO VIN CIAL FIELD SU RVEY REPO RTS 
was a joint responsibility. It was claimed that the bank in Herat was not responsive to the needs of the NSP and thus the resources had been delayed in reaching the people. An average waiting time of two months was stated (for communities to receive necessary resources) but the $\mathrm{OC}$ added that the timeframe varied from project to project.

\section{The Facilitating Partner}

\subsection{Programme management}

\subsubsection{The role of FP}

The FP described its role as "a bridge between the government and the people", to facilitate the whole process. This involved capacity-building, by informing and empowering the people so they can decide best how to use their local resources, and by providing technical assistance.

The FP believed the communities had a good perception because the FP made them very aware of its function and role before the NSP, and then after by having meetings once a month. However, the FP acknowledged that the history of the FP in the communities was an important factor.

\subsubsection{Working relations with the DRRD/OC}

The working relations were described as good, once challenges were tackled. It was claimed that the key was regular coordination meetings with the DRRD and OC to allow a collective problem-solving process. The respondents recalled some initial problems with the OC (delayed approvals) but these were solved and have since maintained constant contact and joint visits.

\subsubsection{Capacity of DRRD}

The respondents claimed that there were some problems with the DRRD's capacity initially but this was addressed successfully. The coordination meetings were a good mechanism in this respect.

\subsubsection{The impact of NSP on relations between communities and government No response}

\subsubsection{Coordination with other ministries and donors \\ No response}

3.1.6 Training and capacity-building in the communities/participation

They had organized leadership training and accounting and procurement training. The FP noted no specific problems concerning illiteracy and the participation of marginalized groups.

However, it was noted that men and women had separate meetings. It was also recognized that the influence of the "already influential people" had been lessened but could not be diminished overnight. Monthly community meetings were held to be a useful way to include marginalized groups.

\subsubsection{The FP's capability}

\section{in relation to the programme demands}

The FP had to increase its capacity by creating new Project Management Offices (PMOs) in each district with NSP. The other office in the field, the Field Management Office (FMO), was described as "partially busy with NSP". Each PMO comprised a site engineer, two community workers (a man and a woman), a driver, a cook, and a guard. Key NSP staff received orientation on the NSP in Kabul. They also had a male and a female trainer in their FMO to provide necessary training for other staff. There were also some workshops in Kabul and Herat.

Regarding NSP training and guidance for the implementation of the programme, the staff recalled orientation in Herat, proposal writing, procurement, and social organization. Each was described as useful and necessary.

Main skills needed were described as community mobilization, technical engineering, and general management skills. At the time of research, there were no stated skill shortfalls that limited effectiveness.

There were no problems noted with the high number of projects since they had increased their capacity accordingly.

It was also stated that there were no particular problems applying the eligibility criteria. People were made aware of it before the priorities were identified.

\subsection{Project management}

(With specific reference to the CDC visited)

Staff allocated to this project: one engineer, and 4 social organizers (two male and two female). 
The project was canal lining, some protection work and a bridge. It was identified by working with the people to identify their needs and then make their Community Development Plan (CDP). A total of 178 households were expected to use it, with farmers as the direct beneficiaries and labourers as the indirect beneficiaries. The FP thought that everyone in the community would gain improvements in their livelihoods as a result of this economic activity.

The respondents did not know if the project would pull people in from other communities. It was claimed that the monthly general public meetings had ensured inclusiveness by contributing to the widening of power and influence.

There was no response from the FP concerning the assessment of environmental factors. The quality of construction was controlled by visits to the project by the FP's engineers at least twice a week. It was claimed that people could contact the FP when they had questions or problems, which advised them to buy the most appropriate material. The FP emphasized the factor of maintenance and noted the presence of a maintenance committee. The wealthier residents also put aside some wheat every year to cover the maintenance costs. The community was expected to run the service in the long-term. The FP thought the facility/service was sustainable but admitted that they could not guarantee how long the water source would last. There was no direct response to the question concerning the long-term viability of the economic activity.

The period of time between identification of the project and the start of implementation was 5 months. The FP believed it would take another two months to complete the project. It was claimed that the FP did not cause delays. The informants stated that the design came from experienced FP designers. This was then checked by their designer at their FMO in addition to general checks by all the FP staff. Safety measures involved rechecking the completed design by experts. The FP claimed that the people consulted them before procuring material and equipment.

\section{The CDC}

\section{Meeting Profile}

Village and District:

Hoftoi Sofla, Robat Sangi

Projects: Water/irrigation

Interviewee/s: CDC Members

Venue: Mosque of the village

\subsubsection{Legitimacy and acceptance of the CDC} The CDC claimed that the leaders consisted of the Qaria Dar (village in charge), Arbab Juma and the elders on the tribal council. The community got involved with the NSP when the district administrator called a meeting for representatives of all 150 villages in the district. Thirty villages were then selected based on a lottery.

The tribal council was the other community group of leaders, which the CDC had almost replaced. Accordingly, the $\mathrm{CDC}$ believed itself to have changed the way the community was governed. The members emphasized that the monthly meetings were very useful, where most of the decisions were made through consultations. Overall, the members believed that the CDC had almost replaced other forms of governance.

\subsubsection{Functioning of the CDC in relation to the whole community}

The CDC functioned using the weekly meeting and sometimes met twice a week in addition to using emergency meetings. The CDC also claimed to be present in the monthly public meetings. There were eight elected and active members.

The CDC activities were documented using the register to record all the decisions and other important points.

In prioritising needs, five main areas or potential projects were identified: irrigation/water, toilets, generator, roads, carpetweaving and tailoring. The CDC recalled that everyone (in the community) agreed upon irrigation/water as the most important. In dealing with different opinions, the decision of the majority was used after trying to find consensus and with people listening to elders. The members claimed there was no disagreement.

The CDC supervised the use of skilled and unskilled labour in the village. It was a fulltime job for the community. The main potential benefit for the community was water for irrigation and the creation of
THE PRO VIN CIAL FIELD SU RVEY REPO RTS 
employment. Towards maintenance, the CDC stated that there was a committee assigned to look after the facility after the completion of a project. They had good experience in this respect from looking after a school building and bridge. The CDC was also present to monitor the project at all times.

\subsubsection{Projects}

The CDC had not initiated further projects or other responsibilities in the community.

\subsubsection{Relationship between the CDC and government}

The project was inaugurated by the director of the DRRD in the presence of a representative from the district administration. They stated that they were proud of the government and that security, reconstruction and cooperation with the government was in their interest. Furthermore, the CDC members believed that the government listened to them. However, it was recommended that sending more representatives to the communities would improve the partnership. When there was a complaint, the CDC stated that they contacted the FP.

\subsubsection{Relationship between the CDC and the FP}

The relationship was described as positive as the FP was familiar with the local context, had bridged the community/government relationship and provided technical assistance.

The training on functioning procedures, procurement and accounting from the FP was described as very useful and necessary. Technical support was also provided by the FP in addition to monitoring and evaluation of the projects.

\subsubsection{The capacity of the CDC}

The CDC stated that they had not experienced any problems implementing the project.

There was skilled and unskilled labour in the community and the $\mathrm{CDC}$ was able to design the structure themselves with the support of the FP. A construction firm had demanded Afs 90,000 to design the structure.

There was no response noted regarding the maintenance of the structure. tive governance and community development capacity.

\section{Leaders of a community without a CDC}

\section{Meeting Profile}

Village and District: Yaka Dokan, Interviewee/s: Elders of the village

Venue: A house in the village

\subsection{Existing governance}

The village had a council of $10-15$ persons. The Qaria Dar (village in charge) was its contact and liaison with the government.

Towards meeting needs, hand pumps for drinking water were installed by DACAAR. The leaders claimed that there was no clinic in the village and they had to go Herat, Tor Ghondi or Robat Sangi ( $25 \mathrm{~km}$ ) to receive medical services. Other assistance besides that from DACAAR included the rehabilitation of the school building by USAID. The village council members thought it was very useful to be partnered with the government.

The leaders knew the main details of the NSP and supported the creation of a CDC in their community. 


$$
\text { or }
$$




\section{$\Delta 7$ Kabul Province Provincial Field Research Findings}

\section{Timing and scope of the research}

The research team ${ }^{1}$ worked in Kabul from 24-26 October with the NSP management teams (DRRD, OC, FP) and from 7-12 November in the rural districts of Estalef and Kalakan. In addition the team leader had visited four completed CDC projects in Shakadara district with the Engineering Consultant on 15 October.

Persons interviewed:

$\checkmark$ The Provincial Governor

$\checkmark$ The Director of DRRD

- The DRRD NSP Administrator and Engineer

- The NSP OC consultant

- The Director and Management Team of SDF(NSP FP)

- The SDF District NSP staff responsible for Estalef

- The CDC of Godara (Estalef District)

$\checkmark$ Representatives of 10 households in Godara

- The District Governor of Kalakan and Council of Elders

- Representatives of 10 households in Kalakan Centre

$\checkmark$ CDCs of Aziz Uddin, Salakhail, Taj Mohammed and Ghaza, Shakadara District.

1 Margaret Chard (Team Leader) with Marina $\mathrm{N}$ awabi and Jawed $N$ ader.

\section{General observations on the conditions in the rural districts}

The field research was carried out in the rural districts to the north of Kabul. Their proximity to the capital meant that before the war they were prosperous and comparatively well-developed, including access to education, at least for men. They have traditionally supplied agricultural produce, especially fruit and vegetables, to the capital as well as developing various manufactures such as pottery, brick-making and carpet weaving and service industry such as tourism. They also had access to urban employment, including professional jobs. These prosperous communities suffered high levels of destruction of property and infrastructure in the war and much of the area was abandoned during the Taliban rule. The returning population therefore has quite a high level of human capital in terms of education, skills and former business experience, but little or nothing in terms of resources or functioning infrastructure. The links to the city remain important. Despite the difficulties, marketing of produce has resumed. Many from the nearer districts work in the city; some of the displaced remain there because they cannot rebuild their homes and livelihoods in the villages.

So far 7 districts have been covered by the NSP and have CDCs in all communities. The other districts still have tribal/non-elected shuras.

\section{The government}

The team was introduced to the Provincial Governor by the DRRD Director and Oversight Consultant, who accompanied them to his office. He made clear that he is generally favourable to NSP and commended the Minister responsible.

As he was recently transferred from Nangahar he based his assessment of NSP 
on his experiences there, and raised the following issues that he felt need to be addressed.

1. There are currently conflicting models for community and district governance: traditional shuras of elders, CDC and proposals for elected district councils. This has to be resolved in a way that creates one inclusive structure.

2. Project sustainability is not given enough consideration.

3. The present management of NSP through MRRD, OC and FP partnership is expensive and has a lot of overheads. Capacity-building of Afghan professionals and government institutions is therefore a priority.

\section{MRRD provincial and district programme management}

The Director of DRRD was interviewed first, followed by a separate interview with the two NSP staff.

\subsection{Kabul DRRD}

The DRRD for Kabul has 28 established staff as well as contracted staff. This includes one construction engineer, two water supply engineers and one hygiene specialist. There are only two full-time NSP staff (an engineer and an administrator).

There are two vehicles; one for the Director and one used by the OC. The Director's fuel allowance only lasts half the month, after which he relies on lifts to carry out supervision.

The office space available for the DRRD and including the $O C$ is very restricted. There is for example no separate meeting room (after meeting the director in his office, he had another meeting and we had to conduct other interviews in the office his deputy shares with another member of staff). All the administrative and secretarial staff work in one room. The OC has one small office.

DRRD staff need training in computer skills and English language to be able to deal with aid projects.

Apart from NSP the DRRD is also involved with three construction programmes:
UNOPS (to which they forward requests from communities for road construction), WATSAN (UNICEF) and NEEP. They are also responsible for a survey of the reintegrated and cooperate with the Micro-Finance programme, where they have one member of staff working, and monitor 'a rough sample' of families involved in the scheme.

\subsection{Experience of community development with the NSP}

The NSP department/activities began in 2003. They currently work in 7 districts with 324 projects. The Director himself has only been in post for 6 months but is clearly closely involved with NSP and strongly in favour of it.

$\mathrm{He}$ and his staff (involved from the start of the programme) carry out direct supervision and promotion in coordination with the $O C$ and $F P$, and have direct contact with the CDC when they initiate projects 'to talk about honesty, maintenance of the project and other issues'.

From his meetings with other provincial DRRD and MRRD staff at the national CDC meeting, the Director realized that in Kabul they have avoided some of the problems of contradictions between traditional and CDC shura described by the Governor. He attributed this to the preparation work carried out by the FP with the involvement of the district governor and, if necessary, intervention from DRRD so that the problems are resolved before the $C D C$ is created.

Both the Director and his staff attributed the success of the FP in establishing and facilitating the CDC to their preparatory peacebuilding work, which prepares the community to receive the programme. The satisfaction of the people with the work of the FP, their evident hard work and honesty, are the criteria by which they judge their success.

Both Director and staff thought that there was now, as a result of NSP, a strong relationship and regular meetings between the communities and provincial and district government. Other relationships have also improved. Tribal and even family tensions have been solved at the CDC level. 'In a village where there had been seven murders (a clan feud) and the governor could not solve it, the CDC solved the problem.' (Both of these social gains were emphasized by the communities themselves.)
THE PRO VIN CIAL FIELD SU RVEY REPO RTS 
The CDCs have also developed the capacity to approach other ministries and organizations to seek funding for their projects. The DRRD issues them with certificates on completion of NSP projects that they can present. They also negotiate top-up funding for projects that exceed the NSP budget (this capacity was evident in several of the CDCs visited by the research team).

\subsection{Training and capacity of the DRRD} The Director reported that 5 of his staff (those responsible for NSP and 3 others) had received training in the NSP programme. He considered that in his first 6 months he had had two 'training experiences': the national meeting of all the CDC representatives and the exchange of ideas with the DRRD representatives attending; a follow-up meeting with the minister.

The two programme staff described two-day workshops provided by GTZ (OC) on community mobilization/understanding society and on supervision of the NSP. They also said they had GTZ working with them (i.e. in a capacity-building role as later described by the OC himself). Although they did not mention fieldwork experience with the FP (mentioned by SDF) they clearly had detailed knowledge of how the FP works in the community, and based their favourable assessment of the FP on the way they approach the communities.

The Director assessed that with the capacity the staff now has the DRRD can continue to complete 70-80 per cent of the work but they are held back by the lack of resources, detailed above.

The NSP staff were also confident in their professional capacity, 'We have successfully implemented 108 projects through the FP and from a technical point of view we have been successful compared to other NGOs.' However they thought that even the present combined DRRD/OC team was not sufficient to monitor the existing 324 projects, never mind the further 608 just passed.

They also pointed out that they do the same work as colleagues contracted by the OC (GTZ) on more than 5 times their salary. 'In three years we have not received either monetary or moral support.' They later said the researchers were the first to enquire about how they are getting on with the programme. Nevertheless, their commit- ment and enthusiasm for NSP seemed undimmed by these difficulties, perhaps because of the relationship they have with the $C D C$, where they were confident they would always be 'kindly received'.

\subsubsection{Constraints due to the NSP procedures}

In general the NSP staff thought the communities did not have great problems in implementing projects, but there are two aspects of the NSP budget arrangements that cause frustration. First, there is a contradiction in calculating the budget for a village on the basis of US \$200 per family, but then putting a cap on the total budget of US $\$ 60,000$. Larger communities quickly find out that they are getting less per family than the others and complain.

The payment of the Block Grant in three instalments, given the limited administrative capacity of the central OC, creates delays which can be prolonged even after the money arrives by the onset of winter. Projects are consequently left incomplete for months. This accounts for ' 40 per cent of the problems' with implementation.

\subsubsection{Coordination with other ministries}

As regards coordination with other ministries, both the Director and the NSP staff said that in general it was good. The Director described joint projects in education and agriculture, sharing of transport and sectoral coordination meetings. The operational staff described discussions with the Ministry of Water and Sanitation to facilitate implementation of water projects through NSP and applying the Ministry of Education standards. In most cases delays in approving plans, which could be up to 4 months, seem to be bureaucratic. However, they did have problems with the Ministry of Energy over a request to link communities that set up their own network to the grid (in this case they seem not to have consulted the Ministry before setting up the projects).

\subsubsection{Community relations}

As described above, the DRRD staff maintain positive relations with the CDC communities. This in turn enables them if necessary to intervene to resolve misunderstandings. There had only been two registered complaints about the implementation of the programme. Both were cases of communities that became suspicious about the handling of their project budget. The DRRD carried out investigations and were able to demonstrate to the villagers that everything had been done correctly. 
Two lessons can be learnt from these incidents. First that there is growing trust in the DRRD as impartial public servants. Second that there is still difficulty in establishing transparency and accountability within an uneducated and often socially marginalized population that has had good reason in the past to doubt the honesty of its leaders.

The household survey in Godara (see 9. below) also showed how poorer and less educated members of the community, who lacked the capacity to scrutinize or understand accounts, were inclined to be suspicious of the financial management of the CDC. The deep distrust of the council leaders by the poor in Kalakan where there is no CDC further illustrates this point (see 10.).

\subsection{The role and impact of NSP/CDC}

Both the Director and the operational staff thought that the NSP had made an important contribution to national solidarity and that this is its main role. Both described the efforts they made in contacting the community to explain the roles of government/MRRD and the NSP and they were sure the communities understand that it is a government programme. They also stressed the importance of the CDC in building solidarity within communities between different ethnic groups:

$$
\begin{aligned}
& \text { 'It is not important how many } \\
& \text { projects are implemented, } \\
& \text { the important point is solidarity } \\
& \text { within the community about } \\
& \text { selecting the project.' } \\
& \text { (NSP/DRRD engineer) }
\end{aligned}
$$

Assessing the impact of the programme in building the CDC capacity for project management, the operational staff thought about 50 per cent would already be able to function in some way if FP support was withdrawn, because they had gained basic knowledge about projects; but in reality they still need technical assistance, especially with proposal writing, and the FP needs to continue to give support to the $\mathrm{CDC}$ for the present.

The Director and staff saw the CDC as effective institutions for community governance and thought that they needed to be established on a more permanent footing. Logically, if there are now to be elected district shura, the elected CDC should be incorporated in the constitution. The operational staff also thought that there needed to be some kind of payment to office holders of the $C D C$ to reimburse expenses and compensate for taking time off from work to support their families.

\subsection{Additional comments from the interviewees on the future of NSP}

The Director and staff made strong pleas for NSP to continue so that the government could sustain its relationship with the people through the $\mathrm{CDC}$.

The operational staff also stressed that 'MRRD has the leading role in implementing NSP - without it the OC and the FP could not implement the programme.' By this they were once again drawing attention to the under-resourcing of the permanent institution compared to the supporting agencies, rather than suggesting that DRRD could at this stage run the programme without facilitation.

\section{The provincial NSP O versight Consultant (OC)}

The Oversight Consultant was interviewed on his own (the other staff had already left work by the time the researchers met with him, as it was Ramadan). In addition to the two DRRD staff, the team consists of 6 men and two women: team leader (himself), one engineer, two monitors, one documentation clerk, two guards and a cleaner.

\subsection{General comments on the strengths and weaknesses of the NSP}

He said the programme had two sides: the physical and the social. In Kabul they had been successful on both sides. The evidence for that was that the armed men had put aside their weapons in order to participate in the projects. There is now solidarity amongst the people as they cooperate to keep the programme, even between some that have been at war with each other for 70 or 80 years.

This was achieved as a result of the two sides of the programme. In the beginning people didn't believe the government could do what it said, or they thought NSP was just another NGO. Once the money was delivered they began to trust in the government. Then there were both technical and
THE PRO VIN CIAL FIELD SU RVEY REPO RTS 
social problems to overcome to implement the projects. The armed men had little understanding of the social work involved. However, the strength of the programme is the participatory work in the community combined with strong support for the projects. This is what helps understanding and cooperation. In Kabul, for example, they had avoided the problem raised by the Governor of conflict between different types of shura.

His main concern was with the pace of expansion. The present OC/DRRD team is already finding it difficult to give daily supervision to the projects as they feel they should, and they are now facing the prospect of expansion to more districts.

\subsection{The capacity-building role of the OC}

He thought they were playing a successful role in building both the capacity of the DRRD, through their joint supervision and monitoring of the projects, and helping the communities to 'be professional and control and continue their work'. He once again pointed out that gunmen had produced good projects as participating stakeholders.

The management team ('we') provide the CDC with the advice they need and he has transferred all he knows to the DRRD staff (he did not at any point refer directly to the role of the FP as the DRRD staff did, but clearly it is they who make the direct input to the community under the supervision of the $\mathrm{OC}$ ).

These claims were vindicated by the level of competence and understanding shown by both DRRD staff and the CDC's visited, especially those which had already successfully completed projects. It was clear that he regarded capacity-building as central to his role as oversight consultant, and as the core activity of the programme as a whole.

\subsubsection{The capacity of the RRD}

From the point of view of professional capacity, he considered the DRRD is now capable of running the programme without an OC, but they do not have enough staff in relation to the number of projects.

\subsection{The supervisory role of the $\mathrm{OC}$}

He saw the supervision as consisting of regular visits in the field (the engineers are out four days a week) and scrutiny of the documentation and project proposals before forwarding to central office. As the number of projects and proposals has increased, he felt that the level of supervision of each project has decreased and is not now as good as it should be.

$\mathrm{He}$ and one other colleague are responsible for checking the proposals before forwarding them to central office. Often, he resorts to taking bundles of proposals home to work on in the evenings in order to keep things moving.

Similarly, the applications for the payment of Block Grant instalments have to be processed within about two days and sent off. Getting the Block Grant allocated takes about 15 days and a further 5 days in central office. In his experience the NSP is efficient in processing the payments, 'but the banks are not'.

\subsection{Additional comments on the future of the NSP}

He thought that the number of staff in the engineering team needed to be increased due to the number of projects. So far they are not behind with the work because they take work home, but with the planned expansion it will become impossible to maintain this standard.

The programme should continue and be made sustainable because it has a positive effect on people and communities, but nothing is planned beyond the three years.

The CDC should be given legitimacy under the constitution. They are elected and therefore the real representatives of the people, and now that they have developed the capacity to participate in the reconstruction of the country they are the active members of those communities.

\section{The facilitating partner: Sanayee Development Foundation (SDF)}

SDF is an Afghan NGO with a history of community development work in Kabul. It is the only FP working in the Province and has facilitated the NSP in 7 districts to the north of the city.

\subsection{The programme management}

The research team interviewed the senior management team of SDF: the Executive 
Director, the General Coordinator, the Project Development Manager and the NSP Manager.

\subsubsection{The role of FP}

In response to this question several members of the management team immediately mentioned 'mobilization' and 'facilitation of the whole process'. The Executive Director referred to 'advocacy, from people to government and from government to people' and 'capacity-building'. The others spoke of the hands-on processes of introducing the NSP, establishing the CDC, assisting them to identify problems, develop technical projects and even fill in the necessary forms.

They all saw it as their role to promote the NSP and convince the communities to participate. In this regard, it was hard to win the trust of the communities in the first year until they began to see visible changes as a result of the projects. Their experience therefore confirms the observation of the $\mathrm{OC}$ that the social developments of the programme are achieved through participation in the projects.

\subsubsection{Working relations with the DRRD/OC}

They described very good working relations with the DRRD but also with MRRD, since it is very close and they can at times deal direct with them. The same applies to the provincial and main $\mathrm{OC}$ offices. Clearly this is a big advantage for the NSP management in Kabul, since they can jointly sort out any difficulties on the spot.

The 3 management bodies basically maintain close contact and support each other 'We think OC, DRRD and SDF are the same team.' For example, they always contact DRRD to take part in opening and closing ceremonies of the projects, but also sometimes ask them to help in solving problems in the CDC (as described by the DRRD Director).

As a result they have not experienced any of the problems they have heard of in other provinces and have been commended by the DRRD for their cooperation.

\subsubsection{Capacity of DRRD}

They think the DRRD works very well. The fact that the two NSP staff have had experience of working with SDF provided them with good training for the programme, which was a very new concept for them. They saw this as their contribution to DRRD capacity-building.

\subsubsection{The programme structure and relations between communities and government}

They make a particular effort to portray the role of government in the NSP to the communities and explain their role as FP. They do this in the introduction to NSP and again at the time of the elections. They said the CDC thank the MRRD, SDF and the World Bank for the programme. In fact all the CDC (see 8 below) visited did say exactly that, so they seem to have got the message across! (More recently, since the funding support has diversified they talk of donors, not just World Bank.)

They thought that the communities were probably not aware of the OC's role as separate from government. In their weekly monitoring visits they check with the people that the FP is working according to the manual, so presumably it is seen as government supervision (and in fact DRRD staff are part of the $O C$ team, see 5 above).

They did think however, that the government is reluctant to give the FP credit for their role in the programme. For example when 5 SDF staff working on the programme were killed they were referred to as government employees. 'The government thinks, when hiring the FP, they are our God.'

The $O C$ in his interview certainly did not mention the FP, but both the DRRD Director and staff were very appreciative. As the SDF staff recognized, NGOs have a very bad reputation, so it may be at the national propaganda level the government seeks to distance itself from them.

Nevertheless, as a result of the NSP programme, their explanations and the frequent visits of DRRD and MRRD as well as OC personnel, SDF sees that the communities feel free to approach even the Minister with their problems. This is in fact the first time in Afghan history that communities are taking the initiative to contact ministries. Before everything came from the top down. NSP has managed to reach even the most remote communities that government never reached before.

\subsubsection{Coordination with} other ministries and donors

They are also encouraged by SDF to contact other ministries and donors and given information about them. Some top-up proposals or additional projects are linked to SDF/NSP
THE PRO VIN CIAL FIELD SURVEY REPO RTS 
projects, as the researchers verified in the communities visited.

However, there has also been a negative reaction at the top level of government. They reckoned that about 70 per cent of the ministries are against NSP and the President has appeared ignorant of its progress. They specifically said that the Education and Health Ministries sometimes obstruct the progress of NSP. This uncompromising opinion is in contrast to the DRRD statements, both in Kabul and Bamyan, that in general coordination is good (see 4.3.3).

\subsubsection{Views on the impact}

\section{and future of NSP and the CDC}

The management team members were concerned that the NSP programme should continue because of its role in developing community governance. They emphasized that the most important gains are not economic but social, and suggested that the communities recognize this. For example, as the CDC develop, there are fewer demands for payment for CDC work, not only because they realize that they can't be paid, but because they begin to value the authority and prestige they hold in their community, and take pride in the projects and development. There is now healthy democratic competition for being head of a CDC.

The NSP Manager said that they value the structure rather than the money because by changing the traditional leadership they have been able to resolve their conflicts within the community.

The General Coordinator, however, cautioned that withdrawal of funding to support projects at this stage would put those gains in jeopardy. He clearly shared the view of the $O C$ that the social gains are achieved through the participation in projects to improve the living conditions of the communities.

This discussion closely reflects the responses obtained by the researchers in the communities. CDC members in all of the communities visited by the researchers stressed that the most important gains from NSP were in establishing inclusive community governance (see 8). Householders in Godara also described increased social unity as the primary gain but cited the material benefits as evidence of the success of the CDC (9). Householders in Kalakan, not yet involved in NSP, were looking primarily for tangible improvements in their economic conditions. Those that mentioned improved governance saw it as a means to ensure that economic benefits reach the poor (10).

Looking to the future the Executive Director said that NSP is a movement, not a project. There are high expectations of it, though this optimism varies from province to province. It is likely to become a legal system of governance. They believe that the government is considering this, which is why they have delayed the district elections, so they can incorporate the CDCs in the district councils.

\subsubsection{Training and capacity-building in the communities}

SDF has a Capacity-building Department which designs and develops training and capacity-building for the communities. NSP staff are then trained in these methods before working with the communities. They are fortunate, in Kabul, in being able to recruit staff with at least secondary education, and often with relevant experience.

The capacity-building aspect of NSP is seen as the most important: 'We believe everything we do with them is a form of capacitybuilding.' It focusses on two areas: participatory governance and being able to manage their projects.

Training and capacity-building are first of all essential to the process of establishing the CDC. Peacebuilding, based on Islamic principles, is key to opening the way for the programme, and this aspect of SDF's approach was referred to by all the other stakeholders, from DRRD to the CDC members and householders. It seems clear that this groundwork is an important factor in the success of SDF's work. Problem analysis, using a problem tree to discuss the communities' needs and project options, is another capacity-building exercise that was commended in Godara and some of the other CDCs.

SDF then gives training in all aspects of CDC functions, record keeping, book keeping and project management as outlined in the Operational Manual. These functional aspects had clearly been very thoroughly transferred to the CDC members. All the CDC visited had a good understanding of the functions of the CDC, the NSP programme and the management of their 
projects. Documentation of their activities and financial transactions was also of a very high standard. The process was no doubt helped by the good standard of education of the CDC members compared to other areas of the country (see 8).

SDF has added other training programmes to the basic NSP requirements, which they think are relevant and help the CDC to function effectively. These include: education, health, literacy, Islamic education and human rights awareness. Again it was clear from the respondents in the communities that they had been exposed to these courses and found them relevant.

The main problems experienced in the training programmes are due to lack of time, especially when introducing new ideas and skills to the less educated. The NSP timeframe is very short for the FP to achieve their objectives. The community members also have limited time as they have their own business to attend to. So although they think, with justification, that their training programmes have been very successful, they have not been able to carry out the whole of their training plan.

\subsubsection{Participation}

The purpose of the peacebuilding workshops as the first step in establishing the $C D C$ is to ensure that all sections of the community participate from the start. The field staff and CDC members interviewed, for example, explained that the former traditional council leaders are generally included in the CDC in some way (on committees etc.), if not actually elected Occasionally a CDC head proves unacceptable to one part of the community and the conflict has to be resolved in another workshop.

Participation of women

The initial NSP concept was to have mixed CDC, but it didn't work. They now have women's CDC with their own projects, but there is cooperation between the two. The women are assisted by the men's CDC on the logistics, such as purchase of goods (women in these communities have no experience of business dealing outside the home; see Godara women's CDC section 8). Women's CDC for their part often contribute financially to the projects of general community benefit run by the men (see again Godara women's CDC).
In Kabul at least, after initial scepticism, the men have accepted the concept, especially when they saw the money coming in and projects being implemented. This seems to be further evidence of the importance of the projects as vehicles for promoting social change.

\subsubsection{The FP's capability in relation to the programme demands}

SDF recruited 120 new staff and redeployed existing staff in order to take on the NSP work. There was a core team that was able to develop the programme, drawing on expertise from other projects, but they needed to develop their capacity. For example, they had to carry out intensive training on community mobilization.

If the NSP were wound up, they would struggle to retain all their staff; they would inevitably have to shed some. However, they felt that in Kabul, with the expertise and experience they had acquired in NSP, they would be likely to find better jobs than before they were recruited.

If, as is happening, the NSP expands and the number of projects continues to increase, they will simply hire and train more social organizers. They don't envisage any problems in that area. However, there is likely to be a problem finding engineers. At present they have two fully qualified engineers and for the next phase they plan to recruit three specialist engineers for water, sanitation and construction.

\subsubsection{Comments on the Operational Manual and changes to the guidelines}

The manual as such is a clear working document. For example, the eligibility criteria are clear and can be easily explained to the communities, who then work to them.

However, it is the changes to the manual that cause problems, because work is initiated on the basis of guidelines that are then altered or cancelled. For example, SDF did a lot of work preparing communities for income generation projects that were then stopped because the World Bank was unsure of their sustainability. This created great disappointment.

In the beginning there was just one project per community, but now where not all the money is used in a first project, a second is started. There are in addition women's projects. This amounts to a lot of extra proposal writing for the FP staff and CDC.
THE PRO VIN CIAL FIELD SU RVEY REPO RTS 
There was a sense of grievance in these comments, not so much at the changes themselves, but that it was not done in a consultative way that took account of the implications for the FP and the communities.

\subsection{Management at district and project level}

Following the interview with the senior management team, the researchers met with staff responsible for the programme in Estalef District: the district organizer, a female social organizer and two supervisors.

One of the engineers from the programme was also asked to respond to a short questionnaire framed by the Engineering Consultant. The responses are discussed in the engineering report.

\subsubsection{Staff capacity-building and training}

The field staff thought that the main requirements for the job were: all except the drivers and guards should have a secondary school certificate (baccalaureate); staff need a good understanding of the society and should know and respect the culture and traditions of the communities; they should have good communication skills, including knowing the local dialect or at least understanding it; conflict resolution skills are also necessary.

Before going to work in the field they received orientation on the NSP concept and training in community mobilization, communication, problem analysis, conflict resolution and peacebuilding. Of these, community mobilization and conflict resolution had proved most useful. For example, they have been called on by communities to resolve conflicts because their expertise is known.

So far they have not felt any lack of skill for the job.

\subsubsection{Project relevance, sustainability and efficiency}

\section{Relevance}

The projects being implemented in Estalef are: road construction; animal husbandry; canal cleaning; water supply and development of springs, and the purchase of crockery for use and hire for festivals, weddings etc. concerns voiced by householders and CDC to the researchers. It therefore seems likely that they are genuine community choices. Road projects and canal cleaning projects are directed at restoring or increasing the returns from growing and marketing fruit, which is the core agricultural activity. The women's crockery project was the idea of women involved in catering for community events, who constantly had to borrow crockery. Now, when their set is not in use they hire it out to raise money for other projects.

SDF staff do however encourage the community to choose and design the projects to include all sections of the community, with special attention being paid to vulnerable groups (widows and the disabled). SDF do not try to make any specific political, economic or sociological analysis themselves, but rely on the fact that the community is fully aware of its own social divisions and therefore who is vulnerable or excluded. This policy follows NSP guidelines and there was evidence in the field of efforts by the CDC to implement it (see 8).

The field staff explained that it was by using the problem tree method of analysis that they were able to work with uneducated people with diverse interests and points of view, and make it possible for them to make these collective decisions. In fact the participants are amazed at what they can achieve in these sessions and generally content with the result (this method was mentioned favourably by the community in Godara, see 8).

While the projects do not directly involve other communities, the projects attract attention from neighbours and, as in the case of crockery, the $C D C$ is able to sell services to them (the householders in Kalakan for example were aware of the projects in neighbouring districts, see 10).

When it comes to planning the projects, SDF technical support is necessary, especially for the more technical projects and when it comes to filling in the forms. However, the CDC still plan in a participatory way.

Sustainability

The quality (and therefore durability) of the projects in terms of design is assured by the FP and $\mathrm{OC}$ engineers, and implementation is closely controlled by SDF engineers, OC 
monitors and the CDC representatives, to ensure that the right quality of materials are used. They also ensure that all projects comply with national development plans.

The sustainability of the projects is of course dependent on this good design as well as the quality of construction. The SDF staff also ensure that the CDC plan how they are going to maintain the facilities, by setting up monitoring committees and by income generation (sale of services for example) to cover the expense. There was evidence of these measures being taken in the $C D C$ visited (see engineering report).

The relevance and acceptability of the projects to community needs must also be a factor for sustaining motivation of the community to maintain the facilities.

Efficiency or effectiveness?

The SDF staff thought that judging the FP performance (or efficiency) on the quantity of projects completed does not value their quality. On this issue it can be said that on quality issues such as relevance/utility to the community, appropriate design and sustainability, the SDF projects observed scored highly. Note also the DRRD and OC concerns about maintaining adequate supervision of an increased number of projects.

They thought that centralization of decision-making on project proposals and the dispersal of the second and third Block Grant instalments costs too much time and effort. It would be more efficient to decentralize the decision-making authority.

\subsubsection{District profile of Estalef}

(Information provided by the field staff)

- Population: The total population is 45,604

- The total families (couples and their children) 10,374

- The average size of a household (i.e. comprising more than one 'family' or several generations) is 15

- The accepted age of adulthood is 17 for boys, though they normally do not marry until aged 25-30. Girls are considered adult and expected to marry at 15 .

Vulnerable people identified are widows (689) and the disabled (308). (The figures are low, if compared to the numbers in Godara, so perhaps mean those widows or disabled not adequately supported by family, i.e. vulnerable?).
Economic conditions

The majority of the population is poor. During the Taliban rule 90 per cent of their houses were burnt as well as their grape farms, which were a main source of livelihood. The Taliban destroyed the grape farms because they were thought to provide cover for Northern Alliance forces.

The main sources of livelihood are now pottery (the most famous in Afghanistan), farming, and working on NSP projects. A few well-to-do people have businesses in Kabul City.

Staff

SDF has 28 staff working in Estalef: two engineers and two engineering monitors; 13 facilitators ( 3 women, 10 men); 4 social organisers (one woman, 3 men); one peacebuilding trainer; one NSP trainer; 3 drivers; 2 guards.

The CDC

The average CDC has 320-330 families. There are 429 members of male councils and 257 members of female councils.

Projects

So far, Afs $10,011,599$ (US $\$ 206,000$ ) have been spent, the bulk of it (Afs 9,561,000) on general projects. See 6.2.2 above for the range of project types.

On the basis of this profile and the sample design, Godara was chosen as the CDC community to visit (see 8 below).

\section{General comments on the management of NSP in Kabul}

\subsection{Successful implementation}

The management of the NSP in Karbul is well coordinated between the three implementing agencies, who basically work as a single team. In particular there has been a conscious effort on the part of the $\mathrm{OC}$ and also the FP to build the capacity of the DRRD staff. All parties share a common understanding and enthusiasm for the NSP aims and concept and this includes the Director of DRRD, who is actively involved. The NSP programme in Kabul also benefits from the practical and political support of District Governors and has the endorsement of the recently transferred Provincial Governor. This unified approach has clearly resulted in successful implementation, which has achieved tangible results in terms
THE PRO VIN CIAL

FIELD SU RVEY REPO RTS 
of both governance and community development. Perhaps the most notable success has been to include, rather than confront, the existing leadership.

The FP (SDF) has played a significant role in this respect, by its use of peacebuilding and problem analysis methodologies, as well as its understanding (as a national NGO) of the culture and moral beliefs of the communities. This has enabled it to work with all the different interest groups to ensure their inclusion.

The quality of the projects in terms of their design, relevance and construction, as well as their sustainability in terms of maintenance, is also due to the quality of the work by SDF combined with the active supervision by OC and DRRD. As a result communities have been able to acquire the capacity to develop new projects and independently seek out funding. High standards of implementation, supervision and monitoring are evident in the end product: a CDC with completed projects going on to develop other activities.

\subsection{Limitations}

It has to be recognized that this success story is partly due to certain advantages enjoyed by this Province compared to more remote areas, as SDF acknowledged. They are able to recruit well-educated personnel, which makes their training easier. In addition, there are many educated individuals in the communities capable of serving effectively on the CDC. The gaps in this scenario are in the participation of women and the less advantaged members of the communities. SDF has comparatively few female staff and the women in the communities do not have anything like the educational level of their menfolk. There are also other sectors of the community that do not take an active part in decision-making due to poverty, lack of education or disability. The consolidation of the CDC as democratic institutions still requires more time in which to build the capacity of women and the disadvantaged to have a meaningful participation. As it is, SDF feels that the training and capacity-building programmes that they see as necessary are being cut short by the time constraints of the programme.

\subsection{Threats to further implementation} There are some potential threats to this largely effective implementation of the programme so far. Despite the team effort the institutional arrangements do generate areas of resentment and potential conflict. The gap in resources and pay between the DRRD and the OC is not sustainable and, as both parties acknowledge, raises the question of how the DRRD can eventually take over the management roles of the OC. There is also some resentment on the part of the FP that, for political reasons, it is not given credit by government for the essential role it plays in the programme.

All parties noted the threat posed by over hasty expansion without adequate resources. SDF were afraid it would lead to loss of quality in the work, both in the groundwork for establishing the CDC and in the projects. The OC and DRRD were afraid they simply wouldn't have the time and staff capacity to meet increased demand. However, having said that, the political imperative to expand and include other districts was evident in the discussions with the Governor, elders and householders in Kalakan, the community without a CDC. Also, if, as all advocate, the CDC becomes the constitutional organ of governance at community level, all communities will have to be included. The threats inherent in this dilemma are: failure to expand is likely to cause discontent; expanding at a pace that does not consolidate the governance of the community or guarantee the relevance and sustainability of projects will also cause disillusion. Both scenarios are potentially destabilising.

\section{The CDCs}

The research team worked in Godara with the men's and women's shura and conducted a household survey. The team leader had previously visited 4 CDC in Shakadara district with the Engineering Consultant and was able to record some comparative observations.

\subsection{Godara, Estalef}

The sample design required the team to research communities at different stages of involvement with NSP. Having observed 4 CDC in Kabul with completed projects Godara was selected as a community where the $C D C$ is established and has a first project in progress. The separation of the men's and women's shura is also a common practice in the Kabul CDC, which the team wanted to research, having observed a mixed CDC in Bamyan. In other respects 
too the community profile (see below) matched the general district profile, so that it could be considered broadly representative.

\subsubsection{Community profile}

(Information provided by the FP with further detail from the CDC and the researchers observation.)

Godara is a community of 400 families living in two main areas of settlement. The ethnic mix of the village is predominantly Tajik with small numbers of Sadaat (Arabs) and Khoja families.

Most of the families are living in poverty. Barely 10 per cent could be described as of middle income and possibly 2 or 3 per cent as rich. It was only in the past year, largely as a result of NSP, that most people got work. They mainly work as labourers as well as in agriculture, which does not provide sufficient income.

However in the past the village had been prosperous and developed, making a good living from grape cultivation, businesses such as pottery (for which the area is famous) and carpentry as well as a popular tourist venue. They have therefore been impoverished by the war and this is immediately evident as many houses are still ruined and previous livelihoods are clearly not yet recovered.

The village was almost totally destroyed (houses and vines and irrigation systems) by the Taliban and abandoned by all the residents for 5 years until the fall of the Taliban. All the residents are therefore returnees, many of whom have only recently returned. Most were displaced internally to the cities, but between 50 and 100 families left the country to Iran and Pakistan. There are also 50 widows and about 100 disabled living in the village. Many of these were victims of the violence.

Because they are all struggling to recover their livelihoods and support their families, the villagers have little time for voluntary work, but the paid NSP work has been very welcome.

\subsubsection{Legitimacy and acceptance of the CDC}

The men's shura is made up of elected representatives from every cluster of 20 households in the community of 400 families. Following this election the Head, Deputy, Treasurer and others were chosen [by the shura but observed by the general public]. The criteria were that they should be honest and transparent with the people. Most attention was paid to selecting an honest treasurer who would be transparent and respected by the people, and accountable. Several members were successful businessmen until ruined by the war; others are professionals (administrator in the Estalef education department, some teachers, a manager in the Ministry of Finance.)

A women's shura was also elected and sits separately from the men. Representatives were elected from each of the 5 Mosque communities. The women gathered in private houses where ballot boxes were set up. It has had a big social impact in that women now know their neighbours and meet regularly to discuss ideas for projects and community projects. Unlike their male colleagues, all but two are illiterate and none is able to manage accounts or keep records. Their treasurer therefore receives help from the men's treasurer.

So far it is the men's shura that constitutes the effective $C D C$ government in the community and in representations to outside bodies, but the women's shura has made some representations to the health department.

The household survey (see 9) suggests that the elections were considered well conducted and both shuras have general acceptance and are believed to be working in the best interests of the community.

The surviving previous leaders of the community, the head of the Mosque in each community, the Malik and elders have been included in the CDC because many are thought to be both knowledgeable and experienced. Respondents to the household survey also mentioned the previous influence of warlords, but suggested their influence had been reduced by the creation of the CDC. This evidence supports the claims by the DRRD, OC and FP that potential conflict between rival community leaders has been successfully avoided in the Kabul CDC.

There are 4 special committees established under the CDC: social affairs; agriculture; health; education. As much as possible, the members have specialist knowledge of the sector concerned, because one function is to represent the village to the government ministries on particular issues. Another
THE PRO VIN CIAL FIELD SU RVEY REPO RTS 
function is to advise the community. The traditional leaders, for example, mostly sit on the social affairs committee.

\subsubsection{Functioning of the CDC}

\section{in relation to the whole community}

The development plan was drawn up by the CDC after a consultation process in which the representatives asked the residents in their respective clusters to identify their problems. The CDC then identified the priorities and reported back to the residents. In other words it was a consultative rather than participatory process for the general population. The size of the population and the fact that they had only recently resettled may have dictated this as the most practical solution at the time.

In the CDC, the process of identifying and prioritizing problems was fully participatory and helped by the use of the problem tree method, introduced to them by the FP. Members felt that without it they would not have identified the root of their problems and been able to agree as easily as they did to start with the road construction. The women's shura also decided to contribute 10 per cent of their funds to this general project as they could see that it is of general benefit.

The responses in the household survey suggest that this choice is mostly acceptable, but some did not seem to have felt very close to the decision-making or that they were fully informed of the details.

The CDC does make efforts to report to the residents through announcements in the Mosque and by encouraging scrutiny of the accounts. All the CDC activities are scrupulously recorded in 14 separate books. Apart from those required by the NSP Operational Manual, they also keep minutes of all meetings with government and outside bodies and have made a point of recording all agreements with landowners who ceded land for the road project. This represents a high level of accountability and transparency. However, it does not overcome the problem of communication with the uneducated members of the community.

The women's shura, since the members are mostly illiterate, does not keep records. The men record all the expenses for them and announce it in the Mosque. The FP social organizers also keep some minutes of meetings and activities in a notebook that is kept in the meeting room.

\subsubsection{Projects}

Two general projects have been planned: the construction of an access road from the main highway to Kabul to the village, and a clean drinking water system.

The access road

The road was prioritized because it would have an immediate impact on livelihoods, enabling the farmers to transport produce with less damage and lower transport costs for sale in Kabul. At present hiring donkeys to transfer the goods to the main road is far more costly per kilometre than the road transport.

The women supported the project with 10 per cent of their fund because it would enable women in labour to get to the maternity clinic safely and it would reduce the cost of goods coming into the village. They also thought it would improve communication with the city and encourage the government to 'come and observe their problems at close quarters'.

Within the village the road is planned to provide access to the hilltop picnic site that was previously an important source of income from tourists. At least one householder from another part of the village did not support this route, as it does not benefit his area. However, by providing access to the village itself the road clearly has a general benefit.

The construction of the road and associated culverts and water channels was being undertaken in an organized and efficient manner and, as far as the research team was able to observe, to a good standard. The design and quality standards were set by the FP engineers, approved by the OC and monitored by both FP and OC/DRRD teams. The process from first identifying the problem to the start of the implementation after receiving the first Block Grant instalment took 3 months. Ten per cent of the cost is to be provided in labour by the villagers (i.e. voluntary in addition to the paid labour).

The project is also overseen by the CDC's Control, Evaluation and Supervision Committee and managed on a daily basis by a CDC member with business management experience who does the purchasing and supervises and hires the villagers paid to work on the project. (There was one complaint from a householder about the allocation of this work see 9.) 
The drinking water project

The drinking water project, which has not yet started, has general approval from the householders as all will benefit. The women were particularly aware of the health benefits and for this reason supported it.

\section{Projects beyond the NSP}

The men's CDC is already engaged in investigating and negotiating further projects (though it seems the general population are not aware of these moves). One of these is a micro-hydropower project to be shared with neighbouring communities and funded by a Korean NGO. The CDC had been engaged in mediating a conflict over land acquisition for this scheme (see below). They are also approaching other ministries and NGOs for projects.

\section{Women's projects}

The women's shura has spent a lot of time in discussing ideas for projects. The list includes: animal husbandry, pottery, carpetweaving, tailoring, a public bath, a beauty parlour and a bakery. They expect to select from these a priority for a future project.

However, at the present they say they have little time free for managing projects. Instead they are investing in skills training. Women with carpet-weaving or tailoring skills, with a teacher and material and machines provided by SDF, are training other women. The women are also taking literacy classes and learning accounting.

Thus SDF is in fact supporting an adult education programme (literacy, numeracy and livelihood skills) with the women to equip them to run their own projects in the future.

\subsubsection{Relationship between the CDC and government}

The men in the CDC explained that previously interaction with government was through influential figures like the Malik and Mullahs and those with education. Now every contact is set up through the CDC.

On the government side, the District Governor has been very supportive of the $\mathrm{CDC}$ and works through them, enlisting their help in various matters, for example in identifying the neediest farmers to benefit from seed distribution, or in resolving disputes such as over the land for the Korean project.

As a result, there is a good partnership between local government and the people. Relations to the central government have also been built through NSP, in particular in the national CDC conference where delegates freely expressed their views and asked questions of the ministers.

The old pattern whereby plans were made in the cities and then imposed on the rural communities without proper surveys, has been reversed. Now development is planned to grow from the rural areas to the cities.

The women also said they readily contacted (local) government with their needs. For example they had made representations to get an obstetric doctor posted to the clinic. They said the relationship was good and they expected it to get better. With peace and this relationship with government, people and government can unite and focus on solving their problems.

\subsubsection{Relationship between \\ the CDC and the FP}

The members of the men's shura were very positive about the role played by the FP, which they said had facilitated all the process so far, cooperating with the community and showing them respect. Although they are aware that there is a complaints box in the SDF district office, they have never had occasion to use it because they have no complaints.

They mentioned training in peacebuilding, community mobilization, human rights from the Islamic perspective, mediation and conflict resolution, finance and administration. They had been deeply moved by the peacebuilding process and the finance and administration training had ensured they could undertake all the daily CDC tasks.

The project had enabled them to acquire the skills they need for future endeavours. Next time they expect to do most of the job themselves, though they will still need technical assistance for engineering and project design issues.

This account and the fact that the CDC is already initiating other projects and using their mediation skills in community relations, suggest that the implementation of the programme by the FP has broadly achieved its objectives for both governance and project management capacity in the case of the men's shura.
THE PRO VIN CIAL FIELD SU RVEY REPO RTS 
The women (in the presence of the SDF social organizer) also expressed satisfaction with SDF's role in the community and the CDC. They too were aware of procedures for complaints but did not say they had used it.

They were most appreciative of how much they had been able to learn from SDF in various training courses: NSP awareness, the role of the CDC, health awareness (about services such as vaccination) as well as the literacy and skills training.

\subsubsection{The capacity of the CDC}

The men's shura

Based on the criteria set out in the OM the men's CDC is classed as: Capable.

The Men's CDC is fully capable of carrying out all the functions envisaged in the manual, including keeping exemplary records and financial accounting. It is now expanding into other areas of representation and community development. It is fully capable of obtaining donor/NGO funding and government services for the benefit of the community. The one area in which it will continue to require technical assistance is in engineering project design.

The household survey however reveals that though they regularly report in the Mosque on their activities and make their records available for scrutiny, there is still a communications gap between them and the more disadvantaged villagers. In particular it seems that the prioritizing of the projects was discussed by the representatives not in the community as a whole, so that an opportunity to engage all the residents was missed. It may well have been impractical given the size of the population but, as in Shah Qadam, relying on the representatives to keep the villagers informed does not seem to meet this challenge.

The women's shura

On the basis of the criteria in the OM the women's CDC is classed as: Not able.

That is they would not be able to carry out all the tasks listed as CDC responsibilities. Having said that, they do have the capacity to examine community problems and set priorities. They are able to communicate their needs and recognize the roles of government and the FP (NSP awareness is good). They are clearly informed about what the men's CDC is doing and have support from them.
The creation of the shura has enormously increased their social interaction and social awareness and the household survey responses indicate that this also includes communicating with non-shura members.

However, they are the first to recognize that they do not have the capacity (or much time) to run projects. Their number one priority is therefore capacity-building, starting with literacy.

It was very clear to the researchers that a very positive capacity-building exercise was being facilitated by the SDF staff and that this was the priority of the CDC members, given the ground they have to make up compared to the men

\subsection{Established CDC in Shakadara District with successfully completed projects: Aziz Uddin; Taj Mohammed; Salakhail; Ghaza}

These short visits were mainly directed at assessing the finished projects while hearing from the CDC members (men only) how the process had been initiated and managed. In the course of the discussions, however, they gave some indications of the functioning of the $C D C$ and their views on its value.

\subsubsection{General observations}

Three of these were agricultural communities similar to Godara, producing fruit and vegetables for sale in Kabul and for that reason had chosen similar priority projects. One community, where drought prevented any resumption of agriculture, depended entirely on labouring work in Kabul for its livelihoods.

The communities ranged in size from 158 to 370 families. As in Godara there was clear evidence of a successful process, both in the establishment of governance through the $C D C$ and in the quality of the projects completed. Relevance and sustainability were clear in the case of the agricultural communities. In the case of Taj Mohammed, its dependence on the urban economy, and lack of any real resources, presented a challenge that the programme is perhaps not equipped to meet.

\subsubsection{Legitimacy and acceptance of the $\mathrm{CDC} /$ elections}

The CDC in all four communities are divided into men's and women's shura. As in Godara, the members confirmed that the 
previous community elders were mostly included in the $C D C$, or no longer had any role as leaders. They expressed the view that the most important gains from the NSP were social: greater social unity and cooperation.

The elections to these councils appear to have followed the procedures envisaged in the manual.

\subsubsection{Functioning of the $\mathrm{CDC} /$ capacity}

The processes described by these CDC and the well-kept documents and notices they presented, suggested that they were now capable of undertaking all the necessary tasks to comply with the NSP manual. The three agricultural communities had also been able to go beyond that: learning how to resolve conflicts and negotiate land concessions, to extend their road construction to neighbouring communities with funding from new donors, and to negotiate the sale of electricity and other services to neighbours. In these cases as well as the collective capacity, there was clear evidence of marketable skills being acquired by individual community members in addition to the benefit of the paid work for the project. The fourth community, Taj Mohammed, with its urban economy, seemed less focussed though its functioning complied with all the guidelines, and were unsure of their future plans.

\section{Projects}

While the infrastructure projects are run by the men on behalf of the whole community the women, as in Godara, had so far concentrated on small productive projects.

Two of the agricultural communities, Aziz Uddin and Ghaza, had chosen road building projects, for the same combination of economic and social reasons as Godara. In Aziz Uddin, for example, they deferred the construction of a school, realizing that by building the access road they would facilitate the construction of the school and at the same time increase income towards paying for it. The projects had been implemented to a good standard under effective community management.

Salakhail had completed a well designed micro hydropower scheme to supply all the households and had established a community payments scheme to pay for a skilled operator to run and maintain the equipment. They also plan to sell power to a neighbouring community.
Taj Mohammed, having no water supply and relying on urban work, had opted for a lighting scheme supplied by diesel generator. Although this too was well executed and managed, its sustainability is in question as the price of fuel rises and the residents' incomes remain at the same low level.

Relationship between the CDC and the FP

In these visits the researchers were accompanied by the SDF staff and did not therefore discuss their role with the CDC members. However, some volunteered favourable comments on, for example, the peacebuilding workshops and mentioned the extra time they often worked. SDF staff, for their part, were relaxed and unassuming in their relations with the villagers, leaving them to conduct the discussions with the researchers. The impression was of a mutually considerate working relationship.

\section{Household Survey: Godara}

\section{Summary of results:}

\subsection{The Sample}

Representatives of 10 households ( 5 women and 5 men) in the two main areas of the village were interviewed.

- Their ages ranged from 24 to 60 (average 40)

9 were ethnic Tajiks (the majority group in the village) and one Saadet (Arab).

- In relation to the village as a whole they rated themselves as poor (3); average (6); rich (1).

- Two were widows and one the son of a widow. Three were disabled (war injuries) and one had a disabled husband (though two of these were able to work).

- Average family size was 9 (with one widow living alone) but few households had more than one or two working adults.

- Two were farmers, 4 families depended on unskilled labouring (including on the NSP project) and 3 had skilled workers (also involved on the project). The widow living alone depended on support from neighbours and visiting relatives.

\subsection{War experience/post-war}

The village was abandoned after it was
THE PRO VIN CIAL FIELD SU RVEY REPO RTS 
sacked and burnt by the Taliban. The householders interviewed had all had their homes destroyed and lost their possessions. 5 had fled to Kabul and one to Mazar. The others had been refugees in Pakistan and Iran. Two men and the husband of one of the women had been disabled in the violence and one woman's husband was killed.

The end of the war enabled them to return to their homes and rebuild what they could. Greater security and calm enabled them to start work but their livelihoods were still precarious. Two families had only returned after the setting up of the CDC. One mentioned the high rents in Kabul as one reason.

\subsection{General understanding and awareness}

All the women, but only 3 of the men, had a good general understanding of the purpose and activities of the CDC and its relationship to government and international aid. They did not understand the way it functions, especially the finances in detail, but were satisfied with the regular briefings from the treasurer. The two young men who had very little involvement were both disabled: one, a grape farmer, struggling to support a widowed mother and younger brother, was "too busy to know"; the other was confined at home in a wheel chair.

The accounts of the householders suggest that the CDC is very active on their behalf, makes efforts to be accountable, and has the trust of the majority. However, the responses reveal some communication gaps, especially to the more disadvantaged. On the other hand the level of general awareness of the women reflects some effective capacity-building work by the FP staff.

\subsection{The history of the CDC}

Two women described the CDC as solidarity. Two women and two men described it as a means for consultation to solve problems and work for the community. One man described it as representation to government of the community's needs. To one woman it meant work. Two men gave no answer.
However, all but one severely disabled man who returned after the elections had either taken part in the elections and /or could give an account of them and judged them to have been well run.

Respondents either said that no means of taking decisions existed before in the community or that warlords and corrupt individuals had taken over incoming aid for their own gain. The CDC had greatly reduced their influence.

At least one returned refugee (but no IDP) had received building materials from UNHCR before the CDC - but still only had one habitable room.

\subsection{The CDC today}

\subsubsection{Projects/priorities/functioning of the shura}

Apart from the two marginalized young men, everyone was aware of the regular meetings of the CDC but there was less clarity about its decision-making. Two women (one the head of the women's shura) described the activities of the women's shura: 'awareness-raising about government and discussing women's projects'. Two other women described the general projects and one said 'we don't know [how it works]'. The 4 men who described the CDC suggested that the representatives debated the priorities and made decisions but did not keep the residents fully informed, although they thought they were mostly doing a good job. One man criticized the foreman of the road project of favouritism in deciding who could be kept on when the labour force was reduced. The disabled young man in a wheel chair said he could not follow what went on but believed the CDC members were 'good people and wholeheartedly work for the benefit of the community'.

The majority thought the two projects (road and clean drinking water) were going to be generally beneficial.

All either said the whole CDC membership or the heads of the CDC were the leaders and only representatives of the community.

All agreed that the CDC had very good relations with government, especially the [District] Governor, who took a keen interest in the CDCs. Two men noted that the police were now active in crime prevention in the village and attributed it to the CDC. 
As regards participation in the project: women did not see any role for themselves but mentioned male relatives who took part. One said she expected to take part in the women's projects. Disabled and elderly men also mentioned sons and brothers who took part.

Two reasons for not participating or finding participation difficult were mentioned:

the road project would not directly benefit one area of the village; villagers have to give priority to earning a living to support their families so the amount of voluntary work they can do is limited.

\subsubsection{Financial management}

One man was able to describe how the CDC managed the finances and had been shown the documentation. Two said it was done in the $C D C$ but the treasurer reported monthly in the mosque. The women either said it was managed in the CDC or that the men/men's treasurer manage it. The majority implied or expressed trust in those responsible but also implied they were not able to follow it closely. However, the young man who admitted he knew nothing about how the CDC works said: 'I know that the money is given to those who do some job but only Allah knows of what happens behind the curtain'.

Three women said the programme was a government initiative funded by the World Bank. One of these (the women's CDC head) also explained how it was facilitated by NGOs. One woman and two men said it was a government programme funded by international aid. Another woman and a man were aware that it was a government programme.

The women all said the $\operatorname{CDC}$ had not approached any other funding agency (3 said 'not yet', as if they expected it). One man gave the same answer and the other said he didn't know. One man thought that the drinking water project involved another agency. [i.e. The householders, including the women's shura head, did not know that the CDC (see C14) was in close discussions with a Korean NGO about a micro-hydro project and in contact with other ministries.]

\subsection{Impact (after 9 months)}

$\checkmark$ Men and women shared an understanding of the CDC/NSP as primarily a community-building exercise.
- Unity was the most commonly used description (4 women, 4 men). [All later agreed that the village was more united as a result of the $C D C$, and one woman described how before they didn't even know their neighbours.]

- Two women and one man spoke of solidarity and another man of cooperation.

- One woman spoke of peace and two men described it as 'calm' and an end to warlordism. One woman said it meant equity.

$\checkmark$ One man described it as a bridge between the community and government to make their needs known.

- Two women also referred to its material benefit and as a means of 'survival'.

However when they described how it had improved their own lives they described material benefits as well as again mentioning improved governance. One woman saw the main gains as 'rehabilitation and work'.

Their understanding of the government's intentions were clearly influenced by their experience of NSP. They thought the government was engaged in: rehabilitation/ rebuilding ( 4 women); promoting unity and security (two women, one man); poverty reduction/developing projects to benefit the people (one man, one woman) and encouraging international assistance (one man). All the women and two men thought the government had demonstrated its interest in their community through its assistance, while other men (thinking back to former times) thought the government had a special interest in Estalef, because they would want to see it restored as a tourist venue which they might visit as before.

These perceptions suggest a significant impact in terms of community and national solidarity within months of the start of the programme in the village (compare with the matched community in Kalakan).

\subsection{Confidence in the future}

Expectations of material benefit are also high. Respondents had a wish list of further inputs to improving their lives: schools, clinic, bakery, literacy, livestock farming, electricity and work for men and women.

All the respondents, including the most marginalized, expressed confidence in the
THE PRO VIN CIAL FIELD SU RVEY REPO RTS 
future. Two women and two men (one severely disabled) said they were very optimistic about the future of the community and the country. Others (one woman and two men) were hopeful if the current unity and peace prevails.

'I am very optimistic about the future because what I have today is beyond my wildest dreams. I even did not imagine I would be back in my own birthplace one day. I have heard with my own ears from Taliban that we should go to Tajikistan. I pray Allah almighty for listening to our prayers. I always tell my sons and grandsons to work for our country and not let it be destroyed again.'

(Unemployed former foreman in a construction company)

'I think the future of my country is very bright. The war has ended and the people are living peacefully. When the peace is there, everything moves forward.'

(Disabled grape-farmer)

'The future is in our hands now; we can both rebuild our country and redestroy it. It depends on us. But I think people are tired of war and want to live in peace and construct their country.' (Farmer)

\section{Matched community without a CDC: Kalakan Centre, Kalakan District}

Since all the villages in Estalef were already participating in the NSP it was necessary to identify a matched community to Godara in a similar neighbouring district.

\subsection{Profile of the district of Kalakan}

This district, like Estalef, was extensively burned by the Taliban during the war and most of the people abandoned the settlements, mostly taking refuge in Kabul. A few stayed and 60 were killed. As elsewhere, the irrigation channels for agriculture and the grape vines were destroyed, as well as infrastructure such as bridges. many residents still cannot return from the city because they have no house and no livelihood. He therefore thought the main priorities for NSP projects were likely to be shelter, irrigation systems and drinking water. (The team certainly observed many buildings in ruins or semi-derelict, including the government offices where the interviews took place.)

Population

- There are currently 56,608 inhabitants.

- There are two ethnicities: Tajik (90 per cent) and Pashton (10 per cent).

- Most are poor, at the lowest economic level.

- 5 per cent are well educated, 15 per cent can read and write.

Livelihoods

$\checkmark$ In general, they have not been able to restore their grape farms, which were the main source of livelihood.

Less than 2 or 3 per cent are drivers there are only 10 car owners.

- A small number are carpet weavers but working for others.

\subsubsection{The village of Kalakan Centre}

Kalakan Centre in Kalakan district was selected as a match for the Godara community on the following grounds:

Geographical proximity: a farming community with links to the urban economy to the north of Kabul City. A 90 per cent Tajik community with a small minority ethnic group.

It had a similar history to Godara: destruction of homes, grape-farming, trading and craft industry by the Taliban, which displaced the population internally and to neighbouring countries. Return of IDPs and refugees has been slow as in Godara due to the destruction. People in the district were aware of NSP (through local contacts and because the Governor was seeking to get NSP introduced to the district) but not yet informed about it.

The view of the Governor was that conditions were similar in all the villages in the district, so it was decided to carry out the survey in Kalkan Centre.

\subsection{Existing governance}

The District Governor was interviewed in his office and was later joined by the council of elders. The SDF NSP manager facilitated 
the meeting and was present.

\section{The District Governor}

The Governor explained he was recently transferred from Estalef where he had worked with NSP. He is anxious to introduce it in Kalakan, comparing it favourably with uncoordinated NGO relief projects:

“...it is an organized programme implemented according to a government plan... assistance is bottom up, which is a positive aspect compared

to NGOs who are not consistent and not transparent and frustrate a lot of people... The important point about NSP is transparency and accountability and a good system of reporting - all the community is clear about it. It builds

a good relationship between the government and the community. Besides that the villagers find work and can choose their own projects and work on them."

The Council of Elders

The Governor has convened a council of elders to work with him, drawn from the following existing councils:

$\checkmark$ Local village committees

- The Scholars Council

- The Health Council

- The Education Council.

In the meeting their main spokesmen were a Mullah and a teacher. They also included former commanders.

After giving a similar account of conditions in the district to that given by the Governor and later by the householders, they said they were interested in introducing the NSP programme in the district and would be prepared to cooperate with the CDC. One interviewed in the household survey said he was happy to stand down if a CDC was elected. They were keen to see NSP in the district and said all the right things about solidarity, unity etc. However, the household survey revealed divergent views about their motivation (see below).

\subsection{The household survey}

\subsubsection{The sample}

As in the other communities, representatives of 10 households ( 5 men and 5 women) living in two different areas of the village were interviewed. It was rather more difficult to achieve a representative sample, relying on the clearly unrepresentative council. As a consequence the male sample seems skewed to the more influential and educated members of the community with close association with the council, and all but one described themselves as 'average' in terms of income. Nevertheless both majority Tajik and minority Pashtun were included, and one war disabled excombatant. The women's sample seems more representative and gives a perspective on the disadvantaged (by gender, illiteracy and poverty etc) as well as the better off.

- Average family size: 7. Average number of children below working age: 4 (some families all adults). The majority were husband and wife with children. Two families had 3 generations (widow, and two generations).

- Four 'poor' families; 5 'average'; 1 'rich.'

- Three families had sick adults to support and one householder, a former combatant, said he had mental illness as a consequence of war injury and therefore did not work.

- Eight Tajik and 2 Pashtun families.

Livelihoods included: carpet-weaving (two women and one man) [as contract workers, not small proprietors, see profile above]; drivers (two husbands); labourers (two sons of women householders); two teachers; two government employees; one street trader (son); two shopkeepers (sons). Two husbands and one male head of household were unemployed. However, the majority had been grape farmers as their main source of livelihood (see below, unanimity in citing water for irrigation as the main priority).

\subsubsection{War experience/post-war}

All the families experienced the same destruction of their homes and property, as well as the grape vines and the irrigation systems from which they made a living. Four were displaced internally. One of these became a fighter and took his family everywhere with him. Six were refugees in Pakistan and/or Iran. One of these left before the Taliban took power, but as a result of the fall of the Communists.

They returned at different times after the fall of the Taliban. Those who returned as recognized refugees had received some (often minimal) relief aid/assistance for rebuilding from CARE, ACTED and UNHCR. The former combatant (member of the council) had been through the DDR
THE PRO VIN CIAL FIELD SU RVEY REPO RTS 
process, received assistance from CARE to rebuild his house, and his sons had had skills training. Another IDP member of the council had also been assisted to rebuild his house. One teacher said that these agencies had built 4 schools and two clinics in the district (but not in this village). However, two women IDPs and one returned male refugee said there had been no assistance.

The main improvement in their lives was security/peace (7). Four women said other than that nothing had changed; they were worse off than before the Taliban. Four men said being able to return with some prospect of work was an improvement. The two teachers cited the opening of schools and one man the new government.

\subsubsection{General understanding and awareness}

The difference from the $\mathrm{CDC}$ community was the clear lack of consensus on the issue of governance and the greater marginalization of women and the poor. The lack of transparency/communication led to distrust and accusations of corruption (whether justified or not). Respondents often seemed to be selective in what they admitted to knowing. 'Don't know', in some cases seemed to be a cover for 'don't want to know', or 'not my business to know.'

In other words there was a lack of trust and solidarity in the community, although there were some potential areas of unity such as the general consensus that water for irrigation was their top priority.

There was also little belief in government although many saw some hope in the current political situation. It was clear that if government delivered some benefit they were prepared to change their opinion.

\subsubsection{The community today}

There were different accounts of the current leadership of the community. The 5 men said it was now led by the District Governor and the Council (made up of representatives from the different villages and other committees, see interview above). One also mentioned the Police Chief.

The 5 women clearly saw that the power was exercised by some key individuals, described as: 'Malik', 'Mullah', 'Mosque leaders', 'elders' and 'commanders'. As an elderly widow put it: "Mosque leaders, commanders, and now they call themselves representatives".
There was a similar divergence on the issue of village unity.

- Five men thought the village was united: "By the grace of God, Kalakan is very united".

- Two women were just as adamant in denying any unity: "No there is no unity. If they receive anything they keep it for themselves, not for a poor family to address their problems."

- Three women saw some social solidarity in participating in ceremonies and parties and that "People are feeling comfortable and are united whenever there is an issue", and "in sitting together and feeling security".

Opinions on community decision-making also diverged.

- The 5 men all said the decisions were made by the District Governor with the council of representatives.

- The woman who described herself as 'rich' said: "Our elders take decisions and all the people sit together in the mosque and focus on the problems of the people to find the main problem."

- Two women said there was no representative means of making community decisions and two said they did not know anything about it.

The same divide was evident on the subject of community participation.

$\checkmark$ The 5 men all reckoned they participated in work for the community, both practical (canal cleaning, mosque building), financial (graveyard fund), and three served on the council (social organizing and conflict resolution).

- Three women said there was no community work. One said she was too old. The 'rich' woman said she would be prepared to participate but so far there had been no project.

When asked if the leaders were working with the government, the 5 men said yes; two said they worked closely and one said the Governor is a good man.

- The 'rich' woman said they did 'if there is some problem'.

- Two women said they did but for their own benefit.

$\checkmark$ One said they did but 'we know nothing of it'.

$\checkmark$ An elderly widow said 'How should I know?

Five women and 4 men thought no approaches had been made for funding other than NSP. One council member said 
they had petitioned the President without result.

The men appeared to be less well informed about NSP than the women. Three knew of the name (two from the radio) but claimed they had no idea what it did. One who listened to the radio knew about it but concluded that the Minister was giving all the projects to his home area. One other thought it was for funding infrastructure projects.

- Two women also said they knew nothing about it.

- However 3 had heard of it and understood its basic principles:

* "Yes, we heard that all should be together in unity and recognize the poor."

* "Yes, from the radio - it means unity."

* "Yes, that we will all select our representative and find work and feel secure."

- The 5 women thought a CDC would be welcome in the community. One specifically said the leaders would welcome it.

- Their opinion was also based on knowledge of the impact in neighbouring areas:

* "Yes we would be happy to have CDC/NSP in our community to improve like Shakardara, Estalef and others."

- Three men on the other hand said they did not know. One said any good government programme would be welcome. Only the former commander and council member gave clear support: * "I know that in the CDC all the new council members should be elected. The people and I am ready to dissolve the current council if $\mathrm{CDC}$ is established."

\subsubsection{Perception of national solidarity}

$\checkmark$ No one felt informed about government plans.

- Four women (although two were apparently informed about NSP) claimed that they could not know anything about government plans, either because they had no radio or TV or were illiterate.

$\checkmark$ One woman, who did have a radio said: "Maybe they are trying to have electricity and bring it from Russia and seek support from other countries."

- Three men also simply said they did not know about government plans. One said the government didn't inform people, another said he elected them but did not know their plans.

There was little confidence in the government's interest in the community:

- Three women and two men thought that the government was not interested in the community because it had done nothing so far. One man thought that it was interested but did nothing. One thought it had to be interested because it was elected.

One woman thought the government was interested, but the elders wanted to take all the benefit. Another said perhaps the Governor might know.

- Only one man said the government was clearly interested because it was encouraging international assistance.

\subsubsection{Confidence in the future}

The respondents were unanimous on what would most improve their lives:

- Water for agriculture/ drinking water (5 women, 5 men)

Other needs were:

Work for men and women ( 3 women)

- School, clinic, roads and electricity (each mentioned by one woman)

The women saw some reasons to be hopeful (such as the prospect of NSP) but were cautious in their aspirations:

- "If the government focusses on our community we will be optimistic, otherwise no." (3 women expressed this view)

"Yes we are optimistic to have a school and for our children to become literate." (woman)

- "Yes we are waiting to have a representative and to work for the community and improve our lives." (woman)

The men based their cautious optimism on the improved political situation:

"I think a bright future awaits us. Our people are tired of the war, but God knows better what will be the future."

- "If God is willing, everything will get better, but the government should invest in youth. How long should we ask the world community to help us?"

- "I think we will have a bright future because we have a powerful state now. The NGOs help us and so does the international community. The parliament is being established. We will certainly live a better life after this."
THE PRO VIN CIAL FIELD SU RVEY REPO RTS 


\section{A8 Kundoz Province Provincial Field Research Findings}

1 Margaret Chard (Team Leader) with Marina $\mathrm{N}$ awabi and Jawed $N$ ader.

\section{Timing and scope of research}

The research team worked in Kundoz from 23 October- 8 November with the NSP management teams (DRRD, OC and FP) and in the rural districts of Chadara and Khan Abad.

\section{Persons interviewed}

The Deputy Provincial Director of DRRD

Provincial and District DRRD staff:

$\checkmark$ Social Protection Officer

- Finance and Admin Officer

- Irrigation and Sanitation Officer

- Contracts Officer

- The NSP Provincial OC

- The Provincial Manager of GRSP

GRSP provincial staff:

- Social Organizer

- Site Engineer

- Facilitator

The GRSP Chardara District Manager

GRSP district staff:

$\checkmark$ Social Organizer

- Facilitator

- The CDC in Chogha-e-Sofla Village, Khan Abad District

- Representatives of 7 households in Chogha-e-Sofla

- The CDC in Dour Robat Village Chardara District

$\checkmark$ Representatives of 11 household in Dour Robat

- Chahar Dara Youth Committee in Dour Robat village, Chardara District

$\checkmark$ Elders of Mangal Abad village, Chardara District (no CDC)

- Representatives of 8 households in Mangal Abad

- Representatives of ACTED in Kundoz

\section{MRRD provincial and district programme management}

The Deputy Director of DRRD in Kundoz province was interviewed, followed by a separate interview with operational staff.

\subsection{Kundoz DRRD}

The Department has 41 members of staff in Kunduz (28 permanent and 13 support staff). Like other provincial departments its main operational problems are lack of transport, limited resources and low staff salaries.

The Community-led Development Department was created when the MRRD was created, by expanding the pre-existing Local Development Department, which had only limited capacity.

In addition to the NSP the Department is responsible for other MRRD projects water sanitation, NEPRA, micro-credit and emergency response. Most of these projects are not directly implemented by the MRRD department, whose role seems to be minor and mostly superficial in support of implementing NGOs. It is only through the emergency programme that the MRRD have managed to find access to some resources with which to help affected areas. However, it is limited to distribution of material rather than any intervention to initiate development projects.

\subsection{Experience of community development with the NSP}

Both the Deputy Director and the staff members interviewed broadly concurred 
that the NSP was a good programme and all understood its basic rationale, which is different from the other programmes in that it is supposed to be planned, implemented and controlled by the communities themselves.

However, they were clearly not happy with their level of involvement in it and thought it would have been better if it had been implemented directly by MRRD. In the meantime with the resources they have, the Deputy Director saw the DRRD's role as monitoring and overall observation of the projects and coordination with other ministries at the provincial level.

It was felt that they could not carry out effective monitoring because the $\mathrm{OC}$ and team works directly with the FP, and the rest of the DRRD department do not know what is going on, and thus feel isolated from the NSP. As one respondent stated, 'The OC is responsible to report directly to Kabul and is not very keen to share NSP developments with the rest of the department. Though we had asked for a joint commission to monitor and observe the NSP programme they overruled.' The staff described how they are further constrained by lack of transport and other resources to visit the projects. They all said they had no direct contact with the CDC.

The Deputy Director, who also felt sidelined, said the facilitating partners are not working with full commitment and honesty. In addition the district administrators regularly interrupt the programme and cause delays in the projects.

On the other hand, coordination with other ministries has not presented any problems because the projects are comparatively small, so coordination is relatively straightforward and coordination mechanisms already existed. (A joint commission of the MRRD, Agriculture ministry and Irrigation ministry has been established and deals with emergency response to natural disasters. The head of the commission is the provincial governor of Kundoz. This joint mission also impacts positively on the NSP.)

\subsection{Training and capacity of the DRRD}

The Deputy Director thought that the DRRD had the capacity and resources to carry out its monitoring and coordination role, but direct implementation would require more staff and resources. $\mathrm{H}$ is staff interviewed said they lacked the means to do it and in any case never have anything to do with NSP and do not consider it part of their workload.

The only training the DRRD have received from the NSP was for three employees who have been sent to work with the FP to get on-the-job training. They are supposed to get on-the-job training from the FP for a period of one year and they have already spent more than seven months. The respondent did not think that there had been any corresponding increase in the capacity of the individuals involved.

The other staff said they had received no training or advice from NSP.

\subsection{Constraints due to issues in NSP management}

All agreed that 'there are complaints coming from the communities and we have shared them with the FP but they have failed to follow it up in some places. The FPs are carrying out the project without informing the communities of the role of the government.'

The Deputy Director thought that more coordination with the DRRD, similar to that which they have with the OC, would be one indicator of good performance by the FP.

$\mathrm{H}$ is staff however said that the DRRD have not developed any such indicators and in any case, they had 'little interaction with FPs as the FPs are contracted by the ministry in Kabul and feel no responsibility to report and share the programme with the MRRD at the provincial level. They are doing their own publicity and sometimes ignore the role of the government itself.'

\subsection{The role and impact of NSP}

The Deputy Director thought the NSP has 'to some extent raised the awareness of the people and they have realized the role of the government in the development of their communities.'

In addition he thought the contact between government and communities is inevitably improved when there is more interaction between the different levels of government and the community through the NSP progresses. For example, the issues and problems raised during the implementation of the projects are always referred to the
THE PRO VIN CIAL FIELD SU RVEY REPO RTS 
district government and, if not solved, to the provincial and central government. This process itself leads to more interaction and better understanding and working relations between communities and the different layers of the government. The DRRD staff also thought the contact between government and communities through the CDC is going well, to the extent that they are recognized as legal entities and other ministries are starting to channel programmes through them.

The Deputy Director had noted an increase in refugee repatriation and thought one of the main factors in this could be the existence of NSP projects in their communities.

The NSP was also seen by both Deputy Director and staff to be contributing to national solidarity by bringing different groups together in the communities or simply by creating jobs in the communities.

\subsection{Future of NSP}

Despite the problems the Deputy Director hoped that the CDCs would remain as a permanent institution. He noted that 'Looking to the short history of the project there are visible improvements in the CDCs and we expect more improvements in the future.' He also hoped that it would further bring different groups closer to each other and improve national solidarity. The staff thought it is difficult to assess the future of the CDC. Some people are doubtful that they will continue with the same enthusiasm and strength once the NSP project ends.

\section{The Facilitating Partner: GRSP (Ghazni Rural Support Programme)}

GRSP is an Afghan NGO that undertakes projects in agriculture/animal husbandry, irrigation engineering, veterinary services, women in development, primary health care and sanitation, and technical training programme education. It has been involved with NSP from the beginning.

\subsection{The role of the FP}

GRSP management and district staff described their role as 'facilitating the process' while the community has 'the main role of planning and implementation of the project'. They also raise awareness of the different roles of government and the FP. They then have a support role ensuring that the project is on the right lines 'with the standards and criteria developed for NSP'. They have also gradually built the capacity of the communities and they are confident they now have the skills for project implementation.

It is notable that at no point did any of the staff refer to the setting up of the CDC, the election process or any continuing issues of governance.

The communities were initially sceptical about their intentions as they had had previous experiences of NGO surveys that were never followed up by any action. They had a number of meetings to discuss this with the communities, and also made it clear that GRSP would not remain after a couple of years and the CDCs therefore have to be prepared to take on the responsibilities in the absence of the FP.

They also thought that as a result of their mobilization work the communities now know the different roles of the FP, the OC and the government in the programme.

\subsection{Working relations with the DRRD and OC}

They thought they had good (but obviously limited) relations with the DRRD which, for example, always helps in registering the CDCs with the local authorities and takes part in opening ceremonies. However, there were also misunderstandings. One manager complained that on occasions 'we have problems with the DRRD and that is because whenever there is any problem with the CDCs the DRRD is blaming the FPs without having full information from the village and the CDCs.' Other staff thought that the DRRD, because of its lack of working capacity and functional limitations, is not really part of the process and feels ignored.

In contrast they stressed that the relations with the $O C$ are very good and cooperative. Nevertheless they recognized that DRRD, $O C$ and FP should really work as a team and this is not happening.

\subsection{Capacity of the DRRD}

The Project Manager commented that DRRD have their own financial problems 
that in turn affect their staff capacity. For example, there is no staff capacity-building and financial constraints mean that they cannot employ professional staff. The DRRD has just one car and that is with the director. The rest of the staff are not allowed to use it to travel to the project areas.

One FP project coordinator summed up that, "If we talk about $O C$ as part of the DRRD in Kudoz then one can say that their capacity is good, but without OC the DRRD has similar problems to other government departments.'

The field staff thought DRRD did not have enough information about the NSP or the approach adopted by the FP in the communities, and the DRRD staff complain that the $O C$ and FP do not share information with them and they feel they are not 'part of the game'.

\subsection{Relations between communities and government}

The FP, at the start of every project, allocates about a month to community mobilization to explain the roles of government, FP and $O C$ in the NSP. The MRRD are also invited to ceremonies at the start and finish of the projects.

They all agreed that contact between the local government and the communities has increased for a number of reasons, and NSP has been the main contributor ( 80 per cent of the increase due to NSP). Contact with local administration is also made in cases where the community faces any problem. The district administration has also started to contact CDCs for different purposes. They get a variety of information from the CDCs and had a valuable contribution in the parliamentary elections. There are also cases where the CDCs are contacted to help the government for purposes of district security.

However, the communities are still reluctant to contact the local administration and vice versa. One respondent attributed this to the 'autocratic' nature of the authorities. The field staff described how disaffected traditional leaders, not in the CDC, were continuing to contact the local administrators as community representatives, and on their part 'the district administration still do not recognize the CDCs and have more contact with other community leaders'.
[Both CDC members and householders in $\mathrm{CDC}$ and non-CDC communities were more explicit in their criticism, describing the district administration and some traditional leaders as corrupt.]

\subsection{Training and capacity-building in the communities}

A number of training workshops have been conducted. CDCs have received training about the NSP, peacebuilding, procurement and book-keeping. In addition there have been workshops, focussing on issues of public health and education (respondents did not elaborate on how this was done or how successful it was).

\subsection{Participation}

GRSP maintain that they have achieved participation of all groups including women. Citing examples from one village they said that because they had four projects 'almost all the community members had benefited in one or another way'. They also saw the level of community contributions as evidence of high participation.

However, as discussed above, some community leaders who did not see the NSP programme as very important were aggrieved when they were not democratically elected by their community, and complained to the government.

\subsection{The FP's capability in relation to the programme demands}

GRSP was not working in Kundoz before and had to establish its office and employ staff for the NSP project; all this took time to establish. Forty-five new staff participated in a number of training workshops in Kabul in order to start the programme, and then had to train others in Kundoz.

GRSP management feel that they have the capacity to meet current programme demands. Even though there are a high number of projects to process, the FP Director stated that 'we increase our staff, and our strategy is that the experienced people who had worked in the NSP programme for the last two years work in mixed teams with the newly employed personnel'.

\subsubsection{Staff capacity and training}

GRSP have one engineer, a social organizer and a community facilitator who together
THE PRO VIN CIAL FIELD SU RVEY REPO RTS 
work on a cluster of 8 communities (a low staffing level compared to some other FPs).The manager stated that 'Capacitybuilding is a continuous process and that needs to go on with the project'. GRSP have benefited from a number of workshops such as community mobilization, peacebuilding, procurement and book-keeping, all of which have been useful.

He felt that staff are working reasonably efficiently and there are no immediate skills gaps.

\subsubsection{Future prospects for NSP trained staff} When the NSP programme ends GRSP may look for other projects, but if the government decides to expand the DRRD structure then their personnel, having worked in the NSP, would be a good (human) resource pool.

[See SDF Kabul (another Afghan NGO) view that NSP experience will have equipped their staff for other jobs in national development, i.e NSP is contributing to the wider national HR development.]

\subsection{GRSP district and project management}

The district staff confirmed that they did not see any immediate need for further training, but were ready to participate in any new training plan to enhance the NSP. They said they had been trained in PRA as well as mentioning the workshops mentioned by the general manger. They thought the financial training was the most important because the CDC did not know how to keep accounts, but that all the training was necessary to be able to implement the programme.

\subsubsection{Project relevance}

While the general manager discussed the projects in the first CDC visited, the district staff spoke of the second CDC community.

They both described the decision-making process in the communities in the same terms: that there were some acute needs that were quickly agreed on (flood protection walls, clean water etc.) and then other needs in the development plan were discussed if money remained (for example a tailoring course for women). In one case a significant minority wanted an electricity project that did not meet the eligibility criteria. On the issue of inclusiveness, in the first case everyone benefited from at least one of the projects, and according to one FP manager more than 80 per cent of the villagers will gain improvement in their livelihood. In the second community everyone in the village will have access to clean drinking water. This will lead to improved health that may also have an impact on livelihoods.

The engineering staff also claimed that their infrastructure designs were relevant because they adapted plans from the engineering department of MRRD to suit specific needs of the community and available resources, resubmitting the altered plans for approval through the OC.

\subsubsection{Sustainability}

GRSP aim to ensure sustainability in a number of ways: from the beginning the community is made aware that they will be responsible for the project; the communities in turn promise that they will try to make some savings for the maintenance of the project, though some of these promises are slightly optimistic.

Many of the projects are fairly simple from a technical viewpoint, and little consideration is given to safety considerations. However, they do take account of any necessary mitigating measures when this is necessary. For example, in the case of the flood protection walls they had tried to make it strong enough to avoid any risk of collapsing.

The Site Engineer and Technical Supervisor then frequently monitor the projects to ensure that the quality is controlled. The quality and the type of the material is specified by the technical staff of the FP and written in the proposal. A procurement committee of three members of the CDC makes the purchases.

However, the Engineer warned that the NSP were 'using the technical standard that existed before in other ministries, and our technical staff are not very sure about technical standards and do not have any idea about NSP technical standards other than their origin in the ministry'. Nevertheless all FP staff felt that in accordance with the engineering plan the facilities should still be functioning in 10 years time.

\subsubsection{Efficiency}

The efficiency of the NSP is maintained because the communities themselves chose 
the project and so have a vested interest in ensuring its smooth completion and operation. Thus the project, as well as being monitored by the $\mathrm{OC}$ and $\mathrm{FP}$, is monitored by the $C D C$ monitoring committee that looks after the implementation of the project.

In the case of Chogha-e-Sofla, it took two months from the identification to the start of the project, and about 7 months from the start to the completion of the project. The remaining Block Grant will be spent on a course to train women in sewing, and a water intake. Although in this instance the delay between proposal submission and the receipt of the money was relatively small, GRSP maintains that delays affect their ability to implement the NSP and often entail GRSP being blamed for NSP problems. They also stated that the delays have increased in number and severity.

\section{Facilitating Partner ACTED}

The research team held a brief meeting with representatives of ACTED, which is also an FP in Kundoz for the NSP. The discussion was focussed on general issues as there was no opportunity to visit any communities facilitated by this FP.

\subsection{The role of the FP}

The representatives thought that their role is to cooperate with the CDC in prioritizing their needs and implementing the project; that is, their role is to facilitate the process.

They found that the CDC, as they gained the capacity to act independently, were likely to perceive the FP as a facilitator. The weaker CDC think that the FP should stay on in some managerial role in the projects.

They had made an effort from the beginning to explain the different roles of government and FP and reiterate it in monthly discussions, but say they can still find people who cannot grasp it. They blamed the people's illiteracy for this.

\subsection{Working relations with the DRRD and OC}

They said they had very good relations with the DRRD and have weekly meetings with them to discuss 'all the issues and problems to be tackled'.
Similarly, working relations with the OC were described as 'very good'.

\subsection{Capacity of the DRRD}

However, they thought the capacity of the DRRD was 'not very satisfactory'. In terms of being able to run the NSP they still have a long way to go. They thought that a lot more effort and resources should be directed at building DRRD capacity.

\subsection{Relations between communities and government}

Contact between the communities and the government had increased significantly and most of the contact was thought to be due to the NSP, which raises issues that the local administration has to get involved in. The local administration is also asked to participate in opening and closing ceremonies.

\subsection{Training and capacity-building in the communities}

Their training in the communities covered: general information about NSP, procurement, book-keeping, prioritizing needs. They were all necessary for the project implementation and they felt successful, particularly the procurement and bookkeeping.

They had not had any particular difficulty in ensuring the participation of vulnerable groups in the activities.

\subsection{The FP's capability in relation to the programme demands}

They had had to increase both the numbers of staff and their professional capacity to take on the NSP. In fact capacity-building has to be a continuous process to update staff on changes in the programme.

\subsection{Staff capacity and training}

They did not however think they had any skills shortfalls that could affect the effectiveness of their work. The staff had been trained in community mobilization, procurement, book-keeping and general information about the NSP as well as PRA. They considered all of these useful and necessary for the implementation of the programme.
THE PRO VIN CIAL FIELD SU RVEY REPO RTS 


\section{The 0 versight Consultant}

\subsection{General comments on the strengths and weaknesses of the NSP}

The $O C$ was very positive in his assessment of the relevance and general impact of the NSP: 'After a long war in the country, Afghanistan needed to have such a programme as NSP. Without such a programme it would have been difficult to reach the remote areas of the country. NSP has managed to raise the awareness of the people and improve their livelihood.'

However he did see that there were problems with the implementation of the projects due to two factors. The communities have no previous experience of such projects and cannot implement them without facilitation. On the other hand the FP has been overloaded by working in an increased number of districts and this has reduced their capacity to work effectively. [Note the FP said they were able to meet current demands.]

The OC did not otherwise see any constraints in the programme itself. Contrary to what is thought (i.e. by the FP), the money is transferred on time and he was not aware of delays.

\subsection{The role of the $\mathrm{OC}$}

The OC described his role as, 'managing and transferring money, checking the proposals'. He also monitors the projects and the programme to ensure it complies with the objective of the NSP, and gives advice and technical assistance to the FPs.

[Until prompted by the next question he did not mention the DRRD]

\subsubsection{Capacity-building}

When asked he described the management capacity of the DRRD as 'satisfactory' but said it still needs the support of expatriates. They might survive without it but would have problems.

When asked what steps had been taken to use the programme to develop institutional and staff capacities he said FPS, DRRD and OC staff had participated in a number of workshops. He agreed that there was a learning process for those involved in the NSP, but specifically for the functioning of the programme.
[Note: he clearly had no real understanding of capacity-building and did not see it as part of his role. Interviews by other researchers with the central HR department indicate that this is consistent with top $O C$ management policy. They define DRRD capacity-building in terms of formal training sessions and regard capacity-building of the $\mathrm{CDC}$ as the main priority.]

Not surprisingly he said categorically that handing over the programme to the DRRD to be run by the two existing NSP staff would not work. It could work if the existing OC management structure was transferred to the MRRD, but there would still be initial problems unless this included the expatriates currently working in NSP.

\subsubsection{Supervision}

The OC said it is his responsibility to make sure that resources are delivered to the communities. Immediately after the money is sent to the bank, the $\mathrm{OC}$ in Kabul informs the provincial OC who then informs the FP, who in turn informs the CDCs and trains them in withdrawing and spending the money. The $\mathrm{OC}$ himself visits about 10 per cent of all the projects to check if the money is spent before authorizing the next instalments.

He claimed that 60 per cent of the projects comply with the eligibility criteria. People have been educated about the criteria of the NSP programme but, as he said, 'You can always find influential people in the villages to modify the project according to their own interests.' As a result, despite negotiation, in a very few cases they cannot convince the communities and so end up submitting a proposal for a project which does not completely fulfil the criteria.

The OC maintains that the time between proposal submission and Block Grant disbursement is dependent upon on how well the CDC have prepared the proposals and other documents. 'It may take about 20 days if there is no need to rework the documents, otherwise it can take a month or a bit more.' The OC also have a team to check the designs in the region and have a unit in Kabul that checks the designs. 


\section{The CDC's}

\subsection{Overview of the communities and their CDC}

General community profile

Chogha-e-Sofla is in Khan Abad District, bordering Takhar province. The CDC leaders explained that it is a mixed community of Pashtoon (70 per cent) Usbek (20 per cent) and Tajik (10 per cent) families, totalling 362 . The community is composed of 3 villages and the population was given as 2147 . They said that there are 53 widows and 16 disabled persons in the community.

They estimated that 80 per cent of the population could be classed as 'poor', 15 per cent as 'middle income' and 5 per cent as 'rich'. (As elsewhere this is a relative rather than objective assessment.) However, the main sources of livelihood are agriculture, small shops and animal husbandry, typical of a predominantly poor rural community.

The CDC has 15 elected members, two of whom are women. (The researchers interviewed the CDC office holders [all men], not the whole council, and had no contact with the women members.)

Apart from the $C D C$ there are two influential residents: a commander on the border with Tajikistan and the chief of the police in Khan Abad District. The community was near to completing its first project, a flood protection wall.

Dour Robat is in Chardara district. The CDC leaders said it is a mixed community of Pashtoon (70 per cent) and Tajik (30 per cent) families, totalling 263. (One householder interviewed also mentioned Turks, and several said that the community consisted of 3 villages.) Thirteen families were said to be displaced, and 6 returned. The population figure given was 1628 , including 26 widows and 17 disabled. The number of children given (111) was clearly not accurate, or misrecorded. They said 60 per cent of the villagers earned a livelihood from agriculture, 20 per cent had fixed employment and 10 per cent depended on day wages. As this livelihood pattern indicates, this is a rural community on the periphery of the urban area.

This community had both a men's and a women's CDC. They said that 65 per cent of men participated in their election but 100 per cent of women participated in theirs.
The men's CDC, whose office holders were interviewed, has 10 members.

They had been recently established and had not yet started on the tube well project they had agreed on.

\subsection{Legitimacy and acceptance of the CDC}

In Chogha-e-Sofla the CDC leaders (the four office holders) said that the CDC is now the sole governing body in the community, which deals with all issues relating to the community.

Before, village issues were resolved by the elders of that particular village in an uncoordinated way, but now disputes and even quite small issues are referred to the CDC, and in fact the elders of the three villages are now working together in the CDC (alongside other elected members).

In Dour Robat the leaders of the CDC described a transitional situation. Until recently the community was led by the Arbabs, but there was no village-level council. After the [NSP] conference in Kabul, responsibilities were gradually being transferred to the $\mathrm{CDC}$, and the central government had given guidance to the district administration to deal with the community through the CDC. However, problems persist: 'Some people try to exert their influence but we hope things will change gradually.'

Apart from the village Arbabs there are district level tribal councils, which have met customarily to resolve conflicts between tribes, when these arise. Since the setting up of the CDC no such problem has arisen so they have not met. However, the CDC leaders did not see how the CDC would replace them as they have a wider responsibility than the village and command much stronger allegiance than the newly formed CDC.

As regards the governance in the village, the respondents said that there is a lot of optimism that the $C D C$ will change the situation but they had not yet done anything (tangible). They were eager to get started on the practical work to improve conditions in the community before considering the social aspects of the $C D C$.
THE PRO VIN CIAL FIELD SU RVEY REPO RTS 


\subsection{Functioning of the CDC in relation to the whole community}

General

In Chogha-e-Sofla the CDC leaders described how their mixed $C D C$ functions. The members of the CDC meet on Fridays, once a week or fortnightly. The respondents said that all 15 members are active, but it is difficult to bring them all together for the CDC meetings, as they may be out of the village.

The two women members bring up issues relating to women, but women in the community 'cannot participate' (for cultural reasons) in the CDC meetings, but can meet individual members of the CDC who are elders or relatives of the women CDC members, to raise their problems.

Minor problems in the separate villages are dealt with by their representatives, but some issues are referred to the full CDC for resolution.

The CDC had recorded all its financial transactions and kept one file for documents relating to the project and a second file of documents recording other issues, such as mutual agreements between parties to a dispute resolved by the CDC. However, they did not keep minutes of their meetings.

The community as a whole (most participated) had spent 10 days prioritizing their needs and making project plans. Agreement was reached by consensus.

In Dour Robat the functioning of the CDC is still being consolidated. (Only the men's CDC was interviewed and no information was given on the women's activities.) The 10 elected members were all said to be active. They were keeping minutes of their meetings but as they had not started the project had no financial records.

They felt the CDC was going well as they had completed the project plan and submitted the proposal. The process had not been without difficulty. After listing the needs identified by the villagers, it had been relatively easy to agree, in a general meeting with the FP present, on providing clean drinking water for the whole community. Then another NGO constructed some tube wells and the villagers realized that they would need less money for the NSP scheme, and some wanted to change the project to link the village to the electricity grid. This type of scheme does not in fact meet the eligibility criteria, though independent generation schemes do, but the villagers did not understand the difference. However, as they said, 'through discussions we convinced those who had different opinions.' They rightly saw this process as a successful exercise.

Project implementation

In Chogha-e-Sofla the CDC said they had provided all the resources for the project: labour, materials and 10 per cent of the cost. They had recruited labour from the whole community to give everyone a chance to earn daily wages and had only had to hire one skilled worker from outside. They did not have any significant difficulties in agreeing on the implementation. The CDC were monitoring the work jointly with the FP. The head of the CDC was almost constantly on the site and other members came from time to time. The maintenance of the wall is to be funded by community contributions to a special account.

The general, and hopefully long-term, benefit will be to save the village from seasonal floods and the damage they cause; that is why it was the first priority of the community. Irrigation channels and the tailoring course (for women) to be implemented with the rest of the money will also have wide benefits in the community.

In addition to the NSP the $\mathrm{CDC}$ has approached some NGOs and government departments to fund projects, so far without success. However, the CDC will be facilitating a Ministry of Agriculture loan scheme for seed and fertilizer to farmers.They had made these contacts in response to requests from the community.

\subsection{Relationship between the CDC and government}

In Chogha-e-Sofla (Khan Abad District) they said communication with government (clearly thinking in terms of local government) had not been encouraging so far. They described the relationship as 'not very bad' and hoped the Kabul conference might make a difference. They also thought other ministries should recognize the CDC. However, they thought the relationship would only really improve if the government recognizes (i.e. officially) the CDC as community representatives.

In Dour Robat (Chardara District) the CDC 
leaders were very circumspect in their answers about government. They had had two meetings with the district administration asking them to contact the CDC about community issues, but apparently the district authorities prefer to deal with other influential figures in the village. The researchers concluded that the $C D C$ is very reluctant to have any close relationship with district government. There seems to be 'a huge lack of trust between the CDC and the district administration'. The CDC themselves said that 'transparency should be encouraged on both sides to improve the partnership'.

[The householders interviewed were more explicit, accusing the district officials of corruption and demanding bribes. Householders in the matched non-CDC community (Mangal Abad) in the same district, also spoke of local government corruption.]

\subsection{Relationship between the CDC and the FP}

In Chogha-e-Sofla the CDC leaders stressed that the FP had guided them in the initial stages and is now assessing their documentation but that it was the community that had implemented the project. They said the FP had given training in procurement, record keeping and general information about NSP. Each course was for one day. When asked what other support the FP had given they said, 'Not very much.' The researchers commented that the duration of training seems very limited. [They also did not (like other CDC) talk of the FP as being available to give advice. The FP staffing levels may have something to do with this. See FP Capacity above.]

They did not know about the complaints procedure but had in any case had no problems with the project.

In Dour Robat they thought the FP had played an important role in raising awareness in the community and overcoming people's scepticism about the NSP. They too had had the one day training sessions and 'nothing more', but thought it was both 'necessary and useful'. They did not know about the complaints procedure. As their project had not started they could not add any more.

\subsection{Capacity of the CDC}

Able to continue without facilitation Assessing the CDC on the basis of the above criteria, which are in turn based on the CDC profile indicated in the Operational Manual, we can conclude that the more established CDC in Chogha-e-Sofla will probably be able to continue without facilitation after the completion of its outstanding projects, notwithstanding some continuing deficits. The CDC had established its leadership of the community, though still lacking full recognition from local government. It showed transparency and inclusiveness in its dealings with the community, including developing mechanisms for including women, within the prevailing cultural constraints. It was able to keep accurate and transparent records of its financial dealings and of the arbitration of disputes. It seemed to be successfully managing its project and was actively pursuing new ventures and taking on other responsibilities consistent with its status as 'sole representative' of the community.

Able to continue only with difficulty without facilitation

Dour Robat CDC was clearly at an early stage of development, but had made considerable gains in governance. It appeared to be negotiating a successful transition from Arbab rule to representative leadership through the CDC and was successfully uniting the different groups in the community. (A women's shura had apparently been established but it was not possible for the all male research team to evaluate it.) The CDC had conducted the project selection in a participatory and transparent way and seemed to have the basic skills to keep written records. However, they had yet to prove themselves in financial and project management, and had a very difficult relationship with local government. On this basis we can conclude that it would have great difficulty in continuing unless it continues to receive adequate support through the project implementation phase, and in its relations with local government.

\section{Community without a CDC}

General community profile

Mangal Abad in Chardara District matches the Dour Robat community in terms of size and location in the same district and similar
THE PRO VIN CIAL FIELD SU RVEY REPO RTS 
sources of livelihood. However, Mangal Abad is a distinctive community in two respects: it is made up entirely of returned Pashtun refugees, all of whom belong to a few extended families who mostly kept together in exile in Pakistan; their village is a new settlement recently registered with the district administration, apparently with a view to joining the NSP. The villagers seem to be more united than other communities because they all belong to one tribe and have lived together as refugees. Decisions in the community are therefore made by a number of elders representing the different families connected by blood ties.

Seven community leaders were interviewed and gave the following profile of their community.

The total population was estimated at 2000 (the researchers felt this was inflated with a view to attracting more funding), but the number of children was put at 300 (at the same ratio of children to adults as in the households interviewed, that would suggest a much smaller population, of less than 1000). Probably both figures are inaccurate. There were said to be 10 widows and 15 disabled persons (as in other communities, it is not clear how they counted these). They said the main source of livelihood was from wage labour (estimated at 65 per cent) and the rest was earned from farming.

\subsection{Existing governance}

There is no formal community government. Normally the elders, representing the different family groups in the community, meet to resolve issues as they arise, but not otherwise.

The community has returned recently and the elders have been making approaches individually to government offices and NGOs to get assistance, but without success. They have not even, as they were led to expect, received assistance from the international community with resettlement, especially in rebuilding their houses.

\subsection{Relationship between the community leaders and the government}

We do not have much communication with government because we do not expect them to be supportive.
Their negative attitude to government was due on the one hand to the same problems of corruption noted by the Dour Robat residents and, the researchers suggest, a common mindset of war-affected people to expect more from aid agencies than government. As a result they mostly try to resolve problems themselves within the village.

However, they were very eager to be included in the NSP and set up a CDC because they perceived it as a way of ensuring project implementation without corruption. [Probably, like several of the householders, they were very well informed about NSP and had actively found out about it.]

\section{Household Survey}

\subsection{Chogha-e-Sofla, Khan Abad District Community with an established CDC}

\section{Summary of results}

\subsubsection{The sample}

Seven representatives of households (all men) were interviewed. Compared to the profile of the community given by the CDC, the sample is reasonably representative in most respects.

The householders, like the majority of the village, make their living from agriculture ( 7 , including one landless family of agricultural labourers). Two also kept livestock. All but one family considered their economic status as 'middle' or average for this generally poor community. The one poor family was also the smallest family: a man and wife with 3 children, including one with mental illness. The average family size was 10 with an average of 6 children, so that most had more than two adults working or assisting with childcare. This may account for their perception of 'middle' income status. However two of these also had disabled adult dependents.

Five of the 7 respondents were Pashtun (70 per cent as in the community as a whole) and two Uzbeck (20 per cent in the general population). No Tajiks (only 10 per cent in the general population) were interviewed.

There are three village clusters in the CDC, but it is not clear if the researchers sampled in all three. 


\subsubsection{War experience/post-war}

The village was in the front line of the fighting between the Taliban and Northern Alliance (mentioned by 3). One respondent's brother with his wife and children were killed, another's father was also killed. Six of the 7 fled the fighting and were displaced for several years. One had his house destroyed by a bomb, another's was looted. Another lost his livestock.

All agreed that things were getting better. There is greater security (2) but on the other hand, though they can work they get very low returns on their agricultural produce (2). One, the only one who considered himself poor, thought that things were improving because there is development in the country.

\subsubsection{General understanding and awareness}

The respondents described the $C D C$ as a village council, council of elders, representative body or NSP council, and most said its purpose was implementing development projects for the community. While they did, when asked, recognize the social value of uniting the three villages in one $C D C$, they did not seem to fully appreciate its significance for governance, especially in representation to government and outside agencies. Most also took little interest in the working of the CDC once they had elected it, and so long as it ran the project efficiently and fairly.

The majority also did not fully understand how the programme came to be set up or who runs it. They did not associate the DRRD with central government or clearly understand that the NSP is a government programme. They also had little or no knowledge of any other government plans. They therefore had little feeling of national solidarity.

On this evidence, it seems that the project implementation and creation of the CDC as a project management body was successful. However, although there were clearly gains in community governance as a result of uniting the villages and their respective elders, the governance and particularly the national solidarity objectives have been less successfully realized.

\subsubsection{The history of the CDC}

The respondents assessed the time the CDC had been functioning as one year (2) or more than a year (2) or two years (3), probably depending on what they consid- ered the starting point (the first contacts or the election).

They had all voted in the election but two, for example, had no knowledge of the electoral commission. The others were aware of one or more outside agencies being involved in setting it up. One simply said 'people from outside' organized it. Another said it was organized by people from Kundoz and village representatives. Another said it was the FP with other people, he wasn't sure who, but it was a free election. The FP with village elders, and the MRRD with village elders, were mentioned by the other two.

Rather than describing how decisions were made in the past, the respondents all described in detail the NSP process of listing and prioritizing needs to make a decision on the project to implement. It is clear from this that they and the whole community were actively involved in this process. One described in detail the disagreement with a minority who wanted a road but were outvoted by the majority.

\subsubsection{The CDC today}

Functioning of the shura

The majority of the respondents did not seem to be following the meetings of the $C D C$ very closely. Two did not know when they meet. One took an interest when they were implementing the project but now does not know. One guessed monthly, another thought fortnightly. A CDC member said it was weekly or every ten days, often after Friday prayers. Only one other respondent knew this.

However, they all thought it was working well. Two mentioned that it consulted and informed the villagers/worked as they wanted. One was unsure if it would continue to function well (be able to get funding) in the future.

They all saw the $C D C$ as leading the community but three also referred to elders either in the CDC or cooperating with it. One said the head of the $C D C$, due to his education and family background, was the leader, with the support of the other CDC members.

(The researchers noted that within the $C D C$, the group of office holders were the most influential and well informed. Ordinary members, such as the one inter-
THE PRO VIN CIAL FIELD SU RVEY REPO RTS 
viewed in the survey, did not fully understand all that was going on.)

The CDC member and one other said the CDC had good relations with the district government and that it also contacted them from time to time. The others all said they didn't know, but either supposed they might or thought they should.

\section{Projects/priorities}

Having clearly participated in the selection of the project after lengthy discussions, all the informants except one said they had participated in the project. Participation for some was in the form of paid labour (the researchers noted they were overwhelmed at receiving a daily wage and by the pay they received). Two others, presumably better off than the rest, paid their share of the 10 per cent community contribution to the project costs but did not work. One of these was a member of the CDC and said he participated that way. One worked as paid labour and paid the 10 per cent.

The general view was that there were few problems in getting almost everyone in the community to participate, in particular all those who needed paid work had the chance to participate. Reasons suggested for not participating were: illiteracy, lack of time and that some objected to paying the 10 per cent. One respondent discussing this said the CDC had made every effort to include everyone. The CDC member noted that participation was good in one village cluster, but the other two had problems with participation.

The respondents were unclear about any future plans of the $C D C$, including the $C D C$ member. He was certain they had not approached any other organizations; the others did not know. However, two supposed that since other projects, a water intake and a tailoring project for women, had been discussed, these might be implemented with the money remaining in the NSP fund.

The researchers realized from the responses of the informants (including the $\mathrm{CDC}$ member) that they were not clear that the programme was initiated by government. They knew that it was initiated by 'Rural Development' (in one case that 'Rural Development' got the money from World Bank) but they did not associate it with the national ministry or government. One respondent said it was NSP, also without understanding that the programme was a government initiative rather then an NGO. Two respondents simply didn't know, one because he was 'too poor and too busy' to know.

Financial management

Four respondents, including the $C D C$ member, said the finances were managed by the CDC, specifically the Treasurer, who then informed the villagers and posted information in the Mosque.

The two respondents who did not know where the money came from but were simply glad to be working, also showed little interest in knowing how the CDC managed the money. One respondent was able to describe the financial arrangements in full. As regards the use of the Block Grant, all except the two that showed no interest in the finances were certain that it had been spent as decided on the project. Two were aware that money was left to be spent on other projects.

\subsubsection{Impact of NSP/CDC}

For 5 of the respondents the $C D C$ is seen as a community council for implementing projects. Two, including the CDC member, emphasized its role in governance and increased social unity. 'It is a body that has united three villages.'

All the respondents mentioned the unification of the villages in one CDC as an improvement resulting from the NSP programme (1) or in answer to the direct question about village unity (7). One suggested there was still more to do in this respect (see comment on participation above).

Four referred to the completed floodwall project as a general benefit but most, thinking of their own lives (especially their economic conditions), thought it had not had much impact on their lives. 'The NSP has just built the wall but it has not changed my personal situation.' As another said, 'it is still new.'

Five respondents said that the improved security and freedom of movement was the main other factor that had improved their lives. The other two could not think of anything else.

\subsubsection{Perceptions of national solidarity}

The impact of the programme in the village does not seem to have increased the 
villagers' awareness of government. Six of the 7 said they did not know anything about government plans. One said it was because he is illiterate, another because he is poor and too busy.

This is probably why most were not confident that government had much interest in their community, using phrases like 'I hope it is. We receive promises but little is done' (1); 'It seems to be' (2). They probably also held this view because, as the researchers realized, they are unsure if the NSP is a government programme.

One of the respondents clearly did understand that the government is responsible for the community development, unlike previous regimes, and so was confident that it is interested in the community.

Another, who appears from his answers to be generally better informed, knew of government schemes for road building and electricity generation as well as some projects in Kundoz. He therefore also thought the government is interested in his community.

\subsubsection{Confidence in the future}

When asked what would most improve their lives, most thought in terms of assistance to farming to improve their livelihoods. Four mentioned seed and fertilizer distribution by government to farmers (it seems they had heard rumours that this might happen), and one mentioned the water intake for irrigation, which was the second priority infrastructure project. Two others thought in terms of province-wide development: 'If the government reconstructs the Khan Abad electricity project it will create jobs and produce enough energy for the whole province.' One offered no ideas.

All the respondents expressed cautious optimism for the future, most because they could see some positive changes and they expected this gradual improvement to continue. One said the increased freedom and security alone made one feel more optimistic.

\subsection{Dour Robat, Chardara District Community with a recently established CDC}

\section{Summary of results}

\subsubsection{The sample}

Eight household representatives, selected from the general population ( 7 men and one woman, possibly a widow?) were interviewed. Three other householders (men) were contacted through the Youth Committee. The sample appears to provide a reasonable cross-section of the community when compared to the profile given by the CDC.

Households had from 8 to 15 members (average 11). Only two were nuclear, each consisting of a couple with six children. The rest of the households had several adults and often more than one generation living together. This means that in all but one case, where both the interviewee and his wife were war disabled, the households had more than just two adults to support and run the household. However some of these were also supporting disabled or sick adults: one family has a man and a woman physically injured in the war; in another a young woman was mentally disabled in the war and the widows of two sons killed in the war live in the same family; in two others a sick adult is supported. (The CDC profile listed 17 disabled and 26 widows in 263 families, so they are either over-represented in the sample or under-recorded.)

In two households all the working adults were farmers. One of these also had livestock and consider themselves 'rich' compared to their neighbours. Two others supplemented income from farming with wage labour and a shop. Several households had no dependence on agriculture. One was supported by salaried income from government employment and teaching, another by a doctor whose son had worked as a labourer but was unemployed. In a third the husband ran a market shop and worked as a night guard. All these considered themselves of 'middle' income.

Four households depended on daily wage labour. Two of these described themselves as 'very poor'. In one case, where the informant worked as a school guard while his son worked as a labourer, he described the family as 'poor'. The fourth family with 4 able adults was described as a 'middle' family.
THE PRO VIN CIAL

FIELD SU RVEY REPO RTS 
In terms of income the sample is therefore broadly representative ( 7 average households, 3 poor and one rich). The three main types of livelihood mentioned by the CDC in this rural community close to the urban area (agriculture 60 per cent, salaried 20 per cent and waged 10 per cent work) are also represented (though not in the proportions suggested by the CDC).

All those from the general population sample were ethnic Pashtun. The three others' ethnicity was not recorded. (The community profile given by the $C D C$ recorded 70 per cent Pashtun, 30 per cent Tajik. Turks were also mentioned by one householder.)

\subsubsection{War experience/post-war}

The village was subjected to attacks and bombardments from Soviet forces and villagers were then also under the control of local warlords. Five of the respondents had a number of family members killed in the Soviet attacks. Three had injured family members, including a man who was himself disabled. Their property was also attacked: 6 had their houses destroyed, one his shop as well. Three were looted. These incidents happened more than once: 3 times for two householders and twice for another two. Not surprisingly most abandoned their homes at some time: 5 within the country, and two for several years as refugees in Pakistan. In addition to the attacks from the Soviet forces, three mentioned being compelled to join or pay for the militias led by local warlords against the invaders.

All agreed that things were to some extent better since the war ended. The security, or at least the absence of war, was the main improvement cited (7) as well as freedom from fear and bullying by warlords (4). For some this meant they can now work or resume their lives (3). One had built a small house; another could now live in his own home and not pay rent, as in Pakistan. However, none of these thought their economic conditions were satisfactory. Two thought things were generally improving, and one of these spoke of the reconstruction of roads and other infrastructure as a sign of this.

8.2.3 General understanding and awareness The majority of householders understood the function of the CDC as a representative development council and were aware of its activities and function. However, only a minority recognized its role in promoting community governance and solidarity. The general perception was of its role in implementing community projects.

The political leadership of the $C D C$ was also not assured. A number of householders still regarded the traditional leaders as those who head the community, particularly in dealing with government.

They were aware of the process of project selection even if they had not participated and approved the choice. They also knew that the Block Grant for the project had not yet been received, but for that reason had no knowledge of how the finances were to be managed. However, most did not clearly understand that the money was distributed through a government programme, partly because they did not associate the DRRD with government or understand the role of the FP.

In fact they had little knowledge of government programmes in general and, as a result, little belief in it. In this regard the programme had yet to have any impact for national solidarity in this community. Only a few believed the government is interested in them. This negative perception was strongly influenced by the corruption and incompetence they had experienced in their contact with the district government, as well as their lack of knowledge of national government.

On the other hand, the majority did recognize the $\mathrm{CDC}$ as contributing to community unity and solidarity.

\subsubsection{The history of the CDC}

Apart from one respondent, who said no one had ever explained the CDC to him, the respondents all understood that the $C D C$ was a village council that works for and is accountable to them. Most thought its main purpose was to implement projects. One appeared to see it as a project management committee and said there might be 'other $\mathrm{CDC}^{\prime}$ to implement other projects. Three others clearly understood its role as a development council for the general recovery of the community. Three also saw that it has a role in 'bringing people together', promoting unity by including Pashtun, Tajiks and Turks, and by not allowing fighting.

Apart from the respondent who said he was not informed and had not been asked to vote, they were all aware that the CDC had 
been set up in the last six months. Two had not been in the village at the time of the election but one of these said his father had voted. The other 9 had all voted, including the woman respondent, and one said all his family had voted. However they had less understanding of how the election was run. One knew that there were 3 members of the commission from the FP and three village representatives. Two others were aware of the FP representatives, and one that there were outside observers. The others clearly did not know, and one said he had not seen, what was done.

As regards the previous governance of the village most (9) spoke of either 'village elders' or a tribal council, but made it clear that there was no process of identifying priorities. One suggested this did not happen because they had no resources to do anything. Others described the council as dealing with 'issues' and resolving conflicts, and one suggested that everything had to be referred to the governor, which took a lot of time. The woman said, "We had a traditional community council which was responsible for decision-making at the community level, but definitely it was not as organized as the NSP one."

One respondent replied to this question by describing the NSP process: how the community identified their needs and then decided in a general meeting on the priorities.

\subsubsection{The CDC today}

Functioning of the shura

Since the CDC has not long been established and is not yet implementing a project, the respondents mostly reserved judgement on its performance. Two said they didn't know how it works. The head of the CDC member said it was too soon to judge. Six seemed to think it is going well now and trusted it so far, but were waiting to see how it handled the project. One described the apparently successful process of choosing the project with the whole community.

It seems that the $C D C$ meets frequently but not necessarily to a fixed timetable. One said the CDC meets once or twice a month, and the majority of the respondents were aware that the meetings took place with this kind of frequency. Four however said they did not know when it meets, one stating that the members didn't normally inform the public.
It is clear from the responses to the question, 'Who leads the community?' that the authority of the CDC is not fully established. Three respondents named two brothers as Arbabs, while two other respondents mentioned other names, one as Arbab and as the other as leader of the Pashtun community, stressing that they are not CDC members. Two cited the head of the CCD, one because of his role as CDC head but also because he is the director of the high school. Two described what is probably the real situation: the $\mathrm{CDC}$ leads the community, but there are also influential figures outside the $C D C$, who are the traditional leaders. Two other respondents were quite reticent about answering this question. They avoided admitting the role of the elders, without naming the CDC head as the overall leader of the village.

However, two of those who did not acknowledge the CDC's overall authority nevertheless saw that it is 'working for the unity and welfare' of the people in the community. It seems that the traditional leaders were still the ones who work with the district government while the CDC and its supporters think it should be doing so, but are not sure how. (Several later described the district government as corrupt, see below.) It is clear from later responses that none of the respondents was hostile to the idea of the CDC, though still waiting to see how it might work out in practice.

Their understanding of the origin of the NSP was still very vague. Two respondents did not know the source of the funding, supposing it might be an NGO. Two said NSP started the programme, but had no idea what NSP is. Two were adamant that whoever started it, it could not be government because, as one said, in that case the money would have been given to warlords or district administration. He believed therefore that the fund was given by foreign governments to the CDC. Another thought GRSP had started it with money from Kabul (source unknown).

Two did actually associate it with government: one simply named the MRRD as responsible; the other said it was a government programme with an NGO implementing partner.

\section{Projects/priorities}

Since the Block Grant had not yet been received, project implementation had not
THE PRO VIN CIAL FIELD SU RVEY REPO RTS 
started. However, no one seems to have been dissatisfied with the way the project was chosen or with the decision made. Those that commented said people had participated in the CDC so far, and expected that they and others would participate in the project.

Two said they had applied to various NGOs before to get funding, without result. One said the elders had got one NGO to dig a well. Obviously, it was too soon for the CDC to be planning further projects.

\section{Financial management}

Since the money had not yet been received, they could not say how it was managed, though one knew a treasurer had been chosen by the CDC. Another said: 'We have many illiterate people in the community and would ask the CDC to give time and verbally explain how the grant is spent, and give a chance to the poor people to work and get daily labour.'

\subsubsection{Impact of NSP/CDC}

All the respondents, including those who still acknowledged the traditional leadership, had a positive perception of the CDC. For one its purpose was simply to implement projects, but most understood that it is a new form of governance: 'something good...different from what we had before'; 'to work for the people'; 'to consult the poor and help them'; 'our own council that hopefully will work for us'. Five respondents saw its main purpose as promoting 'unity and love' at the village level and removing antagonisms between 'nations' in Afghanistan as a whole.

When asked further about the impact on community unity, all agreed that it was improving. Three villages, and three ethnic groups (Pashtun, Tajik and Turks) were united in the $C D C$, and the $C D C$ was mediating disputes. The influence of warlords had been diminished. One estimated that '70-80 per cent of the racial, tribal and language biases' had been removed. Others were more cautious in their claims, saying it 'seems' better than before or that the grudges would take time to be completely removed.

Most thought it was too soon to see any other changes, but one claimed that one result had been large numbers of women enrolling in school, and a general impact in promoting education in the area. One specifically mentioned the fact that they had an elected and accountable council as an important benefit.

\subsubsection{Perceptions of national solidarity}

The villagers had almost no knowledge of any national plans of government. Eight said they knew nothing about it. Some made excuses: being an illiterate woman or too poor and too busy and not having a radio. Two respondents did think the government had plans to rebuild the country, build cities and asphalt roads, but had no knowledge of actual programmes.

The respondents' view of government was in fact mostly cynical, as a result of their experiences with the provincial and particularly district officials, who 4 described as corrupt; taking bribes for example, when asked to resolve disputes. Another three suspected that government promises would prove empty. Only if work started in the village would they believe in it.

Others thought national government was interested in the community, though one said she didn't know why it worked so slowly. Another cited literacy classes in the villages as evidence of government interest and one said 'If it was not interested, you would not have been asked to interview me.'

\subsubsection{Confidence in the future}

Most of the respondents thought material improvements would most change their lives. Four mentioned electricity; 3, road construction (as a means of access to jobs and business) and one clean water. One thought money, so long as it was legally obtained, would make most impact. Two were concerned with securing a better, independent livelihood through skills training: 'If government found vocational training courses for women, especially for widows, the women in this community can be self sufficient in the next few years.' Two needed assistance with basic needs such as building houses and securing enough food. Only one cited improved local governance through greater unity and replacing the corrupt and incompetent district government personnel.

However, two others were not optimistic about the future because they feared there would be no improvement in governance. One said government, especially at district level, is too full of 'corrupt, illiterate and Jehadi people'. The other feared that the corrupt Maliks would be elected to the CDC 
and would just continue as before to appropriate any assistance.

All the others expressed optimism for the future, because there is no war and they have seen some change in the last two or 3 years. One simply said he is optimistic because he believes in God.

\subsection{Mangal Abad, Chardara District Matched community without a CDC}

\subsubsection{The sample}

Representatives of 8 families (all men) were interviewed. Most families were rather small, with less than 10 members. Five were nuclear families of a couple and their children (in one case, one child). Another family unit consisted of a parent, one child and two elderly sick grandparents. This demographic pattern could well be because they are a community of returned refugees. However, as they explained, they did all belong to 4-5 extended family groups that made up the community. In the two nonnuclear households (with 21 and 9 members), able adults outnumbered children and men outnumbered women, but they assessed themselves as 'poor', while the smaller families described themselves as 'middle income'. In all there were 3 families who considered themselves as 'poor' and 5 as 'middle'.

The poor families relied on agriculture and/or casual labour for a livelihood. One middle family were also farmers but the others were drivers, though one was currently unemployed and one also has some land.

Apart from a sick wife and elderly parents there were no disabled dependents, and no widows were mentioned.

All the respondents were Pashtun. In fact there was no indication of any other ethnic group in the community.

The sample seems broadly compatible with the information given by the community leaders interviewed (though the researchers had some doubt about the population figures given).

\subsubsection{War experience/post-war}

The families all shared the same war experiences. It seems, as one said, that they were 'oppressed by both the Soviets and the Mujahideen'. Their homes were destroyed and looted and they fled to Pakistan at an early stage in the war, where they remained together as a community.

They had only recently returned (several said two months ago). UNHCR apparently assisted some with travel costs and one said he had been compelled to return against his wishes by the Pakistan authorities. They had received no other assistance and had problems of shelter. Their houses had yet to be rebuilt; meanwhile, one had to rent accommodation and another spoke of living in tents.

The main improvement was the end of the war and greater security, which allowed them to work. They had yet to experience any material improvement, but 5 said they expected things to get better after they had got settled. One specifically mentioned the fact that he could travel to get work without any 'racial or ethnic discrimination'. Two had decided to return because they judged the general situation to be better under the present government.

\subsubsection{General understanding and awareness} Experience as refugees, and the assessment they made of conditions in the country before returning, seem to have given the householders a good general awareness of political and economic conditions, though no details of government policy. It also enabled them to observe and find out about NSP and its advantages. However, their experiences led them not to expect much of government, to realize that it would take time to re-establish themselves and to think in terms of eventual self-sufficiency.

Also as a result of how they stayed together as a community in exile and returned together, they are essentially already a united community that could easily benefit from NSP.

However, one householder was aware that the authority of the traditional leaders is very strong (they are highly respected) and would have to be reckoned with before a CDC could work.

\subsubsection{The community today}

There was no doubt about the leadership of the community. The respondents named or referred to three elders (those interviewed by the research team) whose leadership they clearly accepted. One described them as 'talented custodians, honest and sincere'. They also had no hesitation in saying the
THE PRO VIN CIAL FIELD SU RVEY REPO RTS 
community was united. Accounts of community decision-making were also consistent. The elders took the decisions, but after a consultation process in the case of important issues. All the respondents also expressed willingness to participate in community work or said they already had participated.

This harmonious picture of the community is probably largely true, given their long association and family ties; however, they were probably also (see below) eager to impress because they wanted the NSP programme in their village. As former refugees they were probably also accustomed to presenting a united front to aid agencies.

Their replies when questioned about their leaders' relations with the district government suggest that their experiences were similar to those of Dour Robat, though most were reticent on the subject. Most said there was no contact or that there might be some. One said they dealt with them on village issues, another to resolve conflicts the elders couldn't solve. One said they did work with them, but 'received no compensation' (that they were not in their pay?). One respondent was completely outspoken and said that they didn't work with them because they did not trust them. Several were more outspoken later when asked their personal views of government.

As regards assistance, they all said there had been nothing so far. Three were aware that applications had been made (by the elders) without success. Others thought no approaches has been made.

They were all keen to get the NSP programme in the village. 3 had seen the projects completed in other villages. One thought it was some kind of agency to assist refugees but 4 spoke of it as a programme for national unity, aimed at removing grudges. Another described it as a programme for 'rehabilitation, reconstruction and welfare'. One gave a completely accurate summary of the CDC aims and functions. This suggests that they had been taking a close interest in NSP since their return and had observed its advantages.

However, one respondent did see a possible difficulty in establishing the CDC: if the Arbabs saw it as replacing their authority, they might obstruct it.

\subsubsection{Perception of national solidarity}

As described above, several respondents were attracted to the NSP objective of national unity and were generally aware of the programme. However, they had no knowledge of any other government plans. Five said they knew nothing of government plans. Two, without having any specific information, supposed the government has plans to develop the country. Another said they had seen a lot of (positive) changes in the last three years and hoped the government would do better in the future. This suggests they have some expectation of the national government.

However, when asked if the government is interested in the community, all thought it had shown little interest so far. Four said they had received no assistance and one said they had not even been asked what their needs are. Another said the government must have been interested because they asked the refugees to come home, but he hoped they weren't forgotten. Two said they would believe in the government if they were assisted. Three were quite bitter about the corrupt practices of the district administration, but one differentiated, saying that the 'senior people' in government were 'good people' but the 'junior' are corrupt. Several others suggested in other responses that they had some faith in national government, though not the local administration.

\subsubsection{Confidence in the future}

Five respondents thought they needed immediate help to build houses. One suggested that after that they would recover their livelihoods and be self-sufficient. Roads, schools and a clinic were each mentioned as needs by 3 respondents and clean drinking water by two. One respondent put electricity as the next priority after housing.

Two respondents saw their best hope for the future in the NSP. One put creating a $C D C$ as a first priority, and another said he hoped part of the NSP budget could be used for women's vocational training and literacy, because this would help the population, 'which is deprived and unaware of their rights'.

All but one respondent expressed optimism for the future. The main reason for this was the end of the war, security and people working together and other signs of positive change, for which two gave the government 
credit. One simply took his optimism from his faith in God. One felt confident there would be no return to war because people had learnt their lesson.

The respondent who was not optimistic was the one who had been forced to return from Pakistan before he was ready. He felt the government was still unstable and there might be a reversion to war. He claimed that many rich people were not yet prepared to return permanently, only to make money from the reconstruction, while encouraging the poor to return. He also saw no tangible results from the huge amounts of international aid given to government. 


\section{Provincial Field Research Findings}

\section{$\Delta C$ Nangarhar Province \\ with feedback and analysis from communities in Laghman Province}

\section{Timing and scope of the research}

The research team ${ }^{1}$ worked with the NSP in Nangarhar Province between 20 October and 13 November conducting semi-structured interviews, focus group activities, observations, household surveys and project appraisals with all the Stakeholders (see below, Section 1.1), but principally: the Provincial MRRD, the Provincial OC, the FP, communities with a CDC and a community without a CDC.

The team also made a brief comparative visit to Laghman Province from 6-12 November, found in Annex 1.

\subsection{Stakeholders consulted}

\section{Nangarhar}

Facilitating Partner:

BRAC Eastern Office, Jalalabad

1. Jahangir Hossain, NSP Manager

2. Md. Nazrualislam, Provincial Manager

3. Dr. Baz Mohammed, Monitoring Officer

4. Eng. Uzzal Chekraborly, Provincial Engineer

5. Farzama Sader, MT Provincial Office

6. Sunita Iqbal, MO Provincial Office

7. Mirwars Cader IT, Provincial Office

8. Hamid Ullah, Provincial Engineer

MRRD Officials, Eastern Region

MRRD Headquarters, Jalalabad

1 Richard Jones (Team Leader) with Khalid Shafari and Idrees Zaman.
1. Dr. Mohammad Asif, Deputy Governor, Nangarhar

2. Eng. Ahmad Wali Hakami, MRRD Director of Nangarhar

3. Abdul Hadi Asim, Regional Coordinator of Nangarhar
4. Eng. Aminuddin Bidav, MRRD Director for Laghman Province

5. Dr. Ahmad Noor Habibzai, Nuristan Province MRRD, Regional advisor

6. MRRD/NSP Staff

7. Abdul Majid, NSP Monitoring and Evaluating Officer (based with Eastern Region Manager - counterpart to A Sattar, but uses OC office)

8. Eng. A Sattar, Director of NSP MRRD Nangarhar

NSP Eastern Region Offices, Jalalabad

1. Ernst Bentzein, Regional Manager, Eastern Region (Nangarhar, Kunar, Nuristan, Laghman, Logar and Khost)

2. Eng. Lal Agha, Provincial Team Leader

3. Eng. Zalmay, Deputy Regional Manager East

4. Gh. Sakhi Razaqi, Training Coordinator, Eastern Region

Other stakeholders

1. Horst Croessmann, German Agro Action, Nangarhar

2. Karin Traenkner, German Agro Action, Nangarhar

3. Noel McCarthy, Site Security Supervisor, UN Office for Project Services, Nangarhar

4. Gerald Becker, USAID/DAI Alternative Livelihoods Program - Eastern Region, ex Team Leader NSP

5. Hamish Nixon, Researcher, AREU

6. Daud Omari, Researcher, AREU

NSP Communities visited and CDCs consulted in Nangarhar

1. Sholana, Chaparhar (including the CDCs of Sholana, Khanan, Miagan and Gulshir)

2. Balla Dehe, Sorkhrod 
3. Kooz Naza Abad, Sorkhrod

4. Ahmadzi, Sorkhrod

5. Dago, Chaparhar

6. Mano, Chaparhar (including the CDCs of Nazier Kalay and Gradal Kalay)

7. Merzaian, Sorkhrod

8. Ditawai Amerkhil, Sorkhrod

9. Khankai Satkai, Achin

10.Asadkhil, Achin

Community visited without NSP

1. Bahsawal, Mohmamdara District

\section{Laghman}

Facilitating Partner:

Maderia, Metherlan Office, Metherlan

1. Eng. Baz Mohammed, NSP Coordinator for Laghman and Nuristan

DACAAR

2. Eng. Rohullah Sultan

3. Koochi S. Asro

NSP Laghman Office

1. Prof. Eng. M. Hamayoon Akseer, Team Leader Laghman

NSP communities visited and

CDCs consulted in Laghman

1. Mashina

2. Shertabad

3. Hussain Abad

4. Koarigi, Alingar District.

5. Kokhi, Alingar District

6. Kahoo and Chinnar Kali, Alishang District

7. Tangi Shakarman, Alishang District

8. Qala I Halim, Alishang District

\subsection{0 ther development programmes in Nangarhar}

There are two main development programmes in Nangarhar and the Eastern Region in addition to the NSP. DAI has two projects. Firstly, the USAID-funded Immediate Needs Cash for Work provides $2,500,000$ labour days for projects paying $\$ 3$ 4 per day on intensive labour projects: canal cleaning, flood protection, small irrigation and some road work. The project spends $\$ 18 \mathrm{~m}$ over one year and USAID wants to continue the project. In specific cases the project will work with established CDCs. Secondly, the Alternative Livelihoods Project is a broader based economic development project which focusses on infrastructure, bridges, roads, intakes, private sector development, micro enterprises, financial services, gender and micro enterprise, and natural resource management. The project will spend $\$ 108 \mathrm{~m}$ over 4 years.

\section{The MRRD at the provincial and district level}

Key Aim: To focus on the management of NSP

The Director of the MRRD, the Deputy Governor of Nangarhar and other MRRD employees are familiar with the NSP process and explained it in detail. The MRRD felt that the NSP improved contact between national and provincial government, provincial and district government, and between the government and communities. As the Director of the MRRD stated 'We at the province level have good relations with the district; this has been consolidated by the jirga to legalize the CDCs. We are reaching down to the communities for the first time in Afghanistan's history and they [the community] appreciate this.' The MRRD maintain that they have a visible presence in the community especially when government representatives come to inaugurate programmes, give certificates, have regular meetings with $\mathrm{FP} / \mathrm{OC} / \mathrm{CDCs}$ and make speeches associated with the NSP.

The Deputy Governor of Nangarhar is a firm advocate of NSP, 'When the community is empowered to move forward, the community can decide everything; if they are empowered they can do anything as the community knows what is best. All programmes in the future must be run by CDCs; if the community selects a programme it will work. Why? Because they have chosen it.' The Regional Advisor was under no illusions, 'The CDCs are permanent institutions that allow communities across Afghanistan to unite to rebuild their country.'

It was also universally accepted that despite the best of intentions there is sometimes conflict within CDCs when certain people do not get what they want. Sometimes the traditional shuras are marginalized, in which case NSP must keep the balance. However they were not aware of the Community-Led Development Department or any complaints procedure.

Out of the 41 MRRD staff there are two NSP staff assisting in the monitoring of the project and checking proposals; one is based in the MRRD, and the other is based with the provincial $O C$ as there is more room in the OC's office.

The MRRD's ability to manage the NSP at
THE PRO VIN CIAL

FIELD SU RVEY REPO RTS 
the programme and district level was not called into question. However, all acknowledged that they do not yet have the capacity to directly implement the programme. It was widely accepted that there was a need for more skilled staff to complement the two core NSP staff (especially engineers and administrators), vehicles, and higher salaries for MRRD personnel. The only training that the MRRD received to date was for the operations and technical manual which was deemed to be most useful for clarifying roles of the relevant groups/organizations.

The MRRD are keen to integrate all other programme initiatives with the CDCs and cite a number of examples of other related programmes in the region such as the USAID, Cash for Work initiative and the Alternative Livelihoods Programme. The MRRD maintain that it is easy to coordinate and share people's priorities with other projects, highlighting for example that there is no conflict between MRRD and Ministry of Public Health and Ministry of Education as they are all in agreement with the NSP on relevant projects.

In terms of actual indicators of success for the NSP, the MRRD members concentrated on: the number of districts where the NSP is being implemented, number of beneficiaries, sustainability of programme, accountability of the people, and the sense of ownership that the programme generates.

Finally the Deputy Governor concluded that he 'would like to see the NSP cover more districts, so far only 5 out of 22 are covered; 12 along the Pakistan border are very isolated and must be included. Once we build up our own capacity I don't foresee any problems in the future when we take over NSP.'

\section{General comments}

1. The senior members of MRRD have a perspective on the NSP which is to 0 optimistic and superficial. It is very obvious throughout the course of the research that they form their opinions of the NSP on the basis of their superiors in Kabul and not on the basis of reality in the communities. Their only contact with the communities is to inaugurate projects and hand out certificates; these positive occasions mask many structural problems which senior members of the MRRD do not wish, or are unable, to acknowledge.
2. The MRRD are optimistic that the CDCs will be 'the government at the district level' without concerning themselves that the capacity of both the CDCs and the MRRD at the provincial level remains very weak.

3. The MRRD is very output focussed: numbers of CDCs created, numbers of projects completed etc. In order for the CDCs to take on a more substantial role in the district their progress to date needs to be consolidated with further capacity-building initiatives. In the headlong rush to increase output there is a very real risk that already established CDCs will lose momentum and any 'governance' gains will diminish.

4. Although the MRRD are confident of an integrated approach from various ministries to wards the NSP, evidence from BRAC, the OC, some of the CDCs, and national level research would suggest otherwise. For example, projects have been delayed whilst ministries argue about whether the NSP should be building a school, initiating an agricultural project or questioning the validity of the NSP in the first place! The government, through all its ministries, does not give united support to NSP despite what the MRRD in the Eastern Region maintain.

5. Although the MRRD acknowledge that they have no capacity to directly implement the NSP, their capacity to indirectly implement or monitor progress is also in doubt given the acute staff shortages, high number of projects, limited understanding of the reality and problems faced. As such, to comment that there will be no problems in the future when the MRRD takes over the NSP, is highly questionable.

\section{The 0 versight Consultant at provincial level}

Key Aims: To assess the effectiveness of the capacity strengthening of the institutions and staff counterparts by the OCs. Has capacity-building been relevant to the changing implementation environment and the rationale of the NSP?

The Provincial OC Ernst Bentzien has been with the NSP in various capacities since its inception. In the Eastern Regional office the $O C$ is coordinating the NSP in seven provinces with various FPs. The $O C$ is trying 
to push the MRRD to take over the programme but they are not prepared. The handover date is set for September 2006 but March 2007 is more likely. However, the FPs and provincial offices are working together; there is good information exchange, and joint problem resolution.

\subsection{SWOT Analysis}

\section{as compiled by the Provincial OC}

\begin{tabular}{|c|c|}
\hline Strengths & Weaknesses \\
\hline $\begin{array}{l}\text { The NSP is a } \\
\text { great idea } \\
\text { There is good } \\
\text { cooperation with } \\
\text { BRAC and other } \\
\text { FPs in the Eastern } \\
\text { Region } \\
\text { Speed of proposal } \\
\text { submission is good } \\
\text { Builds the capacity } \\
\text { of the DAB }\end{array}$ & $\begin{array}{l}\text { Security is a problem, geography makes project } \\
\text { implementation a lot more difficult, (especially in Achin } \\
\text { as it is very mountainous) } \\
\text { Poppy eradication (through offering alternative livelihoods } \\
\text { etc) is very dangerous for any organization to be involved } \\
\text { in } \\
\text { Non-engineering projects are problematic, as results are } \\
\text { hard to define. In addition there is no diversification of } \\
\text { non-engineering projects, e.g. there are too many tailoring } \\
\text { projects (many communities request tailoring but it is not } \\
\text { feasible) } \\
\text { Participation is very difficult especially of women; change } \\
\text { will only happen very slowly. In some areas in the Eastern } \\
\text { region (Achin, Chaparhar) female participation is virtually } \\
\text { impossible } \\
\text { Sometimes the CDCs are not well informed about the NSP } \\
\text { should (or renege on their promises) } \\
\text { procedures and this leads to confusion and false hope } \\
\text { That some good projects cannot be funded } \\
\text { Thegatively affect the impact of the NSP at the community } \\
\text { There is excessive time pressure from MRRD to get output } \\
\text { detriment to building and consolidating CDC capacity. } \\
\text { There needs to be more input in view of building the } \\
\text { CDC potential }\end{array}$ \\
\hline
\end{tabular}




\begin{tabular}{|c|c|}
\hline O pportunities & Threats \\
\hline $\begin{array}{l}\text { CDCs and NSP have } \\
\text { great long-term } \\
\text { potential } \\
\text { Reinforces } \\
\text { 'democracy' } \\
\text { Must be seen as a } \\
10-15 \text { year process } \\
\text { Phase } 2 \text { should } \\
\text { include more } \\
\text { livelihood projects }\end{array}$ & 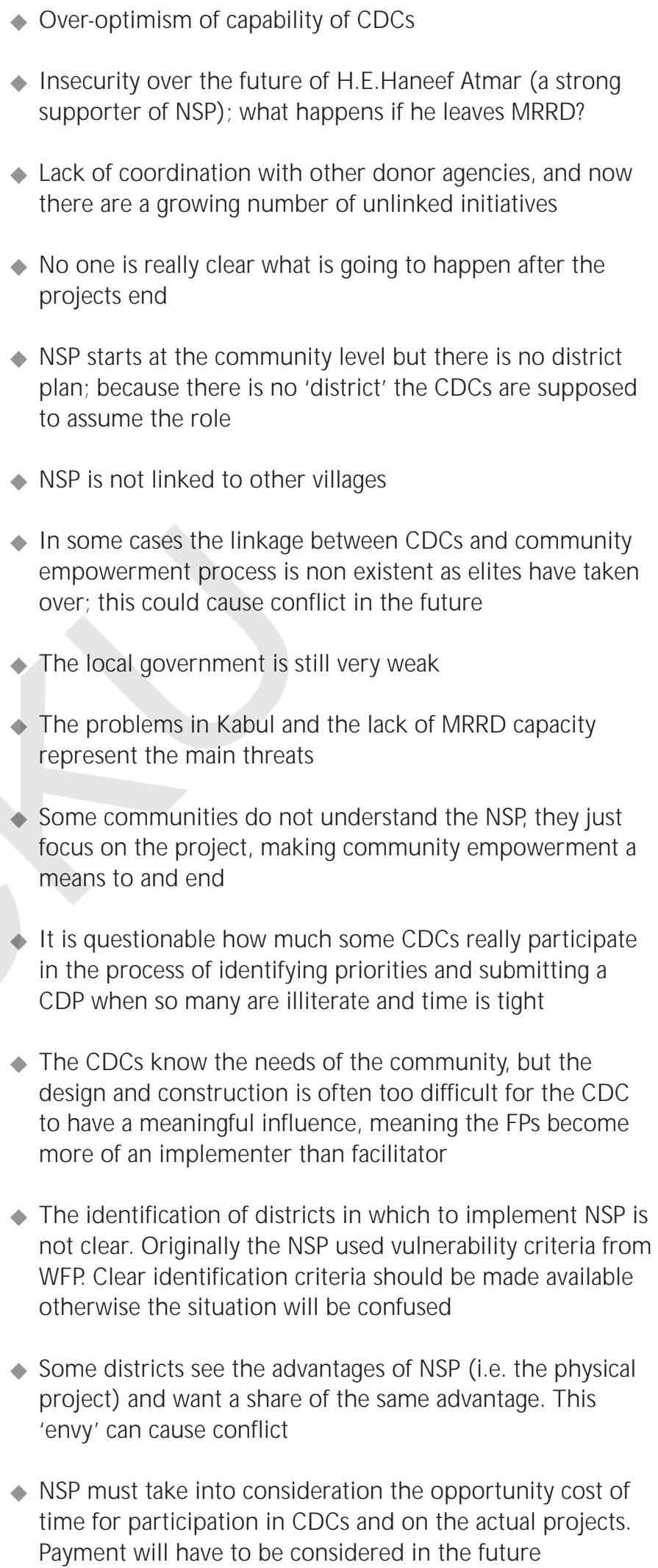 \\
\hline
\end{tabular}




\subsection{Capacity-building role of the $\mathrm{OC}$}

The role of the provincial $O C$ is to facilitate the process of NSP to run smoothly. The OCs are not involved in the management of NSP, the NSP/MRRD coordinator in Kabul is responsible for management. The provincial $O C$ officers explain the situation to OCs in Kabul, who are responsible for supervising the country-wide NSP. As Bentzien cites 'we are the link between the provincial office and the local FP and between the provincial MRRD and the local FP'. The national OC provides training for rural development and management, much of which has now been decentralized to the provincial offices.

MRRD staff management capacity at national, provincial and district level varies. At the national level the MRRD/NSP coordinator acts as an intermediary between the national $O C$ and MRRD, and performs well at promoting the NSP and raising its profile amongst national and international stakeholders. At the provincial level there is a willingness but little capacity to manage the NSP, for example purchasing and procurement is very difficult for MRRD as they have no funds for community equipment etc. Some nepotism also exists. There is no district level as such, the district MRRD concentrate more on security issues than community development. The newly legalized CDCs are likely to become the MRRD at the district level.

In terms of capacity-building a training programme has been introduced for the MRRD to focus on all aspects of the NSP. Training must be viewed as a long-term learning process; currently there is too much technical emphasis and too much emphasis on rural infrastructure. The NSP needs to become good at community development, income generation, microfinance and livelihood development, but training for such initiatives is difficult and their effective implementation and measurement are also complex. When the MRRD take over the role of the regional manager in September 2006 they will also be responsible for the training component.

In the initial implementation of the NSP countrywide, as a regional manager the $O C$ had to concentrate much more on the logistics to build up staff and office resources rather than concentrating on the intrinsic NSP. The logistics behind the NSP still takes up valuable time that should in theory be spent on ensuring the programme is running smoothly, although the situation is improving as the NSP continues to become established.

\subsection{Supervisory role of the $\mathrm{OC}$}

The eligibility criteria are an essential tool for the supervisory role that the $\mathrm{OC}$ plays. The criteria are straightforward, especially once people realize that the NSP cannot build mosques. However, the key issue in terms of supervision is the capacity of the $O C$ to ensure that resources are delivered to the community on time. Bentzien explains: 'FPs give the proposal to the provincial office, the engineers have a look and confirm forms and plans are in order, they are then sent to Kabul for disbursement. However, there are often delays in disbursement, mainly due to the lack of cash in the provincial DAB and bottlenecks at the Kabul level. Now there is a better tracking system so that proposals do not get lost between the provinces and Kabul.'

It is envisaged that communities wait up to six weeks from submission to disbursement. On many occasions however, in places like Kunar, funds are disbursed but there is no cash in the DAB; this fund transfer problem has to be solved. Perhaps it will be better in the future as the DAB expands to the provinces.

\subsection{The role of the provincial NSP manager}

When FPs submit a proposal the provincial manager checks the submission to ensure the proposal is acceptable, with the use of a monitoring system. The provincial manager also goes to the field and checks the actual site, the accounting procedures that the FPs use, and the level of awareness of the NSP in the community. The provincial manger receives direct capacity-building from the FPs in terms of NSP training. In effect the provincial manger receives training from those whom he assesses!

\subsection{Future considerations}

According to the provincial OC the MRRD are not in a position to take over the NSP. As it stands the running of the NSP will be fully transferred to the MRRD, in which case the OCs (as private organizations) cannot remain in a state structure. The programme has been going for nearly two years but much of that has been taken up with establishing the programme. The FPs themselves are not clear about the transfer. FPs have an
THE PRO VIN CIAL FIELD SURVEY REPO RTS 
MoU with MRRD to train them but there are not enough MRRD/NSP employees to be put forward for that training. In the future there needs to be a programme for capacitybuilding training for the MRRD staff. Salaries have improved, but many are trained and then go to the international NGOs who pay more.

The MRRD want all initiatives to go through them and the CDCs to coordinate with the other CDCs and other programmes; this is a good idea but there is no capacity whatsoever to do this. Also, the $\$ 60,000$ cut off means that there are lots of other community priorities that could receive funding from other non-NSP organizations. These should be communicated to potential donors to avoid repeating the whole process of project identification.

There also needs to be integration with other projects like the USAID Work for Cash Project and the Alternative Livelihoods Project. MRRD want to coordinate but it has so little capacity.

\section{General comments}

1. Much of the initial time spent since the NSP commenced has been spent by the $O C$ establishing offices, recruiting staff and building up its own capacity, at a detriment to enabling the intrinsic NSP.

2. The $O C$ is under pressure to roll out more projects at a detriment to ensuring existing CDCs are equipped for the future. This reinforces the MRRD-led over-optimism of what the CDCs are able to undertake.

3. The MRRD will not have the capacity to take over the NSP without continued substantial input from the OCs.

4. There is a high level of political uncertainty regarding the NSP and the handover to the MRRD. This uncertainty also affects the FPs. It is widely acknowledged that $\mathrm{HE}$ Haneef Atmar is a strong supporter for the NSP; if he is moves to another ministry, will a new minister be as supportive?

5. The OC and FP enjoy good relations, underpinned by regular meetings, joint problem solving and an approach of partnership. However the FPs in many circumstances are under pressure to implement rather than facilitate the NSP; this ultimately limits the benefits that the CDC could derive as advocated throughout the NSP, and in most cases is a direct consequence of pressure from the MRRD

\section{The facilitating partner at the local level}

Key Aim: To assess the managerial role of the FP and its ability to act as a channel of communication between the government and the community.

The Bangladeshi NGO BRAC is the only FP in Nangarhar. They operate within 5 of the 22 districts in the Eastern Region. In November 2005 UN-HABITAT and German Agro Action will also be operating in the Eastern Region. Their intervention is as a result of a political desire for additional FPs to boost the roll out of NSP, and by doing so reducing the amount of land dedicated to poppies.

\subsection{The role of BRAC within the NSP}

BRAC understands its role within the NSP as identified in the Manual. The organization sees its role as facilitating different aspects of community development by enabling people to come together to identify priorities, make proposals and then implement the projects. As the Director stated, 'We help the people to build capacity within their communities to help them get to a position where a project can be implemented and sustained.'

The community know that BRAC is working on behalf of the government. BRAC uses social mobilizers to explain the NSP and their role within it to ensure that people are clear that it is a government programme. At first people did not believe that the government was working for them because in the past any developmental work was implemented by NGOs. Around the project sites there are signs and NSP literature emphasizing and promoting the role of the government as distinct to that of the FP BRAC. When the disbursement has been accepted, members of the $C D C$ are given instalments from the Block Grant through the DAB from the government. Periodically government officials visit the communities to reinforce their overall role within the NSP. In addition, the projects are always inaugurated and training certificates distributed by government officials and not BRAC.

In some areas the community accuse BRAC of numerous untruths, ranging from telling ISAF the location of the poppy fields and spying on behalf of the $\mathrm{CIA}$. For example there have recently been night letters in Sorkhrod district claiming that as 
Karzi/Bush/Sharon are all the same, those who support the government will share their same grave. In May 2005 the BRAC offices were attacked following the US soldiers' desecration of the Koran in Guantamino Bay, and staff have come under attack in the districts from IEDs. However, relations with the majority of the communities are good, but BRAC feel acutely vulnerable to any external occurrence involving ISAF and especially America. ${ }^{2}$

At the province level relations with the MRRD are generally positive. Every week the MRRD/OC/FP meet to solve problems and make collective decisions. However, the capacity of the provincial level MRRD is considered to be weak; although they have more resources than any other provincial ministry there remain significant shortages of technical and physical resources.

At the district level the MRRD is also considered to be weak. The MRRD does not have an office at the district level so there is a gap and contact between the community and local government is limited. There are only district administrators, but these are more concerned with security than development. This is a structural problem within all Afghanistan and is the rationale for the newly created CDCs becoming the local government at the district level. The district personnel have inadequate access to transport and a shortage of skilled staff, only having two engineers to cover five districts. In addition, BRAC complain that 'new district governors require a great deal of time to be brought up to speed with the NSP'.

The gap remains between the community and local district government but the contact between the community and provincial government has increased due to the NSP. Never before has the government been so visible in communities with physical reminders through projects, signs, workshops and meetings that strengthen the link between communities and provincial/national government.

The working relations with both the regional and provincial OCs are good. BRAC sees itself as part of a team of which the OCs are vital; there are many meetings where decisions are arrived at jointly and BRAC do not feel overly pressured by the OCs in terms of the actual day-to-day decisions. However, BRAC concede that Nangarhar is not comparing favourably to other provinces in terms of the NSP; this they claim is because of poor security and an NSP national mindset that favours predominately infrastructure projects for which their regional $O C$ skills are biased towards infrastructure, and not poverty reduction/ income generation. ${ }^{3}$

\subsection{BRAC's capability and limitations in relation to programme demands}

There are several key factors for success of the NSP. These include management and capacity, training, community participation, the interpretation of eligibility criteria and an understanding of the consequences of the termination of NSP.

\subsubsection{Management and capacity}

BRAC is an international NGO with a great deal of expertise in community development. There are 127 staff ( 21 women) who are allocated to the NSP. BRAC did not have to increase its capacity as such, but had to tailor its resources from existing training programmes; it did not have to recruit more staff as they already had specific expertise in relevant areas, e.g. engineering, livelihoods and project management. However, as the NSP Manager stated, 'We have often found that we spend a great deal of time and money on training staff who then promptly leave for better paid jobs within the NGO sector. We are philosophical about this and acknowledge that at least our training is having a trickle-down effect so that in some way the country is benefiting.'

There are however significant problems associated with processing the high number of projects. On occasions BRAC has to wait up to six months for the Block Grant to arrive, and these delays cause tension between the CDC and BRAC. For example the increment for the intake project in Sholana was delayed by six months, during which time the community was again flooded because the protection had only been partially constructed. ${ }^{4}$

\subsubsection{Training}

BRAC have organized training for NSP orientation (which clarifies the NSP, the role of the FPs, community representatives, etc), book-keeping, accountancy, procurement and project proposal writing. BRAC uses master trainers who receive their training from the resource centre in Kabul. The master trainers then train social organizers who in turn train the CDCs. This CDC training also includes operation and mainte-
2 The N angarhar region and Jalalabad in particular are garrisoned by an American-led ISAF force.

3 This overemphasis on infrastructure is also due to warlords and other elites in the community wanting physical projects, even though in many circumstances the poorest want poverty reduction. BRAC maintain that this overemphasis of infrastructure is a national phenomenon.

4 Further information regarding the difficulties that FPs in general face can be found in Jones (2005) Preparation Report section $4.3 \mathrm{p} 10$.

THE PRO VIN CIAL FIELD SU RVEY REPO RTS 
nance. Training on the whole is successful, but BRAC complain that often people ignore the training and do what they want. For example, BRAC will inform the people of the main characteristics that make a good CDC representative (honesty, functional literacy, etc), yet the community still choose an illiterate warlord or former commander as CDC representative.

In terms of the skills required by BRAC employees working on the NSP, knowledge about NSP, communication skills, a positive attitude and a good technical grasp are all essential. Although BRAC acknowledge their weaknesses, especially the inadequate number of engineers, their difficulty understanding the technical manual and the confusing technical guidelines for engineers (form 7), they nonetheless feel they have the capacity to run the NSP but would appreciate greater technical training input for specific NSP projects.

BRAC originally received NSP training from UN-HABITAT and the OC training department. The training mainly concerned the five steps to NSP, engineering and irrigation principles, interpretation of the technical manual and other NSP guidelines such as procurement and proposal writing. All this training has proved very useful for BRAC to facilitate the NSP. However, much of the training does not benefit all the people who require training. The $\mathrm{OC}$ only allow two people from the FP it be trained, yet BRAC is operating in 5 provinces across the country, and does not have the time to train others whilst simultaneously rolling out projects. In addition a BRAC engineer stated: 'The main training problem for us is that the procurement policy is designed in Washington and bears no reality to conditions here in Nangarhar. Even BRAC, with all our expertise and resources, find it extremely difficult to get CDCs to understand the procurement policy and accounting guidelines!' Regardless of where the procurement guidelines originate it remains a complex procedure with which BRAC struggle. In addition, training the CDCs to complete sub project proposal forms is also very difficult. As one member of BRAC stated, 'The CDCs are constantly asking for our help with the subproject completion form, we show them, yet still they ask because their capacity is so low. What will happen when we (BRAC) leaves? They will not be able to cope.'

\subsubsection{Community participation}

There remain significant cultural barriers to women's participation in Nangarhar. In the first year of NSP implementation 14 per cent of women were attending CDCs; in year two its nearly 100 per cent. However, not all women vote and in the instances where they are able to, will almost always vote under the influence of their male relative.

From BRAC's experience in the first year in some districts (e.g. Achin) men were refusing to let their wives/female relatives be considered on the survey sheet for the NSP preparation, but this is slowly changing as the NSP gains more acceptance. However there is no occurrence of men and women sitting together to formulate the CDP. In the future however there will be male/female sub groups of a CDC, with an executive made up of two men and two women. On the whole it is difficult to generalize and a community-by-community analysis needs to be undertaken. Despite the NSP objectives for female participation, change will only be gradual.

The participation of other groups is less problematic. Most of the projects have a component for a percentage of vulnerable people who must benefit (this was 10 per cent; now it is left up to the community to decide). There was evidence through the research to show how, for example, widows, orphans and the disabled were specific beneficiaries of some initiatives, e.g. sheep rearing in Sholana. A common observation from both BRAC and this research was that the more people see the benefit of the CDC and what it can bring, the more both men and women want to join.

\subsubsection{The interpretation}

of eligibility criteria

Whilst it is easy to apply the eligibility criteria to the intrinsic project, it is not easy to present this criteria to the community. Almost without exception the first project people want is a mosque. As a BRAC community mobilizer related, 'We tell the communities to work together and identify priorities, to listen to each other and they tell us they want a mosque, even though we have said from the start that we cannot give them a mosque, and they ask us where is the 'democracy' in our thinking, denying them something they all agree upon to be a priority. We are then accused of trying to impose Christianity!'

Some CDCs want large scale infrastructure 
such as dams which, due to cost and scale, fall outside the remit of the NSP $(\$ 60,000)$. Many people ask for carpet-weaving projects, but these have been proved to be very difficult to bring about a positive change because whilst the intrinsic carpetweaving is straightforward, the marketing and distribution of the carpets is far from easy. In summary the eligibility criteria is most relevant to the micro hydro and diesel generation projects, as are cross sectoral projects such as health initiatives which need to be sanctioned by the Ministry of Health and not the NSP.

\subsubsection{NSP termination}

From BRAC's perspective there are serious doubts if the CDCs will be able to function without further capacity-building and direct external support. This is supported by findings from the $O C$ and the CDCs. From an organizational viewpoint BRAC staff can easily be absorbed within the organization when NSP ends.

\subsubsection{Project relevance}

BRAC facilitate a range of projects including irrigation, water intake, diesel generator, protective walls, roads, boring wells, culverts, sheep rearing, school construction, community centre construction and self help. All projects are planned in line with the latest manual.

The projects have a direct relevance to the community needs, although BRAC acknowledge that some projects, such as water intake, are more universally beneficial than others. The most relevant projects demonstrate clear linkages between the newly created CDC and its capacity for community development, and the intrinsic project with other forms of community development.

The projects are identified through a PRAtype process with focus groups identifying problems, ranking priorities for sub project proposal. As BRAC acknowledge and the household surveys indicate, in some instances traditional elites such as warlords still dominate proceedings. In such cases BRAC get people to write or draw their priorities on paper so they will not be directly influenced by the elites. Often though, people are too cowed to respond independently. Conflicts of interest can also occur when a decision on a community priority is evenly split, i.e. where there is a substantial minority who have not got what they want.
As part of the NSP mobilization process BRAC take people from areas where there is no NSP to show them what the NSP has done for particular communities, to practically demonstrate the success of projects. As such, community representatives frequently appear at BRAC's national and regional offices asking for the NSP.

There is a problem of understanding in many of the communities. For example, people want light but many have no appreciation of how the light appears, and how the generation of light needs to be maintained/sustained, and for the poorest power is not a priority. In the experience of BRAC the poorest communities are more likely to ask for an economic activity rather than an infrastructure facility, but the same communities often feel deluded when tangible results do not happen overnight.

The project will only get the go ahead if it is a) technically acceptable; b) within the defined budget; and c) if there is adequate attention given to the future maintenance. It is often necessary for BRAC, and sometimes the Provincial Ocs, to assess for mine risks, undue political pressure, and environment factors other than the ones identified during the feasibility study. For example in 2005 a CDC wanted to initiate a project to generate income through the construction of kilns used for firing bricks. After an environmental assessment the project was turned down because of the negative environmental impact associated with increased incidences of land slides, and the exacerbation of the erosion of the soil due to the need for wood to fire the kilns. In addition relatively intense fires in the arid conditions of Nangarhar are not appropriate.

Although as yet there is no country development document like a PRSP, the projects are broadly integrated with national development plans of reducing poverty and improving infrastructure. However, certain ministries are not appreciative of the NSP, openly questioning the rationale and approach (especially the Ministry of Agriculture).

\subsubsection{Project sustainability}

There are several measures in place to ensure that the facility/service can be maintained. The cost of the maintenance as well as the depreciation of the asset is included within the project cost. The community (per household that benefits) pay a fee
THE PRO VIN CIAL FIELD SU RVEY REPO RTS 
either in cash, or usually in kind once a month an allowance, to enable appointed technicians to maintain the facility, provide for fuel for the project if necessary and to cover depreciation costs. These costs typically account for 20 per cent of the overall investment.

In theory local technicians and not professional personnel will maintain the facility, and the money saved up by the monthly payments will ensure that when the facility is beyond repair a new facility can be purchased. BRAC however, is not very optimistic that this system will work, fearing that even if funds are collected the cash will be spent elsewhere and the facility will fall into disrepair. BRAC comment that it is too early to say if the facilities now in place will be functioning in ten years' time.

Sustainability is also an important factor for the economic activities. However, these are much more difficult to measure and even BRAC is unsure how, for example, microfinance initiatives implemented through the CDCs can help to reduce poverty.

\subsubsection{Project efficiency}

From the viewpoint of BRAC there are several key factors which impact upon project efficiency. Once a sub project proposal is submitted the OC check the proposal in order to make a decision on whether the project should be sanctioned.

The period of time between identification of the project and the start of implementation is typically around three months. However, the average time from implementation to completion is meant to be two-three months but it usually takes six months. There are many delays: delivery of materials, security problems, weather-related and poor CDC/FP management. However, the prime reason for delay is due to the excessive length of time it takes for the Block Grant to be processed by the OCs, and the protracted process of dispersal of funds through the DAB.

BRAC maintain that over the last six months these delays have worsened but this is due to the worsening security situation in the Eastern region and the uncertainty surrounding the election process.

In terms of project efficiency within the actual design and construction of the facility, BRAC always undertake a feasibility study to clarify if the proposed project is appropriate and sound. A BRAC engineer, working on occasions with OC/MRRD representatives, will carry out the feasibility study to survey the design, implementation and maintenance of the project in accordance with the technical manual. BRAC acknowledge that this process requires qualified engineers who are in short supply. Local capacities are assessed, but due to the shortage of engineers not all people are up to the task; hence the role of BRAC as the overseer working through a technical checklist takes on an increased importance. Once the project has received sanction, purchasing of materials takes place in three key ways: direct ( $>$ Afs 500 ), quotation ( $>$ Afs 5000-250,000) and bidding (>Afs 250,000).

Mitigation measures for earthquakes and floods are incorporated in both the architectural and engineering aspects of the design. For example, on a $300 \mathrm{~m}$ protective wall in Sholana expansion joints are placed every $15 \mathrm{~m}$ to allow for seismic movement, and buildings tend to be low and wide. Problems during construction include strict supervision for mixing/timing of the cement. As one BRAC engineer complained, 'Engineers in Afghanistan do not allow for curing because of the lack of water; this causes problems such as weak cement, flaking and cracking etc.'

BRAC feel that to increase the project efficiency the training needs to be more comprehensive and include more NSP-specific projects. Currently there is flexibility for BRAC engineers with autocad experience to design projects that are not covered in the technical manual but have nonetheless been chosen by communities and received sanction from the $\mathrm{OC}$.

The usual considerations of quality, costs and time are of course relevant to the efficiency of the project. The delays in disbursement causes costs to increase. For example in one site at Dago, Chaparhar an original estimate for the price of a bag of cement doubled during the period of time from project submission to first disbursement. Fortunately there is provision for such occurrences within the incremental process that enables increased amounts for the second and third instalments. However the provincial NSP Manager of BRAC summed up, 'The real problem is that the $B R A C$ is involved with 348 projects and the OC/MRRD at the provincial level only have two engineers to visit all the projects and give feedback'. The OC/MRRD at the provin- 
cial level simply do not have the capacity to check the number of projects.

On larger projects there is some effort made for safety of workers, but there are few concessions, no helmets, basic site safety etc.

\section{General Comments}

1. BRAC has a sound knowledge of the NSP, its overall objective and its process of implementation. BRAC accordingly are well aware of its limitations within the constraints imposed and its operating environment.

2. In Nangarhar BRAC is operating in an increasingly insecure environment; attacks on staff and offices are increasing and BRAC is having to take ever more elaborate security measures. The organization feels especially vulnerable to external events, particularly those concerning the USA and ISAF.

3. From the beginning BRAC emphasized the government's role in the NSP. All the evidence from this research confirms that the communities are in no doubt as to the origins of the programme implementer.

4. BRAC trains its staff for different aspects of the NSP, only to find that many trained staff leave for better paid positions with other international NGOs. As with all organizations in Afghanistan BRAC struggles to find enough skilled staff, especially engineers to supervise the projects and operationalize the technical manual which is deemed to be unnecessarily complex. BRAC operate in five provinces throughout the country, yet only two of its staff receive NSP training.

5. The delays in disbursement put BRAC in a difficult position; they are often blamed by the community, projects are delayed and as a result community momentum is lost. In addition costs often increase due to the prolonged wait for sanction.

6. In the experience of BRAC the poorest of the poor do not always benefit from the NSP. When identifying community priorities the poorest tend to want income-earning opportunities on the basis that they have no land and have lived without irrigation, flood protection, a road, electricity etc for so long that it would not make much difference to their lives. However they are overruled by the majority, themselves led by the influential, landed, literate, elites.
7. All communities visited had a sound appreciation of the theoretical need for maintenance for which BRAC must take the credit. Through the use of asher, collections of cash/produce are made to pay someone to oversee the maintenance of the facility and even to cover the costs of depreciation. However, once BRAC have left the community the organization doubts that such funds will be used for their intended purpose due to the weak capacity and inadequate understanding of the CDCs.

\section{The communities with a CDC}

Key Aim: To assess the legitimacy of the CDC and its capacity to plan and manage development projects that benefited the community.

There were 3 core site visits necessary for an effective evaluation: a community where the NSP is nearly completed (Sholana, Chaparhar District); a community where the NSP has just started (Balla Dehe, Surkhrood District); and a community where there is no NSP (Bahsawal, Mohmamdara District). This section concentrates on the former two communities, with additional input from other CDCs from secondary research bases visited in: Kooz Naza Abad, Sorkhrod; Ahmadzi, Sorkhrod; Dago, Chaparhar; Mano, Chaparhar (including the CDCs of Nazier Kalay and Gradal Kalay); Asadkhil, Achin; Khankai Satkai, Achin; Merzaian, Sorkhrod and Ditawai Amerkhil, Sorkhrod. Household surveys were also conducted in Sholana, Balla Dehe and Bahsawal, the findings of which have been integrated into the analysis.
THE PRO VIN CIAL

FIELD SU RVEY REPO RTS 


\begin{tabular}{|c|c|c|c|c|}
\hline Number & Name of CDC & $\begin{array}{l}\text { Date of CDC } \\
\text { Establishment }\end{array}$ & Projects & Status \\
\hline 1 & $\begin{array}{l}\text { Sholana, } \\
\text { Chaparhar District }\end{array}$ & November 2003 & $\begin{array}{l}\text { Intake/irrigation/ } \\
\text { Protective wall } \\
\text { Sheep rearing }\end{array}$ & Nearly completed \\
\hline 2 & $\begin{array}{l}\text { Balla Dehe, } \\
\text { Sorkhrod District }\end{array}$ & May 2005 & $\begin{array}{l}\text { Road/culvert } \\
\text { (started August 2005) }\end{array}$ & Ongoing \\
\hline 3 & $\begin{array}{l}\text { Kooz Naza Abad, } \\
\text { Sorkhrod District }\end{array}$ & September 2005 & $\begin{array}{l}\text { Now prioritizing } \\
\text { projects }\end{array}$ & Ongoing \\
\hline 4 & $\begin{array}{l}\text { Ahmadzi, } \\
\text { Sorkhrod District }\end{array}$ & November 2003 & Boring wells & Completed \\
\hline 5 & $\begin{array}{l}\text { Dago, } \\
\text { Chaparhar District }\end{array}$ & & School construction & Ongoing \\
\hline 6 & $\begin{array}{l}\text { Mano, } \\
\text { Chaparhar District }\end{array}$ & & $\begin{array}{l}\text { Diesel generator } \\
\text { Road/culvert }\end{array}$ & $\begin{array}{l}\text { Generator (complete) } \\
\text { Road/culvert } \\
\text { (ongoing) }\end{array}$ \\
\hline 7 & $\begin{array}{l}\text { Merzaian, } \\
\text { Sorkhrod District }\end{array}$ & M ay 2005 & Road/culvert & Awaiting approval \\
\hline 8 & $\begin{array}{l}\text { Ditakiai Amerkhil, } \\
\text { Sorkhrod District }\end{array}$ & March 2005 & $\begin{array}{l}\text { Boring well } \\
\text { Diesel generator }\end{array}$ & $\begin{array}{l}\text { First well in the } \\
\text { process of being dug }\end{array}$ \\
\hline 9 & $\begin{array}{l}\text { Khankai Satkai, } \\
\text { Achin District }\end{array}$ & May 2003 & Micro hydro power & N early completed \\
\hline 10 & Asadkhil District & December 2003 & $\begin{array}{l}\text { Pipe scheme, } \\
\text { sheep rearing }\end{array}$ & $\begin{array}{l}\text { Completed } \\
\text { (no completion } \\
\text { certificate) }\end{array}$ \\
\hline
\end{tabular}

The Provincial Governor's office ranks the provinces in Nangarhar in terms of development on a scale of 1-3, with 3 being the least developed. Accordingly Sorkhrod is ranked as 1, Achin 2 and Chaparhar as 3.5

\subsection{Project information for primary research bases}

Sholana, Chaparhar District

The village of Sholana in the foothills of the Tora Bora is $45 \mathrm{~km}$ away from Jalalabad; the access road is in a poor condition with only

5 Development rankings in N angarhar Province, August 9th 2005, Provincial Governor 0 ffice, Jalalabad.

$10 \mathrm{~km}$ of tarmac. Chaparhar district is considered to be a difficult place to operate due to the high levels of insecurity and inadequate roads. Sholana is a poor district, too far from Jalalabad and not high enough up the Tora Bora Mountains to benefit from a better climate. According to the MRRD and $B R A C$, and confirmed by the research, the vast majority of the population of Sholana are poor to middle income, the majority moving between the two states as fortune (and poppies) allow. Most men are farmers or labourers. Each family (average size 15 persons: see household survey) has typically a high number of dependents: children, elderly members, disabled and widows/orphans. All people in Chaparhar are Pashtun.

Brief Description

Project Name:

Construction of Protective Wall,

Intake and Irrigation System
Length of intake: $250 \mathrm{~m}$

$\begin{array}{ll} & \text { (+80 m extra) } \\ & =330 \mathrm{~m} \\ \text { Top width: } & 0.6 \mathrm{~m} \\ \text { Bottom width: } & 3.5 \mathrm{~m} \\ \text { Height: } & 6.5 \mathrm{~m} \\ & \text { (including foundation) }\end{array}$


Benefited communities:

Sholana, Khanan, Miagan and Gulshir

Benefited families: 523

Land irrigated: $\quad 10,000$ grebs

Total cost: $\quad$ Afs 5626273

US $\$ 112,525$

NSP Contribution: Afs 2063646

US $\$ 41,273$

CDC contribution: Afs 562627

US $\$ 11,252$

Project status:

Nearly completed (on third instalment)

The main project is an intake channel which brings water from the river to the land surrounding the community; the intake also acts as a protective wall. The intake and accompanying irrigation scheme are nearly finished: all that is remaining is to complete $30 \mathrm{~m}$ of pointing on the sides of the canal and cover the foundations of the wall. The other NSP project, now completed, is for sheep rearing where vulnerable groups widows, orphans and the disabled - are given two sheep.

\section{Balla Dehe, Sorkhrod District}

The village of Balla Dehe is $25 \mathrm{~km}$ from Jalalabad to the northwest along a road only partially tarmaced for the first $10 \mathrm{~km}$ from the city. Like Chaparhar, Sorkhrod District is considered to be a dangerous district to conduct the NSP. Balla Dehe lies in an arid valley in the autumn/winter whilst in the spring/summer the snow melt from the mountain ranges is channelled through several wide rivers nearby. The vast majority of people in Balla Dehe are considered to be poor; despite their relatively close proximity to Jalalabad, few travel to the city to work. Most men are farmers or labourers. The average household size is 11 persons with many dependents - children, the elderly, widows, orphans and the disabled. All people in Sorkhrod are Pashtun.

$\begin{array}{ll}\text { Brief Description } & \\ \text { Project name: } \\ \text { Construction of Road and Culvert } \\ \text { Length of road: } \quad 798 \mathrm{~m} \\ \text { Width of road: } \quad 4 \mathrm{~m} \\ \begin{array}{ll}\text { No. of culverts: } & 13 \\ \text { Benefited families: } & 269 \\ \text { Total cost: } & \text { Afs } 1103004 \\ & \text { US } \$ 22,060 \\ \text { NSP contribution: } & \text { Afs } 1002731 \\ & \text { US } \$ 20,054 \\ \text { Community } & \text { Afs } 100272 \\ \text { contribution: } & \text { US } \$ 2,005 \\ \text { Project status: } & \text { ongoing }\end{array}\end{array}$

The only project for which construction has started is for the road and culvert system. Culvert construction is already underway in preparation for the road construction. Already the newly constructed culverts are having a positive effect on the existing irrigation systems.

\subsection{Information for secondary research bases}

Four additional research bases were visited. The results from these bases complement the findings from the primary research bases of Sholana and Balle Dehe.

\section{Kooz Naza Abed, Sorkhrod District}

The village of Kooz Naza Abed is $15 \mathrm{Km}$ away from Jalalabad with reasonable road access. Many men work in Jalalabad as traders, drivers, masons or labourers; it is considered to be a middle income area. In relative terms Kooz is one of the safer places in which to work. The average household size is 10 , with each household comprising many dependents. All people are Pashtun. The NSP only commenced in August 2005 and the community has just finalized its CDC.

Ahmadzi, Sorkhrod District

The village of Ahmadzi is $25 \mathrm{Km}$ away from Jalalabad with reasonable road access. Most of the men work as farmers and labourers in the valley behind the settlement. It is considered to be a poor area. The average household size is 10 , with each household comprising many dependents. All people are Pashtun. To date in Ahmadzi seven boring wells have been constructed.

Mano, Chaparhar District

The village of Dago is $50 \mathrm{Km}$ away from Jalalabad along a poorly maintained track. Mano is considered to be a highly dangerous area and in recent times there have been frequent attacks against the 'government' (security forces, outsiders, etc). Many of the men are unemployed and those who work are labourers, farmers or tradesman. Mano is considered to be a poor area. The average household size is 12 , with each household comprising many dependents. All people are Pashtun. To date in Mano a school is half way through completion and there are ideas for other projects such as culvert/ irrigation system to follow.

Dago, Chaparhar District

The village of Dago is $48 \mathrm{Km}$ away from Jalalabad along a poorly maintained track.
THE PRO VIN CIAL

FIELD SU RVEY REPO RTS 
Like its neighbour Mano, Dago is considered to be especially dangerous. Most of the men are unemployed or work as labourers, farmers or tradesman. Dago is considered to be a poor area. The average household size is 11, with each household comprising many dependents. All people are Pashtun. The diesel generator project has been completed and 760 families now receive electricity for 5 hours a day. The road/culvert project will commence soon.

\section{Merzaian, Sorkhrod District}

The village of Merzaian is $18 \mathrm{Km}$ away from Jalalabad accessed along a poorly maintained track. Most of the men are employed as labourers in the area or in Jalalabad. The village suffered very badly during the Russian occupation and much of it lies in ruins. The average household size is 10, with each household comprising many dependents. All people are Pastun. The CDC was only formed in May 2005, but already a proposal for a $2.5 \mathrm{~km}$ road has been submitted.

Ditawai Amerkhil, Sorkhord District Ditawai Amerkhil is $15 \mathrm{Km}$ away from Jalalabad and lies directly off the main Jalalabad-Kabul road. Most men are employed as farmers or labourers, many working in Jalalabad. The average household size is 10 , with each household comprising many dependents. All people are Pashtun. The CDC was formed in March 2005 and has just received its first grant to begin construction of seven boring wells.

Achin District (special note)

Achin is a district where poppies are extensively cultivated, and the road to Khankai Satkai passes through several open heroin markets and there are many laboratories for refining the opium. Unsurprisingly there is no formal government control in this tribal region and drug mafias and al-Qaida dominate. ${ }^{6}$ There is an occasional American bombardment of laboratories and spraying of poppies which does not ingratiate the local population to the government or the international community. The poor security, geography and the poor state of the roads mean that Achin is considered the hardest district to implement NSP in the whole of the Eastern Region.

Khankai Satkai, Achin District

The village of Khankai Satkai is $85 \mathrm{Km}$ away from Jalalabad in an extremely remote part of Achin District high in the White Mountains, 3 hours' walk from Pakistan. The track is barely passable and access is especially difficult as the poor security situation dictates that $4 \times 4$ vehicles should not be used. Most men are employed as poppy cultivators, wood collectors or, most lucratively, owners of mules who take the opium down the mountain tracks to the market. Outside poppy related activities there is little other employment. The average household size is 12 , with each household comprising many dependents. The vast majority of the population and nearly all CDC members are illiterate. All people are Pashtun but their first loyalty is to their specific tribe. The CDC was formed in May 2003 and a micro hydro project has just been completed.

\section{Asadkhil, Achin District}

The village of Asadkhil is $70 \mathrm{Km}$ away from Jalalabad in an extremely remote part of Achin District, high in the White Mountains, 4 hours' walk from Pakistan. It has exactly the same characteristics as Khankai Satkai. The CDC was formed in December 2003 and a pipe scheme and sheep rearing project has already been completed.

\subsection{Findings from the communities with CDCs}

The findings of the two CDCs in Sholana and Balla Dehe, with additional input from the other secondary CDCs visited, are broken down into several key areas: legitimacy and acceptance of the CDC, functioning of the $C D C$ in relation to the community, project implementation, maintenance, project monitoring, the relationship between the $C D C$ and the government, the relationship between the CDC and the FP, further initiatives as a result of NSP, and perceptions of national solidarity.

5.3.1 Legitimacy and acceptance of the CDC From the research there are two types of community governance systems. In Sholana each area has a CDC with elected members, who in turn elect representatives for the main CDC. Not only does the CDC concentrate on the project and other community development initiatives, the CDC also resolves community disputes over land, and petty crime, etc. Before, the NSP conflicts were solved through elders but according to some 'there was a problem with the elders; many took bribes, they were not accountable to anyone but themselves'. Feedback from Dago suggested that as a result of the $\mathrm{CDC}$ 'there is a great improvement in the way the community is governed; before any 
community development only assisted the powerful or connected but now all benefit, we are all equal now.'

In Balla Dehe the situation is slightly different: as the NSP is a new concept the CDCs and the traditional shura work in parallel, the CDC concentrating on the project and community development whilst the traditional Malik shura dispenses justice and advice. However, this parallel governance is not to everyone's liking. A Malik leader from a traditional shura was scathing in his views of the $C D C$, complaining that 'the community is no longer united behind the old shura, my power is being eroded and my honour as one of the community leader diminishes'. Evidence from all CDC sites showed that in many cases the traditional Malik leaders and some elders had been absorbed within the new CDC structure.

With the exception of some traditional leaders who appear to be marginalized, the remaining feedback was overwhelmingly positive regarding the acceptance of CDCS. Even some with initial reservations now view the CDC positively. The CDC Chairman for Merzaian explained, 'I was doubtful at first about how CDCs will work and I questioned if the government was really committed, but then I went to the jirga in Kabul and was very impressed by the Ministers and President who showed they fully support what we are doing.'

Even in areas where the CDCs are newly established there is widespread acceptance of these new forms of community government. For the majority the CDCs have changed the way the community is governed for the better. This positive support is not altogether surprising given the existence of the extremely weak district administration that tends only to concentrate on security.

It is hard to generalize about the leadership within the CDCs: in Sholana, Kooz Naza Abed and Balla Dehe the CDC chairmen were older males, whilst in Mano and Dago both $C D C$ chairmen were younger men who in both instances were given the position because they were good communicators and educated.

In terms of being aware of the NSP, all communities highlight how BRAC entered the community and began NSP orientation. Until BRAC appeared no one had heard of the NSP.
General comments

1. In the communities where the NSP is fully established the CDC has taken over as the primary community decision-making unit and is widely accepted as a positive agent for change. In the communities where the NSP is in the process of implementation the CDC is seen as a project implementation unit whilst the traditional malik shura concentrates on all other issues.

2. In some cases traditional leaders have been marginalized. This is especially the case when senior CDC members have been chosen because they are good communicators and literate (as opposed to someone with authority that comes with age). This has caused some resentment, but in the research bases visited even the 'marginalized' admit that the project seems to justify the process.

3. Elites tend to dominate the main CDCs, maliks and immans and former warlords remain influential.

4. All established CDCs could explain the NSP process with reasonable confidence; the accompanying documentation appeared to be in order, although the extent to which the communities could undertake such an exercise in the future without BRAC is highly questionable.

5. There is an opportunity cost to participation in the CDCs. Whilst at the moment voluntarism is accepted, many CDC members wanted some form of future financial incentive.

6. The recent jirga in Kabul was cited by many CDC members to be a defining factor that influenced their perception of the NSP. As a result of hearing ministers and even the President talking about the NSP people became more enthusiastic.

\subsubsection{Functioning of the CDC in relation to the community}

All the CDCs visited (including the newly established $(D C$ ) were able to explain how the $C D C$ functions as clarified in the Operational Manual.

In every $C D C$ meeting room there are the posters explaining the process of the NSP; these no doubt acted as prompts in some cases. But it was clear from the general comments from both male and female CDC members that the process described in the Operational Manual was generally well known. Throughout the course of the
THE PRO VIN CIAL FIELD SU RVEY REPO RTS 
research there were some specific functions of the CDC that act as examples of an understanding of the process of NSP:

\section{Clusters}

'We divided into clusters to elect members for the main CDC.' (Sholana)

\section{Priorities}

'At our first meeting with the clusters we clarified the main problems here and identified the most important. It was decided that the intake and channel was the most important priority for the community. For as long as we can remember we have wanted to harness the river in flood to irrigate our land, but until now we were not able to do so, because of war and insufficient funds. However the poorest did not think that the intake was a priority because they do not have any land from which better irrigation would be a benefit. So we decided that the poor would be the labourers for the project (intake, wall and channel) for which they would be paid. In addition we also gave then Afs 10,000 . Previously the poor could not complain but they are listened to and we hired them for labour, this was agreed with BRAC who then sent an engineer to design the project.' (Sholana)

\section{Elected representatives}

'All members are elected; as this is a voluntary process not everyone is active all the time, but we try to ensure that all people (all men) participate as much as possible. Women may NOT vote, one of the clusters comprises females only, but this cluster did not have a role in the election of the main Sholana CDC.' (Sholana)

\section{Documented activities}

'In all the CDCs visited the Chairman presented the various ledgers, procurement book (stationery, building material, labour etc), bank account information, labour register, minutes of meetings, register for community contribution (in kind/cash). Although in Pashtun these were clarified by national researchers. In addition at most sites where the project was being constructed there were noticeboards to show all the community the objective of the project, costs, community contribution in kind/cash, time, and grant instalment.' (Balle Dehe)

In the regional $\mathrm{OC}$ offices the evaluation team was able to select various random projects and check the documentation, as described in Manual p.18-25 II A B V ABC p.49-54; all documentation appeared to be in order.

\subsubsection{Gender considerations}

As warned by the national and regional OCs as well as BRAC, the participation of women in the NSP in Nangarhar is highly problematic. Evidence from the research, especially in Sholana, Mano, Dago (Chaparhar) and Khankai Satkai and Asadkhil (Achin), supports these warnings.

The district of Chaparhar is the most conservative place in Nangarhar, itself one of the most conservative places in Afghanistan along with Kandahar and Patikya. BRAC community mobilizers faced a myriad of problems concerning the involvement of women. In the first instance men would not allow the women to be on the household list in areas where the NSP was going to commence; the men would not allow the women to participate and BRAC were accused of compiling a list of women to pass on to the CIA for them to interrogate.

However, there has been some relative progress. In most areas women have been able to form a female-only CDC. Most of the female-only CDCs comprise of younger women. The women then give authority to their sons, brothers, husbands, uncles, grandfathers, cousins etc to use their vote to vote on their behalf for the election of the all-male main CDC. Feedback from all the female-only CDCs interviews suggested that the women were happy with this arrangement. As one Mano female CDC member said, 'We are happy to give our men the vote, they know what is best for us, it is natural for us to look to their judgement'. As such the female CDCs have virtually no practical role in the implementation or planning of the priorities, community development plan and project. As one female from Dago explained, 'The men come back to us and explain the priorities to us and how we as women will benefit from the project so they keep us informed.' In Mano women were happy with the proposed construction of a road, as in the past some pregnant women died on the way to the hospital on the back of a mule because the road was so bad; soon women will be able to go by car.

The female CDCs however do want specific projects for women: short courses on literacy (if you are over 21 or married you cannot go to school), tailoring, farming, pottery, and health courses. As one female 
from Sholana commented, 'We are not allowed by our husbands to be vaccinated because the vaccinator is a man. Even if it is allowed the vaccination must be through the clothes to the arm and not on bare skin. Therefore we need female vaccinators as well as training for traditional birth attendants.' In Nangarhar BRAC has introduced some animal husbandry projects specifically for women.

Despite these shortcomings there is one clearly discernable benefit for women that the NSP provides. As the female CDC group from Mano explained: 'Before the NSP we were not allowed out of our houses to talk with the other women, we had to stay in and look after the children and men, we were only allowed out for funerals and weddings. But now we can go to the CDC meeting and we can discuss many issues and chat with our friends, about other things of concern to us...' As one BRAC member commented, 'This is a social revolution in Nangarhar!'

Has the NSP in Nangarhar led to an increase in the empowerment of women? Not necessarily in terms of contribution to community planning for community development, but certainly in terms of being sensitized to other issues. Now there is a forum for the women to meet which is being used tentatively to discuss issues such as domestic violence and female health. This would have been impossible without the NSP.

The situation in Achin is different from Chaparhar; in both the CDCs visited women were not included in any part of the NSP process. Although in both CDCs the men claimed that women benefit from the respective projects.

\section{General comments}

1. Nangarhar is a highly conservative area. The inclusion of women in the NSP in this area has to be viewed in relative terms.

2. Without exception all members of the senior CDCs are male. Women have formed their own CDCs (as specified by the manual). However, the women give their votes to their male relatives who vote for the all-male members of the senior CDC on their behalf. This process was universally accepted by the females in the sites visited.

3. Females do not have a direct say in the process of prioritization and project selection. Feedback from the women suggests that their male relatives inform them as the decision is being made. This was also universally accepted by the females in the sites visited.

4. Females do have their own sets of priorities for gender-specific initiatives health training, micro enterprise and literacy.

5. The NSP gives one key benefit to women. Until the female-only CDCs were established women were not allowed to mix outside of their household. Now, through the CDC, women can meet to discuss NSP matters. The female-only CDCs have become a forum for discussion on other relevant issues (health, domestic violence, literacy, etc) that women could not discuss before for want of a reason, this is a direct result of NSP.

6. The situation in Achin is even more extreme; women are not even part of the NSP process. For the men of Achin this is simply unacceptable.

\subsubsection{Project implementation}

All CDCs visited reported that BRAC had been able to facilitate what the community had wanted once it was established that certain priorities, such as mosques and clinics, were not viable.

Once the project was endorsed the community received cash from the government to purchase materials, pay for labour and in some cases, i.e. Sholana and Balla Dehe, hire one local engineer 7 who oversaw the construction of the project (BRAC also oversaw the local engineer). In both cases the community also contributed cash, labour or payment in kind. However, evidence from Balle Dehe and other CDCs suggest that there was excessive optimism when the $C D C$ was formulating the amount of community contribution.

The only problem experienced was due to the delay in disbursements. In Sholana the CDC had received money within three months of submission but there was a delay in instalments of four months. This meant that the work stopped and a sudden flood also affected the structure which was not yet finished.

An example of problem-solving enabled by the NSP comes from Sholana: during the project implementation one of the CDCs complained that the poor were not benefiting to the extent they should, so it was decided that more workers from especially
7 It later transpired that the local engineer hired in Sholana was in fact a close relative of the chairman.

THE PRO VIN CIAL FIELD SU RVEY REPO RTS 
poor backgrounds would be hired for the earth moving and labouring.

All the CDCs and household surveys suggest that the NSP has provided many benefits. In Sholana for example the NSP was associated with three main benefits: 1 ) the intrinsic project: the protective wall against the flood and prevention of erosion of bank and the irrigation of land that was hitherto considered to be unusable because of poor/nonexistent irrigation. This has also meant that cotton and sugar cane can be grown as cash crops. 2) As a result of the process of identifying and constructing the project the CDCs maintained that they have learnt new skills that can be used to ask donors for additional help, and the community is now more united as a result because the benefits of working together can be seen. 3) Other initiatives have been implemented such as the water wheel to crush wheat which would not have been possible without the NSP.

As one Sholana resident confirmed, 'There is a huge benefit [from the NSP]: before the intake I could only harvest $50 \mathrm{~kg}$ of wheat; now, because of the intake, in the same plot of land I can harvest $400 \mathrm{~kg}$ of wheat. We can now also grow maize because the irrigation is good and we can sell much more and increase our income.' A widow and orphans in Sholana were enthusiastic in their support for the sheep rearing project for which they have received two sheep each for milk, wool and lambs, although they were under the impression that the Chairman of the $C D C$ had given them the sheep and had not heard about the NSP. In the long term the CDCs in Sholana hope that they can cultivate more land and grow more plants, especially fruit, as a result of the NSP.

In Balla Dehe the NSP also has many practical benefits from the road/culvert project and the process of community mobilization. As one Balla Dehe CDC member explained, 'All the community gets benefits from the road: vehicles can visit the community, people who are sick can get to the clinic easier and faster, those who own land are happy because the price of their land that is by the road has increased, goods will be cheaper in the shops, farmers will be able to take their goods to Jalalabad, and more resources can enter the village. We expect more projects in the future because we have opened up access.' In addition the CDC feels it is in a good position to encourage other donors to help the community as they now have experience in project management.

None of the CDCs visited were aware of the complaints procedure, when problems occur BRAC is the first point of contact; if a problem is serious the MRRD in Jalalabad is informed.

\section{General comments}

1. In all bases researched the CDCs were happy with BRAC's performance, helping to deliver on the priorities the CDCs identified.

2. All CDCs provided contributions towards the project, either in cash or in kind. However, in all cases there was excessive optimism regarding what the community could contribute, and in some cases individuals have reneged on their promises and this has caused some division.

3. The delays in disbursement are considered by the CDCs to be the major problem experienced. When the projects are delayed, costs rise since the original estimates were undertaken, and momentum is lost.

\subsubsection{Project monitoring}

Both communities claim that they have a monitoring system in place. Evidence from the documentation at $C D C$ and verified at OC level shows how the progress of the projects has been measured in terms of labour given, materials purchased, funds dispersed and projected targets met (depending of course upon timely disbursements). However, from discussions with BRAC and more in depth discussions with the OC's monitoring officer, as well as questions to the various $\mathrm{CDC}$ members (chairperson, procurement officer etc), it is apparent that BRAC through its regular meetings with the $C D C$ plays the defining role in the monitoring of the project, not just through its own engineers but also through influencing the CDCs in terms of what to write down.

Another monitoring method is also apparent. At the main construction site there is a whiteboard detailing funds disbursed, instalments given, community contribution in cash and in kind and time plan for completion. This provides a visible sign, for the literate in the community, of progress and acts as a form of community monitoring and transparency. 
General comments

1. In all the research bases visited there was evidence of a monitoring procedure as defined in the manual. However, BRAC plays the defining supportive role in the monitoring.

2. The community monitoring is complemented by whiteboards at the key construction site showing all literate community members an updated cost, community contribution, instalment number and targets. This reinforces ownership and transparency.

\subsubsection{Maintenance and sustainability}

All CDCs appeared to appreciate the importance of maintenance of the facility. Without exception all explained that a form of community tax, either in wheat or money, will be levied to pay for someone who will be responsible for the maintenance.

As the Sholana CDC Chairman explained: 'Now we have the experience with BRAC we have planned to maintain the intake in the future. We collect annually wheat for one person who is responsible for the maintenance (asher); all people contribute to this. If there is a problem this person will sort it out and he is paid by wheat.' In Balla Dehe the same arrangement will be in place when the road/culvert system is completed.

\section{General comments}

\section{All CDCs appreciated the need for} maintenance and have planned a community levee, either in cash or in kind (asher), to pay for one person to oversee the maintenance of the facility. However, BRAC and the OC have doubts if this system can be maintained in the long run.

2. The sustainability of diesel generators appears to be particularly problematic as fuel costs have risen substantially since the generators were installed.

3. In some instances communities have developed further initiatives as a result of the NSP project (see Benefits of the NSP 7.4.8).

4. In some of the research bases, the project was complete but a 'Project Completion Certificate' was not forthcoming.

\subsubsection{Relationship between} the CDC and the government The relationship between the $C D C$ and the district level government is poor; the district administration is really the $C D C{ }^{8}$ In both Sholana and Balle Dehe it was clear the district administration have little capacity. Even though both communities have CDCs the district would still communicate through the traditional maliks and not the newly elected CDCs. In addition feedback from all the research bases suggested that the district administration concentrates more on security issues than 'development'.

The relationship between the $C D C$ and the province is better; as one Balle Dehe resident explained, 'We see the provincial leaders when they come to give us our certificates and open our projects. Until now we have never see them before so we appreciate that now they are taking an interest in us.' However there was general agreement to one of the comments from the Balle Dehe CDC, 'Only the MRRD and NGOs work for the people of Afghanistan; other ministries need to be taken over by NGOs so they too will work!'

In terms of improvements all feedback was universal in stating that the district administration needs more resources, or that the CDC should become the district administration as soon as possible and work with the provincial government directly.

\section{General comments}

1. The district administration has practically no capacity to work with the NSP. In addition the research from the $C D C s$, the $O C$ and FPs confirms that the district administration focusses more on security than 'development'. In some cases the findings suggest that the district administration communicates to the community through the traditional malik shuras and not through the CDCs. This in some cases has led to disillusionment within the CDCs that their potential influence is already being undermined by a traditional system

2. The relationship with the provincial government is better, with fairly regular contact especially when certificates are presented and projects inaugurated.

3. The perception that the NSP is a government programme is reinforced with NSP/MRRD signs at key construction sites throughout the community.

4. All the evidence from this research suggests that there has never been greater contact between those communities with CDCs and the provincial government.

\footnotetext{
8 Following the CDC jirga in August 2005, the process to legalize the CDCs to, in essence, become the elected district administration is underway.
} 


\subsubsection{Relationship between the CDC and the FP}

There are many factors which influence the relationship between the CDCs and BRAC, possibly the most crucial is the training that BRAC provides for NSP orientation, problem identification and prioritization, project management, accounting, and procurement, etc.

The training given was useful, as one Sholana CDC representative stated: 'We had NSP orientation and training in finance, book-keeping, procurement, proposal preparation and project planning. All the training was useful and some of us have learnt new skills which we might be able to use in the future. However, many of the forms are too complicated and we asked BRAC to help us (especially the procurement form). The training we received helps us to show the community what we have received and spent and we can show the community the balance, this makes us transparent'. Another Sholana CDC representative observed that, 'We obviously have the knowledge and skills necessary because we have completed the project!'

BRAC also gives day-to-day support and advice, e.g. in Sholana for the second project, sheep rearing. BRAC gave the CDC ideas as to the economic benefits of sheep rearing and medicine for the sheep. However, as clarified above, due to the time pressure BRAC is under from the $O C$ at provincial and national level, whilst the training is given it would be inaccurate to say that the CDC has the full capacity to cope with the NSP or other similar development initiatives if left entirely to its own devices.

1. All NSP communities visited deemed the training provided by BRAC to be very useful.

2. Many of the CDCs whose members are literate find the forms (procurement, accounting, and subproject completion forms) too complicated and are content to rely on BRAC to ensure their completion. This inevitably means the $C D C s$ are not best equipped to face a future without BRAC. In some cases CDCs are just signing already completed forms.

3. BRAC is operating in some areas (e.g. Achin District) where the vast majority of all CDC members are illiterate. In such circumstances there is little option but for BRAC to complete all the forms.
But this again does not mean that the CDCs are now equipped to face the future without BRAC.

4. BRAC are under pressure to complete projects. This inevitably means that there is some degree of fast-tracking the process of NSP through the communities, which is detrimental to ensuring a more in-depth understanding amongst the $C D C$ members.

\subsubsection{Further initiatives as a result of NSP}

In terms of initiating further projects as a result of the NSP the CDCs are optimistic. In Sholana the CDC identified the need to clear traditional irrigation systems: this was funded by DAl. During the elections the $C D C$ was asked to provide voluntary protection for the election site. In Ahmadzi the CDC received GTZ funding for a small bakery.

Although far less advanced in Balle Dehe the $C D C$ feel that they are becoming equipped with the skills and knowledge to approach other organizations. However, the best example of further non-NSP initiatives comes from Sholana where a water wheel has been added to the NSP intake channel to grind the wheat. This was set up through the CDC's own initiative and could only have been made possible through the NSP.

Non-project initiatives are also developing. In the more established CDCs like Sholana, Mano and Ahmadzi, tentative steps are being taken for the CDC to become a wider community problem solving forum. This is not altogether surprising as in most instances the Malik, and often the Imam, have key positions within the CDC.

\subsubsection{Perceptions of national solidarity}

Feedback from all the research bases gave a broadly similar perspective of the NSP's contribution towards national solidarity countrywide. Common responses to how the communities' experience of NSP leads to national solidarity were defined at community and national level:

\section{Community level}

- 'The NSP provides unity as the CDCs do not just concentrate on the project; we have interacted with each other to create the project and so our community is more united and stronger as a result, and this helps the country as we see the government is helping us; this has not happened before.'

(CDC representative, Mano) 
- 'We coordinate our work between the other CDCs, we meet and share ideas; this has created unity.'

(CDC representative, Sholana)

$\checkmark$ 'The main benefits are that people are coming together to solve community problems and as a result we improve our community with a project.' ( $C D C$ representative, Dago)

$\checkmark$ 'The CDCs will exist in the future because we have the training and knowledge to identify priorities and submit proposals for projects to other organizations other than BRAC.' (CDC representative, Sholana)

$\checkmark$ 'The CDCs will exist because they are through election, and everybody can vote (not women); as the CDC is transparent it will continue.' (CDC representative, Mano)

$\checkmark$ 'We are optimistic for the future in Ahmadzi because there has been elections at district level and country level and eventually the CDCs will become the governing structure at the district level and we will be paid.' (CDC representative, Ahmadzi)

- 'Unity increases when people work together to build the project and participate in decisions that affect the project. The management, monitoring and construction that the community has to undertake can also increase unity as we are all working together. Unity would also be created if larger projects affecting several districts would be undertaken.'

( $C D C$ representative, Sholana)

National level

$\checkmark$ 'The NSP is very useful at country level too as it contributes to the development of Afghanistan and we get a project in our community.' (CDC representative, Balle Dehe)

- As all communities in Afghanistan have NSP (incorrect) this will help us be unified.' (CDC representative, Ahmadzi)

$\checkmark$ 'There are many communities with NSP, it shows us the government wants to help us and is listening to different communities all over Afghanistan, therefore it is helping to unify us.' (CDC representative, Sholana)

$\checkmark$ 'We know the government does not have the resources so it is asking foreigners to help us, but we appreciate, but our loyalty is always first to Allah and our tribe.' (CDC representative, Mano)

$\checkmark$ 'As we are voluntary we are in fact doing the government's job all over
Afghanistan; we are doing government work, they are not paying us, the money the government saves can be used for other reconstruction purposes. As we are all working for the government together we are united in a purpose for reconstructing the whole country.' (CDC representative, Dago)

$\checkmark$ 'NSP weakens the power of warlords, decision-making is at the grass roots and because of employment and better livelihoods, people will not want to fight.'

(CDC representative, Ditawai Amerkhil)

$\checkmark$ 'We are very optimistic about future unity in Afghanistan. There has been many years of war but NSP gives us hope and we know that the world is supporting Afghanistan. We are Tajik, Pashtun, Uzbek, Communist, mujudaheen and were divided, but this programme helps us come together.' (CDC representative, Merzaian).

General comments on the benefits of the NSP in the communities The NSP is associated with several key benefits:

1. The formation of the $C D C$, forming a $C D P$, selecting priorities and then jointly implementing a project has given a huge boost of collective confidence and esteem to the communities where the NSP is being undertaken. Such communities are more optimistic about the future than those communities where there is no NSP.

2. Without exception all communities knew that it was a government programme and understood the connection between community empowerment, joint decision-making and the improvement of rural infrastructure with improved livelihoods and a greater feeling of local and national unity. Quite simply the government is listening and responding to community needs - a very welcome process unheard of until now.

3. The NSP process has introduced new skills to the community, which certainly need to be consolidated, but nonetheless contribute to community confidence, especially when it comes to approaching other donors for assistance and using the CDC as a problem solving forum.

4. The intrinsic projects in the sites visited were generally well designed and constructed appropriately. In particular those projects which bring multiple
THE PRO VIN CIAL FIELD SU RVEY REPO RTS 
benefits are especially noteworthy, such as the culvert/road, protection wall/intake, boring well projects, and tended to benefit the most number of people regardless of economic status or participation in the CDC process.

5. The NSP facilitates other community-led initiatives that could not otherwise have been undertaken. Additional infrastructure is often added to the NSP project which enhances the value of the NSP, demonstrates community ownership and initiative, and to an extent augurs well for the sustainability of the project in the future.

6. There is a clear link between the projects implemented and poverty reduction at a community level. For example from the sites visited the NSP was associated with several discernible poverty reduction benefits which included the communities' ability to: grow more produce, especially cash crops such as sugar and cotton, and sell the surplus; adopt year-round cultivation and generate more income which is spent within the community. The communities also benefit from cheaper goods because of improved transport; a reduction in transport costs; greater levels of protection against natural disasters; better levels of communication and higher levels of education.

7. There is a direct benefit on poppy eradication objectives at the local level, as through the NSP community livelihoods are improved through other means than poppy cultivation. However, it is recognized that the effects in this regard are fairly limited and poppy cultivation is still deemed to be lucrative.

\section{The community without a CDC}

For comparison purposes and to show the real impact of NSP the matched non-NSP community of Bahsawal in Mohmamdara District was selected.

The village of Bahsawal is $55 \mathrm{~km}$ from Jalalabad and $10 \mathrm{~km}$ from the Pakistan border. The majority of the men are unemployed, only finding occasional labouring work in Pakistan. The only community infrastructure is the school, mosque, and community centre. It is a poor area, similar to the other research bases with the exception that Bahsawal does not have the NSP. The average household size is 15 , with each household having many dependents, especially children, widows, the elderly, the disabled and the sick.

\subsection{Existing traditional forms of governance within the community}

There is no regular system of shuras; the Imam leads the people along with village elders, who solve problems together. The community struggles to meet its needs; there are no 'development' initiatives, only reactions to events such as flooding. In such cases asher is used to meet immediate needs.

The community leaders maintain that the reason they are unable to get assistance is because of their geographic position between Pakistan and Afghanistan, making assistance difficult and dangerous. As one senior leader said: 'We have a lot of problems but no one wants to listen to us. We need clinics, intakes, flood protection our houses and fields are often destroyed because of flooding. The road is also bad and there are no culverts in place. There are no employment opportunities for labourers to earn a wage.'

\subsection{Relationship between the community leadership and the government}

The relationship with the district administration is adequate. As the Imam highlighted, 'The district government told us about poppy eradication so we have stopped growing poppies. We go to the district government when we need something, like an intake, flood protection system but they cannot help us. They do not undertake such schemes, they are more concerned with security. At the provincial level there is no relationship. We have asked MRRD for help before and we have waited a long time and still no help is forthcoming. We have no reason to be optimistic about the future.'

\subsection{Prospects for NSP}

Most people had not heard of the NSP; those who were familiar with the NSP had heard about it on the radio and in the newspapers, but were unaware of the NSP's objectives and rationale. Once the NSP process was explained the initial reaction was broadly positive, although the leaders 
were slightly suspicious that the CDCs might undermine their status. In addition all present maintained that the community is always unified. However, it was universally agreed that any programme that could address some of their basic priorities would be welcome and as one elder enthused: 'If we had CDCs everywhere we can formulate development across the country. There will be no need for government/aid agencies to ask what we want they can just go directly to the CDCs!'

\section{The Household Survey}

1. Sholana, Chaparhar District (NSP nearly completed)

2. Balle Dehe, Sorkhrod District (NSP recently started)

3. Basawol, Mohmahandara District (matched non NSP community)

\subsection{Sholana, Chaparhar District, Nangarhar (NSP nearly completed)}

Profile (information from FP and CDC) The village of Sholana in the foothills of the Tora Bora is $45 \mathrm{~km}$ away from Jalalabad; the access road is in a poor condition with only $10 \mathrm{~km}$ of tarmac. Chaparhar District is considered to be a difficult place to operate due to the high levels of insecurity and inadequate roads. Sholana is a poor district, too far from Jalalabad and not high enough up the Tora Bora Mountains to benefit from a better climate. According to the MRRD and BRAC, and confirmed by the research, the vast majority of the population of Sholana are poor to middle income, the majority moving between the two states as fortune (and poppies) allow. Most men are farmers or labourers, either for landowners in Sholana, in the poppy fields (seasonal, but relatively well paid)* or in Pakistan. Each family has typically a high number of dependents - children, elderly members, disabled and widows/orphans. All people in Chaparhar are Pashtun.

* Many of the community males benefited from working in the poppy fields before it was banned by the Taliban. Now, due to less central control, poppies are once again starting to be cultivated in the area and providing some much needed employment.
Brief Description

Project Name:

Construction of Protective Wall,

Intake and Irrigation System

Length of intake: $250 \mathrm{~m}$

$$
\text { (+80 m extra) }
$$$$
=330 \mathrm{~m}
$$

Top width:

$$
0.6 \mathrm{~m}
$$

Bottom width:

$3.5 \mathrm{~m}$

Height:

$6.5 \mathrm{~m}$ (including foundation)

Benefited communities:

Sholana, Khanan, Miagan and Gulshir

Benefited families: 523

Land irrigated: $\quad$ 10,000 grebs

Total cost: $\quad$ Afs 5626273

US $\$ 112,525$

NSP Contribution: Afs 2063646

US $\$ 41,273$

CDC contribution: Afs 562627

US $\$ 11,252$

Project status:

Nearly completed (on third instalment)

The main project is an intake channel which brings water from the river to the land surrounding the community; the intake also acts as a protective wall. The intake and accompanying irrigation scheme are nearly finished: all that is remaining is to complete $30 \mathrm{~m}$ of pointing on the sides of the canal and cover the foundations of the wall. The other NSP project, now completed, is for sheep rearing where vulnerable groups widows, orphans and the disabled - are given two sheep.

\section{Sample}

Representatives of 12 households ( 12 men) were interviewed. Interviewees were contacted in advance and the interviews were conducted in the individuals' houses. Under the circumstances the sample was considered as representative as possible given that a random sample was not possible.

Respondents came from 3 areas of the community.

The CDC, FP and evidence from the MRRD define the community as 'poor' and only one respondent defined his household as 'middle'. The vast majority were poor because of lack of arable land and non-agricultural sources of income (one middle, 11 poor).

The average household size was 14 (largest 30 smallest 7). Three nuclear families in which husband and wife were outnumbered
THE PRO VIN CIAL FIELD SU RVEY REPO RTS 
by their dependent children. 9 families of more than one generation and/or adult siblings living together in which adults outnumber children. The average number of children was 6 (apart from the nuclear families, not large numbers of dependent children but see below).

The majority of householders (10) defined all those not wage earning or generating income as 'dependent'. However, in two cases, the wife of the householder was apparently not included in the total of dependents. On this basis, the average number of dependents was given as 13 . This, in all but two cases, included all women, whether able to carry out domestic work or not, and all children. It also included a number of men, either unemployed younger men or the elderly. However, the one case mentioned of a disabled head of household, a father unable to work, was not counted as dependent. Similarly, a disabled son in another family runs a canteen and was logically not counted as dependent. One family was supporting 3 widows (who might have been elderly) but 3 wives were also seen as dependent. No other adults who might be unable to contribute their labour to the household due to sickness or disability were specifically mentioned, though they may well have been present.

One reason for this perception of dependence might be the fact that the households sampled were all landless (no farmers were included) and therefore totally dependent on income from external sources. Perceptions of the status of women and their work in the home seems to be another reason.

The main or important livelihood activity in 4 households was given as labouring. In one case 4 sons working in poppy cultivation. Three households had members who are teachers. One household was supported by two police constables, one by a government worker. Two families had skilled trades: one as masons and one with a tailoring shop. One was a general shopkeeper. Additional incomes were earned by an engineer and a flour-mill worker in one family, and a security guard in another.

War experience/post-war situation The area was very badly affected by the Russian invasion and many people fled to Pakistan. Six householders interviewed had migrated to Pakistan. Six had had their homes destroyed or partly destroyed by bombs or missiles. Two of these had nevertheless remained throughout the war. Two householders had migrated due to drought and unemployment (rather than fear for their lives) to Jalalabad and Sholana. One had a son imprisoned by the Russians and then released in a prisoner exchange. One had a son killed. Respondents were keen to tell of the injustices suffered during the war, especially the deaths and injuries suffered. However one respondent said he had been unaffected by the war.

The Taliban period was associated with relative stability although some disliked the hard-line approach, as one respondent commented, 'Under the Taliban I had to pray 5 times a day, now I only have to pray twice - I am happier now!'

The majority of the respondents (9) did think life is better since the fall of the Taliban and end of the war. At least one had felt able to return home. Three spoke of better opportunities for work and business. Two saw the NSP as bringing work and the prospect of more work in the future. One thought having an elected shura responsive to their needs was a big improvement. Three simply felt happier and felt they had personal freedom since the Taliban had gone. Two cited the end of the drought as a good omen, due to the demise of the Taliban according to one, and to the return of the King for another.

Three however felt insecure in the new situation. One said security had been very good under the Taliban but now they are fearful. Another said the security situation was worse and as government employees they were always fearful. Another was concerned that poppy cultivation that provided opportunities for labouring jobs would be banned again.

General understanding and awareness The respondents' replies to questions about the CDC/NSP and government suggest that there is a gap between the intrinsic process of NSP and how this is understood by nonCDC members in the community of Sholana. They mostly saw it as a community development project, rather than the creation of a new form of governance, though they recognized its value in promoting greater unity.

They were however, well informed about the working of the $C D C$ and the project in general terms but did not follow it in detail. 
They all understood that NSP is a government programme while appreciating the work of the FP. They were also conscious of the government's limitations in providing assistance for the recovery of the country, given the lack of resources and the security situation. Nevertheless, the majority thought it had good plans and is interested in their community.

\section{History of the CDC}

All respondents knew that the $C D C$ was some form of shura and that its representatives were elected through clusters, a process everyone questioned took part in. They also knew that an electoral commission of 4 had been selected, but did not say how. They all estimated that the CDC had been functioning for about a year.

However, all respondents questioned highlighted that the community has always known what its priorities were and that the former shura was able to define these priorities. The difference now is that there is funding available to meet those priorities.

\section{CDC today}

Functioning and legitimacy

All knew that the CDC would meet after Friday prayers and all were able to give a very brief explanation of how the CDC could select members and vote on priorities that benefited the community. All were of the opinion that the CDC leaders were now the genuine leaders of the community and not maliks or local warlords. However, they were unsure if the CDC were working with government and thought that it was the former Maliks who did.

Projects

All knew that the project was a government/MRRD initiative implemented through BRAC. They all knew how labour was assigned and that there were specific days when they had to work. Though none had actually participated so far, they said there were no problems in getting people involved. (The work was in fact delayed due to disbursement problems but they did not mention this.) They were confident that the CDC dealt with everything.

They had not heard of the CDC approaching any other organizations for funding, but knew that the CDC has a plan for the next project because it would follow the list of priorities that everyone in the community is familiar with.
Financial management

They were all certain that the Block Grant had been spent, in instalments on the protection wall and intake and on sheep rearing. However, none could clarify how, for example, finances were managed, transparency shown or how procurement took place, though they expressed confidence in the CDC mechanism and its members.

Impact of the NSP/CDC

In answer to the question, 'What does NSP/CDC mean to you?' all respondents referred to it as a project but descriptions of its purpose varied; but most were concerned with reconstruction and development: 4 described it as a development project; 3 to help the poor/alleviate poverty; 3 respondents described it as a government assistance or reconstruction project for the whole country; 3 mentioned that it was aimed at poor/rural communities; one simply equated it with the village intake project. Only two mentioned the social aspects of the programme: 'to bring unity', 'to cement people together.'

Nine respondents claimed that the NSP had improved their own lives as well as the community as a whole, mostly due to the protection from the floods, irrigation of land, temporary employment and improved agricultural productivity. Four also noted greater unity in the community. As one respondent said, 'The NSP has helped a lot, we are more united as a community and have a project that gives us hope and I can also produce more wheat.'

Two respondents said the NSP had not benefited them personally, though one said the villagers as a whole were happy and benefiting from the project. One (a teacher) said, 'No, it has not helped us.'

They all cited the FP as the main help besides the programme itself.

They also generally agreed that there was more unity in the community as a result of meeting more frequently and sharing problems.

All the respondents were able to mention additional positive changes resulting from the NSP. Most (7) mentioned material changes: the water wheel, easier cultivation, higher crop yields, more employment. Three saw better prospects for the future due to the ability to discuss development (1), and skills for future projects (1); greater
THE PRO VIN CIAL FIELD SU RVEY REPO RTS 
hope for the future (1). Two mentioned here greater unity.

Perceptions of government

Respondents had mixed views about government plans for the country. Four thought the government did not have the capacity to implement any plans. One of these did not think it had any plans beyond guaranteeing security, 'Government is busy arranging security for the people and it has not time to think about other aspects of life.' The others credited it with having plans but not the resources or ability to implement them. Four others thought the government has good plans for the country and their future. One of these suggested government had other plans like the NSP. Three said the government has no plans, one adding that only NGOs work. One feared the government plans to eradicate poppy cultivation.

Confidence in the future

All respondents cited employment opportunities as the one thing that would transform their lives. Finally, all respondents were optimistic about the future because they have seen the benefits of government help in the community with the NSP, and life is now better than under the Taliban.

\subsection{Balla Dehe, Sorkhrod District (NSP recently started)}

Profile (as given by the FP and CDC) The village of Balla Dehe is $25 \mathrm{~km}$ from Jalalabad to the northwest, along a road only partially tarmaced for the first $10 \mathrm{~km}$ from the city. Like Chaparhar, Sorkhrod District is considered to be a dangerous district to conduct the NSP. Balla Dehe lies in an arid valley in the autumn/winter whilst in the spring/summer the snow-melt from the mountain ranges is channelled through several wide rivers nearby. The vast majority of people in Balla Dehe are considered to be poor, and despite their relatively close proximity to Jalalabad few travel to the city to work. Most men are farmers or labourers. The average household size is 11 persons with many dependents - children, the elderly, widows, orphans and the disabled. All people in Sorkhrod are Pashtun.

\author{
Brief Description \\ Project name: \\ Construction of Road and Culvert \\ Length of road: $798 \mathrm{~m}$ \\ Width of road: $\quad 4 \mathrm{~m}$ \\ No. of culverts: 13
}

Benefited families: 269

Total cost:

Afs 1103004

US $\$ 22,060$

NSP contribution: Afs 1002731

US $\$ 20,054$

Community

contribution: Afs 100272

US $\$ 2,005$

Project status:

ongoing

The only project for which construction has started is for the road and culvert system. Culvert construction is already underway in preparation for the road construction. Already the newly constructed culverts are having a positive effect on the existing irrigation systems.

Sample

Representatives of 7 households (all men) were interviewed. Interviewees were contacted in advance and the interviews were conducted in the individuals' houses. Under the circumstances the sample was considered as representative as possible given that a random sample was not possible. In addition the sample was similar to that of the community of Sholana in that all were 'poor' and had many similar livelihood characteristics.

Respondents came from 3 areas of the community.

- The CDC, FP and DRRD define the community as 'poor' and all respondents described themselves as such.

- The average household size is 10 (smallest 5, largest 16). Three were nuclear families of husband wife and children (average of 6). Four families consisted of adults of more than one generation, or siblings with their spouses and children. The average number of children in these households was also 6 .

$\checkmark$ As in Sholana, all those not earning (women, unemployed men and children), were described as 'dependent' (average 8) though none were said to be disabled, sick or elderly.

$\checkmark$ Four respondents were illiterate.

- All respondents were Pashtun.

$\checkmark$ Two householders were farmers; two were drivers for an NGO. One of these had two brothers working as teachers; one was a shop owner; one a carpenter; one family had 3 men working as labourers. 
War experience/post-war situation Four of those questioned in Balle Dehe said they were not affected by the war. However one went to Pakistan to avoid recruitment by the Communists during the Russian invasion of Afghanistan. Two others migrated, one to Pakistan and one to Jalalabad, but this may have been for economic reasons. One respondent who said he was not affected, noted that girls were left illiterate as a result of laws under the Taliban.

The majority (6) maintain that their lives have improved since the change of government. Two said they had freedom (though no other personal change); two said there is more employment. One of these (working for an NGO) attributed this to the government encouraging foreign assistance; two were already noting benefits in more water for irrigation and better crop yields due to the project. One respondent noted no change in his life.

General understanding and awareness The respondents' replies to questions about the CDC/NSP suggest that there is a gap between the intrinsic process of the NSP and how this is understood by non-CDC members in the community of Balle Dehe. However, this is to be expected as the CDC has only been working for a few months and construction work has only just begun on the road project.

They seemed to lack full understanding of the democratic/representative nature of the $C D C$, though they had all voted for it. It seems clear that the $C D C$, for example, has not yet fully assumed the role of representing the community to government. However, they all understood the process of establishing priorities and choosing the project as well as the receipt of the money and the way the participation in the work was being allocated, though they thought others did not. They also understood that the NSP is a government programme administered by the MRRD and the FP. However, they had no understanding of the detailed financial management of the project and seemed to be content to leave it to the CDC.

They had little knowledge and less confidence in the governments plans for the country but most were prepared to concede that it is interested in their community.

For them the main impact of the CDC has been the benefits to be gained from the road project, and they identified further projects as the main factor for improving their lives. The majority expressed optimism for the future, though often as a matter of faith. A minority were extremely negative about the future.

\section{History of the CDC}

All respondents agreed that the $C D C$ was some type of shura, though two still saw it in traditional terms calling it, for example, 'a gathering of elders' or 'elders shura'. Two others described it as an advisory council or decision-making forum. One thought it was a 'four member forum'. Only two recognized its democratic role as 'our representative forum'.

Responses varied as to how long it had actually been set up (from two-six months) and no one knew how the election commission was set up. However, they had all voted although they did not appreciate why they had to vote or the actual voting process.

There were different ideas on how priorities had been set before the CDC. Three said it had not been done before. Three said the elders decided, and one said it was done 'in the Mosques through the people's participation'.

\section{CDC today}

Functioning and legitimacy

All respondents knew that the $C D C$ met once a week but opinions differed on where and when.

They were all able to explain the CDC process from community mobilization, voting for the $C D C$, identification of priorities, the community development plan, to the receipt of funds and the project.

Six respondents named the $C D C$ leader, Malin Mohamed, a teacher 'with a good past', as the leader of the community ( $\mathrm{Mr}$ Mohamed has always been a prominent member of the Balle Dehe community). One respondent said he did not know.

When asked who works with the district government, respondents revealed that the CDC's role as community representative has still to be established. Four said that the CDC does make contact with the district government but one added that the government has no interest. Two other respondents shared this view, one saying the district government is too busy with other matters like security.
THE PRO VIN CIAL FIELD SU RVEY REPO RTS 
The respondent who 'did not know' who the leaders are, said unequivocally, 'The maliks contact the district government.'

\section{Projects}

All knew that the NSP was a government/ MRRD initiative and knew that BRAC was the FP.

All respondents said they had helped (or will be involved in) labouring according to their agreed allocation, in the construction of the road.

On the level of participation in general most thought there had been problems: one said 'some people were too poor to become involved'; 3 suggested people did not understand because of illiteracy; two suggested it was 'complicated', there were 'petty personal conflicts'. However, one said clearly that there were no real problems, 'people know what is bad and what is good even if they are illiterate'.

Four respondents were aware of another project being considered: two referred to a dam and two to an electricity project. Three said they did not know about future projects.

Financial management

None of the respondents was able to explain how the finances, procurement procedures or other administrative procedures work within the CDC; they are content to trust those appointed to the various tasks, which includes the spending of the Block Grant.

Impact of NSP

It must be remembered that the NSP is relatively new in Balle Dehe. However, responses on the impact of NSP were broadly positive. All the respondents cited that the NSP was a forum for discussion and valued it for the project.

It was the impact of the road construction that they all cited as how NSP/CDC had improved their lives, by improving access to markets, both to buy and sell. As one respondent said, 'Yes, there are positive changes due to the road project; land prices have increased and transport costs are reduced'. Another person clarified, 'Yes, there has been a big social change; it is easier for people and goods to access our village. Before goods were expensive now they are cheaper and we can take our produce out of the village to sell.'
When asked what else had helped them they said 'Only BRAC'.

All agreed that the village was more united as a result of the CDC. Three described this as due to working together on the project and all benefiting from it, 'The road project has been a rallying point'; 'Yes, we have seen what we can do as a community'; 'Yes, because everybody uses the road without discrimination, even the poorest. Three said it was the frequent meetings that brought people together: 'Due to frequent meetings we become aware of each other's problems and try to solve them'. One said it was due to being represented by the $C D C$, 'Yes, we are more united because we are represented by the CDC.'

When asked what other changes had occurred they all reiterated the view that there is a greater feeling of unity, and that they know each other more now as a result of more frequent contacts.

Perceptions of government

There was no broad consensus about the government plans for the country. Three were doubtful if the government had any plans. One said it must have good plans but he had not heard of them. Three others thought the government had plans but two said unless there was peace it could not implement them. The third said it lacked the resources.

Four thought the government is interested in their community. Three thought it is not and one said 'probably'.

Confidence in the future

When asked what would most improve their lives they all spoke of further development projects: options varied from an electricity booster, intake/flood protection, water wells, agricultural projects and an extension of the road.

- Three expressed simple optimism about the future, because they had 'tasted improvement', have the road and the Taliban are gone.

- Two others were cautiously optimistic but still worried about security as one respondent stated, 'We are tired of war, we want peace, development helps us to live more peaceful lives'.

- Two were pessimistic. One said, ' No nothing will really change, who's in power? Many former warlords'. Another stated that, 'No CDC or a road will make much difference'. 


\subsection{Bahsawal, Mohmamdara District (No NSP)}

Profile

The village of Bahsawal is $55 \mathrm{~km}$ from Jalalabad and $10 \mathrm{~km}$ from the Pakistan border. The majority of the men are unemployed, finding occasional work in Pakistan. The only community infrastructure is the school, mosque, and community centre. The only other 'development initiative' in the village was a hand pump from DACAAR.

\section{Sample}

Representatives of 7 households (7 men) were interviewed. Interviewees were contacted in advance and the interviews were conducted in the individuals' houses. Under the circumstances the sample was considered as representative as possible given that a random survey was not possible. In addition Bahsawal is an appropriate 'matched non-participating community' that has similar characteristics to both Sholana and Balle Dehe.

Respondents came from 3 areas of the community.

The DRRD and FP data defines the community as 'poor' and only one respondent defined his household as 'middle'. The vast majority were poor because of the lack of arable land and limited non-agricultural employment opportunities.

The average household size is 20 (smallest 4 , largest 57). There were two small nuclear families of a husband and wife and children (two and 4). The larger households had at least 14 members, including adults of different generations and siblings with their spouses. The ratio of adults to children in all families was between 1:1 and 1:4.

As with the two CDC communities the householders defined all who do not earn as dependent. In one case the whole family of 14 were dependent on 'neighbours and the goodwill of others' because none had work. The nuclear families were supported by the husband. In the two largest families over half the men were working; in the other two, half and one in 4.

As well as economic dependents, the two large families also supported, in one case, two disabled women and two widows, and in the other two elders and a disabled daughter.
- Six of the 7 respondents were illiterate.

$\checkmark$ All respondents were Pashtun.

- Five families earned a living entirely from labouring, two mainly in nearby Pakistan.

- One respondent was also a labourer but his brother had a shop.

- One family had no income, 'We ask from shops and I pay when I have money'.

War experience/post-war situation The community was badly affected by the Russian invasion. One said he lost his animals to the Russian troops and his house was looted by the Communists. All had migrated to Pakistan. When they returned they found their property destroyed by the Russians.

They thought some aspects of life have improved since the fall of the Taliban (cursed by one respondent). Two thought there were a few more job opportunities, but not in the area and hard to get. Two others simply said there were no employment opportunities. Four thought security was much improved; one mentioned that some people were disarmed and the power of warlords reduced, another welcomed the fact that children can go to school. However, two pointed out that their personal situation had not improved, they remain poor. Two commented on improved governance: that an elected government has been established; that there are new personnel in the district administration. This last respondent also highlighted that there is now a unity among people, 'Before some of the villagers were Communists working with the government whilst others were Mudjahadeen and migrated to Pakistan; now we are all living together'. However, this view was not shared by others (see below).

General understanding and awareness The respondents held divergent views on most subjects except what is needed to materially improve their lives: the need for employment and income generating opportunities, and irrigation and drinking water projects. Their responses indicate that the community does not have an undisputed leadership, though the majority recognize some form of traditional authority. They had been deeply divided politically by the elections and while they had all fled from the Russian troops and also had little sympathy with Taliban authority, some of the more religious were also suspicious of continuing Communist influence.
THE PRO VIN CIAL FIELD SU RVEY REPO RTS 
A few had heard of the NSP or of other government plans, but this did not encourage them to be particularly optimistic. They were waiting to be convinced by tangible evidence, not only of government intentions, but ability to maintain security and deliver economic improvement. Others were totally negative about government and the future.

However, when the NSP was explained to them, they reacted positively, though several saw that it would challenge the privileged (and some alleged, corrupt) position of the present leaders.

\section{The community today}

When asked who leads the community today the respondents either said there was no formal leadership (2) or that the community was led by a tribal malik or maliks, or the community leaders led by a malik or by the elders and Mullahs. This reflects the informal arrangement described by the leaders to the researchers.

$\checkmark$ Only one respondent said the community is united because they are all one tribe. Another said they were only united if there is a problem (i.e. an external threat).

$\checkmark$ Three said they had been deeply divided by the parliamentary elections. 'The elections divided us into small pieces.'

- Two said there were problems of leadership, 'The elders say they unify us but they do not'; 'Too many people think they are in charge'.

On the subject of determining community priorities, 3 said the decisions are made by the elders and maliks. One of these said they had drawn up a list of needs and submitted it to the local administration but had no response.

- Three other respondents said decisions were reached in the mosque.

$\checkmark$ One said he did not know.

- Five respondents said they had participated or were ready to participate in community repair work, usually after a flood. Two said they had not.

$\checkmark$ Four thought the leaders, (3 said the malik) were in contact with the district government, but one added, 'they give us nothing'. Three said there was no contact.

The respondents knew of no organization N AN GARHAR PRO VIN CE approached. Two said they had no idea where or who to contact. Three were disillusioned by the contact with MRRD, 'We have contacted the MRRD, but they just offer us lip service; there have been no practical steps taken to help us'.

Two respondents had heard of the NSP through the radio but one did not know what it is for. The other thought it was something to do with rehabilitation.

After a brief explanation all respondents agreed that the NSP would be beneficial to Basawal but some had reservations, 'It would be difficult to convince the malik and elders... if there was a CDC with everything transparent the elders and malik would lose their lucrative positions'. (One accused them of appropriating aid that had been given in the past.)

Perceptions of government

Four respondents had a negative perception of government saying it had no plans for them: one respondent stated that, 'The government only has plans to eradicate opium, whilst at the same time adultery, drinking alcohol and every other vice and evil practice is free'. Another said, 'The government has no plan for us; throughout our history the government has never helped us'.

Three respondents thought the government has plans to reconstruct the country. All 3 thought it aimed to expand/improve education, one mentioned electricity, another agriculture. Two recognized that it did not have the resources itself and is seeking foreign assistance; however, as one put it, the government wanted to 'invite Afghans to return home, and reconstruct the country' but acknowledged that 'Karzai has no money and there are still many weapons and warlords are controlling the government.'

Unsurprisingly 4 were adamant that the government had no interest in their community. One was unsure because he had seen no visible change so far. One thought it is interested but has no resources, and only one believed the government was interested in rehabilitating the village.

Confidence in the future

Six of the respondents saw the creation of employment/job opportunities - by setting up factories (3), improved irrigation to 
increase agricultural yield (2) - as the main factor that could improve their lives. In addition, clean drinking water supply was mentioned by two and one wanted food aid. The seventh respondent wanted good schooling with teachers from outside the area who are 'not Communists, who are brainwashing our kids'.

The respondents expressed little optimism for the future. One asserted his optimism simply through faith, because 'God is Great'. Two were prepared to be optimistic only if national security is fully established, one also requiring an increase in job opportunities. The other 4 were pessimistic: 'I don't see any light', said one, whilst another maintained that 'Karzai has appealed for assistance from all other countries, but where are the benefits here? One however, although he was not optimistic, did think the peace will last.

\section{Annex 1: Laghman Province}

Comparisons between Laghman and Nangarhar show that the conditions in which NSP operates in each are very different. Therefore Laghman is briefly analyzed separately. There are two FPs in Laghman - Maderia (French) and DACAAR (Danish).

\section{A1. Maderia communities}
9. Mashina
10. Shertabad
11. Hussain Abad

\section{Community profiles}

Mashina, Shertabad and Hussain Abad are located around $50 \mathrm{~km}$ away from Jalalabad and $50 \mathrm{~km}$ away from Mehtarlam, the Provincial city for Laghman. The communities are similar: they are situated on fertile, well irrigated plains, the vast majority of people own land and can grow many crops including courgettes, lemons, grapes, cauliflower, cotton, sugar cane, maize, rice and wheat. Most people are farm labourers; their excess produce is sold mainly in Jalalabad, Kabul or Mehtarlam. The access tracks are in generally poor condition; the 'bridges' over the deep irrigation channels are especially bad. The average household size is 9 with many dependents; all people are Pashtun and the area is less socially conservative than neighbouring Nangarhar, with higher education levels. All the CDCs are relatively new and are in the process of identifying priorities. All the feedback is similar to the Nangarhar research with some notable exceptions:

\section{The CDCs}

$\checkmark$ Even though NSP is a new concept, the CDCs are starting to take on a role beyond project implementation. Conflict management, social mobilization and community arbitration are also undertaken.

- All members of the CDC are literate and mainly retired from high ranking positions within the army or civil service.

- The jirga in Kabul again played a central role in convincing CDC members of the worth of the NSP.

$\checkmark$ Opportunity cost of participation.

\section{Training}

- The training received has been very useful, everybody had a much better knowledge of the training and could discuss it as it followed in the manual.
THE PRO VIN CIAL FIELD SU RVEY REPO RTS 
Unity

$\checkmark$ Until the NSP came along, there were still splits in the community Communists and Mudjadeen; now we are all together working out our priorities and solutions jointly.

Project

- The road will mean it's cheaper and easier for us to take goods to Kabul// alalabad. The land owner will make more money and so his wife and his labourers will also benefit!

Future

General high levels of optimism, especially whilst $\mathrm{HA}$ is in power (he hails from Laghman).

- It is good that we have more control. An NGO came here before and did not show us anything, and then just built a school.

- If we have village unity we have the basis for national unity.

Women's CDC

Women voted only for female CDCs, but were completely aware of the structure of the NSP, objectives, roles and responsibilities etc.

$\checkmark$ NSP has given women more power; they had one disagreement with the men and said that they would boycott the election for CDC members unless the men agreed to their request, which they duly did.

- The women shared the priority of the road, 'Laghman women are usually fat so their husbands do not like carrying them along a track to the clinic. However the road will mean a car can be used.'

- The women even identified their own priority as culverts to complement the road.

Women are informed by the men at each stage.

- Most women are illiterate, but are still capable.

$\checkmark$ The priority of the road is a joint priority and women are fully supportive.

\section{A2. DACAAR communities}

Five DACAAR communities were visited; with the exception of Kahoo and Chinnar all had similar community profiles to the Maderia communities above.

1. Koarigi. Alingar District

2. Kokhi, Alingar District
3. Kahoo and Chinnar Kali, Alishang District

4. Tangi Shakarman, Alishang District

5. Qala I Halim, Alishang District

Koarigi, Alingar District: MHP in the process of construction $7.8 \mathrm{~kW}$, have weekly construction plan which is activated during construction, i.e. when there is the money.

- Kokhi, Alingar District: MHP completed, electricity poles up, $8 \mathrm{~kW}, 1 \mathrm{~kW}=$ Afs 4 , every house has meter, now we can have light, use computers, watch DVD and videos and listen to music (no national TV coverage). People are not using kerosene lamps which were dangerous. Excellent project.

$\checkmark$ Kahoo and Chinnar Kali CDCs: 3 km road construction through mountains, pneumatic drills to cut through rock (dynamite forbidden by NSP!!). Very impressive, extremely labour-intensive, before road it was a 4 hour walk to the nearest village and men would have to take women on their backs; now vehicles can be used. Cars mean that the cost of goods are considerably cheaper. We used to have to hire a donkey for Afs 400 to take produce up to the village, now the same amount of produce is only Afs 80 in a car. There is no arable land in our village so we have to fetch produce from the valley below. If government support continues we can maintain it, we have a maintenance committee. Already some of the villagers have purchased cars and are using them for commercial activities (they earned money through labouring in Pakistan or Kabul). $1.4 \mathrm{~km}$ still to go.

- Tangi Shakarman Alishang: Road project, widening existing track for vehicular access, labour-intensive, each person earns around Afs 120 a day. Usual benefits and maintenance plans. Under construction.

$\checkmark$ Qala I Halim: Canal and aqueduct: Decent technical specification, still under construction.

\section{A3. Comparison between Laghman and Nangarhar}

- General levels of development are much higher in Laghman, life is less of a struggle, education is better and people are certainly more capable of participating fully within the NSP.

$\checkmark$ The inclusion of women in the NSP is generally good, with several female projects completed and underway. 
- Community priorities are similar $\mathrm{road} / \mathrm{culvert}$, MHP, wells

(same links to PR).

- Unlike in Nangarhar where the CDCs seem more passive and reliant upon the FP, in Laghman they appear to take much more of an active role, showing initiative and a much greater understanding of the process. This is not necessarily because they have received better training from Maderia or DACAAR, but their levels of development are much higher to begin with, thus their ability to grasp the salient points of the NSP is greater.

- Female participation is much better; although most women CDC members are illiterate they appear much more capable. 

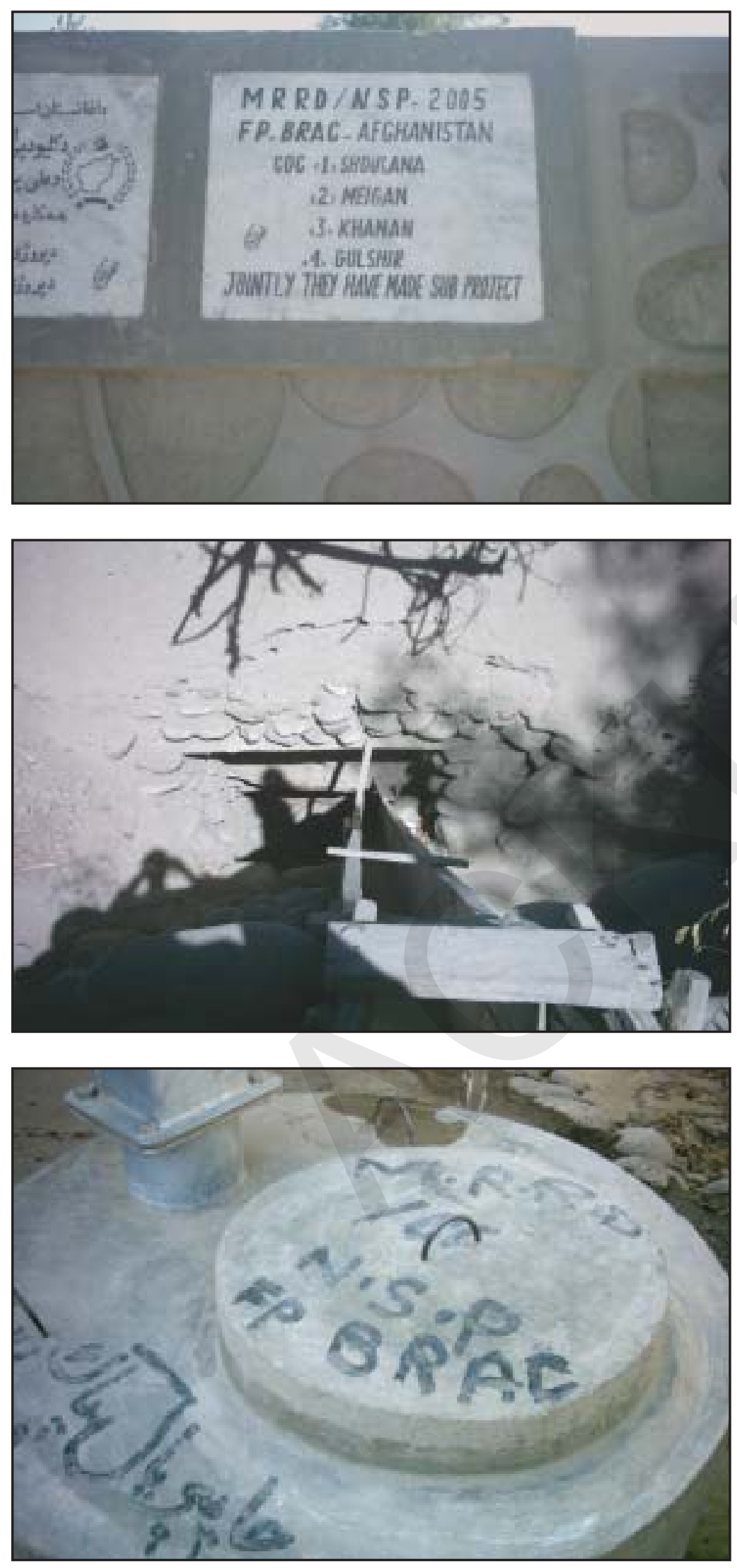

\section{NANGARHAR \& LAGHMAN \\ Supporting Photographs}

Top:

A joint project was found to increase levels of unity. (Sholana, Chaparhar District, Nangarhar)

\section{Middle:}

Example of a joint initiative

- a waterwheel. This bodes well for the sustainability of the original project. (Sholana, Chaparhar Province, Nangarhar)

\section{Bottom:}

Promoting the NSP at every opportunity in Sorkhrod District, Nangarhar. 
NANGARHAR \& LAGHMAN Supporting Photographs

Top:

Raising awareness of the NSP at the construction site in Sholana, Chaparhar District, Nangarhar.

Middle:

As a result of NSP, more wheat can be grown. Now farmers in Sholana, Chaparhar District, Nangarhar, can grow $450 \mathrm{Kg}$ of wheat, up from $50 \mathrm{~kg}$ before the NSP project.
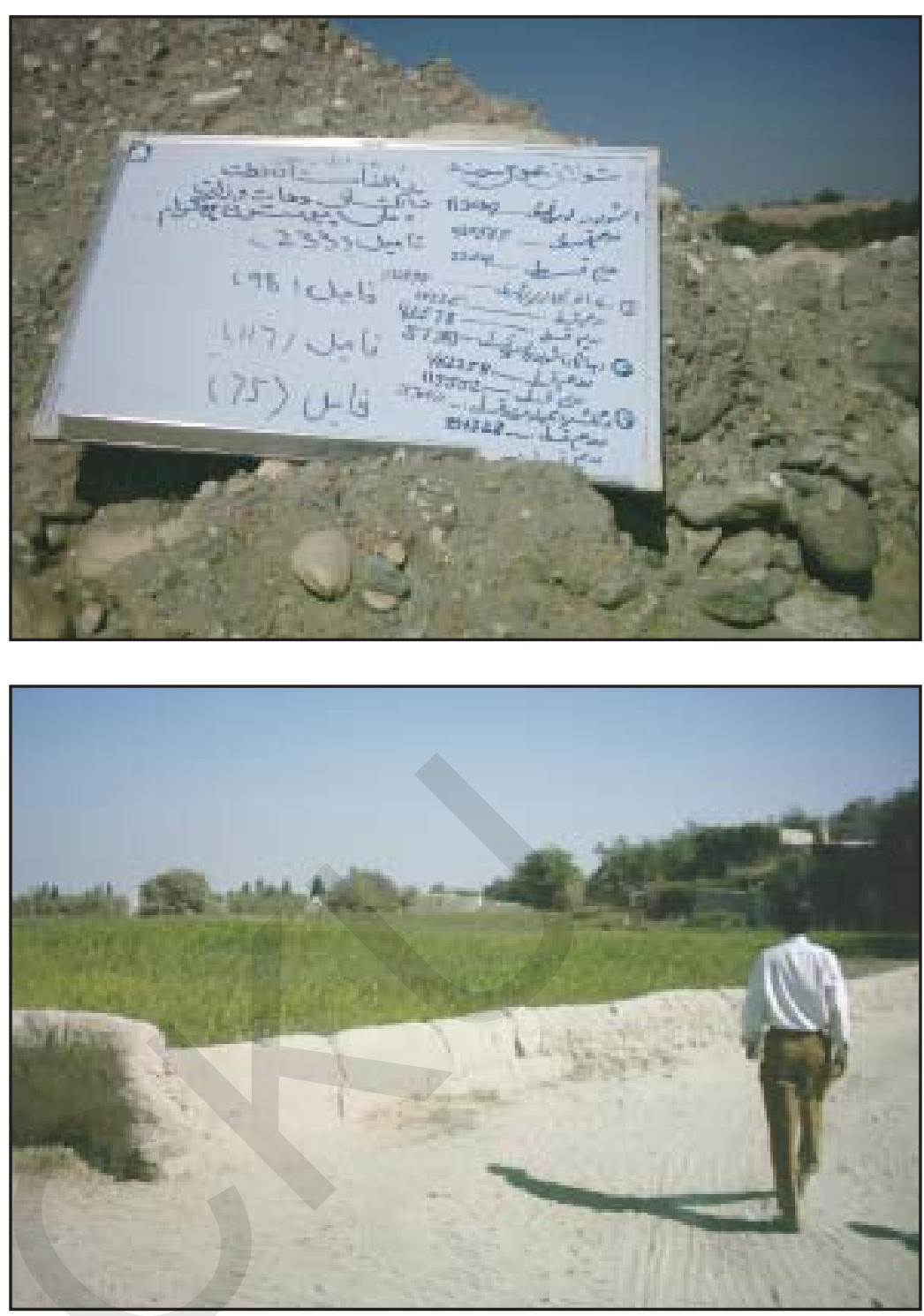

Bottom:

The construction of the road in Kahoo and Chinnar Kali, Alishing District, Laghman, has reduced the cost of transport substantially.

Before the project people had to hire a donkey to carry produce between Kaboo and Chinnar Kali, at a cost of Afs 400 a time. Now, due to the road, the same amount of produce can be taken in a car for only Afs $\mathbf{8 0 .}$

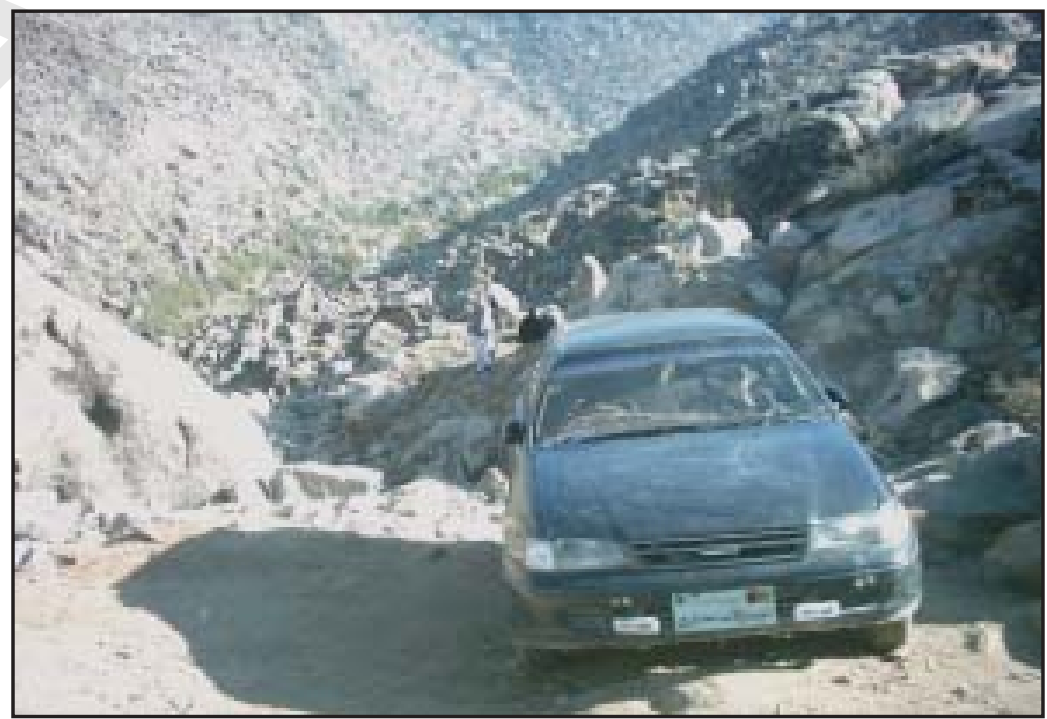




\section{Timing and scope of the research}

A rapid appraisal was carried out in the province on 25-26 October, by the Engineering Consultant and two Afghan researchers from the Kundoz team. ${ }^{1}$ The main purpose was a technical appraisal of the implementation of engineering projects, but the researchers also took the opportunity to conduct a limited number of interviews, applying the general research guidelines, and to make informal enquiries about the functioning of the CDC.

Persons interviewed:

$\checkmark$ Director of DRRD

- CDC members in Bar Dawlat Khel, Nader Shah Khel and Fatch Khan Khel

- Householders in Bar Dawlat Khel

\section{MRRD provincial and district management in Paktia}

The Director of the DRRD was interviewed in his office in Gardiz.

\subsection{Paktia RRD}

The Director said there were 40 RRD staff in the province, but did not give further details. This is similar to the staffing levels in other provinces where about three-quarters are permanent staff and the rest contracted.

1 Richard Brown with Samiullah N azemi and Kushal Akhtar.
However, they have difficulty recruiting well qualified staff because they cannot offer high salaries. In fact they are generally under-resourced and lack modern equipment.

The Department is running other rural improvement programmes in addition to NSP, for sanitation, health and construction etc. (probably the same national programmes as elsewhere).

\subsection{Experience of community development with the NSP}

The Director has worked for 15 years in community development work during and after the war. The Community-led Development Department (responsible for NSP) was set up after the establishment of the interim government.

He described their active supervisory role in the programme. They work directly with the $C D C$, overseeing their activities and verifying the accounts. The FP's performance is judged on the effectiveness of the projects, their quality and benefit to the communities rather than quantity.

He considered the NSP to be one of the more successful government programmes, 'which invites the public to obey the rules and regulations of central government' and motivates the district, provincial and national government to work together. He predicted that it would 'remove anarchy' from the country and make the Afghan government internationally acceptable.

\subsection{Training and capacity of the DRRD}

The staff had received training in management and accounting and technical training to enable them to implement the NSP However, the most useful input had been staff capacity-building, given the fact that the staff are not qualified in the fields in which they work. He did not specify how 
this was delivered, but presumably the OC was responsible.

He thought however, that although the staff try hard to implement the projects they still have many difficulties due to lack of technical knowledge, qualifications, resources and equipment. Implementation problems cannot therefore be ruled out.

\subsubsection{0 ther operational constraints}

Delays in receiving the project instalments are the other main constraint. He attributed the delays not to NSP management, but to the lack of a proper bank transfer system and the fact that everything is slowed down by the 'ravaged transport system'.

\subsubsection{Coordination with other ministries}

$\mathrm{He}$ said there were regular meetings with representatives of other ministries at which they negotiate and solve any problems that have arisen.

\subsubsection{Community relations}

$\mathrm{He}$ described these purely in terms of the DRRD's supervisory role. There was no mention of any initiative on the part of the CDC to contact government, although he said that in the present environment 'even a guard's complaint can reach a minister'.

However, he did think the CDC could become permanent institutions if, over the next two to three years, the government helped them to become self-sufficient and influential in their communities.

\subsection{The role and impact of NSP/CDCs}

$\mathrm{He}$ thought there had been many changes in the communities as a result of the NSP. They have 'legally registered councils' (in fact their legal status is unclear but they are officially recognized) whose 'leaders work only for the unity and welfare of the people'.

He expected that as a result of NSP, national unity would increase, corruption would be reduced, there would be economic growth and poverty reduction. The increased capacity of DRRD staff is also likely to increase confidence in government.

\section{Visits to projects in three CDCs}

The researchers visited the following community projects: Bar Dawlat Khel, water mill construction; Nader Shah Khel, diese generator, water supply and culverts; Fatch Khan Khel, reservoir for irrigation and water supply.

The visits to the projects afforded some opportunities to see how the NSP was being managed on the ground, and the household survey confirmed some of the observations. Nevertheless, the following conclusions can only be tentative since no structured interviews were held with the FP or the CDC on matters beyond the implementation of the projects.

The FP, CARE, seems to have helped each of the three communities to involve the community in the identification and prioritization of projects. As a result all three appear to be relevant to the communities' needs and were being successfully implemented, with community involvement, including skills development. (The Engineering Consultant's report discusses their quality and sustainability, so no comment is offered here.) It seems therefore, as the householders' comments tend to confirm, that the CDC visited have developed capacity for managing community development projects.

It is less clear that the governance objectives of the programme have been fully achieved. In the first place, the $C D C$, at least in the community surveyed, does not consider that the CDC leads the community, nor has the traditional leadership become involved with the CDC. It was also observed in the same community, that there appears to be no involvement of women in the CDC and their priority for a project, a school, was not considered in the choice of projects. This does not necessarily mean that the involvement of women is being neglected. It is clear that women's participation in the programme is limited everywhere by cultural constraints and their own lack of experience.

\section{General comments on the NSP management in Paktia}

It is clearly not possible to make a general assessment of the management of the programme without inputs from the $O C$ and FP as well as detailed discussion with the CDC members. However, there are indications that the NSP concept of governance is not fully understood. The Director of DRRD understands that NSP is directed at
THE PRO VIN CIAL FIELD SU RVEY REPO RTS 
building the capacity of government and establishing national unity, but sees this from a top-down perspective. The supervision of the programme is directed at the project implementation, not the functioning of the CDC as an institution of community governance, and the evidence from the communities visited suggests that this emphasis may be shared by the other implementation partners, $\mathrm{OC}$ and FP.

\section{Household survey: Bar Dawlat Khel, Ahmad Abaa District}

\subsection{The sample}

Six male representatives of households were interviewed in a rapid appraisal exercise. Due to the short period of time, sampling was rapid and several of the respondents were apparently interviewed together (giving or agreeing certain replies together). Families ranged from nuclear (wife, husband and children) to three generational families with an elderly parent and many adults. (16 largest, 5 the smallest). Only one respondent described his family as 'poor', the others as 'average for the community'. Two families earned a livelihood from labouring; three from farming with additional income: one from labouring, one from small business, one from the salary of an office worker. One family representative was a carpenter. Probably all were ethnic Pashtun (only three were recorded).

\subsection{War experience/post-war}

The responses suggest that the village was subject to episodes of violence rather than wholesale destruction and expulsion, in that most remained in their homes.

Two respondents each mentioned only that one relative was injured in the war. The poorest respondent said his house was looted and two family members 'martyred' by the Soviet troops. Another family had three members killed and one had two injured and the house damaged. Only the carpenter had left as a refugee to Pakistan and Iran.

Three agreed without further comment that things were now better. One specifically mentioned the NSP. Two thought that only security had improved. One of these (the poorest member of the group) said:
'We have improved in terms of security, but other improvements will take a long time. In my opinion, reconstruction in a 25-years war-ravaged country won't be a simple task. We have lost our national constitution, our army, our police, our education system and the most important, our national unity all over the country and trust in each other; therefore I can't say that our lives improved in a short period of three years.'

\subsection{General understanding and awareness}

(From reading the transcripts only) It seems that some in this community were very well informed about the CDC and NSP including its financial management (which suggests transparency and communication). The majority were less well informed though most had some idea of its purpose. They also all showed awareness of the broader political situation. The lack of detailed knowledge of the CDC of some individuals seems to be more from lack of interest/cynicism about outside help (relying more on their own individual efforts) than lack of understanding.

However, it was also clear that whatever their view of the $C D C$, they still thought that the leadership of the community remained with the tribal council. In other words, they welcomed the NSP as the only programme that had effectively delivered community projects, but did not see it as changing the way the community governed.

\subsection{The history of the CDC}

Estimates of how long the CDC had been functioning varied from 4 months to two years (perhaps taking the date from the beginning of the process or from the date of election?)

Two respondents gave a correct definition of the title. One explained that it was a representative council. One said it was a council for running the NSP project and two thought CDC stood for Community Development Consultant. (Suggesting that for at least 3 respondents it is a project management committee only.)

Three respondents said the election was overseen by CARE International. Three said they did not know how it was organized, one saying he was away at the time. One 
said he and his whole family had voted. Two others had also voted. The carpenter had not yet returned from exile; another was also away, and one sick.

Three said that in the past community priorities were set by the traditional leader (Malik), as one explained, 'We have tribal councils in Paktia which make plans for and manage all social affairs of our communities'. Two said it had been the governor. The carpenter said he didn't know because he wasn't there.

\subsection{The CDC today}

\subsubsection{Projects/ priorities/functioning of the shura}

While there was general agreement that the community is still led by the Malik, most were also happy with the work of the CDC even though their knowledge of it was in some cases vague.

They all gave the name of the tribal leader (Malik) as the leader of the community, one pointing out that he is not on the CDC. No one saw the $C D C$ as leading the community. What the Malik did was less clear. Three thought he did not work with government, one didn't know. Two thought he worked with the district government, one suggesting 'He does, but for bonus'.

As regards the $C D C, 4$ thought the $C D C$ was working well and representing their interests. 'Well, very well, we are happy with our CDC, because it works for our welfare and with the suggestion of our community; they don't make decisions without our suggestion.' One was waiting to see, and one misunderstood the question.

As to the details of its functioning, 3 thought the $C D C$ met once a month, one twice a month and one 'when an issue arises'. One said he didn't know.

On the subject of the project, most were also unclear of the arrangements. Three thought that CARE International had initiated the mill project. One of these didn't know where the money came from, two thought NSP. One thought the government and CARE had initiated the project and it might be international money. One explained that MRRD was responsible and implementation was through facilitating partners. One did not know.
However, 4 had participated in the project work, though two said that they had other demands on their time. Two others said they were not free to participate.

Three thought the other villagers had participated. One said his brother had. The two who had not participated did not know who else did.

Those who participated thought there were no particular problems for participation other than the people's illiteracy so that it took time for them to understand (the advantage?).

As to the future plans of the $C D C$, one thought that the $\mathrm{CDC}$ was already planning new projects. The others didn't know but expected it would be. Three said the community had had many contacts with other funding agencies. Two cited the IOM women's literacy course.

\subsubsection{Financial management}

Four did not know how the finances were managed by the CDC. Two clearly understood the processes and had seen the documentation.

\subsection{Impact of NSP/CDC}

Most had grasped something of the purpose and concept of the programme, though some seemed to have some misconceptions:

Three respondents knew that NSP meant 'National Solidarity Programme'. Two said NSP was a donor. Three described the CDC as a community or community development council. Two thought it meant 'community development consultant'. The poor labourer was the most articulate and enthusiastic:

* 'NSP/CDC means national unity.

* NSP means formation of nations.

* NSP means removal of adversities all over the country.

* NSP means removal of tribal, racial and language biases.

- NSP means economic growth all over the country.'

Opinions also differed as to the impact it had on their lives, but none thought it had been very great so far. Two said their lives had not improved as a result of NSP or anything else.
THE PRO VIN CIAL FIELD SU RVEY REPO RTS 
Most saw some social improvements: two said the community had become less clannish and one said that there was greater security. Four thought the community was more united, but two said it was only 'comparatively' better.

At this point 3 said there were no other changes, but the others mentioned the water mill and one said he expected things to improve and said the only assistance before was one well, provided by CARE.

Attitudes to government were also not enthusiastic. No one had heard of any government plans, two said they were too busy to hear. They also did not credit the government with much interest in their community: two said it was not interested, one said it was interested, 'but not much'. Two thought there were signs that it was (such as if it was government supporting NSP).

\subsection{Confidence in the future}

Their priorities for improving their lives were: education (2); electricity (2); employment (2); and a clinic (1).

- Four said they were optimistic for the future because there is no longer war (one thought people had learnt a lesson from the war; one that there is now greater national unity).

- Two however expressed the view that the warlords were still in power and the government weak, so they were not optimistic.

II can predict that while the warlords are in power, our country can't improve.' 


$$
\text { or }
$$


Timing and scope of the research The Badghis research team ${ }^{1}$ conducted a rapid survey in Paktika Province from 22-24 October. Interviews were conducted with DRRD,FP, OC and two CDC.

\section{Department of Rural Rehabilitation and Development (DRRD)}

Meeting Profile

Interviewee/s: DRRD Director and staff

\subsection{MRRD provincial and district programme management}

\subsubsection{Training and capacity of the DRRD}

The DRRD staff raised the number of community projects and programmes run by the DRRD including NEEP, WATSAN, $M F C$, etc to demonstrate their relevant experience. The Community-led Development Department was established in 2004. At the time of the research, there were 28 staff members working in the DRRD in Paktika. Other projects included literacy and health awareness courses.

In terms of training and guidance the respondents were invited to Kabul to attend a 14-day orientation programme and were given all the necessary training on the NSP

1 Waheed 0 mer (Team Leader) with Malaiz Doud and Roydar Q utabuddin. manual. The director and deputy director also received a 3-day training course in community mobilization conducted by BRAC (the FP). They found the latter to be very helpful although difficult to understand as it was conducted in English.
The DRRD staff argued that they did not have "enough capacity to handle the projects that we are supposed to handle". While conflicting with the initial total given, they maintained that they had only two staff in their NSP department but needed "at least 20 people to reach all the places where NSP programmes are running". It was also noted that were was a lack in capacity "in terms of professional training".

\subsubsection{Constraints for NSP implementation}

Staff noted many problems with processing the high number of projects: difficulties in monitoring or assessing the programmes; delays in the transfer of money because the number of projects was very high.

On the other hand their main indicator of success used for assessing the FPs was mainly the quality of the project, not the quantity. Particular reference was made to the sustainability of the projects. They also claimed to have not been paid their 2003 salaries.

\subsubsection{Coordination with other ministries}

DRRD staff noted that relevant ministries were "hardly visible here in Paktika" because of weak capacity.

\subsubsection{Community relations}

The respondents believed that the NSP had "built firm bridges between the people and the government at the national, provincial, and district levels". The informants believed that there was "no standard complaints procedure". However, they noted that they received written complaints, which are either tackled immediately or sent to the MRRD in Kabul if necessary. 


\subsubsection{The role and impact of NSP/CDC}

The respondents thought there was a good chance that the CDCs would be sustainable as the NSP has built upon the traditional shura system. They described their working relations with the CDCs as "friendly and cooperative", with no problems. Consequently, they believed that the NSP was contributing to national solidarity because of the bridges built among the people and actors at the different levels. They thought that ultimately this had helped the "government stretch its authority".

\section{Provincial O versight Consultant (OC)}

Meeting Profile

Interviewee/s: Head of OC

Venue: BRAC Office in Paktika

\subsection{General comments on the strengths and weaknesses of the NSP}

The OC assessed that NSP was "going very well in Paktika compared to many other provinces", because of the immense interest shown by the people and their support.

The $\mathrm{OC}$ felt there were no serious problems apart from: a) it takes two months to reach people from the time of "disbursement statement" and b) people take a long time to understand the programme and its dividends due to the low level of education.

\subsection{The capacity-building role of the $O C$}

The $O C$ described its role as ensuring coordination and cooperation among the actors involved and providing advice. Therefore, their role did not entail management.

Regarding the capacity of the DRRD, the $O C$ felt that they did not have enough professional staff to run the programme independently but hoped this would develop in a few years.

The $O C$ argued that steps were taken to develop individual capacities in the form of training, which contributed directly to developing institutional capacity. They also thought there was a learning process.

\subsection{The supervisory role of the $\mathrm{OC}$}

The OC felt the criteria was strictly applied and between 90-95 per cent of the projects were eligible from a technical point of view.

The $O C$ estimated that the communities had to wait one and half months for resources after the project approval.

\subsection{Additional comments on the future of the NSP}

The OC believed that a transfer of responsibility to DRRD was not possible immediately, but perhaps within two years.

\section{The Facilitating Partner (FP)}

Meeting profile

The Name of FP: BRAC Bangladesh

Interviewee/s: Provincial Manager, Provincial Engineer, Provincial Engineer, Master Trainer, and District Coordinator of Muta Khan and Sharana Districts

\subsection{Programme management}

Staff at management level only were interviewed.

\subsubsection{Role of FP}

The FP described its role as a bridge-builder or facilitator between the NSP funds and the community. It was stated that the MRRD owned the programme.

The respondents added that in the beginning the people associated the NSP with the FP only. With the start of the OC, the people then understood that the DRRD/Government of Afghanistan was the main player.

\subsubsection{Working relations with the DRRD/OC}

The FP thought the DRRD was very cooperative and supportive. Working relations with the DRRD were described as very good and they had been able to solve any problems arising together as a team. They believed the decision-making process was participatory.

\subsubsection{Capacity of DRRD}

The FP felt that the DRRD had stretched itself too much and therefore did not pay enough attention to the NSP. They stated that there was a degree of ignorance about the NSP in the DRRD and there was insufficient staff. Therefore, it was proposed that the DRRD needed to increase its staff in order to meet the work requirements.
THE PRO VIN CIAL FIELD SU RVEY REPO RTS 
Accordingly, it was recommended that orientation on the NSP should be provided to all (especially new) staff of the DRRD.

\subsubsection{Programme structure and relations between communities and government} The FP felt that it was usually difficult for people to understand the different roles of the actors since the level of education was very low in the province and people became confused. Furthermore, it was stated that even some of the government officials, intellectuals and educated people either found it difficult or did not understand the different roles. They stated that even the Governor of Paktika knew little about the NSP.

Nevertheless, the FP believed that the people trusted and valued the government since it was helping them: the NSP had enhanced contact but this took time. The FP claimed to have also made the government's presence more visible. For example, they invited government representatives to the CDC elections. However, it was asserted that there was still not enough contact between the government and the community, nor was this institutionalized in the NSP since there was no specific mechanism to strengthen the linkage between the government and the community. They thought that the government should have a monitoring role within the district level administration.

\subsubsection{Views on the impact and future of NSP and the CDC}

In preparation for the termination of the NSP, BRAC was thinking of encouraging people to start some income generation or self-run schemes in order to create sustainable livelihoods. BRAC's future presence in Paktika would be at the policy level. Security would determine if other projects would be implemented in the province.

\subsubsection{Training and capacity-building in the communities}

Regarding training for the CDCs, the FP claimed to have provided orientation frequently; for example, training on accounting, procurement procedures, leadership, development and literacy. There was also project-specific training on health and hygiene for hand pump projects, and sheep rearing. Other activities included exposure visits and debate programmes between the CDCs and community leaders on the NSP.

It was stated that there were problems con- cerning participation at the start of the programme (2003) as "some people thought it was an American trick to trap them". Also, the FP noted that people were not ready to register the names of women for the programme. It was claimed that the situation had completely changed, as people were not only willing to register women's names but also increased their contribution to the projects.

\subsubsection{FP's capability in relation to the programme demands}

BRAC claimed to have no problems related to the number or projects since they had enough staff (28) and the CDCs were well in control of their work.

They faced no problems applying the eligibility criteria since orientation on the eligible projects was provided after the formation of the CDCs. Therefore, it was claimed that people restricted their proposals to the criteria. However, BRAC had noted some problems in the first year of the NSP as many people asked to build mosques.

One hundred and ten staff were allocated to the NSP by BRAC including engineers, social mobilizers, and service staff etc. There were 10 women among the staff.

The main project skills needed were community mobilization, effective communication and monitoring. BRAC noted that a lack of professional staff in accounting and documentation limits effectiveness.

\subsubsection{Staff capacity-building and training}

The FP staff claimed to have received orientation on the Operational Manual. They had also received training on accounting, procurement procedures, engineering and the technical manual. All of the training was held to be useful.

\section{The CDCs}

\subsection{Sapawol Village, Sharan District}

\section{Meeting profile}

The Name of CDC: Sapawol

- Community Development Council

Village and District: Sharan

Interviewees: Chairperson,

Vice Chairperson, and Member

Venue: A house in Sharan 


\subsubsection{Community profile}

There were 226 families in the village, which was one of the poorest in the city. There were not many signs of aid support to the community other than the paved road and water hand-pumps which were provided by the NSP.

\subsubsection{Legitimacy and acceptance of the CDC}

The community was governed by a community of 6 elders (shura). It was claimed that they met every 15 days and discussed the village issues. Most of the time they were involved in social issues, for example, conflict resolution.

The community got involved with the NSP after BRAC informed them about the programme. They then sent people to explain the government's plan to help communities develop a shura to facilitate support to the community.

The CDC had changed the way the community was governed since it now had a budget and could provide services. These were two important differences compared to the traditional shura. Moreover, it was felt that the CDC complemented the traditional form of governance through freedom of speech and co-ordination.

\subsubsection{Functioning of the CDC in relation to the whole community}

The CDC claimed 10 elected members Activities were documented by simply writing down their decisions and these are referred to the FP or OC where relevant.

In planning the project, the CDC decided the priorities in its meeting based on its expertise in the issues affecting the community. It was concluded that they needed a road and also clean water.

The community group noted that there were no disagreements over the priorities because the community all shared the same ideas, and decisions were reached through discussion and based on consensus.

\subsubsection{Projects}

The first project was road paving and they also had projects for water pumps etc. They claimed that these projects were decided after using the training on organizing a fair decision-making process. The projects were implemented by local contractors in the city. It was claimed that the CDC oversaw the work and had sometimes asked them to redo the work where there were faults and after consulting the $\mathrm{OC}$ engineer.
The projects took up 30 per cent of the community's daily time: involving meetings, overseeing the work in progress, talking to the FP, OC and RRD.

The water well (with a hand pump) had really helped them fight against the acute shortage of clean drinking water in the community. It meant that they no longer had to travel miles to get drinking water and their children no longer had to suffer.

The community group had not considered arrangements to maintain the facility/ activity when the project funding ended

The CDC and the shura took turns to monitor the implementation of the project.

At the time of research, the CDC was only dealing with NSP-related issues and did not intervene in other issues since these were typically handled by shura.

\subsubsection{Relationship between the CDC and government}

The CDC claimed to be in constant contact with the governor and had visited and talked with him twice about their work. They also pointed to regular contact with the DRRD, which had visited the community. The CDC thought the partnership with the government was good and important. Towards improvement, more regular co-operation was recommended. They had never needed to use the NSP complaints procedure.

\subsubsection{Relationship between the CDC and the FP}

The CDC believed that BRAC had played a central role in the process by providing essential information on the aims and objectives of the NSP, facilitating the CDC elections and contact with the RRD and OC. The two days of training for procurement were considered to be really useful. Other support included advice on implementation.

\subsubsection{The capacity of the CDC}

The CDC claimed to have experienced no problems implementing the projects. However, aspects of democratic governance and community leadership are still unresolved.

Meeting profile

The Name of CDC: Loy Jomat CDC

Village and District: Sarawza, Sarawza

Interviewee/s: Mohammad Ghaus
THE PRO VIN CIAL

FIELD SU RVEY REPO RTS 
(Chairperson) and some members of the CDC

Venue: A house in Sarawza

Project: Improvement to water canal in village

\subsection{Sarawza village, Sarawza District}

8.1.1 Legitimacy and acceptance of the CDC The community had khans and maliks which led the community in addition to a district council. The latter was described as ineffective and not functioning properly.

The community got involved with the NSP when the FP came, as their district was designated for intervention.

There was no response to the question that the $C D C$ had changed the way the community was governed

It was claimed that the $C D C$ replaced the district council since it was almost paralysed.

\subsubsection{Functioning of the CDC} in relation to the whole community

The CDC functioned by meeting and discussing the main issues and then making decisions. There were 9 elected and active members. The $C D C$ failed to produce proof of documented activities. The CDC claimed to have planned the project and formed the community's priorities through a participatory method of decision-making. The group stated that they dealt with different opinions by respecting the vote of the majority.

\subsubsection{Relationship between the CDC and government}

The group claimed that the district administration office was very close and were informed of all developments. They considered the partnership with the government to be good and very important. Improvements would stem from mutual respect, provision of services and reconstruction efforts by the government. They were aware of the NSP complaints procedure but had not used it.

\subsubsection{Relationship between}

\section{the CDC and the FP}

The CDC was satisfied with the work of the FP, which had provided "invaluable guidance" and cooperation. They assessed the training to be good; for example, the orientation on NSP, procurement, creating a good accounting mechanism, and looking after livestock. The FP had also provided radios to listen to the NSP publicity.

\subsubsection{The capacity of the CDC}

In the past, the leaders had implemented the projects but they claimed that they now contracted-out the project. Benefits from the construction of the improved canalization system included less mosquitoes, which in turn reduced the risk of transferable diseases. There were no problems noted during the implementation of the project.

The group could not answer the questions concerning: arrangements for maintaining the facility/activity when the project funding ended; the mechanisms for monitoring implementation; the assessment of the benefits; and pre-project skills in the community. 


$$
\text { or }
$$




\section{$\Delta 12$ \\ Takhar Province \\ Provincial Field Research Findings}

\section{Timing and scope of the research}

The research team from Kundoz ${ }^{1}$ worked in Takhar from 9-15 November 2005 and completed a rapid partial survey. The Director of DRRD and the OC were interviewed but not the NSP staff. CDC representatives were interviewed but no householders. No matched non-NSP community was visited. Only FP district staff responsible for the CDC visited were interviewed.

\section{Persons interviewed \\ - Provincial Director of DRRD \\ - OC team leader in Takhar Province \\ $\checkmark$ CONCERN (FP) staff working in Versage \\ District: \\ * Four Community Development Officers \\ * Finance Officer \\ * Members of Dar-e-Hawili CDC, Versage District \\ - Members of Sar-e-Tang CDC, Versage District.}

\section{The DRRD at the provincial and district level}

The Director of the DRRD was interviewed in the department office in Talqan.

1 Mirwais Wardak (Team Leader) with Samiullah $\mathrm{N}$ azemi and Kushal Akhtar.

\subsection{Experience of community development with the NSP}

The Director thought the NSP is a good programme and has been very well received by the public. However, he felt that the DRRD's role had been reduced to a mere formality, as the programme is carried by the other actors. At the same time, expectations have been raised in the communities that have not been fulfilled and they expect the DRRD, as one of the more important government departments at the provincial level, to respond. Their ability to do so is severely limited by lack of resources.

\subsection{Training and capacity of the DRRD}

NSP training was restricted to two staff who were allocated to work with the OC. The Director had no knowledge of how useful the training may have been to them. As already mentioned, the DRRD has insufficient staff and resources to play a full role in the NSP. They have to trust the $O C$ and sign all the project proposals vetted by him without being able to make complete checks.

\subsubsection{Constraints due to the NSP structure/procedures/workload}

The Director believed that the operational problems in what is otherwise a good programme are due to the number of actors involved and their poor coordination. The OC operates as a separate body from the DRRD so, for example, DRRD was not involved in deciding which districts to prioritize for inclusion in the programme, and has nothing it can offer to representatives who come and ask for the NSP in their districts. 
Meanwhile, the FPs tend to take the credit for the NSP without making clear that it is a government programme, including putting their signs on the projects. At the same time some have other programmes in the area to which they give greater priority, to the neglect of NSP. The best criteria for judging the success of an FP would be if they honestly work towards the goal of the programme, which is that people in the most remote areas of the country should feel the presence of the government. However, they ignore these concerns and, rather than coordinating with the DRRD, they sideline them.

They also have no information about the terms of the contract between the FPs and the NSP main office; for example, the number of staff they are supposed to employ on the NSP.

He concluded that either coordination has to be improved or the number of actors reduced. $\mathrm{H}$ is preference seemed to be to cut out the FP and $\mathrm{OC}$, with their high operating costs, and strengthen the capacity of the DRRD to work directly with the CDC.

If the programme achieves the intended levels of community participation, the main responsibility for project implementation will be assumed by the CDCS and in this case there will not be a problem of overload for the administration of the programme by the DRRD.

\subsubsection{Coordination with other ministries}

The Director said they did not have any problems in coordinating with the relevant ministries for the implementation of the projects.

\subsubsection{Community relations}

NSP had created an opportunity to enhance the contact between the people and the government. DRRD NSP staff and the OC make regular visits to the communities to discuss issues related to the programme. The department has also decided to invite the heads of $C D C$ to a meeting to ensure they know that NSP is a government-funded programme, that it is MRRD not the FP that owns it. It will also give them a chance to raise any problems they have.

\subsection{The role and impact of NSP/CDC}

The Director was unsure of the long-term viability of the $C D C$ independent of the FP and OC. He seemed to suggest that the FP's facilitation was not achieving this outcome. As regards national solidarity, after 25 years of war that will not be easy. Money itself will not achieve it. The important thing is how the money is spent; once that has been evaluated it will be possible to say if it has brought solidarity.

\section{The Provincial NSP O versight Consultant $(\mathrm{OC})$}

The Oversight Consultant was interviewed on his own.

\subsection{General comments on the strengths and weaknesses of the NSP}

The OC thought that in general the programme is doing well. Strengths of the programme are that it reaches the most remote communities (some CDC representatives have never been to the provincial centre, Talqan). It therefore increases awareness and also builds capacity through direct involvement in the whole process, for example in planning projects and using the local banking system to access the money, both new experiences.

He identified a number of operational problems in the local NSP management. First that monitoring is inadequate, both because there are too few staff (the two NSP [DRRD] monitors have to cover more than 347 projects) and because their knowledge and skills need to be enhanced. A second problem is that the FPs do not have enough staff, especially technical staff and women, to ensure the quality of the work and promote women's participation.

This situation is difficult to tackle when there is no transparency about the FPs' contracts. Neither the OC nor the DRRD knows what the FP is contracted to deliver in terms of staffing and performance. They have been told that the contracts are confidential between the FPs and the World Bank who contracts them. However, this makes it difficult to monitor them and hold them accountable.

As regards central management, there is an unwillingness to delegate authority, and inputs from operational staff are largely ignored in a top-down complex administrative and decision-making process.
THE PRO VIN CIAL FIELD SU RVEY REPO RTS 


\subsection{The role of the $\mathrm{OC}$}

The $O C$ saw his main role as coordinating and monitoring the whole process, as well as administrating the grant.

He also said that they had included capacitybuilding as an important element of the programme. They had developed a staff evaluation form on the basis of which they defined training needs and organised workshops for OC and NSP (i.e. DRRD) staff.

\subsubsection{The capacity of the DRRD}

While the capacity of the DRRD is improving, the staff are not professionally qualified. The two NSP staff are supposed to work as a general project monitor and an engineer to assess technical standards, but it is difficult for them to do this well and also difficult for the $\mathrm{OC}$ to build their capacity.

He felt that there was little learning on the part of the government staff, because they did not take the training opportunities seriously. He implied that this attitude emanated from the Director (clearly, see the Director's comments above, the relationship between OC and DRRD is not satisfactory).

When asked if it would be possible to transfer the programme management to the DRRD within the proposed timeframe, he said, 'Not at all'.

\subsection{The supervisory role of the $\mathrm{OC}$}

Describing key aspects of the oversight process, he said there were almost no problems in getting the communities to understand and comply with the eligibility criteria.

Delivering the grant through the local banking system had some problems. While NSP and the OC fulfil their part, the banks delay paying the $C D C$ even though they have the money.

There are in fact two reasons for delays in payment to the CDC. The problem with the banks is one. The other is the disbursement of the money in instalments. They apply after using 80 per cent of the first, but quickly spend the final 20 per cent and have to stop working while they wait for the next to arrive.

\section{The Facilitating Partner}

Only members of the district staff of CONCERN were interviewed.

\subsection{The role of FP}

The staff described their role as facilitative, trying to enable the community to do all the project work themselves. They thought the community understood this and learnt from the staff's practical role. In addition they thought their awareness was raised by NSP publications, media and informal discussions. This confirms the accounts from the $C D C$ that they had very little formal training and, since they were largely illiterate (and therefore unable to read the literature), explains their lack of awareness about the NSP.

It is noticeable that the FP staff made no mention at this point of government. This, and the evidence from the $C D C$, confirms the DRRD director's complaint that the FPs are not adequately representing the NSP as a government programme. Later when asked directly they said 'Before they get the project they are fully educated about the various roles of $\mathrm{FP}$, government and CDC.'

It also seems clear that they saw the programme as essentially about enabling communities to run projects. They made no mention at any point of the $C D C$ as a form of democratic governance or of the facilitation process for setting it up.

\subsubsection{Working relations} with the DRRD and OC

They defined their relations with the DRRD as good because they always participate in the opening of projects, but seemed to be unaware of any other input. They appeared to have more contact with the district administration who are asked to resolve onsite problems and observe the elections.

They said they are cooperating with the $\mathrm{OC}$ and relations are 'smooth'.

\subsubsection{Capacity of DRRD}

When asked about the capacity of the DRRD they said they could not assess it because they came from the provincial capital to monitor the project, and they had never worked with them to be able to judge how capable they are. It seems that the infrequent visits of both DRRD and the FP do not coincide. 


\subsubsection{The impact of NSP on relations between communities and government}

NSP has increased the contact between the communities and the district administration, mainly through participation in opening and closing ceremonies. They are also contacted to help the FP and CDC resolve conflicts on the project sites and to observe elections.

\subsubsection{Training and capacity-building in the communities}

The FP has organized workshops that they considered necessary for the NSP projects: finance, procurement, documentation and 'CDC responsibility'. They said the finance and $C D C$ responsibility workshops were for 4 days each and the others two days. They also had carried out follow-up sessions with those CDC that took longer to assimilate the necessary skills. Their assessment was that 'almost all the training' was successful (this account differs from that of the CDC; see below).

\subsubsection{Participation}

On the subject of impediments to participation, they said illiteracy was a major problem. In much of the district it was difficult to find literate people to take on the project management, but they did not think that this meant that an educated minority used their advantage to exploit others or hinder their participation in the project.

Participation of women

They did not mention the participation of women.

\subsubsection{The FP's capability in relation to the programme demands}

The FP had had to increase the staff and their capacity to take on the NSP. Those interviewed had been recruited and had been given relevant training because they had no previous experience of working with the FP. They had no idea what might happen to their employment after the end of the NSP projects.

\subsection{Management at district and project level}

The staff described difficulties they were experiencing in ensuring that the projects were properly implemented. While there was no difficulty in explaining and applying the eligibility criteria in the selection of the projects, the high number of projects has meant both a reduction in the number of staff working with each $C D C$ and a reduction in the frequency of visits to the CDC. Previously 8 staff were responsible for 18 CDC (this is already a low cover compared to other FP) but now it is a ratio of 3 to 24. As a result CDC may not receive a visit for up to two months.

\section{Staff capacity-building and training}

They had received training in finance, procurement, community mobilization and maintenance of the projects, all of which was necessary and effective as far as it went However, they felt they needed technical training to be able to deal with the engineering aspects of the projects (the teams at district level include no engineers). They are frequently faced with issues at the community project implementation level that they are unable to answer.

\subsection{Project relevance, sustainability and efficiency}

\section{Relevance}

Referring to the project visited with the research team, they said relevance was assured because the villagers had simply opted for reinitiating a hydro-electric project they had all agreed on and tried to implement before. Since all households will benefit and use the facility it is inclusive and it was planned by the community with the help of the FP.

They claimed that environmental factors had been taken into account and there was no particular issue of integration with national development plans. Nevertheless the district administration had been involved in selecting the site to avoid any future conflict.

\section{Sustainability}

The quality of the construction and its conformity with the standard design was assured by frequent visits by the FP, OC and the head of CDC to the site.

Two people had been trained to maintain and operate the facility. At the moment they are being paid out of the project budget They said that in the long term the community would be responsible for paying for this from the income raised (through charges). This would cover not only the routine maintenance by the two villagers, but buying in technical help for major repairs.

For these reasons, and the fact that the FP
THE PRO VIN CIAL

FIELD SU RVEY REPO RTS 
could be recalled to fix any problems, they thought it would be sustainable in the longterm.

\section{Efficiency and effectiveness}

This particular project took 3 months from identification to the start, and 7 months from the start to completion. However, delays do occur both in proposal approval and transfer of funds, although these have decreased.

Since those interviewed were CDOs, they could not comment on efficiency and effectiveness related to the technical aspects of design and construction.

\section{General comments on the management of NSP in Takhar}

Both the DRRD and OC were positive about the NSP concept and thought it had achieved benefits in terms of community development, and improved contacts between government and communities. However, they both thought the impact was less than it might have been due to poor coordination and poor performance by the FP, and the evidence collected by the research team supports that view. The $O C$ also felt frustrated by the lack of delegation of decision-making by the central NSP.

There were clearly communication and coordination problems between the DRRD, $O C$ and FP. As both the director of DRRD and the $O C$ suggested, this is largely a question of capacity. The DRRD is even more short staffed than most and the two staff allocated to work with the OC have low levels of professional education. The FP is also seriously understaffed in terms of numbers and technical expertise (the accounts of DRRD, OC and the FP's district staff concur in this).

These weaknesses are then exacerbated by lack of transparency and trust between the operational partners. The director of DRRD does not feel he has been sufficiently involved in decisions about implementation policy or informed about the training his staff receive from the $\mathrm{OC}$, though he fully accepted the department's lack of capacity for direct implementation. The OC, for his part, felt he had given quite a lot of priority to capacity-building but was not supported by the DRRD. Neither is satisfied with the performance of the FP.
The two problems identified in the FP's performance by the other two partners, and corroborated by the interviews with $C D C$, are the staff shortages discussed above and the fact that they do not present the NSP as a government programme to the communities.

Though the FP staff seem to have good relations with the communities, they have little understanding of the governance objectives of NSP. So, for example, they see no need to involve the DRRD but rely instead on contacts with the district administration, which both communities visited suggested is less than honest. They appear to be simply running the NSP like their other projects, that is concentrating on the sub-project implementation (with some success) but giving little attention to developing community governance. As a result the communities continue to be run by nonelected elites. The FP's lack of staff has also resulted, at least in the two communities visited, in spending less time on capacitybuilding of the CDC than even their own guidelines require, so that only the already able are equipped to run further projects without assistance.

\section{The two CDCs}

\subsection{Dar-e-Hawili CDC, Versage District}

The research team interviewed the head, treasurer and two members of the Dar-eHawili CDC with the head of the CDC in Papani, the village with which they shared the hydro-electric project (all men).

\subsubsection{Community profile (provided by the FP district staff)}

The village has 94 families and a population of 564 . The number of widows was put at two and disabled one. There were said to be 157 women, 132 men and 91 children (totalling only 380 ).

There were no displaced or refugee families. One family was classed as rich, 12 of middle income, 37 as poor and 44 as very poor. (It was not possible in the time available to validate/clarify or supplement this information with a household survey.)

6.1.2 Legitimacy and acceptance of the CDC When asked who governs the community and who are its leaders, the $C D C$ represen- 
tatives said that the elders and the Mullah of the mosque decide community issues. Without consulting them as well as the people in the community, the CDC cannot decide on village issues. Nevertheless they insisted that the CDC is the only form of government in the village and did think the $C D C$ had changed the way the community is governed. The decisions of the CDC are respected in the community and there is more transparency.

The researchers observed that though the $\mathrm{CDC}$ claim to be the representatives of the community and are the only formally constituted committee in the village, their operations and authority appear to be very much confined to the NSP sub-project. They are concerned with very little beyond project implementation and the handling of the finance.

\subsubsection{The functioning of the CDC in relation to the whole community}

The CDC has 8 members: 4 men and four women. The men's and women's sections meet separately and function as two separate CDCs. In the men's CDC they said they ask other villagers to participate and they think it is working well.

However, the researchers, as noted above, thought that few matters not directly related to the NSP project were dealt with. They also concluded that the women's CDC was 'not very visible' and had no influence in the decisions made by their male counterparts (most of which relate to the expenditure of the Block Grant on a large infrastructure project).

The decision-making process over the priorities for spending the NSP grant were said to be straightforward. The existing hydro project was no longer working so 'most of the villagers' saw the NSP as an opportunity to reconstruct it, and agreed to negotiate with Papani village and $\mathrm{CDC}$ for a joint scheme. When asked how they had handled differences of opinion over this as a priority, they said that didn't arise because 'most of the villagers agreed unanimously'.

All the documentation required in the NSP Operational Manual was present but it was clear to the researchers (given the level of illiteracy) that this work had been done with the help of the FP. It was not clear what arrangements the $C D C$ had for briefing the largely illiterate population about their decisions and accounting. They did however claim to be resolving some community conflicts (the researchers thought these were mostly related to the NSP project).

\subsubsection{The project}

Apart from contracting an engineer, all the work on the project had been done by the community. There were no difficulties over the implementation. The CDC tried to give a chance to all the community members to benefit from the paid labour. People worked hard and paid their contributions to the 10 per cent of costs.

The project was going to provide electricity to every household and will help them reduce expenditure on lighting, even taking into account the charges based on use metered in every house. They thought it would also improve livelihoods in the long term but did not explain why.

They had calculated that the project would generate Afs 12000 a month, which would cover the cost of hiring the operator and providing a fund to pay for major repairs. The project implementation had been monitored by the head of the CDC and a supervisor, and the FP had also monitored it.

Although this project was nearing completion, they had no plans for any new project.

\subsubsection{Relationship between the CDC and government}

Relations between the CDC and the district administration, which is the only part of government they are aware of, are formal but not cordial, 'Our responsibility is to make them guests and theirs to give orders.' They did not find it helpful, blaming it for excessive corruption and nepotism.

They had little knowledge of other levels of government, and did not associate the MRRD role in the NSP with government.

They had no knowledge of any complaints procedure but said the first complaint was that they were not paid for their work for the CDC.

\subsubsection{Relationship between the CDC and the FP}

It was the FP that approached the village about NSP. They then started working together and the FP had been able to facilitate what they wanted (the hydro project).
THE PRO VIN CIAL FIELD SU RVEY REPO RTS 
When asked about the training they had received, they did not immediately understand what was meant. It appears that they had mainly been briefed informally in meetings and discussions. They did not mention formal training. They said it had all been useful and necessary for implementing the project but, as the researchers observed, it has not equipped them to keep the records and accounts for themselves.

They could not think of any other support they had received from the FP (there was no mention of the elections or democratic functions of the CDC for example).

\subsubsection{The capacity of the CDC}

It was difficult to assess the capacity of the CDC on the basis of this interview, though the deficits were clear. The CDC has not assumed the leadership of the community, though its management of the project appears to have general acceptance and its implementation has mobilized community participation. Nevertheless, CDC members seem to have little understanding of its democratic and representative functions and the women members are excluded from decision-making.

As regards project management capacity, it is by no means certain that they could plan and implement a completely new project without the assistance of the FP, and they have not acquired the necessary skills for documentation and accounting, though they may well be able to manage funds.

On balance this was a CDC that would not be able to function as the Operational Manual stipulates. It requires not just more facilitation but a better quality of facilitation especially for governance which appears to have been largely lacking.

\subsection{Sar-e-Tang CDC, Versage District}

The research team interviewed the head and secretary of the CDC and a community elder.

\subsubsection{Community profile}

No community profile was provided by the FP for this community.

\subsubsection{Legitimacy and acceptance of the CDC}

The respondents said that the community is governed by the elders, some of whom are in the $\mathrm{CDC}$ (the $3 \mathrm{CDC}$ representatives interviewed were: a teacher, a Mullah and an elder).
They clearly did not see the CDC as much more than a project management committee, and in fact it seems to have simply replaced a pre-existing committee set up by the FP for a previous project. One respondent not only identified the earlier committee as the 'CDC for irrigation' but the NSP CDC as 'the CDC for the chicken farm'.

Having said that, the NSP CDC has introduced some significant changes: access and responsibility for the management of resources; greater participation. Also, when asked if the CDC complemented the activities of other forms of governance, they did say the CDC is the sole form of government. The leadership of the elders, as in Dar-eHawili, though powerful, appears to be a non-formal institution.

\subsubsection{The functioning of the CDC} in relation to the whole community The CDC has 11 elected and active members. Several are also educated, so they have been able to complete all the documentation and keep adequate accounts. They described their approach to working with the community as consulting the community 'on the issues that need to be decided by the $C D C^{\prime}$. So for the project, the villagers came together and identified their needs and the CDC decided on the project, made the project proposal and submitted it to the FP. They said that there were no big differences of opinion on the needs so they did not need to sit with the community and discuss it further.

The researchers noted very little evidence of women's participation, as was to be expected in this social context.

\subsubsection{The projects}

The CDC had planned three projects. The first, road construction, had been completed by the whole community. The second, a chicken farm, was ongoing and had been contracted to a villager, and the third was to buy a diesel generator, extend the electric lines and connect all households. The villagers had wanted a microhydro scheme for electricity, but they had been advised by the engineer who inspected the site that it was not feasible.

When implementing the first project they had tried to give everyone a chance to benefit from the paid labour, and the community provided all the labour and 10 per cent of the cost. The road has had 
immediate benefits in terms of easier travel and the electricity will benefit everyone. The idea of the chicken farm is to generate funds to meet other community needs. In the long term it is hoped that the projects will contribute to the livelihoods of the villagers.

The road and the diesel generator are to be maintained by the villagers. The running of the chicken farm has not yet been decided but it is likely to be contracted to a villager with the necessary experience.

The projects are monitored by the FP, which they rely on for the technical knowledge, and the $\mathrm{CDC}$ make frequent monitoring visits themselves.

\subsubsection{Relationship between the CDC and government}

The CDC members were very reticent in their discussion of their relations with government. As in Dar-e-Hawili, government for them is the district administration and they have no clear awareness that NSP is a government programme.

They have very little contact with the district administration. The relationship is distant and described as 'good enough'. However, they did say it could be improved by bringing more accountable and transparent staff into the public administration.

They were unaware of the NSP complaints procedure.

\subsubsection{Relationship between \\ the CDC and the FP}

As mentioned above, the community had worked with the FP before on an irrigation project. It was one of the elders, who had been head of the previous project committee, who approached the FP to ask them to set up an NSP CDC. He was the head of the CDC at first but now works in the district administration.

The researchers observed that the relationship was good in terms of mutual cooperation but the FP seemed to have little time to work with the CDC and, as in Dar-e-Hawili, they mostly worked through informal visits and practical project implementation. The CDC said they had had training in finance and procurement that was useful, but nothing else.

\subsubsection{The capacity of the CDC}

The CDC is clearly able to plan and manage individual projects but also has a grasp of community development strategy. They already had some of this knowledge before they joined NSP, but it has allowed them to develop this existing expertise.

Without a household survey it is difficult to assess the gains in democratic governance. However, the CDC themselves and the FP made no mention of it, and the indications are that the nature of governance has not changed much. It continues to be paternalistic and potentially nepotistic. The representative role of the CDC is restricted within the community, since leadership remains with the elders, and externally due to the poor relations with district administration. On this basis the CDC cannot be said to be fully capable according to the NSP criteria.

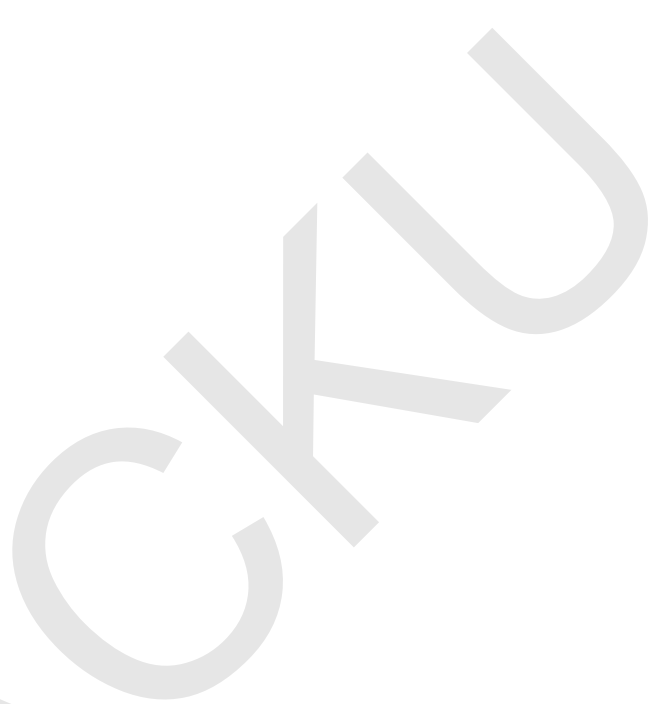




\section{Introduction}

In 2002, after nearly 25 years of conflict, there is a profound need for extensive intervention to address rehabilitation and development needs in the rural areas of Afghanistan. The transitional administration of the country further recognized that acceptance by the rural population depended in no small measure on its ability to deliver long-awaited assistance to rural communities across the country.

The National Solidarity Programme (NSP) is built on the operational partnership between local and international NGOs and the Government that was started under the NSP component of the Emergency Community Empowerment \& Public Works Project of IDA. It is envisioned that this partnership will enable the Afghan Government to develop its National Community Driven Development programme framework further, while drawing on the strength and experience of NGOs for programme facilitation.

\section{Programme goal and objectives}

The goal of the NSP is to reduce poverty through empowering communities with regard to improved governance, and social, human, and economic capital.

The objectives of the programme are to:

1. lay the foundations for a strengthening of community level governance, and to

2. support community-managed subprojects comprising reconstruction and development that improve the access of rural communities to social and productive infrastructure and services.

\section{Implementation strategy and plan}

The design of NSP consists of four core elements:

- Facilitation at the community level to assist communities establish inclusive community institutions through elections, reach consensus on priorities and corresponding sub-project activities, develop eligible sub-proposals that comply with NSP appraisal criteria, and implement approved project sub-proposals;

- A system of direct Block Grant transfers to support rehabilitation or development activities (sub-projects) planned and implemented by the elected Community Development Councils;

$\checkmark$ A series of capacity-building activities to enhance the competence of Community Development Council members (both men and women) for financial management, procurement, technical skills, and transparency; and

$\checkmark$ Activities linking local institutions to government administration and aid agencies with available services and resources.

Quality of process is essential for the longterm sustainability of community investments and for the success of a programme like the NSP. As such, community level planning must follow an approach that complies with the basic principles below: 
- participatory planning of activities through inclusive community meetings and representative elected development councils;

- community contributions to capital costs and operation and maintenance;

- transparency and accountability of budgeting and accounting.

The goal of this approach is to ensure that communities are able and inclined to institute a broad-based inclusive decisionmaking system (which includes women as well as members from marginalized sections of the villages) through community meetings and development councils. Through this process the communities will acquire or strengthen the skills and attitudes necessary to enhance their capacity to define, manage and govern their development. To achieve this goal, the role of the Facilitating Partners (FPs) and the NSP will be to create an enabling environment through facilitation of inclusive community planning, technical assistance, and timely release of funds, which will enable communities themselves to manage implementation of the projects they have defined.

\section{Role and responsibility of the Facilitating Partners}

The FP serve as the operational outreach to facilitate community participation in the planning, implementation and management of sub-projects financed by the NSP Block Grants.

The FP provide the foundation of experience that is used to transfer technical knowledge and management capacity to the community level. How they do this - the level and quality of participation engendered, equity assured, gender outreach and sustainable practices extended - will ultimately determine the impact of NSP and whether the programme achieves a longterm strengthening of local governance as well as sustainable sub-projects. The NSP Operational Manual describes their responsibilities as:

facilitation at the community level regarding election of inclusive Community Development Councils, development of Community Development Plans defining priorities and corresponding project activities, development of sub-project proposals, and technical assistance for communitymanaged implementation of approved project proposals;

$\checkmark$ undertaking capacity-building to enhance the competence of the communities for financial management, procurement, technical skills and transparency;

$\checkmark$ conducting monitoring and reporting.

The performance of the Facilitating Partners has been evaluated in June and July of 2004, prior to entering into the second round of contracts for NSP year II.

This evaluation identified a potential for 'programme leakage' or dilution of effort, as communication is delivered between the various actors of the programme (see diagram on following page). This study referred to these articulations in order to separate internal problems specific to the facilitating partners and their management structures from externalities that lay beyond the control of the FP.

The Evaluation Consultant will be required to take full account of the FP evaluation study, and assess the pertinence of the information gathered in the field and the analysis and recommendations made by the FP Evaluation Consultant, for the present programme evaluation.

\section{Role of the O versight Consultant}

The Oversight Consultant is responsible to MRRD for the overall management and supervision of the NSP.

The NSP Oversight Consultant has staff at the central level, in five regional offices, and in all provincial level MRRD offices. The Oversight Consultant is placed in MRRD and works with MRRD counterparts in the Community-Led Development Department to strengthen capacity for community development and programme management at central and provincial levels.

The key tasks of the Oversight Consultant are:

$\checkmark$ appraisal of community project proposals;

- management of the NSP Block Grants for community projects (including effecting fund transfers, tranche payments, financial management, accounting, and reporting);
N SP AFG HAN ISTAN Mid-term EVALUATION REPO RT 
- supervision of the performance of Facilitating Partners;

$\checkmark$ planning and conducting training for staff of MRRD and Facilitating Partners (either directly or through sub-contracting), together with regular workshops to exchange lessons learned and adjust the programme implementation approach as required;

$\checkmark$ undertaking technical and financial monitoring, and producing consolidated progress reports, and

$\checkmark$ management of an information and communication campaign on NSP.

\section{Role of the Ministry of Rehabilitation and Rural Development}

The NSP is implemented by MRRD. As a result of more than two decades of conflict, exodus of trained personnel, low pay, and lack of exposure to new approaches, the government's institutional capacity is generally weak. To address this issue, MRRD's leadership has instituted a comprehensive reform within the Ministry. The mandate, principles, policies and objectives of MRRD have been revised, with community empowerment at the core of the Ministry's work to ensure that communities have both the authority and capacity to own decisions over their reconstruction and development.

MRRD's reformed mandate is policy and strategy formulation, programme coordination, programme and project execution (involving implementation through contracting partners - NGOs, UN and private sector), monitoring and supervision, and information dissemination. The NSP and other national priority programmes managed by MRRD reinforce the Government's policy and regulatory role to support the private sector through competitive contracting.

\section{Current Funding and Implementation Status}

The NSP received initial funding from an IDA Grant of US $\$ 22$ million through the community empowerment component of the Emergency Community Empowerment $\&$ Public Works Project, and an IDA followup grant of US \$95 million - the Emergency National Solidarity Project - became effective on 5 April 2004. In addition, commitments have been made by several donors (UK, USA, Canada, EC) to co-finance the NSP through ARTF with a total of US $\$ 45$ million, and Denmark is directly cofinancing the programme with US $\$ 7.7$ million. Including a proposed JSDF funded project, the NSP has funding of US $\$ 180.7$ million, which is expected to cover expenditures until June 2005.

The NSP target for the first year of implementation (August 2003 to July 2004) is about 5,500 communities in 3 selected districts per province. As of 31 May 2004, the programme was under implementation in 101 districts in all of Afghanistan's provinces:

\begin{tabular}{|l|c|}
\hline $\begin{array}{l}\text { Communities with } \\
\text { ongoing social mobilization }\end{array}$ & 5,414 \\
\hline $\begin{array}{l}\text { Community Development } \\
\text { Councils elected }\end{array}$ & 4,600 \\
\hline $\begin{array}{l}\text { Community Development } \\
\text { Plans completed }\end{array}$ & 3,410 \\
\hline $\begin{array}{l}\text { Community sub-projects } \\
\text { approved }\end{array}$ & 1,425 \\
\hline $\begin{array}{l}\text { Disbursements to } \\
\text { sub-projects (US \$ million) }\end{array}$ & 11.5 \\
\hline $\begin{array}{l}\text { Commitments to } \\
\text { sub-projects (US \$ million) }\end{array}$ & 23 \\
\hline
\end{tabular}

It is expected that the programme will expand to reach about $10-11,000$ communities in Year 2 of field implementation (August 2004 - July 2005).

\section{Mid-term evaluation}

The purpose of these Terms of Reference is to outline the key areas for an evaluation of the National Solidarity Programme after 18 months of field operation: its implementation (efficiency and effectiveness), early impact, rationale and long term strategy.

\section{(i) Implementation}

The evaluation will focus on the following aspects of the Programme implementation:

\section{Efficiency}

The resources mobilized to deliver the nationwide programme are considerable in terms of expertise, training, staffing and personnel, as well as equipment and physical installations. The programme delivery mechanism consists of Facilitating 
Partners, an Oversight Consultancy charged with the overall management of NSP, and ministry personnel mobilized in support of the programme.

A constant concern for MRRD is that these resources are being used in the most efficient manner to achieve programme results.

\section{Effectiveness}

The degree to which the programme resources deliver tangible and measurable results in all the rural areas of Afghanistan reflects the effectiveness of NSP. Communities have been mobilized and supported in the election of Community Development Councils (CDC), in the preparation of Community Development Plans (CDP), and in the design and implementation of sub-projects.

Has the programme delivered sufficient training, technical support and funding to rural communities and their CDC to allow for a recognizable presence in the country? Could these results have been delivered in any other, less costly, way?

\section{(ii) Impact}

The impact of the NSP will be measurable in 4 to 5 years; however it will be possible to arrive at some indication of the impacts that might be expected after one and a half years. The impacts in terms of the two project objectives, namely: improvement of local governance through inclusive community based institutions, and improved community access to social and productive infrastructure and services leading to a reduction of poverty within NSP communities, must be assessed to ensure that the programme is able to contribute to these outcomes.

\section{(iii) Rationale}

The NSP rationale was defined some two years prior to this evaluation and it is important to ask whether socio-political and economic conditions have evolved over that period of time. While it is not expected that the fundamental rationale of the programme would change, there may be critical conditions that modify the manner in which the programme goal is addressed.

\section{(iv) Long term Strategy.}

Given the temporary nature of programmes, it is necessary to consider the strategy required to incorporate relevant institutional functions of NSP in the structure and work plan of the MRRD. The expediency of employing the Facilitating Partners and Oversight Consultants must be evaluated in the light of the Ministry's longterm institutional development plan. The exit strategy proposed by the Oversight Consultant should be assessed, as well as the role of the Facilitating Partners, within the context of future rural development in Afghanistan.

\section{Scope of services}

Based on these elements, the Evaluation Consultant will evaluate:

$\checkmark$ the resources used to deliver NSP in terms of the appropriateness of both resource quality and quantity, and in terms of timeliness of delivery;

$\checkmark$ the progress of NSP in delivering outputs and contributing to tangible results in most provinces in the country;

$\checkmark$ the institutional arrangements in terms of their effectiveness to deliver the programme across the country and build capacity with the Afghan Government;

the potential impact of NSP on improved local governance and poverty reduction: assessing the appropriateness of the NSP approach for achieving the programme objectives; the involvement of women in community elections, decision-making on the use of Block Grant funds, and as beneficiaries of Block Grant investments;

$\checkmark$ the impact of the various types of sub-project on the incidence of environmental and social risks within the communities;

- the programme environment (socio-political and economic) and its implications for the rationale of the programme.

The consultant will report conclusions as to the efficiency and effectiveness of the implementation of the NSP as well as to the potential impact, rationale and long-term strategy adopted at present.

The Consultant will also provide recommendations with respect to:

1. the programme approach and institutional arrangements to improve the delivery and impact of the programme 
2. the long-term strategy for the integration of relevant programme functions (e.g. M\&E; community project oversight; design standardization) in the institutional profile of the Ministry.

\section{Duration of assignment and reporting ${ }^{1}$}

The assignment will take place during an 8month period and will involve two evaluation exercises. The first evaluation exercise is scheduled for March-April 2005, and the second 6 months after submission of the report of the first evaluation. The assignment may be extended based on an assessment of performance of the consultant.

The timing of submission of draft and final evaluation reports will be based on the agreed time schedule for the assignment.

\section{Proposals}

Proposals shall include:

1. Organizational and staffing set-up for the assignment, including the CVs for the proposed staff to occupy key positions in the evaluation team (e.g. team leader, institutional specialist, community development specialist, engineering specialist).

2. Approach to the assignment including (i) analysis of key issues and challenges involved in the assignment (e.g. access to high security risk areas), and proposed solutions, (ii) proposed key indicators to measure achievement of NSP objectives (improved local governance and improved community access to social and productive infrastructure and services, leading to a reduction of poverty), (iii) sampling of communities to achieve representative data in terms of the programme scale and its geographical and ethnic variations, (iv) coverage of institutional implementation issues, and

$1_{\text {This time frame was }}$ superseded when it became clear that the evaluation could not commence before 0 ctober 2005. (v) time-bound implementation plan.

3. Financial proposals must be submitted in a separate sealed envelope. The financial proposal will only be opened for the agency rated highest for the quality of its proposal. If negotiations with that agency fail to result in a contract agreement within two weeks (14 calendar days) of opening of the financial proposal, the financial proposal of the organization rated second for quality of proposal will be opened, and so on.

MRRD will make available to short-listed consultants the following documentation to facilitate proposal development:

- Technical Annex (project document) for the second IDA Grant,

- NSP Operational Manual and NSP Technical Manual,

- Quarterly Status Reports

\section{Evaluation Consultant selection criteria}

The proposals from short-listed consultants will be assessed by a points system on the following criteria (max 100 points):

\begin{tabular}{|l|c|}
\hline $\begin{array}{l}\text { Specific experience of } \\
\text { the consultant related } \\
\text { to the assignment }\end{array}$ & 10 \\
\hline $\begin{array}{l}\text { Adequacy of the proposed } \\
\text { work plan and methodology } \\
\text { in responding to the TOR }\end{array}$ & 35 \\
\hline $\begin{array}{l}\text { Qualifications and competence } \\
\text { of key staff for the assignment }\end{array}$ & 50 \\
\hline $\begin{array}{l}\text { Local participation } \\
\text { (nationals among key staff) }\end{array}$ & 5 \\
\hline
\end{tabular}




$$
\text { or }
$$




\section{C1 \\ Stakeholders Consulted}

\section{NSP O versight Consultants Team}

- Andreas Schild, Team leader

- Jovita Thomas, Deputy Team Leader

- Abdul Rahman, Management Assistance

- Lyn Wan, Manager FP Windows Dept

- Anne Johnson, Manager FP Windows Dept

- M. Isaaq Atmar, Training Coordinator

- Hanife Kurt, Training Co-Manager

- Humayun Ayubi, Senior Programme Officer

- Ernst Bentzein, Regional Manger, Eastern Region

- M Hamayoon Akseer, Team Leader POC Laghman

- Arya Saboor, Technical Support Unit Leader

- Linda Hasse, Head of Block Grant and Finance

- Lorane Flamins, M\&E

- Lene Petersen, Trainer Expert, Dept of HR and Training

- Christian Marks, Director Public Communications Unit

- M, Haroon Chakhansuri, Head Information Coordination Unit

- Yahya Haider, General Administration

\section{Ministry for Rural Rehabilitation and Development}

- HE Hanif Atmar, Minister for RRD

- Ehasan Zia, Deputy Minister for RRD

- Raz Mohammad, Deputy Minister (Finance) for RRD

- Asif Rahimi, NSP Chief Coordinator

- Sayed Abed Rekhtiya, Development Budget Officer, MRRD

- Saifullah Abid, Project Coordinator, Ministry of Agriculture, Animal Husbandry and Food/MRRD
- Assadullah Zamir, Economic Development and Financial Management Advisor, MRRD M. Salim Qayum, Director of Programme Management Office

Ministers and Junior Ministers were consulted in the following Departments of State:

\section{- Agriculture \\ Education \\ Finance \\ - Rural Rehabilitation and \\ Development \\ - Water and Energy \\ - Women's Affairs}

\section{National Area Based Development Programme}

- Mizuho Yoko, Monitoring and Reporting Advisor

- Nazir Ahmed

\section{AREU}

- Hamish Nixon, Researcher

- Daud Omari, Researcher

- Palwasha Kakar, Research Officer, Local Governance

\section{Embassy of Canada}

- Nipa Banerjee, Head of Aid

- Tamin Asey, Senior Development Officer

\section{European Union}

- Martin Bezart 


\section{Embassy of the}

Federal Republic of Germany

- Micro Kreibich, First Secretary, Development Cooperation and Economic Affairs

\section{Embassy of Norway}

- Carsten Carlsen, Embassy of Norway

\section{DfID}

- Essa Shamal, Deputy Programme Manager

- Anthea Kerr, Livelihoods Advisor

\section{Japan International Cooperation Agency}

- Makiko Watanabe, Assistant Resident Representative

\section{IFRC}

- Jamila Ibrohim, Head of Delegation, IFRC

\section{UNDP}

- Nazir Ahmad, Deputy Programme Manager

$\rightarrow$ Sitara

\section{USAID}

- Barbara Rodey, Senior Advisor for Gender and Social Development, USAID

- Gerald Becker, USAID/DAI Alternative Livelihoods Programme - Eastern Region, ex Team Leader NSP

\section{UNHCR}

$\rightarrow$ K Murata

\section{World Bank}

$\checkmark$ Nihal Fernando, Senior Rural Development Specialist

$-\quad$ Norman Picconni, Lead Rural Development Specialist, Agriculture and Rural Development Sector, South Asia Region

- Mohammad Arif Rasuli, Environment and Social Specialist, World Bank

- Matt Stephens, Social Development

- Deborah Davis, NSP, Agriculture and Rural Development Sector, South Asia Region

\section{Others}

- Fasial Amin, Regional Project Chief Engineer, Food and Agriculture Organization of the UN

- Lother Dulbarg, Project Manager, SME Development, GTZ

- Horst Croessmann, German Agro Action, Nangarhar

- Karin Traenkner, German Agro Action, Nangarhar

- Noel McCarthy, Site Security Supervisor, UN Office for Project Services, Nangarhar

Khalid Sharifi, Project Manager, Care of Afghan Families

- S Qutabuddin Roydar, Head of Field Operations, Joint Electoral Management Body Secretariat

$\checkmark \quad J a w e d$ Nader, Media Officer, Afghan Civil Society Forum

\section{FPs in Kabul}

- Graham Lowe, Chief Technical Advisor, UN-HABITAT

- Bijay Karmacharya, Project Advisor NSP, UN-HABITAT

- Raz Mohammad Dalili, Executive Director, SDF

- Sayed Ihsanullah Dileri, General Coordinator, SDF

- Mohammad Esehaq Zeerak, Director, GRSP

- Khadim Nazari, Programme Manager, GRSP

- Aine Fay, Country Director, Concern

- Paul Barker, Country Director, CARE

- M Nader Taher, Rural Assistance Programme Manager, CARE

- Michelle Kendall, Assistant Country Director, CARE

$\checkmark$ Jagannath Kumar Dutta, DM\&E Advisor, CARE

- Shahjahan, Programme Manager, BRAC

- Sarder Jahangir Hossain, NSP Manager, BRAC

$\checkmark$ Mohammed Fareed Waqfi, Acting Director, CHA

- Adele Jones, Country Manager, AKDN

- Steve Mason, Programme Grant Manager, AKDN

- Sachin Sacheva, Deputy National Programme Coordinator, AKDN

- Sultan Mahmood, Regional Community Development Manager, AKDN

- GB Adhikari, Country Director, Action Aid 


\section{MRRD/D onor Workshop Attendees 23rd February $2006^{1}$}

1. Asif Rahimi

2. Sofia Orrebrink, Programme Officer, Sida

3. Lars Olot Ellasson, Programme Officer, Sida

4. Najbullah Najib, Programme Officer, World Food Programme

5. Shrikant Deshpande, Governance Officer, UNAMA

6. M Mekdi Jawari, Advisor, Ministry of Public Works

7. A Rahman Magood, Director of Population Registration, Ministry of the Interior

8. Kai Murata, Deputy Representative, UNHCR

9. Andreas Schild, NSP

10. M. Yassin Noory Wardak, Dutch Embassy

11. Mohammad Asheef, Advisor, Ministry AAHF

12. Charlotte Osen, Deputy Head of Mission, Danish Embassy

13. A Schpeldessen, First Secretary, Embassy of Norway

14. Tamin, Desy, Senior Development Officer, CIDA

15. Ashor Nigam, Director, UNAMA

16. Wais Ahmed, Chief Coordinator, NRAP, MRRD

17. James Medhurt, Team Leader, DfID

18. Essa Shamal, Deputy Programme Manager, DflD

19. Mir Ahmad, Operations Officer, World Bank

20. Abdullah, Ministry of Education

21. David Omari, Research Assistance, AREU

22. Palwasha Kaker, Research Officer, AREU

23. Makko Matanube, Assistant Researcher, JICA

24. Barbara Rodey, Advisor, Committee for Social Development, USAID

25. Khalid Khusbin, Budget Officer, Ministry of Finance

26. Basis Fedq, Development Coordinator, Embassy of Germany

\section{Provincial Field Research}

\section{Badghis}

- The Provincial Director of DRRD

- The DRRD Manager of NSP and a member of the monitoring team

- The Provincial Head of OC

- The Provincial Manager of BRAC

- The District Managers of BRAC Ab Kamari and BRAC Jawand

- The BRAC engineering team (Central Office Project Engineer, Provincial and District Engineers (7) and a monitoring officer)

- Chairman and members of the Mobarak Shah CDC

- Chairman and members of the Dai Zangi CDC

- 9 householders (8 men and 1 woman) in Mobarak Shah

- 8 householders ( 7 men and 1 woman) in Dai Zangi

- Community Leaders of Charsangi

- 9 householders ( 7 men and 2 women) in Charsangi

\section{Balkh}

- The Provincial Governor

- The Provincial Director of DRRD

- The DRRD Manager of NSP and Team

- The Provincial Head of $O C$ and Team

- The Provincial Management of CHA

- The Provincial Management of UNHABITAT

- The DRRD District Management

- The District Management and Team of $\mathrm{CHA}$

- The District Management and Team of UN-HABITAT

- The CDC of Markaz-e-Dawlatabad

- The CDC of Choba Temorak Karni Khail

- The village of Taimorak

- The CDC of Yakhdan

- The CDC of Alichopan

- The CDC of Aliseena

\section{Bamyan}

- The Deputy Governor

- The Director of DRRD

- The NSP OC Consultant and team (including 2 DRRD staff)

- The DRRD NSP Administrator

$\checkmark \quad$ The Director of AKDN (NSP FP)

$\checkmark \quad$ The AKDN Regional Manager of NSP

- The AKDN Finance Manager

- The AKDN/NSP Director for Shibar District

$\checkmark$ AKDN/NSP D istrict field staff

$\checkmark \quad$ The CDC of Shah Qadam (Shibar District) 
- Representatives of 10 households in Shah Qadam

- The Director of UN-HABITAT/NSP and Programme Engineer

\section{Herat}

$\checkmark \quad$ The Director of the DRRD

$\checkmark$ BRAC Regional Manager

- NSP OC

- The CDC of Hoftoi Sofla

- The CDC of Robat Sangi

$\checkmark$ The village of Yaka Dokan

\section{Kabul}

- The Provincial Governor

- The Director of DRRD

- The DRRD NSP Administrator and Engineer

- The NSP OC Consultant

- The Director and Management Team of SDF(NSP FP)

- The SDF District NSP staff responsible for Estalef

- The CDC of Godara (Estalef District)

- Representatives of 10 households in Godara

- The District Governor of Kalakan and Council of Elders

- Representatives of 10 households in Kalakan Centre

$\checkmark$ CDCs of Aziz Uddin, Salakhail, Taj Mohammed and Ghaza, Shakadara District

\section{Kundoz}

The Deputy Provincial Director of DRRD

- Provincial and District DRRD staff

- Social Protection Officer

- Finance and Admin Officer

- Irrigation and Sanitation Officer

- Contracts Officer

- The NSP Provincial OC

- The Provincial Manager of GRSP

GRSP Provincial Staff:

$\rightarrow$ Social Organizer

$\checkmark$ Site Engineer

- Facilitator

- The GRSP Chardara District Manager

GRSP District Staff:

- Social Organizer

- Facilitator

- The CDC in Chogha-e-Sofla Village, Khan Abad District

- Representatives of 7 households in Chogha-e-Sofla

- The CDC in Dour Robat Village Chardara District

- Representatives of 11 household in Dour Robat
- Chahar Dara Youth Committee in Dour Robat village, Chardara District

- Elders of Mangal Abad village, Chardara District (no CDC)

- Representatives of 8 households in Mangal Abad

$\checkmark$ Representatives of ACTED in Kundoz

\section{Nangarhar}

Facilitating Partner:

BRAC Eastern Office, Jalalabad

$\rightarrow$ NSP Manager

- Provincial Manager

$\checkmark$ Monitoring Officer

- Provincial Engineer

- MT Provincial Office

- MO Provincial Office

$\checkmark$ IT, Provincial Office

- Provincial Engineer

MRRD Officials, Eastern Region MRRD Headquarters, Jalalabad

- Deputy Governor, Nangarhar

- MRRD Director of Nangarhar

- Regional coordinator of Nangarhar

- MRRD Director for Laghman Province

- Nuristan Province MRRD, Regional Advisor

$\checkmark \quad$ NSP Monitoring and Evaluating Officer (based with Eastern Region Manager counterpart to A Sattar, but uses OC office)

Director of NSP MRRD Nangarhar

NSP Eastern Region Offices, Jalalabad

- Regional Manager, Eastern Region (Nangarhar, Kunar, Nuristan, Laghman, Logar and Khost)

- Provincial Team Leader

- Deputy Regional Manager East

- Training Coordinator, Eastern Region

NSP Communities visited and CDCs consulted in Nangarhar

- Sholana, Chaparhar (including the CDCs of Sholana, Khanan, Miagan and Gulshir)

$\rightarrow$ Balla Dehe, Sorkhrod

- Kooz Naza Abad, Sorkhrod

- Ahmadzi, Sorkhrod

- Dago, Chaparhar

- Mano, Chaparhar (including the CDCS of Nazier Kalay and Gradal Kalay)

- Merzaian, Sorkhrod

- Ditawai Amerkhil, Sorkhrod

- Khankai Satkai, Achin

- Asadkhil, Achin

Community visited without NSP

- Bahsawal, Mohmamdara District
N SP AFGHAN ISTAN Mid-term EVALUATION REPO RT 


\section{Laghman}

Facilitating Partner:

Maderia, Metherlan Office, Metherlan

$\checkmark \quad$ NSP Coordinator for Laghman and Nuristan

\section{DACAAR}

$\checkmark$ NSP Engineer

$\checkmark$ Team leader

NSP Laghman Office

$\checkmark$ Team Leader Laghman

NSP Communities visited and

CDCs consulted in Laghman

- Mashina

- Shertabad

$\checkmark$ Hussain Abad

- Koarigi, Alingar District.

- Kokhi, Alingar District

$\checkmark$ Kahoo and Chinnar Kali, Alishang District

- Tangi Shakarman, Alishang District

- Qala I Halim, Alishang District

\section{Paktia}

- Director of DRRD

- CDC members in Bar Dawlat Khel, Nader Shah Khel and Fatch Khan Khel

- Householders in Bar Dawlat Khel

\section{Paktika}

$-\quad$ Director of DRRD

- BRAC Regional Manager

- Provincial Manager

- Provincial Engineer

- Master Trainer

- District Coordinator of Muta Khan and Sharana Districts

$\rightarrow$ OC

$\checkmark$ CDC members of Sapawol

- Village and District: Sharan

$\rightarrow$ CDC members of Loy Jomat

- Village and District: Sarawza, Sarawza

\section{Takhar}

$\checkmark$ Provincial Director of DRRD

- OC team leader in Takhar Province

$\checkmark$ CONCERN (FP) staff working in Versage District

- 4 Community Development Officers

$\checkmark$ Finance Officer

- Members of Dar-e-Hawili CDC, Versage District

$\checkmark$ Members of Sar-e-Tang CDC, Versage District 


$$
\text { or }
$$




\section{D1 References}

Afghan Red Crescent Society (ARCS) (2005) 'Programme Update', Kabul, ARCS: 31 May.

ARCS and the Afghanistan Ministry of Public Health (undated) 'Joint Memorandum of Understanding'.

Afghanistan Information Management Service (AIMS) (2005) 'Maps of Provinces and Districts in Afghanistan',

www.aims.org.af/services/customer/kbl_ma ps_list/kbl_maps_list.html, accessed ${ }^{-} 10$ October 2005.

Afghanistan Research and Evaluation Unit (AREU) (2005) The A-Z Guide to Afghanistan Assistance, Kabul, AREU: August, 4th ed.

Altai Consulting (2004) Assessment of NSP Facilitating Partners, Common Final Report II, Kabul, Altai: August.

Ambrose, P. (2005) 'Urban Regeneration,' in D. Taylor and S. Balloch (eds.), The Politics of Evaluation, Bristol: Policy Press.

Arksey, Hilary and Peter Knight (1999) Interviewing for Social Scientists: An Introductory Response with Examples, London: SAGE Publications.

AusAID (2000) Good Governance: Guiding Principles for Implementation, Canberra: Australian Government.

Baker, Judy L., (2000) 'Drawing on "Good Practice" Impact Evaluations', Evaluating the Impact of Development Projects on Poverty. A Handbook for Practitioners, Washington D.C., World Bank, pp. 65-82.
Barakat, Sultan (ed.), (2005) After the Conflict: Reconstruction and Development in the Aftermath of War, London: I.B. Tauris.

Barakat, Sultan and Arne Strand (2000), 'Forced Migration and dilemmas of humanitarian assistance: challenges for applied research', Norsk Geografisk TidsskriftNorwegian Journal of Geography, Vol. 54, pp. 134-136.

Barakat, Sultan, M. Chard, T. Jacoby, and W. Lume (2002) 'The Composite Approach: research design in the context of war and armed conflict', Third World Quarterly, Vol. 23, No. 5, pp. 991-1003.

Barzealy, M. (2000) The New Public Management, Berkley: University of California Press.

Beetham, D. (ed.), (1994) Defining and Measuring Democracy, London: Sage.

Boesen, Inger W. (2004) From Subjects to Citizens: Local Participation in the National Solidarity Programme, Working Paper Series, Kabul, AREU: August.

Bourguignon, Francois and Luiz Pereira da Silva (eds.) (2003) The Impact of Economic Policies on Poverty and Income Distribution: Evaluation Techniques and Tools, Washington D.C.: World Bank and Oxford University Press.

British Agencies Afghanistan Group (2005) 'Afghanistan', Monthly Review, September.

Burnes, B. (2004) Managing Change: A strategic approach to organizational dynamics, Harlow, FT Prentice Hall: Chapters $7 \& 8$, 4th ed. 
Carnall, C (2002) Managing Change in Organisations, Harlow: FT Prentice Hall, 4th ed.

Carvalho, Soniya, Gillian Perkins, and Howard White (2002) 'Social Funds, Sustainability and Institutional Development Impacts: Findings from an OED Review', Journal of International Development, 14, pp. 611-625.

Central Intelligence Agency, 'Afghanistan', The World Fact Book,

http:www.cia.gov/cia/publications/factbook/ geos/af.html, accessed 30 August 2005.

Coles, Anne, Phil Evans, with Charlotte Heath (1998) 'Impact Assessment, Process Projects and Output-to-Purpose Reviews: Work in Progress in the Department for International Development', David Mosse, John Farrington and Alan Rew (eds.), Development as Process: Concepts and Methods for Working with Complexity, London and New York, Routledge: pp. 84-96.

Coordination of Humanitarian Assistance (CHA) (2005) 'NSP data for Charbolak District', Mazar-e-Sharif, CHA: 31 October.

CHA (2005) 'NSP Phases and their Steps'.

CHA (2005) 'NSP data for Dawlatabad District', Mazar-e-Sharif, CHA.

CHA (2005) 'NSP Achievements up to 25th October 2005', Mazar-e-Sharif, CHA

CHA (2005) 'Facilitating Partner Quarterly Progress Report Aggregation Table', Mazare-Sharif, CHA.

CHA (2005) 'List of Villages in Charbolak under NSP Coverage', Mazar-e-Sharif, CHA.

CHA (2005) 'Table for Collecting Information from Charbolak Villages', Mazar-e-Sharif, CHA.

Darwin, J, P. Johnson, and J. McAuley (2002) Developing Strategies for Change, FT Prentice Hall: Harlow.

Dawson, P. (2003) Understanding organisational change: the contemporary experience of people at work, London, Sage: Chapters 2 and 10.

Drucker, P. (1995) Managing in a time of great change, Butterworth: Heinemann.
Eade, D. (1997) Capacity-Building: An Approach to People-Centred Development OXFAM: Oxford, U.K.

Evans, Anne, Nick Manning, Yasin Osmani, Anne Tully, and Andrew Wilder (2004) A Guide To Government in Afghanistan, Washington and Kabul: AREU and World Bank.

Goodhand, Jonathan (2000) 'Research in conflict zones: ethics and accountability', Forced Migration Review, no. 8, pp. 12-15.

Hamlin, B., J. Keep, and K. Ash (2001) Organisational Change and Management, Harlow, FT Prentice Hall: Chapter 2.

Heffron, F. (1989) Organisational theory and Public Organisations: the political connection, Prentice Hall, Harlow: Chapter 5.

Hogwood, B., D., Judge, D and M. McVicar (2000) 'Agencies and Accountability' in R. Rhodes (ed.), Transforming British Government, Basingstoke: Palgrave.

Hood, C. (2000) The Art of the State: Culture, Rhetoric and Public Management, Oxford: Oxford University Press.

Hood, C. (1995) 'Contemporary Public Management: a new global paradigm', Public Policy and Administration, Vol.10, No.2, pp. 104-117.

Hood, C. (1991) 'A public management for all seasons? Public Administration, 69, pp. 3-19.

Ibbs, R. (1988) Improving Management in Government: the Next Steps, London: Cabinet Office.

Independent Evaluation Group (2005) 'The Effectiveness of World Bank Support for Community-based and -driven Development', Washington: World Bank, http://www.worldbank.org/ieg/cbdcdd/, accessed 3 March 2006.

International Crisis Group (2005) Afghanistan Elections: Endgame of New Beginning, Asia Report No 101, 21 July.

ILO Technical Advisory Services to the Joint Programme Management Unit (JPMU), National Emergency Employment Programme (undated), 'A Framework for a Streamlined Inclusion of Vulnerable Groups under NEEP', Draft Copy, Kabul: JPMUNEEP.
N SP AFG HAN ISTAN Mid-term EVALUATION REPO RT 
Isaac-Henry, K., C. Painter and C. Barnes (1997) Management in the Public Sector: Challenge and Change, London: International Thomson Business Press, 2nd ed.

Islamic Republic of Afghanistan (2005) 'CDC By-laws Template'.

Jacobsen, Karen and Loren B. Landau (2003) 'The Dual Imperative in Refugee Research: Some Methodological and Ethical Considerations in Social Science Research on Forced Migration', Disasters, Vol. 3, No. 27, pp. 95-116.

James, O. (2003) The Executive Agency Revolution in Whitehall, Palgrave: Macmillan.

James, O. (2001) 'Business Models and the Transfer of Business-like Central Government Agencies', Governance, Vol. 14, No. 2, pp. 233-52.

Kakar, Palwasha (2005) Fine-tuning the NSP: Discussions of Problems and Solutions with Facilitating Partners, Draft Copy, Kabul, AREU: November.

Kettl, D.F. (2000) The Global Public Management Revolution, Washington D.C.: The Brookings Institution.

Kettl, D.F. (2002) The Transformation of Governance, Baltimore: John Hopkins.

Ministry of Foreign Affairs of Denmark (MFAD) (2005) Humanitarian and Reconstruction Assistance to Afghanistan, 2001-05, A Joint Evaluation, Main and Summary Reports, Copenhagan, MFAD: October.

Ministry for Rural Rehabilitation and Development (MRRD) (2005) 'National Solidarity Programme - Phase II, Proposal for a 5-year Program Extension', Kabul, MRRD: October.

MRRD (2005) 'Monthly Program Report for the National Solidarity Programme' (Saratan-Asad 1384), Kabul, MRRD: July.

MRRD (2005) 'Goals and Objectives', Kabul, MRRD: May.

MRRD (2005) 'Newsletter', Vol. 2, Issue 2, Kabul, MRRD: April.

MRRD (undated) 'Presentation to the Budget Committee Mid-Year Review 1384 National Budget', Kabul: MRRD.
MRRD (undated) 'National Solidarity Programme (NSP) [cartoon guide for CDCs]', Kabul: MRRD.

MRRD and National Solidarity Programme (NSP) Oversight Consultants (2006) Operational Manual, Kabul, MRRD/NSP: 15 January.

MRRD and NSP Oversight Consultants Team (2005) Operations Manual, Kabul, NSP: July and October.

MRRD and NSP Oversight Consultants Team (2005) 'Oversight Consultant Quarterly Report, 1 April - 30 June 2005', Kabul, MRRD/NSP: July.

Mintzberg, H and J.B. Quinn (eds.), (2003) The Strategy Process: Concepts, Contexts and Cases, Pearson Education: Harlow.

Moore, M. (1995) Creating Public Value: Strategic Management in Government Cambridge, Mass: Harvard.

National Emergency Employment Programme - Joint Programme Management Unit (2004) 'Project Concept Note: NEEP- Rural Access Planning', Action Planning Concept Note, Kabul, MRRD: 25 April.

National Solidarity Programme (NSP) (2005) 'Reporting Form 5: Implementation Monitoring (Progress, technical quality and process)', Kabul, NSP: 29 October.

NSP (undated) 'Reporting Form 5, Spot Check Reporting Form', Kabul: NSP.

NSP (undated) 'Monitoring and Evaluation Community Progress Report', Kabul: NSP.

NSP Oversight Consultant (OC) (2006) Analysis of the Experiences and Lessons Learned in Program Implementation, 2003-2006, Kabul, GTZ-IS: March.

NSP OC (2005) 'Restructuring the Organisation: From the Outsourcing of the Implementation to a National Program Structure', paper presented, Kabul, NSP: 31 December.

NSP Oversight Consultants Team (2005) 'NSP I: Lessons Learned', Kabul, NSP: October.

NSP Oversight Consultants Team (2005) 'Implementation Progress Report as of 30 September', Kabul: NSP. 
NSP Oversight Consultants Team (2005) 'Status Report of the National Solidarity Program', Kabul, NSP: 13 August.

NSP Oversight Consultants Team (2005) 'Implementation Progress Report as of 31 July', Kabul: NSP.

NSP Oversight Consultants Team (2005) '2nd Quarter Report from 1/4/05 - 30/6/05': Annex A, 'FP Reporting Progress Form'; Annex C '-1C-2C-3 NSP Progress Tables'; Annex D, 'OC, MRRD and FPs Training Status'; and Annex E, 'Summary of Activities and Reports of the M\&E Unit', Kabul, NSP: July.

NSP Oversight Consultants Team (2005) 'Aide Memoir: Afghanistan - National Solidarity Program (NSP) Joint Government and Donor Supervision April - May 2005', Kabul, NSP: 17 May.

NSP Oversight Consultants Team (2005) 'Annex II, Community Development Planning; Annex III, NSP/OC Operational Changes to Overcome Bottlenecks to Subproject Disbursement and Completion; Annex IV, Guidelines for Diesel Generator Projects; Annex VI, NSP's Gender Policy; and Annex VII, Concept Paper for Implementation Criteria for the NSP "top-up grant"', Kabul: NSP.

NSP Oversight Consultants Team (2005) 'Copy of NSP Roll Out Plan - all Years', Kabul: NSP.

NSP Oversight Consultants Team (2004) 'Operations Manual, March 2004', Kabul, NSP: 1 March.

NSP Oversight Consultants Team (2004) 'Status as of 31 March 2004 Report', Kabul, NSP: April.

NSP Oversights Consultant Team (undated) 'Standard List of Sectors and Outputs Developed by MIS technical groups', Kabul: NSP.

NSP Oversight Consultants Team (undated) 'Follow up of the Aide Memoire of the Donor Supervision Mission: the Report of the Oversight Consultant concerning the Tasks of OC', Kabul: NSP.

Organisation for Economic Cooperation and Development (OECD) (2002) Distributed Public Governance: Agencies, Authorities and other Autonomous Bodies, Paris: OECD.
OECD (1998) Survey of Public Management Developments, Paris: OECD.

Peters, B. (1997) 'Policy Transfer Between Governments: the Case of Administrative Reforms', West European Politics, Vol. 20, No. 4. pp. 71-88.

Post-war Reconstruction and Development Unit (PRDU) (2005) Inception and First Draft Report of the NSP mid-term Evaluation, York, University of York: 21 November.

PRDU (2005) 'Preliminary Field Summaries by RAT Leaders', Confidential Internal Reports, Kabul, University of York: November.

PRDU (2005) 'Data Checklist, Final Notes and Interview Questions for Evaluation Phase I: Final Version', Internal Document, York, University of York: 20 November.

PRDU (2005) Preparation Report for the Evaluation of the Afghanistan National Solidarity Programme, Confidential Internal Report, York, University of York: 26 August.

PRDU (2005) 'Technical Proposal Submission Form [for the NSP mid-term Evaluation]', York, University of York: 20 April.

Pratt, Brian and Peter Lozios (1992) Choosing Research Methods: Data Collection for Development Workers, Development Guidelines no. 7, Oxford: Oxfam Print Unit.

Rahman, Habib Ur (2004) 'Strengthening Local Governance Through CommunityBased Development Programmes', MA Dissertation, PRDU, York: University of York.

Rhodes, R. (2000) 'Governance and Public Administration', in J. Pierre (ed.), Debating Governance, Oxford: OUP.

Richter, Carole (2003) Action Planning: The Challenges Facing Decentralised Local Government Recovering During Low Intensity Conflict, with Special Reference to Adjumani and Moyo, Uganda, PhD Thesis, PRDU, York: University of York.

Senior, B. (2002) Organisational Change, Harlow, FT Prentice Hall: Chapters $1 \& 6$.
N SP AFG HAN ISTAN Mid-term EVALUATION REPO RT 
Simons, H., G. Hart, and C. Walsh (1997) One Clear Objective: Poverty Reduction through Sustainable Development, Report of the Committee of Review on the Australian Overseas Aid Programme (the Simons Report), Canberra: AusAID/ Australian Government.

Stoker, G. (2005) Public Value Management: A New Narrative for Networked Governance? Institute for Political and Economic Governance (IPEG), Manchester: University of Manchester, U.K. (available from the PRDU).

Stoker, G. (2004) Transforming Local Governance, Basingstoke: Macmillan Palgrave.

United Nations Cartography Section, 'Map of Afghanistan',

http://www.un.org/Depts/Cartographic/map /profile/afghanis.pdf, accessed 10 October 2005.

United Nations Development Programme (UNDP) (Afghanistan Country Office) (2005) Promotion of Sustainable Livelihoods Programme, Kabul, UNDP: 1 August.

UNDP (2004) Security with a Human Face: Challenges and Responsibilities, www.undp.org/dpa/nhdr/af/AfghanHDR200 4.htm, accessed September 2005.

UNDP (2000) Concepts of Governance and Sustainable Human Development.

United Nations Office for Project Services (UNOPS) (2005) 'Inception Report for Ministry for Rural Rehabilitation and Development (MRRD)', Component A (1), National Emergency Employment Program for Rural Access (NEEPRA), Kabul: UNOPS.

Vulnerability Analysis and Mapping (VAM) Unit of the World Food Programme and the Vulnerability and Analysis Unit (VAU) and MRRD (2004) Report on Findings from the 2003 National Risk and Vulnerability Assessment (NRVA) in Rural Afghanistan, December.

Whyte, A. (2004) Landscape Analysis of Donor Trends in International Development Human and Institutional Capacity Building 2, Rockefeller Foundation. Solidarity Program (NSP) Supervision Mission, Washington D.C., World Bank: November.
World Bank (Agriculture and Rural Development Sector Unit, South East Asia) (2005) 'Implementation Completion Report on a Grant in the Amount of SDR33.7 Million (US\$42 Million equivalent) to the Islamic Republic of Afghanistan for the Emergency Community Empowerment and Public Works Project', Report No. 33120-AF, Washington D.C., World Bank: 27 July.

World Bank (2005) Afghanistan - National Solidarity Program (NSP) Joint Government and Donor Supervision, April-May 2005, Kabul/Washington D.C.: World Bank.

World Bank Operations Evaluation Department (2004) Bosnia and Herzegovina: Post-Conflict Reconstruction and the Transition to a Market Economy, An OED Evaluation of World Bank Support, Washington D.C.: World Bank.

World Bank Operations Evaluation Department (2004) Croatia Country Assistance Evaluation, Report No. 30714, Washington D.C., World Bank: 17 November.

World Bank (1994) Governance; the World Bank's Experience, Washington, D.C.: World Bank.

World Bank, 'Project Profiles on Agriculture \& Rural Development, Poverty, Public Sector Governance and Social Protection', http:www.worldbank.org, accessed September-October 2005. 


\section{Post-war Reconstruction \& Development Unit (PRDU)}

\section{'...linking theory and practice \\ for enablement and development.'}

The Post-war Reconstruction and Development Unit (PRDU) is a leading centre for research, consultancy and learning on post-war reconstruction and development. Founded in 1992 at the University of York, the PRDU's mission is to advance education and learning in the management and planning of reconstruction after war, humanitarian intervention in complex emergencies and peacebuilding.

PRDU links theory and practice for the enablement and development of war-affected societies. The Unit's work focuses on three core areas:

\section{Conceptualisation:}

Facilitating the development of a vision for reconstruction based on context analysis, with participatory needs assessment and strategy development.

\section{Institution Development and Transformation:}

Supporting the development of human resources, appropriate administrative systems and institutional responses in the transition from crisis management to long-term development programmes.

\section{Participatory Evaluation:}

Promoting people-centred evaluation of progressive goals and strategies and the dissemination of good practice.

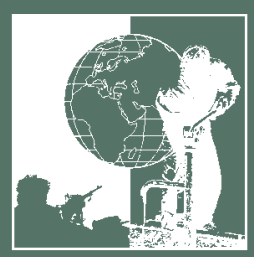

